$$
\text { NYSERDA--97-9 }
$$

\title{
Development of Monitoring and Control Technology Based on Trace Gas Monitoring
}

Final Report 97-9

1150

$\angle 666 \angle 1 d A S$

व $\exists \wedge 1 \exists \supset \exists \forall$
New York State Energy Research and Development Authority

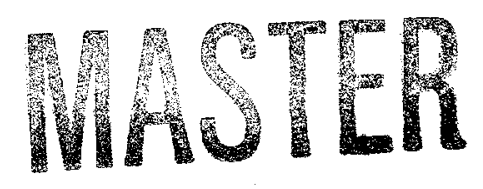


The New York State Energy Research and Development Authority (NYSERDA) is a public benefit corporation created in 1975 by the New York State Legislature.

NYSERDA has major programs in energy and environmental research, radioactive and hazardous waste management, tax-exempt bond financing, energy analysis and planning, and energy efficiency grants. Its responsibilities include:

- Conducting a multifaceted energy and environmental research and development program to meet New York State's diverse needs;

- Helping industries, schools, hospitals, and not-for-profits implement energy efficiency measures;

- Providing objective, credible, and useful energy analysis to guide decisions made by major energy stakeholders in the private and public sectors;

- Managing the Western New York Nuclear Service Center at West Valley, including: (1) overseeing the State's interests and share of costs at the West Valley Demonstration Project, a federal/State radioactive waste clean-up effort, and (2) managing wastes and maintaining facilities at the shut-down State-Licensed Disposal Area;

- Participating in the Malta Rocket Fuel Area "Superfund" site clean-up and managing facilities at the site on behalf of the State;

- Coordinating the State's activities on nuclear matters, and designing, constructing, and operating State facilities for disposal of low-level radioactive waste, once siting and technology decisions are made by the State; and

- Financing energy-related projects, reducing costs for ratepayers.

NYSERDA derives its basic research revenues from an assessment levied on the intrastate sales of New York State's investor-owned electric and gas utilities. Additional research dollars come from limited corporate funds and a voluntary annual contribution by the New York Power Authority. More than 245 of NYSERDA's research projects help the State's businesses and municipalities with their energy and environmental problems. Since 1990, NYSERDA has successfully developed and brought into use more than 60 innovative, energy-efficient, and environmentally acceptable products and services. These contributions to the State's economic growth and environmental protection are made at a cost of less than $\$ 1$ per New York resident per year.

Federally funded, the Energy Efficiency Services program is working with more than 220 businesses, schools, and municipalities to identify existing technologies and equipment to reduce their energy costs.

For more information, contact the Technical Communications unit, NYSERDA, Corporate Plaza West, 286 Washington Avenue Extension, Albany, New York 12203-6399; (518) 862-1090, ext. 3250; or on the World Wide Web at http://www.nyserda.org/

State of New York

George E. Pataki

Governor
Energy Research and Development Authority William R. Howell, Chairman F. William Valentino, President 


\section{DEVELOPMENT OF MONITORING AND CONTROL TECHNOLOGY BASED ON TRACE GAS MONITORING}

Final Report

Prepared for

THE NEW YORK STATE

ENERGY RESEARCH AND DEVELOPMENT AUTHORITY

Barry Liebowitz

Project Manager

Prepared by

MBI INTERNATIONAL

and

EFX SYSTEMS, INC.

Lansing, Michigan 48910

Project Team

M. Wu

J. Shi

B. Hickey

DISTPBUTION OF THS DOCHENT IS UMUMTED

1738-ERER-MSW-92 


\section{NOTICE}

This report was prepared by MBI International and EFX Systems, Inc. In the course of performing work contracted for a sponsored by the New York State Energy Research and Development Authority (hereafter "NYSERDA"). The opinions expressed in this report do not necessarily reflect those of NYSERDA or the State of New York, and reference to any specific product, service, process, or method does not constitute an implied or expressed recommendation or endorsement of it. Further NYSERDA, the State of New York, and the contractor make no warranties or representations, expressed or implied, as to the fitness for particular purpose or merchantability of any product, apparatus, or service, or the usefulness, completeness, or accuracy of any processes, methods, or other information contained, described, disclosed, or referred to in this report. NYSERDA, the State of New York, and the contractor make no representation that the use of any product, apparatus, process, method, or other information will not infringe privately owned rights and will assume no liability for any loss, injury, or damage resulting from, or occurring in connection with, the use of information contained, described, disclosed, or referred to in this report. 
DISCLAIMER

Portions of this document may be illegible in electronic image products. Images are produced from the best available original document. 


\title{
A NYSERDA Report in Brief
}

\author{
Report: \\ Development of Monitoring and Control Technology Based on Trace Gas Monitoring \\ Report 97-9
}

Project Manager:

Barry Liebowitz

Contractor:

\author{
MBI International and EFX Systems Inc.
}

Background: The purpose of this project was to develop a method to monitor and control the biological treatment of high-strength organic wastewater based on earlier research with anaerobic sludge digestion. In this scheme, hydrogen $\left(\mathrm{H}_{2}\right)$ and carbon monoxide $(\mathrm{CO})$, which are trace gases, are monitored, in addition to total gas production, methane, and carbon dioxide $\left(\mathrm{CO}_{2}\right)$ concentration. These trace gases (in the parts per million and parts per billion range) were found to be sensitive to changes in organic and hydraulic loading, as well as heavy metal and toxic organic contaminations.

Objectives: Experiments were conducted using upflow anaerobic sludge blanket (UASB) reactors treating a synthetic brewery wastewater. The dynamic behavior of the UASB system based on hydraulics, biological kinetics and mass transfer characteristics was analytically and physically modeled. Steady- and unsteady-state (cyclic) experiments were conducted to provide data upon which to base a control model. Nine organic loading rates $(4-25 \mathrm{~kg}$ Chemical Oxygen Demand COD $/ \mathrm{m}^{3}-\mathrm{d}$ ) and system hydraulic retention times (HRT) (0.5-1.5 days) were used to develop steadystate data. Harmonic and random step-wise perturbation experiments were conducted. Data were analyzed using time-series analysis and other statistical techniques. Step-wise cyclic loading and random perturbation experiments to bring the system to failure (up to $60 \mathrm{~kg} \mathrm{COD} / \mathrm{m}^{3}-\mathrm{d}$ ) were used to test the trace gas control model. Tests were conducted with and without $\mathrm{pH}$ control.

R\&D Results: $\mathrm{CO}$ and $\mathrm{H}_{2}$ were found to be good indicators of the state of the system. Under steady state conditions these parameters plotted in a bivariate plot of the ratio of $\mathrm{CO}$ and $\mathrm{H}_{2}$ concentration to gas production (GP), in units of $\mathrm{ppb} / \mathrm{mL} / \mathrm{hr}$ and $\mathrm{ppm} / \mathrm{mL} / \mathrm{hr}$, were within an envelope of $\{2,1\}$. This was not the case for perturbations leading to failure when these parameters leave this envelope. Early warning, however, was not obtained by monitoring these parameters. High-rate anaerobic wastewater treatment proved to be more robust and difficult to bring to failure than expected. The experience at higher loading rates demonstrated the capability of UASBs to handle a wide range of organic loadings without compromising operation. The UASB reactor was able to handle $25 \mathrm{~kg} \mathrm{COD} / \mathrm{m}^{3}-\mathrm{d}$ without a problem. In all cases, the UASB reactor was able to recover after "failure."

Trace gases provided early indications of process upsets to toxic contaminants, (e.g., phenol), but MBI and NYSERDA staff felt this wasn't sufficient to justify further development.

Copies Available: To order copies of this report, contact the National Technical Information Service (NTIS): (800) 553-6847; (703) 487-4650 outside the U.S.; via Internet: http://www.ntis.gov/ordering.htm NTIS product or order questions: info@ntis.fedworld.gov

For information on other NYSERDA reports, contact: New York State Energy Research and Development Authority, Corporate Plaza West, 286 Washington Avenue Extension, Albany, New York 12203-6399;

voice: (518) 862-1090, ext. 3241; fax: (518) 862-1091; e-mail: amt@nyserda.org; http://www.nyserda.org/ 


\begin{abstract}
Trace gases are generated by many biological reactions. During anaerobic decomposition, trace levels of hydrogen $\left(\mathrm{H}_{2}\right)$ and carbon monoxide $(\mathrm{CO})$ gases are produced. It was shown previously that these trace gases are intrinsically related to the biochemical reactions occurring and, therefore, offer promise for online process monitoring and control. This work was designed to test how effectively hydrogen and $\mathrm{CO}$ could be to monitor high-rate anaerobic systems that has significant mass transfer and complex hydraulics.

An experimental program was designed to examine the behavior of an upflow anaerobic sludge blanket (UASB) reactor system under steady state and in response to organic loading perturbations. The responses of trace gases $\mathrm{CO}$ and $\mathrm{H}_{2}$ were tracked using an on-line, real-time gas-monitoring system linked to a computer-controlled data acquisition package. Data on conventional process parameters suck as $\mathrm{pH}$, chemical oxygen demand (COD), volatile fatty acids (VFAs) were concurrently collected.
\end{abstract}

Monitoring of conventional process indicators (i.e., $\mathrm{pH}$, VFA, gas production) and trace gas $\left(\mathrm{H}_{2}\right.$ and $\mathrm{CO}$ ) indicators was conducted using a matrix of nine different steady-state OLRs (4-23 kg $\left.\mathrm{COD} / \mathrm{m}^{3}-\mathrm{d}\right)$ and system HRTs ( 0.5 to 2.5 days) was performed to determine any correlation among the indicators. Of OLR, HRT, and influent COD, only OLR had any significant influence on the process indicators examined. All parameters except methane increased with increases in OLR; methane decreased with increased OLR. The OLR and gas production rate (GP) were observed to be linearly correlated.

The best method of applying trace gases for monitoring was observed to be the use of a bivariate plot of $\mathrm{CO} / \mathrm{GP}$ versus $\mathrm{H}_{2} / \mathrm{GP}$. All of this "normalized" data fell within a narrow operating envelope of $\{2,1\}$ for all the steady state data.

A series of six unsteady state experiments with on-line data for $\mathrm{CO}, \mathrm{H}_{2}, \mathrm{GP}$, and methane collected at 10-minute intervals was conducted. The first three experiments examined step and impulse increases in OLR at times and amplitudes that did not significantly affect performance of the UASB system. This was followed by three experiments (one with $\mathrm{pH}$ control, two without) during which the OLR was increased to $60 \mathrm{~kg} \mathrm{COD} / \mathrm{m}^{3}-\mathrm{d}$ for a sufficient period to induce process upset or failure. In all cases, $\mathrm{CO}$ and $\mathrm{H}_{2}$ did not provide early warning. It was observed that dissolved $\mathrm{CO}$ and $\mathrm{H}_{2}$ concentrations were not close to being in equilibrium with the gas phase. $\mathrm{CO}$ in the liquid phase was much higher than would be expected based on the gas phase samples and $\mathrm{H}_{2}$ was much lower than would be expected. The ratios of aqueous to gas phase varied randomly and to a significant extent for both gases.

The use of the bivariate plot of $\mathrm{CO} / \mathrm{GP}$ and $\mathrm{H}_{2} / \mathrm{GP}$ was observed to accurately depict when system failures occurred. Because $\mathrm{CO}$ remained at elevated concentrations after the system recovered, the use of this type of control chart for tracking recovery is not appropriate.

Final conclusions are that although there is some merit in using $\mathrm{CO}$ and $\mathrm{H}_{2}$ as process indicators, particularly the use of a bivariate plot or control chart using CO/GP versus $\mathrm{H}_{2} / \mathrm{GP}$, the additional benefit in terms of providing early warning was not realized on a consistent basis. The added cost of a trace gas monitoring system for a typical industrial application does not appear justified based on these results. 


\section{ACKNOWLEDGMENTS}

The authors would like to thank Michelle van de Walle, Jeff Cook, Jeff Nye and Leslie Neilson for their technical assistance in performing this work. Thanks also due to Susan Kessner for help in preparation of the manuscript. Finally, a special thanks to Dr. Wei-Min Wu for his insight and help. 
TABLE OF CONTENTS

$\underline{\text { Section }}$

Page

SUMMARY S-1

INTRODUCTION.

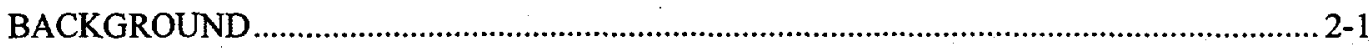

METHANOGENESIS AND METHANE PRODUCTION ............................................... 2-1

SUBSTRATE TRANSPORT AND UTILIZATION WITHIN ANAEROBIC

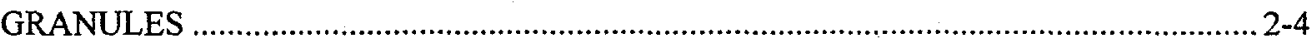

PROCESS MONITORING AND DYNAMIC MODELING ……................................... 2-6

3. OBJECTIVES AND PROCEDURAL OVERVIEW

OBJECTIVES

EXPERIMENTAL APPROACHES

THEORETICAL DEVELOPMENT

HYDRAULIC CHARACTERISTICS OF AN UPFLOW ANAEROBIC SLUDGE BLANKET (UASB) REACTOR $5-1$

INTRODUCTION

ORGANIC LOADING RATE AND HYDRAULIC FLUX EFFECTS .

EVALUATION OF EXISTING FLUID FLOW MODELS AND MODEL

DEVELOPMENT

DISCUSSION

MONITORING AN UASB REACTOR TREATING A SYNTHETIC BREWERY WASTE $\ldots . .6-1$ INTRODUCTION.

MONITORING CO AND H2 DURING PSEUDO-STEADY STATE OPERATION

UNSTEADY STATE OLR PERTURBATIONS AND SYSTEM RESPONSES - NO

PH CONTROL

UNSTEADY STATE OLR PERTURBATIONS AND SYSTEM RESPONSE - WITH

PH CONTROL

ANALYSIS OF UNSTEADY STATE MONITORING RESULTS

CONFIRMATION EXPERIMENT - UNSTEADY STATE (USS6) - NO PH

CONTROL 
TABLE OF CONTENTS

Section

N-PROPANOL FORMATION AND CONSUMPTION DURING ETHANOL

OXIDATION BY ANAEROBIC BREWERY GRANULES $7-1$

INTRODUCTION

MATERIALS AND METHODS

RESULTS

DISCUSSION

CONCLUSIONS

INTRODUCTION.

INTRINSIC KINETICS OF ACETATE, PROPIONATE, ETHANOL AND $\mathrm{H}_{2}$ UTILIZATION

MASS TRANSFER WITHIN BREWERY GRANULES

TEMPERATURE EFFECTS

THRESHOLD AND REACTION THERMODYNAMICS OF SUBSTRATE

UTILIZATION

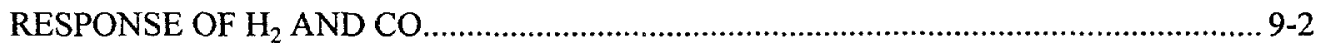

RESPONSE OF GAS PRODUCTION RATE AND METHANE CONTENT .....................9-4

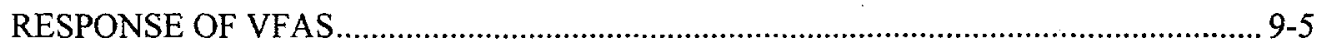

RESPONSE OF ETHANOL AND PROPANOL …....................................................... 9-8

ANALYSIS OF CO/GP AND $\mathrm{H}_{2}$ /GP RESPONSE ................................................... 9-8

SUMMARY

APPENDIX A - MEDIUM AND FEED COMPOSITION

APPENDIX B - MATERIALS AND METHODS

APPENDIX C - QUALITY ASSURANCE AND QUALITY CONTROL

APPENDIX D - DETERMINATION OF MONOD KINETIC CONSTANTS km AND Ks BY NONLINEAR LEAST SQUARE METHOD

APPENDIX E - FORTRAN PROGRAM OF THE HYDRAULIC REACTION DIFFUSION MODEL REFERENCES 


\section{FIGURES}

Figure

2-1 Carbon and electron flow in methanogenic environments. Metabolic groups involved:

I. Hydrolytic and fermentative bacteria; II. Proton-reducing acetogenic bacteria;

III. Methanogenic bacteria a) hydrogenophilic b) acetophilic; IV. Homoacetogenic

bacteria; V. Fatty acid-synthesizing bacteria. After Zehnder et al. (1981).

2-2 Effect of hydrogen partial pressure on the Gibbs free energy changes of conversion of ethanol, propionate, acetate and hydrogen during methane formation. After McCarty (1981).

Flow chart of model 1 - UASB reactor at low gas production.

Effect of organic loading rate on hydraulic behavior at $2 \mathrm{gpm} / \mathrm{sq}$. $\mathrm{ft}$.

Comparison of effect at two surface upflow rates and an organic loading rate of $10 \mathrm{~g}$ $\mathrm{COD} / \mathrm{L}$ bed-d.

Comparison of effect at two surface upflow rates and an organic loading rate of $5 \mathrm{~g}$ $\mathrm{COD} / \mathrm{L}$ bed-d.

Results obtained using the Cholette-Cloutier model at OLR $4 \mathrm{~g}$ COD/L bed-d and HRT $99 \mathrm{hrs}$.

Results obtained using the Hall model at OLR $4 \mathrm{~g}$ COD/L bed-d and HRT $99 \mathrm{hrs}$.

Results obtained using the Van der Meer model at OLR $4 \mathrm{~g}$ COD/L bed-d and HRT $99 \mathrm{hrs} . . . .5-13$

$5-11$

$5-12$

$5-13$

Results obtained using the new model at OLR $4 \mathrm{~g}$ COD/L bed-d and HRT $99 \mathrm{hrs}$.

Measured data compared with ideal CSTR at OLR $10 \mathrm{~g}$ COD/L bed-d and HRT $11 \mathrm{hrs.}$

Results obtained using the Cholette-Cloutier model at OLR $10 \mathrm{~g} \mathrm{COD/L}$ bed-d and HRT $11 \mathrm{hrs}$.

Results obtained using the model 2 at OLR $10 \mathrm{~g}$ COD/L bed-d and HRT $11 \mathrm{hrs.......................} \mathrm{5-18}$

5-19 Results obtained using the model 2 at an OLR $4 \mathrm{~g} \mathrm{COD/L}$ bed-d and HRT $99 \mathrm{hrs}$................... 5-19

6-1 Schematic representative of the bench-scale UASB reactor with on-line data acquisition system.

6-2 Typical profiles of (a) $\mathrm{CO}$, (b) methane, (c) H2, (d) acetate and propionate, and (e) gas production rate at pseudo-steady state. (OLR $15 \mathrm{~kg}$ COD/m3-d, HRT $1.5 \mathrm{~d}$, feed concentration $13.7 \mathrm{~kg}$ COD/m3.) Time scale: (a)-(d) in hours; (e) in days. Data collected from Nov. 30 to Dec. 7, 1992. operation. Bars represent $95 \%$ confidence intervals. Note: in most cases, error bars are smaller than size of the symbol. 


\section{FIGURES}

Figure

Page

6-5 Mean and confidence intervals of acetate and propionate during pseudo-steady state operation. Bars represent $95 \%$ confidence intervals.

Schematic diagram of correlations among monitoring variables at pseudo-steady state operations (based on results from correlation analysis; $(+)$ indicates a positive correlation;

$(-)=$ negative correlation; correlation test at $\alpha=0.01)$.

Bivariate plot of $\mathrm{CO}$ versus acetate at each pseudo-steady state.

Bivariate plot of $\mathrm{H}_{2}$ versus acetate at each pseudo-steady state.

Free energy change of propionate oxidation and methanogenesis during pseudo-steady state operation. (Headspace $\mathrm{CO}$ and $\mathrm{H}_{2}$ used for calculation.)

Free energy change of propionate oxidation and methanogenesis during pseudo-steady state operation. (Dissolved $\mathrm{CO}$ and $\mathrm{H} 2$ used for calculation. $\mathrm{CO}$ and $\mathrm{H}_{2}$ were headspace concentrations in equilibrium with measured dissolved gas concentration.)

6-11 Applied OLR and HRT and reactor methane content variation during OLR loading variation experiments (OLR: $5-15 \mathrm{~kg} \mathrm{COD} / \mathrm{m} 3-\mathrm{d}$ ).

6-12 Hydrogen, carbon monoxide, and gas production rate during loading variation experiments (OLR: $5-15 \mathrm{~kg} \mathrm{COD} / \mathrm{m}^{3}-\mathrm{d}$ ).

6-13 Acetate, propionate, and $\mathrm{pH}$ during variation experiments (OLR: $5-15 \mathrm{~kg} \mathrm{COD} / \mathrm{m}^{3}-\mathrm{d}$ )..

Applied OLR and HRT and reactor methane content variation during OLR loading variation experiments (OLR: $5-25 \mathrm{~kg} \mathrm{COD} / \mathrm{m}^{3}-\mathrm{d}$ ).

6-15 Hydrogen, carbon monoxide, and gas production rates during OLR variation experiments (OLR: $5-25 \mathrm{~kg} \mathrm{COD} / \mathrm{m}^{3}-\mathrm{d}$ ).

Acetate, propionate, butyrate, isobutyrate and $\mathrm{pH}$ during OLR variation experiments (OLR: $5-25 \mathrm{~kg} \mathrm{COD} / \mathrm{m}^{3}-\mathrm{d}$ ).

6-17 Volatile suspended solids (VSS) during OLR variation experiment (OLR: $5-25 \mathrm{~kg}$ $\left.\mathrm{COD} / \mathrm{m}^{3}-\mathrm{d}\right)$.

Applied OLR and HRT and reactor $\mathrm{H} 2$ responses during OLR variation experiments (OLR:10-104 kg COD/m $\mathrm{m}^{3}-\mathrm{d}$ ).

6-19 Gas production rate, $\mathrm{CO}$ and methane content during OLR variation experiments (OLR:10$\left.104 \mathrm{~kg} \mathrm{COD} / \mathrm{m}^{3}-\mathrm{d}\right)$.

Acetate, propionate and soluble COD during OLR variation experiment (OLR:10-104 $\left.\mathrm{kg} \mathrm{COD} / \mathrm{m}^{3}-\mathrm{d}\right)$.

6-21 Four and five-carbon compounds measured during OLR variation experiment (OLR:10-104 $\left.\mathrm{kg} \mathrm{COD} / \mathrm{m}^{3}-\mathrm{d}\right)$.

$\mathrm{pH}$, total suspended solids (TSS), and volatile suspended solids (VSS) during OLR variation experiments (OLR:10-104 $\mathrm{kg} \mathrm{COD} / \mathrm{m}^{3}-\mathrm{d}$ ).

6-23 Applied OLR and HRT and reactor methane content variation during loading experiment (OLR: $10-104 \mathrm{~kg} \mathrm{COD} / \mathrm{m}^{3}-\mathrm{d}$ ).

6-24 Gas production rate, $\mathrm{H} 2$ and $\mathrm{CO}$ responses during OLR variation experiments (OLR:10-60 $\mathrm{kg} \mathrm{COD} / \mathrm{m} 3-\mathrm{d})$.

Acetate, propionate, butyrate, and isobutyrate during OLR variation experiment (OLR:10-60 $\mathrm{kg} \mathrm{COD} / \mathrm{m}^{3}-\mathrm{d}$ ).

Ethanol, n-propanol, valerate, isovalerate, and 2-methyl-butyrate during OLR variation

experiments (OLR:10-60 kg COD/m3-d); $2 \mathrm{MB}$ : 2-methyl-butyrate.

$\mathrm{pH}$ variation during OLR experiment (OLR: $10-60 \mathrm{~kg} \mathrm{COD} / \mathrm{m}^{3}-\mathrm{d}$ ).

Headspace and dissolved $\mathrm{H}_{2}$ variation during OLR perturbation...

Headspace and dissolved CO during OLR perturbation. 


\section{FIGURES}

Figure

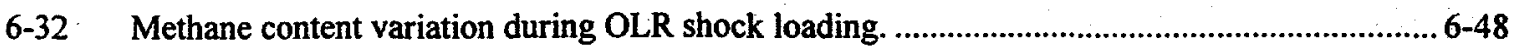

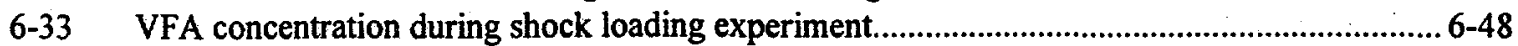

6-34 Hydrogen variation during OLR shock loading............................................................................6-49

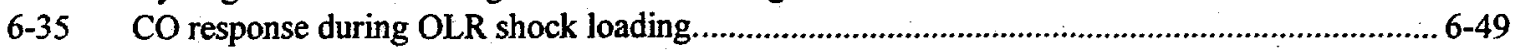

6-36 $\mathrm{pH}$ response during shock loading experiment. .......................................................................6-50

6-37 OLR variation during OLR shock loading (5/23/94)................................................................. 6-51

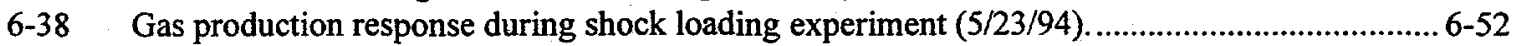

6-39 Methane content variation during OLR shock loading (5/23/94). ..............................................6-52

6-40 $\mathrm{pH}$ response during shock loading experiment (5/23/94)........................................................ 6-53

6-41 Hydrogen variation during OLR shock loading (5/23/94) .....................................................6-54

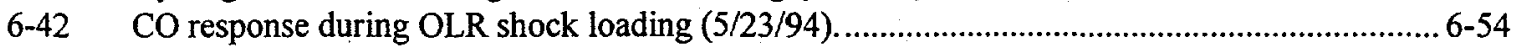

6-43 VFA concentration during shock loading experiment (5/23/94) ............................................ 6-55

6-44 Isobutyrate, 2-methyl-butyrate, iso-valerate and valerate concentration during shock loading

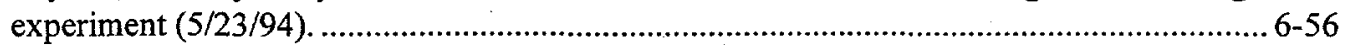

6-45 Ethanol and n-propanol response during shock loading experiment $(5 / 23 / 94) \ldots \ldots \ldots \ldots \ldots \ldots \ldots \ldots . . . .6-56$

6-46 (A) Applied organic loading rate and CO concentration during harmonic load variation experiment (USS1); and (B) Gas production rate and $\mathrm{H}_{2}$ concentration during harmonic load variation experiment (USS1).

6-47 (A) OLR variation and $\mathrm{H}_{2}$ response during harmonic variation experiment (USS2); and

(B) Gas production rate and CO response during harmonic variation experiment (USS2)... 6-59

6-48 (A) Harmonic random variation experiment (OLR variation and $\mathrm{H} 2$ response) (USS3); and

(B) Harmonic random variation experiment (gas production rate and $\mathrm{CO}$ response)

(USS3).

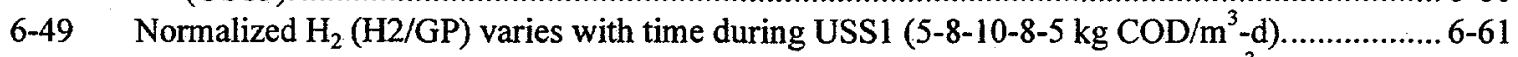

6-50 Normalized $\mathrm{CO}(\mathrm{CO} / \mathrm{GP})$ varies with time during USS1 $\left(5-8-10-8-5 \mathrm{~kg} \mathrm{COD} / \mathrm{m}^{3}-\mathrm{d}\right) \ldots \ldots \ldots \ldots \ldots . .6-61$

6-51 Normalized $\mathrm{H}_{2}\left(\mathrm{H}_{2} / \mathrm{GP}\right)$ varies with time during USS2 (5-10-15-20-15-10 $\left.\mathrm{kg} \mathrm{COD} / \mathrm{m}^{3}-\mathrm{d}\right) \ldots \ldots .6-62$

6-52 Normalized CO (CO/GP) varies with time during USS2 (5-10-15-20-15-10 $\left.\mathrm{kg} \mathrm{COD} / \mathrm{m}^{3}-\mathrm{d}\right) \ldots .6-62$

6-53 Normalized $\mathrm{H}_{2}\left(\mathrm{H}_{2} / \mathrm{GP}\right)$ varies with time during USS3 (10-15-20-25-30-50-60-104 kg $\left.\mathrm{COD} / \mathrm{m}^{3}-\mathrm{d}\right)$.

6-54 Normalized CO (CO/GP) varies with time during USS3 (10-15-20-25-30-50-60-104 kg $\left.\mathrm{COD} / \mathrm{m}^{3}-\mathrm{d}\right)$.

6-55 Bivariate plot of $\mathrm{CO} / \mathrm{GP}$ and $\mathrm{H}_{2} / \mathrm{GP}$ during OLR perturbations (5-8-10-8-5 kg $\mathrm{COD} / \mathrm{m}^{3}$-d) on bench UASB reactor (USS1).

6-56 Bivariate plot of $\mathrm{CO} / \mathrm{GP}$ and $\mathrm{H}_{2} / \mathrm{GP}$ during OLR perturbation (5-10-15-20-15-10-5 kg $\mathrm{COD} / \mathrm{m}^{3}-\mathrm{d}$ ) on bench UASB reactor (USS2).

6-57 Bivariate plot of $\mathrm{CO} / \mathrm{GP}$ and $\mathrm{H}_{2}$ /GP during OLR perturbation (10-15-20-25-30-60-104 $\mathrm{kg} \mathrm{COD} / \mathrm{m}^{3}-\mathrm{d}$ ) on bench UASB reactor (USS3).

6-58 Headspace $\mathrm{H} 2$ and gas production rate during OLR shock loading experiment (10 minute data, $\mathrm{H}_{2}$ low readings adjusted).

6-59 Headspace $\mathrm{H} 2$ and gas production rate during OLR shock loading experiment (10 minute data, $\mathrm{H}_{2}$ low readings not adjusted).

6-60 Headspace $\mathrm{CO}$ variation during OLR shock loading experiment (10 minute data)....................6-67

6-61 Methane content in headspace during OLR shock loading experiment (10 minute data).......... 6-68

6-62 H2/gas production versus time during OLR shock loading experiment (based on 10-minute data).

6-63 $\mathrm{CO} /$ gas production versus time during OLR shock loading experiment (based on 10-minute data). 


\section{FIGURES}

Figure

6-64 Bivariate plot of $\mathrm{CO} / \mathrm{GP}$ and $\mathrm{H}_{2} / \mathrm{GP}$ during OLR shock loading experiment (based on 10minute data).

6-65 (A) Bivariate plot of $\mathrm{CO} / \mathrm{GP}$ and $\mathrm{H}_{2} / \mathrm{GP}$ during organic shock loading experiment;

(B) Response curve of CO/GP during organic shock loading; and (C) Response curve of $\mathrm{H}_{2}$ /GP during organic shock loading. (GP - gas production; 4th run).

6-67 Responses of gas production and $\mathrm{H} 2$ during OLR shock loading............................................. 6-74

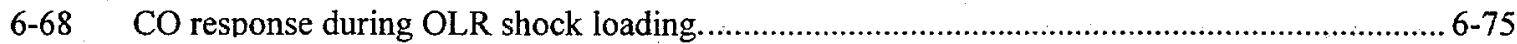

6-69 Normalized $\mathrm{CO}(\mathrm{CO} / \mathrm{GP})$ variation where $\mathrm{GP}$ is gas production rate..................................... 6-76

6-70 Normalized $\mathrm{H}_{2}\left(\mathrm{H}_{2} / \mathrm{GP}\right)$ variation where $\mathrm{GP}$ is gas production rate....................................... 6-77

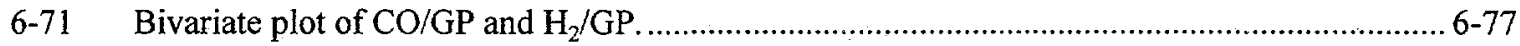

6-72 Methane content variation during OLR shock loading (USS6) .............................................. 6-78

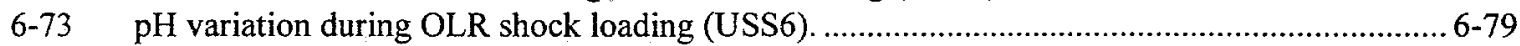

6-74 Acetate and propionate variations during OLR shock loading experiment................................... 6-80

6-75 Ethanol and $n$-propanol variation during OLR shock loading. ................................................6-81

6-76 Butyrate and isobutyrate variation during shock loading............................................................ 6-81

6-77 Valerate, isovalerate and 2-methyl-butyrate variation during shock loading.............................. 6-82

7-1 Substrate and products concentration profile (ethanol, acetate, propanol, propionate, hydrogen, formate, carbon monoxide, carbon dioxide, and methane) during ethanol fermentation.

7-2 Typical progress curves of ethanol, acetate, propionate, and n-propanol during ethanol degradation using whole granules (experiment was stopped after 71 hours)......................... 7-8

8-1 Schematic diagram of bench-top CSTR set-up. ....................................................................... 8-4

8-2 Acetate utilization by brewery granules flocs and fitted Monod kinetics (Ks $=0.45 \mathrm{mM}$, $\mathrm{km}=5.11 \mathrm{~g} / \mathrm{g} \mathrm{VS}-\mathrm{d}$ )

8-3 Propionate utilization by brewery granule flocs and fitted Monod kinetics (Ks $=0.40 \mathrm{mM}$, $\mathrm{km}=6.25 \mathrm{~g} / \mathrm{g}$ VS-d)

8-4 Ethanol utilization by brewery granule flocs with fitted Monod kinetics (Ks $=5.49 \mathrm{~g} / \mathrm{g}$ $\mathrm{VS} \mathrm{d}, \mathrm{km}=3.37 \mathrm{mM}$ ).

8-5 Hydrogen consumption by brewery granule flocs during ethanol conversion (Ks $=5.9 \mu \mathrm{M})$. Hydrogen consumption rate $=5.4 \mathrm{mM} / \mathrm{g}$ VS-h.

8-6 Acetate utilization rate at various impeller speeds (acetate $=7 \mathrm{mM}$, biomass $=2 \mathrm{~g}, \mathrm{pH}=7.0$, temperature $=37^{\circ} \mathrm{C}$ ).

8-7 Acetate utilization by whole granules, disrupted granules and flocs in batch assays $\left(31^{\circ} \mathrm{C}\right)$. Time scale was adjusted by biomass (VS, g). The slope represents utilization rate in $\mathrm{mM}$ acetate/g VS-h.

8-8. Acetate utilization by whole granules, disrupted granules and flocs in batch assays $\left(31^{\circ} \mathrm{C}\right)$. Time scale was adjusted by biomass (VS, g). The slope represents utilization rate in $\mathrm{mM}$ acetate/g VS-h.

8-9 Acetate utilization rate at different acetate concentrations and granule sizes (temperature $=$ $37^{\circ} \mathrm{C}$, granule diameter - flocs $=33 \mu \mathrm{m}$, whole granules $\left.=1.85 \mathrm{~mm}\right) \ldots \ldots \ldots \ldots \ldots \ldots \ldots \ldots \ldots \ldots \ldots \ldots \ldots \ldots . . .14$

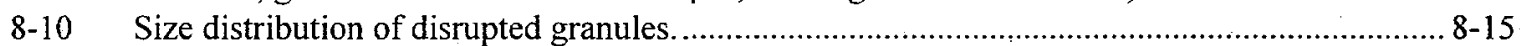

8-11 Acetate utilization at $37^{\circ} \mathrm{C}, 31^{\circ} \mathrm{C}, 26^{\circ} \mathrm{C}$ by whole granules. Time scale was adjusted by biomass (VS, g). The slope represents utilization rate in $\mathrm{mM}$ acetate/g VS-h. .................... 8-15

8-12 Acetate consumption rate of flocs and whole granules at $37^{\circ} \mathrm{C}, 31^{\circ} \mathrm{C}$, and $26^{\circ} \mathrm{C}$ (bars represent \pm SD of two repeated assays)........................................................................ 8-16

8-13 Linearization of $\mathrm{km}$ and temperature effects for acetate utilization by flocs $(y=33.44793$ $9888.54 \times \mathrm{R} 2=0.95)$. 


\section{FIGURES}

Figure

8-14 Linearization of $\mathrm{km}$ and temperature effects for acetate utilization by whole granules $(y=$

$$
25.658 \text { - } 7854.31 \times \text { R2 }=0.95 \text { ). }
$$

9-1 Influent phenol concentration during inhibition experiment (7/13/94)

Gas production response during phenol inhibition experiment (7/13/94).

9-6 pH response during phenol inhibition experiment (7/13/94).

9-7 VFA concentration during phenol inhibition experiment $(7 / 13 / 94)$

9-8 Isobutyrate, 2-methyl butyrate and iso-valerate concentration during phenol inhibition experiment $(7 / 13 / 94)$.

9-9 Ethanol and n-propanol response during phenol inhibition experiment (7/13/94).

9-10 CO/GP response during phenol inhibition experiment (7/13/94).

9-11 $\mathrm{H}_{2} / \mathrm{GP}$ response during phenol inhibition experiment (7/13/94).

9-12 Bivariate plot of $\mathrm{CO} / \mathrm{GP}$ and $\mathrm{H}_{2} / \mathrm{GP}$ during phenol inhibition experiment (7/13/94). 


\section{TABLES}

5-1 Operational conditions of bench-scale UASB reactor during hydraulic experiments................... 5-5

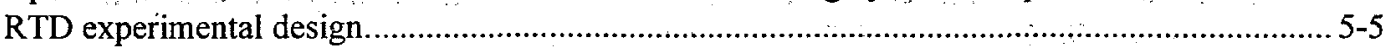

$5-3$

Effect of organic loading rate on UASB reactor hydraulic characteristics. ................................. 5-9

$5-4$

Effect of recirculation on UASB reactor hydraulic characteristics ${ }^{\mathrm{a}}$.......................................... 5-9

$5-5$

Fluidization index of UASB reactor under different operating conditions and granule sizes..... 5-21

6-1

Operational conditions of the bench-scale UASB reactor during pseudo-steady state experiment.

Range of mean, coefficient of variances and standard error of monitoring variables during pseudo-steady state experiment.

Analysis of variance of each monitoring variable among OLRs operated at pseudo-steady state $(\alpha=0.05)$.

Results from Duncan's multiple range test and LSD test on means of monitoring variables (grouped by OLR).a.

Maximum frequency of acetate, propionate, $\mathrm{CO}, \mathrm{H} 2$, gas production, and methane at different OLRs (calculated from periodogram)...

Fisher's white noise test results for each variable at different organic loading rate.

6-10 Mean, SD and STDerr of CO/GP and $\mathrm{H} 2 / \mathrm{GP}$ during steady state operation. ..

6-11 Gibbs free energy change for propionate oxidation and methanogenesis at standard conditions.

Headspace and dissolved $\mathrm{H} 2$ and $\mathrm{CO}$ in the bench-scale UASB reactor.

Mean, standard deviation and standard error of normalized $\mathrm{CO}(\mathrm{CO} / \mathrm{GP})$ of three OLR overloading experiments (USS1 - USS3) in $\mathrm{ppb} / \mathrm{ml} / \mathrm{h}$.

Mean, standard deviation and standard error of normalized H2 (H2/GP) of three OLR overloading experiments (USS1 - USS3) in $\mathrm{ppm} / \mathrm{ml} / \mathrm{h}$.

6-15 Steady state baseline calculation of CO/GP and H2/GP during steady state operation and OLR overloading.

6-16 Mean, SD and STDerr or CO/GP and H2/GP at steady state (in-control) during OLR shock loading experiment USS4.

Possible reactions involving n-propanol, propionate and ethanol during ethanol degradation and their standard Gibbs free energy.

Substrate and major products acetate and propionate concentration varied with propanol during ethanol assay ${ }^{\mathrm{b}}$

$\mathrm{GC} / \mathrm{MS}$ results from ${ }^{13 \mathrm{C}}$ labeled ethanol degradation assay.

Sampling frequency for the acetate utilization assays........................................................... 8-5

8-3 Sampling frequency for the propionate utilization assays....................................................... 8-5

8-4 Summary of literature values of acetate and propionate utilization kinetics compared to results from this study.

8-5 Kinetics of ethanol and hydrogen utilization by the brewery granules compared to reported values in the literature.

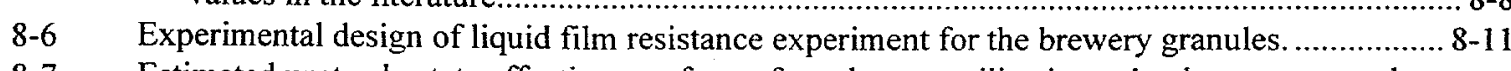

8-7 Estimated unsteady state effectiveness factor for substrate utilization using brewery granules at $37^{\circ} \mathrm{C}$ and $\mathrm{pH}=7.0$. 


\section{TABLES}

Table

Page

8-8 Estimated $\mathrm{km}$ of whole granule and flocs at $37^{\circ} \mathrm{C}, 31^{\circ} \mathrm{C}$, and $26^{\circ} \mathrm{C}$, in g/g VS-d. 8-16

8-9 Acetate threshold and calculated minimum available Gibbs free energy during acetate metabolism.

8-10 Reported acetate threshold values.

8-22

8-11 Reported hydrogen threshold values for different hydrogenotrophic anaerobes. 8-22 


\section{SUMMARY}

The potential of using trace gases $\mathrm{H}_{2}$ and $\mathrm{CO}$ for monitoring and/or control of anaerobic treatment systems based on work with anaerobically digested sludge appeared promising. The long hydraulic residence time (HRT) in typical municipal digesters (15-30 days), however, means that most problems in these type systems can be adequately handled using currently practiced techniques. One potential application of trace gas monitoring that held promise was its application to high-rate anaerobic treatment systems used for industrial wastewater purification. Being able to reliably detect the onset of operational difficulties on-line would allow these type systems to be designed at high applied organic loading rates (OLRs), and therefore reduce the size and capital costs of the treatment system.

An experimental program was designed to examine the behavior of an upflow anaerobic sludge blanket (UASB) reactor system under steady state and in response to organic loading perturbations. The responses of trace gases $\mathrm{CO}$ and $\mathrm{H}_{2}$ were tracked using an on-line, real-time gas-monitoring system linked to a computer-controlled data acquisition package. Data on conventional process parameters such as $\mathrm{pH}$, chemical oxygen demand (COD), volatile fatty acids (VFAs) were concurrently collected.

The most widely used anaerobic treatment system worldwide (and in the United States) is the UASB process. It is estimated that more than $90 \%$ of the high-rate anaerobic treatment systems installed worldwide are UASB or modified UASB-type systems. In the United States, the use of this process to treat brewery wastes is gaining rapid acceptance and popularity. A total of four systems had been installed in the United States for brewery waste treatment at the time this work was initiated.

For this work, a laboratory-pilot UASB reactor was constructed and instrumented for on-line data acquisition. The UASB reactor was used to treat a synthetic brewery waste developed based on a 5day sampling at a brewery. A series of steady- and unsteady state experiments was used to study system response and examine process control algorithms by simulating cyclic and cyclic random inputs to the reactor and modeling these results using time-series analysis, statistical techniques, and control charts and plots for evaluating the data collected.

System hydraulics, biological kinetic rates, and mass transfer are important factors in the performance of any biological treatment system. In order that results obtained from this work, using laboratory pilot-scale reactors, could be readily applied for field-scale systems, careful characterization of these attributes were made.

A review of existing hydraulic models was performed and a theoretical framework for an integrated reaction, diffusion, and hydraulic model developed (Section 4). This framework included mass transport and diffusion into a finite "active" biofilm layer of the granules, and is therefore appropriate for use with other biofilm systems such as anaerobic fluidized bed reactors.

The hydraulics of the UASB system were characterized under various hydraulic and organic loading rate conditions. At OLRs, hydraulics were dominated by the surface upflow rate. At high OLRs, gas production was the major factor controlling system hydraulics. For high OLRs, none of the models available accurately described system hydraulics. A new model that described the UASB as a continuously stirred tank (CSTR), with dead volume and by-pass flow, granule bed in series with a dispersion plug flow reactor (the clarifier volume above the granule bed) was developed. This model fit all observed data at high OLRs (Section 5).

Monitoring of conventional process indicators (i.e., $\mathrm{pH}, \mathrm{VFA}$, gas production) and trace gas $\left(\mathrm{H}_{2}\right.$ and $\mathrm{CO})$ indicators using a matrix of nine different OLRs $\left(4-23 \mathrm{~kg} \mathrm{COD} / \mathrm{m}^{3}-\mathrm{d}\right)$ and system HRTs $(0.5$ to 2.5 days) was performed to determine any correlation among the indicators. Of OLR, HRT, and influent $C O D$, only OLR had any significant influence on the process indicators examined. All 
parameters except methane increased with increases in OLR; methane decreased with increased OLR. The OLR and gas production rate (GP) were observed to be linearly correlated. The other parameters were correlated in a non-linear fashion. Results of spectral analysis indicated no periodicity for the parameters measured.

The best method of applying trace gases for monitoring was observed to be the use of a bivariate plot of $\mathrm{CO} / \mathrm{GP}$ versus $\mathrm{H}_{2} / \mathrm{GP}$. All of this "normalized" data fell within a narrow operating envelope of $\{2,1\}$ for all the steady state data.

A series of six unsteady state experiments with on-line data for $\mathrm{CO}, \mathrm{H}_{2}, \mathrm{GP}$, and methane collected at 10-minute intervals was conducted. The first three experiments examined step and impulse increases in OLR at times and amplitudes that did not significantly affect performance of the UASB system. This was followed by three experiments (one with $\mathrm{pH}$ control, two without) during which the OLR was increased to $60 \mathrm{~kg} \mathrm{COD} / \mathrm{m}^{3}-\mathrm{d}$ for a sufficient period to induce process upset or failure. In all cases, $\mathrm{CO}$ and $\mathrm{H}_{2}$ did not provide early warning. It was observed that dissolved $\mathrm{CO}$ and $\mathrm{H}_{2}$ concentrations were not close to being in equilibrium with the gas phase. $\mathrm{CO}$ in the liquid phase was much higher than would be expected based on the gas phase samples and $\mathrm{H}_{2}$ was much lower than would be expected. The ratios of aqueous to gas phase varied randomly and to a significant extent for both gases.

The use of the bivariate plot of $\mathrm{CO} / \mathrm{GP}$ and $\mathrm{H}_{2} / \mathrm{GP}$ was observed to accurately depict when system failures occurred. Because $\mathrm{CO}$ remained at elevated concentrations after the system recovered, the use of this type of control chart for tracking recovery is not appropriate.

The failure of $\mathrm{CO}$ to respond as anticipated was investigated further and was observed to be in part related to the appearance of n-propanol in the system effluent during the upset conditions. Some investigation of this phenomenon was performed (Section 7). The failure of $\mathrm{CO}$ to be correlated as well with acetate as during previous work is believed due to the fact that 1) other reactions involving $\mathrm{CO}$ production and consumption occur during the degradation of sugars, and 2) dissolved and gasphase $\mathrm{CO}$ were not in equilibrium, as was the case in experiments performed using sludge and a completely mixed chemostat type system.

Finally, the effect of perturbing UASB with addition of phenol was examined. During this experiment, $\mathrm{CO}$ increased rapidly in response to phenol addition well in advance of the upset and prior to response of any other process indicator monitored. The bivariate plot was observed to work well for predicting upset, but was not effective in indicating when system recovery occurred. This is again due to $\mathrm{CO}$ concentrations remaining elevated after recovery had occurred as measured by all other process indicators.

Final conclusions are that although there is some merit in using $\mathrm{CO}$ and $\mathrm{H}_{2}$ as process indicators, particularly the use of a bivariate plot or control chart using CO/GP versus $\mathrm{H}_{2} / \mathrm{GP}$, the additional benefit in terms of providing early warning was not realized on a consistent basis. The added cost of a trace gas monitoring system for a typical industrial application does not appear justified based on these results. 


\section{Section 1}

\section{INTRODUCTION}

Anaerobic processes have been used for wastewater treatment for more than a century. Over the past 20 years, anaerobic treatment has attracted considerably greater attention due to the development of high-rate anaerobic process advanced monitoring and control technologies, and new discoveries in anaerobic microbiology.

Many studies have been performed using high-rate anaerobic processes such as UASB (upflow anaerobic sludge blanket) reactors, anaerobic fluidized bed reactors (AFBRs) and anaerobic filters. UASB and AFBR reactors with their ability to operate at short retention times (6-12 hrs), high organic loading rates $\left(10-15 \mathrm{~kg} \mathrm{COD} / \mathrm{m}^{3}-\mathrm{d}\right)$, and high removal efficiency, have broad applications in the food industry worldwide. There has been considerable application of UASB systems in the USA and Netherlands. Anaerobic granules in UASB reactor systems are aggregates of microbial consortia composed of 3-5 major groups of organisms. These granules have the advantages of high volumetric densities of microorganisms. This high density of biomass accumulation allows excellent treatment performance in small reactor volumes. All three major steps in the process of anaerobic degradation (hydrolysis, acetogenesis, and methanogenesis) are involved in treating brewery wastewater. The complexity of the UASB process and wide range of potential applications demonstrate the importance of developing strong engineering and scientific knowledge to achieve stable and controlled performance.

In biological wastewater treatment processes, the primary method of characterizing a process is to combine the knowledge of physico-chemical and microbial kinetics to allow a better understanding of the degradation process. Studying UASB reactors includes studying the inherent properties and physicochemical-biological characteristics of system inputs and the use of on-line monitoring to help determine the responses of system variables. Such research should result in the ability to control the process with greater confidence. This can further improve system performance and prevent gross process failure. The present research focused on an overall description of UASB reactor performance in treating a synthetic brewery waste using anaerobic granules, including 1) characterization of UASB reactor hydraulics, 2) determination of metabolic performance of the anaerobic granules, and 3) monitoring and modeling of UASB reactor performance. 


\section{Section 2}

\section{BACKGROUND}

\section{METHANOGENESIS AND METHANE PRODUCTION}

Methanogenesis is the terminal step in anaerobic degradation once inorganic electron acceptors such as nitrate and sulfate are exhausted. It is, therefore, the most important process in anaerobic freshwater lake sediments, sewage sludge, or the rumen, where the supply of nitrate or sulfate is small compared with the input of organic substrates. Chemically speaking, the entire, rather complex, process of anaerobically transforming complex organic substances to methane and carbon dioxide is a disproportionation of organic carbon into its most oxidized and its most reduced form. Carbon and electron flow in methanogenic environments can be described by a three-step process (Figure 2-1). Complex organic matter is first broken down to alcohols and carboxylic acids (long-chain fatty acids) through hydrolysis and fermentation. These compounds are further converted to acetate and $\mathrm{H}_{2}$ during acetogenesis. Finally, methane is produced from the acetate and $\mathrm{H}_{2} / \mathrm{CO}_{2}$. Major metabolic groups involved are: hydrolytic and fermentative bacteria (I), proton-reducing acetogens (II), methanogens (hydrogenotrophic and acetoclastic) (III), and homoacetogenic bacteria (IV). Depending on the beginning substrate, acetoclastic methanogenesis contributes about $70 \%-80 \%$ of the methane produced. The remaining $20 \%-30 \%$ of methane is formed by hydrogenotrophic methanogenesis. The percentage of methane in the gas mixture formed depends on the oxidation state of the substrate used. Carbohydrates are converted to equal amounts of methane and carbon dioxide, while catabolism of methanol and lipids produces more methane than carbon dioxide. During brewery wastewater treatment, all three steps of the anaerobic degradative process are involved. Theoretically, about $75 \%$ methane and $25 \% \mathrm{CO}_{2}$ were produced from degradation of the brewery waste used in this study.

Anaerobic degradation of complex organics requires the interactions of different groups of microorganism to form a "network" for a complete conversion of the organics to $\mathrm{CO}_{2}$ and $\mathrm{CH}_{4}$. Variation of environmental conditions could result in significant changes in microbial populations within the system and affect performance. Methanogenic bacteria are very sensitive to $\mathrm{pH}$ variations. A low $\mathrm{pH}$ environment can inhibit methane production to a great extent.

Methanogens are specialized for a unique form of energy metabolism. The central metabolic pathway in autotrophic methanogens involved the stepwise reduction of a one-carbon unit, which was derived from the growth substrate, such as $\mathrm{CO}_{2}$. Acetoclastic methanogenesis is dependent upon the ability of the cell to cleave the acetate molecule, reduce the methyl substituent, and oxidize the carboxyl substituent. 


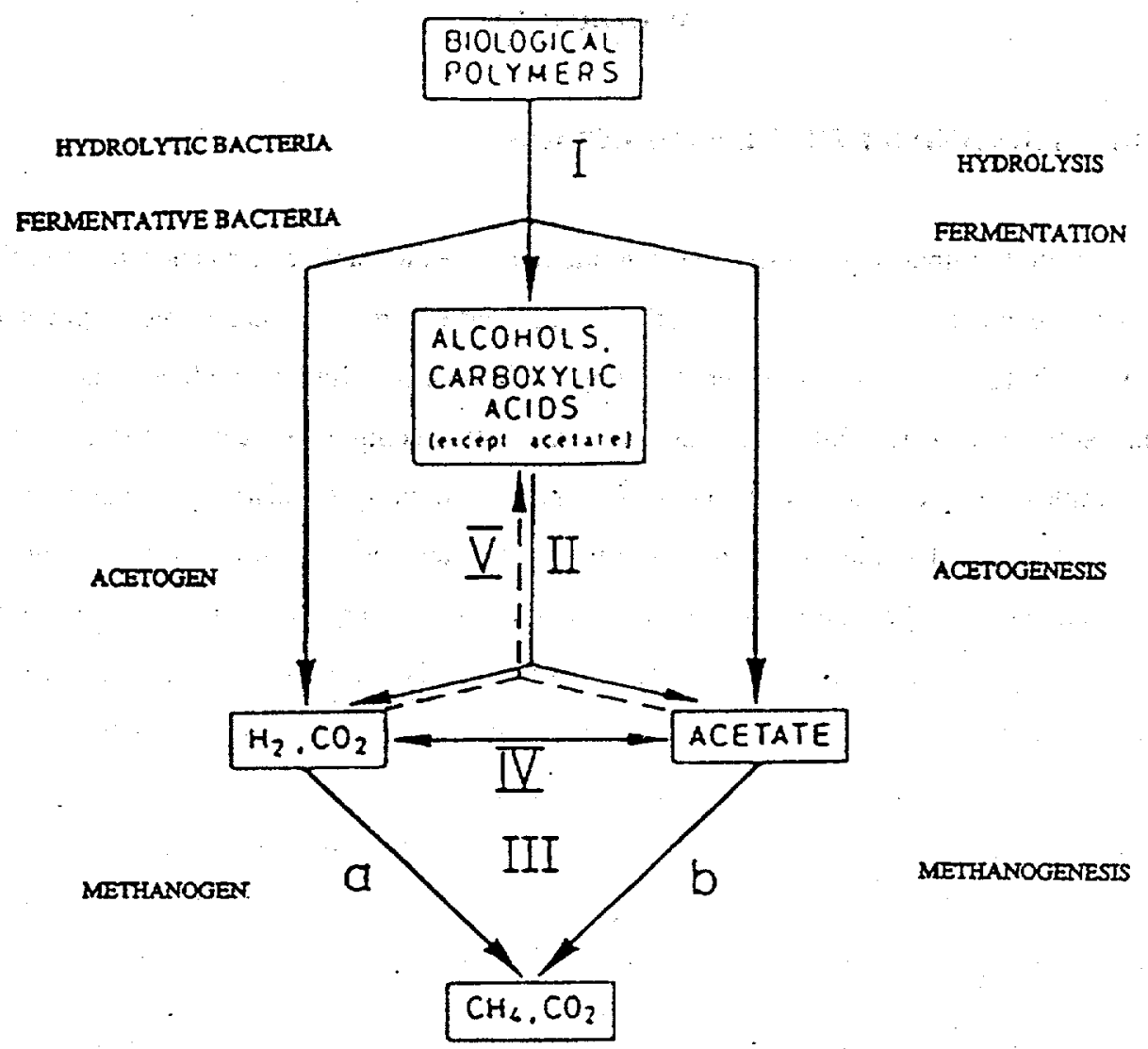

Figure 2-1. Carbon and electron flow in methanogenic environments. Metabolic groups involved: I. Hydrolytic and fermentative bacteria; II. Proton-reducing acetogenic bacteria; III. Methanogenic bacteria a) hydrogenophilic b) acetophilic; IV. Homoacetogenic bacteria; V. Fatty acid-synthesizing bacteria. After Zehnder et al. (1981).

Unique coenzymes found in methanogens include factor $F_{420}$, MFR (methanofuran, carbon dioxide reduction factor), methanopterin, nickel-containing factor $F_{430}$, mobile factor (required by Methanomicrobium mobile), component B of the methylreductase system. These coenzymes play a major role in the methanogenic pathways. Methanogenesis from acetate to methyl coenzyme $\mathrm{M}\left(\mathrm{CH}_{3}-\mathrm{S}-\mathrm{CoM}\right)$ involves coenzyme $M$ as a methyl equivalent carrier, carbon monoxide dehydrogenase (CODH) which oxidizes the carboxyl carbon, and cobamides. Methanogenesis from $\mathrm{CO}_{2}$ and $\mathrm{H}_{2}$ involves three coenzymes - MFR, $\mathrm{H}_{4} \mathrm{MPT}$, and Coenzyme $\mathrm{M}$ - as carbon carriers during the sequential reduction of $\mathrm{CO}_{2}$ to $\mathrm{CH}_{4}$. The terminal reduction of $\mathrm{CH}_{3}$-S-CoM by hydrogen involves two additional cofactors, component $\mathrm{B}$ and factor $\mathrm{F}_{430}$ of the $\mathrm{CH}_{3}-\mathrm{S}-\mathrm{CoM}$ methylreductase system, which reduces the methyl moiety to methane.

Methanogens are limited to simple growth substrates and can only obtain limited amounts of energy from these substrates. A comparison of the free energy changes of hydrolysis of ATP $(-31.8 \mathrm{~kJ} / \mathrm{mol})$ and those of methane formation from the substrates hydrogen and carbon dioxide $\left(-135.6 \mathrm{~kJ} / \mathrm{mol}\right.$ of $\left.\mathrm{CH}_{4}\right)$, formate 
$(-130.1 \mathrm{~kJ})$, methanol $(-104.9 \mathrm{~kJ})$, methylamines (about $-74 \mathrm{~kJ})$, carbon monoxide $(196.7 \mathrm{~kJ})$ and acetate $(-31.0 \mathrm{~kJ})$ lead to the conclusion that only small amounts of energy are available to these organisms (Daniels et al., 1984; Thauer et al., 1977). Membranes of methanogens are important in proton-dependent energy coupling. This includes a membrane-associated, proton-dependent ATPase coupled to a sodium/proton antiporter. $\mathrm{A} \mathrm{Na}^{+}$gradient is maintained by a Na${ }^{+} / \mathrm{H}^{+}$antiporter implicated in ATP synthesis. Active transport has been described in transport coenzyme $M$, nickel, and amino acids. Hydrogenase is central to methanogen bioenergetics. Methanogenesis and its energetics have been thoroughly reviewed (Jones et al., 1987; Daniels et al., 1984).

Many of the bacteria of groups I, III, and IV have been cultivated and studied in detail. Not much is known about the bacteria of group II because they are difficult to cultivate independently; a sink for the reducing equivalents they produce is required if the acetogenic reactions are to have favorable energetics.

The Gibbs free energy change $\left(\Delta G^{\prime}\right)$ of a single chemical reaction

$$
a A+b B \rightarrow c C+d D
$$

can be written in the form

$$
\Delta \mathrm{G}^{\prime}=\Delta \mathrm{G}^{\mathrm{o}^{\prime}}+\mathrm{RT} \ln \left(\frac{c^{c} d^{d}}{a^{a} b^{b}}\right)
$$

Lowercase letters $a, b, c$, and d signify molar concentrations of compounds $A, B, C$, and D. Primes denote evaluation in aqueous solution at $\mathrm{pH}$ 7. The standard free energy change $\left(\Delta \mathrm{G}^{\circ}\right)$ denotes the free energy change in aqueous solution with all other reactants and products present at $1 \mathrm{M}$ concentration at 1 atmosphere and $273^{\circ} \mathrm{K}$. In a closed system, the reaction will proceed from left to right if and only if $\Delta \mathrm{G}^{\prime}$ ' is negative.

Since the proton reducing acetogenic bacteria (group II) catalyze reactions which are thermodynamically endergonic under standard conditions, they can be cultivated only in the presence of hydrogen-scavenging bacteria such as methanogens, which maintain a sufficiently low hydrogen partial pressure to allow substrate degradation (Wolin 1976). A scheme that visualizes the thermodynamically delicate situation of ethanol and propionate degrading bacteria is given in Figure 2-2. In order for propionate to be converted to acetate, the $\mathrm{H}_{2}$ partial pressure must be maintained lower than $10^{-4} \mathrm{~atm}$. Methanogenic hydrogen consumers, however, require a $\mathrm{H}_{2}$ level higher than $10^{-6} \mathrm{~atm}$ to maintain a negative $\Delta \mathrm{G}^{\prime}$ for 
methanogenesis. The lower bound of $\mathrm{H}_{2}$ reflects a minimum energy. Energy requirements form the basis of the concept of substrate thresholds. A threshold is the substrate concentration below which a specific organism can no longer use that substrate as the primary growth substrate.

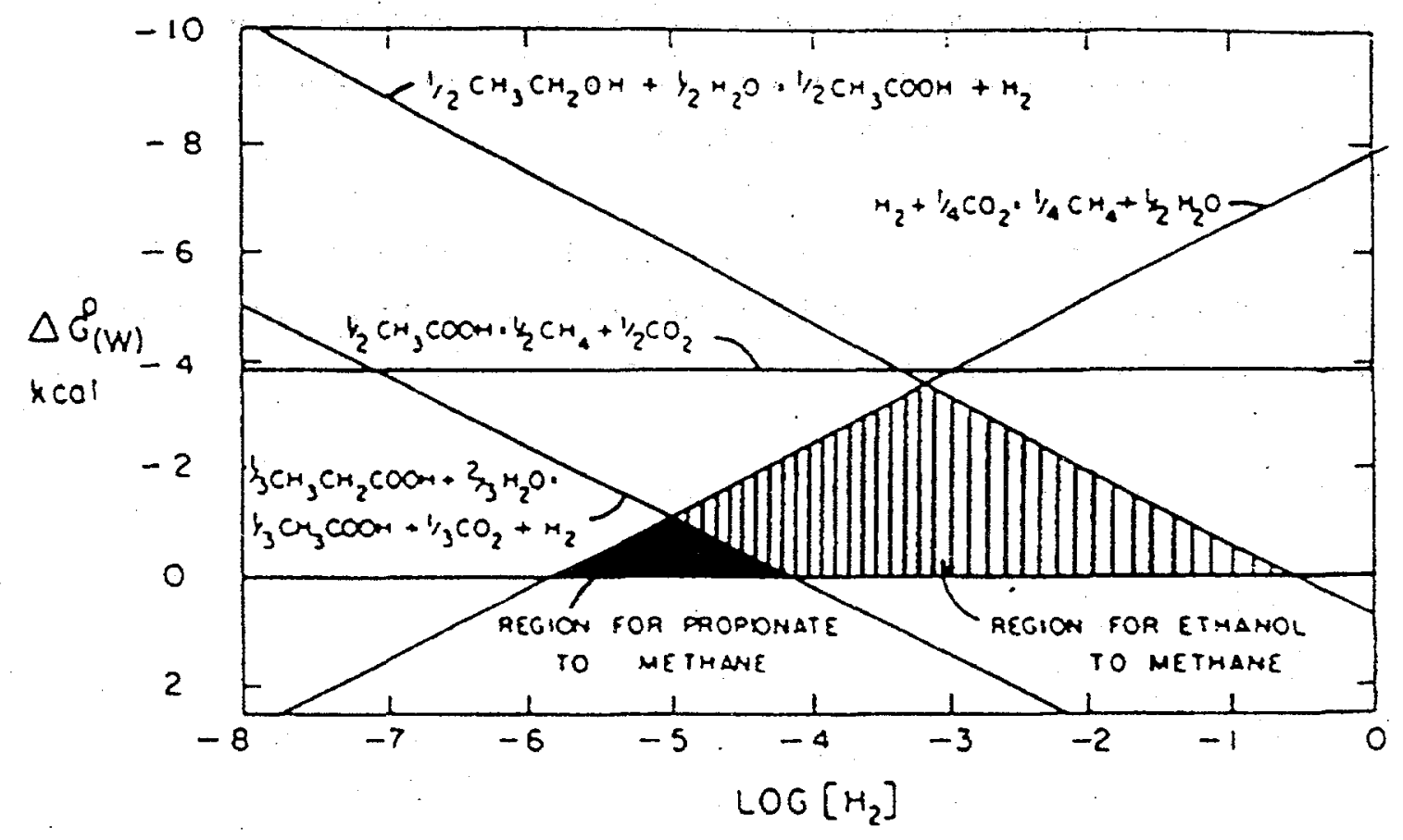

Figure 2-2. Effect of hydrogen partial pressure on the Gibbs free energy changes of conversion of ethanol, propionate, acetate and hydrogen during methane formation. After McCarty (1981).

\section{SUBSTRATE TRANSPORT AND UTILIZATION WITHIN ANAEROBIC GRANULES}

Reaction kinetics within biofilm systems (including anaerobic granules) often involve mass transfer into biofilms and simultaneous substrate utilization. The effect of mass-transfer or diffusion on a specific system can be described by a coupled reaction-diffusion relationship. When using mixed cultures, substrate utilization can be generally described by Monod equation $\left(\frac{d S}{d t}=\frac{k m X S}{K s+S}\right)$ when there are no mass transfer limitations. For Monod limiting substrate kinetics, when the substrate concentration is small $(\mathrm{S}<<\mathrm{Ks})$, substrate utilization rate is proportional to $\frac{\mathrm{km}}{\mathrm{Ks}}$, the ratio of specific maximum substrate utilization rate $(\mathrm{km})$ to half velocity constant $(\mathrm{Ks})$ times the biomass concentration $(\mathrm{X})$ and substrate concentration $(\mathrm{S})$. The reaction rate approaches a constant $(\mathrm{kmX})$ when the substrate concentration 
becomes very large $(\mathrm{S}>>\mathrm{Ks})$. Kinetic parameters $\mathrm{km}$ and $\mathrm{Ks}$ reflect the intrinsic properties of microorganisms for a specific substrate.

In a biofilm system, calculation of the observed rate of substrate disappearance requires evaluation of the concentration profile of substrate within the biofilm. Substrate must first traverse the external film or liquid boundary layer from bulk liquid and subsequently diffuses into biofilms, where the biochemical reactions occur. The external mass transfer (substrate flux, [Ns] in mass per unit time per unit area) of substrate from the bulk liquid to the interface of liquid film and biofilm is described by the following equation:

$$
\mathrm{Ns}=\mathrm{K}_{\mathrm{L}}(\text { So-S })
$$

where $\mathrm{K}_{\mathrm{L}}$ is the mass transfer coefficient. $\mathrm{S}$ and So are the substrate concentrations at the interface and in the bulk liquid, respectively. The diffusion of substrate follows Fick's law, or in $\mathrm{X}$ axis direction

$$
\frac{\partial S}{\partial t}=-D \frac{\partial^{2} S}{\partial x^{2}}
$$

where $\mathrm{D}$ is substrate diffusivity. The observed overall reaction rate (apparent rate) in the bulk liquid, therefore, is a function of both reaction and mass transfer. Substrate concentrations within the biofilm vary with time and position. At steady state, the rate of substrate transported into the biofilm is balanced by substrate consumption, so that a substrate profile within the biofilm is established. There are several factors affecting substrate utilization under a mass transfer limited biofilm system: 1) biofilm thickness or granule diameter, 2) intrinsic kinetic parameters, 3) temperature and $\mathrm{pH}, 4)$ substrate concentration in the bulk liquid, 5) diffusion and mass transfer coefficients, and 6) liquid film thickness. Using a dimensional analysis, the mass transfer limitation in the biofilm system can be described by an effectiveness factor $(\eta)$. The $\eta$ is defined as the ratio of observed reaction rate at the surface of the biofilm to the reaction rate without mass transfer limitation, or the intrinsic reaction rate. When $\eta$ is less than 1 , the system is mass transfer limited. When $\eta$ approaches 1 , reaction becomes rate-limiting. The effectiveness factor is influenced mostly by biofilm thickness or granule size. A detailed description of effectiveness factor and its evaluation is described elsewhere (Bailey and Ollis 1986). Mass diffusion through biofilm appears species dependent. The diffusivity of different species varies (Bennett and Myers, 1982). For the same substrate, the diffusivity changes with temperature. Within the biofilm, diffusion is described by an effectiveness diffusion coefficient which combines influences of the substrate diffusivity in the bulk liquid, 
particle porosity, tortuosity factor and restricted diffusion situation in pores, internal surface chemistry, and charge.

\section{PROCESS MONITORING AND DYNAMIC MODELING}

Process monitoring is performed to detect changes of key parameters from a target level or to observe the variability of the process. Monitoring can be combined with control measures to maintain a process at a certain level of performance. Monitoring is accomplished using process indicators. Process indicators are used to: 1) tell how the process is operating currently, 2) tell how the process may be behave in the near future, and 3) identify periods of poor operation when assignable causes exist. Ideal process indicators should: 1) be sensitive to changes in the process with low noise, 2) be easy to measure, 3) have intrinsic meaning, 4) provide early warning, and 5) be amenable to on-line measurement.

Anaerobic wastewater treatment processes, in general, are $\mathrm{pH}$ - and temperature-sensitive, vulnerable to toxicants, and require a certain range of hydrogen concentration to maintain a balance between hydrogen producers and hydrogen utilizers. For best performance of high-rate systems, the process must be monitored on a real-time basis. Various methods have been developed to detect variations in anaerobic wastewater treatment process, including on-line or off-line of the liquid, solid, or gas phase monitoring. Conventional process indicators in an anaerobic system have included reactor liquid $\mathrm{pH}$, effluent VFA and $\mathrm{COD}$, gas production, and methane production. Another category of monitoring has focused on parameters that have intrinsic meaning for biological consortia. These include using enzymatic, immunological, or gene probe assays, lipid composition analysis, $\mathrm{F}_{420}$ (growth factor), and fatty acids methyl ester (FAME) variation among methanogens. Most of these methods are off-line and time consuming. With improvements in monitoring technology and instrumentation, on-line monitoring in anaerobic wastewater treatment is becoming increasingly available. In recent years, there has been considerable interest in online monitoring of the trace gases $\mathrm{CO}$ and $\mathrm{H}_{2}$. A computerized, on-line monitoring system along with process indicators that are simple and sensitive and reflect microbial or biochemical variations can contribute significantly to the operation of a high-rate anaerobic treatment process. Successful process monitoring allows application of a control strategy and can prevent system failure.

Mathematical modeling is still more of an art than a science. Several different approaches are possible based on existing information, hypothesis formulation in the literature, or theoretical knowledge from other branches of engineering and science. These lead to an explanation of phenomena known to occur in the field but not predicted by existing models. In wastewater treatment processes, mathematical modeling can serve many purposes. Modeling serves as a conceptual framework upon which to build and test 
hypotheses, and it allows for exploration of the impact of a wide range of system variables, thereby extending knowledge. Modeling allows the development of control strategies by facilitating the investigation of treatment system response to a wide range of inputs without jeopardizing actual system performance. Dynamic modeling for bioreactors is used to describe unsteady state reactor performance and to characterize transient behavior. The application of mathematical models to anaerobic waste treatment was initially based on substrate utilization and growth of biomass. These simple models, although not a great advance over empirical equations for design and operating treatment systems, were a step forward. The models were not, however, satisfactory in describing dynamic behavior and treatment of complex organic waste under different reactor flow conditions. For these cases, a more complex structured model is necessary. A structured model is one which considers the biomass and substrate to be divided into several components, with biomass growth mediating the conversion of substrate to intermediates and final products. Physical, chemical and biological interactions during this process within the boundary volume (i.e., the reactor) are considered. Because of the unique characteristics of the bacteria in anaerobic treatment systems (low growth rates, high sensitivity to environmental factors, and complex syntrophic populations) and variations of reactor configurations, use of such a modeling approach becomes especially important.

To mathematically describe the biological processes, the kinetics, stoichiometries, mass transport, and hydraulic relationships are incorporated into process material balances. This results in a family of simultaneous mathematical equations (a model) which can be used to describe and predict system performance under a variety of conditions. 


\section{Section 3}

OBJECTIVES AND PROCEDURAL OVERVIEW

\section{OBJECTIVES}

The goal of this study was primarily to extend engineering knowledge in the area of anaerobic treatment. The objective is to develop the information base needed to improve process monitoring, control, and design of UASB reactors. Specific tasks within this objective included:

- Characterize the UASB reactor in terms of its hydraulic, kinetic, and mass transfer aspects.

- Monitor UASB reactor overall performance under pseudo-steady state and dynamic conditions using conventional parameters and the trace gases $\mathrm{CO}$ and $\mathrm{H}_{2}$.

\section{UASB Reactor Hydraulics}

The objectives with regard to UASB reactor hydraulics were to:

- Examine the effect of organic loading rate (OLR) and hydraulic flux on UASB reactor hydraulics and performance.

- Evaluate existing flow models.

- Develop of improved flow models for the UASB reactor.

\section{Metabolic Performance of UASB Reactors}

The objectives with regard to metabolic performance of UASB reactors were to:

- Examine the metabolic activity of brewery granules using different substrates.

- Examine mass transfer and diffusional limitations within the granules during substrate utilization.

- Examine the effect of temperature and substrate flux on overall substrate utilization.

- Examine acetate threshold during methanogenesis.

- Identify granule structure and predominant microbial groups.

- Identify pathway(s) of ethanol fermentation including n-propanol formation. 


\section{Monitoring and Modeling UASB Reactors}

The objectives with regard to monitoring and modeling. UASB reactors were to:

- Examine the impact of hydraulic loading, OLRs and organic composition on $\mathrm{H} 2$ and $\mathrm{CO}$ responses in the UASB reactor and relate these to reactor performance.

- Examine the potential of using $\mathrm{H} 2$ and $\mathrm{CO}$ to detect onset of unstable conditions and system failure.

- Develop a dynamic mathematical model for UASB reactors by integrating reactor hydraulic, kinetic, and mass transfer information.

\section{EXPERIMENTAL APPROACHES}

\section{UASB Reactor Hydraulics}

Experiments were conducted using a tracer study followed by flow modeling. An inert tracer, lithium chloride, was used. An impulse of the tracer was imposed on the reactor system and the response (residence time distribution curves) measured. Several existing models were evaluated. Improved models were then developed and compared with these previous models.

\section{Metabolic Performance of Biomass from an UASB Reactor}

Experiments were conducted in a batch Multigen Bench-Top Fermentor, continuously stirred tank reactor (CSTR). Liquid film boundary layer mass transfer limitation was examined by controlling mixing in the reactor. Temperature was controlled in order to examine temperature effects. Anaerobic granules were disintegrated to help examine the extent of diffusional limitations. Substrates analyzed included ethanol, propionate, acetate, and $\mathrm{H}_{2}$ (during ethanol degradation).

Microscopy was performed to examine the internal physical structure and biological properties of anaerobic granules. Labeled substrate was used in determining the potential pathways of n-propanol production during ethanol degradation.

\section{Monitoring and Modeling UASB Reactors}

These experiments were conducted in a bench-scale UASB reactor equipped with an on-line data acquisition system for monitoring $\mathrm{H}_{2}, \mathrm{CO}$, methane content, and gas production rate. During pseudosteady state, the reactor was operated at various combinations of OLR, HRT and feed composition. During unsteady state operation, organic overloading was imposed on the reactor. The responses of $\mathrm{H}_{2}$ and CO and the system performance were examined using statistical analysis. 
Dynamic modeling was based on single substrate and one microbial population. A series of mass balances were established describing reactor mass transport and transformations. A hydraulic flow model and a diffusion-reaction model were incorporated into the dynamic model. The problem was solved numerically by developing a computer program (in FORTRAN) and using subroutines from IMSL. Model calibration and verification were performed using a separate set of data gathered from the UASB reactor. Parameter sensitivities were analyzed. 


\section{Section 4}

\section{THEORETICAL DEVELOPMENT.}

\section{A DYNAMIC MODEL OF UASB REACTOR WITH GRANULAR SLUDGE}

\section{Reactor Hydraulics and Fluid Flow Model}

Reactor flow can be ideally described by two flow patterns: plug flow (in a plug flow reactor [PFR]) and complete mixed flow in a CSTR. In reality, real reactors never fully follow these ideal flow patterns, and deviations from these can be considerable. Deviations can be caused by channeling of fluid flow or by creation of stagnant regions in the reactor. These problems of non-ideal flow are intimately tied to those of scale-up because the question of whether to conduct pilot-scale testing and at what scale rests in large part on how much control we have of all the major variables for the process. Often the uncontrolled factor in scale-up is the magnitude of the non-ideality of flow. Ignoring this factor may lead to gross errors in design.

Non-ideal flow behavior such as short circuiting and dead volume may be present in UASB reactors. In this section, non-ideal flow in a bench-scale UASB reactor was considered to consist of different regions interconnected in various ways. The modeling was accomplished using a combination of dispersion model and a network of ideal reactors (PFR or CSTR), connected in series or parallel. Since biogas production from the degradation of organic material affects reactor fluid mixing, several fluid flow models were developed (Chapter 5) to describe UASB reactor flow under low and high biogas production regimes. Theoretical derivations of these flow models are presented in this section.

Parallel CSTRs and a Dispersion PFR in Series. with a PFR (model 1). Under conditions of low gas production, the UASB can be characterized as two CSTRs and a dispersion plug flow reactor in parallel followed by a plug flow reactor, as indicated by Figure 4-1. 


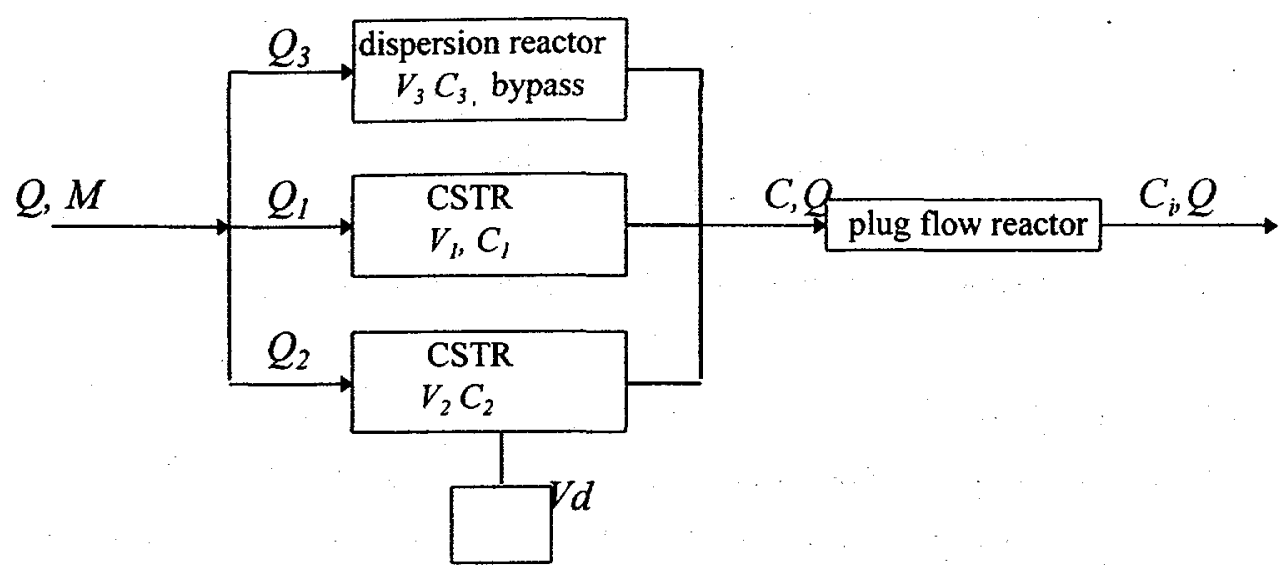

Figure 4-1. Flow chart of model 1 - UASB reactor at low gas production.

In this model, $M$ is the amount of mass input into the system, $V$ is volume, $Q$ is flow rate, $C$ is concentration, and $V d$ is dead space volume. The by-pass flow is characterized by a dispersion model which is in-between mixing in actual flow and a diffusional process. Two parallel CSTRs and a dead volume describe the granular bed. The first CSTR constitutes the main mixing region in the bed $\left(V_{l}\right)$. The other CSTR constitutes a small volume between this main mixing volume and a dead space. The dispersion reactor and CSTRs are followed by a plug flow reactor representing the clarification zone above the sludge bed.

Dispersion Model. The mixing process involves a shuffling or redistribution of material either by slippage or eddies. This is repeated a considerable number of times during the flow of fluid through the reactor. We can consider theses disturbances to be statistical in nature, somewhat as in molecular diffusion. For molecular diffusion in still water, the governing differential equation is given by Fick's law

$$
\frac{\partial C}{\partial t}=D_{f}\left[\frac{\partial^{2} C}{\partial X^{2}}+\frac{\partial^{2} C}{\partial Y^{2}}+\frac{\partial^{2} C}{\partial Z^{2}}\right]
$$

where $\mathrm{C}$ is concentration in reactor, $\mathrm{t}$ is time, $D_{f}$ is the diffusion coefficient. In an analogous manner, we may consider all the contributions to backmixing of fluid flowing in the $\mathrm{X}, \mathrm{Y}$, and $\mathrm{Z}$ directions to be described by a similar expression, namely, 


$$
\frac{\partial C}{\partial t}=D_{p}\left[\frac{\partial^{2} C}{\partial X^{2}}+\frac{\partial^{2} C}{\partial Y^{2}}+\frac{\partial^{2} C}{\partial Z^{2}}\right]
$$

where the parameter $D_{p}$, which we call the axial dispersion coefficient, uniquely characterizes the degree of backmixing occurring. Since here only one-dimensional dispersion is considered, equation $4-2$ is reduced to

$$
\frac{\partial C}{\partial t}=D_{p}\left[\frac{\partial^{2} C}{\partial X^{2}}\right]
$$

When advection (bulk flow) is also present, a moving coordinate system ( $X, t$ axis) should be introduced. This $X$ coordinate moves along with the stream at the mass-average velocity $(u)$. The fixed coordinate system $\left(X^{\prime}, t^{\prime}\right)$ is defined by $X^{\prime}=X+u t, t^{\prime}=t$, where $t$ is time. By differentiation, we have

$$
\begin{aligned}
& d X^{\prime}=d X, \\
& \frac{d X^{\prime}}{d t}=u, \\
& d t^{\prime}=d t, \\
& \frac{d t^{\prime}}{d X}=0
\end{aligned}
$$

Hence

$$
\begin{aligned}
& \frac{\partial C}{\partial t}=\frac{\partial C}{\partial X^{\prime}} \frac{\partial X^{\prime}}{\partial t}+\frac{\partial C}{\partial t^{\prime}} \frac{\partial t^{\prime}}{\partial t}=u \frac{\partial C}{\partial X^{\prime}}+\frac{\partial C}{\partial t^{\prime}} \\
& \frac{\partial C}{\partial X}=\frac{\partial C}{\partial X^{\prime}} \frac{\partial X^{\prime}}{\partial X}+\frac{\partial C}{\partial t^{\prime}} \frac{\partial t^{\prime}}{\partial X}=\frac{\partial C}{\partial X^{\prime}}
\end{aligned}
$$

Substituting the relations into equation 4-3, the equation for dispersion and advection in a fixed coordinate system has the form

$$
\frac{\partial C}{\partial X^{\prime}} u+\frac{\partial C}{\partial t^{\prime}}=D_{p} \frac{\partial^{2} C}{\partial X^{\prime 2}}
$$




$$
\frac{\partial C}{\partial t^{\prime}}=D_{p} \frac{\partial^{2} C}{\partial X^{\prime 2}}-u \frac{\partial C}{\partial X^{\prime}} \quad 0<t^{\prime}, 0<X^{\prime}<L
$$

Let $Z=\frac{X^{\prime}}{L}$, where $L$ is the length of dispersion plug flow reactor. Equation (4-4) becomes

$$
\frac{\partial C}{\partial t^{\prime}}=\left(\frac{D_{p}}{L^{2}}\right) \frac{\partial^{2} C}{\partial Z^{2}}-\left(\frac{u}{L}\right) \frac{\partial C}{\partial Z} \quad 0<t^{\prime}, 0<Z<l
$$

The dimensionless form of the above differential equation is:

$$
\frac{\partial C}{\partial \theta}=\left(\frac{D_{p}}{u L}\right) \frac{\partial^{2} C}{\partial Z^{2}}-\frac{\partial C}{\partial Z}
$$

where $\theta=\frac{t^{\prime}}{\bar{t}}=\frac{t^{\prime} u}{L} ; \bar{t}$ is mean residence time. The dimensionless group $\frac{D_{p}}{u L}$, called the vessel dispersion number, is the parameter which measures the extent of axial dispersion. When $\frac{D_{p}}{u L} \rightarrow 0$, the dispersion is negligible; hence, conditions approach plug flow. When $\frac{D_{p}}{u L} \rightarrow \infty$, the dispersion is large and conditions approach completely mixed flow.

Under an idealized impulse, the solution to equations 4-5 and 4-6 yields a symmetric concentration curve

$$
\frac{C}{C_{o}}=\frac{L}{2 \sqrt{\pi t^{\prime} D_{p}}} \exp \left[-\frac{u^{2}\left(\frac{L}{u}-t^{\prime}\right)^{2}}{4 t^{\prime} D_{p}}\right]
$$


Equation (4-8) is a normalized form of equation (4-7). The UASB reactor by-pass flow in this model is described by above dispersion plug flow equations.

$$
\frac{C}{C_{o}}=\frac{1}{2 \sqrt{\frac{\pi \theta D_{p}}{u L}}} \exp \left[-\frac{(1-\theta)^{2}}{4 \theta\left(\frac{D_{p}}{u L}\right)}\right]
$$

Mixed Flow and Plug Flow Model. The granular bed was characterized by two parallel CSTRs. The clarification zone was best characterized by a plug flow reactor. A mass balance was performed, after an inert tracer impulse, on the liquid volume of the CSTRs with time ( $\left(t^{\prime}\right)$, which led to the following expressions:

$V_{1} \frac{d C_{1}}{d t^{\prime}}=-Q_{1} C_{1}$, with initial condition $C_{l}(0)=\frac{Q_{1}}{Q} \frac{M}{V_{1}} \ldots$

and

$V_{2} \frac{d C_{2}}{d t^{\prime}}=-Q_{2} C_{2}$, with initial condition $C_{2}(0)=\frac{Q_{2}}{Q} \frac{M}{V_{2}} \ldots$

Integrating the above equations gives

$$
\begin{aligned}
& C_{1}=\frac{Q_{1}}{Q} \frac{M}{V_{1}} \exp \left[-\frac{Q_{1}}{V_{1}} t^{\prime}\right] \\
& C_{2}=\frac{Q_{2}}{Q} \frac{M}{V_{2}} \exp \left[-\frac{Q_{2}}{V_{2}} t^{\prime}\right]
\end{aligned}
$$

or

$$
\frac{C_{1}}{C_{o}}=\frac{Q_{1}}{Q} \frac{V}{V_{1}} \exp \left[-\frac{Q_{1}}{V_{1}} t^{\prime}\right]
$$




$$
\frac{C_{2}}{C_{o}}=\frac{Q_{2}}{Q} \frac{V}{V_{2}} \exp \left[-\frac{Q_{2}}{V_{2}} t^{\prime}\right]
$$

where $C_{o}=\frac{M}{V}$ is effluent concentration at $t^{\prime}=0$ in an ideal CSTR. Applying a mass balance on the whole system gives

$$
Q C=Q_{3} C_{3}+Q_{2} C_{2}+Q_{1} C_{1}
$$

Substituting equations $4-7,13$ and 14 into equation $4-15$, the UASB hydraulic model equation has the form.

$$
\frac{C_{i}}{C_{o}}=\frac{A}{\sqrt{t^{\prime}}} \exp \left[-\frac{B}{t^{\prime}}\left(T_{d}-t^{\prime}+T_{d 1}\right)^{2}\right]+C \exp \left[-D\left(t^{\prime}-T_{d 1}\right)\right]+E \exp \left[-F\left(t^{\prime}-T_{d 1}\right)\right]
$$

where $C_{i}$ is effluent concentration of the UASB reactor at time $i ; A=\frac{Q_{3} L}{2 C_{o} Q \sqrt{\pi D_{p}}}$;

$$
\begin{aligned}
& B=\frac{u^{2}}{4 D_{p}} ; C=\left(\frac{Q_{1}}{Q}\right)^{2} \frac{V}{V_{1}} ; D=\frac{Q_{1} V}{Q V_{1}} ; T_{\mathrm{d} 1} \text { is lag time of plug flow reactor; } T_{d} \\
& =\frac{L}{u} ; E=\left(\frac{Q_{2}}{Q}\right)^{2} \frac{V}{V_{2}} ; F=\frac{Q_{2} V}{Q V_{2}} .
\end{aligned}
$$

Two CSTRs in Series Followed by a PFR (Van der Meer Model). At higher organic loading rates (ea. $10 \mathrm{~kg} \mathrm{COD} / \mathrm{m}^{3}$ bed-d), increased biogas production enhances the extent of mixing within the granular bed. The UASB can be described by the Van der Meer model, in which two CSTRs and a plug flow reactor are in series. By-pass and dead volume are present. The model was as follows: 


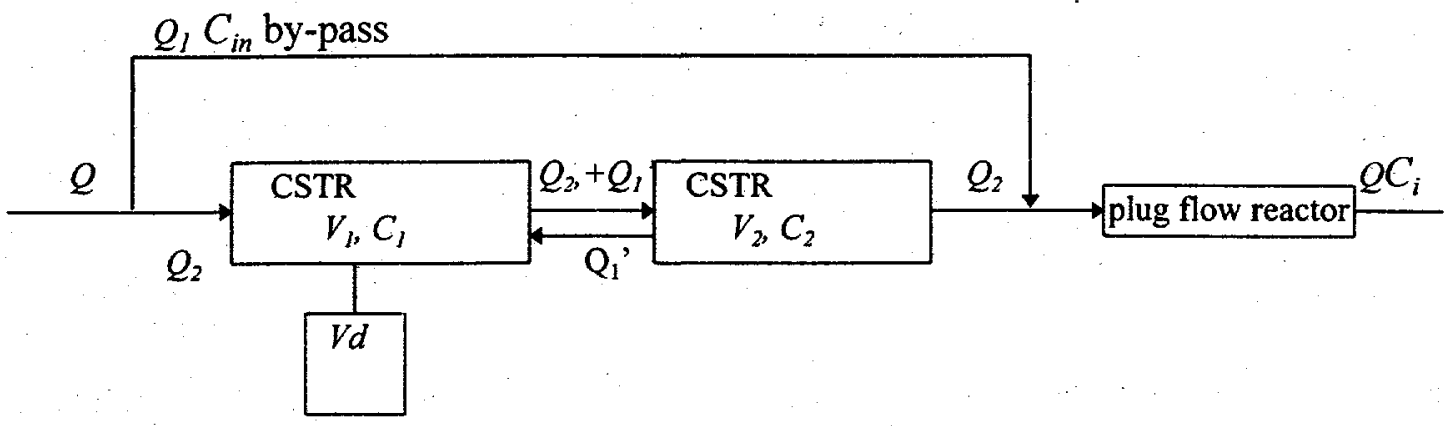

Figure 4-2. Flow chart of Van der Meer model.

The by-pass stream is assumed not to occupy any fluid volume. One of the CSTRs $\left(V_{l}\right)$ represented the sludge bed in which the granular sludge was relatively compact and well settled. The other CSTR described the sludge blanket with upper layer granules and was more fluidized. The plug flow reactor represented the clarification zone. Performing a mass balance on the mass contained within the liquid volume in CSTRs with time $t$, in the case of a conservative tracer impulse, resulted in the following expressions:

$$
\begin{aligned}
& V_{1} \frac{d C_{1}}{d t}=-\left(Q_{2}+Q_{1}^{\prime}\right) C_{1}+Q_{1}^{\prime} C_{2} \\
& V_{2} \frac{d C_{2}}{d t}=\left(Q_{2}+Q_{1}^{\prime}\right) C_{1}-\left(Q_{2}+Q_{1}^{\prime}\right) C_{2} \\
& Q C_{i}=Q_{2} C_{2}+Q_{1} C_{i n}
\end{aligned}
$$

where $Q=Q_{1}+Q_{2}, V=V_{1}+V_{2}+V_{d}+V_{p f}$. Initial conditions were:

$$
C_{1}(0)=\frac{M}{V}, C_{2}(0)=0
$$

Solutions to equation 4-17 and 18 have the form

$$
C_{1}=A_{1} \exp \left[\lambda_{1} t\right]+B_{1} \exp \left[\lambda_{2} t\right]
$$




$$
C_{2}=A_{2} \exp \left[\lambda_{1} t\right]+B_{2} \exp \left[\lambda_{2} t\right]
$$

where

$$
\begin{aligned}
& A_{1}+B_{1}=C_{1}(0) \\
& A_{2}+B_{2}=C_{2}(0)
\end{aligned}
$$

Considering PFR following the CSTRs, and normaliziong $C$ and $t$ for the whole system, the effluent tracer concentration of the UASB were given by

$$
\frac{C_{i}}{C_{0}}=\frac{A_{2}}{C_{0}} \exp \left[-H R T \lambda_{1}\left(\theta-T_{d}\right)\right]+\frac{B_{2}}{C_{0}} \exp \left[-H R T \lambda_{2}\left(\theta-T_{d}\right)\right] \quad \ldots
$$

where $\theta=\frac{t}{\bar{t}}=\frac{t}{H R T} ; T_{d}$ is normalized delay time as a result of plug flow or $\frac{R T_{P F}}{H R T}$. To simplify, let $C=\frac{A_{2}}{C_{0}}, D=\frac{B_{2}}{C_{0}}, E=-H R T \lambda_{1}, F=-H R T \lambda_{2}$. Equation $4-24$ becomes

$$
\frac{C_{i}}{C_{0}}=C \exp \left[-E\left(\theta-T_{d}\right)\right]+D \exp \left[-F\left(\theta-T_{d}\right)\right]
$$

One CSTR and a Dispersion PFR in Series (Model 2). A second model (model 2) was developed to describe the UASB reactor hydraulics at high OLR. Compared to the Van der Meer model, this model used a simpler expression of one CSTR for the granular bed. The clarifier section is represented by a dispersion PFR. Both by-pass flow and dead volume are present. Model 2 has the following form:

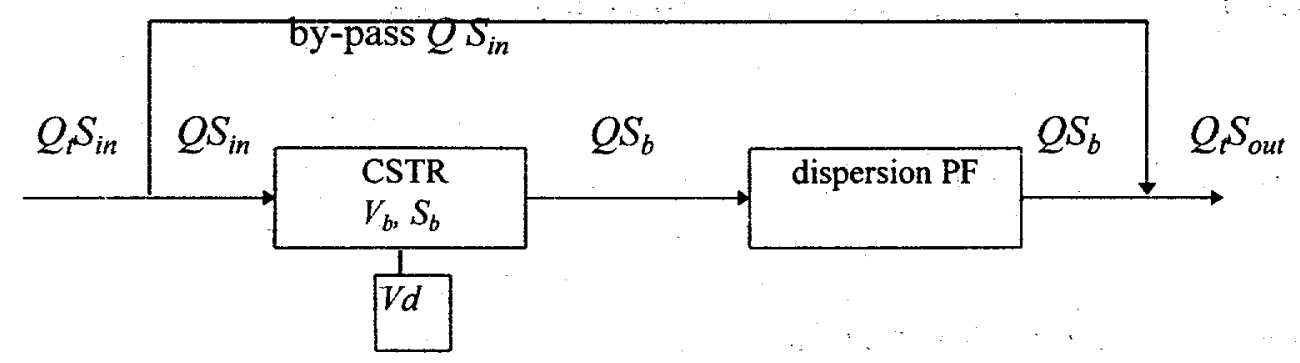

Figure 4-3. A schematic representation of model 2, describing UASB reactor at high gas production. 
For the case of addition of an impulse of a conservative tracer, the CSTR of model 2 can be expressed by the following equations:

$$
\begin{aligned}
& V_{b} \frac{d C}{d t}=V_{b} E(t)-Q f C(t) \\
& E(t)=\left\{\begin{array}{rll}
\frac{M f}{V_{b} T_{i n}}, & \text { if } \quad 0 \leq t \leq T_{i m} \\
0, & \text { if } \quad T_{i n} \leq t & \text { For impulse }
\end{array}\right.
\end{aligned}
$$

where $C(t)$ is concentration within CSTR; $V_{b}$ is working volume of CSTR $\left(=V-V_{d}\right) ; V_{d}$ is dead volume within CSTR; $E(t)$ is an input function; $S_{b}$ is bulk tracer concentration; $f$ is fraction; $Q f$ is the flow fraction that enters the main stream; $M f$ is fraction of mass input that go through reactor working volume; and $T_{\text {in }}$ is tracer injection time.

The clarifier section is described by a dispersion plug flow reactor. Only vertical direction advection and dispersion were considered in this part. Equation (4-5) is rewritten to have the form

$$
\begin{aligned}
& \frac{\partial C_{p f}}{\partial t}=\frac{D_{p}}{L} \frac{\partial^{2} C_{p f}}{\partial Z^{2}}-\frac{u}{L} \frac{\partial C_{p f}}{\partial Z}, \triangleright 0,0<Z<1, \\
& \text { BC: } \quad C_{p f}(0, t)=C(t) \\
& \text { IC: } \quad C_{p f}(Z, 0)=C_{o}
\end{aligned}
$$

where $C_{p f}$ is concentration in dispersion PFR, and $X$ is a vertical coordinate. An inert tracer response after an impulse to the UASB reactor can be predicted by solving equations 4-26 to 4-30.

\section{Integrated Reaction-Diffusion and Hydraulic Model}

Substrate transport and consumption within a granular sludge bed can be described by a reaction-diffusion model. The model can then be integrated with reactor hydraulic characteristics discussed above, in order to characterize the dynamic behavior of UASB reactors under organic impulse and step OLR increase events. The theoretical development of this dynamic coupled reaction-diffusion-hydraulic model is presented in this section. 
Reaction-Diffusion Model. The kinetic properties of the granular sludge bed in a UASB reactor depend on coupled mass transfer and biochemical reaction processes. A reaction-diffusion type model can be used to describe the interaction of mass transport and reaction of the granules as a means to determine the overall activities. The mass transport and biochemical reaction interactions in a slab of biofilm are presented in Figure 4-4.

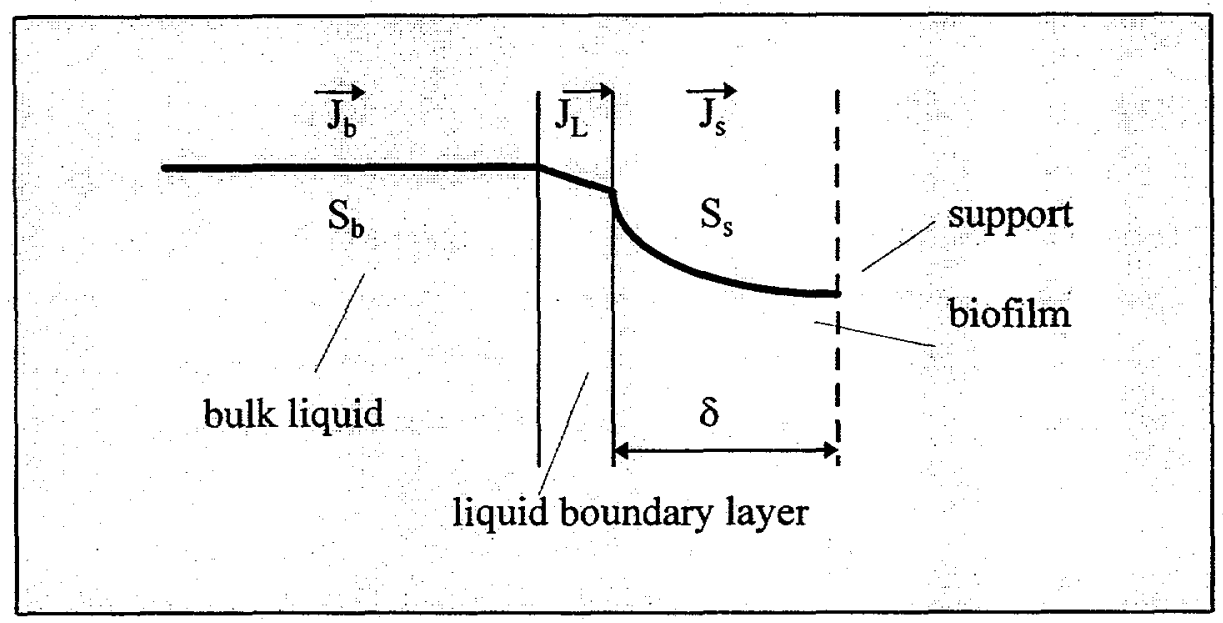

Figure 4-4. Mass transport, diffusion, and reaction within a slab of biofilm.

Substrate $\left(S_{b}\right)$ is transported from bulk liquid to a stagnant film or boundary layer at the outside of the biofilm. A concentration gradient is established across the liquid film. Substrate is then concurrently diffused through the biofilm and consumed $\left(S_{s}\right)$. By continuity of mass, at the interface of the bulk liquidboundary layer and the boundary layer-granule, the fluxes are equal. Thus, $J_{b}=J_{L}$ at the bulk-boundary layer interface, and $J_{L}=J_{s}$ at boundary layer-biofilm interface. These phenomena result in the substrate profile indicated in Figure 4-4. This profile can be described quantitatively in terms of the following parameters: bulk substrate concentration $\left(S_{b}\right)$, intrinsic kinetic parameters $(\mathrm{km}, \mathrm{Ks})$, effective diffusion coefficient $(D)$, mass transfer coefficient through the boundary layer $\left(K_{L}\right)$ and biofilm thickness $(\delta)$. Mixing or flow of substrate solution adds a convective transport contribution to the movement of substrate from bulk solution to the external surface. As indicated in Figure 4-4, reaction occurs within the biofilm at rates which are determined by the concentrations within the slab. Because of concentration gradients arising between the bulk solution far from the biofilm and reaction event which are occurring at the active sites, local reaction rates vary as a function of internal position. Thus, substrate concentrations within the biofilm $\left(S_{s}\right)$ vary with internal position as well as time. At steady state, the total rate of substrate 
consumption is equal to the rate of substrate transport into the biofilm. The analytical framework for description of these interacting processes within anaerobic granules is given below.

Granular sludge can be approximated with a spherical geometry with a radius of R. It is assumed that substrate diffuses through a layer of the granules with a constant thickness of $\delta$ (active layer) that was observed from microscopy. This active layer $(\delta)$ was composed of different group of microorganisms involved in anaerobic degradation of a complex waste, and formed as a result of a long period of acclimation to this waste at a certain range of OLRs. There are only traces of substrate beyond that layer (central core), indicated from much lower cell density at that area compared to the cell density in the outer layer. The assumption is therefore made that diffusion and reaction in the central core are small compared to that in the active layer and can be ignored. Due to the slow growth rate of methanogens, the growth and decay of granule biomass were ignored. Substrate concentration profiles through the granules are symmetric about the center of the granules. A basic model is shown in Figure 4-5. Several assumptions are made: 1) effective substrate diffusivity within the granules is constant and 2) the reaction can be described using Monod kinetics.

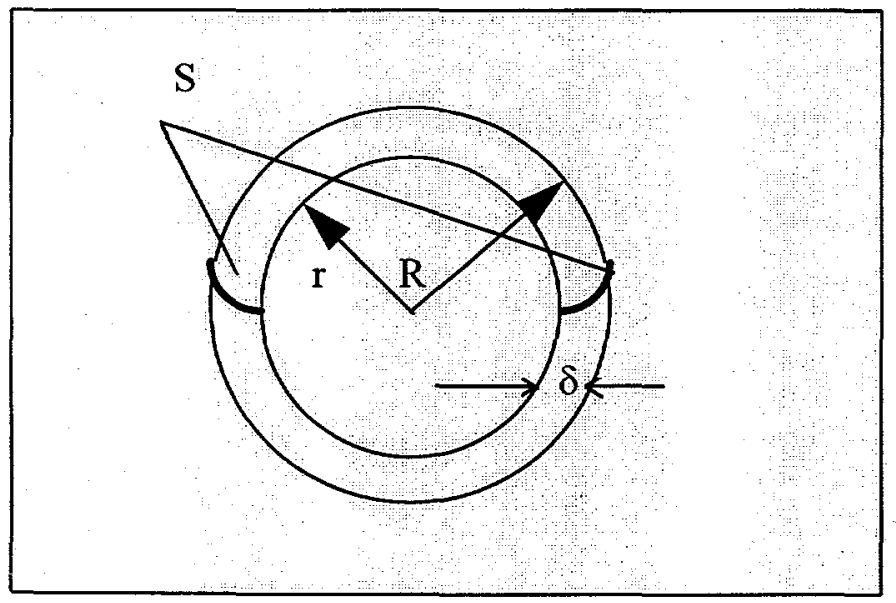

Figure 4-5. A crossection of a granule with radius $R$, active layer thickness $\delta$, and substrate profile $\mathbf{S}$.

The shell balance on substrate, $S$, in radial coordinates, results in a second-order partial differential equation, as follows:

$$
\frac{\partial S}{\partial t}=D\left(\frac{\partial^{2} S}{\partial r^{2}}+\frac{2}{r} \frac{\partial S}{\partial r}\right)-\frac{k_{m} X_{m} S}{K_{s}+S}
$$


with boundary conditions
(i) $D \frac{\partial S}{\partial r}+K_{l} S=K_{l} S_{b} \quad r=R$
(ii) $\frac{\partial S}{\partial r}=0$,
$r=R-\delta$

and initial condition

$$
\text { (i) } S(r, 0)=S_{s}(r) \quad r \in(R-\delta, R)
$$

where term $D\left(\frac{\partial^{2} S}{\partial r^{2}}+\frac{2}{r} \frac{\partial S}{\partial r}\right)$ is the rate at which substrate diffuses into the granules; $\frac{k_{m} X_{m} S}{K_{s}+S}$ is substrate reaction rate; $D$ is effective substrate diffusivity; $S_{s}$ is substrate concentration within the biofilm at steady state; $k_{m}$ is specific substrate utilization rate; $X_{m}$ is biomass density within the active layer $(\delta)$ of the granules; $K_{s}$ is half the velocity constant; and $K_{l}$ is the mass transfer coefficient. Let us introduce a new variable termed $x$. The $x$ axis originates from the surface of granule towards the center. We define $x=R-r$, then $d r=-d x$. By changing of variables, equations 4-31 to 4-34 become:

$$
\frac{\partial S}{\partial t}=D\left(\frac{\partial^{2} S}{\partial x^{2}}-\frac{2}{R-x} \frac{\partial S}{\partial x}\right)-\frac{k_{m} X_{m} S}{K_{s}+S}
$$

BCs: $\quad$ (i) $-D \frac{\partial S}{\partial x}+K_{l} S=K_{l} S_{b}, \quad x=0$

(ii) $\frac{\partial S}{\partial x}=0$,

$$
x=\delta
$$

IC:

$$
\text { (i) } S(x, 0)=S_{s}(x) \quad x \in(0, \delta)
$$

At steady state $\frac{\partial S}{\partial t}=0$ for equation 4-35, thus we have following second-order ordinary differential equation 


$$
D\left(\frac{\partial^{2} S_{s}}{\partial x^{2}}-\frac{2}{R-x} \frac{\partial S_{s}}{\partial x}\right)=\frac{k_{m} X_{m} S_{s}}{K_{s}+S_{s}}
$$

$\mathrm{BCs}: \quad$ (i) $-D \frac{\partial S_{s}}{\partial x}+K_{l} S_{s}=K_{l} S_{b 0}, x=0$

(ii) $\frac{\partial S_{s}}{\partial x}=0$,

$x=\delta$

where $S_{b o}$ is the steady state substrate concentration in bulk liquid. Equations 4-35 to 4-38 and 4-39 to 4-41 can be solved numerically for a description of substrate variation within the granular bed of UASB reactor at unsteady state and steady state, respectively.

\section{Development of a Dynamic Model Including a Flow Model Combined with a Reaction-Diffusion}

Model for UASB Reactors. As discussed above in Chapter 4, UASB reactor flow can be characterized as several CSTRs, PFRs, and dispersion PFR interconnected in series or in parallel. The hydraulic model (model 2) is integrated into the reaction-diffusion model presented above to develop a dynamic model for UASB reactors. A schematic representation of the dynamic model is presented in Figure 4-6.

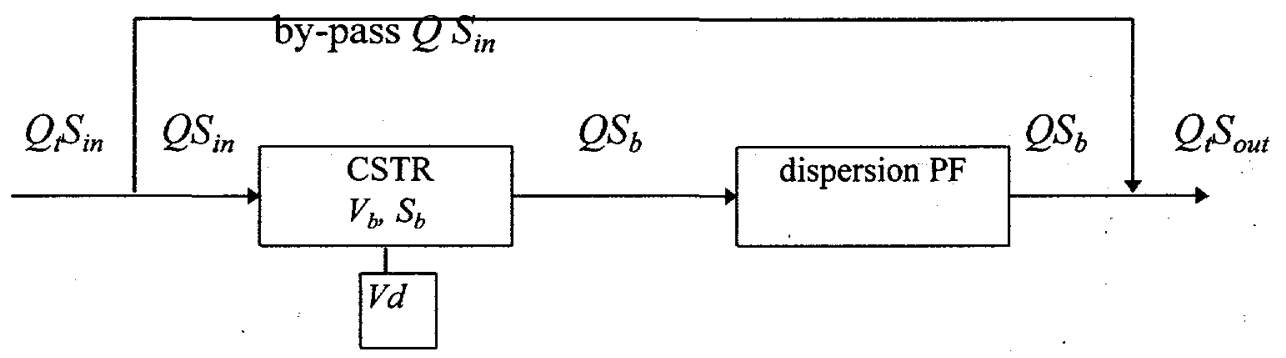

Figure 4-6. Schematic representative of the dynamic model.

A mass balance can be performed on the substrate within the boundary volume of the CSTR, at organic impulse and step increase:

$$
V_{b} \frac{d S_{b}}{d t}=V_{b} E(t)-Q f S_{b}(t)-K_{L} A_{r}\left(S_{b}-S(0, t)\right) \quad \ldots
$$


IC: $\quad S_{b}(0)=S_{b o}$

$$
\begin{aligned}
& E(t)=\left\{\begin{array}{ccc}
\frac{M f}{V b T_{i n}}, & \text { if } & 0 \leq t \leq T_{i n} \quad \text { For an impulse } \quad \ldots \\
0, & \text { if } & T_{i n} \leq t
\end{array}\right. \\
& E(t)=\left\{\begin{array}{ccc}
Q f S_{b k g d}, & \text { if } & 0<t<T_{s t p 1} \\
Q f S_{s t p 1}, & \text { if } & T_{s t p 1} \leq t<T_{s t p 2} \text { Ior a step increase .. } \\
Q f S_{s t p 2}, & \text { if } & T_{s t p 2} \leq t
\end{array}\right.
\end{aligned}
$$

where $V_{b}$ is working volume of the CSTR; $V d$ is dead volume of CSTR; $E(t)$ is an input function; $A_{r}$ is total granule surface area; $S_{b}$ is bulk substrate concentration; $S$ is substrate concentration within the granules at unsteady state; $Q f$ is the flow fraction that enters the main stream; $M f$ is fraction of mass input that goes through the reactor's working volume; $S_{b k g d}$ is feed concentration before any step increase; $S_{s l p l}$ is feed concentration at first step increase; $S_{s p p}$ is feed concentration at second step increase. $T_{s p l}$ is the time the first step is initiated; $T_{s p 2}$ is the time the second step is initiated, and $T_{i n}$ is the substrate injection time.

Very few granules were observed in the clarifier section. Thus, the reaction term was neglected. For the substrate concentration within the PFR, $S_{d}$, the dispersion PFR described in equations 4-28 to 4-30 is rewritten as:

$$
\frac{\partial S_{d}}{\partial t}=\frac{D_{p}}{L^{2}} \frac{\partial^{2} S_{d}}{\partial Z^{2}}-\frac{u}{L} \frac{\partial S_{d}}{\partial Z}, t>0,0<Z<1
$$

$\mathrm{BC}: \quad S_{d}(0, t)=S_{b}(t)$

IC: $\quad S_{d}(Z, 0)=S_{b o}$

The UASB reactor responses under organic impulse and step increases can be simulated by simultaneously solving equations $4-35$ to $4-48$, using numeric methods. 
Section 5

HYDRAULIC CHARACTERISTICS OF AN UPFLOW ANAEROBIC SLUDGE BLANKET (UASB) REACTOR

\section{INTRODUCTION}

A number of high-rate anaerobic treatment systems have been developed over the past two decades. Despite the demonstrated benefits of these processes, hydraulic mixing efficiency problems are frequently observed. These must be taken into account when scaling up from laboratory reactors to pilot- and full-scale systems. Clogging and short-circuiting in anaerobic reactors are major concerns since these problems can lead to reduction in the volume of active biomass, and therefore reduced removal efficiency. The UASB system is the most widely used high-rate anaerobic process. The UASB process is generally reported to have good hydraulic mixing (Hall 1984, 1985). The design of UASB reactors has been primarily based on empirical relationships or the assumption that the process behaves as a CSTR. How well these systems approximate ideal CSTRs has not been adequately evaluated under different organic and hydraulic loading rates.

Several studies have been conducted in attempts to characterize reactor hydraulics. Macmullen and Weber (1935) presented an analytical study for short circuiting in completely mixed flow (CMF) reactors in series in the early 1930s. Cholette and Cloutier (1959) described three factors influencing reactor fluid flow mixing patterns: effective volume, short circuiting, and plug flow. Van der Meer (1979), studying the hydraulic characteristics of UASB reactors at bench-; pilot-, and full-scale, observed that biogas production, due to increases in organic loading rate, did not result in significantly altered fluid flow patterns. He further suggested that dead 0volume can be reduced by control of the amount of sludge and internal recirculation. In treating cane sugar wastewater, it was observed that at low organic loading rates, adequate mixing of an UASB reactor contents did not take place (Manjunath et al.. 1989). Bolle et al. (1986) developed a model in which both sludge bed and sludge blanket can be described as completely mixed flow reactors with short-circuiting flow paths, while the settler volume was best described as a plug flow reactor. Short-circuiting flow through the sludge bed was a function of the bed height. Hall (1985) suggested that gas production has a major impact on mixing under low hydraulic retention time (HRT $<1$ day) conditions. Other researchers considered dead volume and mixing-zone volume without by-passing flow (Monteith and Stephenson 1981; Xu 1983).

Three different models which have been used to describe reactor hydraulics are summarized in Figure 5-1. Cholette and Cloutier (1959) modified the CSTR model to include the effects of dead volume and short circuiting, resulting in the expression 


$$
\frac{C_{i}}{C_{o}}=\frac{f_{1}}{f_{2}} \exp \left\{-\frac{f_{1} Q}{f_{2} V} t_{i}\right\}
$$

where $C_{i}$ is effluent concentration at time $i ; C_{o}$ is effluent concentration at time $=0$ in an ideal CSTR; $f_{l}=\frac{V_{1}}{V}$, where $V_{1}$ is mixing volume $(V m), V$ is total volume; $f_{2}=\frac{Q_{1}}{Q}, Q_{1}$ is working flow rate, $Q$ is total flow rate; $t_{i}$ is time ; $V=V_{1}+V_{\mathrm{d}}$, where $V_{\mathrm{d}}$ is dead volume; $Q=Q_{1}+Q_{2}$, where $Q_{2}$ is bypass flow rate. Van der Meer (1979) presented a general flow model scheme (Figure 5-1) based on two coupled CSTRs; one was for the sludge bed and the other for the sludge blanket portion of the reactor volume, with back mixing in between. A dead volume and short circuit portion were also assumed to be present in the sludge bed, followed by a PFR representing the liquid layer above the sludge blanket. Hall (1985) proposed a parallel mixing hydraulic model for UASB reactors (Figure 5-1). Instead of assuming flow could short-circuit directly to the effluent from the inlet without mixing, a mixed bypass flow zone, parallel to the working zone, was assumed. The reported model equation is:

$$
\frac{C_{i}}{C_{o}}=\frac{B_{1}}{B_{2}+B_{3}} \exp \left\{-\frac{B_{1}}{B_{2}} \theta_{i}\right\}+\frac{1-B_{1}}{B_{2}+B_{3}} \exp \left\{-\frac{1-B_{1}}{B_{3}} \theta_{i}\right\}
$$

where $B_{1}=\frac{Q_{2}}{Q}$, where $Q_{2}$ is by-pass flow; $B_{2}=\frac{V_{1}}{V}$, where $V_{1}$ is active volume; $V_{2}$ is by-pass volume; $B_{3}=\frac{V_{d}}{V}$, where $V_{d}$ is dead volume; $\theta_{i}=\frac{t_{i}}{H R T} ; Q_{1}+Q_{2}=Q ; V_{1}+V_{2}+V_{d}=V$ (total volume). Hall concluded that the hydraulics in a UASB can be well described by the CSTR model, but that some deviation does exist during the initial period in tracer experiments. 


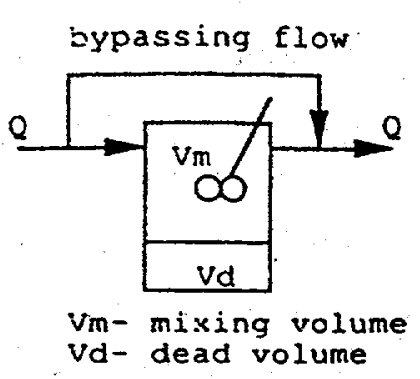

Cholette-cloutier model

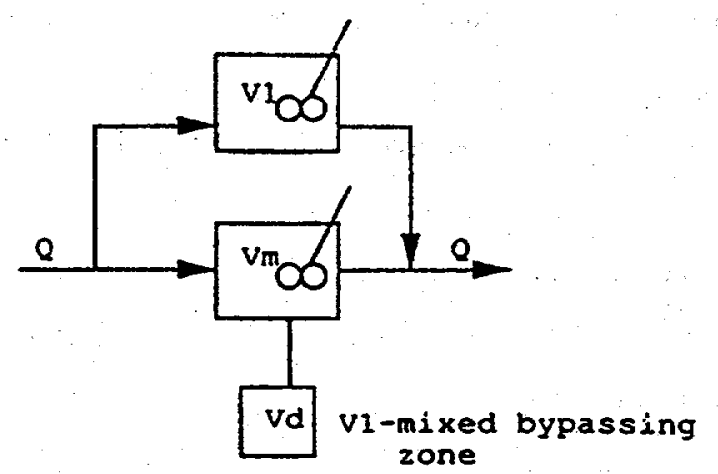

Hall model

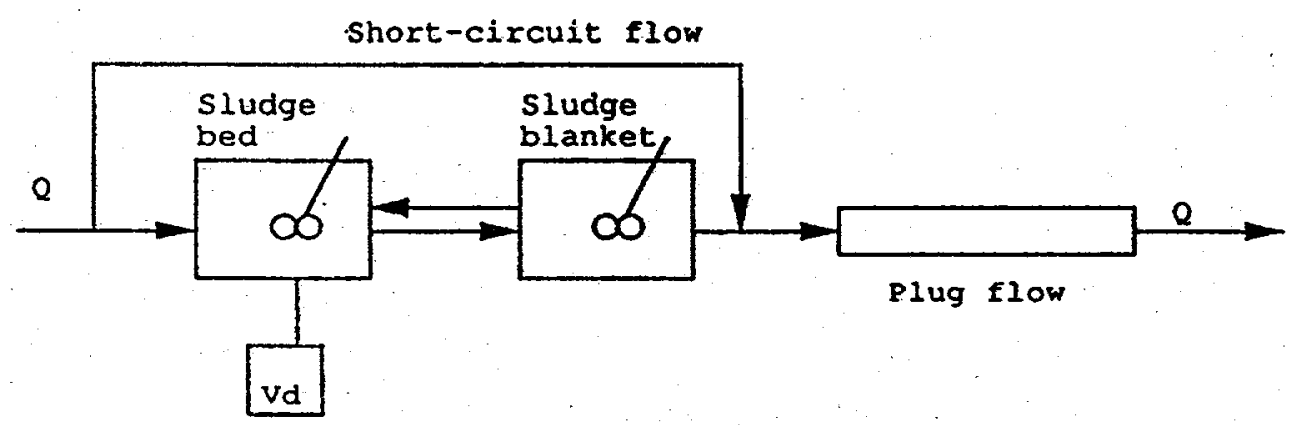

Yan der Meer model

Figure 5-1. Schematic representations of fluid flow models evaluated.

Fluid-flow model parameter estimates were accomplished using both linear regression and the nonlinear least square techniques (Chapman 1983). The hydraulics in a UASB reactor with granular sludge are similar to those observed in liquid-solid fluidized bed reactors (FBRs). Richardson and Zaki (1954) discussed in detail various factors that affect fluidization and presented an empirical correlation between particle velocity and bed voidage during fluidization. Iza et al. (1988) demonstrated that the hydraulic behavior of a pilot-scale FBR could be described by this correlation. The Richardson-Zaki equation was modified by Fouda and Capes (1977) for describing the fluidization of non-spherical particles. Other correlations have been developed based on Reynolds number and particle velocity (Garside et al. 1977) and Galileo number, Reynolds number, and bed voidage (Wen and Yu 1966). Andrews and Tien (1979) observed that the growth of biomass causes the bed in an FBR system to expand. This phenomenon can be described by a linear function of biomass with bed expansion.

Tracer studies are commonly used for the study of fluid flow (Levenspiel 1972). Rebhun and Argaman presented a tracer analysis for a reactor which includes dead volume, mixing volume, and a plug flow reactor 
using F curve techniques (Rebhun and Argaman, 1965). Riemer et al. (1980) suggested the diffusion of tracer dye into and out of biological films could cause tailing in the residence time distribution curve. Stevens et al. (1986) presented a model that accounts for the diffusion of a tracer within a biofilm.

UASB reactors can be operated over a wide range of HRTs depending on the design organic loading rate and influent substrate concentration. The organic loading rate relates directly to biogas production in the sludge bed. The formation of gas bubbles contributes to the mixing intensity in the sludge bed zone. Flow recirculation rate also exerts an influence on the hydraulic behavior. If the reactor upflow rate is high enough, it will also affect the sludge bed hydraulics. Accumulation of biomass may cause dead volume and reduce active working volume. How strong these influences are and the interactions between them under different operational conditions has not been systematically studied.

The present work investigated the hydraulic characteristics of a laboratory-scale UASB reactor operated at different HRTs, ranging from 11 hours to 5.6 days, organic loading rates ranging from 5 to $15 \mathrm{~kg} \mathrm{COD} / \mathrm{m}^{3}-\mathrm{d}$, and surface upflow velocities ranging from 2 to $5 \mathrm{gpm} / \mathrm{sq}$. $\mathrm{ft}$. $(0.14$ to $0.34 \mathrm{~cm} / \mathrm{s})$ of reactor cross-sectional area. The initial hypothesis was that at low OLRs, effluent recirculation would play a major role in mixing; at high OLRs, the biogas production would be the predominant factor affecting mixing. This hypothesis was examined using two sets of experiments: 1) tracer studies of the UASB at various organic loading and hydraulic flux rates, and 2) fluid flow modeling and model evaluation at low and high OLRs.

\section{ORGANIC LOADING RATE AND HYDRAULIC FLUX EFFECTS}

During this portion of study, the UASB reactor was operated at OLRs between 5 and $15 \mathrm{~kg} \mathrm{COD} / \mathrm{m}^{3}-\mathrm{d}$. The hydraulic flux rate was varied from 2 to $5 \mathrm{gpm} / \mathrm{sq}$. $\mathrm{ft}$. The UASB is considered to be a linear system with respect to hydraulic behavior during the entire residence time distribution (RTD) period. That is, the changes of response under various operational conditions are consistent for the whole RTD curve. Since the only major discrepancies from CSTR behavior exist during the early period of the overall HRT, this study focused on residence time distribution during the initial period of the system HRT. This is the time period where differences in behavior would be expected as a result of changes in substrate concentration, flow rate, etc.

\section{UASB Reactor}

An all-glass, water-jacketed bench-scale UASB reactor (described in detail in Section 6) with an empty bed volume of $3.1 \mathrm{~L}$ was used for all hydraulic experiments. The unit was sealed from the atmosphere to prevent oxygen entry. Influent flow was pumped upward through the reactor continuously (using a Watson-Marlow model $503 \mathrm{U}$ tubing pump), contacted with the granular sludge bed, and discharged via effluent tubing. Mixing was provided by both biogas production and by hydraulic recirculation. The recycle flow was pumped back to the bottom of the reactor and mixed with the feed just prior entering the reactor proper. Gas/liquid/solid 
separation was accomplished using a gas collector at the top of the reactor. A concentrated synthetic brewery waste, based on a waste analysis of a full-scale UASB plant where the granules used in this study were taken from, was used as the influent feed (see Appendix A). Seed granular sludge was acclimated with the synthetic waste for more than six months prior to initiating hydraulic studies. The granules ranged in size from 1 to 3 $\mathrm{mm}$ in diameter. Operational conditions of the bench-scale UASB are presented in Table 5-1.

\begin{tabular}{|l|c|}
\hline \multicolumn{2}{|c|}{$\begin{array}{c}\text { Table 5-1. Operational conditions of bench-scale UASB reactor during hydraulic } \\
\text { experiments. }\end{array}$} \\
\hline Parameters & Range \\
\hline Influent COD (g/L) & 14.1 \\
\hline Organic Loading (gCOD/L-d) & $5-15$ \\
\hline Biogas Production (1/L-d)* & $2.5-7.0$ \\
\hline Reactor Surface & \\
\hline Upflow rate (gpm/sq. ft.) & $2-5$ \\
\hline Upflow velocity (cm/s) & $0.14-0.34$ \\
\hline pH & $6.82-7.0$ \\
\hline Bed Expansion (\% of total volume) & $63-77$ \\
\hline *based on sludge bed volume (unexpanded) & \\
\hline
\end{tabular}

\section{Tracer Study}

RTD studies were performed using the tracer techniques described by Levenspiel (1972). Lithium was used as a conservative tracer material. For these experiments, $122 \mathrm{mg}$ of lithium chloride was injected into the recirculation tubing just before the reactor inlet to produce an impulse input. Samples were collected at a sampling port in the recirculation tubing as the flow exited the reactor proper. The sampling frequency was 1 minute for the recirculation effect study. Samples were centrifuged, and the supernatant collected for analysis. Lithium concentration was determined by ion chromatography (Dionex model 4000 ). The pseudo-steady state RTD experimental design is shown in Table 5-2.

\begin{tabular}{|c|c|c|c|}
\hline \multicolumn{5}{|c|}{ Table.5-2. RTD experimental design. } \\
\hline Run No. & HRT (d) & $\begin{array}{c}\text { Organic Loading } \\
\text { (g COD/L-d) }\end{array}$ & $\begin{array}{c}\text { Surface Upflow Rate } \\
\text { (gpm/sq. ft.) }\end{array}$ \\
\hline 1 & 5.6 & 5 & 2 \\
\hline 2 & 5.6 & 5 & 5 \\
\hline 3 & 3.6 & 8 & 2 \\
\hline 4 & 3.6 & 8 & 5 \\
\hline 5 & 2.9 & 10 & 2 \\
\hline 6 & 2.9 & 10 & 5 \\
\hline 7 & 2.0 & 15 & 2 \\
\hline 8 & 2.0 & 15 & 5 \\
\hline
\end{tabular}




\section{Organic Loading and Hydraulic Flux Effects}

It was assumed that pseudo-steady state conditions were reached after a minimum of three hydraulic retention times at each OLR, and the control parameters, (i.e. $\mathrm{pH}$, gas production, methane concentration, and effluent volatile fatty acids), varied less than $10 \%$ from the mean. Changes in the OLR were made by varying the influent feed rate while maintaining a constant feed concentration. The sludge-bed volume was fixed such that the unexpanded (settled) volume in the reactor was $1.5 \mathrm{~L}$ throughout these experiments. The degree of the fluidization of the sludge blanket was controlled by the hydraulic recirculation rate.

The matrix of RTD experiments for the early period of overall hydraulic retention time for each organic loading and recirculation rate is presented in Table 5-2. The effluent from the reactor was tracked for more than one recirculation after adding a pulse of lithium to the reactor. For each OLR, HRT, and surface upflow rate, biogas production and bed height (fluidized) were monitored. Dispersion number and bed expansion were then calculated. Statistical comparisons were performed on the experimental data. The RTD results are presented in Figures 5-2 to 5-5, and Tables 5-3 and 5-4. The gas production rate increased proportionally with the OLR (2.8 times, see Table 5-3), as expected. Dispersion number as well as bed expansion $\left(V_{b} / V_{t}\right)$ varied primarily with surface upflow rate. A multiple comparison test was performed on dispersion numbers (averaged) at four OLRs. The least significant difference at the 0.05 level was 0.1008 , which means the reactor hydraulic mixing patterns under four OLRs tested were not significantly different. A similar test was conducted for the dispersion numbers (averaged) at two surface upflow rates. Results indicate a significant difference (Table 5-4). The tracer profiles during the early period of an impulse varied considerably with surface upflow rate (Figures 5-4 and 5-5). These profiles varied slightly with OLR (Figures 5-2 and 5-3). The extent of mixing was predominantly affected by effluent recirculation, or surface upflow rate. For the final experimental condition ( $15 \mathrm{gCOD} / \mathrm{L}-\mathrm{d}, \mathrm{HRT}=2 \mathrm{~d})$, the combination of high gas production and high hydraulic loading rate ( $5 \mathrm{gpm} / \mathrm{sq}$. ft.) resulted in excessive loss of solids and required termination of the experiment. This result shows the influence of gas production at high organic loading rates. The mixing provided by the gas bubbles becomes increasingly important compared to hydraulic flux effects when the HRT is low. This agrees with results reported by Hall (1985). 


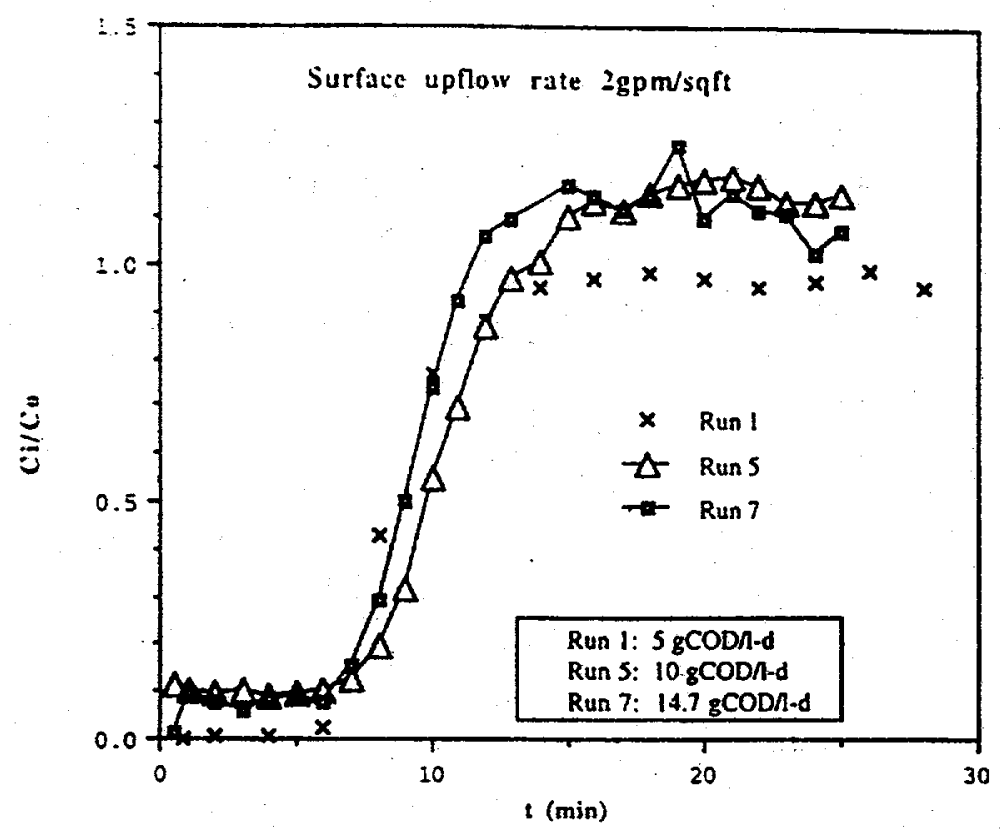

Figure 5-2. Effect of organic loading rate on hydraulic behavior at $2 \mathrm{gpm} / \mathrm{sq}$. $\mathrm{ft}$.

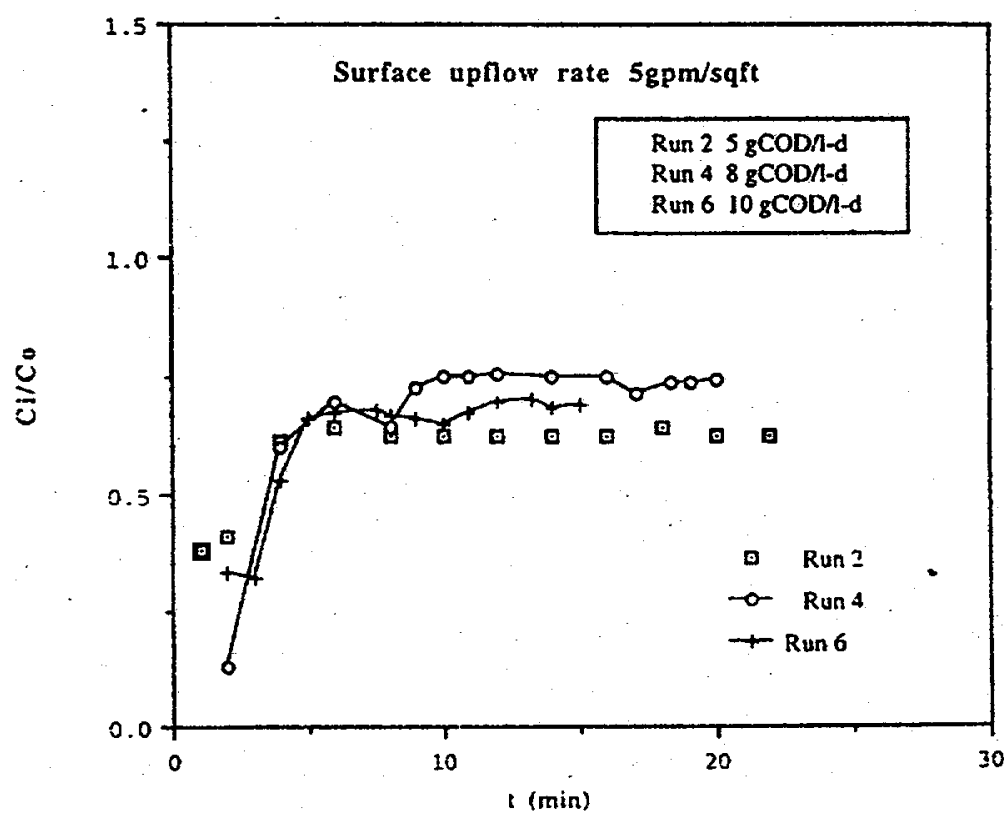

Figure 5-3. Effect of organic loading rate on hydraulic behavior at $5 \mathrm{gpm} / \mathrm{sq}$. $\mathrm{ft}$. 


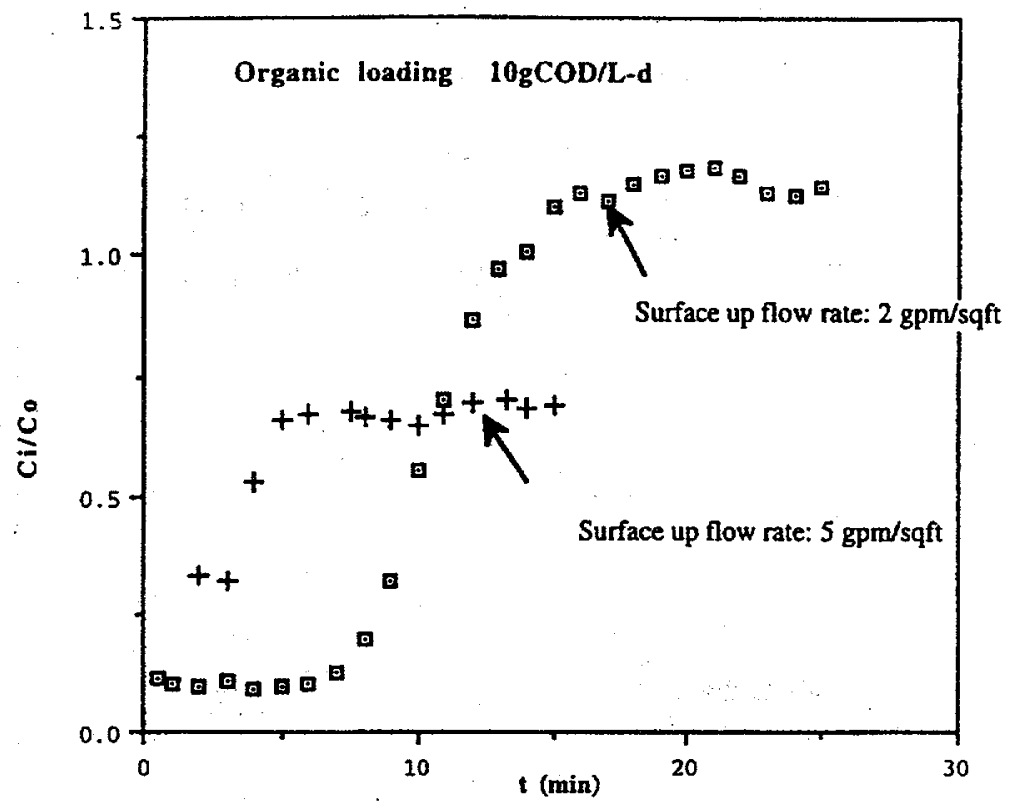

Figure 5-4. Comparison of effect at two surface upflow rates and an organic loading rate of $10 \mathrm{~g}$ COD/L bed-d.

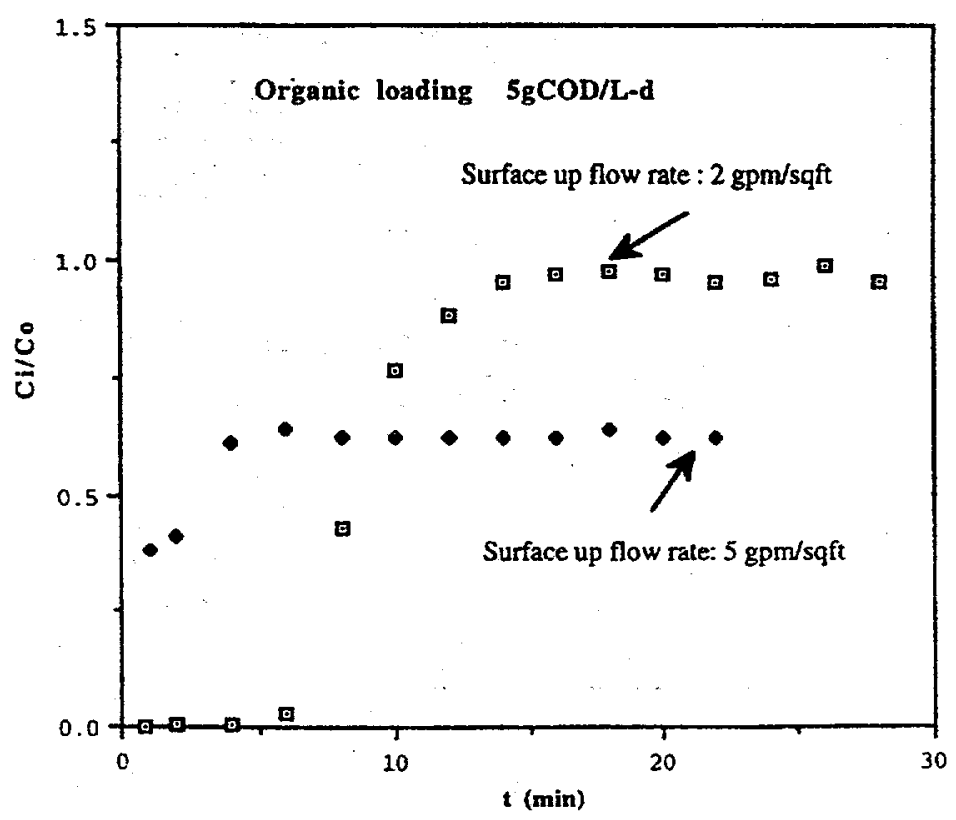

Figure 5-5. Comparison of effect at two surface upflow rates and an organic loading rate of $\mathbf{5} \mathbf{g}$ COD/L bed-d. 


\begin{tabular}{|c|c|c|c|c|c|}
\hline \multicolumn{6}{|c|}{ Table 5-3. Effect of organic loading rate on UASB reactor hydraulic characteristics. } \\
\hline $\begin{array}{c}\text { Organic } \\
\text { Loading } \\
\text { (g COD/L-d) }\end{array}$ & $\begin{array}{c}\text { Surface } \\
\text { Upflow Rate } \\
\text { (gpm/sq. ft.) }\end{array}$ & $\begin{array}{c}\text { Vb/Vt } \\
(\%)\end{array}$ & $\begin{array}{c}\text { Dispersion } \\
\text { Number per } \\
\text { Cycle }\end{array}$ & $\begin{array}{c}\text { HRT } \\
\text { (d) }\end{array}$ & $\begin{array}{c}\text { Biogas } \\
\text { Production } \\
\text { (m/hr) }\end{array}$ \\
\hline 5.2 & 2 & 60.0 & 0.051 & 5.6 & 155 \\
\hline & 5 & 80.0 & 0.11 & & 156 \\
\hline 8.0 & 2 & 61.6 & 0.069 & 3.6 & 253 \\
\hline & 5 & 74.5 & 0.097 & & 257 \\
\hline 10.0 & 2 & 62.9 & 0.045 & 2.9 & 305 \\
\hline & 5 & 77.0 & 0.102 & & 300 \\
\hline 14.7 & 2 & 68.4 & 0.048 & 2.20 & 440 \\
\hline & 2.2 & 69.0 & 0.049 & & 444 \\
\hline
\end{tabular}

\begin{tabular}{|c|c|c|c|c|}
\hline \multicolumn{3}{|c|}{ Table 5-4. Effect of recirculation on UASB reactor hydraulic characteristics ${ }^{\mathrm{a}}$. } \\
\hline $\begin{array}{c}\text { Surface Upflow } \\
\text { Rate } \\
\text { (gpm/sq. } \mathrm{ft} \text {.) }\end{array}$ & $\begin{array}{c}\text { Vb/Vt } \\
(\%)\end{array}$ & $\begin{array}{c}\text { Dispersion } \\
\text { Number per } \\
\text { Cycle }\end{array}$ & C/Colt $=0$ & $\begin{array}{c}\text { Student } \mathrm{t} \text { test } \\
\text { Results }\end{array}$ \\
\hline 2 & 63.2 & 0.053 & 1.07 & \\
\hline 5 & 77.2 & 0.103 & 0.69 & $\begin{array}{c}\mathrm{df}=5 \\
\mathrm{t}=6.986^{* * *} \\
\text { significant }\end{array}$ \\
\hline
\end{tabular}

\section{EVALUATION OF EXISTING FLUID FLOW MODELS AND MODEL DEVELOPMENT}

Modeling experiments were performed using a stimulus-response technique at OLRs of 4 and $10 \mathrm{~kg} \mathrm{COD} / \mathrm{m}^{3}-\mathrm{d}$ and HRT ranging from 11 to $99 \mathrm{hrs}$. The surface upflow velocity used was $2 \mathrm{gpm} / \mathrm{sq}$. ft. The Cholette-Cloutier model, Hall's parallel CSTR, model and the Van der Meer model were evaluated and compared. Two new hydraulic models (model 1 and model 2) were developed to describe the hydraulic behavior of UASB under low and high OLRs. Residence time distribution (E curve) of an inert tracer following an impulse was used for modeling. The $F$ curve (the integration of the E curve) analysis was employed for determination of tracer recovery and dead volume. In a dimensionless plot of the $F$ curve, the area between $F=1$ and $F(\theta)$ equals 1 for ideal CSTRs. An area that is less than 1 indicates the existence of dead volume. Sampling frequencies here were $10 \%$ of the HRT. Model parameters estimation of the Cholette-Cloutier model, Hall's parallel CSTR model, the Van der Meer model, and model 1 were performed using the software SYSTAT. For the model 2, a computer simulation program written in FORTRAN and IMSL was developed. The theoretical development of the models is described in Section 4. 


\section{Modeling at Low OLR}

For the UASB reactor operated at OLR of $4 \mathrm{~kg} \mathrm{COD} / \mathrm{m}^{3}-\mathrm{d}$ and HRT of $99 \mathrm{hrs}, 11 \mathrm{mg}$ of lithium chloride was injected into the reactor inlet to produce an impulse. Approximately $90.4 \%$ of the lithium applied was recovered during the initial 1.4 HRT. There is a big discrepancy between measured data and ideal CSTR behavior under the operating conditions tested (Figure 5-6). Description of this non-ideal flow was attempted using four models: 1) the Cholette-Cloutier model, 2) the Hall model, 3) the Van der Meer model, and 4) model 1. Model 1 (Figure 5-7) includes a dispersion plug flow reactor for the by-pass flow, two parallel CSTRs for the granular bed and a plug flow reactor for the clarifier. Granular sludge bed has a mixing region, dead volume and a by-pass flow region. The first CSTR describes the main mixing region of the bed $\left(V_{l}\right)$. The other CSTR describes the volume in-between this volume and the stagnant region, or dead volume $\left(V_{d}\right)$. Following parallel CSTRs and a dispersion PF is a plug flow reactor. The model is expressed as the following equation (for derivation, see Section 4):

$$
\frac{C_{i}}{C_{o}}=\frac{A}{\sqrt{t^{\prime}}} \exp \left[-\frac{B}{t^{\prime}}\left(T_{d}-\left(t^{\prime}-T_{d 1}\right)\right)^{2}\right]+C \exp \left[-D\left(t^{\prime}-T_{d 1}\right)\right]+E \exp \left[-F\left(t^{\prime}-T_{d 1}\right)\right]
$$

where $C_{i}$ is the tracer concentration in the effluent at time $i ; C_{o}$ is the effluent concentration at $t^{\prime}=0$ in an ideal CSTR; $A=\frac{Q_{3} L}{2 C_{o} Q \sqrt{\pi D_{p}}} ; D_{p}$ is the axial dispersion coefficient; $u$ is fluid velocity; $L$ is length of dispersion plug flow reactor; $B=\frac{u^{2}}{4 D_{\rho}} ; T_{d}=\frac{L}{u} ; C=\left(\frac{Q_{1}}{Q}\right)^{2} \frac{V}{V_{1}} ; D=\frac{Q_{1} / Q}{V_{1} / V} ; T_{d l}$ is lag time of the plug flow reactor; $E=\left(\frac{Q_{2}}{Q}\right)^{2} \frac{V}{V_{2}} ; F=\frac{Q_{2} / Q}{V_{2} / V}$. Details on the development of this flow model are provided in Section 4 .

Results obtained using the above-referenced models are shown in Figures 5-8 through 5-11. The first few data points in the tracer study represent the bypass flow, expressed as a delta function. This initial portion of the RTD curve was not fit well by any of the existing models. Following this initial portion of the curve, an exponential decay curve was observed; this was described reasonably well by the Cholette-Cloutier, Hall, and the Van der Meer models. The model developed during this work (model 1) fit the experimental data, including the initial portion of the data, extremely well. 


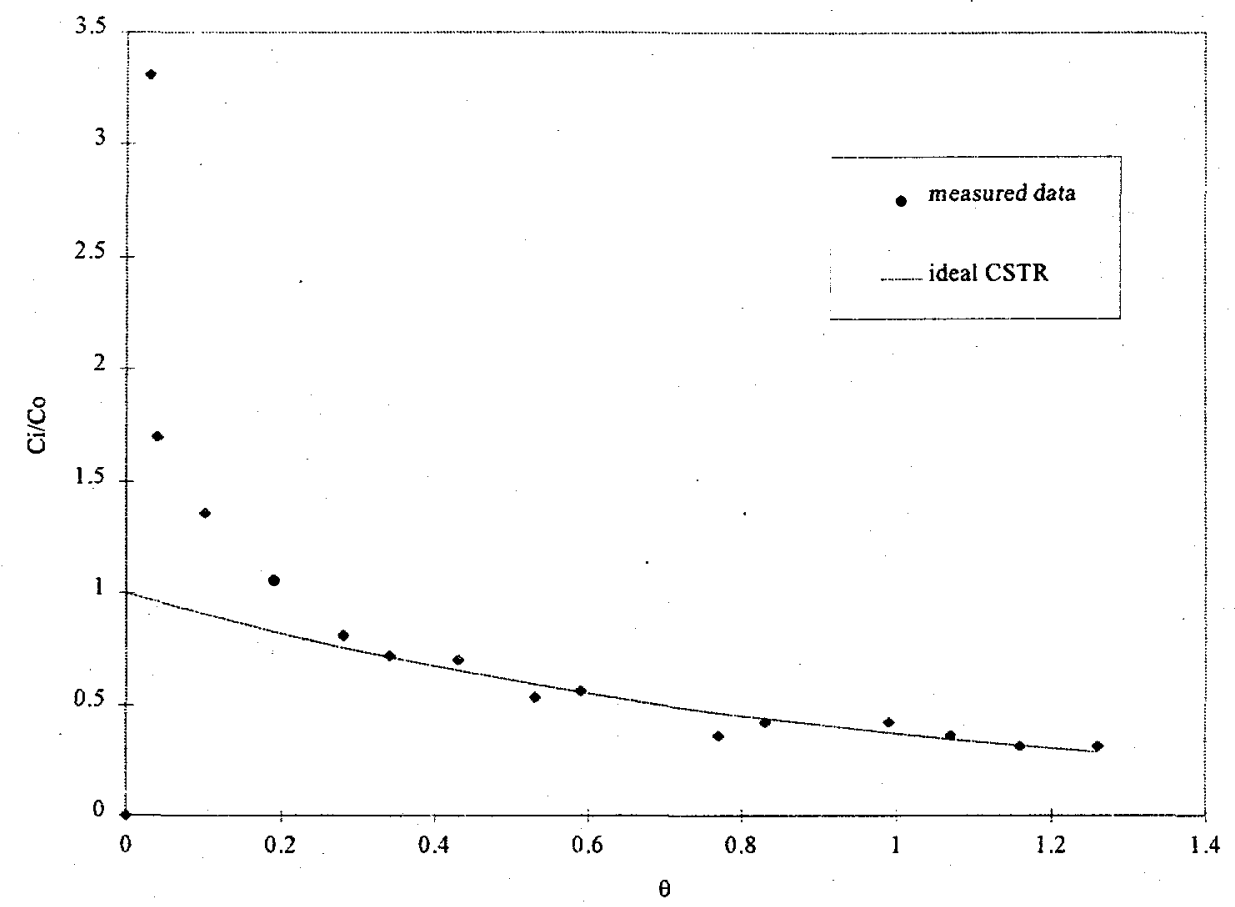

Figure 5-6. Measured data compared with ideal CSTR at $4 \mathrm{~g}$ COD/L bed-d and HRT $99 \mathrm{hrs}$.

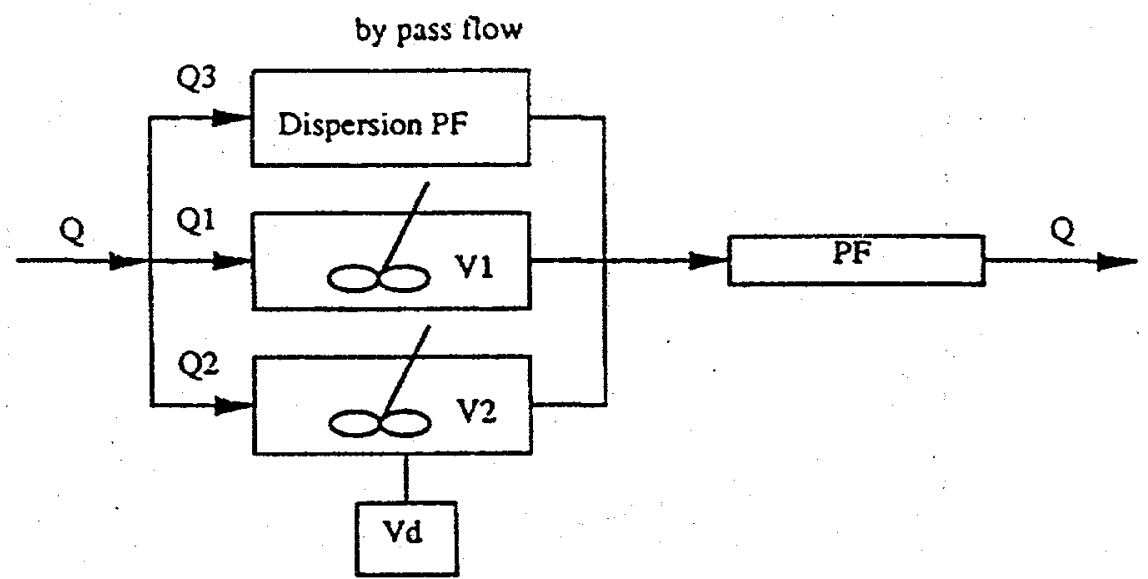

Figure 5-7. Representative of Model 1 used to desccribe UASB hydraulics at low OLR and high HRT. 


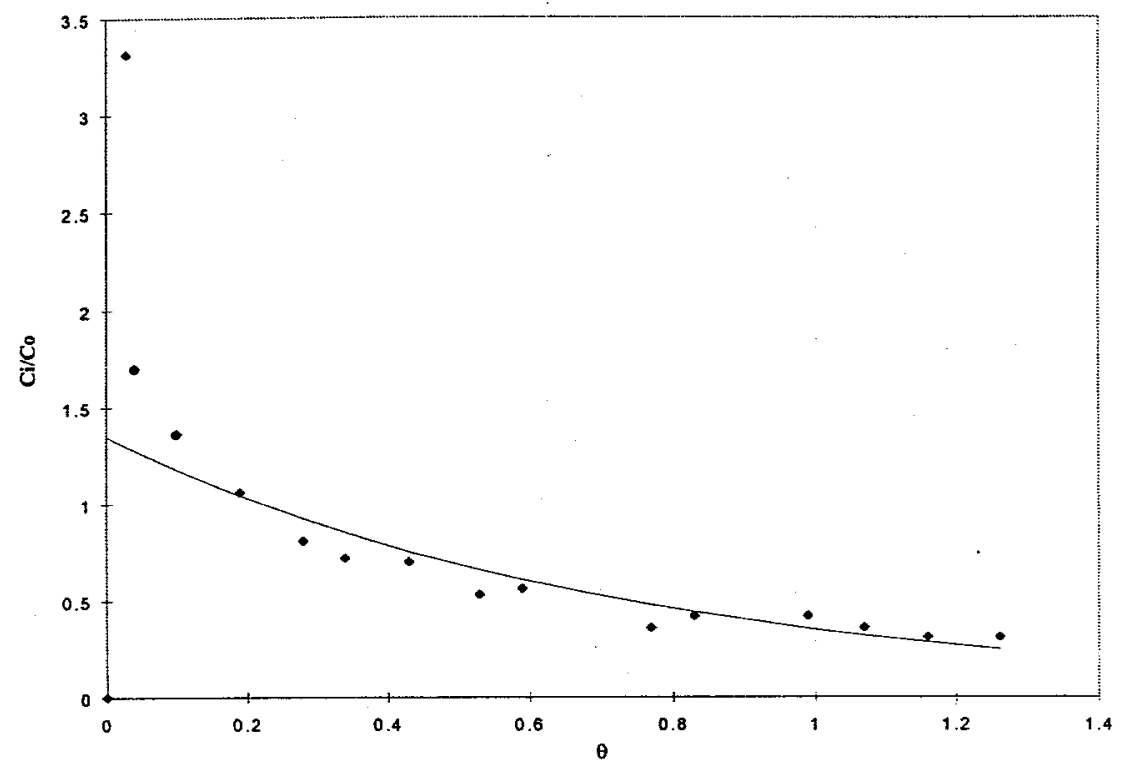

Figure 5-8. Results obtained using the Cholette-Cloutier model at OLR $4 \mathrm{~g}$ COD/L bed-d and HRT 99 hrs.

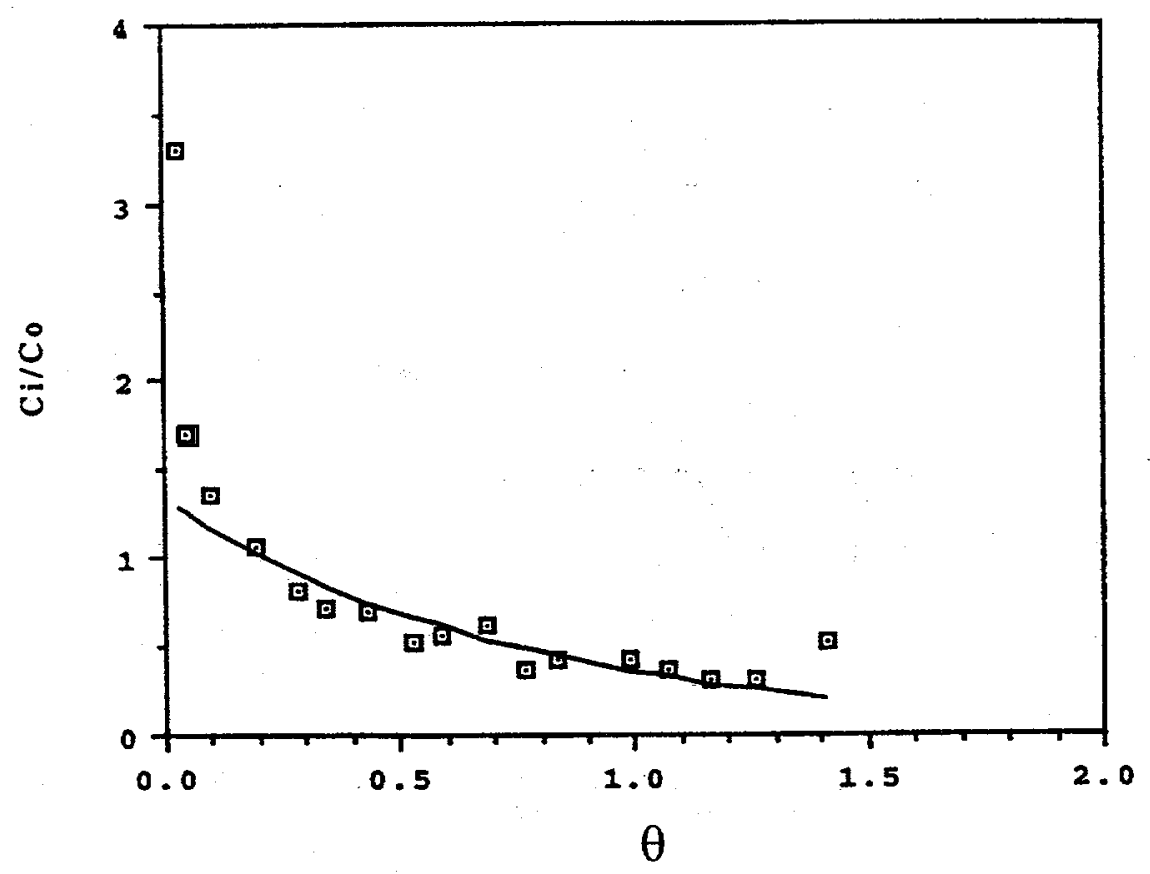

Figure 5-9. Results obtained using the Hall model at OLR $4 \mathrm{~g}$ COD/L bed-d and HRT 99 hrs. 


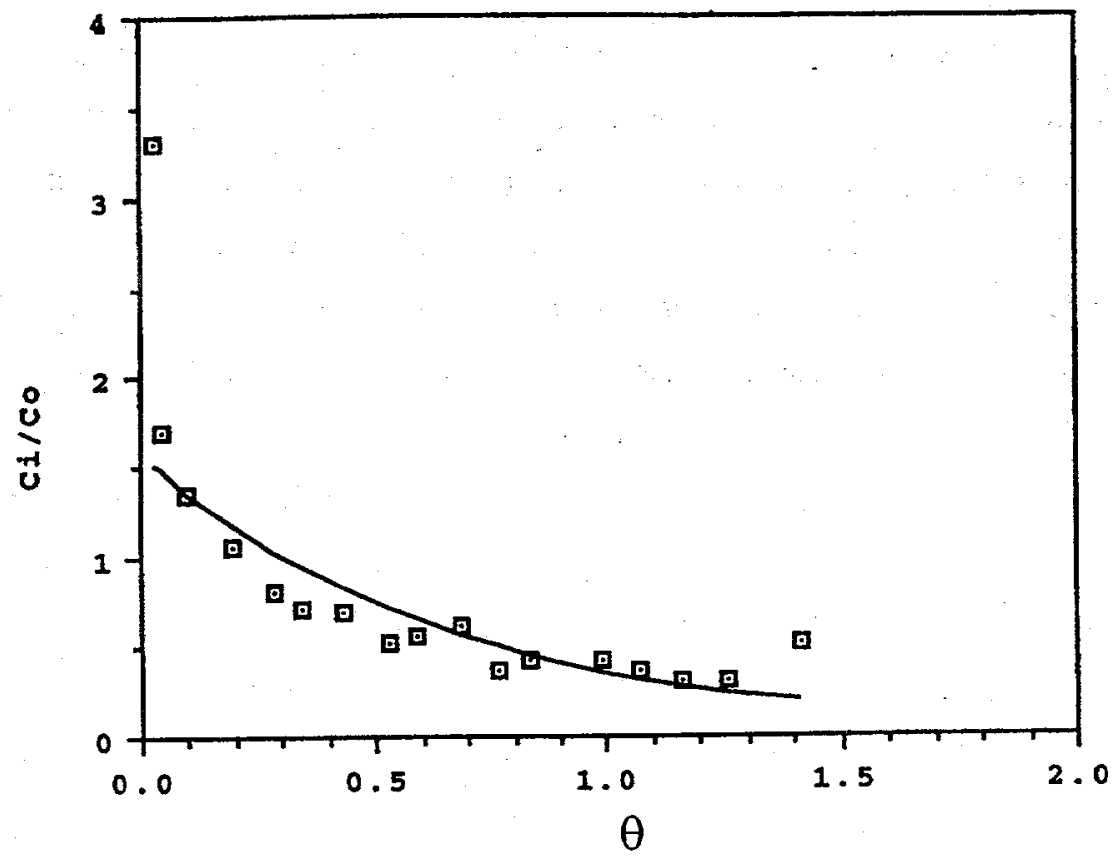

Figure 5-10. Results obtained using the Van der Meer model at OLR $4 \mathrm{~g}$ COD/L bed-d and HRT $99 \mathrm{hrs}$.

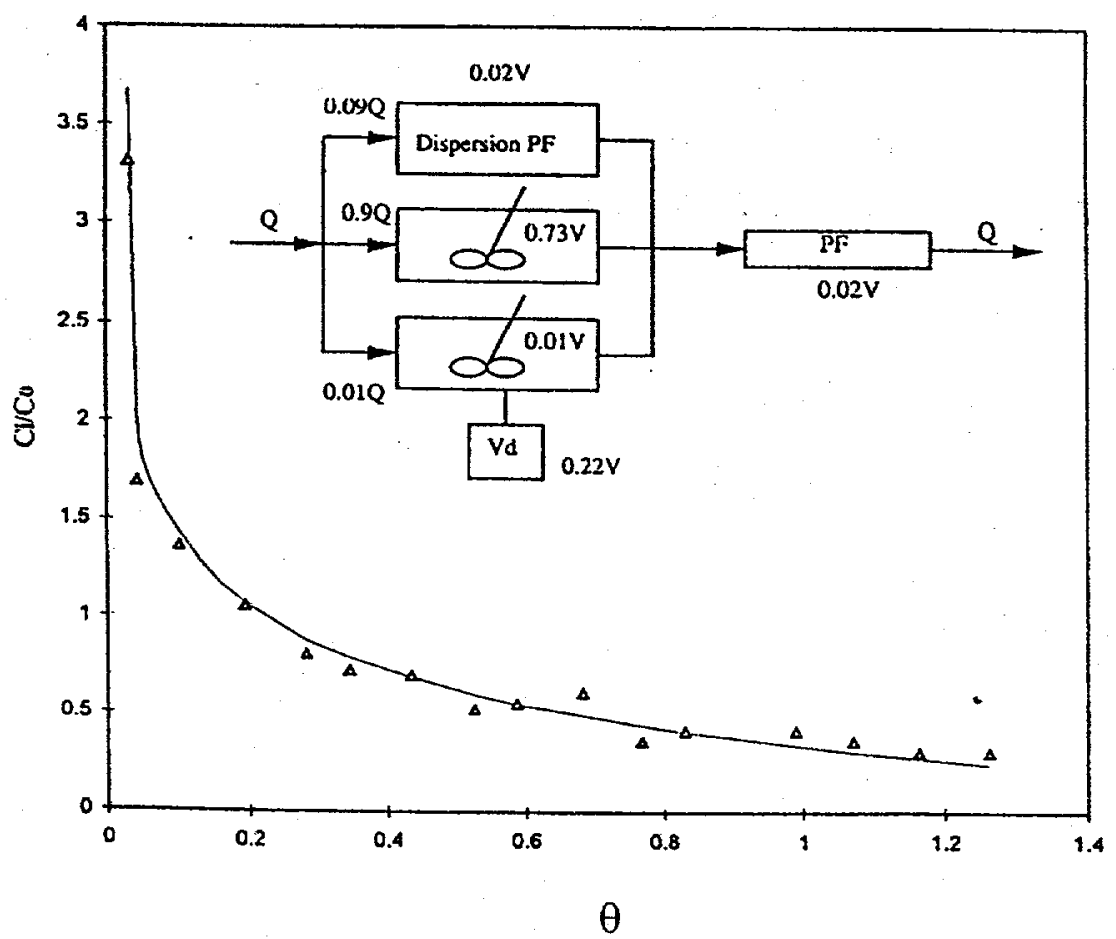

Figure 5-11. Results obtained using the new model at OLR $4 \mathrm{~g}$ COD/L bed-d and HRT $99 \mathrm{hrs}$. 


\section{Modeling at High OLR}

The bench-scale UASB was operated at an OLR of $10 \mathrm{~kg} \mathrm{COD} / \mathrm{m}^{3}-\mathrm{d}$ and HRT of 11 hours. Lithium chloride $(160 \mathrm{mg}$ ) was injected at the base of the reactor. Recovery of LiCL was $100 \%$ at $5.3 \mathrm{HRT}$. As expected, when the OLR was increased, gas production increased. This in turn produced better mixing within the sludge bed. Thus, a model with a larger mixing volume would describe the UASB well. Initial results show the UASB does not represent an ideal CSTR (Figure 5-12). Parameters of Cholett-Cloutier, Hall, and Van der Meer models and model 1 were estimated with this data set (Figures 5-13 through 5-16. Van der Meer's model describes the UASB reactor with good fit. Cholett-Cloutier's, Hall's models and model 1 were unable to fit the data. An. attempt was made to describe the reactor hydraulics at high OLR using one CSTR, with bypass flow, in series with PFR. The model parameters showed no physical significance. A second model 1 (model 2) was developed. Model 2 consisted of a single CSTR with dead volume and by-pass flow to represent the granular bed, followed by a dispersion plug flow reactor (Figure 5-17). This model was developed for high OLR operation because of the different hydraulic regime, the result of increased gas production. In practice, we are looking for a model as simple and meaningful as possible. There are several differences or simplifications between model 2 and the Van der Meer model. Since the interface layer of sludge bed and sludge blanket in a UASB reactor is usually not distinguishable by visual inspection and uneasy to determine, the two CSTRs which describe the sludge bed and sludge blanket in Van der Meer model are simplified to one CSTR. The clarification zone above the sludge blanket is represented by a dispersion plug flow reactor rather than a simple plug flow reactor, because increased gas production during the high OLR contribütes to increased mixing in this layer. By-pass flow, instead of going through the bed only, passes to the end of the reactor. A computer program written in FORTRAN and IMSL has been developed for model 2. Finite difference (Ames 1977) was used as solution technique. Equations for this model are:

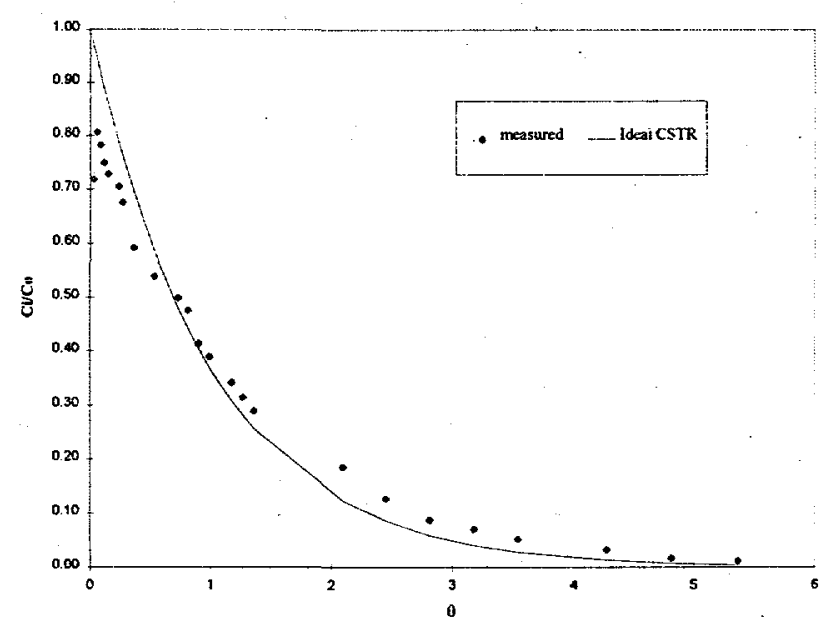

Figure 5-12. Measured data compared with ideal CSTR at OLR $10 \mathrm{~g}$ COD/L bed-d and HRT 11 hrs. 


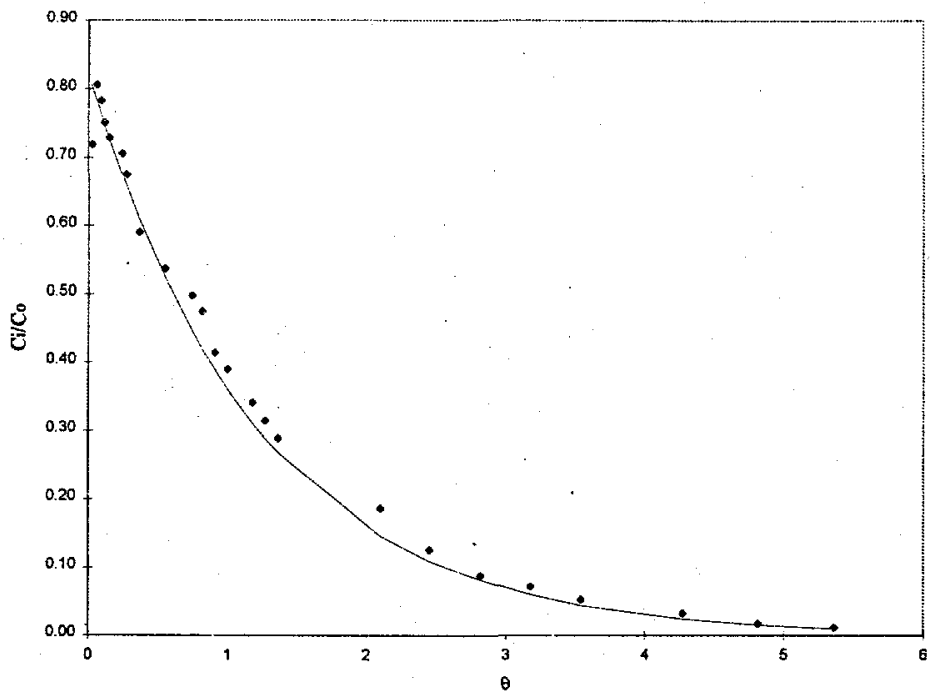

Figure 5-13. Results obtained using the Cholette-Cloutier model at OLR $10 \mathrm{~g}$ COD/L bed-d and HRT 11 hrs.

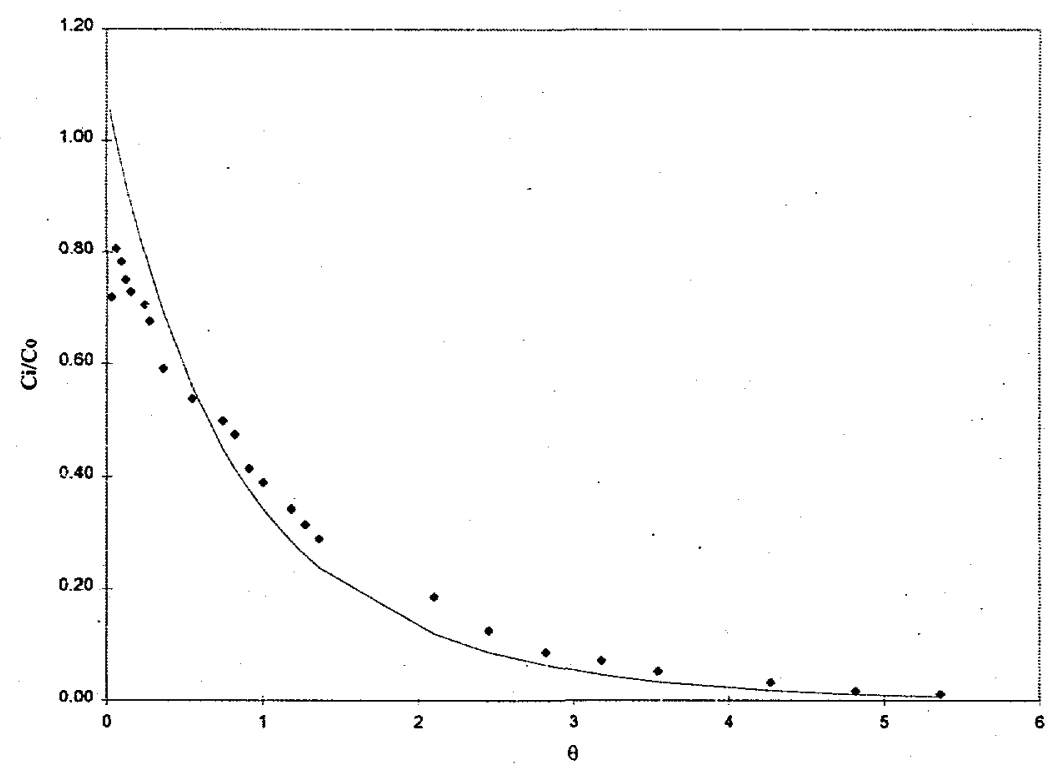

Figure 5-14. Results obtained using the Hall Model at OLR $10 \mathrm{~g}$ COD/L bed-d and HRT $11 \mathrm{hrs}$. 


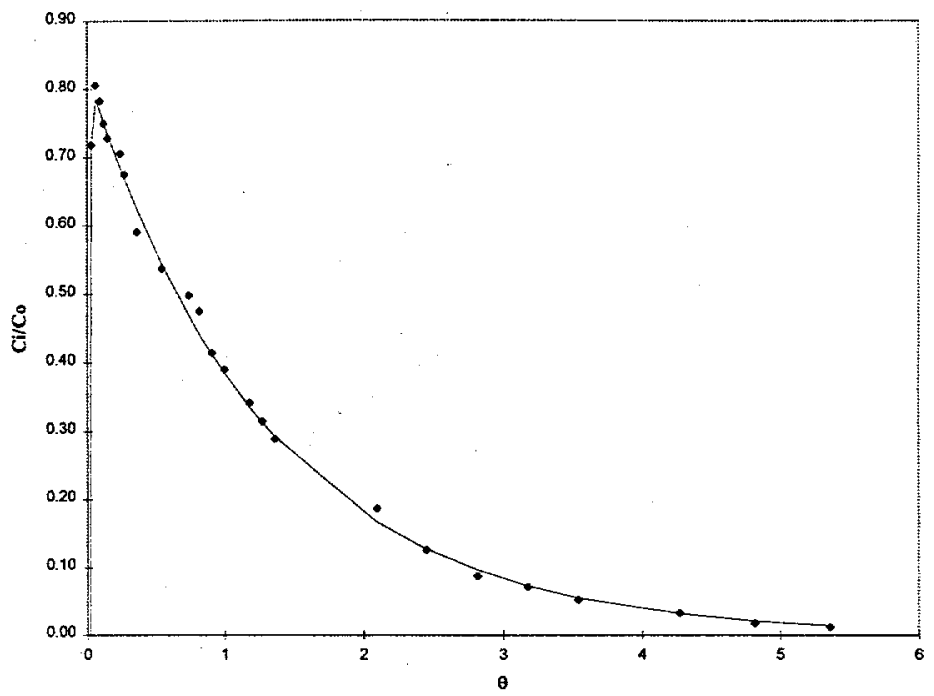

Figure 5-15. Results obtained using the Van der Meer model at OLR $10 \mathrm{~g} \mathrm{COD/L}$ bed-d and HRT 11 hrs.

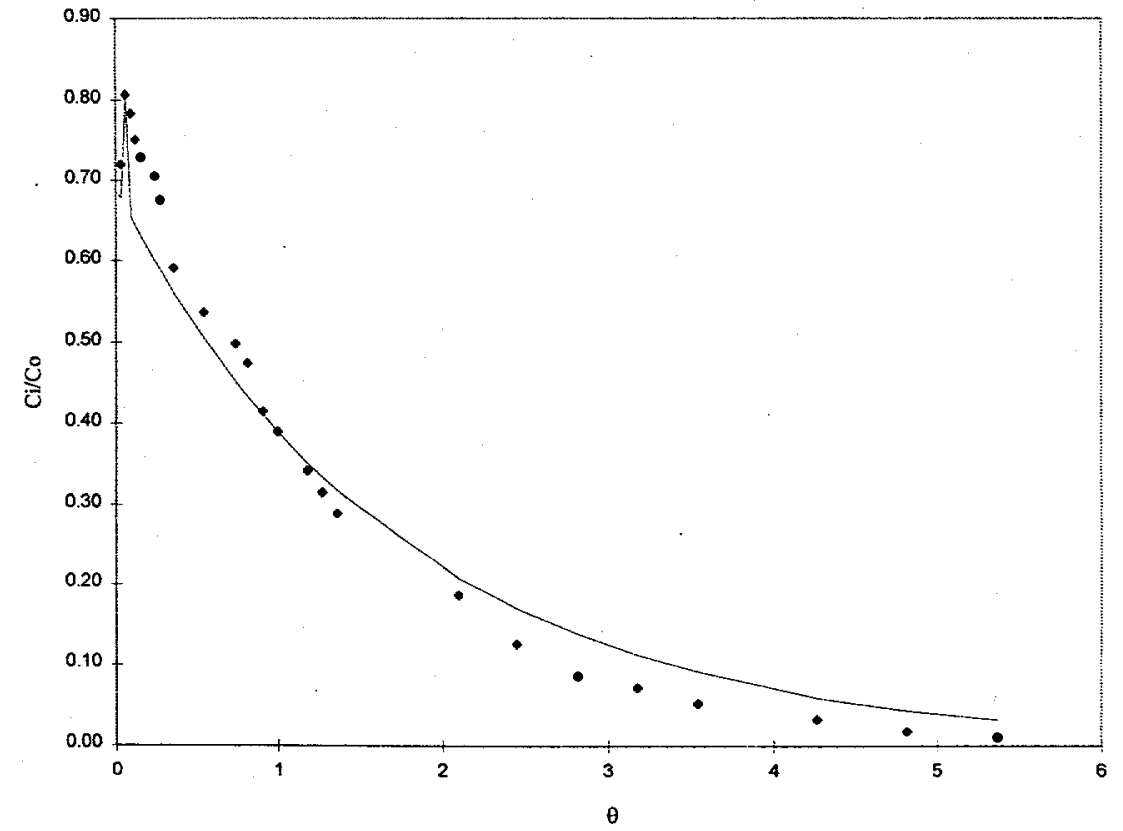

Figure 5-16. Results obtained using the model 1 at an OLR $10 \mathrm{~g}$ COD/L bed-d and HRT $11 \mathrm{hrs}$. 


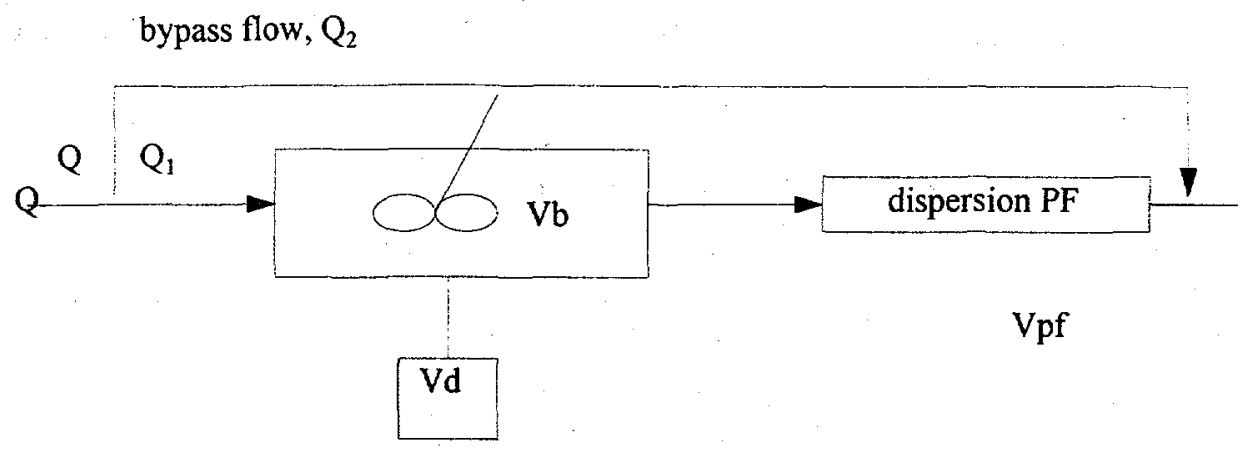

Figure 5-17. Model 2 describes UASB at high OLR and low HRT.

$V_{b} \frac{d C}{d t}=V_{b} E(t)-Q f C(t)$

$$
\begin{aligned}
& E(t)=\left\{\begin{array}{ccc}
\frac{M f}{V_{b} T_{i n}}, & \text { if } & 0 \leq t \leq T_{\text {in }} \quad \text { For i } \\
0, & \text { if } & T_{\text {in }} \leq t
\end{array}\right. \\
& \frac{\partial C_{p f}}{\partial t}=\frac{D_{p}}{L} \frac{\partial^{2} C_{p f}}{\partial Z^{2}}-\frac{u}{L} \frac{\partial C_{p f}}{\partial Z}, t>0,0<Z<1,
\end{aligned}
$$

$\mathrm{BC}: \quad C_{p f}(0, t)=C(t)$

IC: $\quad C_{p f}(Z, 0)=C_{o}$

where $C(t)$ is concentration within CSTR; $C_{p f}$ is concentration within dispersion plug flow reactor; $V_{b}$ is working volume of CSTR ( $\left.=V-V_{d}\right) ; V_{d}$ is dead volume within the CSTR; $E(t)$ is an input function; $S_{b}$ is bulk tracer concentration; $f$ is fraction; $Q f$ is the flow fraction that enters the main stream; $M f$ is fraction of mass input that goes through reactor working volume; ${ }_{\text {in }}$ is tracer injection time; $C_{p f}$ is concentration in dispersion PFR; $X$ is a vertical coordinate; $D_{p}$ is dispersion coefficient; $\mathrm{u}$ is flow velocity within the reactor; $L$ is the length of the PFR. Detailed derivations are provided in Section 4. Model 2 fit the tracer data reasonably well (Figure 5-18). The estimated working volume (excluding the plug flow region), plug flow volume, dead volume and by-pass flow for the model 2 and the Van der Meer model, respectively, were $91 \%$ and $97 \%$ of the total reactor volume, $2 \%$ and $3 \%$ of the total volume, $7 \%$ of total volume and zero, and $24 \%$ and $31 \%$ of the total flow, (Figures 5-15 and 5-18). Dead volume in Van der Meer model was estimated from F curve analyses. 
The dispersion factor $\left(\frac{D_{p}}{L^{2}}\right)$ was 0.001 for model 2. A ratio of flow velocity $(u)$ to the length of the PFR $\left(\frac{u}{L}\right)$ of 0.635 was observed. Model 2 does not describe the UASB hydraulics under low OLR $\left(4 \mathrm{~kg} \mathrm{COD} / \mathrm{m}^{3}-\mathrm{d}\right.$, Figure 5-19) because of differences in hydraulic regime between low and high OLR. This hydraulic model is used in the dynamic modeling of UASB reactor during organic perturbations (Section 9). The two factors, $\frac{D_{p}}{L^{2}}$ and $\frac{u}{L}$ will be compared with that obtained from dynamic modeling.

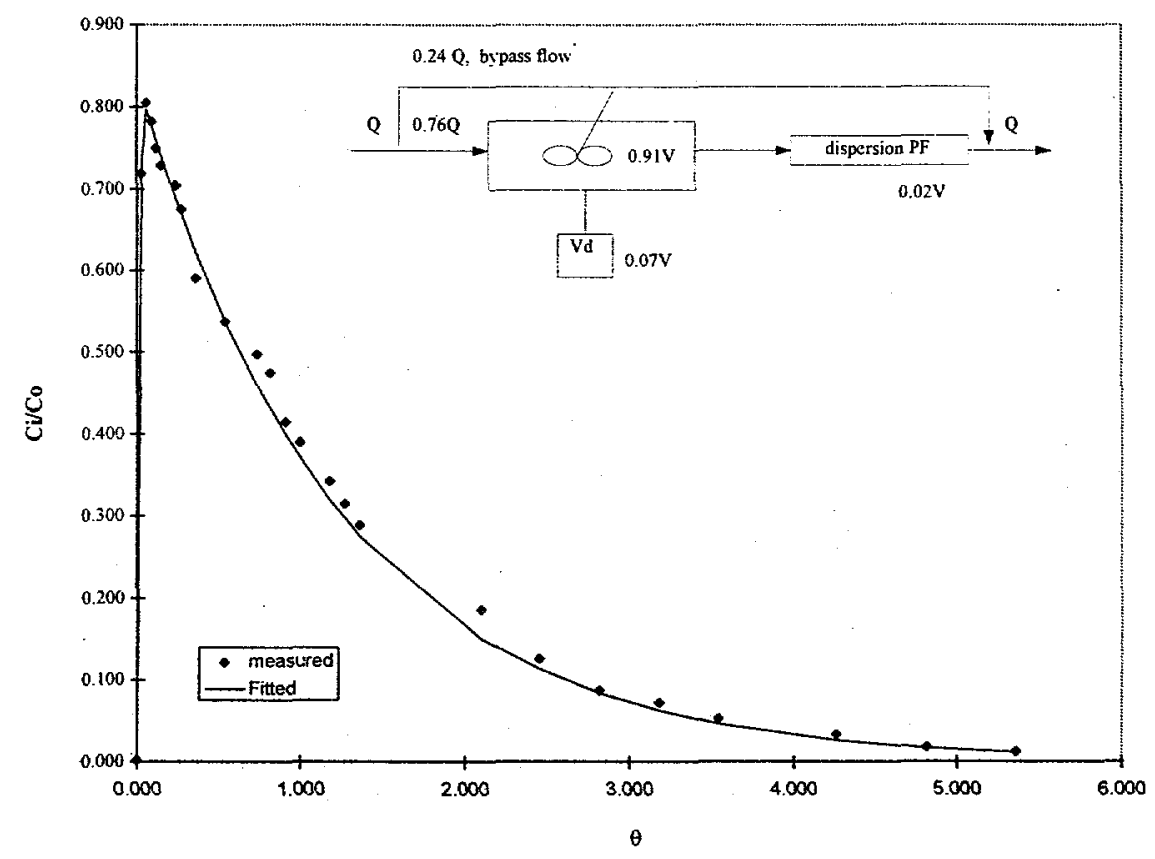

Figure 5-18. Results obtained using the model 2 at OLR $10 \mathrm{~g}$ COD/L bed-d and HRT $11 \mathrm{hrs}$. 


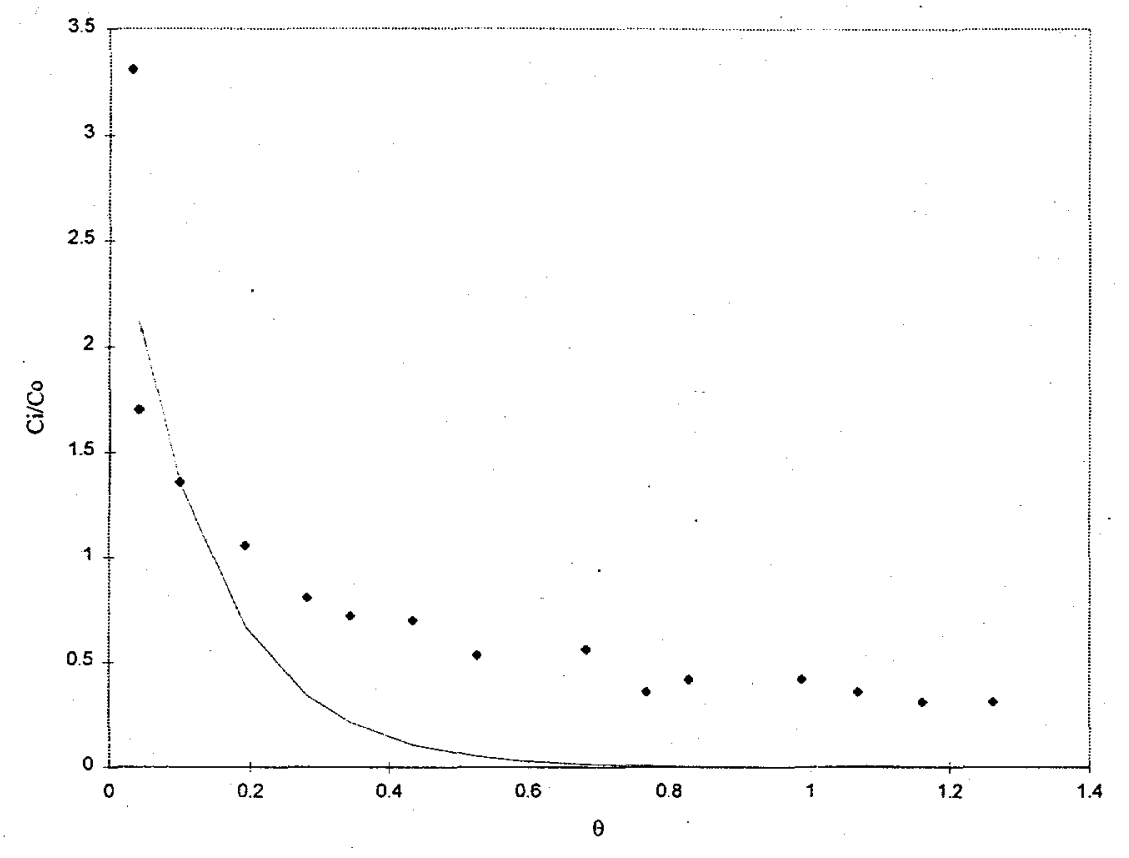

Figure 5-19. Results obtained using the model 2 at an OLR $4 \mathrm{~g}$ COD/L bed-d and HRT 99 hrs.

\section{DISCUSSION}

UASB reactors do not represent CSTRs under the experimental conditions tested. Hydraulic flux had a strong influence on the mixing efficiency of the UASB system at HRTs of 2 to 5.6 days, applied OLR of 5 to $10 \mathrm{~kg}$ $\mathrm{COD} / \mathrm{m}^{3}-\mathrm{d}$, and an upflow velocity between 2 and $5 \mathrm{gpm} / \mathrm{sq}$. ft., based on dispersion number analysis. By comparing Figure 5-2 with Figure 5-3, one can observe that at the recirculation rate of $2 \mathrm{gpm} / \mathrm{sq}$. $\mathrm{ft}$, an increase in the organic loading rate by a factor of 2.8 did not significantly change the hydraulic characteristics, despite a 2.8-fold increase in biogas production ( $280 \mathrm{ml} / \mathrm{hr}$ additional production, Table 5-3). However, an increase in the recirculation rate (surface upflow rate) of 2.5 times did significantly improve mixing at OLR of 5 to $10 \mathrm{~kg}$ $\mathrm{COD} / \mathrm{m}^{3}-\mathrm{d}$. This is demonstrated by examining the calculated dispersion numbers (based on one turnover) shown in Table 5-4. A dispersion number larger than 0.02 is generally considered to be significant in a closed plug flow system. Under high reactor hydraulic loading rates ( $5 \mathrm{gpm} / \mathrm{sq}$. $\mathrm{ft}$.) the dispersion number was 0.1 , double that observed (0.05) at the lower hydraulic loading rate of ca. $2 \mathrm{gpm} / \mathrm{sq}$. $\mathrm{ft}$. Results from student $\mathrm{t}$ tests showed that the dispersion number for the two different surface upflow rates were significantly different (Table 5-4). Multiple comparisons (least significant difference test) for dispersion numbers under four organic loadings revealed an $\operatorname{Lsd}_{(0.05)}=0.1008>$ all differences of means (Table 5-3). This indicates that the differences among the dispersion numbers for the four organic loading rates were not significant. During the initial period the reactor exhibits a pattern of plug flow with high dispersion under all operating conditions tested. The degree of mixing increased with increased recirculation and resultant increase in the expansion of the granular bed. Distribution curves were flatter for the higher upflow rate, indicating that increased internal 
circulation smoothed the RTD curve by providing greater mixing, and more homogenous distribution. A lower peak ratio of $\mathrm{Ci} / \mathrm{Co}$ was observed at the higher flow rates (Figure 5-3). This ratio should approach 1.0 for an ideal CSTR, but only reached 0.69 (on average) in the experiment at a surface upflow rate of $5 \mathrm{gpm} / \mathrm{sq}$. $\mathrm{ft}$. This indicates that some flow by-pass occurred. A peak $\mathrm{Ci} / \mathrm{Co}$ ratio of greater than 1 was observed for runs at the lower surface upflow rate. This indicates the presence of a significant amount of dead volume, probably as a result of insufficient expansion of and channeling through the granular bed. This dead volume was reduced at higher internal recirculation (surface upflow) rates. It thus appears that recirculation serves to decrease deadvolume but concurrently increases the degree of short-circuiting that occurs.

However, at the same range of upflow velocities, HRTs of $11-99$ hours and OLRs of $4-10 \mathrm{~kg} \mathrm{COD} / \mathrm{m}^{3}-\mathrm{d}$, the organic loading rate has shown to have a major influence on mixing, observed from modeling experiments (model 1 and 2). It thus appeared that the organic loading effect was not consistent. The mixing experiment was focused on dispersion number per cycle at the initial period of the RTD curve, thus local effect; while the modeling experiment examined the whole RTD curve and the descriptions were more general. Under the variations of OLR flux and hydraulic flux, granular bed expansions were increased ( $7 \%$ and $14 \%$, respectively), demonstrating that both OLR and SUV (surface upflow velocity) affected reactor mixing, and the hydraulic flux had a stronger effect. This improvement of mixing through increased gas production was supported by modeling experiments where SUV was fixed, as described by the models 1 and 2 . Dispersion number failed to indicate this change suggesting this is not a good tool for evaluating reactor hydraulics where significant gas production occurs.

A correlation of fluidization index $(n)$ with bed voidage and superficial velocity (or empty bed velocity) $\left(U_{b s}\right)$, has been used to describe fluidized bed expansion (Wen and Yu 1966; Fouda and Capes 1977; Garside and AlDibouni 1977). The bed voidage can be related to superficial velocity in reactor by the Richardson-Zaki equation:

$$
\mathrm{U}_{\mathrm{bs}}=\mathrm{U}_{\mathrm{i}} \varepsilon
$$

where $U_{b s}$ is superficial velocity (empty bed velocity), $U_{i}$ is terminal particle settling velocity, $\varepsilon$ is bed voidage, and $\mathrm{n}$ is the index. The correlation between the index with reactor system variables can be determined by following relationships:

$$
\mathrm{n}=4.65+19.5 \frac{d}{D} \quad \operatorname{Re}<0.2
$$




$$
\begin{array}{ll}
\mathrm{n}=\left(4.35+17.5 \frac{d}{D}\right) \operatorname{Re}^{-0.3} & 0.2 \leq \operatorname{Re}<1.0 \\
\mathrm{n}=\left(4.4+18 \frac{d}{D}\right) \operatorname{Re}^{-0.1} & 1.0 \leq \operatorname{Re}<200 \\
\mathrm{n}=2.39 & 500 \leq \operatorname{Re}
\end{array}
$$

where $\mathrm{d}$ is granule diameter, $\mathrm{D}$ is reactor diameter, and Re is Reynolds number. The index for the two sizes of granules observed in this study ( $d=3 \mathrm{~mm}, 1 \mathrm{~mm}$, respectively) for two different upflow velocities is presented in Table 5-5. By visual observation, the lower portion of the bed (sludge bed) tended to have larger granules and appeared as a compact, nearly static bed; the upper part of the bed (sludge blanket) had smaller granules and fluidization could be maintained quite well. Results presented in Table 5-5 reflect the fact that the hydraulics were greatly different between the sludge bed and sludge blanket, with lower Reynolds number values in the sludge bed region. This resulted in non-uniform expansion and different $\mathbf{n}$ values for the sludge bed and sludge blanket region. The poor expansion of the sludge bed is likely the primary cause of the dead volume observed during experiments with low OLRs and high HRTs. This may contribute, in part, to the differences between UASB reactor performance and that expected from ideal CSTR behavior.

\section{Table 5-5. Fluidization index of UASB reactor under different operating conditions and} granule sizes.

\begin{tabular}{|c|c|c|c|c|}
\hline $\mathbf{U}_{\text {bs }}{ }^{2}$ & \multicolumn{2}{|c|}{ Granule d=3 mm } & \multicolumn{2}{c|}{ Granule d=1 mm } \\
\hline$($ Spm/sqft) & \multicolumn{2}{|c|}{ Sludge bed } & \multicolumn{2}{c|}{ Sludge blanket } \\
\hline & $\operatorname{Re}$ & $\mathrm{n}$ & $\operatorname{Re}$ & $\mathbf{n}$ \\
\hline 2 & 5.23 & 4.63 & 710 & 2.93 \\
\hline 5 & 12.70 & 4.24 & 710 & 2.93 \\
\hline a empty bed velocity & \multicolumn{3}{|c|}{} \\
\hline
\end{tabular}

All three existing models (Cholette-Cloutier's, Hall's and Van der Meer's) failed to describe the UASB reactor at low applied OLRs ( $4 \mathrm{~kg} \mathrm{COD} / \mathrm{m}^{3}-\mathrm{d}$ ). Model 1 , however, fit the experimental data well. The duration for the net working flow (total flow rate minus by-pass flow rate, $0.91 \mathrm{Q}$ ) to go through the working volume (total reactor volume minus dead space, $0.78 \mathrm{~V})$ is $0.86 \mathrm{HRT}\left(0.86=\frac{0.78 \mathrm{~V}}{0.91 Q}=\frac{0.78}{0.91} \mathrm{HRT}\right)$. This means the time the fluid stayed within the reactor was $14 \%$ less than would be anticipated. By-pass flow has been observed in the bench-scale UASB reactor, especially between the bed and the glass wall of the reactor. Nine percent of the total flow entering the reactor by-passed the working volume region. At low OLR, the sludge bed was relatively compact due to low gas production and thus poor mixing occurred within the bed. In fact, compact clusters of large granules in the sludge bed were often observed. The calculated dead space of $22 \%$ of total 
reactor volume suggests a significant portion of the granule bed has not being used for treatment. The space between the main working volume and the dead volume was described by a small CSTR ( $1 \%$ of total volume and total flow). The clarification zone above the sludge blanket in the bench-scale UASB reactor was about $20 \%$ of the total volume. There was essentially no granular sludge in this portion of the reactor, although some granules passed upward through this volume when buoyed by attached gas bubbles and downward through this region after gas/solid separation occurred. However, the gas bubbles produced continuously due to degradation of organic materials migrated from the sludge bed, up through this region. This contributed to the extent of mixing in this region. At the top layer of this region, gas and solids were separated. Obviously, the hydraulics in this zone could be different from those of both the sludge bed and sludge blanket. Ideally, this portion of the flow could be described as a dispersion-piug flow or a plug flow and a CSTR. In the case of low OLR, a plug flow reactor and a CSTR joined with sludge bed work well, as was predicted by the model 1 (Figure 5-11). At high OLR, a dispersion PFR better describes the clarification volume in UASB (Figure 5-18). The plug flow reactor has $2 \%$ of total reactor volume at low OLR. This means a majority of the space in the clarifier was well mixed by the gas bubbles. The model 1 appears adequate in describing the non-ideal behavior of UASB reactor at low applied OLRs.

At high OLRs, the bench UASB does not behave as an ideal CSTR. Neither Cholette-Cloutier's or Hall's models, nor model 1 describe the UASB hydraulics well. The Van der Meer model and model 2 fit the data well (Figures 5-15 and 5-18). The reactor working volumes from these two models were close ( $3 \%$ difference in the total volume). By comparison, the by-pass flow estimated by model 2 ( $22 \%$ of the total flow) was more reasonable than that estimated with Van der Meer model (31\% of the total flow). A $31 \%$ by-pass flow means a maximum about $70 \%$ of organics removal can be achieved. However, operational data from the UASB reactor showed a COD removal efficiency of $80 \%$ and above. Thus, the UASB reactor tested is unlikely to have $30 \%$ of total flow bypassed. Model 2 has fewer compartments (one less CSTR) than does the Van der Meer model, and thus a reduced set of differential equations which resulted in much simpler computations. Apparently, the higher the OLR, the more gas is produced and the larger the mixing volume becomes. By comparing these results with the results from the low OLR modeling, one can observe that the volume of CSTR increased $17 \%$, from $74 \%$ (model 1, Figure 5-11) to $91 \%$ (model 2, Figure 5-18), of total reactor volume. The increased mixing space is mostly a result of a reduction in the dead volume (22\%). This means more granules in the bed were exposed to the incoming substrate. The by-product of this improvement is a $13 \%$ increase in by-pass flow. The fit obtained with the different flow models changed significantly when the OLR was increased from 4 to $10 \mathrm{~kg} \mathrm{COD} / \mathrm{m}^{3}-\mathrm{d}$, and the HRT was decreased from 99 to $11 \mathrm{hrs}$. The two parallel CSTRs became one CSTR, a dispersion plug flow by-pass stream was reduced to a simple by-pass flow, and a PFR was replaced by a dispersion PFR (Figures 5-7 and 5-17), suggesting improved axial mixing in the reactor. This is the main reason model 2 did not fit data obtained at low OLRs (Figure 5-19). 


\section{Section 6}

\section{MONITORING AN UASB REACTOR TREATING A SYNTHETIC BREWERY WASTE}

\section{INTRODUCTION}

The complex degradation sequence in anaerobic treatment of organic matter in wastewater, coupled with the sensitivity of the various microbial populations, requires a strong monitoring and control strategy, to adequately detect instability of a process or any change in system responses from a target level. Improved monitoring and control should lead to improved system performance and avoidance of gross process failure. Numerous attempts have been made to reveal the causes of instability and better control anaerobic processes using control charts, pattern recognition, fussy control and expert systems (Olsson et al. 1989; Berthouex 1989; Locher et al. 1990; Boscolo et al. 1993; Barnett and Andrews 1992). Recent developments in anaerobic microbiology and available instrumentation have expanded monitoring of the anaerobic treatment process to a variety of system parameters. Successful process monitoring can be accomplished by using several process indicators which characterize current process status. In the near future, these indicators may be used to help identify the causes when poor operation exists: Ideal process indicators have the features of: 1) being sensitive, with low noise, 2) being easy to measure, 3) having intrinsic meaning, 4) providing early warning, and 5) featuring on-line measurement.

Early process indicators used for anaerobic digestion systems included pH (Clark and Speece 1970; Zoetemayer et al. 1982), VFA (Asinari di San Marzano 1981; Powell and Archer 1989), bicarbonate (Colin 1984; Rozzi et al. 1985), redox potential (Dirasian et al. 1963), and gas and methane production (Dague 1968). Among these parameters $\mathrm{pH}, \mathrm{VFA}$, and gas production are good process indicators for detecting slow-to-develop system failures such as those experienced for sludge digestion. In high-rate anaerobic systems such as UASB reactors, however, monitoring of process parameters that provide a fast response under shock loading and other perturbations is required to avoid serious system failure. Automation of $\mathrm{pH}$ monitoring is available. A reduction in $\mathrm{pH}$, which could lead to inhibition of methanogenesis, is caused by accumulation of acids when the buffering capacity is exhausted. Therefore, it is the result of a system imbalance rather than an early warning sign. The measurement for bicarbonate is usually performed via a titration technique which is not easily automated. VFA accumulation is a sign of lack of balance between acetogens and methanogens. The determination of VFA at present is off-line and observed to be a less sensitive indicator than gas production. Variation of the composition of the major gases $\mathrm{CH}_{4}$ and $\mathrm{CO}_{2}$ is sensitive and reflects intrinsic imbalances in the digestion of sludge. However, the response of the gas composition is observed only when system failure is well-developed. Gas production and methane production responsed rapidly to changes in organic loading rate, and on-line automation is available. 
However, the variation of methane production and gas production can be either a sign of inhibition of methanogen or a result of background influent organic loading rate fluctuations.

Another class of methods tested focus on the microbial populations in the digesters. These methods use enzymatic, immunological means, gene probe and lipid composition analysis to detect enzyme activity (Agardy et al. 1963; Thiel and Hattingh 1967; Lenhard 1968), fatty acids variation (Henson et al. 1988a, 1988b), antibodies (Strayer and Tiedje 1978; Macario and Conway de Macario 1983) and $F_{420}$, a co-factor specific to methanogens ( Schulze et al. 1988). DNA and ATP monitoring (Agardy and Shepherd 1965; Chung and Neethling 1988) have also been investigated. An immunological method has been successfully used in UASB for studying long-term population shifts (van Lier et al. 1991). These methods, however, are slow and off-line. A detailed review of monitoring technologies in anaerobic wastewater treatment is provided by Switzenbaum et al. (1990).

Hydrogen and $\mathrm{CO}$ are intermediates of methane fermentation of organics. Accumulation of $\mathrm{H}_{2}$ is inhibitory to hydrogen-producing microorganisms. As a result of this inhibition, more reduced products can build up as alternative electron sinks (Chung 1976; Kaspar and Wuhrmann 1978). CO is a metabolic intermediate involved in synthesis of carboxyl group of acetyl-CoA and decarboxylation of acetate via CODH (Krzycki et al. 1982; Stupperich et al. 1983; Zeikus et al. 1985; Eikmanns and Thauer 1984; Nelson and Ferry 1984; Krzycki and Zeikus 1984). Monitoring trace gases $\mathrm{H}_{2}$ and $\mathrm{CO}$ has attracted attention for anaerobic process monitoring due to the fact that they are relatively easy to measure, slightly soluble in water, sensitive, can be measured on-line, and have the potential of indicating metabolic status. $\mathrm{H}_{2}$ and $\mathrm{CO}$ were observed to have fast responses to organic overloading before VFA accumulation or build-up, $\mathrm{pH}$ and methane decrease (Hickey and Switzenbaum 1988; Hickey et al. 1987a; Hickey et al. 1989; McCarty and Smith 1986). Mosey (1983) developed a mathematical model based on $\mathrm{H}_{2}$ variations in sludge digesters. Carbon monoxide had characteristic responses under heavy metal inhibition of digester (Hickey et al. 1987b). A thermodynamic relationship between $\mathrm{H}_{2}, \mathrm{CO}$, methane content, $\mathrm{CO}_{2}$ and effluent acetate concentration has been postulated to predict acetate concentrations during organic overload of sludge digesters (Hickey and Switzenbaum 1990). However, controversies still exist on whether $\mathrm{CO}$ and $\mathrm{H}_{2}$ are useful monitoring parameters for the control of anaerobic process. The $\mathrm{H}_{2}$ level in a fixed bed reactor was observed to be affected by differences in reactor configuration (Harper and Pohland 1987). Pauss et al. $(1990,1993)$, using a hydrogen probe to measure liquid phase $\mathrm{H}_{2}$ on-line, observed no correlation between OLR and the ratio of $\mathrm{H}_{2(\mathrm{~L})} / \mathrm{H}_{2}{ }^{*}{ }_{(\mathrm{L})}$ because of variations in the liquid-gas mass transfer limitations of $\mathrm{H}_{2}$ within the reactor they used. CO production in a CSTR during glucose, formate and acetate perturbations were reported to be inconsistent (Bae and McCarty 1993). 
This portion of the study focused on examining responses of $\mathrm{H}_{2}$ and $\mathrm{CO}$ and reactor performance during various hydraulic loading rates, organic loading rates, and variation in feed composition at pseudo-steady state, and examining the potential of using $\mathrm{H}_{2}$ and $\mathrm{CO}$ as indicators for monitoring UASB reactor system to detect the onset of unstable conditions (organic overloading) and system failure. The experiments were conducted during pseudo-steady state and unsteady state perturbations on a UASB reactor treating a synthetic brewery waste. Data were analyzed using statistical methods to detect any recognizable patterns of $\mathrm{H}_{2}$ and $\mathrm{CO}$, including mean and variance analysis, correlation between trace gases and performance variables, trend of $\mathrm{CO}$ and $\mathrm{H}_{2}$ during pseudo-steady state and perturbations and spectra analysis.

\section{MONITORING CO AND $\mathrm{H}_{2}$ DURING PSEUDO-STEADY STATE OPERATION}

\section{On-line Monitoring System of the Bench-Scale UASB Reactor}

Monitoring experiments were performed using a bench-scale UASB reactor (described in Section 5) equipped with an on-line data acquisition and control system PARAGON (Intec) through an analog/digital (A/D) interface (OPTO-22) and a personal computer (386). The reactor set-up used for gas, liquid, and data acquisition is presented in Figure 6-1.

Gas phase $\mathrm{CO}, \mathrm{H}_{2}$, and $\mathrm{CH}_{4}$, and gas production from the UASB were sampled and analyzed on-line. Headspace samples were collected from a gas loop connected to the reactor headspace. Gas generated from the reactor first passed through a condenser to remove moisture and then entered the gas loop. The gas stream was pumped continuously into an infrared Methane Analyzer (ADC SB100) for on-line quantitation of methane. Analog signals from the Methane Analyzer were transmitted to the host computer. The gas stream then exited the Methane Analyzer, where the flow was split into two streams: the majority of the gas stream went back to the reactor headspace, while the other branch was passed through the sample loop of a Trace Gas Analyzer ( $R G A 3$ ). A sample for $\mathrm{CO}$ and $\mathrm{H}_{2}$ was collected via automated actuated gas sampling valves and analyzed in the Trace Gas Analyzer. The components that remained in the column were backflushed to vent with carrier gas. Data analysis of $\mathrm{H}_{2}$ and $\mathrm{CO}$ was performed automatically by the integrator/controller module (ICM) in the RGA3. The ICM was programmed for complete operation, which was monitored by the PARAGON program in the host computer. Gas produced from the reactor passed through a three-way valve which was connected to a gas meter and an exhaust pipe. Gas production was measured by means of a liquid displacement technique. Each gas count (cc. $3-5 \mathrm{ml}$ ) was recorded and cumulative gas production totaled using the PARAGON system. 
(19)

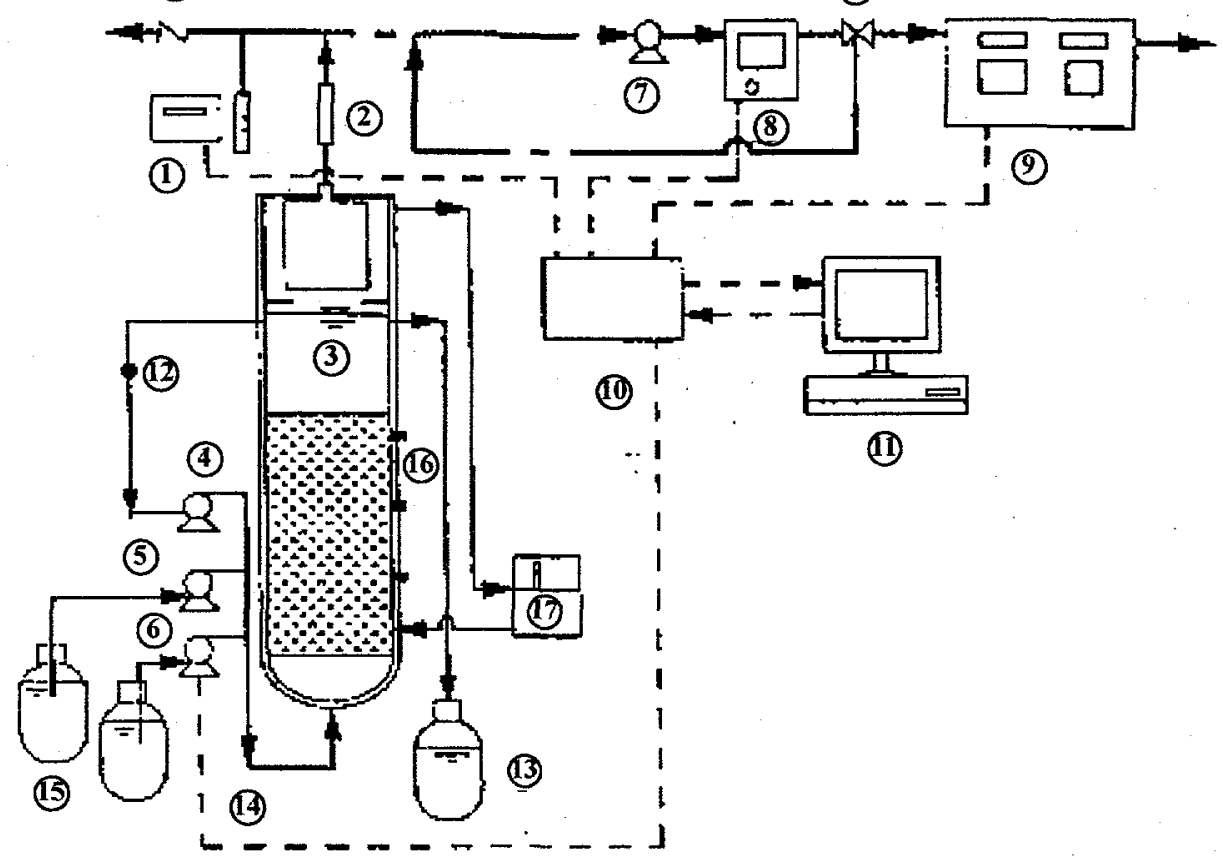
(1) gas counter
(9) trace gas analyzer
(17) water bath
(2) moisture condensor
(10) $D / A$ interface
(B) gas vent valve
(3) laboratory UASB reactor
(II) PC control
(19) gas split valve
(4) recycle pump
(12) liquid sampling port
- liquid line
(5) media pump
(13) effluent
(6) feed pump
(14) feed
(7) gas pump
(15) media
— gas line
(8) methane analyzer
(10) sludge waste
- data acquisition \& control line

Figure 6-1. Schematic representative of the bench-scale UASB reactor with on-line data acquisition system.

The inlet liquid flow rate to the UASB reactor was controlled via an automated pump (Watson-Marlow 503U) connected to the PARAGON system to ensure the desired OLR was attained. A mixture of inlet and recycled flow was continuously passed upward through sludge bed/blanket and clarifier. Effluent was collected at the top of the reactor. The majority of the reactor effluent from the clarifier zone was recirculated (Watson-Marlow 503S). Liquid samples were collected manually from the reactor recirculation line for VFAs, $\mathrm{pH}$, and alcohols analysis. Biomass samples were collected through sampling ports in the sludge bed. Detailed descriptions of the data acquisition system, analytical methods and $\mathrm{QA} / \mathrm{QC}$ procedures for gas, liquid, and solid phase sample analysis are presented in Appendix C. 


\section{Pseudo-Steady State Experiments}

A synthetic brewery waste $\left(11.4 \mathrm{~kg} \mathrm{COD} / \mathrm{m}^{3}\right.$, Appendix A) was used as feed for the UASB reactor.

Anaerobic granules were cultivated in the UASB reactor, operated at $37^{\circ} \mathrm{C}$. Liquid $\mathrm{pH}$ was maintained at 6.8-7.0. Operational conditions of the UASB reactor during pseudo-steady state are shown in Table 6-1.

Pseudo-steady state was assumed to have been attained when all effluent parameters stabilized after a change in OLR and more than three HRTs. Experiments began about three weeks after start-up. The OLR was varied from 4 to $23 \mathrm{~kg} \mathrm{COD} / \mathrm{m}^{3}$-d, HRT from 0.5 to 2.5 days, and feed concentration from $6-14 \mathrm{~kg}$ $\mathrm{COD} / \mathrm{m}^{3}$. The experiment was designed to examine each parameter individually, by operating the UASB reactor at different combinations of OLR, HRT, and feed concentration. First, OLR was varied at two levels ( 15 and $23 \mathrm{~kg} \mathrm{COD} / \mathrm{m}^{3}$-d) while HRT (0.5 days) and feed concentration ( $\left.14 \mathrm{~kg} \mathrm{COD} / \mathrm{m}^{3}\right)$ were held constant. Then, HRT was varied at two levels $\left(0.5,1.5\right.$ days) while OLR (15 kg COD $\left./ \mathrm{m}^{3}-\mathrm{d}\right)$ and feed concentration $\left(14 \mathrm{~kg} \mathrm{COD} / \mathrm{m}^{3}\right)$ remained unchanged. Feed concentration effects were examined at two levels $\left(9\right.$ and $11 \mathrm{~kg} \mathrm{COD} / \mathrm{m}^{3}$ ) while keeping OLR at $10 \mathrm{~kg} \mathrm{COD} / \mathrm{m}^{3}-\mathrm{d}$ and HRT at $1.5-1.8$ days. The effect of increasing the OLR through changing feed pumping rate (HRT varies, feed concentration fixed) or changing both feed and mineral pumping rates (fixed HRT, feed concentration varies) were examined at three levels $\left(4,10,14\right.$, and $6,10,15 \mathrm{~kg} \mathrm{COD} / \mathrm{m}^{3}$-d, respectively). A total of eight runs of different combinations were conducted (Table 6-2). Reactor gas, liquid and solid phases were monitored for nine months during this experimental period. Gas phase $\mathrm{H}_{2}, \mathrm{CO}, \mathrm{CH}_{4}$ content and gas production rate were measured hourly. Reactor effluent VFA and pH were measured daily. Biomass in the effluent (TSS and. VSS) were measured weekly. Sludge bed solids concentration (TS and VS) were measured monthly. The pseudo-steady state data files were combined on a semiweekly basis and then transferred as as SAS data series. Computations were made for gas production rate based on cumulative hourly monitoring data. Minor disturbances of the system which happened during operation (i.e., methane analyzer failure and trace gas analyzer error signals) were corrected.

\begin{tabular}{|l|c|}
\hline \multicolumn{2}{|c|}{$\begin{array}{c}\text { Table 6-1. Operational conditions of the bench-scale UASB reactor during } \\
\text { pseudo-steady state experiment. }\end{array}$} \\
\hline Organic Loading Rate $\left(\mathrm{kg} \mathrm{COD} / \mathrm{m}^{3}-\mathrm{d}\right)$ & $4.2,5.8,10,15,23$ \\
\hline Hydraulic Retention Time $(\mathrm{d})$ & $0.5,1,1.5,2.5$ \\
\hline Feed Concentration $\left(\mathrm{kg} \mathrm{COD} / \mathrm{m}^{3}\right)$ & $5.7,9.1,11.4,13.7$ \\
\hline Temperature $\left({ }^{\circ} \mathrm{C}\right)$ & 37 \\
\hline $\mathrm{pH}$ & $6.8-7.0$ \\
\hline Reactor Liquid Volume (L) & 3.1 \\
\hline Headspace Volume $(\mathrm{L})$ & 0.2 \\
\hline Granular Bed Volume $(\mathrm{L})$ & 1.5 \\
\hline Bed Expansion $(\%)$ of total liquid volume & 65 \\
\hline Up Flow Velocity (ml/min) & 165 \\
\hline Gas Recirculation Rate $(\mathrm{L} / \mathrm{min})$ & 0.5 \\
\hline
\end{tabular}




\begin{tabular}{|c|c|c|c|c|}
\hline $\begin{array}{l}\text { Experiment } \\
\text { group }\end{array}$ & $\begin{array}{c}\text { OLR } \\
\left(\mathrm{kg} \mathrm{COD} / \mathrm{m}^{3}-\mathrm{d}\right)\end{array}$ & $\begin{array}{l}\text { HRT } \\
\text { (day) }\end{array}$ & $\begin{array}{c}\text { Feed Concentration } \\
\left(\mathrm{kg} \mathrm{COD} / \mathrm{m}^{3}\right)\end{array}$ & $\begin{array}{c}\text { Effects } \\
\text { Examined }\end{array}$ \\
\hline I & 23 & 0.5 & 13.7 & OLR \\
\hline I & 14.5 & 0.5 & 13.7 & \\
\hline II & $\overline{14.5}$ & 0.5 & 13.7 & HRT \\
\hline II & 15 & 1.5 & 13.7 & \\
\hline III & 10 & 1.5 & 9.1 & Feed conc. \\
\hline III & 10 & 1.8 & 11.4 & \\
\hline IV & 4.2 & 2.5 & 11.4 & OLR (vary HRT) \\
\hline IV & 10 & 1.8 & 11.4 & \\
\hline IV & 14 & 1.0 & 11.4 & \\
\hline $\bar{V}$ & $\overline{5.8}$ & 1.5 & 5.7 & OLR (vary feed) \\
\hline $\mathrm{V}$ & 10 & 1.5 & 9.1 & \\
\hline $\mathrm{V}$ & 15 & 1.5 & 13.7 & \\
\hline
\end{tabular}

Typical profiles of acetate, propionate, $\mathrm{CO}, \mathrm{H}_{2}, \mathrm{CH}_{4}$, and gas production rate during pseudo-steady state operation are shown in Figure 6-2. The largest variation was observed for $\mathrm{H}_{2}$ concentration; methane varied the least. CO fluctuated at $\pm 0.2 \mathrm{ppm}$. During the entire operational period, acetate and propionate concentrations remained below $2 \mathrm{mM}$ and $1 \mathrm{mM}$, respectively. At an OLR $<14 \mathrm{~kg} \mathrm{COD} / \mathrm{m}^{3}-\mathrm{d}$ the acetate and propionate concentrations were near or below detection limits $(0.1 \mathrm{mM})$. During the entire pseudosteady state operations, COD removal efficiency ranged from 71 to $94 \%$, the average being $85 \%$. Methane production, based on COD removed, ranged from 0.28 to $0.37 \mathrm{LCH}_{4} / \mathrm{g}$ COD removed, with an average of $0.34 \mathrm{LCH}_{4} / \mathrm{g}$ COD removed.

\section{Statistics of $\mathrm{H}_{2}, \mathrm{CO}$, and Other Process Variables}

General Statistics. Statistical analysis of the pseudo-steady state operational data was performed. For mean, variance, standard error, coefficient of variance ( $\mathrm{CV}$, the ratio of variance to mean), correlation, Student $t$ statistics, confidence interval, and population distribution for acetate, propionate, $\mathrm{CH}_{4}$, gas production, $\mathrm{pH}, \mathrm{CO}$, and $\mathrm{H}_{2}$, at each pseudo-steady state operational condition. The CVs were then averaged to obtain a mean of $\mathrm{CV}$ for overall steady state operation. The mean, $\mathrm{CV}$, and standard error for each variable during the overall pseudo-steady state is presented in Table 6-3. 


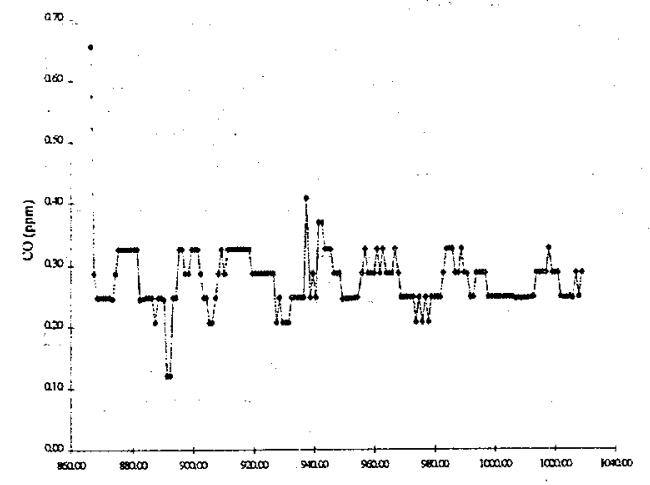

(a)

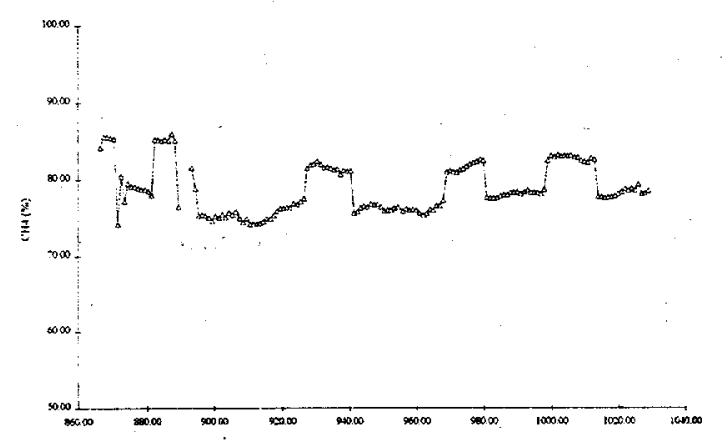

(b)

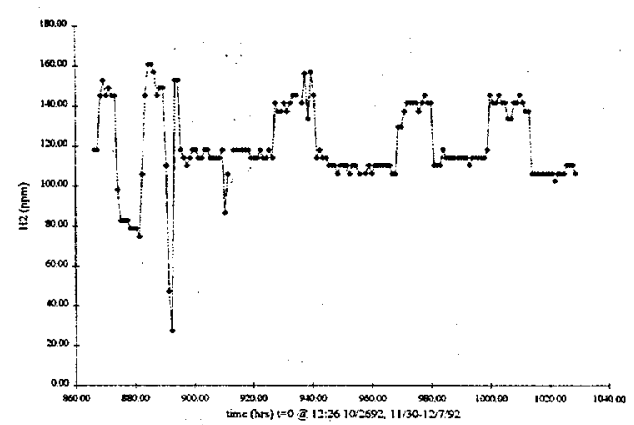

(c)

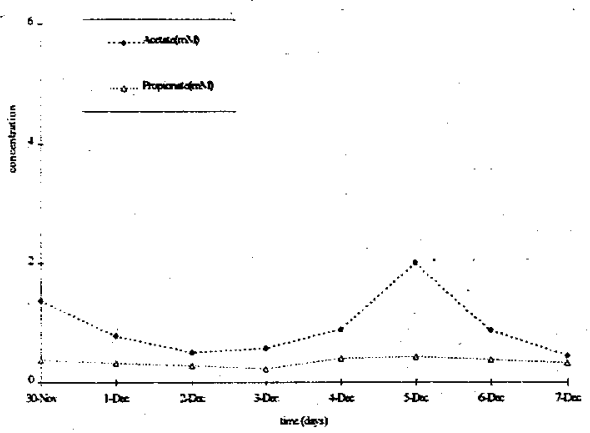

(d)

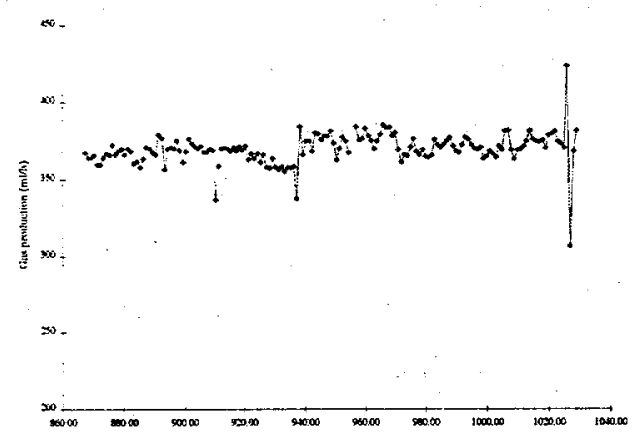

(e)

Figure 6-2. Typical profiles of (a) $\mathrm{CO}$, (b) methane, (c) $\mathrm{H}_{2}$, (d) acetate and propionate, and (e) gas production rate at pseudo-steady state. (OLR $15 \mathrm{~kg} \mathrm{COD} / \mathrm{m}^{3}-\mathrm{d}$, HRT $1.5 \mathrm{~d}$, feed concentration $13.7 \mathrm{~kg} \mathrm{COD} / \mathrm{m}^{3}$.) Time scale: (a)-(d) in hours; (e) in days. Data collected from Nov. 30 to Dec. 7, 1992. 


\begin{tabular}{|l|c|c|c|}
\hline \multicolumn{4}{|c|}{ Table 6-3. Range of mean, coefficient of variances and standard error of monitoring } \\
variables during pseudo-steady state experiment. \\
\hline \multicolumn{1}{|c|}{ Component } & Mean range & $\begin{array}{c}\text { Coefficient of Variance } \\
\text { (mean of 8 operations) }\end{array}$ & Standard error range \\
\hline $\mathrm{H}_{2}$ & $19-173 \mathrm{ppm}$ & 75.2 & $0.936-4.999$ \\
\hline Acetate & $0.08-1.04 \mathrm{mM}$ & 49.1 & $0.005-0.168$ \\
\hline $\mathrm{CO}$ & $0.10-0.58 \mathrm{ppm}$ & 36.9 & $0.002-0.010$ \\
\hline Propionate & $0.10-0.72 \mathrm{mM}$ & 9.9 & $0.015-0.061$ \\
\hline Gas production & $104-592 \mathrm{ml} / \mathrm{h}$ & 6.0 & $0.334-4.174$ \\
\hline $\mathrm{CH}$ & $74.2-85.6 \%$ & 2.6 & $0.064-0.234$ \\
\hline $\begin{array}{l}\text { Ranged among eight pseudo-steady state operations } \\
\alpha=0.05\end{array}$ & & \\
\hline
\end{tabular}

Mean, Coefficient of Variance, Population Distribution and Standard Error. Population distribution tests indicated all variables followed normal distribution. Methane content had the narrowest range (74.2\%-85.6\%) for the mean, while $\mathrm{H}_{2}$ had the widest (19-173 ppm). The variation of each variable was estimated by the value of the coefficient of variation (CV). The higher the $\mathrm{CV}$, the greater the fluctuation or higher the sensitivity. $\mathrm{H}_{2}$ had the highest $\mathrm{CV}(75.2), \mathrm{CH}_{4}$ the lowest (2.6). The variation of $\mathrm{CO}(36.9)$ was moderate, as was that of acetate (49.1). These variables, grouped according to their variance were: $\mathrm{H}_{2}$ $>>$ acetate $>\mathrm{CO}>$ propionate $>$ gas production $>\mathrm{CH}_{4}$. The standard error was highest for $\mathrm{H}_{2}$, indicating high background noise for $\mathrm{H}_{2}$.

Confidence Level and Mean as a Function of OLR. Confidence levels of each monitoring variable were calculated using a Student $t$ test at the $\alpha=0.05$ level. Acetate, propionate, $\mathrm{CO}, \mathrm{H}_{2}, \mathrm{CH}_{4}$, and gas production were computed using standard error. The mean and confidence interval $(\mathrm{CI})$ of each variable were then plotted against OLR (Figures 6-3, 6-4, and 6-5). The means of acetate, propionate, $\mathrm{CO}$, and gas production all increased with increased applied OLR. This increase was clearly linear for gas production and non-linear for acetate, propionate and $\mathrm{CO}$. The $\mathrm{CH}_{4}$ concentration decreased with increased OLR, also in a non-linear fashion. There was no discernible pattern to the mean of $\mathrm{H}_{2}$ concentration. The CIs of gas production, $\mathrm{CH}_{4}$, and $\mathrm{CO}$ were small and consistent throughout the entire OLR range tested. The $\mathrm{CI}$ of $\mathrm{CO}$ increased slightly at high OLR $\left(23 \mathrm{~kg} \mathrm{COD} / \mathrm{m}^{3}-\mathrm{d}\right)$. In contrast to the other variables, the $\mathrm{CI}$ of $\mathrm{H}_{2}$ was high. The $\mathrm{CI}$ of $\mathrm{H}_{2}$ overlapped between OLRs of 10 and $23 \mathrm{~kg} \mathrm{COD} / \mathrm{m}^{3}-\mathrm{d}$, indicating there was no statistical differences in $\mathrm{H}_{2}$ concentrations between these two OLRs. Acetate and propionate had considerably higher CIs, which increased at the highest OLR $\left(23 \mathrm{~kg} \mathrm{COD} / \mathrm{m}^{3}-\mathrm{d}\right)$. 


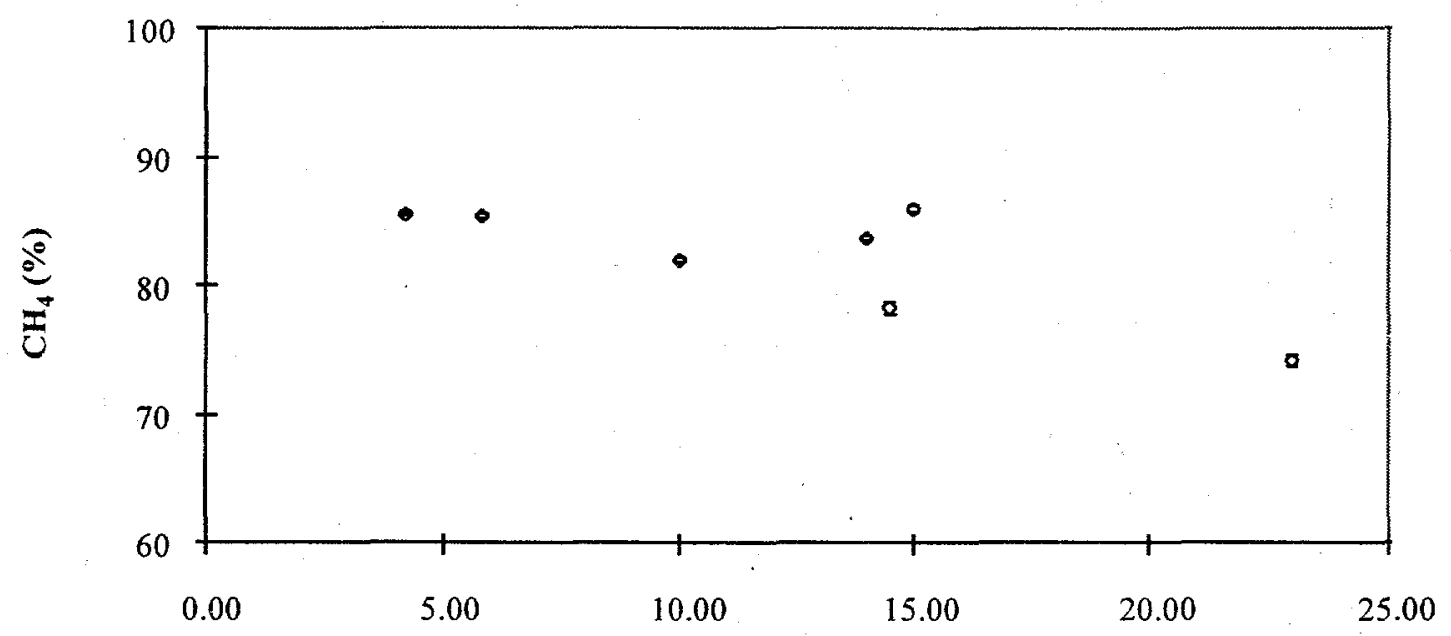

OLR (kg COD/m $\left.\mathrm{m}^{3}-\mathrm{d}\right)$

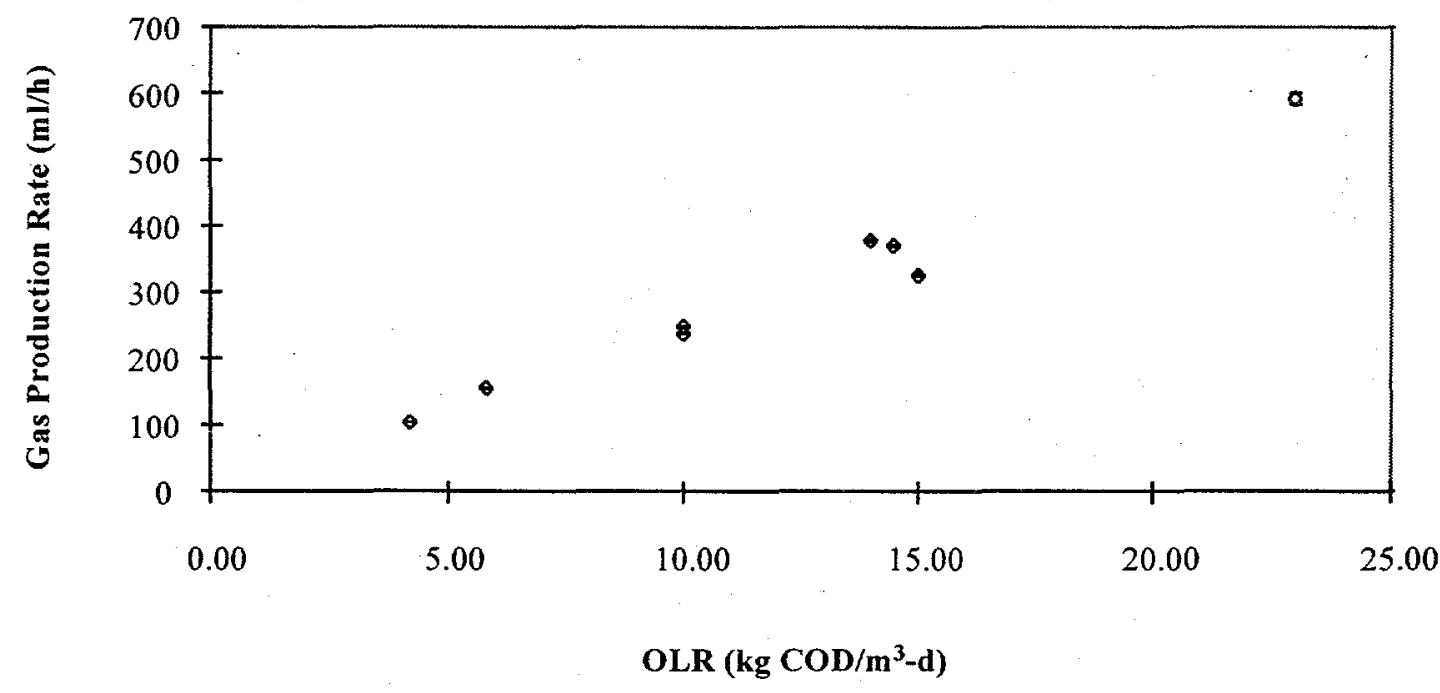

Figure 6-3. Mean and confidence intervals of methane and gas production during pseudosteady state operation. Bars represent $95 \%$ confidence intervals. Note: in most cases, error bars are smaller than size of the symbol. 

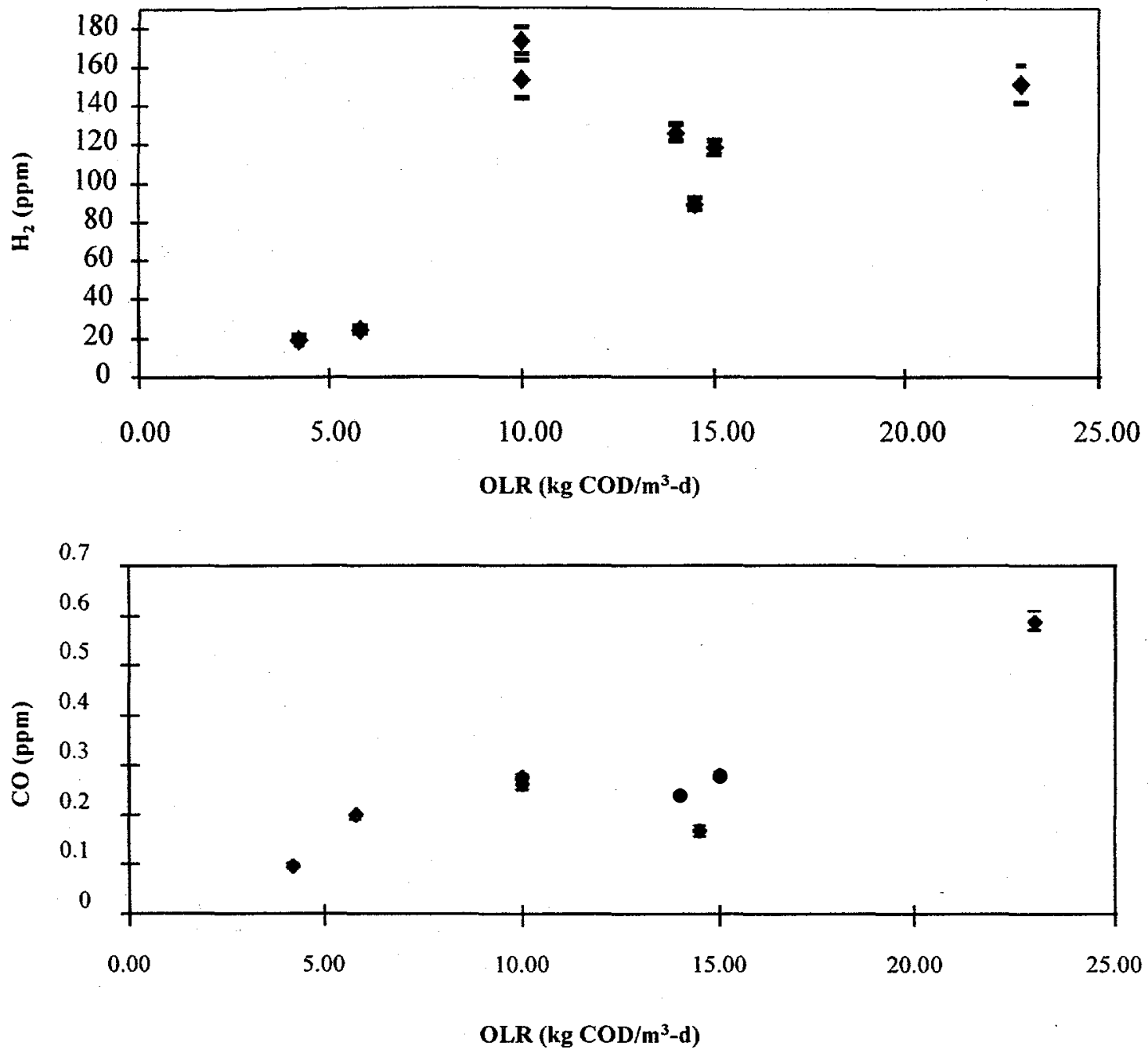

Figure 6-4. Mean and confidence intervals of $\mathrm{H}_{2}$ and $\mathrm{CO}$ during pseudo-steady state operation. Bars represent $95 \%$ confidence intervals. 

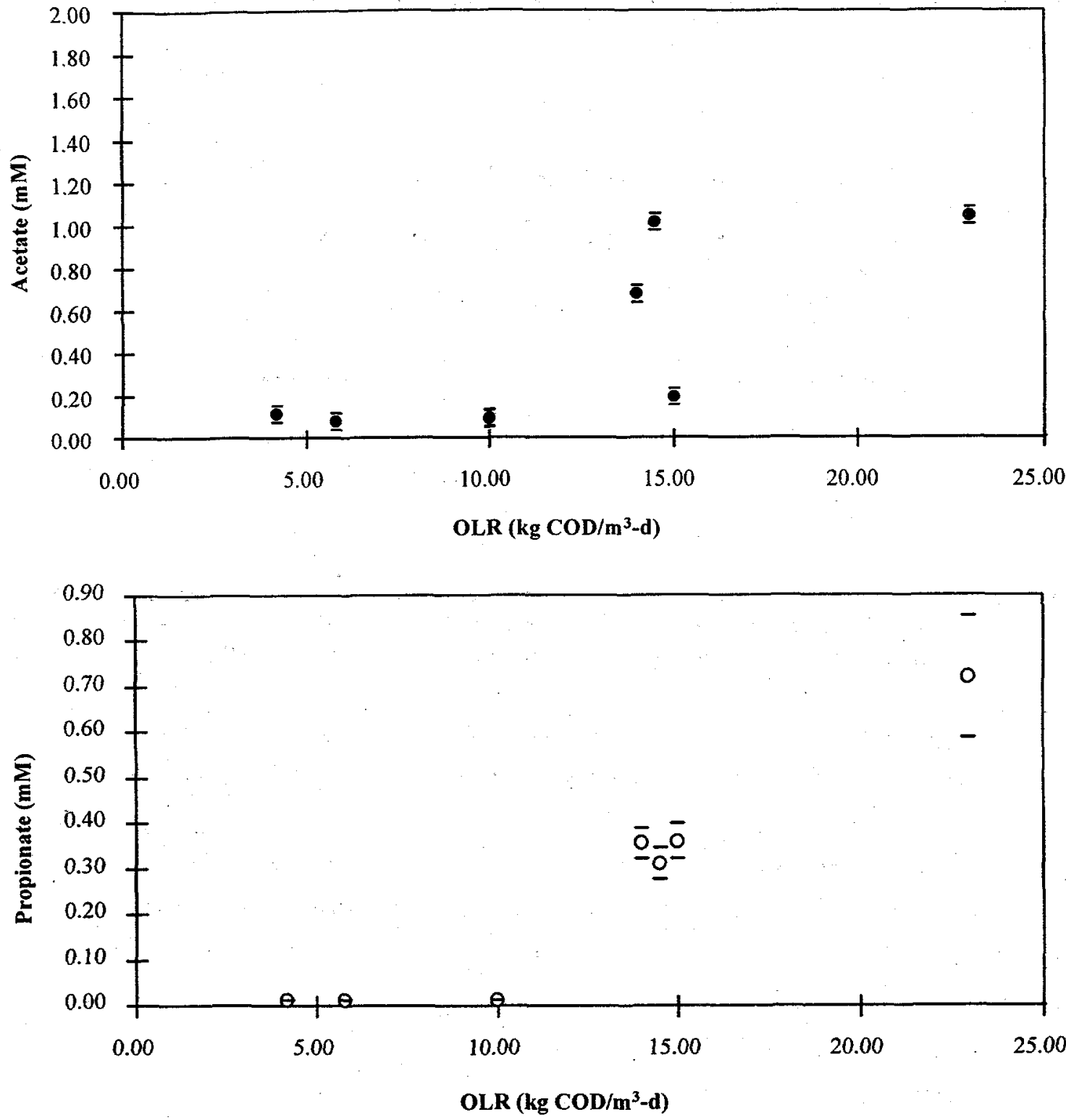

Figure 6-5. Mean and confidence intervals of acetate and propionate during pseudosteady state operation. Bars represent $95 \%$ confidence intervals.

Correlation. Correlation analysis showed acetate, propionate and methane content were most closely correlated with other variables (at $\alpha=0.01$; Figure 6-6). $\mathrm{CH}_{4}$ was negatively correlated with propionate, acetate, $\mathrm{CO}$ and gas production. Gas production and $\mathrm{CO}$ concentration were related to three other variables. There was no correlation between $\mathrm{H}_{2}$ and any other variables.

Bivariate plots of $\mathrm{CO}$ and $\mathrm{H}_{2}$ with acetate for eight pseudo-steady state operations were used to examine the correlation between acetate and trace gases. The results (Figures 6-7 and 6-8) indicate that $\mathrm{CO}$ 
concentration was scattered in some individual runs although it correlated with acetate based on all of the data.

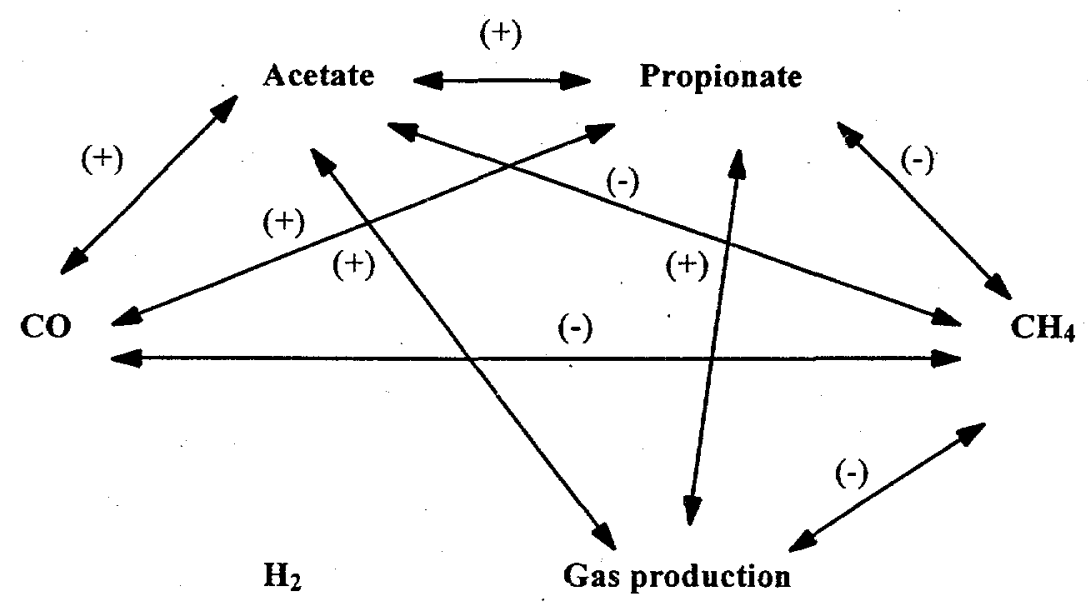

Figure 6-6. Schematic diagram of correlations among monitoring variables at pseudosteady state operations (based on results from correlation analysis; $(+)$ indicates a positive correlation; $(-)=$ negative correlation; correlation test at $\alpha=0.01$ ).

Analysis of Variance and Multiple Comparison Tests. Analysis of variance (ANOVA) was performed on the six monitoring variables to test the significance in variation among the OLRs tested. Results of significance tests, presented in Table 6-4, indicated high $F$ values for all of the variables. The values of Fs were significant at $\alpha=0.001$ level (indicated by three ' + ' signs), which provided strong evidence of real differences among the means of each variable for the eight OLRs tested. Thus, it can be concluded that every individual monitoring variable does not belong to a population within a common mean $(\mu)$ at different OLRs.

To further examine at which two OLRs variables are different from each other, multiple comparison tests, Duncan's multiple range test, and LSD (least significant differences) tests were conducted on the population means of each variable $(\alpha=0.05)$. The variables were then grouped based on OLR (Table 6-5). Acetate and propionate were grouped similarly. Gas production and $\mathrm{CH}_{4}$ were close, as were $\mathrm{CH}_{4}$ and $\mathrm{CO}$. All values for OLR $23 \mathrm{~kg} \mathrm{COD} / \mathrm{m}^{3}-\mathrm{d}$ were different from the others, except that for $\mathrm{H}_{2}$. Most variables showed only small differences at low OLRs. 

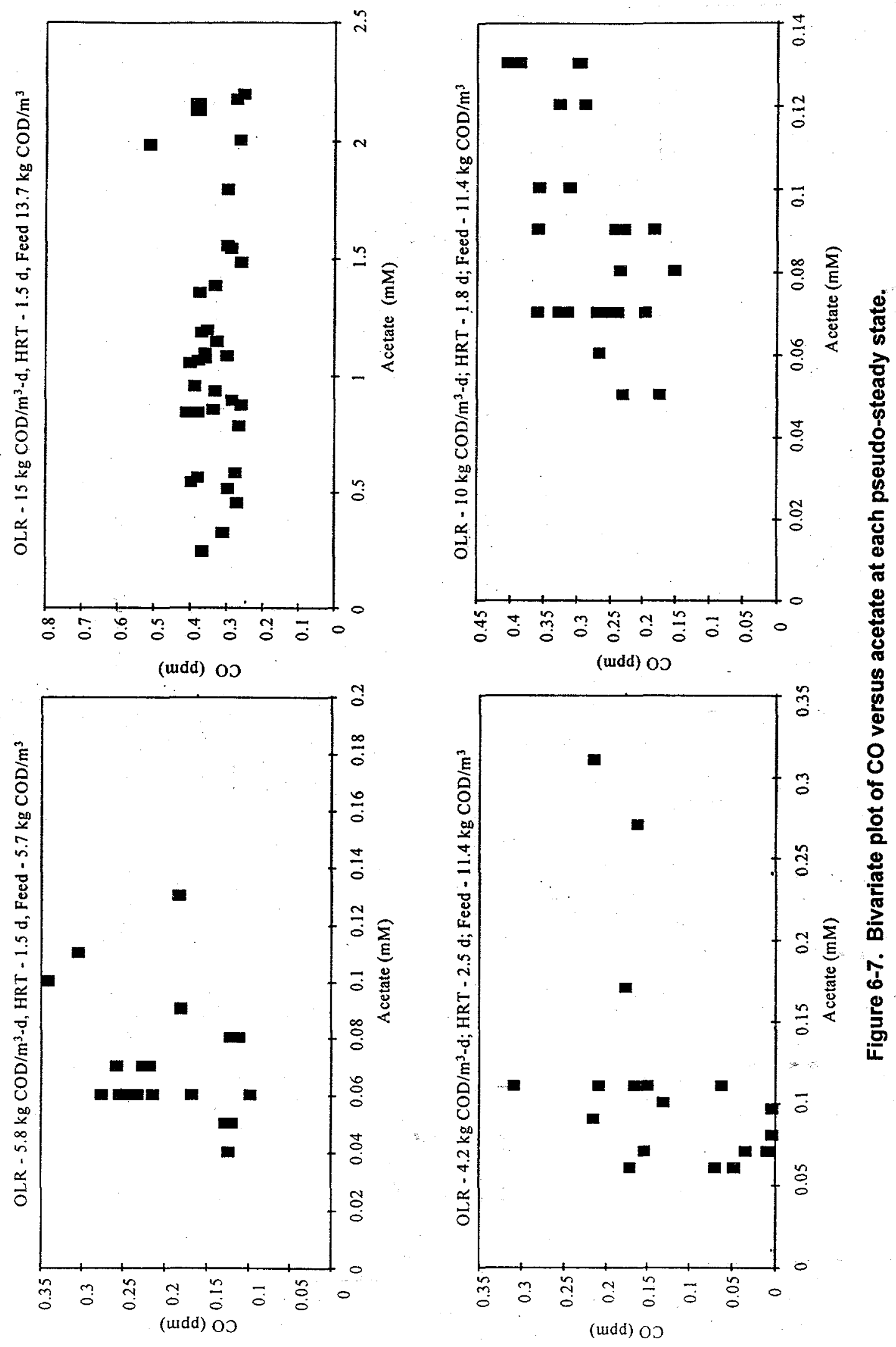


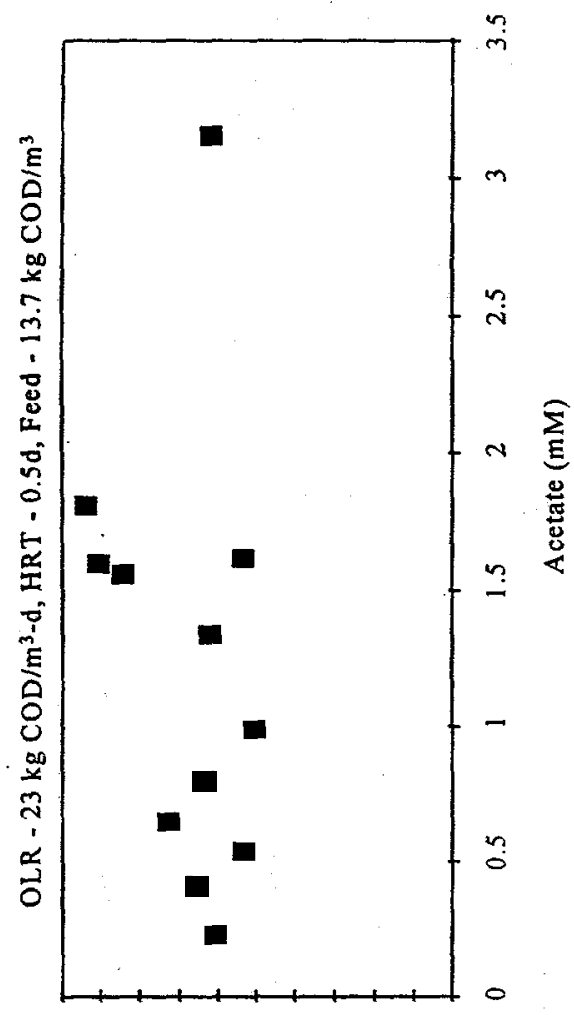

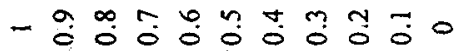
(wdd) $0 \supset$

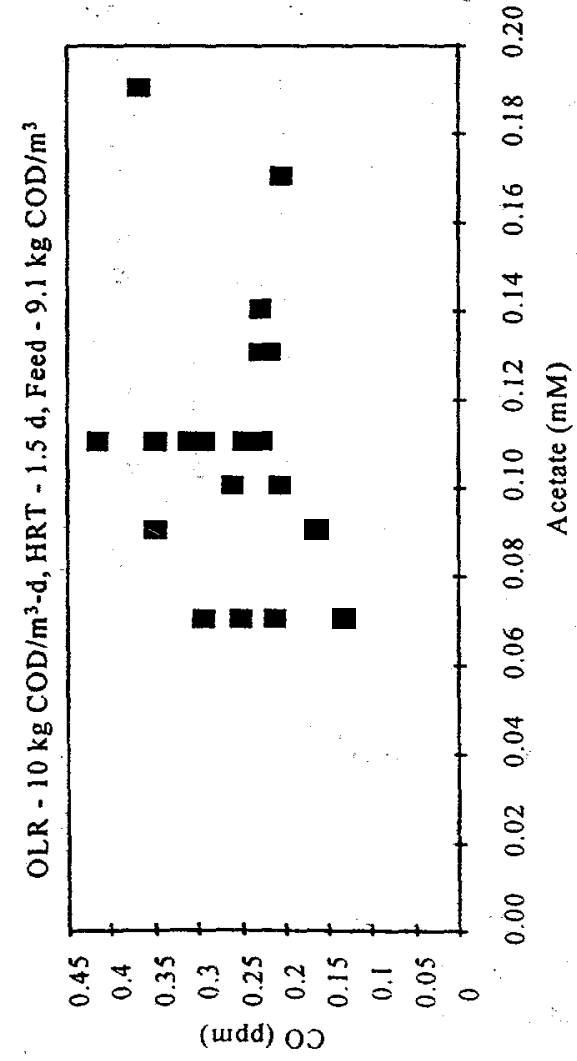

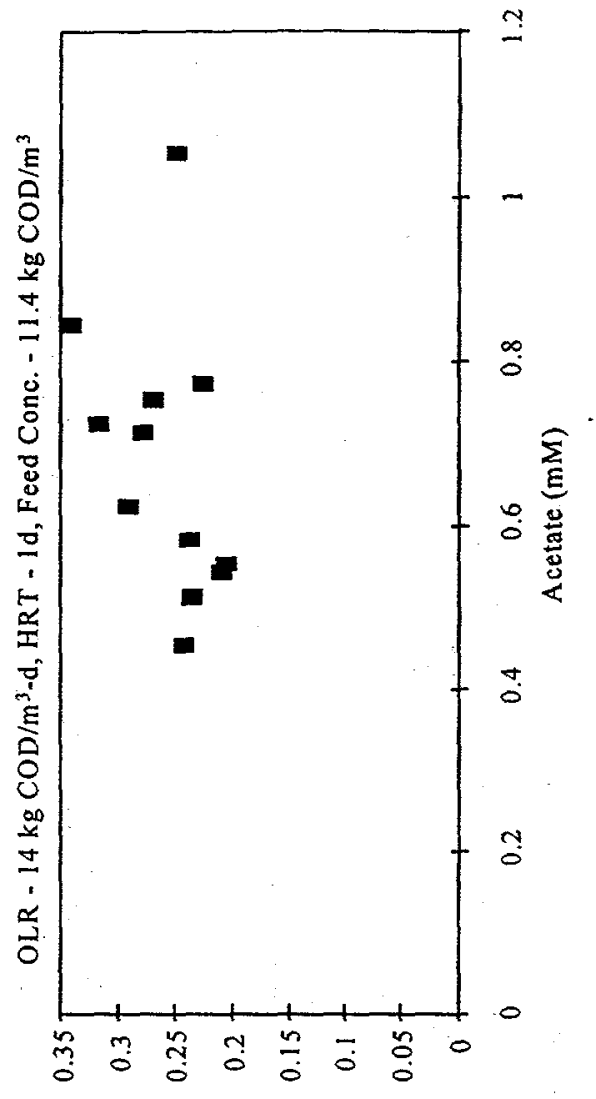

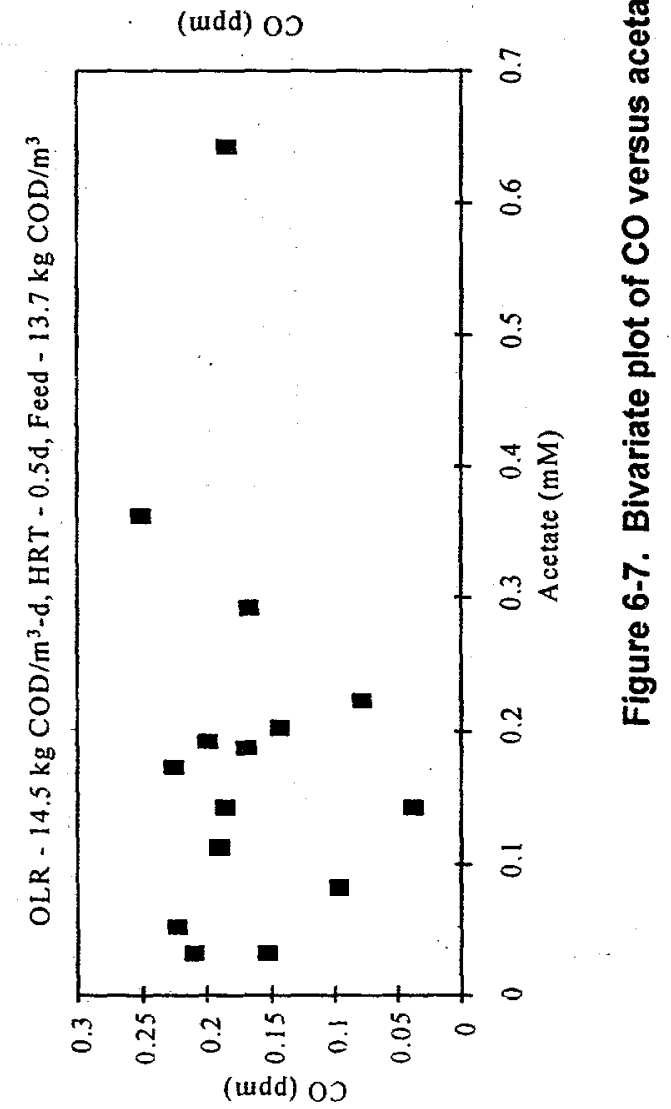



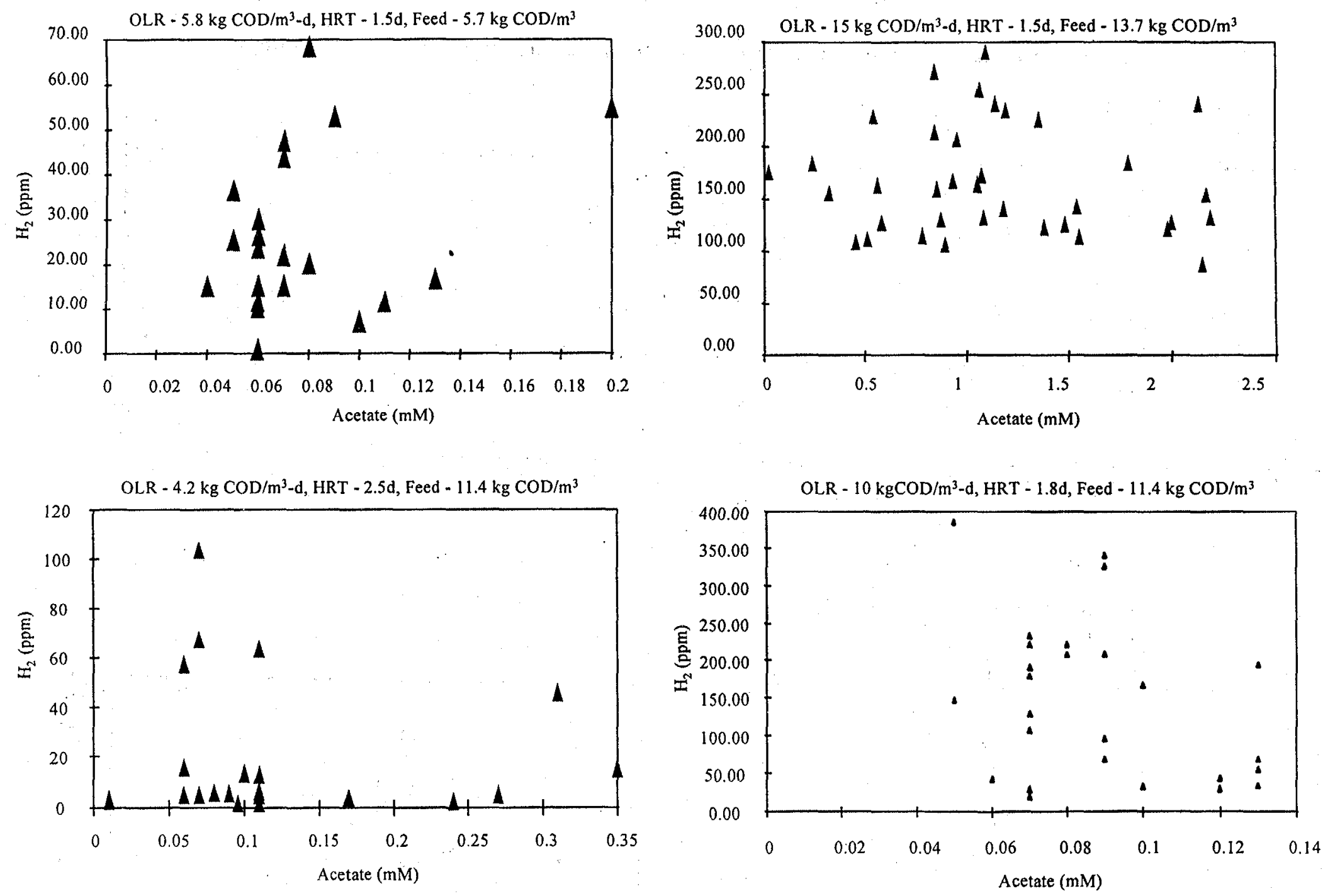

Figure 6-8. Bivariate plot of $\mathrm{H}_{2}$ versus acetate at each pseudo-steady state. 
OLR $-10 \mathrm{~kg} \mathrm{COD} / \mathrm{m}^{3}-\mathrm{d}, \mathrm{HRT}-1.5 \mathrm{~d}$, Feed $-9.1 \mathrm{~kg} \mathrm{COD} / \mathrm{m}^{3}$
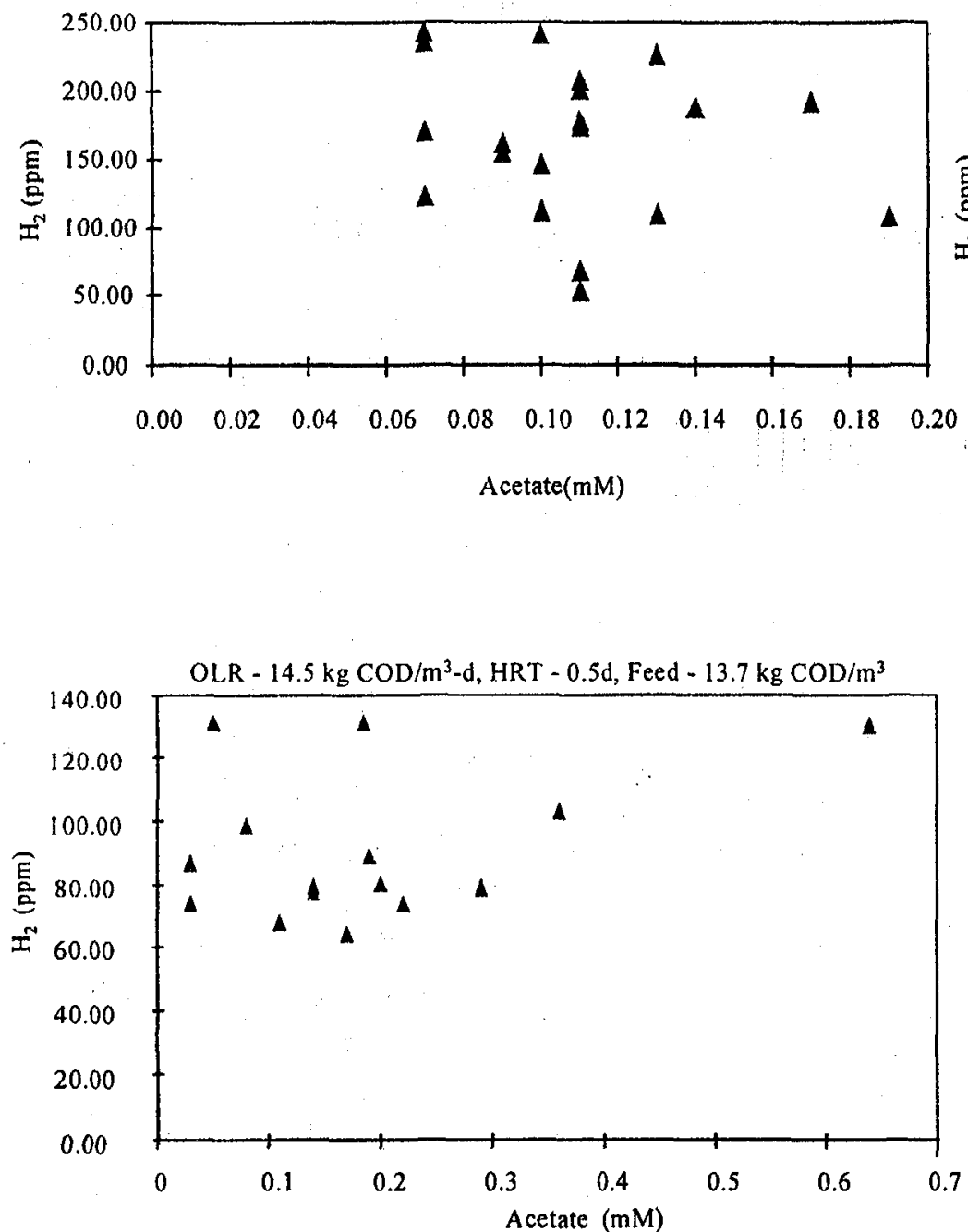

OLR $-23 \mathrm{~kg} \mathrm{COD} / \mathrm{m}^{3}-\mathrm{d}, \mathrm{HRT}-0.5 \mathrm{~d}$, Feed $-13.7 \mathrm{~kg} \mathrm{COD} / \mathrm{m}^{3}$

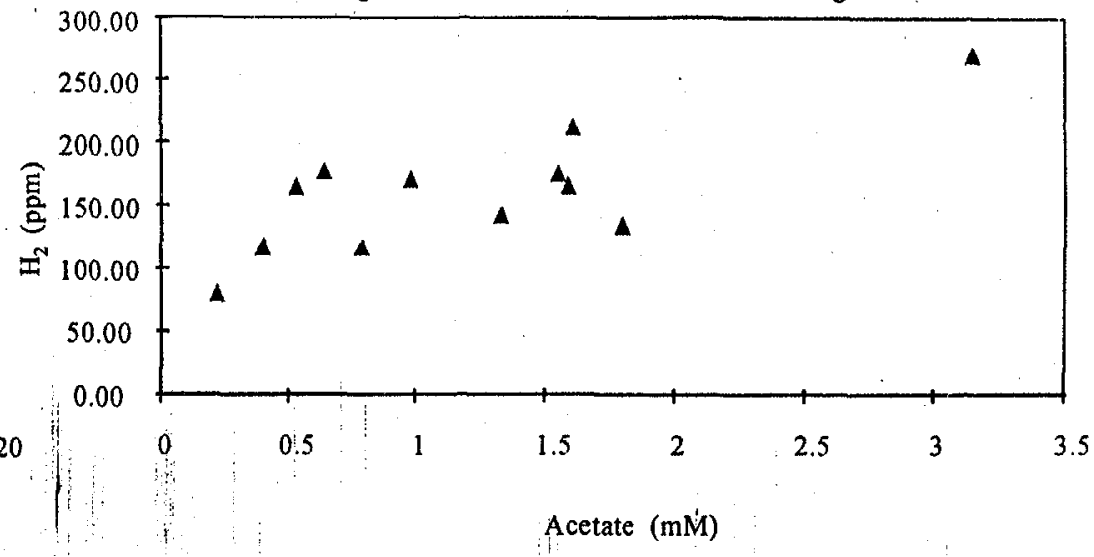

Acetate $(\mathrm{mM})$

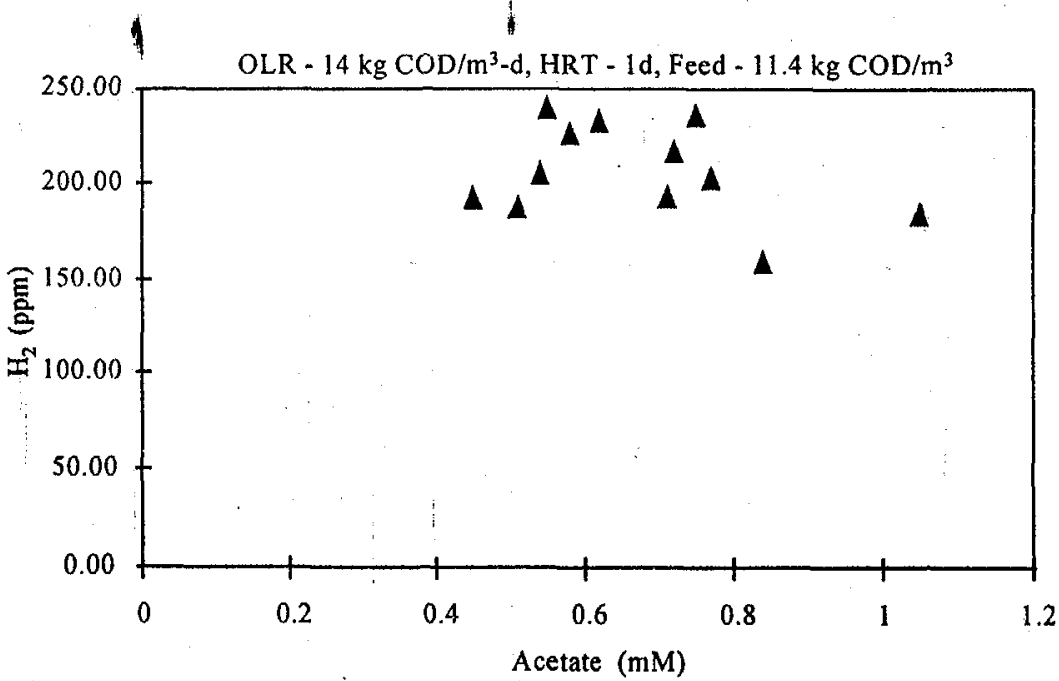

Figure 6-8. Bivariate plot of $\mathrm{H}_{2}$ versus acetate at each pseudo-steady state (continued). 


\begin{tabular}{|l|c|c|c|c|}
\hline \multicolumn{5}{|c|}{$\begin{array}{c}\text { Table 6-4. Analysis of variance of each monitoring variable among OLRs } \\
\text { operated at pseudo-steady state }(\alpha=\mathbf{0 . 0 5}) \text {. }\end{array}$} \\
\hline \multicolumn{1}{|c|}{ Variables } & Observations & OLR levels & F value & Significance Test \\
\hline Acetate & 157 & 7 & 52.98 & +++ \\
\hline Propionate & 157 & 7 & 260.28 & +++ \\
\hline $\mathrm{CO}$ & 157 & 7 & 70.9 & +++ \\
\hline $\mathrm{H}_{2}$ & 157 & 7 & 15.79 & +++ \\
\hline $\mathrm{CH}_{4}$ & 157 & 7 & 71.94 & +++ \\
\hline Gas production & 157 & 7 & 1297.91 & +++ \\
\hline a OLR at $4.2,5.8,10,14,14.5,15$, and $23 \mathrm{~kg} \mathrm{COD} / \mathrm{m}^{3} \mathrm{~b}-\mathrm{d}$. \\
\hline
\end{tabular}

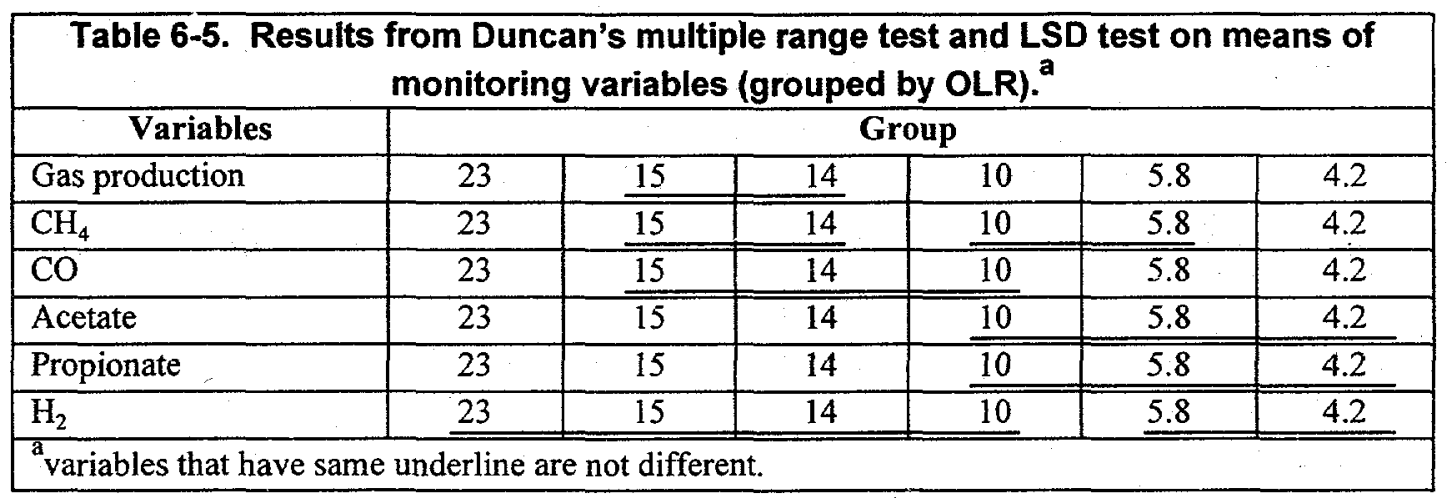

OLR. HRT and Feed Concentration Effects. Sample means of the eight pseudo-steady state operational data sets were shaped into five groups according to different control variables. The mean of acetate, propionate, $\mathrm{H}_{2}, \mathrm{CO}, \mathrm{CH}_{4}$, and gas production at different combinations of OLR, $\mathrm{HRT}$, and feed concentration are listed in Table 6-6. Within each group, means were compared in an attempt to detect trends. The monitoring variables followed OLR variations. Acetate, propionate, gas production, and CO generally varied in parallel with $\mathrm{OLR}$. $\mathrm{CH}_{4}$ varied in the opposite direction.

When HRT and feed concentration were both held constant at 0.5 days and $14 \mathrm{~kg} \mathrm{COD} / \mathrm{m}^{3}$, means of all variables, with the exception of methane, increased with an increase in the OLR from 14.5 to $23 \mathrm{~kg}$ $\mathrm{COD} / \mathrm{m}^{3}$-d. When the HRT was decreased while OLR and feed concentration remained about the same, $\mathrm{CO}, \mathrm{H}_{2}$, propionate, and gas production changed slightly. $\mathrm{CH}_{4}$ decreased and acetate increased. At a fixed OLR of $10 \mathrm{~kg} \mathrm{COD} / \mathrm{m}^{3}-\mathrm{d}$ and HRT varying at 1.5-1.8 days, the responses were weak. When the OLR was increased by increasing the pumping rate (HRT decreased), acetate, propionate, $\mathrm{CO}, \mathrm{H}_{2}$, and gas production increased; $\mathrm{CH}_{4}$ decreased as $\mathrm{OLR}$ was increased. When the OLR was increased by increasing the feed concentration (HRT remained constant), the same phenomena were again observed. All the variables increased or decreased $\left(\mathrm{CH}_{4}\right)$ with increased OLR. A reduction in HRT caused an increase in $\mathrm{CO}, \mathrm{H}_{2}$ concentrations, and gas production. The reduction in HRT resulted in a slight decrease in $\mathrm{CH}_{4}$, in one case, and the opposite in another case. This implies that.HRT does not have a strong influence on the 
gas monitoring variables at the OLR and HRT ranges studied. This was also the case when feed concentration was varied. The OLR appears to be the parameter that most affected the variables monitored.

\begin{tabular}{|c|c|c|c|c|c|c|c|c|}
\hline $\begin{array}{c}\text { OLR } \\
(\mathrm{kg} \\
\left.\operatorname{COD} / \mathrm{m}^{3}-\mathrm{d}\right)\end{array}$ & $\begin{array}{l}\text { HRT } \\
\text { (d) }\end{array}$ & $\begin{array}{c}\text { Feed } \\
\left(\mathrm{kg} \mathrm{COD} / \mathrm{m}^{3}\right)\end{array}$ & $\begin{array}{l}\text { Acetate } \\
(\mathbf{m M})\end{array}$ & $\begin{array}{c}\text { Propionate } \\
(\mathbf{m M})\end{array}$ & $\begin{array}{l}\mathrm{CH}_{4} \\
(\%)\end{array}$ & $\begin{array}{c}\text { CO } \\
(\mathrm{ppm})\end{array}$ & $\begin{array}{c}\mathbf{H}_{\mathbf{2}} \\
(\mathrm{ppm})\end{array}$ & $\begin{array}{c}\text { Gas } \\
\text { Production } \\
(\mathrm{m} / \mathrm{h})\end{array}$ \\
\hline 14.5 & 0.5 & 13.7 & 0.2 & 0.3 & 85.4 & 0.17 & 89.2 & 326 \\
\hline 23 & 0.5 & 13.7 & 1.0 & 0.7 & 74.2 & 0.59 & 150.9 & 592 \\
\hline 14.5 & 0.5 & 13.7 & 0.2 & 0.3 & 85.4 & 0.17 & 89.2 & 326 \\
\hline 15 & 1.5 & 13.7 & 1.0 & 0.4 & 78.3 & 0.28 & 118.4 & 370 \\
\hline 10 & 1.8 & 11.4 & 0.1 & $\mathrm{ND}^{\mathrm{a}}$ & 82.0 & 0.28 & 153.1 & 248 \\
\hline 10 & 1.5 & 9.1 & 0.1 & ND & 82.0 & 0.26 & 173.0 & 239 \\
\hline 4.2 & 2.5 & 11.4 & 0.1 & ND & 85.6 & 0.10 & 19.0 & 104 \\
\hline 10 & 1.8 & 11.4 & 0.1 & ND & 82.0 & 0.28 & 153.2 & 248 \\
\hline 14 & 1.0 & 11.4 & 0.7 & 0.4 & 83.7 & 0.24 & 126.1 & 378 \\
\hline 5.8 & 1.5 & 5.7 & 0.1 & ND & 85.5 & 0.20 & 24.3 & 155 \\
\hline 10 & 1.5 & 9.1 & 0.1 & ND & 82.0 & 0.26 & 173.0 & 239 \\
\hline 15 & 1.5 & 13.7 & 1.0 & 0.4 & 78.3 & 0.28 & 118.4 & 370 \\
\hline
\end{tabular}

Spectral analysis. Spectral analysis was conducted on pseudo-steady state operational data for six monitoring variables (acetate, propionate, $\mathrm{H}_{2}, \mathrm{CO}, \mathrm{CH}_{4}$, and gas production) in order to detect any cyclical patterns. The spectral technique uses finite Fourier transformation to reduce data into a sum of sine and cosine waves of different amplitudes and wavelengths (Brockwell and Davis 1987). The periodogram represents a sum of the squares. The periodogram is smoothed by a weighted moving average to produce an estimate for the spectral density of the series. Frequencies of each series are plotted against the periodogram. The maximum frequency calculated from the periodogram indicates any hidden periodicity. The data was further examined by Fisher's test at each OLR to differentiate any hidden periodicities from white noise. The hypothesis ( $\mathrm{HO}$ ) that the data is generated by a Gaussian white noise sequence was tested against the alternative hypothesis (H1) that the data is generated by a Gaussian white noise sequence with a superimposed deterministic periodic component. The test was computed using the following equation:

$$
P\left(E_{q} \geq x\right)=1-\sum_{j=0}^{q}(-1)^{j}\left(\begin{array}{l}
q \\
j
\end{array}\right)\left(1-\frac{j x}{q}\right)_{+}^{q-1} \quad \ldots
$$

where $P$ is probability; $E_{q}$ is a realized value of $x ; q$ is $\frac{n-1}{2} ; n$ is data size; $x$ is Kappa test statistics. $\alpha=0.05$ was used in the test. 
Cross-correlation of monitoring variables under the pseudo-steady state operation was analyzed to examine the time phase between the spectra (delay in response) of different variables. Phase spectrum periodograms were computed for each pair of variables at each OLR.

Spectral analyses were conducted by writing several SAS programs and plotting results for each variable. The maximum frequencies determined are presented in Table 6-7. Acetate and $\mathrm{CH}_{4}$ concentrations have the same maximum frequency throughout the operation. In three out of seven cases, propionate had the same common frequency as acetate and $\mathrm{CH}_{4}$. For two out of seven cases, $\mathrm{CO}$ had the same common frequency as acetate. The maximum frequencies of acetate and $\mathrm{CH} 4$ ranged from $0.26-2.62$; five out of seven data sets had values that were within the range of $0.26-0.57$. Similarly, propionate had a maximum level between 0.26 to 0.63 for five out of seven OLRs. $\mathrm{CO}, \mathrm{H}_{2}$ and gas production ranged from 0.11-0.84 for most of the experimental conditions tested. The maximum frequency of each monitoring variable appears to be independent of the OLR of the system. $\mathrm{CH}_{4}$ and acetate were related to some degree in frequency. The variation of gas production and $\mathrm{H}_{2}$ did not appear to be periodical in nature.

White noise tests were performed using SAS for Kappa's test (x) and q. Fisher's test was then calculated manually using equation 6-1 for each variable at each OLR. The probability was compared at the $\alpha=0.05$ level, and the decision made to either reject or accept the hypothesis HO. Rejection of HO means the data series has a hidden periodicity. Accepting $\mathrm{H} 0$ means that the data is described by random noise. The probability levels for each variable are listed in Table 6-8. In three out of seven cases, propionate and $\mathrm{CO}$ had periodicity (H0 was rejected). At less than two cases, each variable showed some degree of periodicity. However, white noise was normally observed for all the variables tested. The periodicities, however, were weak for most variables.

\begin{tabular}{|c|c|c|c|c|c|c|}
\hline \multicolumn{6}{|c|}{$\begin{array}{c}\text { Table 6-7. Maximum frequency of acetate, propionate, } \mathrm{CO}, \mathrm{H}_{2} \text { gas production, } \\
\text { and methane at different OLRs (calculated from periodogram). }\end{array}$} \\
\hline OLR & Acetate & Propionate & $\mathbf{C O}$ & $\mathbf{H}_{2}$ & $\begin{array}{c}\text { Gas } \\
\text { Production }\end{array}$ & $\mathbf{C H}_{4}$ \\
\hline 4.2 & 0.26 & & 0.26 & 0.52 & 0.27 & 0.26 \\
\hline 5.8 & 0.57 & 0.28 & 1.79 & 0.30 & 1.71 & 0.57 \\
\hline 10 & 0.42 & 0.63 & 0.63 & 0.42 & 0.10 & 0.42 \\
\hline 14 & 2.62 & 0.52 & 0.48 & 1.45 & 0.48 & 2.62 \\
\hline 15 & 1.14 & 1.14 & 2.28 & 0.57 & 0.57 & 1.14 \\
\hline 14.5 & 0.42 & 0.42 & 0.84 & 0.84 & 0.42 & 0.42 \\
\hline 23 & 0.52 & 0.52 & 0.52 & 3.14 & 2.62 & 0.52 \\
\hline OLR in $\mathrm{kg} \mathrm{COD} / \mathrm{m}^{3}-\mathrm{d}$ & & & & & \\
\hline
\end{tabular}




\begin{tabular}{|ccccccc|}
\hline \multicolumn{2}{|c|}{ Table 6-8. Fisher's white noise test results for each variable at different organic } \\
loading rate.
\end{tabular}

Results of cross-correlation analysis using SAS are presented in Table 6-9. For each pair of variables, a real periodogram was plotted with time-phase ranging from $-\pi$ to $\pi . \mathrm{CH}_{4}$ had a delay from $\mathrm{CO}$ ranging from -0.1 to -0.25 in most cases. Acetate and propionate had the same time-phase when OLR was high. Time-phase correlation for the rest of the monitoring variables was unclear.

Bivariate plots. An attempt was made to determine whether the $\mathrm{CO}$ and $\mathrm{H}_{2}$ data could be manipulated into a form where a "stable" operation region could be identified. A surrogate was sought to normalize both $\mathrm{CO}$ and $\mathrm{H}_{2}$ on the applied OLR. The OLR is not available on-line in field situations. Gas production rate (GP), however, did track the OLR well for all steady state testing. Therefore, the ratios of CO/GP and $\mathrm{H}_{2} / \mathrm{GP}$ were selected as the variables to investigate.

The $\mathrm{CO} / \mathrm{GP}$ and $\mathrm{H}_{2} / \mathrm{GP}$ ratios at each steady state $\left(4.2-23 \mathrm{~kg} \mathrm{COD} / \mathrm{m}^{3}-\mathrm{d}\right)$ were calculated. The mean $+3 \alpha$ was calculated using the above data (mean and standard deviation) as baselines. There were $2.46 \mathrm{ppb}$ $\mathrm{CO} / \mathrm{ml}$ gas-hr for $\mathrm{CO} / \mathrm{GP}$ and $1.21 \mathrm{ppm} \mathrm{H}_{2} / \mathrm{ml}$ gas-hr, for the steady state operation. The steady state operation data of $\mathrm{CO} / \mathrm{GP}$ and $\mathrm{H}_{2} / \mathrm{GP}$ is presented in Table 6-10. Results are reasonably consistent for both $\mathrm{CO} / \mathrm{GP}$ and $\mathrm{H}_{2} / \mathrm{GP}$ especially for data collected at OLR of $10 \mathrm{~kg} \mathrm{COD} / \mathrm{m}^{3}-\mathrm{d}$ and higher. 
Table 6-9. Time phase between each pair of monitoring variables in frequency.

\begin{tabular}{|c|c|c|c|c|c|c|c|c|c|c|c|c|c|c|}
\hline$\overline{\text { OLR }}$ & $\overline{\mathrm{A} / \mathrm{P}}$ & $\overline{\mathrm{A} / \mathrm{CO}}$ & $\overline{A / H_{2}}$ & $\mathrm{~A} / \mathrm{CH}$ & A/GP & & $\mathbf{P} / \mathbf{H}$ & & & & & & & \\
\hline 4.2 & -0.4 & -0.4 & 1.0 & 1.8 & 0.1 & -018 & -1.6 & -075 & NA & $\overline{N A}$ & & & & \\
\hline 5.8 & -1.2 & -0.6 & -0.5 & 0.0 & $\overline{0.6}$ & -31 & -025 & 055 & 13 & 01 & 25 & & & \\
\hline 10 & -0.6 & 0.3 & 3.0 & -28 & $\overline{N A}$ & 0.3 & 14 & 11 & 11 & $\overline{\mathrm{NA}}$ & 08 & 00 & & $\frac{3.1}{20}$ \\
\hline 14 & 0.22 & 0.13 & -0.8 & -2.8 & 1.1 & $-0,35$ & 00 & 00 & $\mathrm{NA}$ & $\overline{N A}$ & 01 & 7,5 & 00 & \\
\hline 15 & 00 & -15 & 075 & 12 & -15 & $n$ & 31 & & & & & & & \\
\hline 145 & 0 & 20 & 14 & 07 & 01 & & & & & & & & -1.1 & 0.0 \\
\hline & 0.0 & -2.8 & & & 0.1 & 0.0 & -0.42 & 1.7 & 2.0 & -1.8 & 1.1 & NA & 1.15 & 0.11 \\
\hline 23 & 0.0 & 0.53 & -0.1 & -2.17 & NA & 0.5 & 0.0 & -3.1 & $\mathrm{NA}$ & 0.0 & $-1.5 !$ & $-1: 1$ & 0.0 & 0.0 \\
\hline
\end{tabular}




\begin{tabular}{|c|c|c|c|c|c|c|c|c|}
\hline \multicolumn{9}{|c|}{ CO/GP } \\
\hline$\overline{\text { OLR }}$ & 4.2 & 5.8 & 10 & 10 & 14 & 15 & 14.5 & 23 \\
\hline MEAN & 1.423 & 1.273 & 1.106 & 1.090 & 0.700 & 0.738 & 0.528 & 1.210 \\
\hline$\overline{\text { SD }}$ & 1.526 & 0.580 & 0.355 & 0.298 & 0.231 & 0.114 & 0.227 & 0.303 \\
\hline STDerr & 0.063 & 0.028 & 0.015 & 0.015 & 0.014 & 0.009 & 0.013 & 0.020 \\
\hline $\mathrm{n}$ & 580 & 445 & 527 & 408 & 258 & 161 & 309 & 234 \\
\hline \multicolumn{9}{|c|}{$\mathrm{H}_{2} / \mathbf{G P}$} \\
\hline$\overline{\text { OLR }}$ & 4.2 & 5.8 & 10 & 10 & 14 & 15 & 14.5 & 23 \\
\hline MEAN & 0.189 & 0.165 & 0.623 & 0.739 & 0.547 & 0.325 & 0.277 & 0.274 \\
\hline SD & 0.297 & 0.132 & 0.476 & 0.297 & 0.098 & 0.059 & 0.088 & 0.091 \\
\hline STDerr & 0.012 & 0.006 & 0.021 & 0.015 & 0.006 & 0.005 & 0.005 & 0.006 \\
\hline n & 580 & 428 & 525 & 406 & 259 & 158 & 317 & 226 \\
\hline
\end{tabular}

\section{Reaction Energetics}

Acetogenesis and methanogenesis are the two major processes involved in the biodegradation of the synthetic brewery waste. During biodegradation, ethanol degraded quickly. During pseudo-steady state operations, ethanol was never detected in the reactor effluent (detection limit $0.1 \mathrm{mM}$ ). Thus, the reaction thermodynamics were performed primarily using propionate and acetate degradation. Values for the mean of each monitoring variable, derived using statistical analysis, were used in the energy calculations. The major biochemical reaction equations and their Gibbs free energy under standard conditions (after Thauer et al. 1977) are shown in Table 6-11. In order to track the influence of $\mathrm{CO}$ and $\mathrm{H}_{2}$, reactions 2 and 3 were split from the reaction Acetate $\rightarrow \mathrm{CH}_{4}+\mathrm{CO}_{2}$.

At standard conditions, the Gibbs free energy for propionate degradation is positive. From a thermodynamic point of view, the reaction could therefore not proceed to the right. To reach a negative value of $\Delta \mathrm{G}, \mathrm{H}_{2}$ must be low. $\Delta \mathrm{G}$ for each $\mathrm{OLR}$ was calculated using the actual concentrations during pseudo-steady state operations and the reactor operational conditions $\left(37^{\circ} \mathrm{C}, \mathrm{pH}=7\right.$; Figure 6-9). $\mathrm{CO}$ and $\mathrm{H}_{2}$ were analyzed using the headspace concentration. The values of the first 2 points of each of the four reactions were different from the values of the rest of the points of these reactions. This may be caused by the low concentration of acetate and propionate (near detection limits) at an OLR of 4.2 and $5.8 \mathrm{~kg}$ $\mathrm{COD} / \mathrm{m}^{3}-\mathrm{d}$. This also affected the level of the other variable. The calculated $\Delta \mathrm{G}^{\prime}$ of propionate degradation (reaction 1) was positive. The reaction was therefore not likely to occur. However, the propionate concentration in the feed $(15 \mathrm{mM})$ decreased down to less than $1 \mathrm{mM}$ during the operation. The discrepancy between the calculated free energy values was probably due to the lack of equilibrium between the gas present in the headspace and the gas dissolved in the aqueous phase. 


\begin{tabular}{|l|c|}
\hline \multicolumn{2}{|c|}{ Table 6-11. Gibbs free energy change for propionate oxidation and methanogenesis } \\
at standard conditions.
\end{tabular}

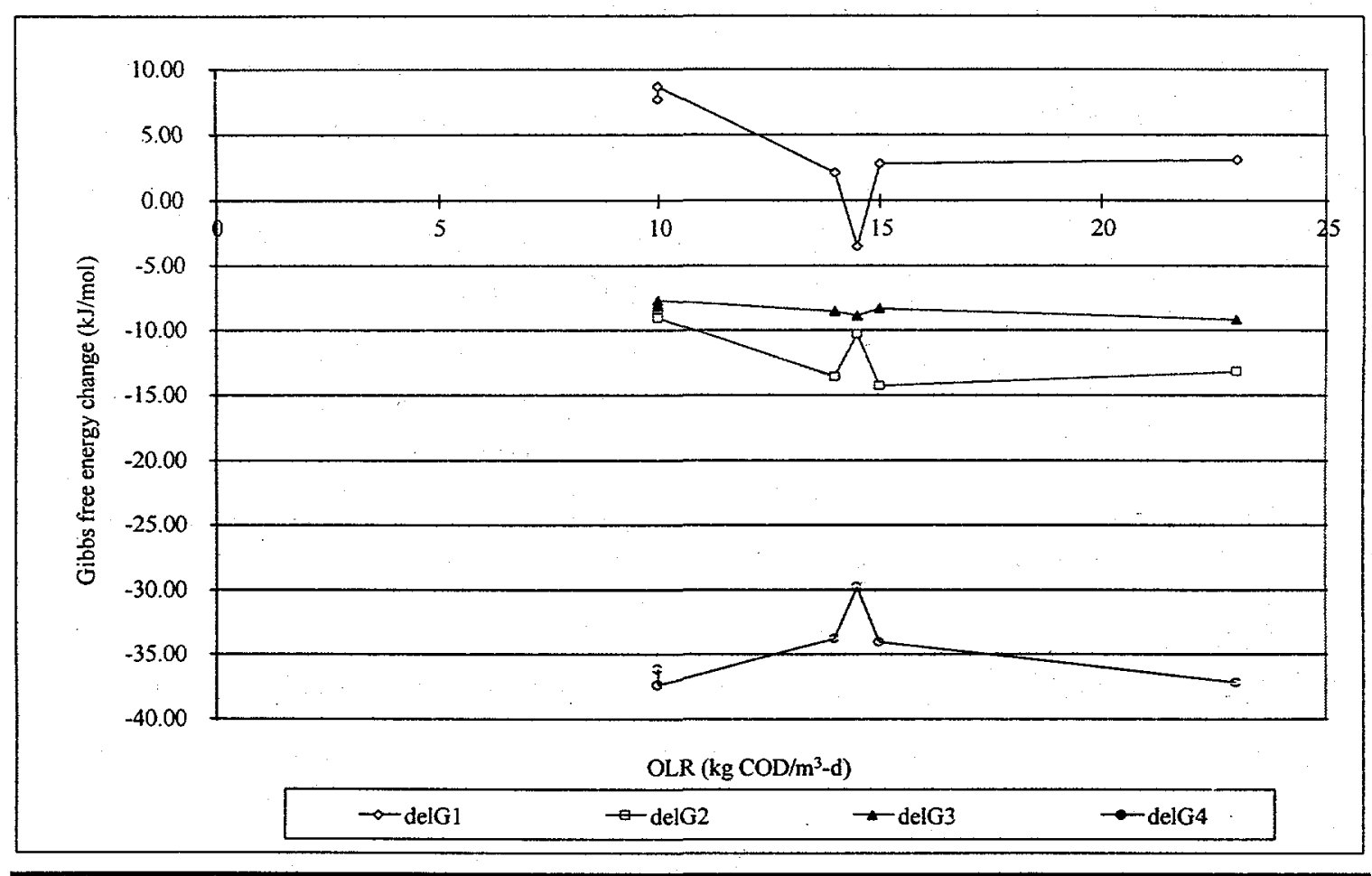

Propionate degradation

1. $\mathrm{CH}_{3} \mathrm{CH}_{2} \mathrm{COO}^{-}+3 \mathrm{H}_{2} \mathrm{O} \rightarrow \mathrm{HCO}_{3}^{-}+\mathrm{H}^{+}+3 \mathrm{H}_{2}+\mathrm{CH}_{3} \mathrm{COO}^{-}$

Acetate degradation

2. $\mathrm{CH}_{3} \mathrm{COO}^{-}+\mathrm{H}_{2}+\mathrm{H}^{+} \rightarrow \mathrm{CH}_{4}+\mathrm{CO}+\mathrm{H}_{2} \mathrm{O}$

3. $\mathrm{CO}+\mathrm{H}_{2} \mathrm{O} \rightarrow \mathrm{CO}_{2}+\mathrm{H}_{2}$

$\mathrm{CO}_{2}$ reduction

4. $\mathrm{CO}_{2}+4 \mathrm{H}_{2} \rightarrow \mathrm{CH}_{4}+2 \mathrm{H}_{2} \mathrm{O}$

Figure 6-9. Free energy change of propionate oxidation and methanogenesis during pseudo-steady state operation. (Headspace $\mathrm{CO}$ and $\mathrm{H}_{2}$ used for calculation.) 
$\mathrm{H}_{2}$ and $\mathrm{CO}$ present in the headspace do not necessarily represent the concentration in the liquid phase that microorganisms actually experience. Pauss et al. (1990a) reported a 70-times difference between dissolved $\mathrm{H}_{2}$ and headspace $\mathrm{H}_{2}$. This could be due to 1) limiting mass transfer from liquid to gas phase (Pauss et al. , 1990a, 1990b), 2) hydrogen's rapid turnover rate and its perhaps widely varying concentration in solution. An attempt was made to measure dissolved $\mathrm{H}_{2}$ and $\mathrm{CO}$ in the UASB reactor in a separate experiment at various head-space concentrations (for method, see Appendix $\mathrm{C}$ ). The value of the pseudo-steady state gas phase $\mathrm{H}_{2}$ and $\mathrm{CO}$ concentrations were adjusted using the results obtained from dissolved gas analysis from the same UASB reactor in a separate test. The ratio of measured gas concentration to gas concentration at equilibrium with liquid phase concentration $\left(\mathrm{H}_{2}{ }^{*}(\mathrm{~g})\right.$ and $\left.\mathrm{CO}^{*}(\mathrm{~g})\right)$, calculated based on the measurements of dissolved gas concentrations, are presented in Table 6-i2. A ratio of less than one, where the gas phase concentration is smaller than equilibrium gas concentration $\left(\mathrm{H}_{2}{ }^{*}(\mathrm{~g})\right.$ or $\left.\mathrm{CO}^{*}(\mathrm{~g})\right)$, indicates that mass transfer of the compound from liquid phase to gas phase is limited. This ratio for $\mathrm{H}_{2}$ was greater than one, while it was smaller than one for $\mathrm{CO}$. The results suggested that mass transfer from liquid phase to gas phase was limiting for $\mathrm{CO}$ but not for $\mathrm{H}_{2}$. Dissolved gas concentrations of $\mathrm{H}_{2}$ and $\mathrm{CO}$ during pseudo-steady state operations were then estimated (Figure 6-10). The free energy of the propionate degradation calculated in this fashion was negative at pseudo-steady state. For each reaction within the OLR range studied, the $\Delta G^{\prime}$ values were quite stable. Reaction 2 (acetate $\rightarrow \mathrm{CO}$ ) had three positive points. However, $\Delta G$ 's for the whole reaction of acetoclastic methanogenesis (reactions $2+3$ ) were negative. The average free energy level of propionate oxidation (reaction 1) was $-20 \mathrm{~kJ} / \mathrm{mol}$; of acetate decarboxylation (reaction 2+3) -20 $\mathrm{kJ} / \mathrm{mol}$; of $\mathrm{H} 2$ oxidation (reaction 4) $-5 \mathrm{~kJ} / \mathrm{mol}$.

\begin{tabular}{|c|c|c|c|c|c|c|}
\hline & $\begin{array}{c}\mathbf{H}_{2} \text { (I) } \\
\mathbf{n M}\end{array}$ & $\begin{array}{c}\mathrm{CO}(\mathrm{l}) \\
\mathrm{nM}\end{array}$ & $\begin{array}{l}\mathbf{H}_{2}(\mathrm{~g}) \\
(\mathrm{ppm})\end{array}$ & $\begin{array}{l}\mathrm{CO}(\mathrm{g}) \\
(\mathrm{ppm})\end{array}$ & $\frac{H_{2(g)}}{H_{2}^{*}(g)}$ & $\frac{C O_{(g)}}{C O_{(g)}^{*}}$ \\
\hline mean & 4.83 & 9.25 & 53.71 & 0.158 & 16.3 & 0.145 \\
\hline SD & 5.59 & 17.94 & 34.53 & 0.058 & 17.3 & 0.129 \\
\hline Range & $1.36-18.50$ & $0.71-51.45$ & $9.6-94.5$ & $0.11-0.26$ & $2-50$ & $0.02-0.34$ \\
\hline \multicolumn{7}{|c|}{$\begin{array}{l}\text { a. Total eight observations. Three replicates each sample for dissolved gas analysis. } \\
\text { b. } \mathrm{H}_{2}^{*}(\mathrm{~g}) \text { and } \mathrm{CO}(\mathrm{g}) \text { are gas phase } \mathrm{H}_{2} \text { and } \mathrm{CO} \text { concentrations that are in equilibrium with liquid } \\
\text { phase concentrations, calculated from dissolved gas measurements. }\end{array}$} \\
\hline
\end{tabular}




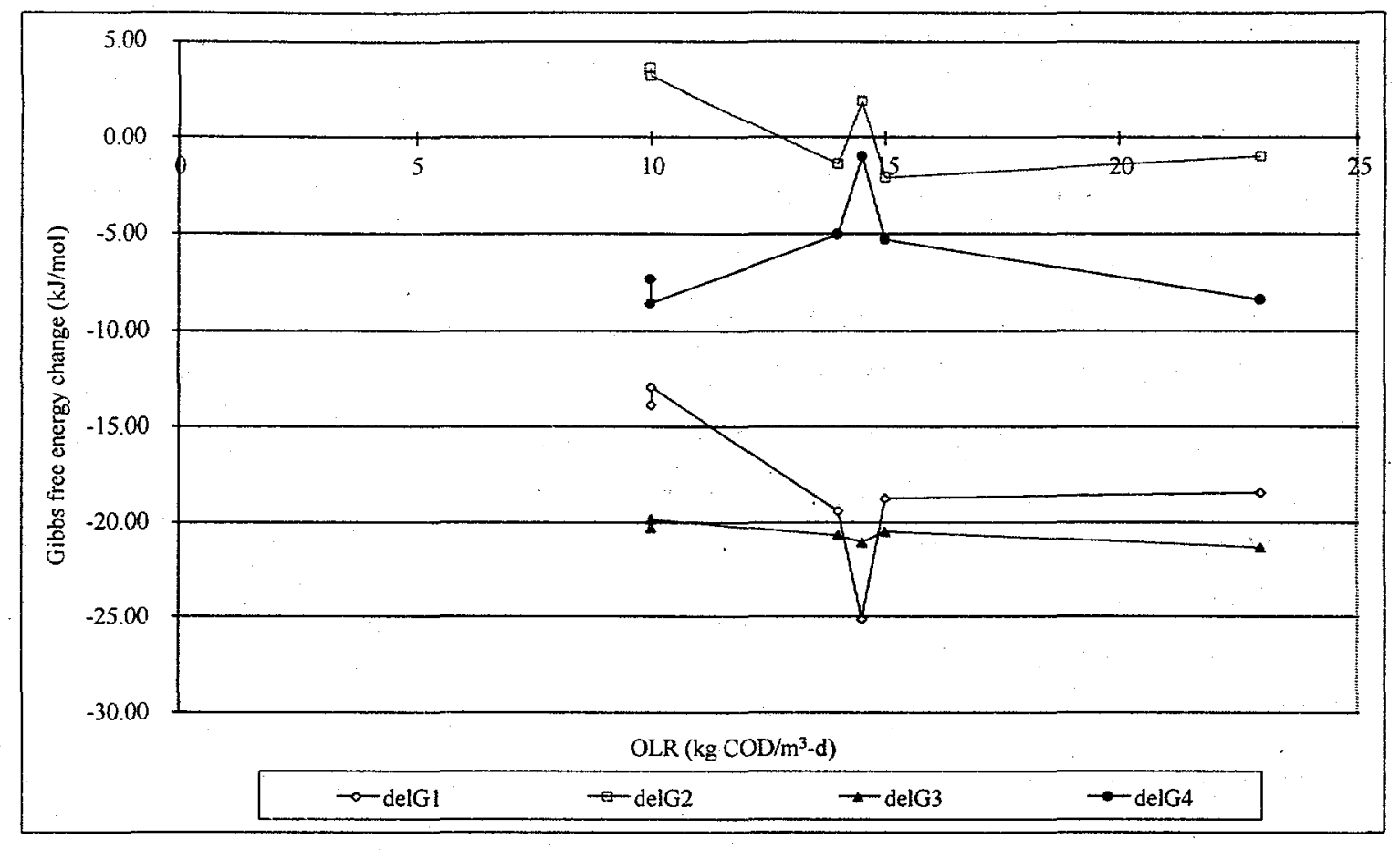

Propionate degradation

1. $\mathrm{CH}_{3} \mathrm{CH}_{2} \mathrm{COO}^{-}+3 \mathrm{H}_{2} \mathrm{O} \rightarrow \mathrm{HCO}_{3}^{-}+\mathrm{H}^{+}+3 \mathrm{H}_{2}+\mathrm{CH}_{3} \mathrm{COO}^{-}$

Acetate degradation

2. $\mathrm{CH}_{3} \mathrm{COO}^{-}+\mathrm{H}_{2}+\mathrm{H}^{+} \rightarrow \mathrm{CH}_{4}+\mathrm{CO}+\mathrm{H}_{2} \mathrm{O}$

3. $\mathrm{CO}+\mathrm{H}_{2} \mathrm{O} \rightarrow \mathrm{CO}_{2}+\mathrm{H}_{2}$

$\mathrm{CO}_{2}$ reduction

4. $\mathrm{CO}_{2}+4 \mathrm{H}_{2} \rightarrow \mathrm{CH}_{4}+2 \mathrm{H}_{2} \mathrm{O}$

Figure 6-10. Free energy change of propionate oxidation and methanogenesis during pseudo-steady state operation. (Dissolved $\mathrm{CO}$ and $\mathrm{H}_{2}$ used for calculation. $\mathrm{CO}$ and $\mathrm{H}_{2}$ were headspace concentrations in equilibrium with measured dissolved gas concentration.)

\section{UNSTEADY STATE OLR PERTURBATIONS AND SYSTEM RESPONSES - NO PH CONTROL}

Unsteady state OLR variation experiments were performed by imposing step OLR increases and decreases as well as imposing impulse loads on the bench-scale UASB reactor treating a synthetic brewery waste.

OLR was varied by changing the feed rate. Perturbation of different OLR strengths and durations were tested. The effect of fixed duration of steps (regular variation) and a combinations of impulse and step increases (random variation) were also examined. The OLR was increased high enough to cause a system failure. Trace gases $\mathrm{H}_{2}$ and $\mathrm{CO}$ and performance variables acetate, propionate, gas production rate, 
methane content, $\mathrm{pH}$, and suspended solids were monitored. Reactor granule volume was maintained at 1.5-1.7 L (unexpanded bed volume).

\section{OLR Variation at $5,8,12,15 \mathrm{~kg} \mathrm{COD} / \mathrm{m}^{3}-\mathrm{d}$ (USS1).}

A regular perturbation experiment performed by varying OLR at a fixed frequency ( 24 hours) and duration of each step (3 hours) was conducted (Figure 6-11). Three perturbations were imposed on the UASB reactor. The background OLR was $5 \mathrm{~kg} \mathrm{COD} / \mathrm{m}^{3}-\mathrm{d}$. The OLR was increased stepwise from 5 to 8,12 , and $15 \mathrm{~kg} \mathrm{COD} / \mathrm{m}^{3}-\mathrm{d}$, and then back by increasing and then decreasing the forward flow rate to the reactor (decreasing HRT from 2.6 to 1.3 days). Results of the experiment are graphically presented in Figures 6-11 through 6-13. The UASB responded quickly to changes in OLR. Gas production rate followed the changes in OLR extremely well. CO also appeared to track the changes in OLR with little delay (Figure 6-12). No discernible trend was observed for $\mathrm{H}_{2}$. Acetate and propionate levels rose only slightly at each new step OLR (0.1 $0.3 \mathrm{mM})$. Methane content decreased by $3-4 \%$ as the OLR was increased. After the OLR was decreased, methane concentration increased rapidly, reached a peak value and then returned to the normal steady state range (Figure 6-11). Reactor $\mathrm{pH}$ also decreased slightly $(0.2 \mathrm{pH}$ unit) during the step OLR increases (Figure 6-13). Since the responses were relatively low (i.e., there was little accumulation of acetate, propionate, etc.), a high level of OLR perturbation was desired.

\section{OLR Variation at $5,10,15,20,25 \mathrm{~kg}$ COD $/ \mathrm{m}^{3}-\mathrm{d}$ (USS2).}

A second experiment was conducted to examine response to a regular variation of OLR with the same frequency and duration of each step but at a higher amplitude in the OLR increase. The OLR was varied from $5 \mathrm{~kg} \mathrm{COD} / \mathrm{m}^{3}-\mathrm{d}$ to $25 \mathrm{~kg} \mathrm{COD} / \mathrm{m}^{3}-\mathrm{d}$. The HRT was concurrently varied from 2.6 days to 22 hours. Three perturbations were imposed upon the laboratory UASB reactor (Figure 6-14). The gas production rate followed increases and decreases in OLR quite well. The CO concentration also increased and decreased in concert with OLR. $\mathrm{H}_{2}$ response was poor. A decrease in system performance was observed when the OLR was increased to $25 \mathrm{~kg} \mathrm{COD} / \mathrm{m}^{3}$-d during the second and third perturbations. Gas production rate decreased from $1120 \mathrm{~mL} / \mathrm{h}$ at the peak rate of the second day $(29-31$ hours $)$ to $800 \mathrm{~mL} / \mathrm{h}$ at the peak of the third perturbation (53-56 hours). Maximum $\mathrm{CO}$ concentrations increased from $0.4 \mathrm{ppm}$ (first and second perturbation) to $0.6 \mathrm{ppm}$ (third perturbation; Figure 6-15). A lag was observed in the response of $\mathrm{CO}$ to increases in the OLR. Nevertheless, CO concentration appeared to track the changes in OLR and gas production reasonably well. Effluent VFAs accumulated when the OLR was at its peak (Figure 6-16). During the third day, acetate and propionate concentrations peaked at $0.5 \mathrm{mM}$ compared to $0.28 \mathrm{mM}$ and $0.12 \mathrm{mM}$, respectively, for the second day. Butyrate and iso-butyrate were also observed in the effluent at this time (Figure 6-16). The peak concentration of acetate occurred at approximately the same time as peak concentration of $\mathrm{CO}$. Methane varied in the same pattern as for the previous experiment. It decreased gradually when the OLR was high and increased quickly when the OLR was 
decreased (Figure 6-14). Reactor $\mathrm{pH}$ decreased slowly from 7.0 when VFAs were observed to accumulate, reaching 6.7 at the end of the experiment.
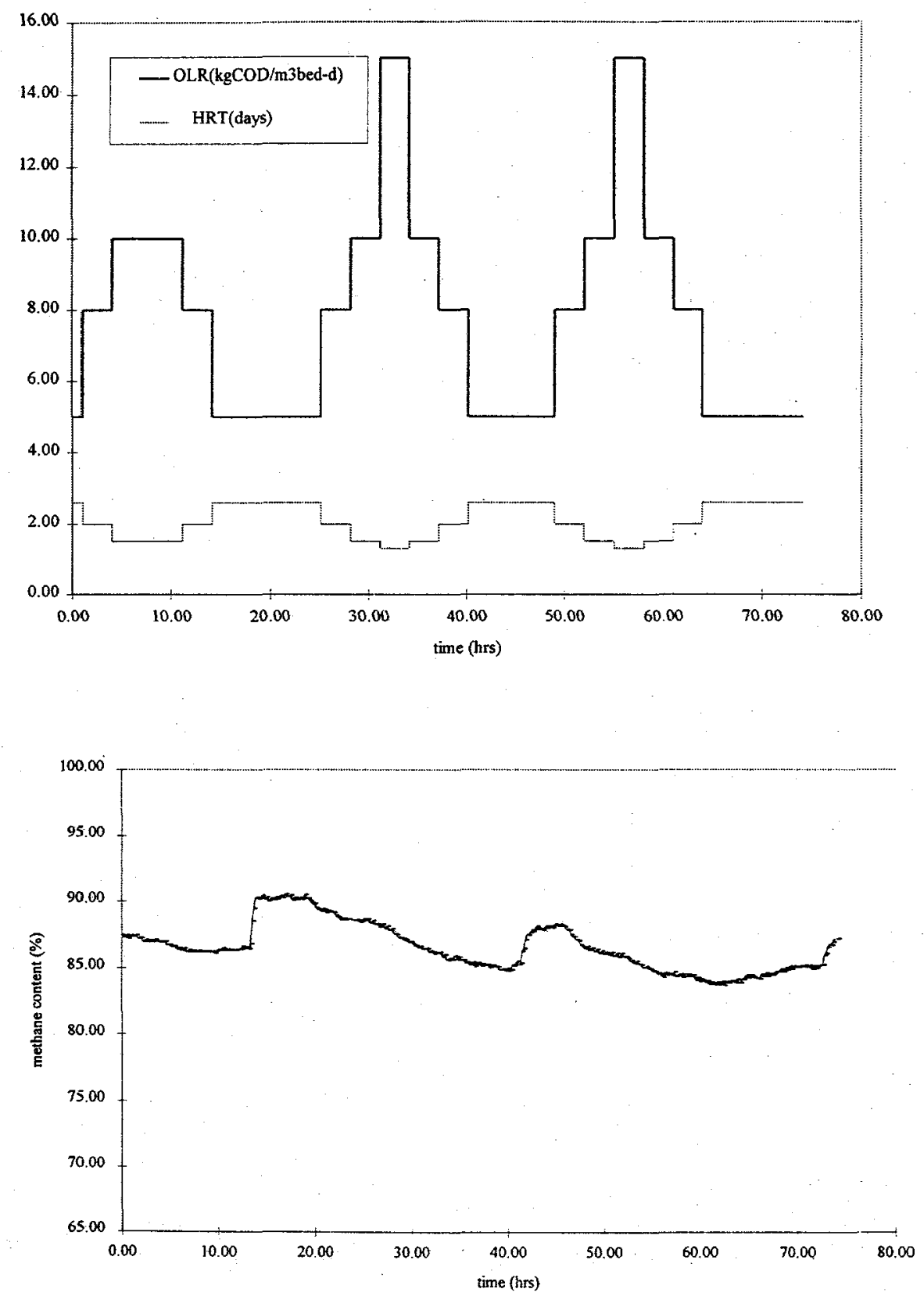

Figure 6-11. Applied OLR and HRT and reactor methane content variation during OLR loading variation experiments (OLR: $5-15 \mathrm{~kg}$ COD/m${ }^{3}-\mathrm{d}$ ). 

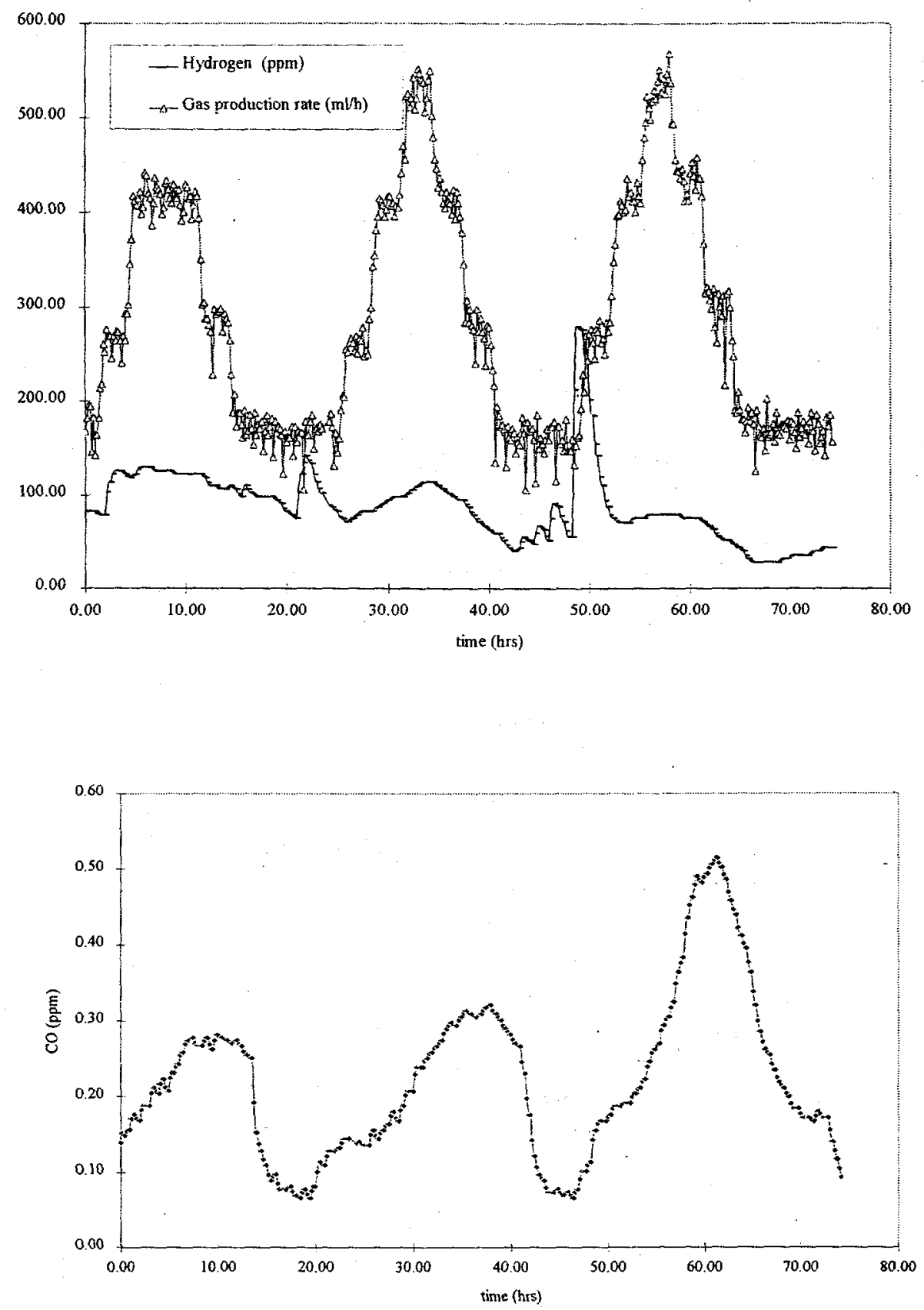

Figure 6-12. Hydrogen, carbon monoxide, and gas production rate during loading variation experiments (OLR: $5-15 \mathrm{~kg} \mathrm{COD} / \mathrm{m}^{3}-\mathrm{d}$ ). 

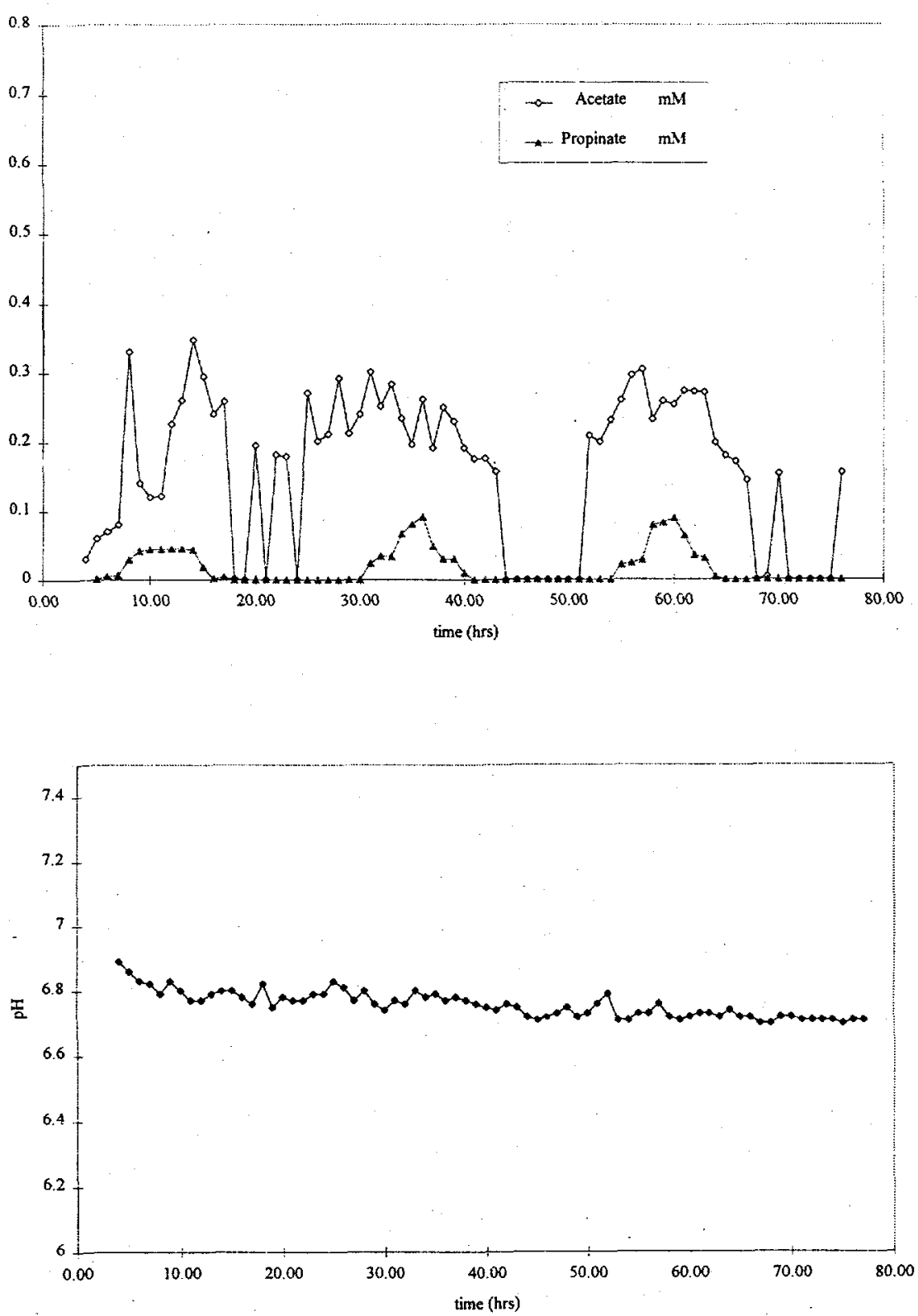

Figure 6-13. Acetate, propionate, and pH during variation experiments (OLR: $5-15 \mathrm{~kg}$ $\left.\mathrm{COD} / \mathrm{m}^{3}-\mathrm{d}\right)$.

There was no significant change in effluent volatile suspended solids (VSS) concentration during the initial two days. VSS concentration increased slightly during the third day $(120 \mathrm{mg} / \mathrm{L})$ from a level of $20 \mathrm{ppm}$ and did not immediately return back to previous level once the experiment was discontinued and the OLR maintained at the starting level of $5 \mathrm{~kg} \mathrm{COD} / \mathrm{m}^{3}-\mathrm{d}$ (Figure 6-17). 

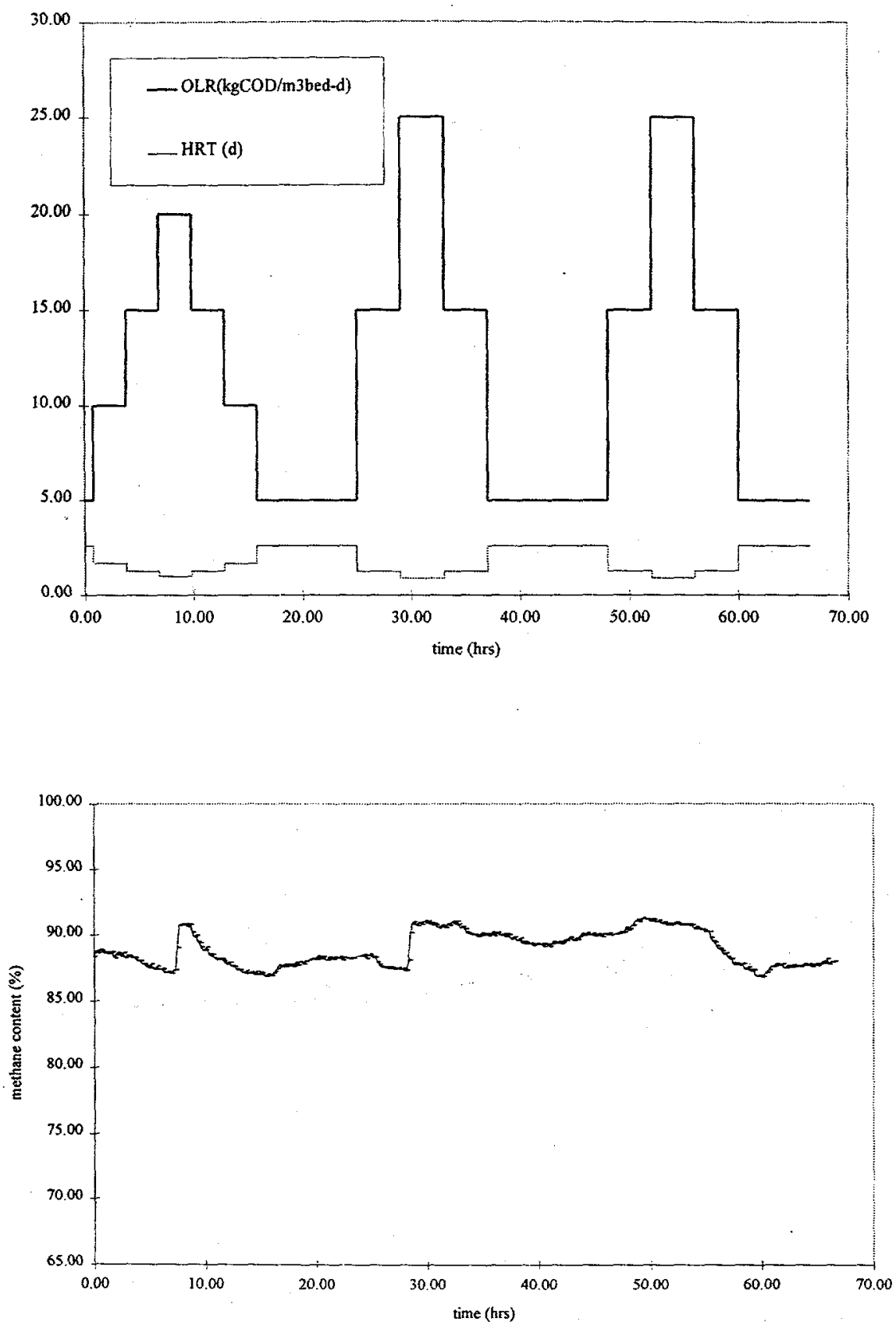

Figure 6-14. Applied OLR and HRT and reactor methane content variation during OLR

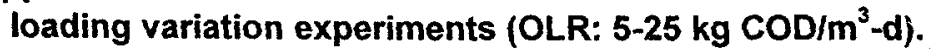



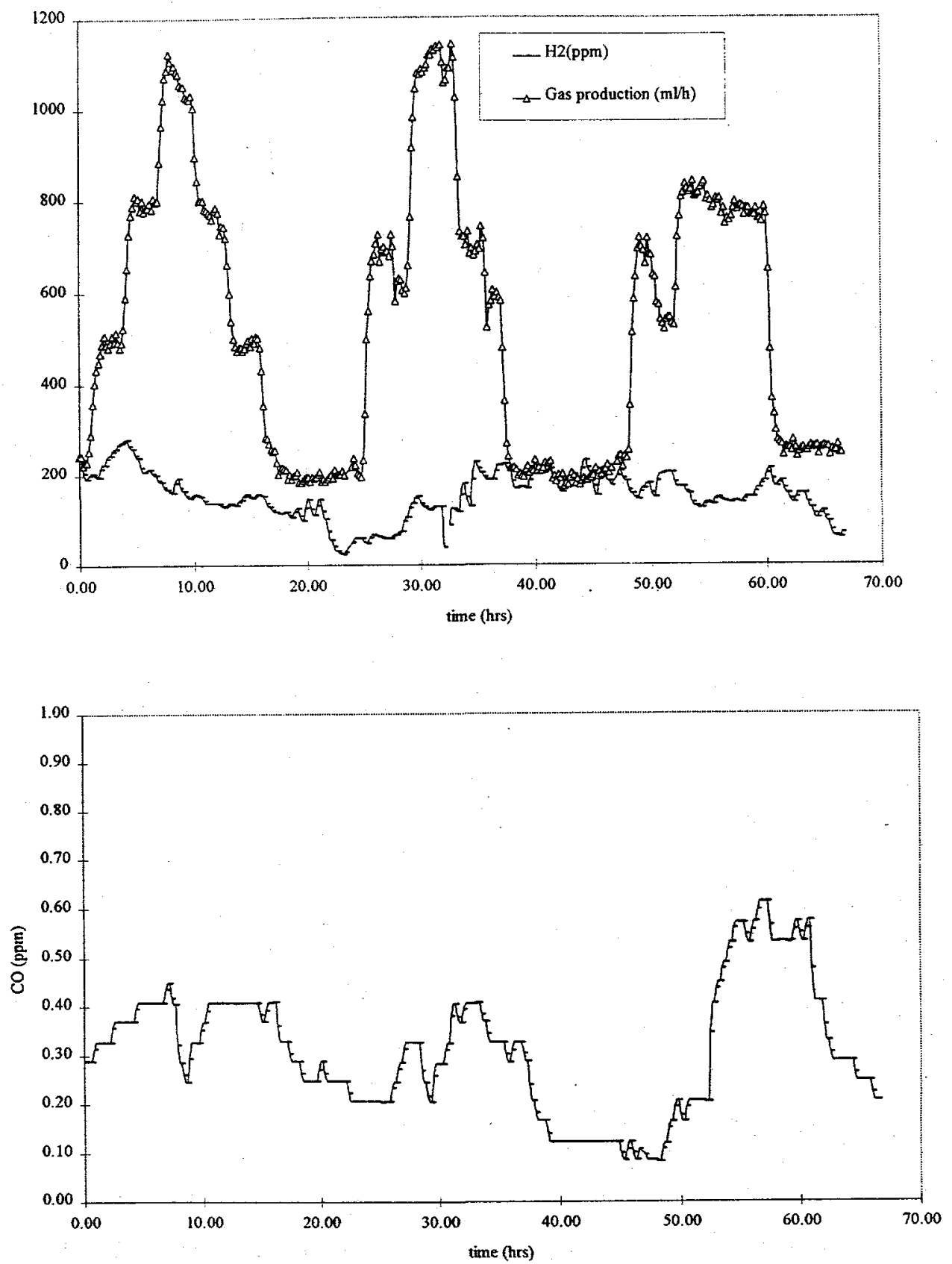

Figure 6-15. Hydrogen, carbon monoxide, and gas production rates during OLR variation experiments (OLR: $5-25 \mathrm{~kg} \mathrm{COD} / \mathrm{m}^{3}-\mathrm{d}$ ). 

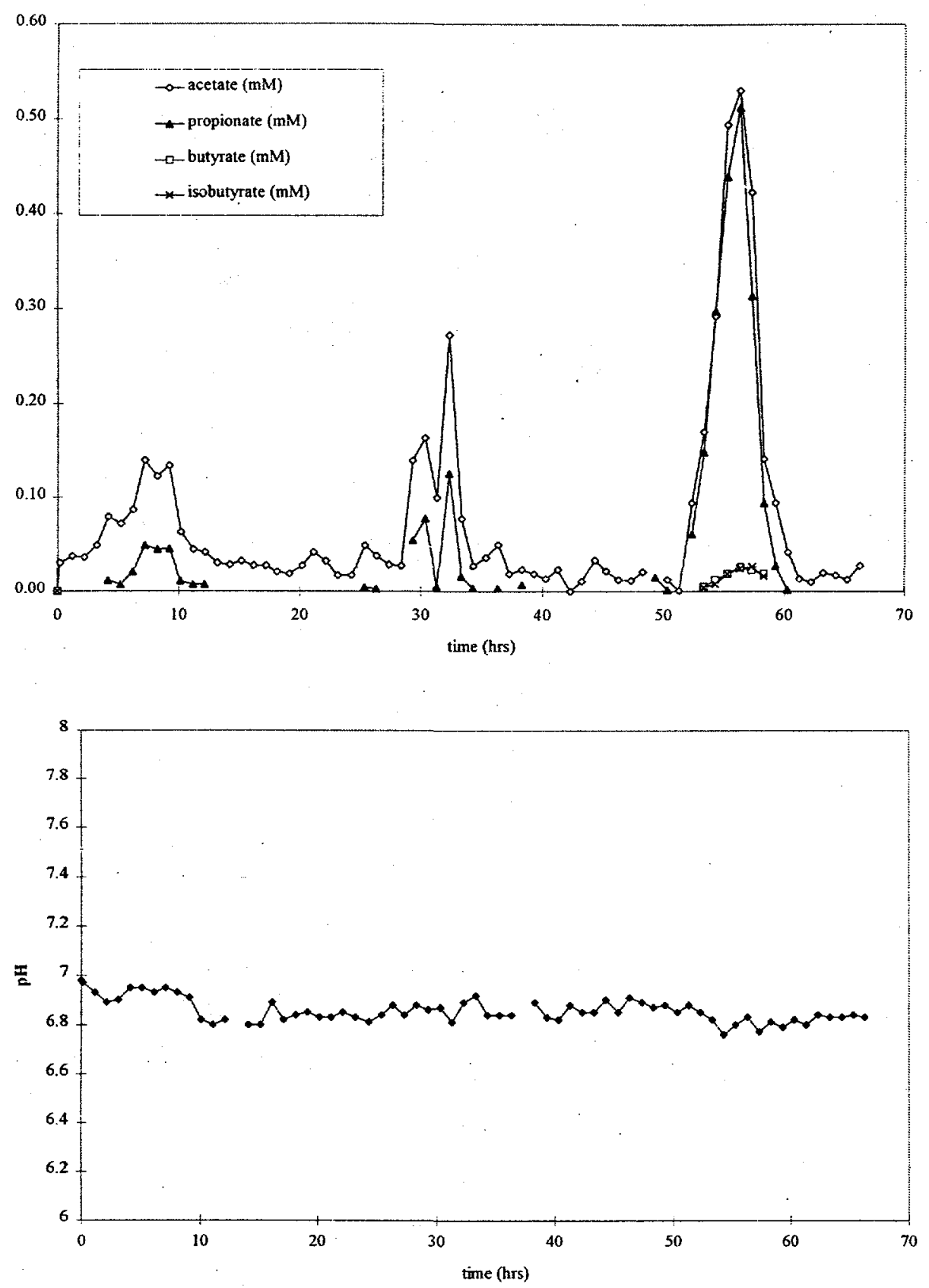

Figure 6-16. Acetate, propionate, butyrate, isobutyrate and $\mathrm{pH}$ during $\mathrm{OLR}$ variation experiments (OLR: $5-25 \mathrm{~kg} \mathrm{COD} / \mathrm{m}^{3}-\mathrm{d}$ ).

6-32 


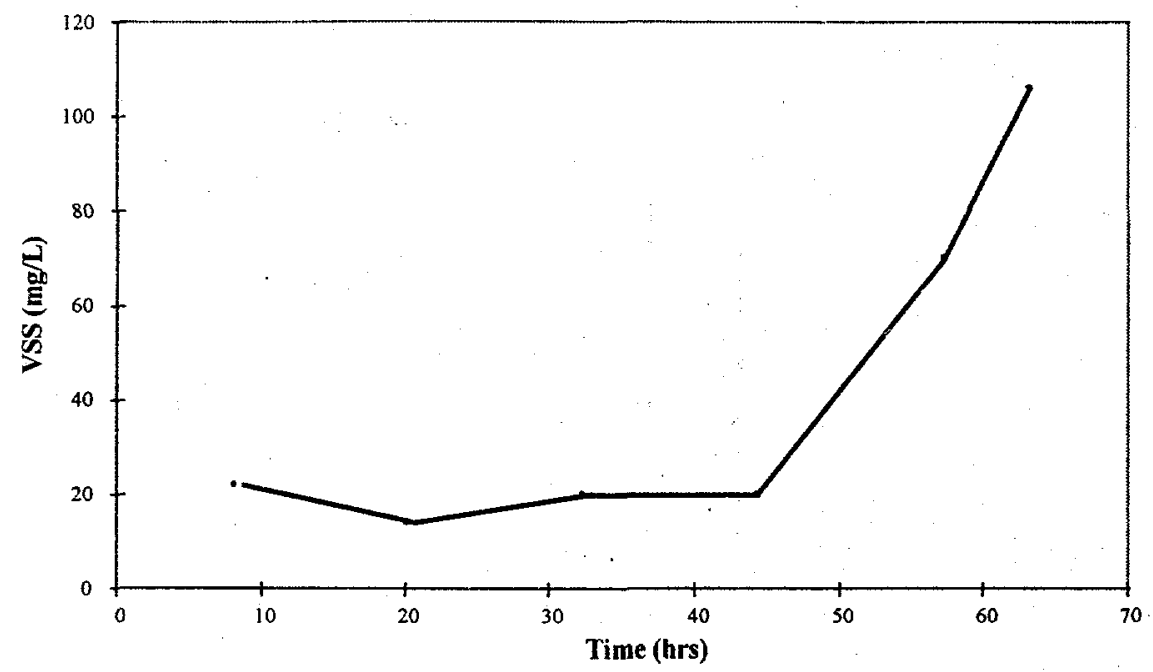

Figure 6-17. Volatile suspended solids (VSS) during OLR variation experiment (OLR: 5-25 $\left.\mathrm{kg} \mathrm{COD} / \mathrm{m}^{3}-\mathrm{d}\right)$.

\section{OLR Variation at 10,30, 40,50,60 and $104 \mathrm{~kg}$ COD $/ \mathrm{m}^{3}-\mathrm{d}$ (USS3).}

To examine the responses of random versus regular OLR variations, a four-consecutive-day experiment was conducted. Two types of variations, random and regular, were applied, each for 24 hours. Random OLR variations were accomplished by a combination of steps (variable duration of 1 to 3 hours) and impulses. The OLR ranged from $10-60 \mathrm{~kg} \mathrm{COD} / \mathrm{m}^{3}-\mathrm{d}$ up to $104 \mathrm{~kg} \mathrm{COD} / \mathrm{m}^{3}-\mathrm{d}$ during an impulse. The HRT was varied from 6 to 12.6 hours. The applied OLR and HRT during this experiment are presented in Figure 6-18. A regular variation of OLR at 10 and $25 \mathrm{~kg} \mathrm{COD} / \mathrm{m}^{3}-\mathrm{d}$, with a fixed duration of 2 hours for each step increase, was first imposed on the system. This was followed by a random variation up to $30 \mathrm{~kg}$ $\mathrm{COD} / \mathrm{m}^{3}-\mathrm{d}$ in steps and an impulse of $104 \mathrm{~kg} \mathrm{COD} / \mathrm{m}^{3}-\mathrm{d}$. On the third day, a high strength random variation was imposed on the reactor to push the system to its limit. The applied OLR was increased up to $60 \mathrm{~kg} \mathrm{COD} / \mathrm{m}^{3}-\mathrm{d}$. Duration of each step increase at 30,60 , and $50 \mathrm{~kg} \mathrm{COD} / \mathrm{m}^{3}-\mathrm{d}$ was 3 hours.

Immediately after this perturbation, a random variation similar to the one performed on day 2 was repeated to allow studying the impact of the day 3 perturbation on the system.

The gas production rate had a distinct response pattern to the variations in OLR. It was one of the most sensitive variables tested (Figure 6-19). Gas production rate closely followed the input pattern of OLR, although a 1- to 2-hour lag was observed. The total gas production was 11.9 liter on day 2 (20-34 hr) and 12.1 liter on day 4 (68-91 hours). Under the perturbation conditions imposed during day 3 (44-68 hours) the gas production rate decreased to $68 \%$ of the theoretical potential production (growth not included in the analysis). This indicates the methanogens were probably overloaded. Methane production was estimated to be $0.28 \mathrm{~m}^{3} \mathrm{CH}_{4} / \mathrm{kg}$ COD removed during the third perturbation. Background methane production was $0.38 \mathrm{~m}^{3} \mathrm{CH}_{4} / \mathrm{kg}$ COD removed. 

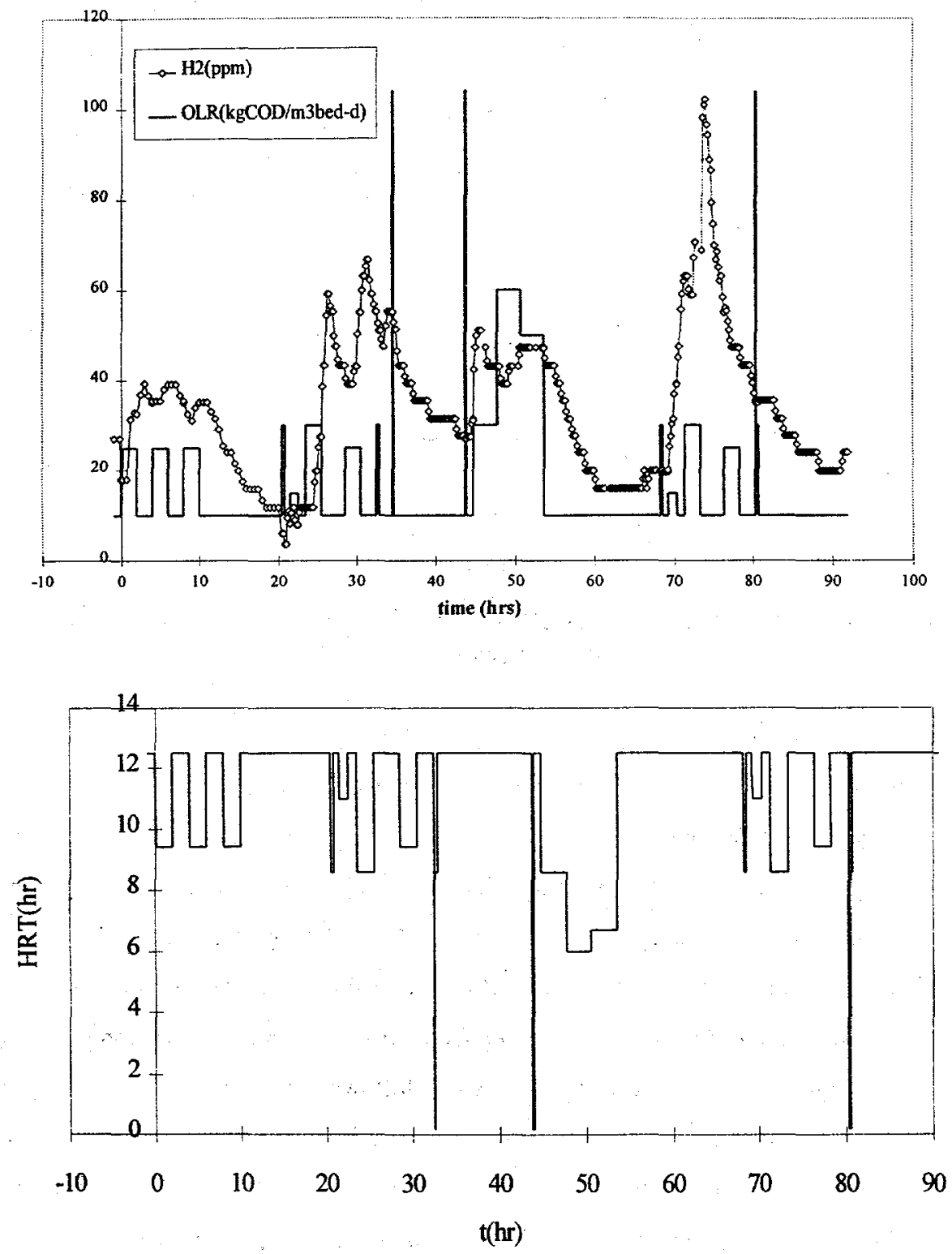

Figure 6-18. Applied OLR and HRT and reactor $\mathrm{H}_{2}$ responses during OLR variation experiments (OLR:10-104 kg COD/m $\mathrm{m}^{3}-\mathrm{d}$ ).

During this perturbation, $\mathrm{H}_{2}$ responded to the changes in OLR (Figure 6-18). About a 1-hour delay in response was observed. After the system had been significantly disturbed, on day $3, \mathrm{H}_{2}$ had a slightly higher response to the random perturbation performed on day 4 , compared to a similar perturbation on day 2 (Figure 6-18).

The CO concentration parameter appeared sensitive to both the step increase and impulse in OLR (Figure 6-19). Once $\mathrm{CO}$ accumulated, it took an average of 10 hours to return to the initial level. On day 4 (68-91 hours), during the repeated random perturbations, the $\mathrm{CO}$ concentration remained relatively stable at a 
level of $400 \mathrm{ppb}$. The initial CO concentration was $500 \mathrm{ppb}$, higher than the expected level of $200 \mathrm{ppb}$. This may be the result of the system being exposed to air when a gas reservoir was installed and a gas valve replaced prior to initiating the experiment.
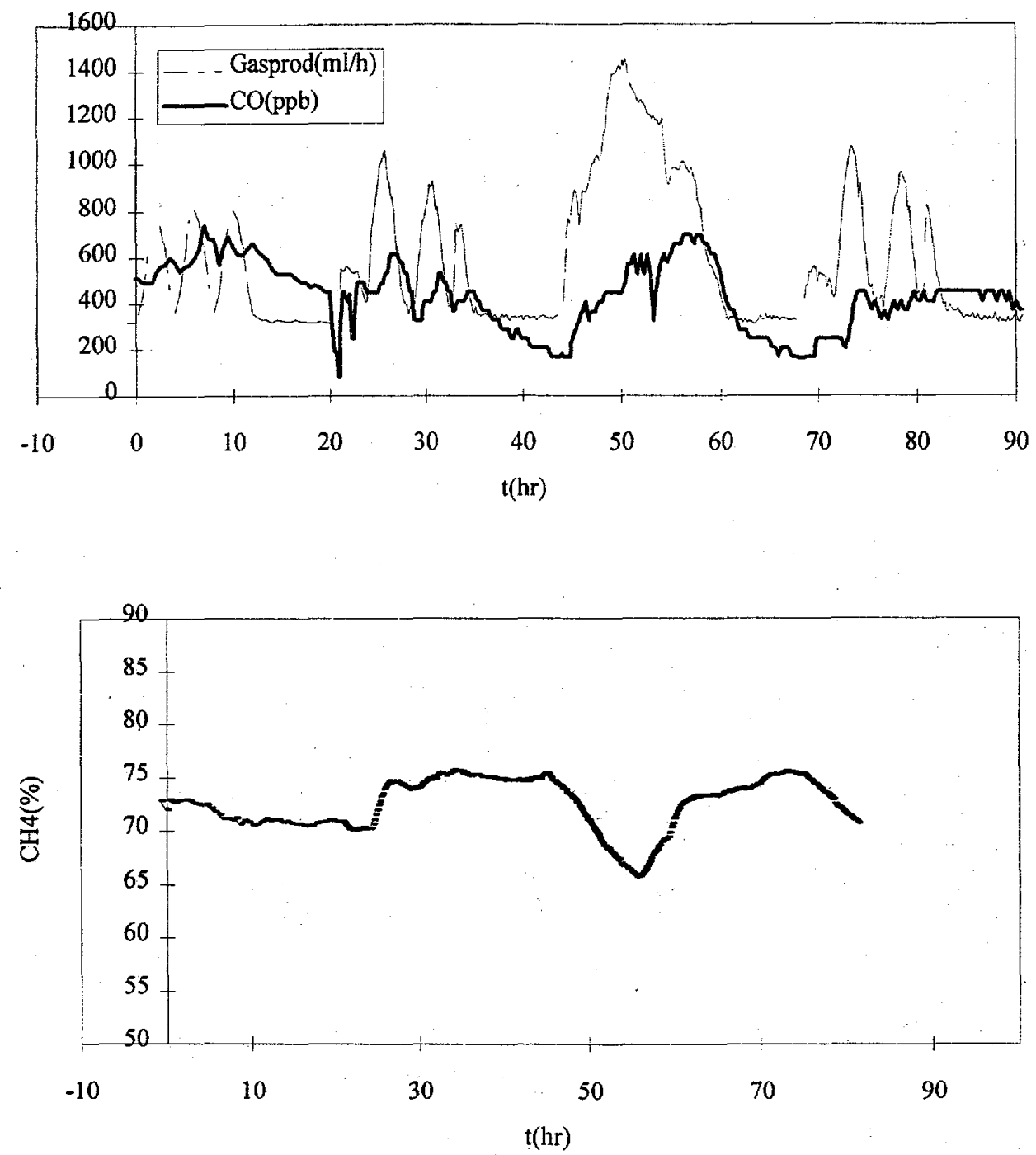

Figure 6-19. Gas production rate, $\mathrm{CO}$ and methane content during OLR variation experiments (OLR:10-104 kg COD/m ${ }^{3}-\mathrm{d}$ ).

The effluent VFA did not have any strong response to the OLR during the low strength perturbations of days 1, 2, and 4 (0-44 hours and 68-91 hours.; Figure 6-20). On day 3, however, the high level OLR variation resulted in significant accumulation of acetate, propionate, COD and higher molecular weight VFAs including iso-valerate, $n$-valerate, iso-butyrate, n-butyrate and 2-methyl-butyrate (Figures 6-20 and 6-21). A mass balance performed on the system showed that the majority of effluent-soluble COD came 

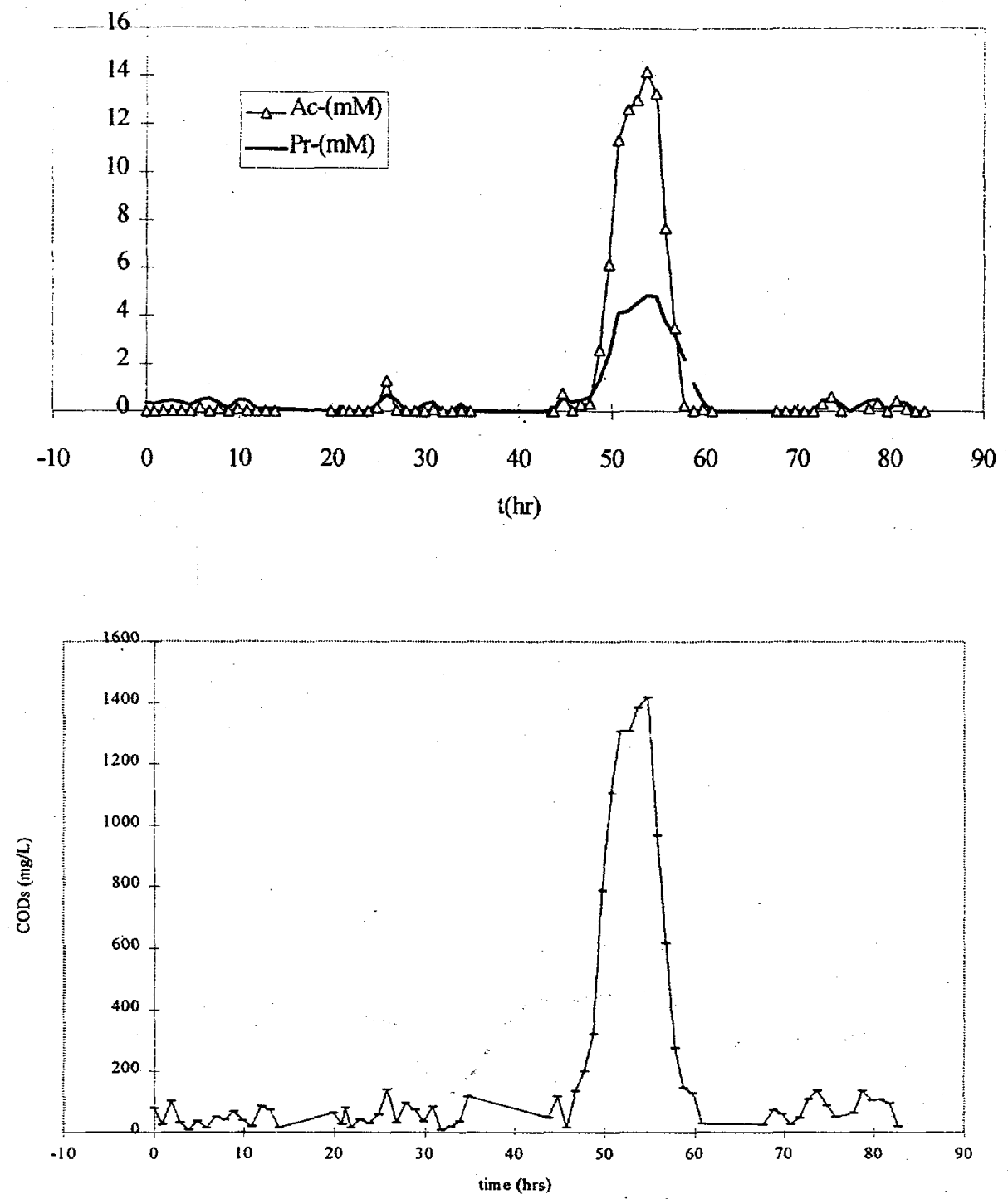

Figure 6-20. Acetate, propionate and soluble COD during OLR variation experiment (OLR:10-104 kg COD/m ${ }^{3}$-d).

from acetate and propionate (Figure 6-22). VFAs began to accumulate significantly when the OLR was increased from $30 \mathrm{~kg} \mathrm{COD} / \mathrm{m}^{3}-\mathrm{d}$ to $60 \mathrm{~kg} \mathrm{COD} / \mathrm{m}^{3}-\mathrm{d}$, during the third perturbation. The VFA concentration continued to increase even when the OLR was decreased down to $50 \mathrm{~kg} \mathrm{COD} / \mathrm{m}^{3}-\mathrm{d}$, indicating that the acetoclastic methanogens were unable to keep pace with acetate production. Acetate and propionate reached peak concentrations of $14 \mathrm{mM}$ and $5 \mathrm{mM}$ (COD of $1450 \mathrm{mg} / \mathrm{L}$ ), respectively, by 54 hours. VFAs with 4-5-carbons such as butyrate, iso-butyrate, 2-methyl-butyrate, valerate, and iso-valerate were detected when acetate and propionate concentrations were high (Figure 6-21). Once the perturbation was stopped (OLR decreased back to $10 \mathrm{~kg} \mathrm{COD} / \mathrm{m}^{3}-\mathrm{d}$ ), the concentrations of VFAs decreased. 

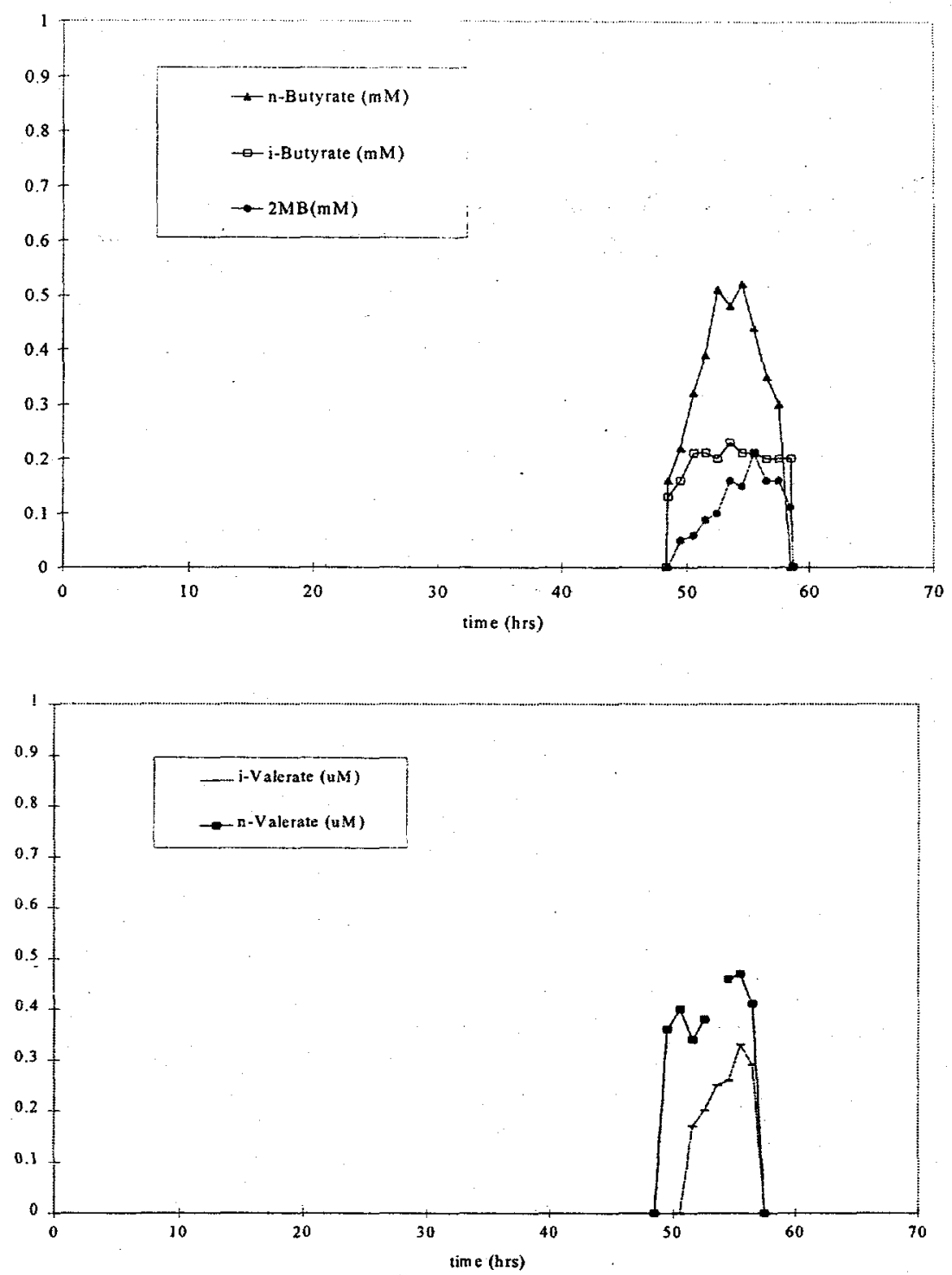

Figure 6-21. Four and five-carbon compounds measured during OLR variation experiment (OLR:10-104 kg COD/m $\mathrm{m}^{3}-\mathrm{d}$ ).

Methane content, $\mathrm{pH}$ and suspended solids exhibited weak response during the first and second OLR perturbations (0-44 hours; Figures 6-20 and 6-22). Under the high-strength OLR perturbation of day 3 (44-68 hours), methane content decreased continuously from $75 \%$ to $65 \%$ over 10 hours until the perturbation was stopped. The $\mathrm{pH}$ declined from 7.0 to 6.2 , during this period. Methane content and $\mathrm{pH}$ recovered after 10 and 5 hours, respectively. The random variation repeated on day 4 (68-91 hours) had a stronger impact on these variables. Methane concentration decreased by $5 \%$ during this period, compared to during the identical random variation of day 2 (20-44 hours) when methane remained quite stable $(75 \%)$. The $\mathrm{pH}$ decreased to a lower level and remained at that level longer than during the first random variation. 

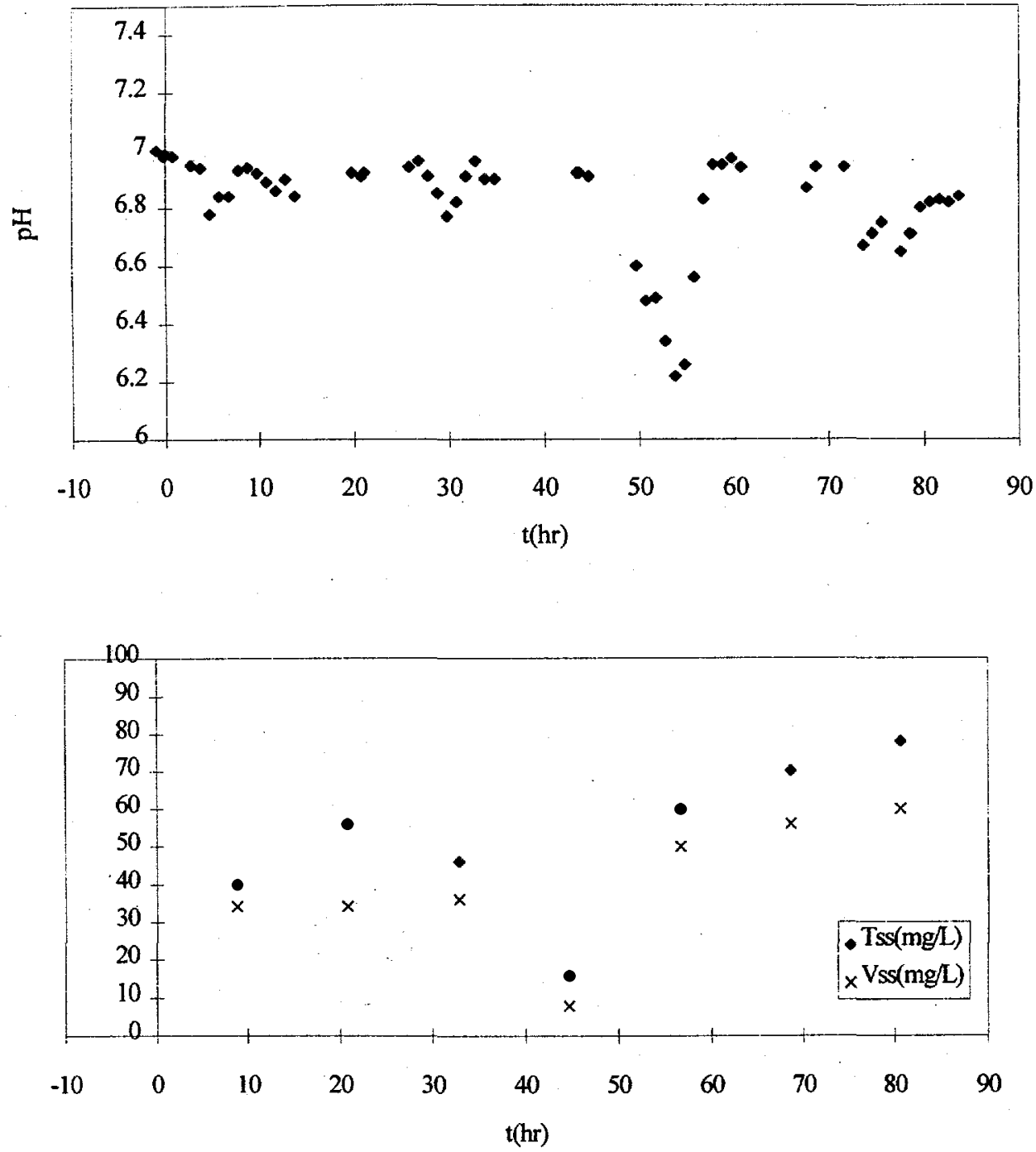

Figure 6-22. $\mathrm{pH}$, total suspended solids (TSS), and volatile suspended solids (VSS) during OLR variation experiments (OLR:10-104 kg COD/m ${ }^{3}-\mathrm{d}$ ).

The response observed for suspended solids was again the slowest and the most insensitive to OLR variation. A slight increase in both total suspended solids (TSS) and VSS, both below $100 \mathrm{mg} / \mathrm{L}$ level, was observed during the experiment. The VSS/TSS ratio was 0.8 , indicating the TSS was essentially all biological in nature. The granular sludge bed was stable throughout the four-day period. Breakdown of the granules and appearance of flocs within the bench-scale UASB was observed about two weeks after the conclusion of this experiment. Whether this was related to the perturbation experiment is not clear.

The perturbations due to regular and random variations at low OLR levels during the initial two days were insufficient to significantly perturb system performance as judged by accumulation of effluent VFAs. The 
strong random variation performed during day 3 (44-68 hours) did result in a significant response, reflected by the accumulation of effluent acetate and propionate ( $>10 \mathrm{mM}$ and $5 \mathrm{mM}$, respectively; Figure 6-20). Effluent COD accumulation (1450 mg/L; Figure 6-20) as well as the appearance of four and five-carbon compounds (Figure 6-22) was also observed. Gas production, methane concentration, and pH all decreased (Figures 6-18, 6-19 and 6-21). These results demonstrated that a high strength OLR (i.e., 50-60 $\mathrm{kg} \mathrm{COD} / \mathrm{m}^{3}-\mathrm{d}$ ) perturbation applied to a UASB reactor for more than 6 hours had a pronounced effect on the system. If continued, this OLR could lead to system failure.

The random variation performed on day 4 after the strong disturbance on the system had a greater effect on methane, $\mathrm{pH}, \mathrm{CO}$, and $\mathrm{H}_{2}$ than the same variation performed on day 2 (Figures 6-18 and 6-19). Gas production, effluent VFA, and COD did not significantly differ between days 2 and 4 . Results suggested that impulse, random, and regular variation at low OLR had relatively weak impact on system performance, while step increases at high strength and longer duration could perturb the system significantly.

\section{OLR variation at $10,30,40,50,60 \mathrm{~kg} \mathrm{COD} / \mathrm{m}^{3}-\mathrm{d}$ (USS4).}

An unsteady state OLR regular variation experiment was performed (a repeat of the perturbation used during day 3 of USS3, previous experiment, but with an increased duration of each step). The purpose was to examine the maximum OLR level that the system could tolerate, system recovery, and the response of system variables. The OLR was increased from 10 to $30,40,50$, and $60 \mathrm{~kg} \mathrm{COD} / \mathrm{m}^{3}-\mathrm{d}$ (Figure 6-23). The HRT was varied from 11 to 5.3 hours (Figure 6-23). The duration of each step was 24 hours (increased from 3 hours used for the prior experiment).

Initial results are shown in Figures 6-23 through 6-27. Performance of the bench-scale UASB reactor was markedly affected by the increased duration and strength of the OLR step increases used in this experiment. The $\mathrm{H}_{2}$ concentration increased to over $1000 \mathrm{ppm}$ after 60 hours from a starting value of 200 ppm; the $\mathrm{pH}$ concurrently decreased to 5.2 from 7.0, VFAs accumulated, and gas production rate decreased at an OLR of $60 \mathrm{~kg} \mathrm{COD} / \mathrm{m}^{3}$-d. The methane content decreased from $83 \%$ to $75 \%$ during this period. The presence of 3-, 4-, and 5-carbon and higher-molecular weight compounds, such as butyrate, valerate, 2-methyl-butyrate, propanol, and ethanol was observed. The duration of the step down from 60 to $50 \mathrm{~kg}$ $\mathrm{COD} / \mathrm{m}^{3}-\mathrm{d}$ was cut short because of imminent reactor failure. Two hours after the decrease in OLR to 50 $\mathrm{kg} \mathrm{COD} / \mathrm{m}^{3}-\mathrm{d}(\mathrm{t}=72-74$ hours. $)$, the gas production rate continued to decrease while VFAs continued to accumulate; $\mathrm{H}_{2}$ (g) remained at $>1000 \mathrm{ppm}$ and the $\mathrm{pH}$ continued to decline. To observe the system recovery, the shock loading was terminated by reducing the OLR to the initial $10 \mathrm{~kg} \mathrm{COD} / \mathrm{m}^{3}-\mathrm{d}$ level (at $\mathrm{t}$ 
$=75$ hours). Most monitoring variables, including $\mathrm{H}_{2}, \mathrm{CO}$, gas production rate, $\mathrm{pH}$, and VFAs returned to near-steady state levels within the next 10-20 hours.
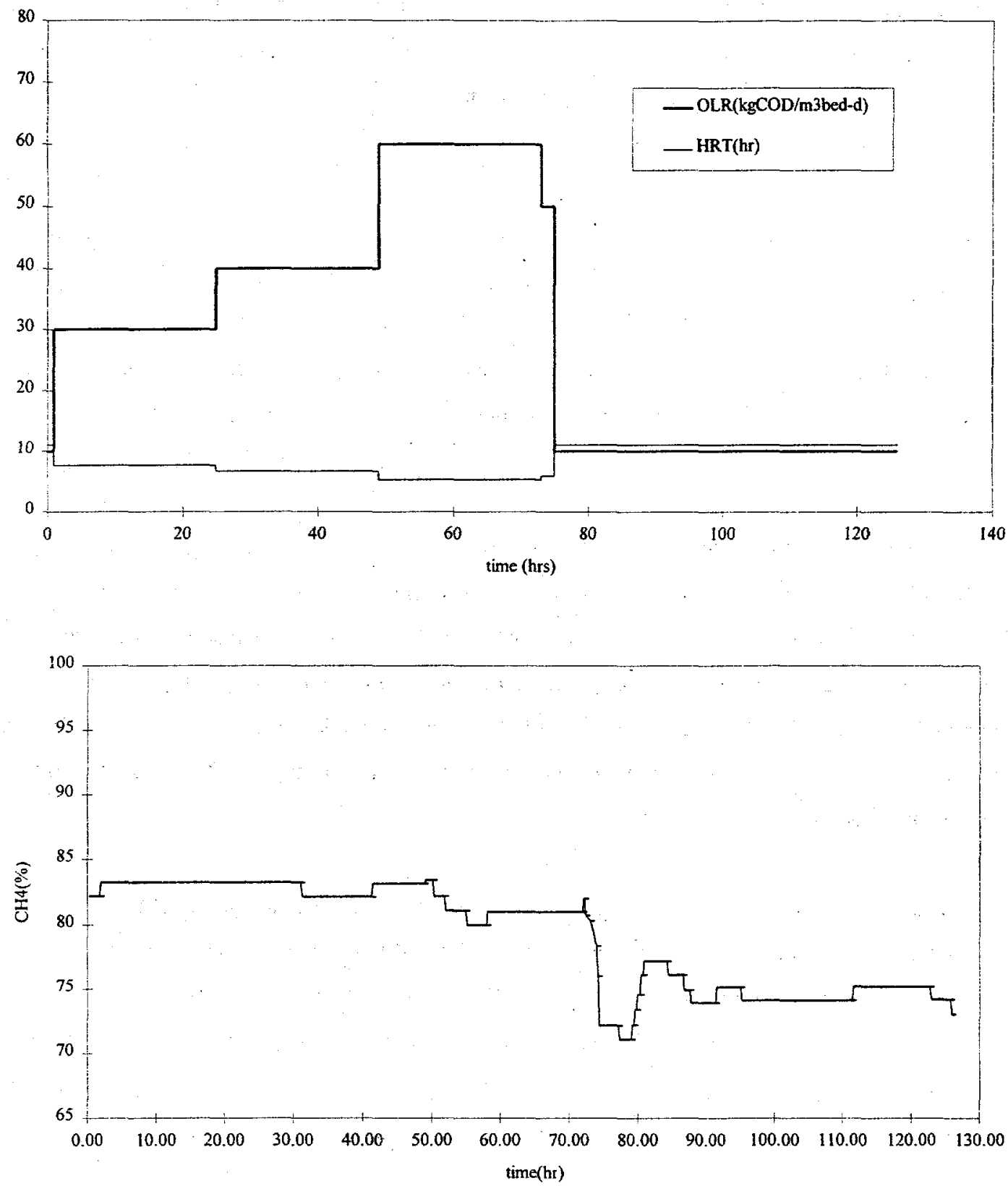

Figure 6-23. Applied OLR and HRT and reactor methane content variation during loading experiment (OLR:10-104 kg COD/m ${ }^{3}-\mathrm{d}$ ). 

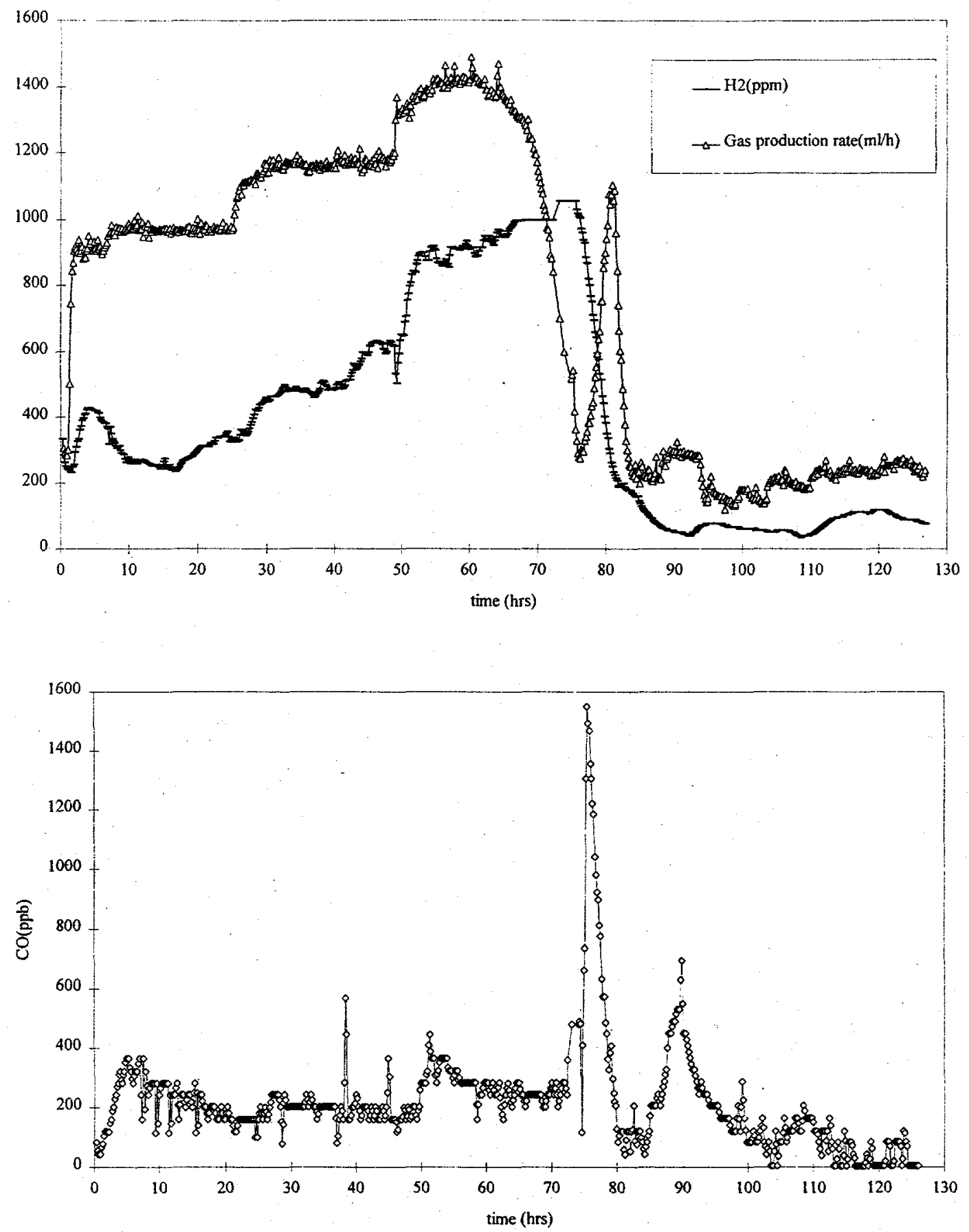

Figure 6-24. Gas production rate, $\mathrm{H}_{2}$ and $\mathrm{CO}$ responses during $\mathrm{OLR}$ variation experiments (OLR:10-60 kg COD/m ${ }^{3}-d$ ). 

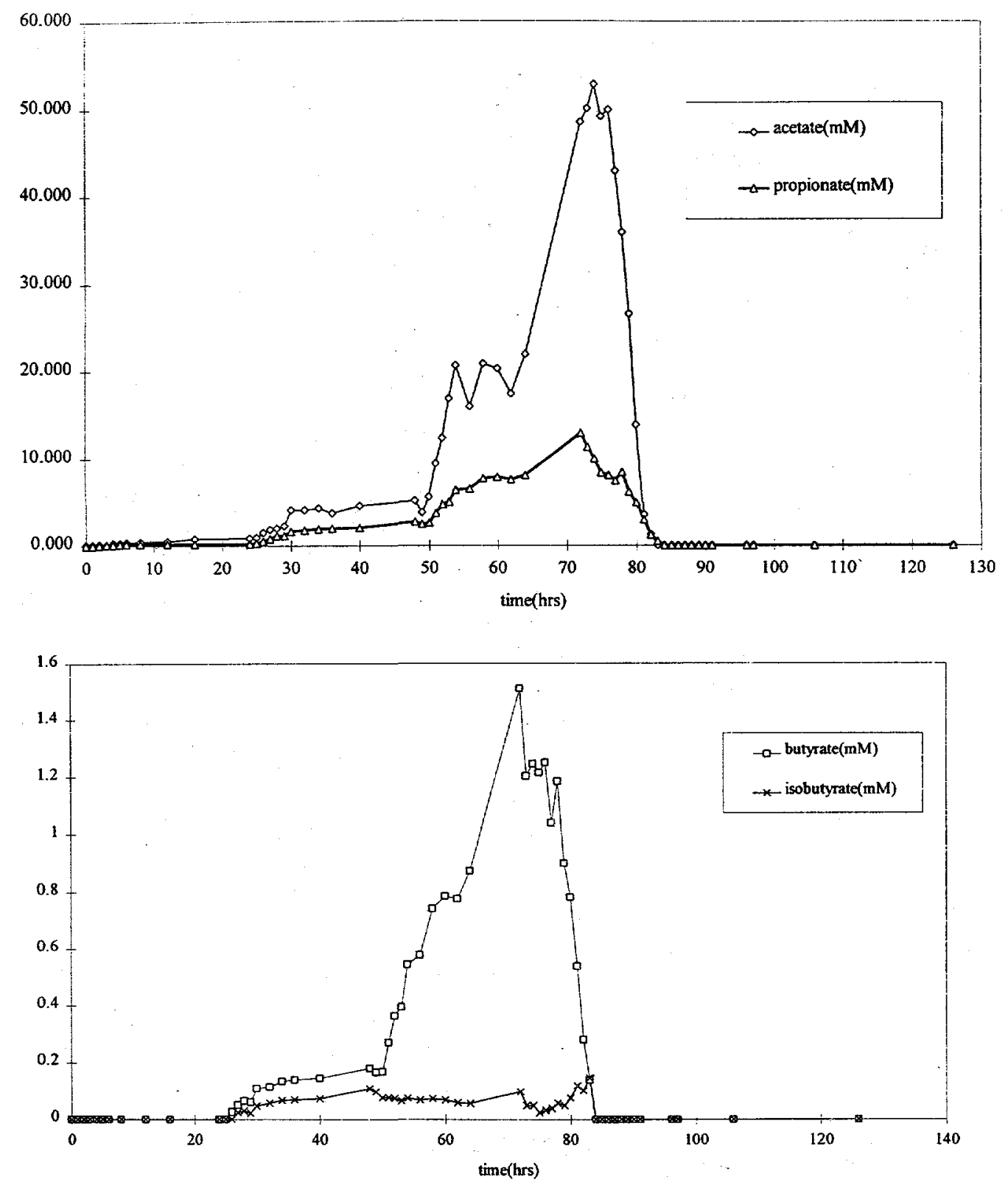

Figure 6-25. Acetate, propionate, butyrate, and isobutyrate during OLR variation experiment (OLR:10-60 kg COD/m $\left.{ }^{3}-\mathrm{d}\right)$.

The pattern of the gas production rate mirrored the changes in OLR during the first and second OLR steps (30 and $40 \mathrm{~kg} \mathrm{COD} / \mathrm{m}^{3}-\mathrm{d}$ ) and remained at $1.0 \mathrm{~L} / \mathrm{h}$ and $1.18 \mathrm{~L} / \mathrm{h}$, respectively (Figure 6-24). When the OLR was set to $60 \mathrm{~kg} \mathrm{COD} / \mathrm{m}^{3}-\mathrm{d}$, the gas production rate initially increased to $1.4 \mathrm{~L} / \mathrm{h}$ and then began to decline. This decrease in gas production even continued 3 hours after the OLR was reduced to the original OLR of $10 \mathrm{~kg} \mathrm{COD} / \mathrm{m}^{3}-\mathrm{d}$. Gas production peaked again at $\mathrm{t}=81$ hours due to the consumption of 
accumulated VFAs, ethanol, and propanol. It took 20 hours for the gas production rate to return to the background level at an OLR of $10 \mathrm{~kg} \mathrm{COD} / \mathrm{m}^{3}-\mathrm{d}$.
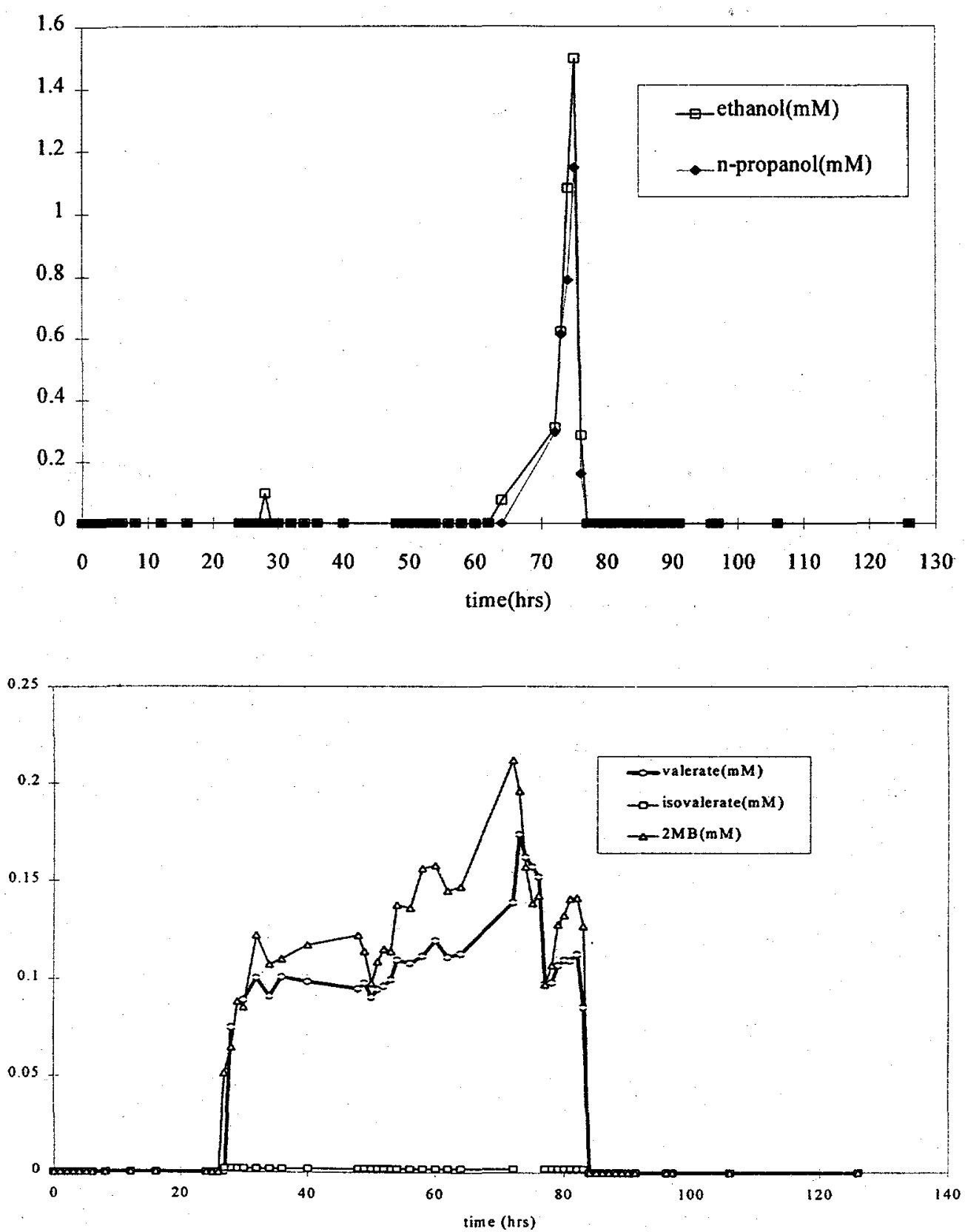

Figure 6-26. Ethanol, n-propanol, valerate, isovalerate, and 2-methyl-butyrate during OLR variation experiments (OLR:10-60 kg COD/m $\mathrm{m}^{3}-\mathrm{d}$ ); $2 \mathrm{MB}$ : 2-methyl-butyrate. 


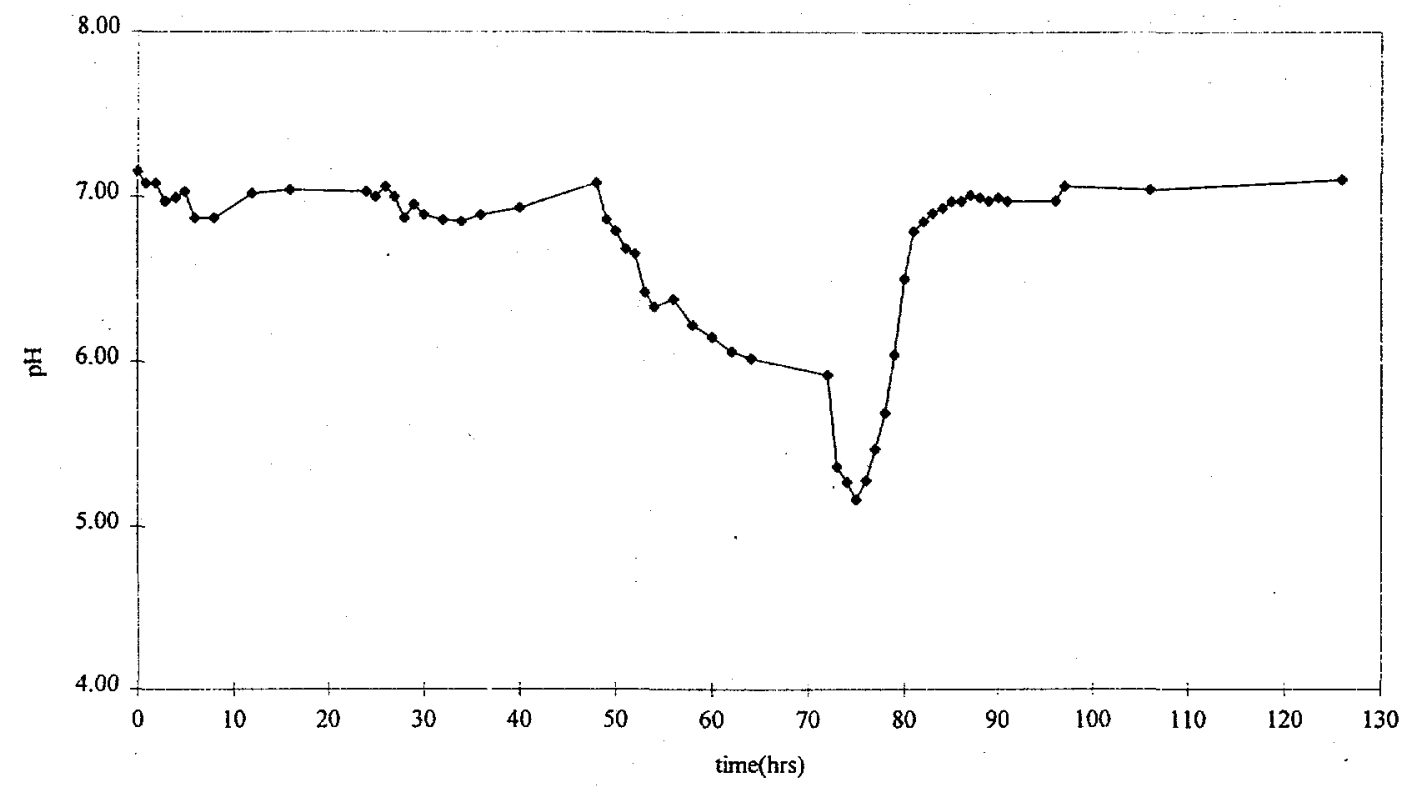

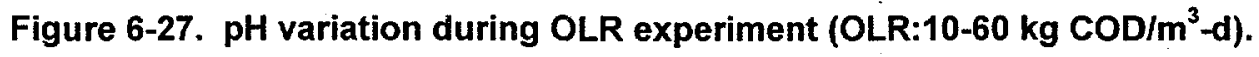

$\mathrm{H}_{2}$ tracked the changes in OLR (and GP) reasonably well (Figure 6-24). Yhe $\mathrm{H}_{2}$ concentration reached $1000 \mathrm{ppm}$ when the OLR was increased to $60 \mathrm{~kg} \mathrm{COD} / \mathrm{m}^{3}-\mathrm{d}$. Two hours after the OLR was reduced to 10 $\mathrm{kg} \mathrm{COD} / \mathrm{m}^{3}-\mathrm{d}$, the $\mathrm{H}_{2}$ concentration started to decrease. It took 12 hours for the $\mathrm{H}_{2}$ (g) concentration to return to background levels. The response pattern of $\mathrm{H}_{2}$ was different from that of gas production rate during the period between 65 and 95 hours, when the system was near failure, the decrease in OLR and during recovery hours 72 and $74 . \mathrm{H}_{2}$ concentration decreased rapidly in concert with the decrease in OLR; gas production did not.

It appeared that $\mathrm{CO}$ increased in response to each increase in OLR imposed on the system and then stabilized at a certain level. Headspace CO increased initially and then stabilized at $200 \mathrm{ppb}$ for the first and second steps ( 30 and $40 \mathrm{~kg} \mathrm{COD} / \mathrm{m}^{3}$-d; Figure 6-24). The CO concentration reached $300 \mathrm{ppb}$ when the OLR was increased to $60 \mathrm{~kg} \mathrm{COD} / \mathrm{m}^{3}$-d. During the system recovery, CO peaked at 75 hours (c. 1600 ppb), similar to when peak concentration of ethanol and n-propanol were observed. CO had greater fluctuation during the recovery period than the OLR step increase period. It took 20 hours for CO to return to background levels after a secondary peak at 90 hours which was apparently not related to any of the variables measured during the experiment.

Methane was the slowest of the gaseous components measured in responding to the perturbation. The OLR step increases to 30 and $40 \mathrm{~kg} \mathrm{COD} / \mathrm{m}^{3}-\mathrm{d}$ did not cause any change in methane content. Methane content 
was reduced by $3 \%$ by the end of $60 \mathrm{~kg} \mathrm{COD} / \mathrm{m}^{3}$-d shock loading. A significant decrease and then rapid increase of methane content to $70 \%$ and $78 \%$ were observed after the decrease in OLR to $10 \mathrm{~kg} \mathrm{COD} / \mathrm{m}^{3}-\mathrm{d}$ (77-81 hours). A new level of $76 \%$ in methane content was established $t=95$ hours. Return of methane content to the original (pre-shock) level did not occur until 2 weeks later.

Ethanol and n-propanol were the major alcohol components found in the effluent (Figure 6-26). Ethanol and n-propanol had almost identical response curves. Their concentrations reached peak values $(1.5 \mathrm{mM}$ and $1.2 \mathrm{mM}$, respectively) at the 73-hour mark when the reactor system approached failure. The concentration of these alcohols decreased immediately after the OLR was decreased. Ethanol was one of the major substrates being fed to the system. Its accumulation is likely due to kinetic and/or thermodynamic limitations. N-propanol was not fed to the system, but appears to have been produced under the perturbation conditions.

Most higher-molecular-weight acids (with the exception of iso-butyrate and iso-valerate) exhibited similar response patterns during the second and third steps of OLR increase and during recovery. All VFAs measured appeared in the effluent during the second step OLR increase and disappeared at the 81- to 82hour mark. Acetate concentration increased in accordance with OLR (Figure 6-25) after the first step. After an initial increase at the second step in OLR, acetate concentration stabilized at $4 \mathrm{mM}$ (from 30-48 hours). The third step in OLR resulted in acetate reaching a concentration of $20 \mathrm{mM}$. Fourteen hours after operation at this OLR of $60 \mathrm{~kg} \mathrm{COD} / \mathrm{m}^{3}-\mathrm{d}$ (62 hours), a rapid increase in acetate concentration was observed. When the OLR was reduced to $10 \mathrm{~kg} \mathrm{COD} / \mathrm{m}^{3}-\mathrm{d}$, the acetate concentration decreased from 55 $\mathrm{mM}$ to $0.1 \mathrm{mM}$ in a period of 10 hours. The response of propionate was similar to that of acetate except that concentrations were lower (Figure 6-25). OLR increases to 40 and $60 \mathrm{~kg} \mathrm{COD} / \mathrm{m}^{3}-\mathrm{d}$ resulted in an increase in propionate concentration to $3 \mathrm{mM}$ and $8 \mathrm{mM}$, respectively. A peak of $10 \mathrm{mM}$ was observed at 72 hours. The reduction in propionate concentration was also rapid after the OLR was decreased. Propionate concentration decreased to its background level in less than 10 hours. Butyrate had the same pattern of variation as acetate (Figure 6-25) during the perturbation. An initial increase followed by a stable concentration during the second step in OLR of $40 \mathrm{~kg} \mathrm{COD} / \mathrm{m}^{3}-\mathrm{d}$. Butyrate reached $1.5 \mathrm{mM}$ at about 71 hours as system failure proceeded and it returned to background level in 7 hours once the perturbation was stopped. Iso-butyrate was not present at equal concentrations with butyrate when butyrate concentration exceeded $0.2 \mathrm{mM}$ (Figure 6-25). The variation in the five-carbon fatty acids (i.e., valerate, iso-valerate and 2-methyl-valerate) is presented in Figure 6-26. Valerate and 2-methyl-butyrate varied in similar patterns. Peaks of $0.2 \mathrm{mM}$ and $0.17 \mathrm{mM}$ (2-methyl-butyrate and valerate, respectively) was observed at 72 hours. 
Little variation in $\mathrm{pH}$ was observed during the first and second steps of OLR (Figure 6-27). During the 60 $\mathrm{kg} \mathrm{COD} / \mathrm{m}^{3}$-d OLR operational period, $\mathrm{pH}$ gradually decreased from 7.0 to 5.9 by 71 hours. A significant decrease of $\mathrm{pH}$ to 5.2 within three hours (71-74 hours) occurred, which signaled a system failure. Immediately after the shock loading was lifted, $\mathrm{pH}$ increased back to 7.0 in 10 hours.

Dissolved gas analyses were performed during the OLR perturbation for both $\mathrm{H}_{2}$ and $\mathrm{CO} . \mathrm{H}_{2}$ (l) had high fluctuations around a reasonably stable mean level (Figure 6-28). $\mathrm{H}_{2}$ (l) was observed to be less than $\mathrm{H}_{2}$ (l eq.) during the steady state operations and mass transfer of $\mathrm{H}_{2}$ from the gas to liquid appears to limit $\mathrm{H}_{2}$ (l) concentration. When $\mathrm{H}_{2}(\mathrm{~g})$ reached $1000 \mathrm{ppm}$, about 10 times steady state background level, for about 10 hours the concentration of $\mathrm{H}_{2}$ (1) did not accumulate (Figure 6-28). $\mathrm{CO}$ (1) had high noise (Figure 6-29) and apparently did not track the gas phase $\mathrm{CO}$ concentration well. Mass transfer was limited from the liquid to gas phase for $\mathrm{CO}$ at pseudo-steady state and most of the perturbation period here. However, during the system failure (72 to 80 hours), when $\mathrm{CO}(\mathrm{g})$ reached $1.5 \mathrm{ppm}, \mathrm{CO}$ (l) did not concurrently increase. There appears to be little correlation between the aqueous and gas phase concentrations of either $\mathrm{H}_{2}$ or $\mathrm{CO}$.

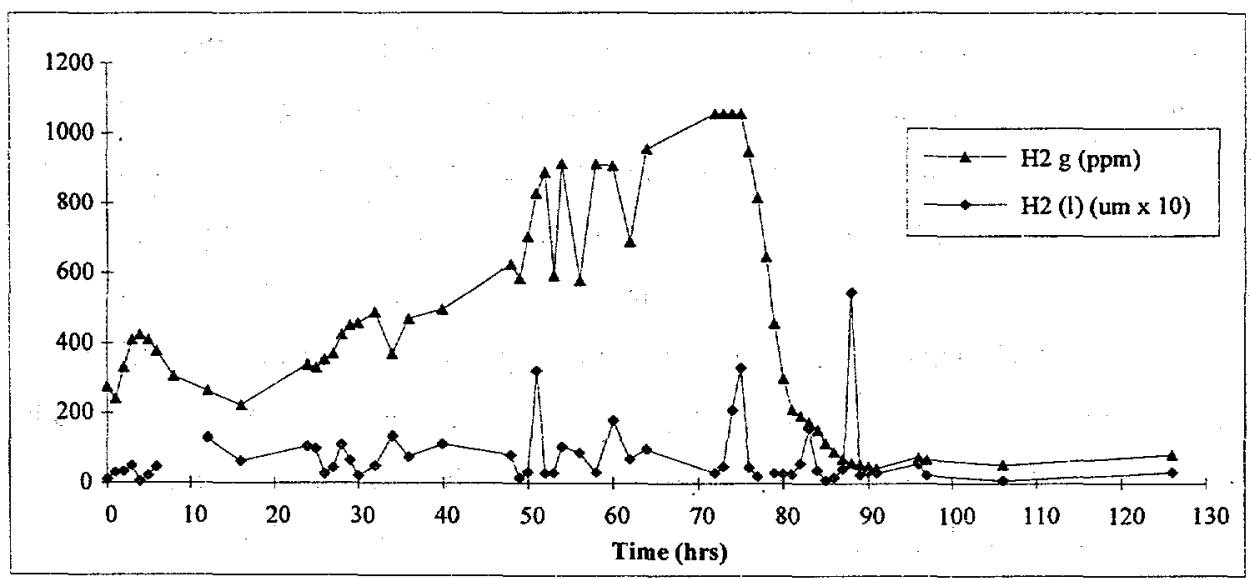

Figure 6-28. Headspace and dissolved $\mathrm{H}_{2}$ variation during OLR perturbation.

\section{UNSTEADY STATE OLR PERTURBATIONS AND SYSTEM RESPONSE - WITH PH}

\section{CONTROL}

\section{OLR Variation at $10,30,40,60,50 \mathrm{~kg} \mathrm{COD} / \mathrm{m}^{3}-\mathrm{d}$ (USS5).}

An experiment was conducted with $\mathrm{pH}$ control ( $\mathrm{pH}$ maintained between 6.8 and 7.0 via partial feed of sodium carbonate). The OLR pattern used was the same as employed in the previous experiment (USS4). One-day step increases in OLR from 10 to 30,40 , and $60 \mathrm{~kg} \mathrm{COD} / \mathrm{m}^{3}-\mathrm{d}$ followed by a step down to $50 \mathrm{~kg}$ $\mathrm{COD} / \mathrm{m}^{3}-\mathrm{d}$ for 5 hours and finally a return to $10 \mathrm{~kg} \mathrm{COD} / \mathrm{m}^{3}-\mathrm{d}$ (Figure 6-30) was used. 


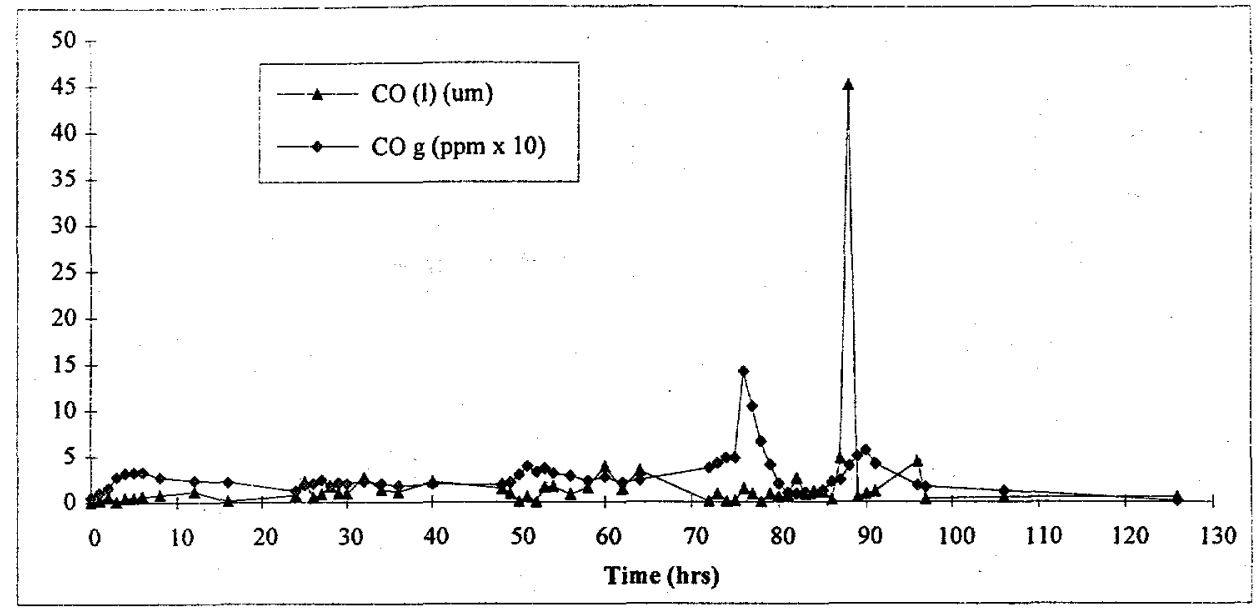

Figure 6-29. Headspace and dissolved $\mathrm{CO}$ during OLR perturbation.

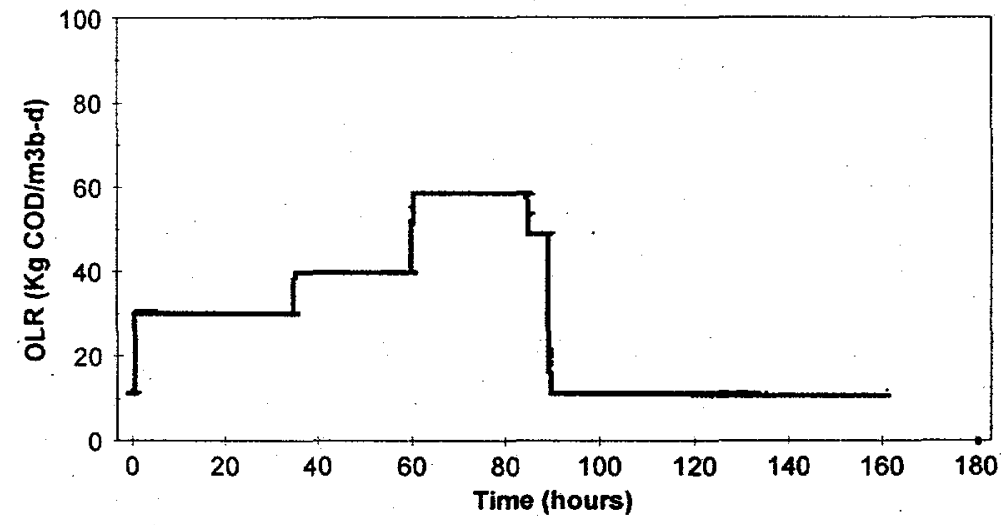

Figure 6-30. OLR variation during OLR shock loading.

Gas production rate increased commensurate with the first step increase in OLR (Figure 6-31). After the increases to 40 and $60 \mathrm{~kg} \mathrm{COD} / \mathrm{m}^{3}-\mathrm{d}$, however, the gas production increased to only $1270 \mathrm{~mL} / \mathrm{hr}$ or $66 \%$ of what would have been anticipated at $60 \mathrm{~kg} \mathrm{COD} / \mathrm{m}^{3}-\mathrm{d}$. After the OLR was decreased back to $10 \mathrm{~kg}$ $\mathrm{COD} / \mathrm{m}^{3}-\mathrm{d}$, the gas production rate gradually decreased to the baseline level in about one day and then remained at that level:

Methane content varied between 80 and $70 \%$, decreasing as VFAs accumulated in response to the step OLR increase (Figure 6-32). 


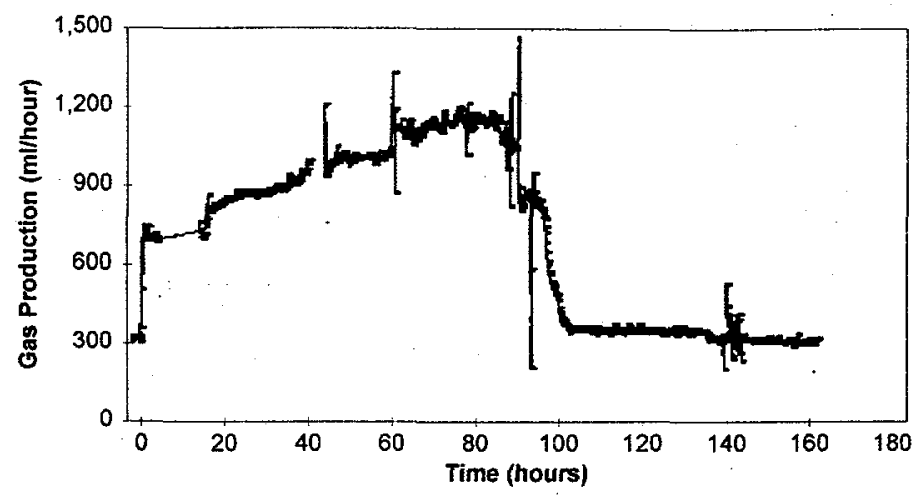

Figure 6-31. Gas production response during OLR shock loading.

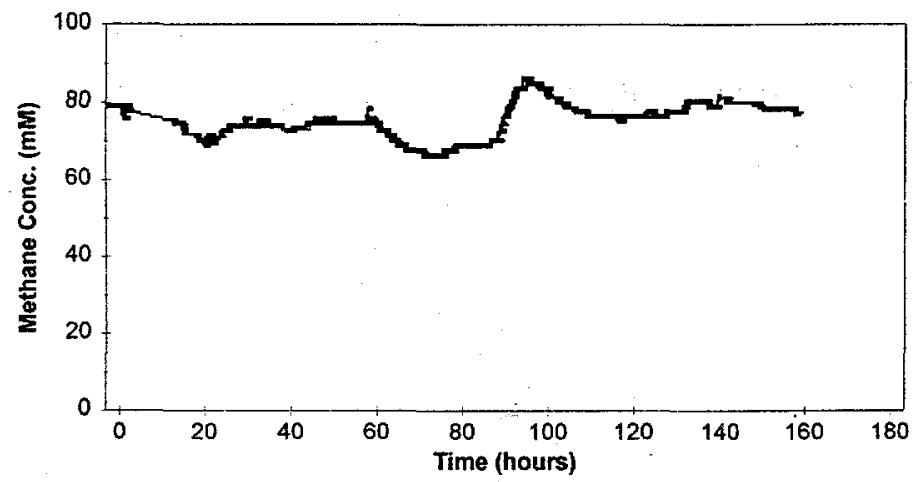

Figure 6-32. Methane content variation during OLR shock loading.

Acetate and propionate concentrations in the effluent increased in response to each step increase in OLR (Figure 6-33). Acetate concentrations peaked at close to $50 \mathrm{mM}$ and propionate at $14 \mathrm{mM}$ (one hour after the OLR was decreased back to $10 \mathrm{~kg} \mathrm{COD} / \mathrm{m}^{3-} \mathrm{d}$ ). Acetate was $42 \mathrm{mM}$ and propionate was $11.5 \mathrm{mM}$ at the final sample taken at an OLR of $60 \mathrm{~kg} \mathrm{COD} / \mathrm{m}^{3}$-d. This is virtually the same as observed during USS4 when there was no $\mathrm{pH}$ control. The accumulation of acetate is apparently not due to the decrease in $\mathrm{pH}$ during USS4.

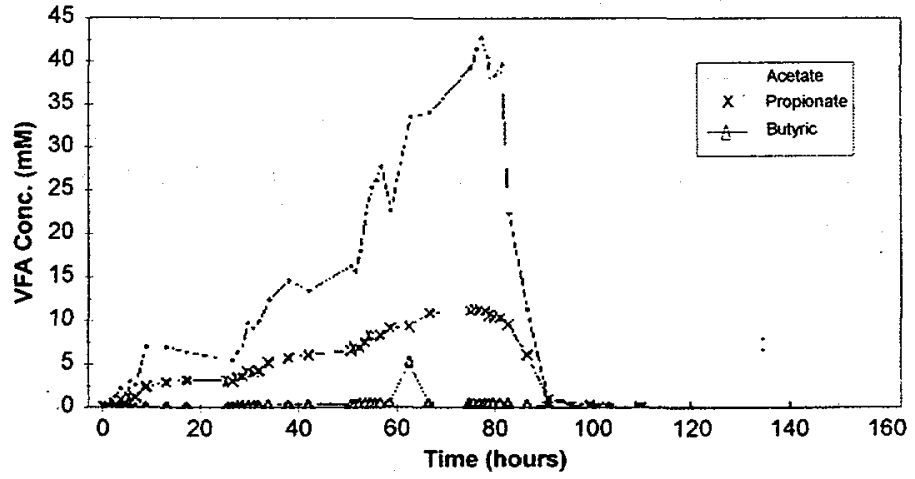

Figure 6-33. VFA concentration during shock loading experiment. 
This leads to an interesting question of what is an OLR failure. During the peak OLR, the COD removal was quite low, c. $57 \%$, but upon reduction of the OLR to $10 \mathrm{~kg} \mathrm{COD} / \mathrm{m}^{3}-\mathrm{d}$ the system quickly returned to normal operation when $\mathrm{pH}$ control was exercised. The system here recovered more quickly than when a similar step load experiment was conducted without $\mathrm{pH}$ control. In order to determine failure, it was necessary to pick an operational definition. A COD removal efficiency of $75 \%$ was arbitrarily selected. Based on this definition, the system can be seen to be at failure during the $60 \mathrm{~kg} \mathrm{COD} / \mathrm{m}^{3}-\mathrm{d}$ step OLR increase.

The response of trace gases $\mathrm{CO}$ and $\mathrm{H}_{2}$ was different during this run compared to prior experiments without $\mathrm{pH}$ control. Hydrogen increased in a similar fashion, but a little more quickly, during the OLR step of $40 \mathrm{~kg} \mathrm{COD} / \mathrm{m}^{3}-\mathrm{d}$ (Figure 6-34). CO remained near normal levels (Figure 6-35) just as during experiment USS4. When the OLR was increased to $60 \mathrm{~kg} \mathrm{COD} / \mathrm{m}^{3}-\mathrm{d}, \mathrm{H}_{2}$ increased from c. 900 to 1200 $\mathrm{ppm}$. The concentration of $\mathrm{CO}$ during this 24 -hour step increase in OLR rose continually from c. 300 to $1600 \mathrm{ppb}$, in contrast to USS 4 when CO concentration remained at near $400 \mathrm{ppb}$.

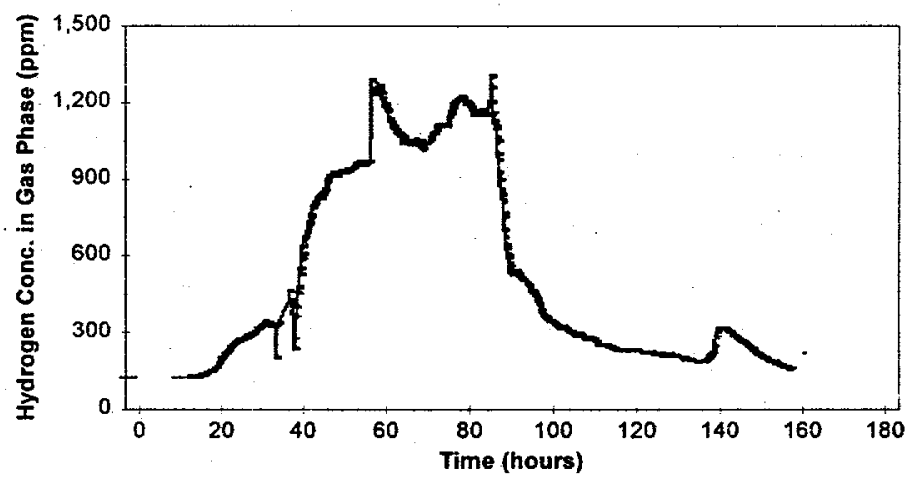

Figure 6-34. Hydrogen variation during OLR shock loading.

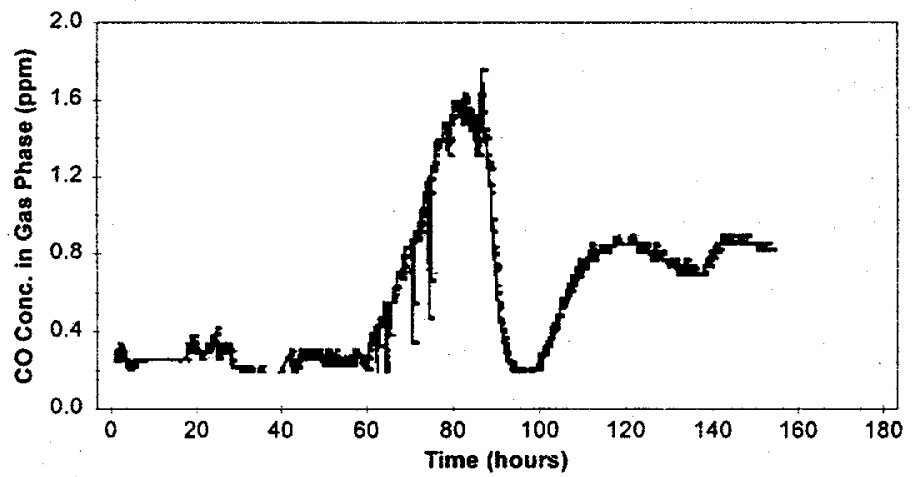

Figure 6-35. CO response during OLR shock loading. 
A constant $\mathrm{pH}$ of c. 6.9 was maintained during the OLR increase due to alkali addition. When the OLR was decreased to $10 \mathrm{~kg} \mathrm{COD} / \mathrm{m}^{3}-\mathrm{d}$, the degradation of accumulated acetate and propionate resulted in recovery of alkalinity that had been titrated by the produced VFAs and a corresponding increase in $\mathrm{pH}$ up to c. 7.4 (Figure 6-36).

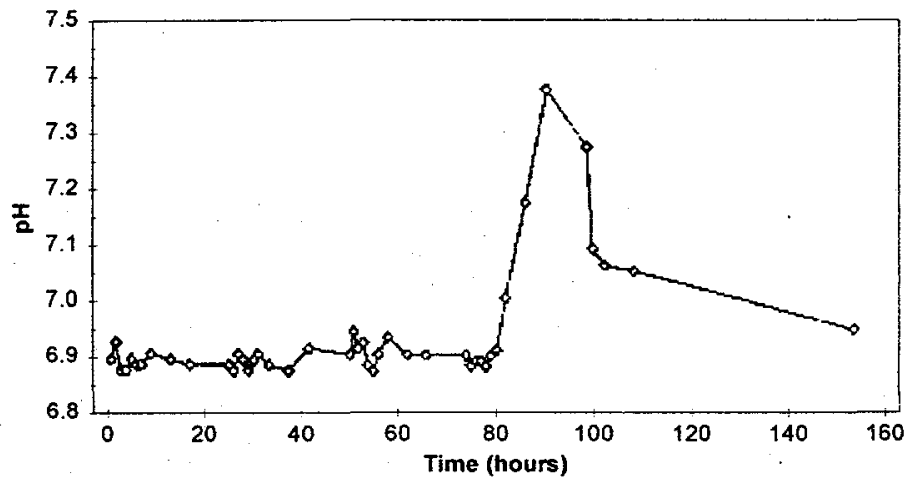

Figure 6-36. pH response during shock loading experiment.

\section{OLR Variation at $10,40,60 \mathrm{~kg} \mathrm{COD} / \mathrm{m}^{3}-\mathrm{d}$ (USS6)}

An OLR step variation was imposed on a second bench-scale reactor, which has a similar configuration to the one used in USS5, a total volume of 3.8 liters, and granular bed volume of 1.4 liters. The reactor had been operated at an OLR of $10 \mathrm{~kg} \mathrm{COD} / \mathrm{m}^{3}-\mathrm{d}$ and HRT of 12 hours for about a month before this perturbation study was initiated. The feed to the reactor was a synthetic brewery waste, the same composition as used in all previous UASB reactor experiments. The experiment was run using $\mathrm{pH}$ control ( $\mathrm{pH}=6.8$ to 7.0) using sodium bicarbonate as the alkalinity source. Gas phase $\mathrm{H}_{2}$ and $\mathrm{CO}$, gas production rate, $\mathrm{pH}$, and effluent VFAs and alcohols were measured during the course of this experiment. The OLR was increased from the base level of 10 to 40 and then $60 \mathrm{~kg} \mathrm{COD} / \mathrm{m} 3-\mathrm{d}$. Each OLR was maintained for 24 hours, as shown in Figure 6-37 ( $t=5$ to $t=53$ hours). At the 53-hour mark, the response of $\mathrm{H}_{2}$ was so high that it exceeded the linear range of the Trace Gas Analyzer. The feed was stopped for 40 minutes before being reduced to an OLR of $10 \mathrm{~kg} \mathrm{COD} / \mathrm{m}^{3}-\mathrm{d}$. Based on a mass balance, the total COD removal at 52 hours (OLR $60 \mathrm{~kg} \mathrm{COD} / \mathrm{m}^{3}-\mathrm{d}$ ) was $60 \%$. 


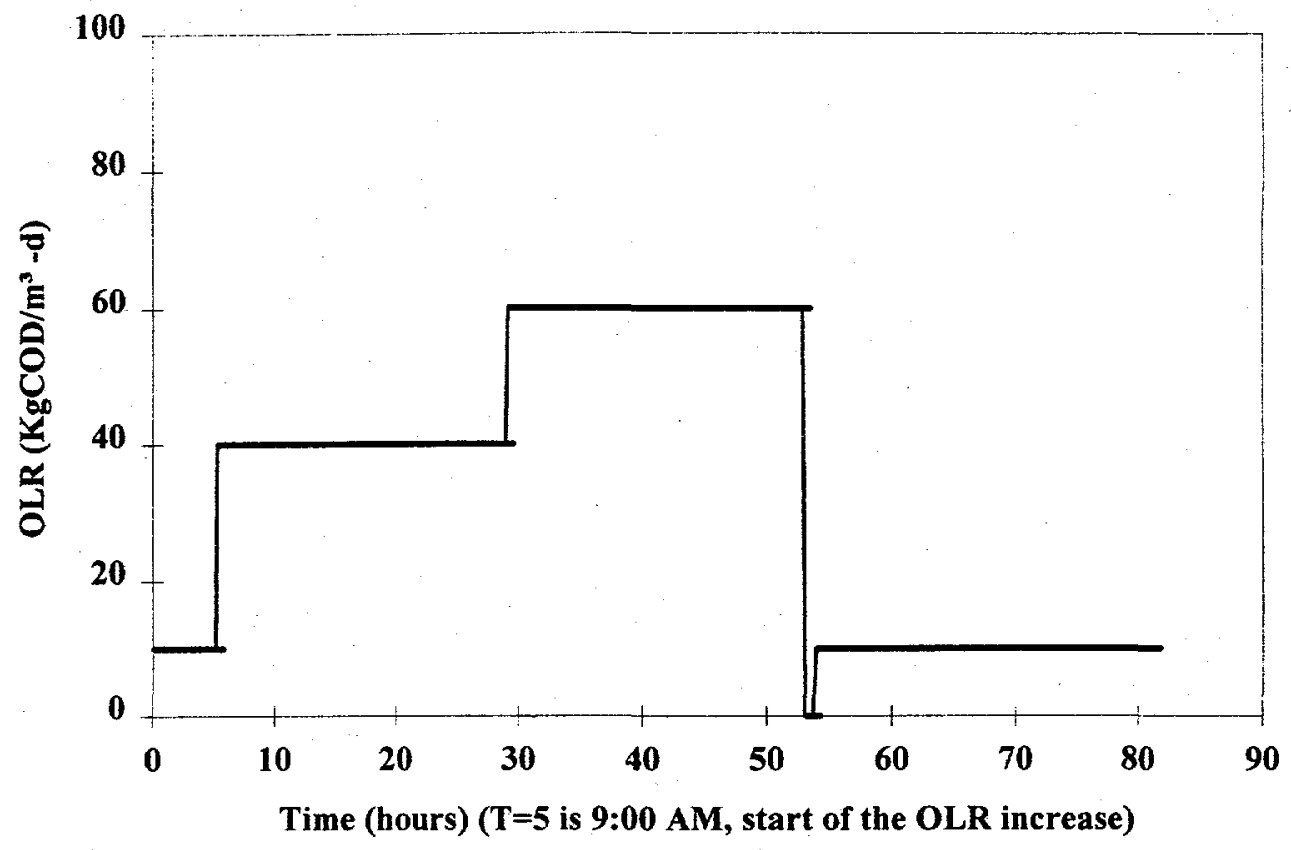

Figure 6-37. OLR variation during OLR shock loading (5/23/94).

Gas production increased rapidly in response to step OLR increases (Figure 6-38). The gas production rate (GP) was $1000 \mathrm{~mL} / \mathrm{h}$ after about five hours at an OLR of $40 \mathrm{~kg} \mathrm{COD} / \mathrm{m}^{3}$-d. Twelve hours later, the GP decreased to $800 \mathrm{ml} / \mathrm{h}$. During the rest of the OLR increase period $\left(40 \mathrm{~kg} \mathrm{COD} / \mathrm{m}^{3}-\mathrm{d}\right.$ and $60 \mathrm{~kg}$ $\mathrm{COD} / \mathrm{m}^{3}$-d, from 20 hours to 52 hours), gas production remained at $800 \mathrm{~mL} / \mathrm{h}$ with little variation. The GP declined soon after the OLR increase was stopped. GP returned to the background level at 70 hours, 18 hours after the OLR was returned to $10 \mathrm{~kg} \mathrm{COD} / \mathrm{m}^{3}-\mathrm{d}$. The continued elevated gas production rate is primarily due to degradation of alcohols and VFAs that accumulated during the perturbation period. The on-line gas counting equipment was not functioning during the experiment. The gas production was, therefore, manually recorded during the experiment. Gas production at an OLR of $60 \mathrm{~kg} \mathrm{COD} / \mathrm{m}^{3}-\mathrm{d}$ level was $57 \%$ of total expected value, assuming $100 \%$ conversion of input soluble COD.

The variations in methane and $\mathrm{pH}$ are shown in Figures 6-39 and 6-40. Methane content decreased from $84 \%$ to $72 \%$ and remained at that level during the shock loading. Methane concentration increased rapidly to $86 \%$ after the OLR was reduced. Changes in methane concentration were gradual and relatively smooth. 


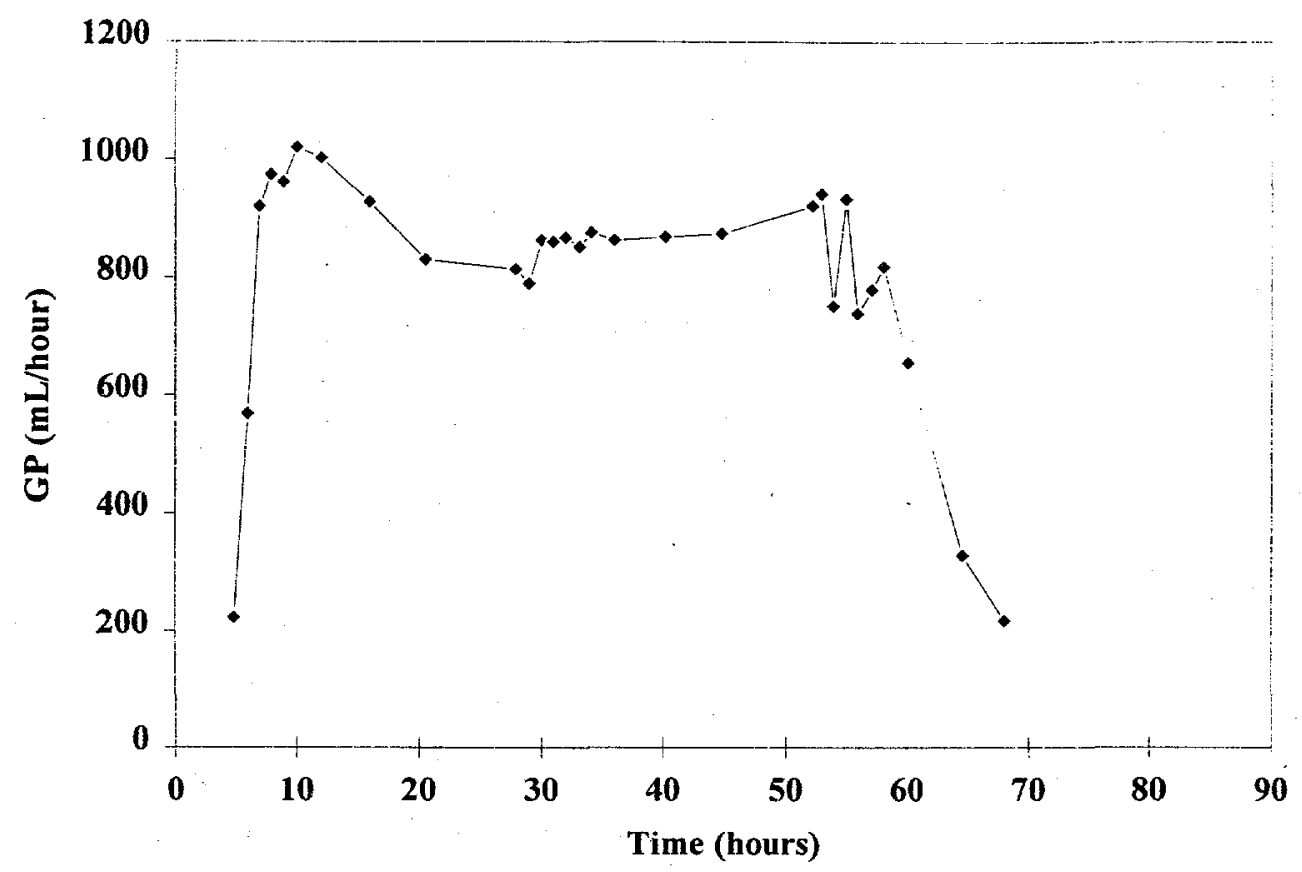

Figure 6-38. Gas production response during shock loading experiment (5/23/94).

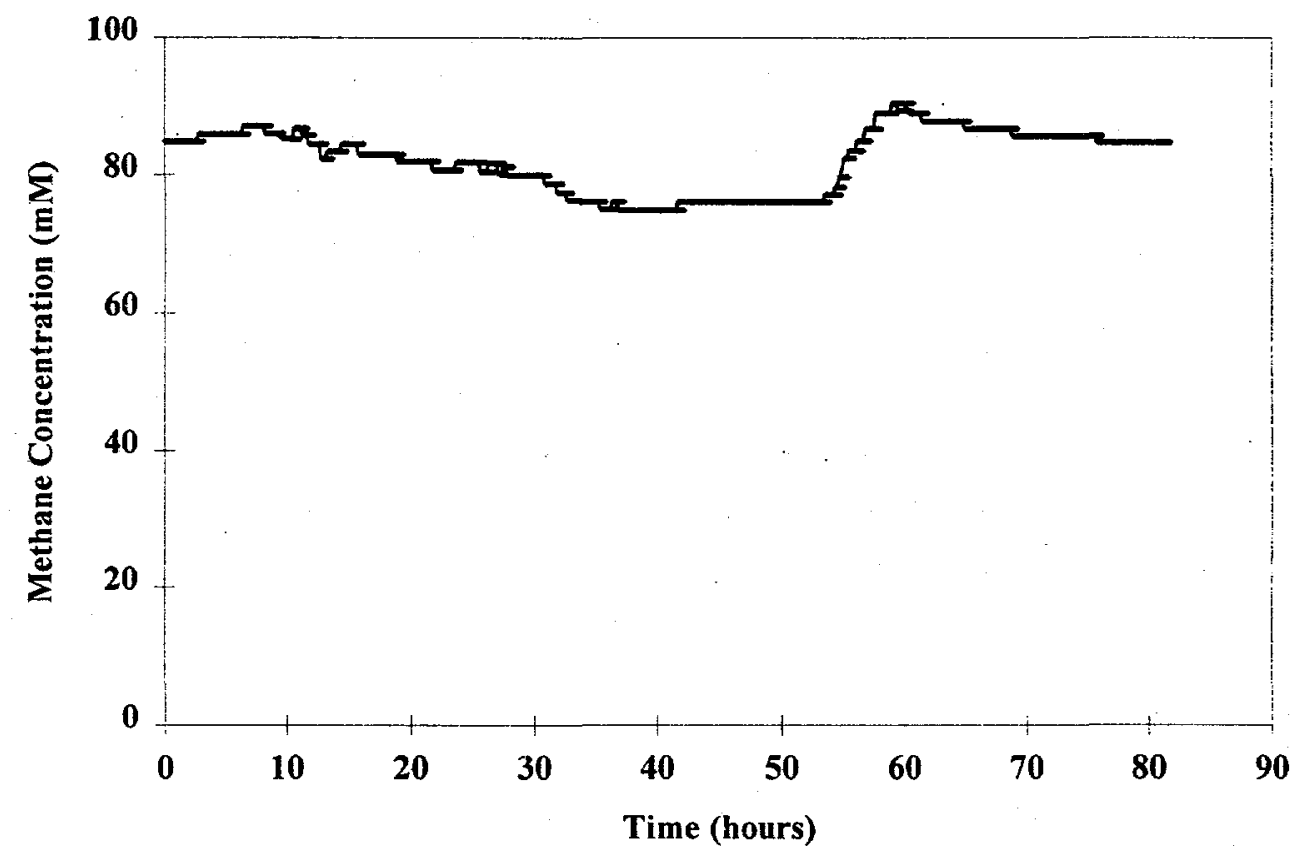

Figure 6-39. Methane content variation during OLR shock loading (5/23/94). 


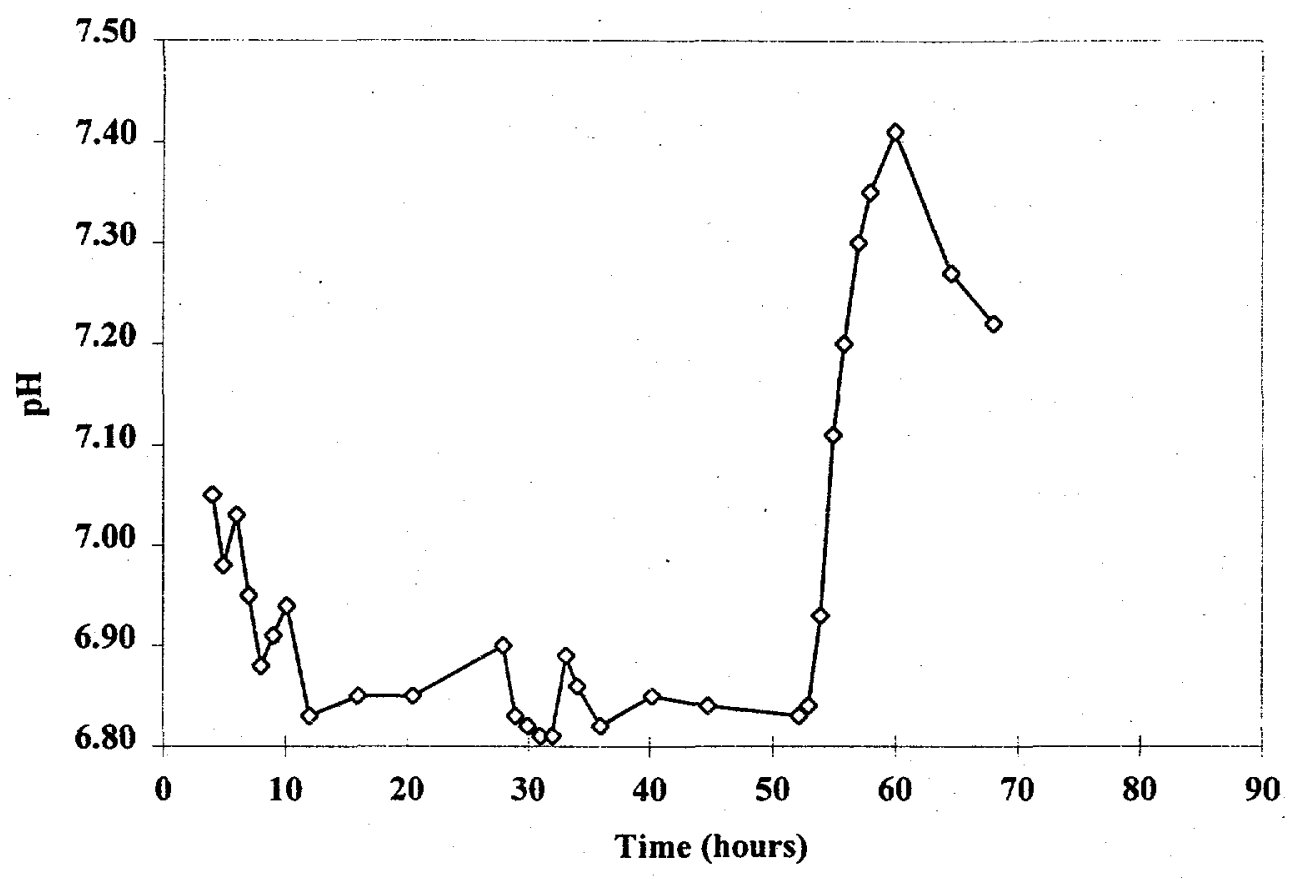

Figure 6-40. $\mathrm{pH}$ response during shock loading experiment (5/23/94).

The $\mathrm{pH}$ controller was set at a lower limit of 6.8. During the initial five hours, $\mathrm{pH}$ decreased from 7.05 to 6.8 and remained at that level thereafter. The pH increased immediately to 7.4 when the OLR was reduced to $10 \mathrm{~kg} \mathrm{COD} / \mathrm{m}^{3}-\mathrm{d}$.

$\mathrm{H}_{2}$ responded to the increase in OLR to $40 \mathrm{~kg} \mathrm{COD} / \mathrm{m}^{3}$-d immediately (Figure 6-41). The concentration of gas phase $\mathrm{H}_{2}$ was $1500 \mathrm{ppm}$ at $40 \mathrm{~kg} \mathrm{COD} / \mathrm{m}^{3}-\mathrm{d}$ and $2200 \mathrm{ppm}$ at $60 \mathrm{~kg} \mathrm{COD} / \mathrm{m}^{3}-\mathrm{d}$. The background $\mathrm{H}_{2}$ concentration was $300-400 \mathrm{ppm}$. For an unknown reason, $\mathrm{H}_{2}$ concentration reached $1000 \mathrm{ppm}$ a few hours before the experiment started. Thus, the net increases of $\mathrm{H}_{2}$ were $500 \mathrm{ppm}$ for the first step and $700 \mathrm{ppm}$ for the second step. $\mathrm{H}_{2}$ returned to $500 \mathrm{ppm} 7$ hours after the OLR was reduced to $10 \mathrm{~kg} \mathrm{COD} / \mathrm{m}^{3}-\mathrm{d}$ and remained at that level thereafter. Compared with previous runs, the response of $\mathrm{H}_{2}$ to an OLR of $40 \mathrm{~kg}$ $\mathrm{COD} / \mathrm{m}^{3}-\mathrm{d}$ was high. During most shock loading experiments conducted, the net increase in $\mathrm{H}_{2}$ was only several hundred ppm in response to this level of OLR.

The behavior of $\mathrm{CO}$ was similar to the previous run using the other bench-scale UASB reactor (Figure 6-42). The concentration of CO displayed little variation at an OLR of $40 \mathrm{~kg} \mathrm{COD} / \mathrm{m}^{3}-\mathrm{d}$. CO increased rapidly when the OLR was increased to $60 \mathrm{~kg} \mathrm{COD} / \mathrm{m}^{3}-\mathrm{d}$, reaching a peak value of $1400 \mathrm{ppb}$. CO decreased immediately after shock loading was stopped. Five hours later, $\mathrm{CO}$ returned to a background level of $200 \mathrm{ppb}$. 


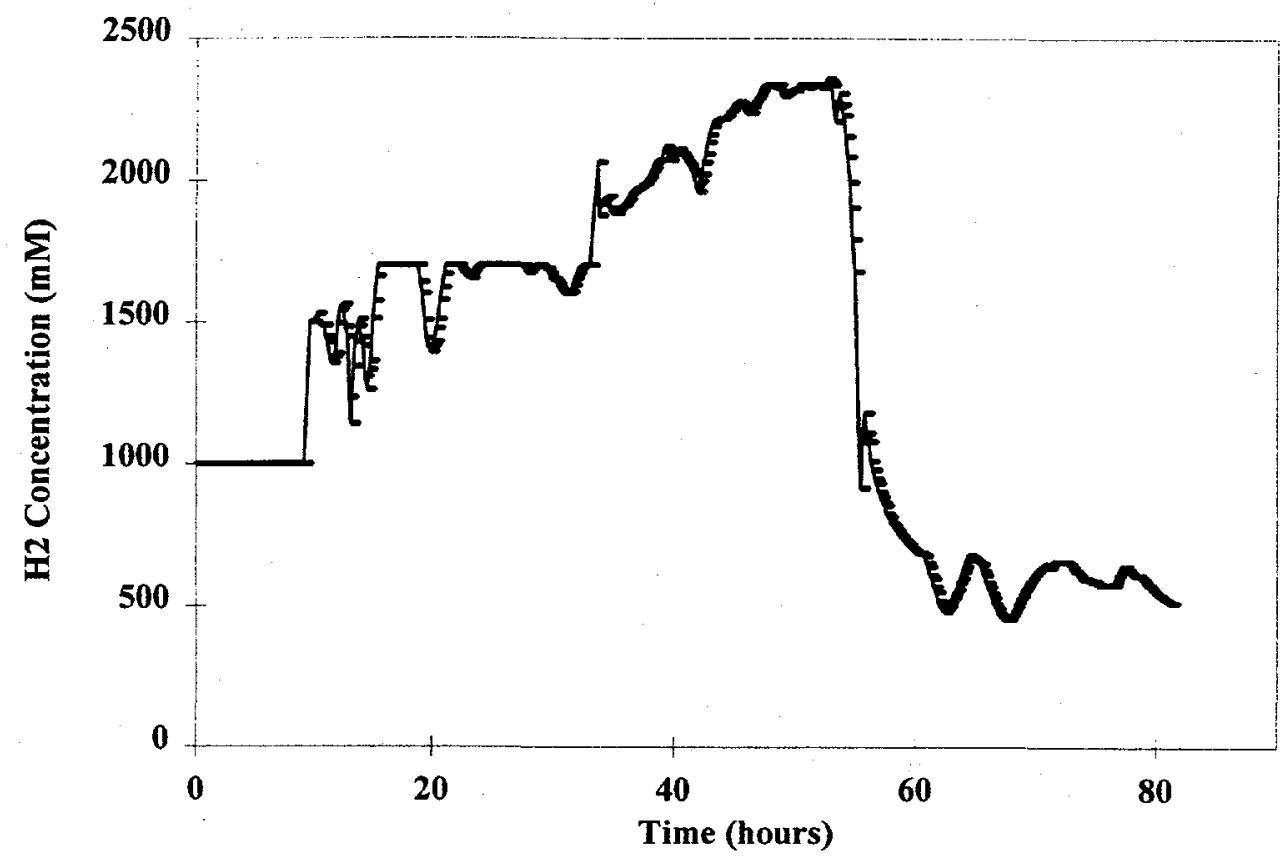

Figure 6-41. Hydrogen variation during OLR shock loading (5/23/94).

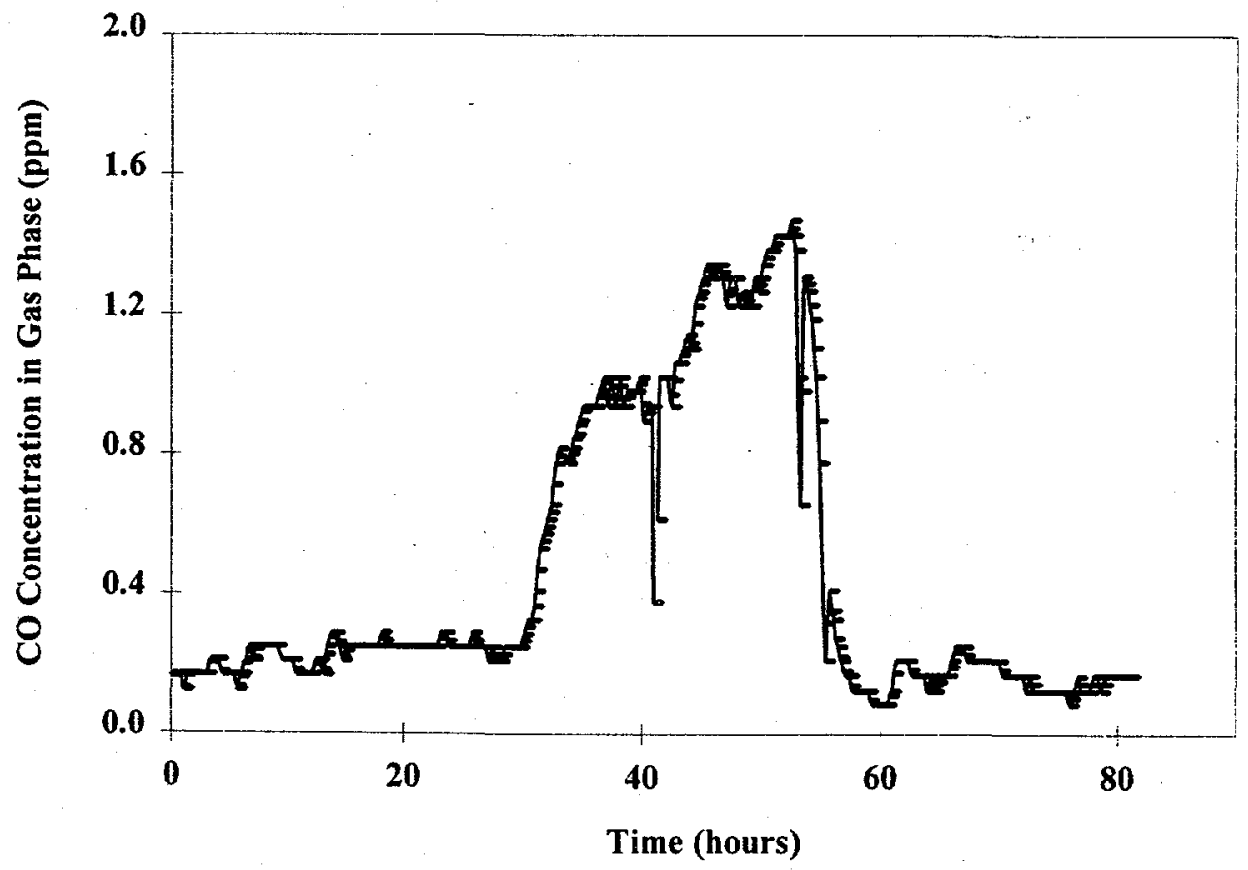

Figure 6-42. CO response during OLR shock loading (5/23/94).

As expected, acetate, propionate, butyrate and other four-and five-arbon acids were all observed to accumulate during the shock loading (Figures 6-43 and 6-44). Acetate accumulated immediately after the 
OLR was increased to $40 \mathrm{~kg} \mathrm{COD} / \mathrm{m}^{3}-\mathrm{d}$. Acetate reached a concentration of $10 \mathrm{mM}$ by the end of the first OLR step increase (30 hours). During the second OLR step increase, to $60 \mathrm{~kg} \mathrm{COD} / \mathrm{m}^{3}-\mathrm{d}$, acetate concentration reached a peak value of $34 \mathrm{mM}$ at 52 hours. One hour after shock loading had been stopped, acetate concentration decreased to $15 \mathrm{mM}$. Because of the oxidation of accumulated alcohols and highermolecular-weight VFAs, acetate accumulated again between the 53-and 58-hour time period, returning to background levels at 65 hours. Propionate increased in a pattern similar to acetate. Propionate peaked at 5 $\mathrm{mM}$ at an OLR of $40 \mathrm{~kg} \mathrm{COD} / \mathrm{m}^{3}-\mathrm{d}$ and $10 \mathrm{mM}$ at an OLR of $60 \mathrm{~kg} \mathrm{COD} / \mathrm{m}^{3}-\mathrm{d}$. The peak value of propionate was $10.5 \mathrm{mM}$ at 52 hours. Eight hours after the shock loading was stopped, propionate returned to its background level.

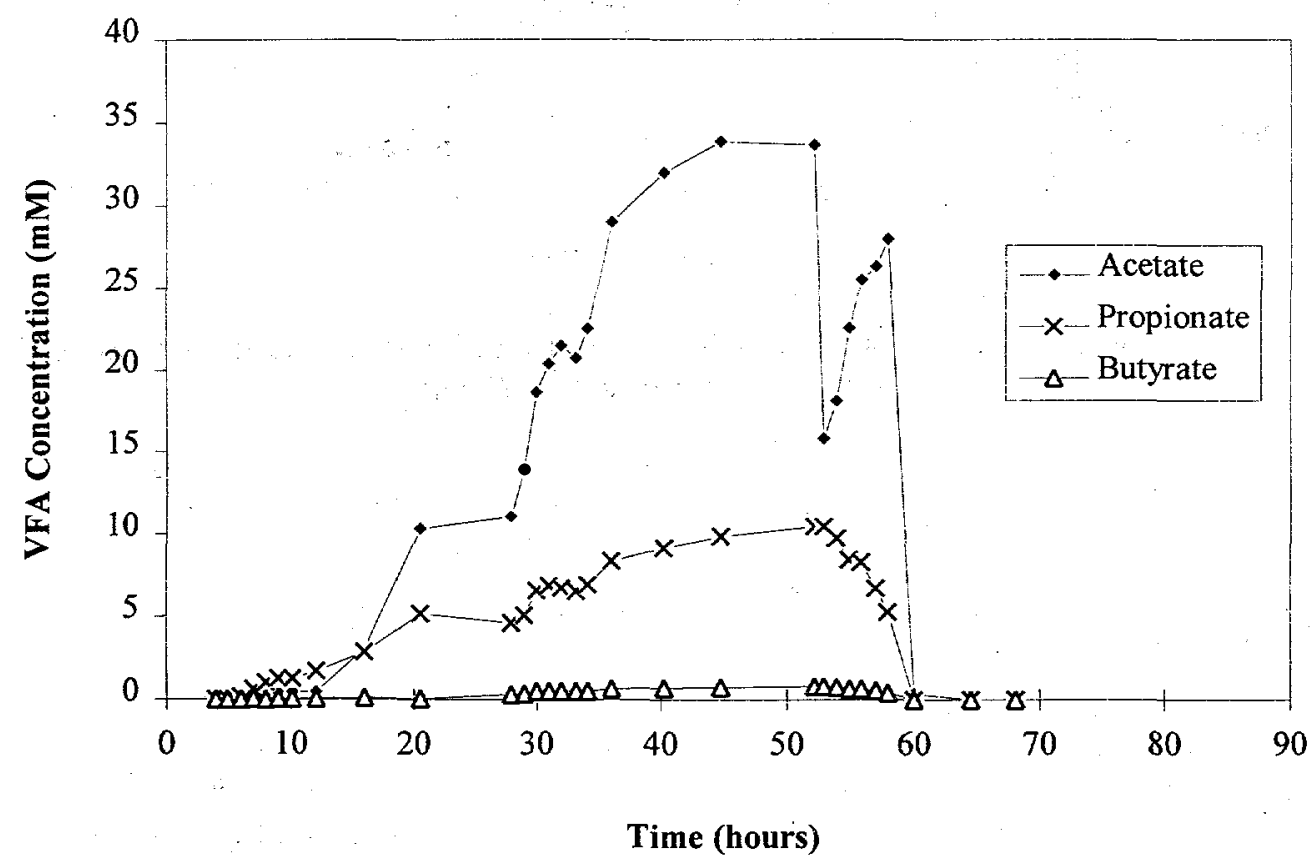

Figure 6-43. VFA concentration during shock loading experiment (5/23/94).

Butyrate, iso-butyrate, valerate, iso-valerate, and 2-methyl-butyrate accumulated immediately at an OLR of $40 \mathrm{~kg} \mathrm{COD} / \mathrm{m}^{3}-\mathrm{d}$. They disappeared from the reactor liquid eight hours after the shock loading was stopped.

Ethanol and propanol were observed as shown in Figure 6-45. Ethanol accurnulated to $7 \mathrm{mM}$, while $\mathrm{n}$ propanol reached a peak concentration of $1 \mathrm{mM}$. The peak value of both alcohols was observed at 45 hours, about seven hours earlier than the peak VFAs. The reason for this is unknown. Ethanol and propanol disappeared one hour after the OLR was decreased to $10 \mathrm{~kg} \mathrm{COD} / \mathrm{m}^{3}-\mathrm{d}$. 


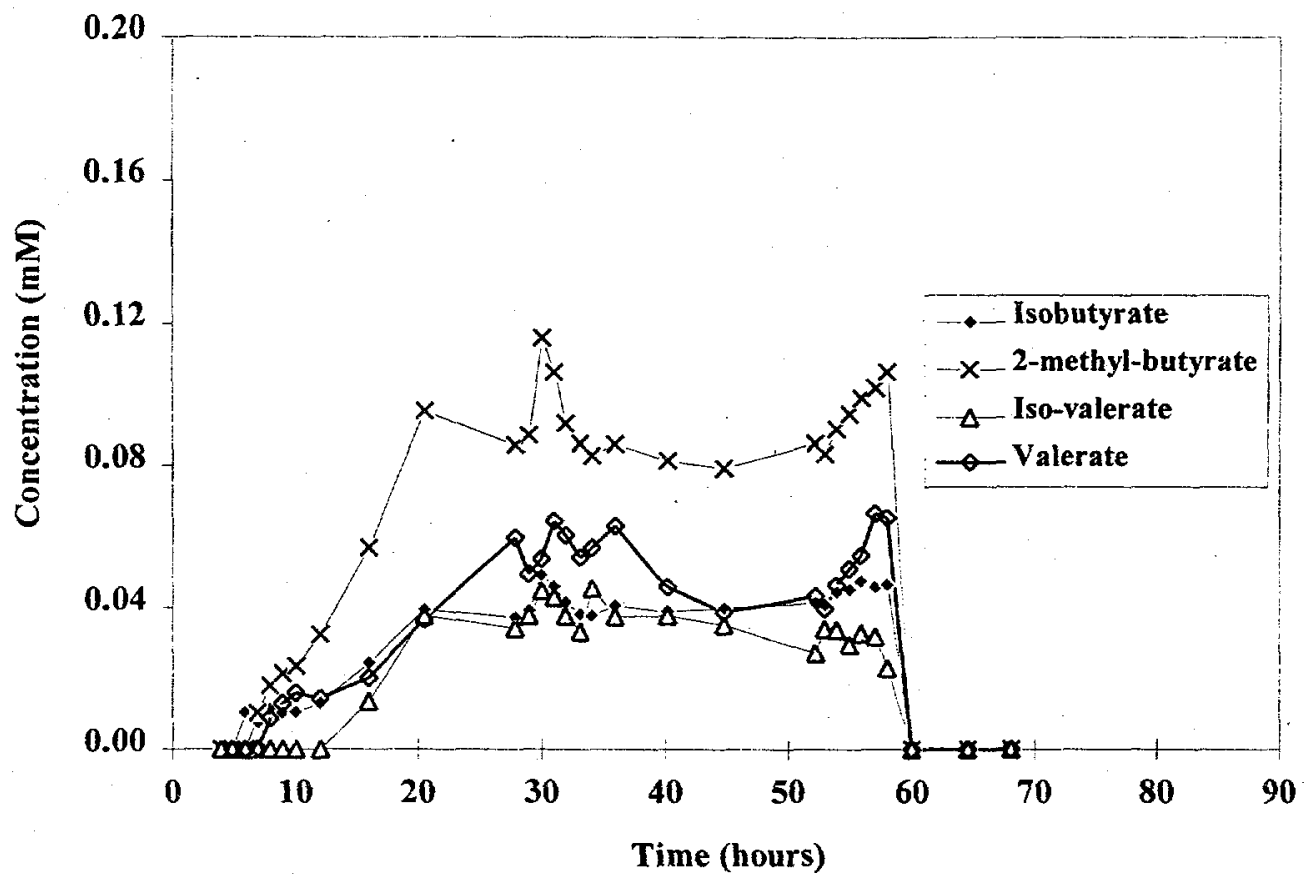

Figure 6-44. Isobutyrate, 2-methyl-butyrate, iso-valerate and valerate concentration during shock loading experiment (5/23/94).

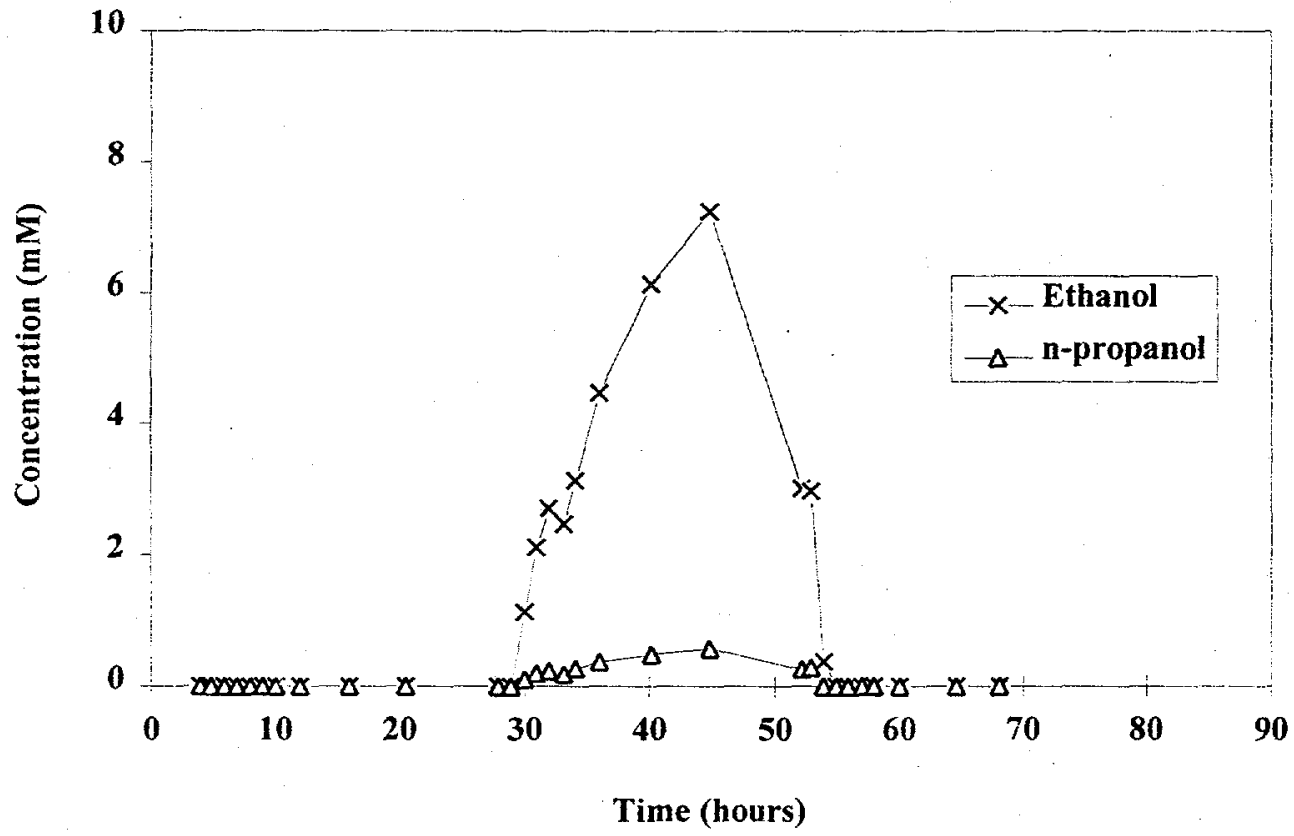

Figure 6-45. Ethanol and n-propanol response during shock loading experiment (5/23/94). 


\section{ANALYSIS OF UNSTEADY STATE MONITORING RESULTS}

\section{Data Transformation of Three OLR Perturbation Experiments - Non-failure Tests (USS1-USS3)}

Data analyses were performed on three sets of unsteady state OLR experiments (USS1 through USS3) conducted without $\mathrm{pH}$ control. During the first OLR variation (USS1), a fixed interval of step-up and stepdown in the OLR in the sequence 5-8-10-8-5 $\mathrm{kg} \mathrm{COD} / \mathrm{m}^{3}-\mathrm{d}$ was imposed on the bench-scale UASB reactor. In the second experiment (USS2), the OLR schedule was 5-10-15-20-25 $\mathrm{kg} \mathrm{COD} / \mathrm{m}^{3}-\mathrm{d}$. A combination of regular and random variation of OLR, using both step and impulse, with a larger amplitude scale (OLR 10-15-20-25-30-60-104 $\mathrm{kg} \mathrm{COD} / \mathrm{m}^{3}-\mathrm{d}$ ) was used for experiment USS3, the third OLR perturbation experiment. Trace gases $\mathrm{CO}, \mathrm{H}_{2}$, and gas production rate were monitored throughout these experiments.

During the first and second perturbation, the UASB system performance was not significantly affected. Effluent VFAs and gas production rates increased in response to the increase in OLR, but remained within the steady state region (Figures 6-46 and 6-47). During the third shock loading experiment, the system was significantly perturbed. Effluent VFAs increased to $14 \mathrm{mM}$ and effluent COD increased up to $1380 \mathrm{mg} / \mathrm{L}$. Higher molecular weight VFAs were observed in the system effluent. The $\mathrm{pH}$ and methane content of the headspace gases were reduced in response to the high level of OLR and increase in VFAs. Because of the overloading, gas production decreased to $68 \%$ of theoretical conversion rate and remained at that level (Figure 6-48). A shock OLR of 10 hours on day three of this experiment did not result in the system failure or the system going "out of control."

For each data set of shock loading experiments (USS1 - USS3), the $\mathrm{CO}$ and $\mathrm{H}_{2}$ concentrations were normalized by gas production rate data (as a surrogate for OLR). A time series plot of the transformed CO and $\mathrm{H}_{2}$ data (i.e., $\mathrm{CO} / \mathrm{GP}$ ) for the three sets of experiments is presented in Figures 6-49 through 6-54.

$\mathrm{CO} / \mathrm{GP}$ (gas production) and $\mathrm{H}_{2} / \mathrm{GP}$ did not increase with increased OLR. In general, during OLR perturbations when the UASB system was "in control," the CO/GP ratio remained below $2.0 \mathrm{ppb} / \mathrm{ml} / \mathrm{h}$, and the $\mathrm{H}_{2} / \mathrm{GP}$ ratio was lower than $1.0 \mathrm{ppm} / \mathrm{ml} / \mathrm{h}$. 


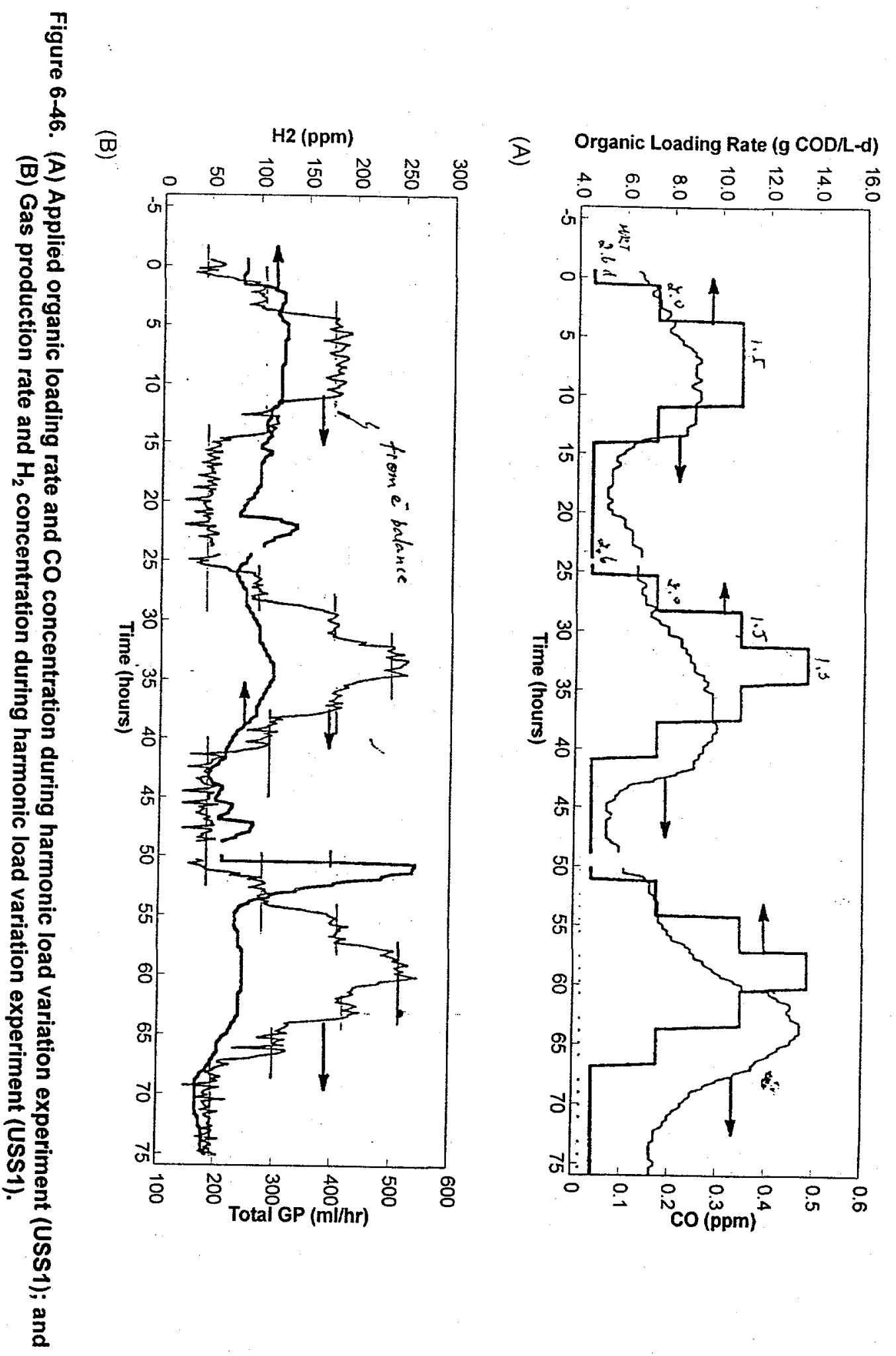




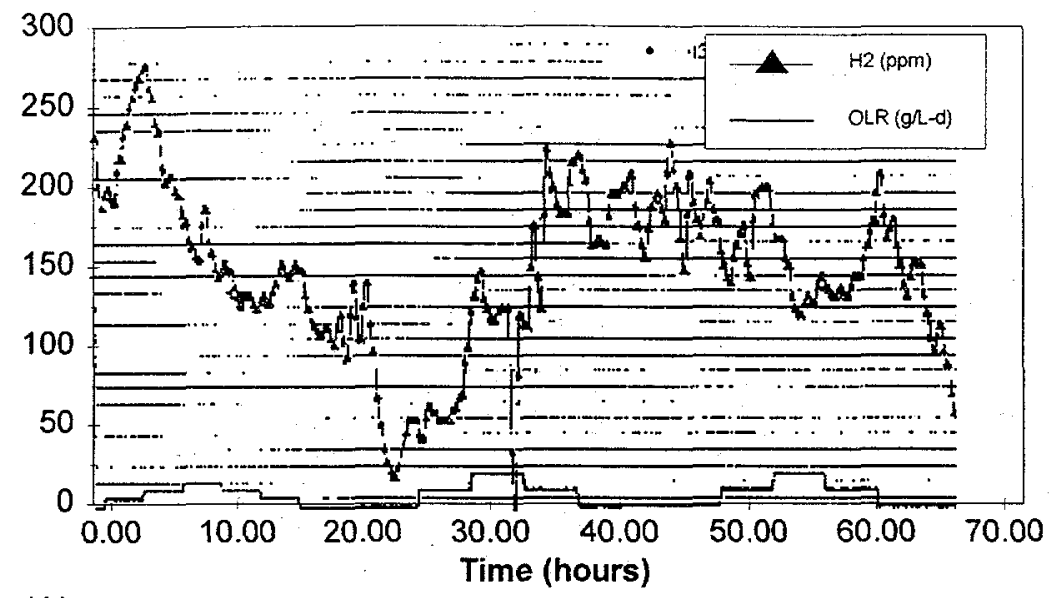

(A)

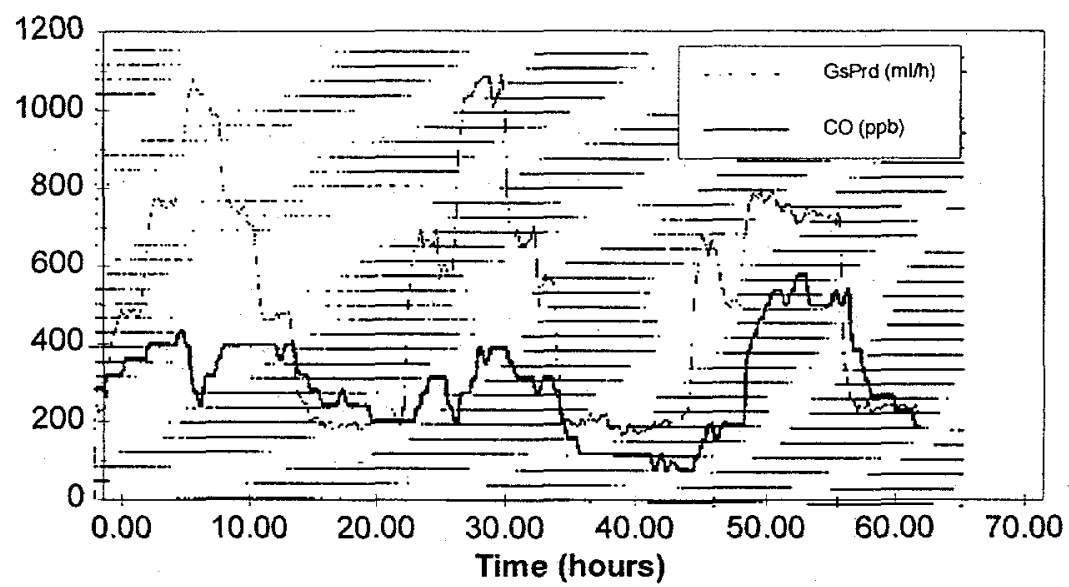

(B)

Figure 6-47. (A) OLR variation and $\mathrm{H}_{2}$ response during harmonic variation experiment (USS2); and (B) Gas production rate and $\mathrm{CO}$ response during harmonic variation experiment (USS2).

The mean and standard deviations of these data sets were calculated, and the results compared to the mean and standard deviation of steady state periods and the last OLR shock loading data. Finally, a baseline was determined based on mean +3 sigma for $\mathrm{CO} / \mathrm{GP}$ and $\mathrm{H}_{2} / \mathrm{GP}$. A summary of steady state and the four sets of perturbation results are shown in Tables 6-13 and 6-14. The CO/GP ratio during the third shock loading was calculated using time equal to 50 hours because of a possibility that air in the reactor headspace prior to the experiment influenced $\mathrm{CO}$ levels during the early portion of the study (Figure 6-54). These data were averaged again, to have a final baseline of $\mathrm{CO} / \mathrm{GP}$ and $\mathrm{H}_{2} / \mathrm{GP}$ (Table 6-15). CO/GP was $0.71 \pm 0.44$ $\mathrm{ppm} / \mathrm{ml} / \mathrm{h} . \mathrm{H}_{2} / \mathrm{GP}$ was $0.35 \pm 0.23 \mathrm{ppb} / \mathrm{ml} / \mathrm{h}$. The mean +3 sigma were $2.03 \mathrm{ppb} / \mathrm{ml} / \mathrm{h}$ and $1.04 \mathrm{ppm} / \mathrm{ml} / \mathrm{h}$ for $\mathrm{CO} / \mathrm{GP}$ and $\mathrm{H}_{2} / \mathrm{GP}$, respectively. 


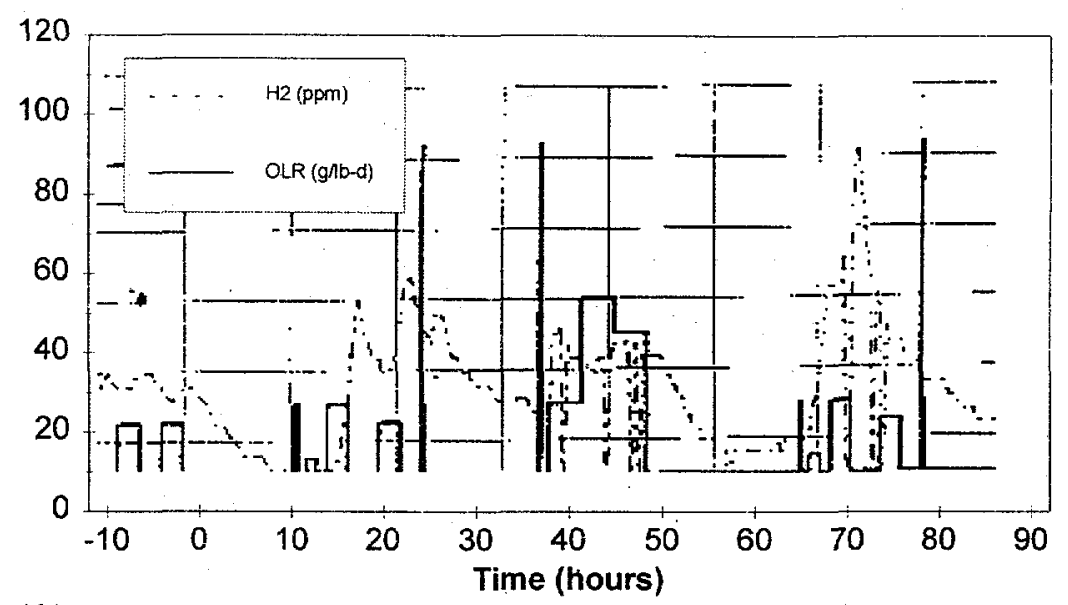

(A)

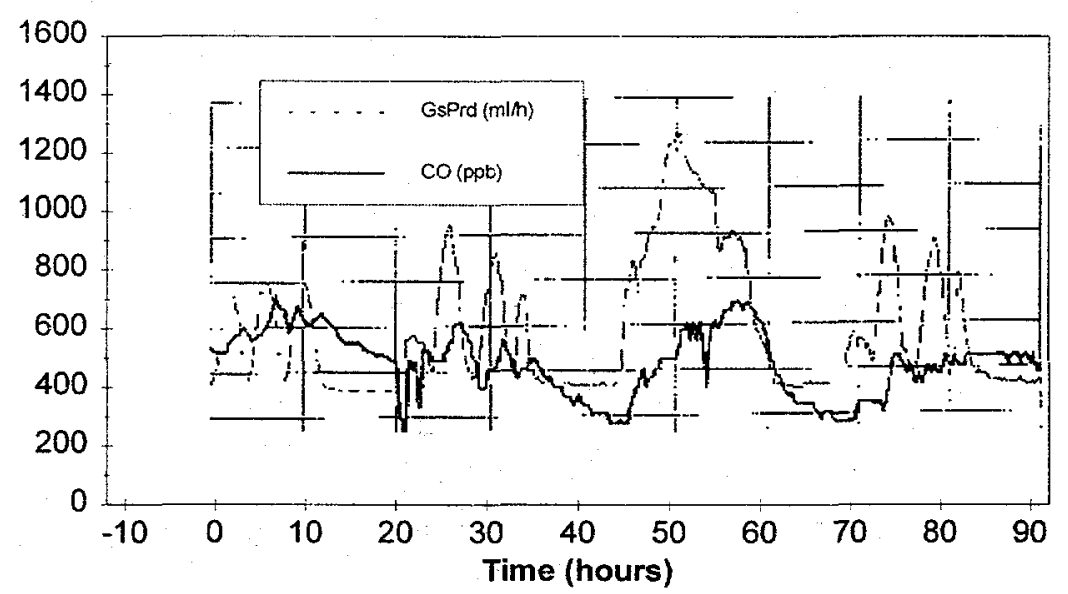

(B)

Figure 6-48. (A) Harmonic random variation experiment (OLR variation and $\mathrm{H}_{2}$ response) (USS3); and (B) Harmonic random variation experiment (gas production rate and $C O$ response) (USS3). 


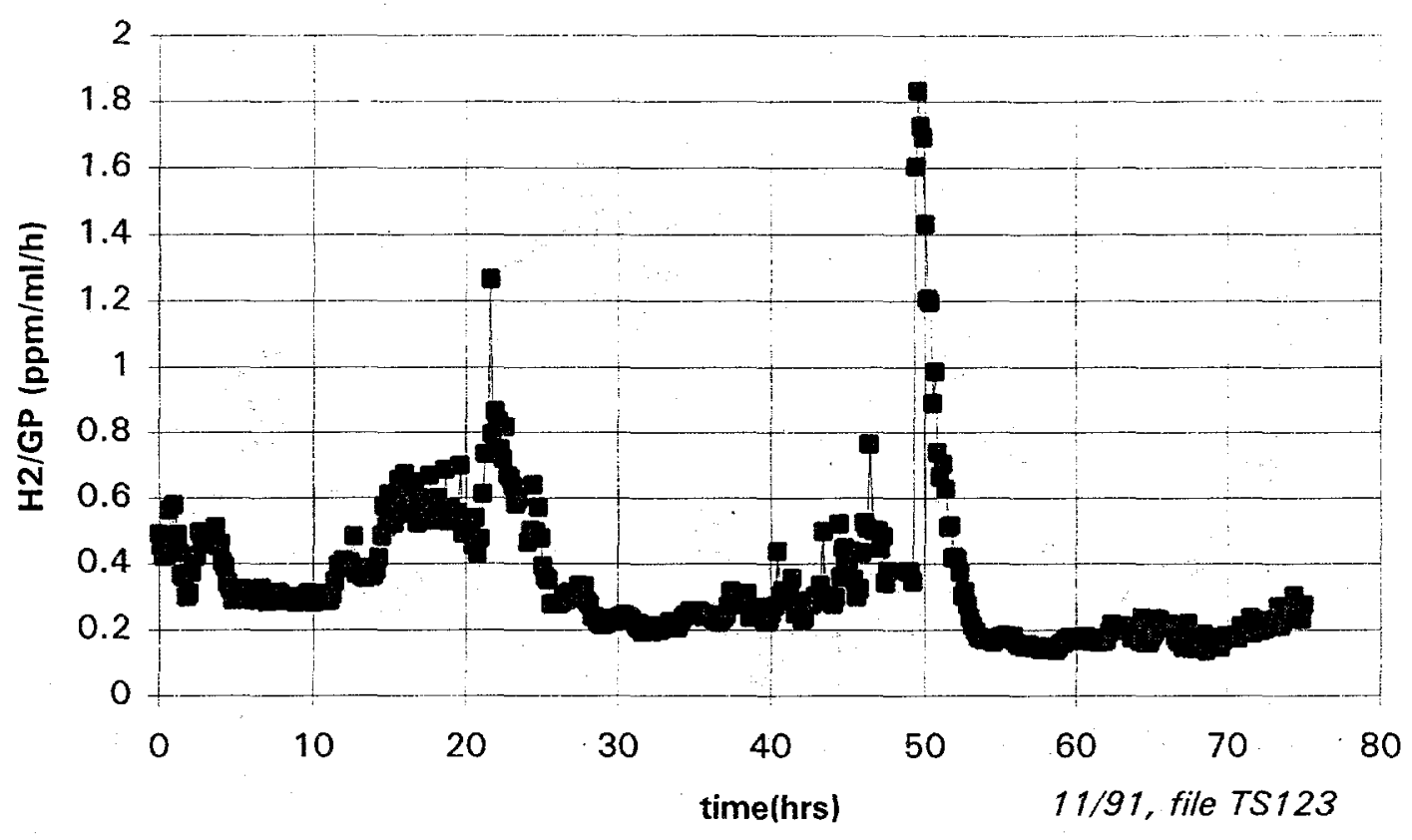

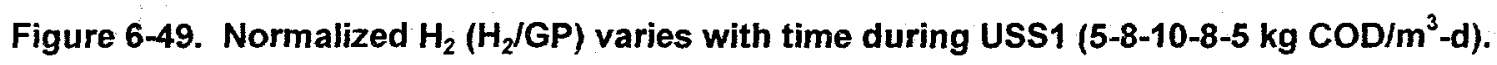

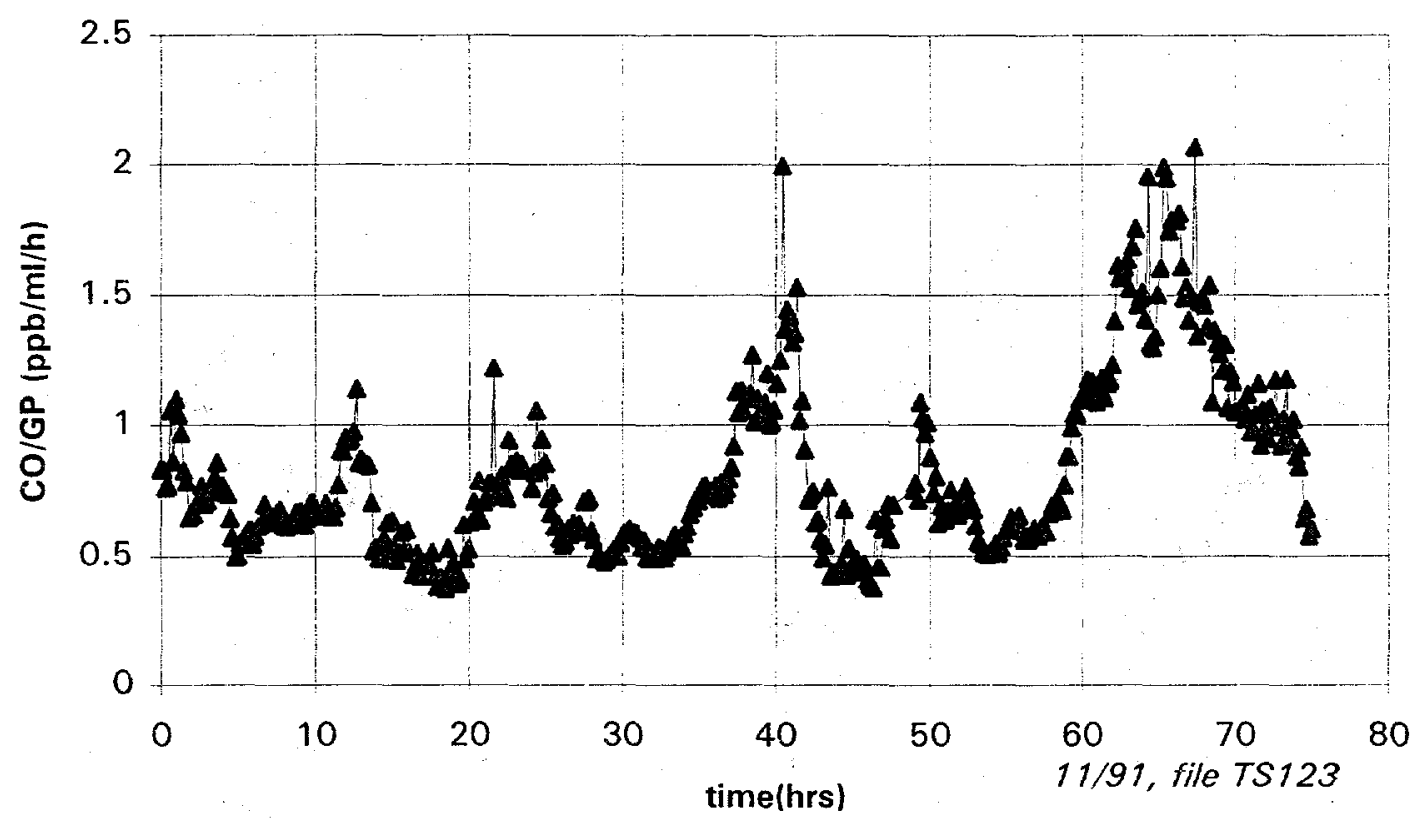

Figure 6-50. Normalized CO (CO/GP) varies with time during USS1 (5-8-10-8-5 kg $\left.\mathrm{COD} / \mathrm{m}^{3}-\mathrm{d}\right)$. 


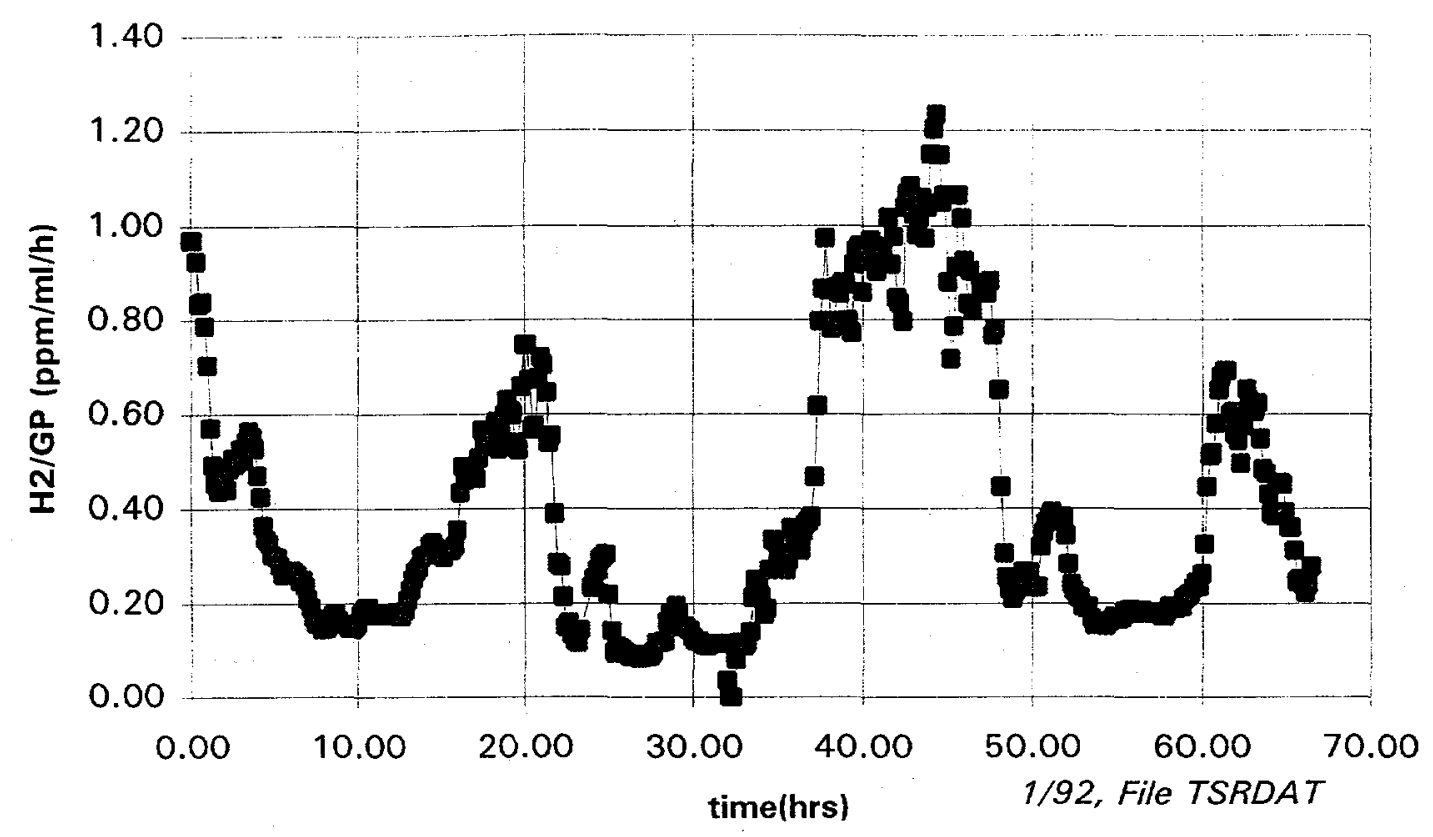

Figure 6-51. Normalized $\mathrm{H}_{2}\left(\mathrm{H}_{2} / \mathrm{GP}\right)$ varies with time during USS2 (5-10-15-20-15-10 kg $\left.C O D / m^{3}-d\right)$.

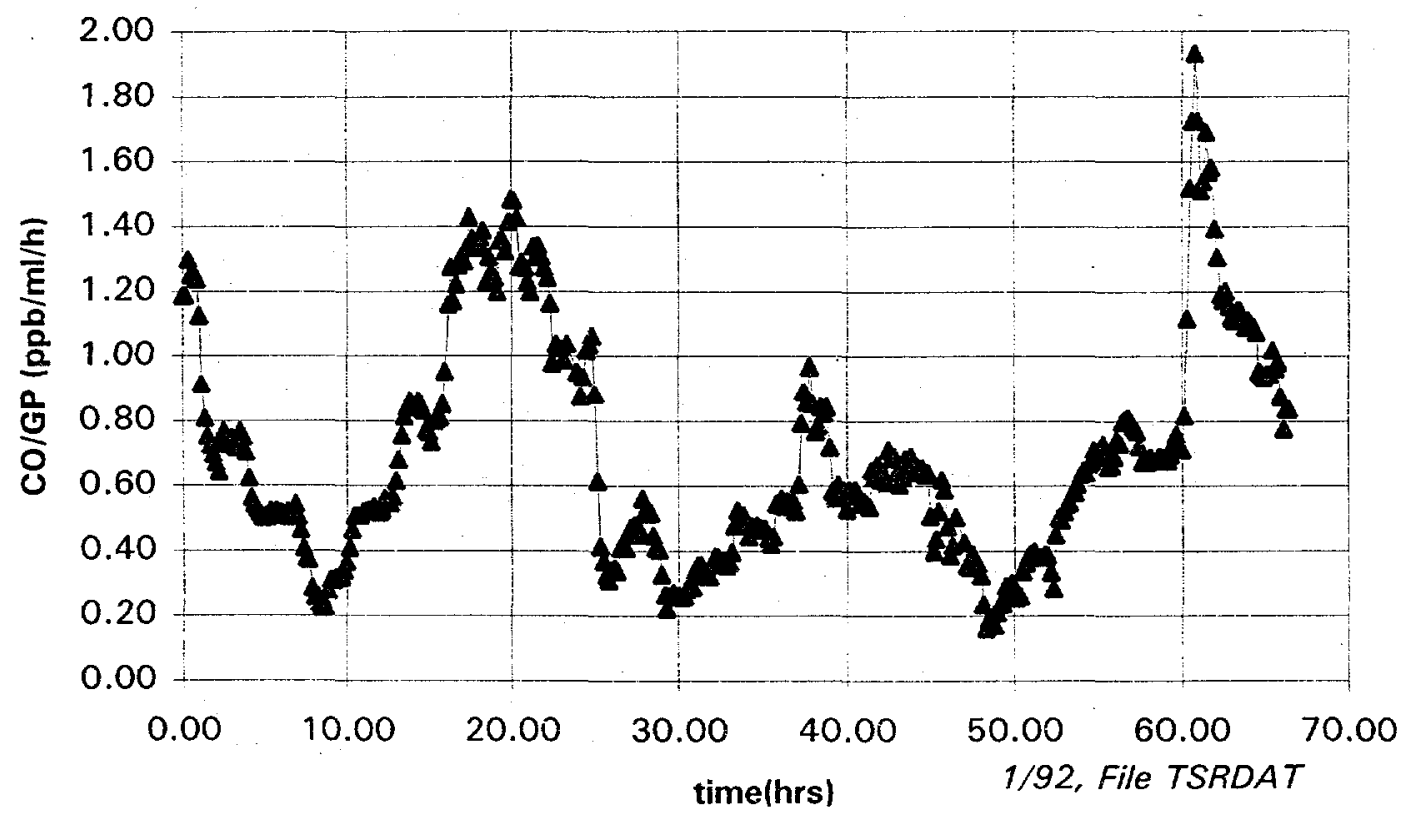

Figure 6-52. Normalized CO (CO/GP) varies with time during USS2 (5-10-15-20-15-10 kg $\left.\mathrm{COD} / \mathrm{m}^{3}-\mathrm{d}\right)$. 


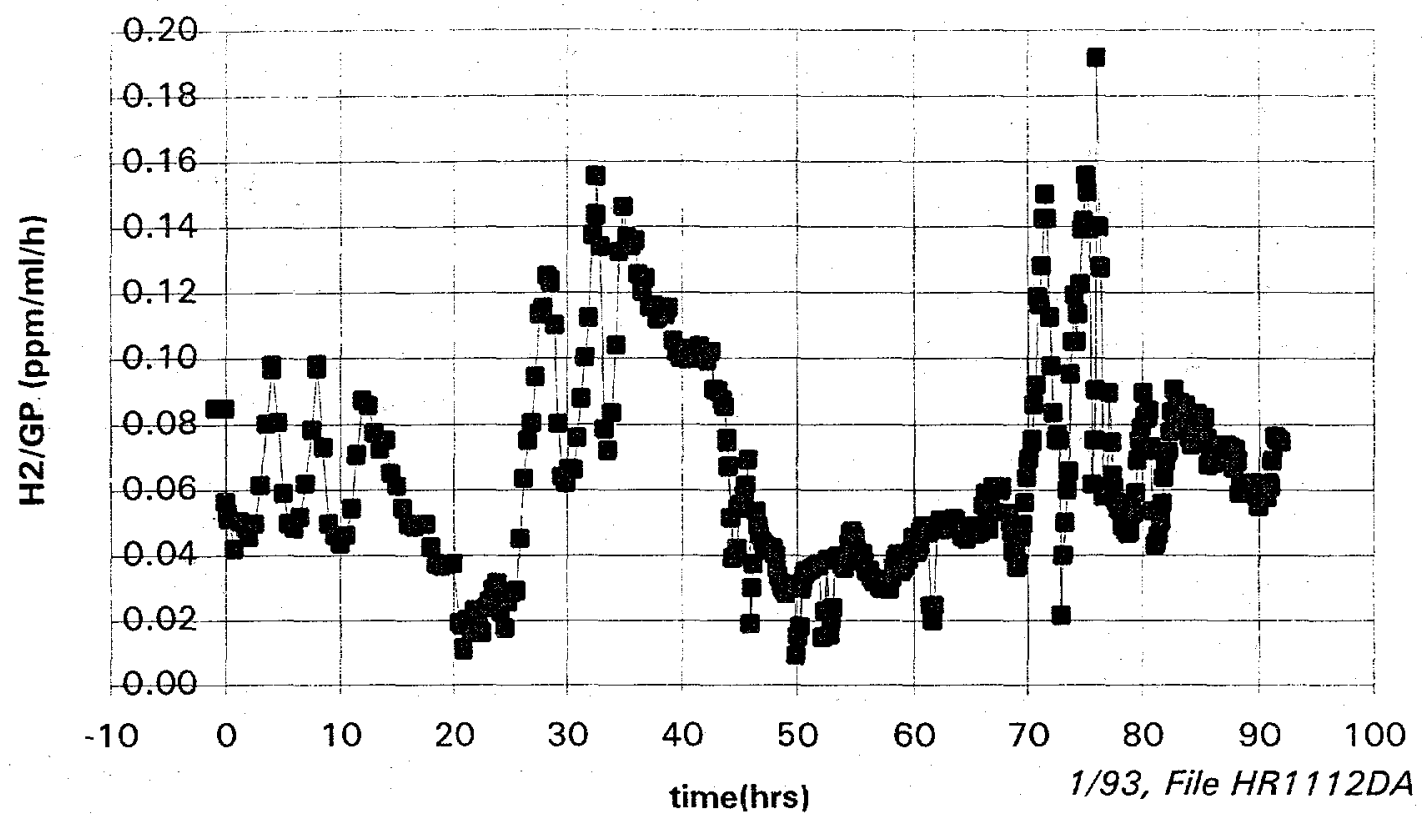

Figure 6-53. Normalized $\mathrm{H}_{2}\left(\mathrm{H}_{2} / \mathrm{GP}\right)$ varies with time during USS3 (10-15-20-25-30-50-60-104 $\left.\mathrm{kg} \mathrm{COD} / \mathrm{m}^{3}-\mathrm{d}\right)$.

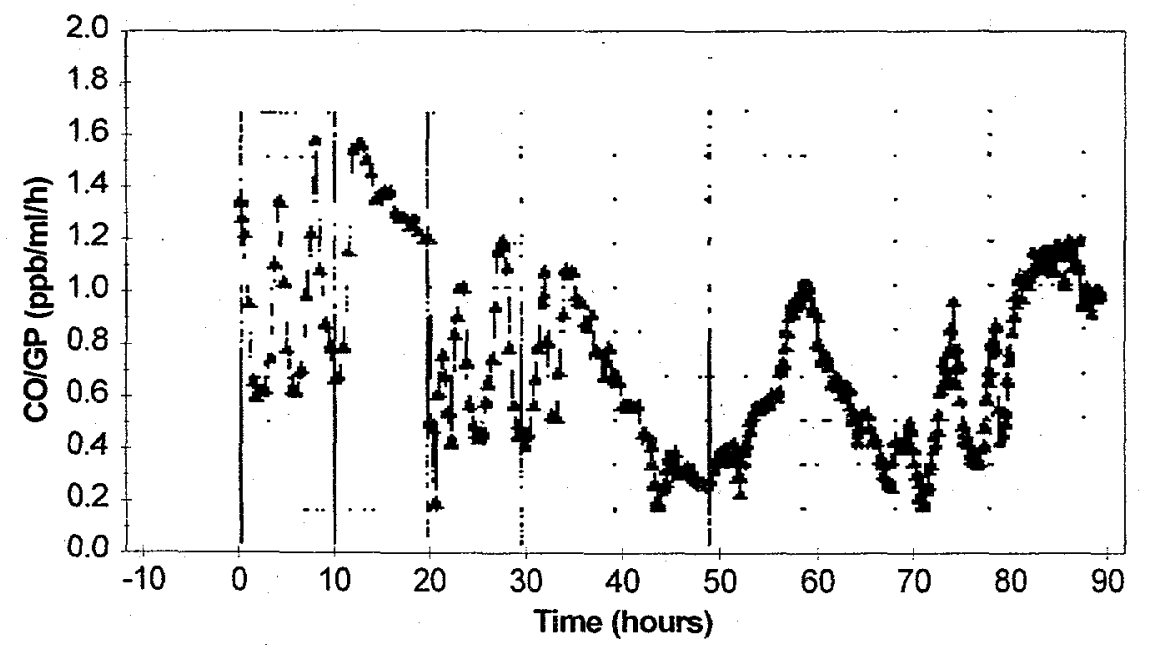

Figure 6-54. Normalized CO (CO/GP) varies with time during USS3 (10-15-20-25-30-50-60$\left.104 \mathrm{~kg} \mathrm{CCD} / \mathrm{m}^{3}-\mathrm{d}\right)$. 


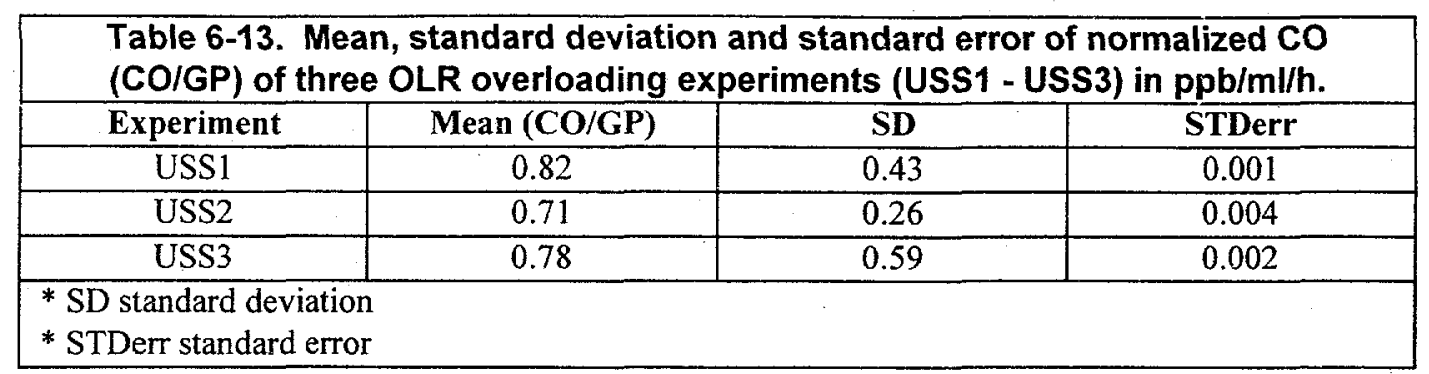

Table 6-14. Mean, standard deviation and standard error of normalized $\mathrm{H}_{2}\left(\mathrm{H}_{2} / \mathrm{GP}\right)$ of three OLR overloading experiments (USS1 - USS3) in ppm/ml/h.

\begin{tabular}{|c|c|c|c|}
\hline Experiment & Mean (CO/GP) & SD & STDerr \\
\hline USS1 & 0.35 & 0.25 & 0.0006 \\
\hline USS2 & 0.41 & 0.51 & 0.008 \\
\hline USS3 & 0.06 & 0.05 & 0.0001 \\
\hline * SD standard deviation \\
* STDerr standard error
\end{tabular}

\begin{tabular}{|c|c|c|c|c|c|c|c|c|}
\hline \multirow{2}{*}{ Operation } & \multicolumn{2}{|c|}{ USS1 } & \multicolumn{2}{|c|}{ USS2 } & \multicolumn{2}{|c|}{ USS3 } & \multicolumn{2}{|c|}{ Steady state } \\
\hline & $\mathrm{CO} / \mathrm{GP}$ & $\mathrm{H}_{2} / \mathrm{GP}$ & $\mathrm{CO} / \mathrm{GP}$ & $\mathrm{H}_{2} / \mathrm{GP}$ & $\mathrm{CO} / \mathrm{GP}$ & $\mathrm{H}_{2} / \mathrm{GP}$ & $\mathrm{CO} / \mathrm{GP}$ & $\mathrm{H}_{2} / \mathrm{GP}$ \\
\hline Mean & 0.82 & 0.35 & 0.71 & 0.41 & 0.78 & 0.06 & & \\
\hline Mean +3 & 2.11 & 1.10 & 1.50 & 1.95 & 2.56 & 0.20 & 2.46 & 1.21 \\
\hline Note & & & & & $\mathrm{t}>50 \mathrm{hrs}$ & & & \\
\hline
\end{tabular}

The CO/GP ratio was very consistent for all three experimental data sets.

Based on the above information, further analyses were performed to search for a criteria to determine when the system was out of control (failure) and when it was in control. Data from steady state operation and these three OLR variation experiments were considered to indicate a UASB reactor system in control. Bivariate plots of all three sets of unsteady state OLR shock loading experiments were made. Within the OLR range from 5 to $60 \mathrm{~kg} \mathrm{COD} / \mathrm{m}^{3}-\mathrm{d}$ (duration of any of the OLRs of no longer than three hours), and $100 \mathrm{~kg} \mathrm{COD} / \mathrm{m}^{3}-\mathrm{d}$ (duration of OLR no longer than 15 minutes), the majority of the points fall within 2 and 1 for $\mathrm{CO} / \mathrm{GP}$ and $\mathrm{H}_{2} / \mathrm{GP}$, respectively (see Figures 6-55 through 6-57). Similarly, the normalized $\mathrm{CO}$ and $\mathrm{H}_{2}$ for steady state operation were inside the region $\{2,1\}$. 


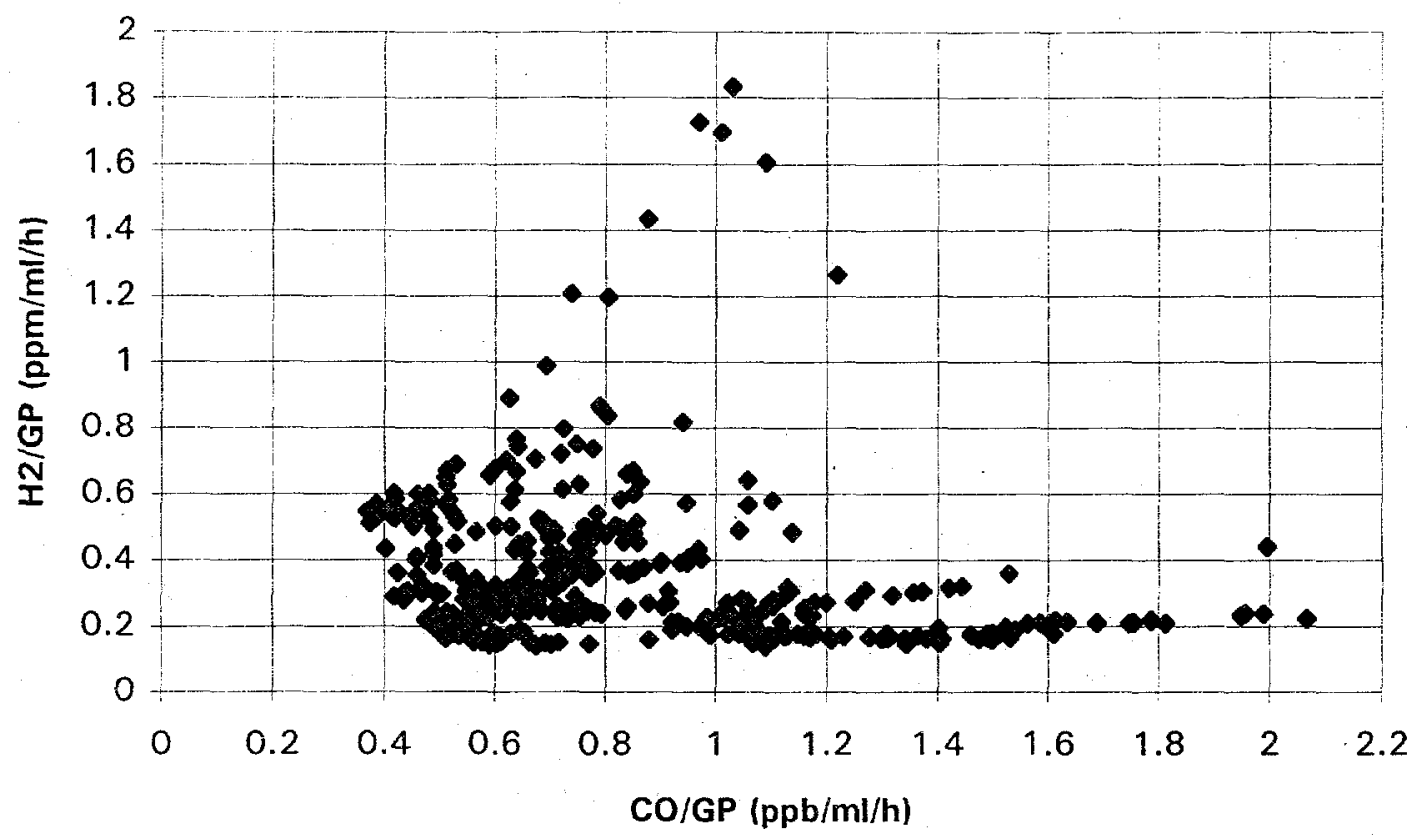

Figure 6-55. Bivariate plot of $\mathrm{CO} / \mathrm{GP}$ and $\mathrm{H}_{2} / \mathrm{GP}$ during OLR perturbations (5-8-10-8-5 $\mathrm{kg}$ $\mathrm{COD} / \mathrm{m}^{3}-\mathrm{d}$ ) on bench UASB reactor (USS1).

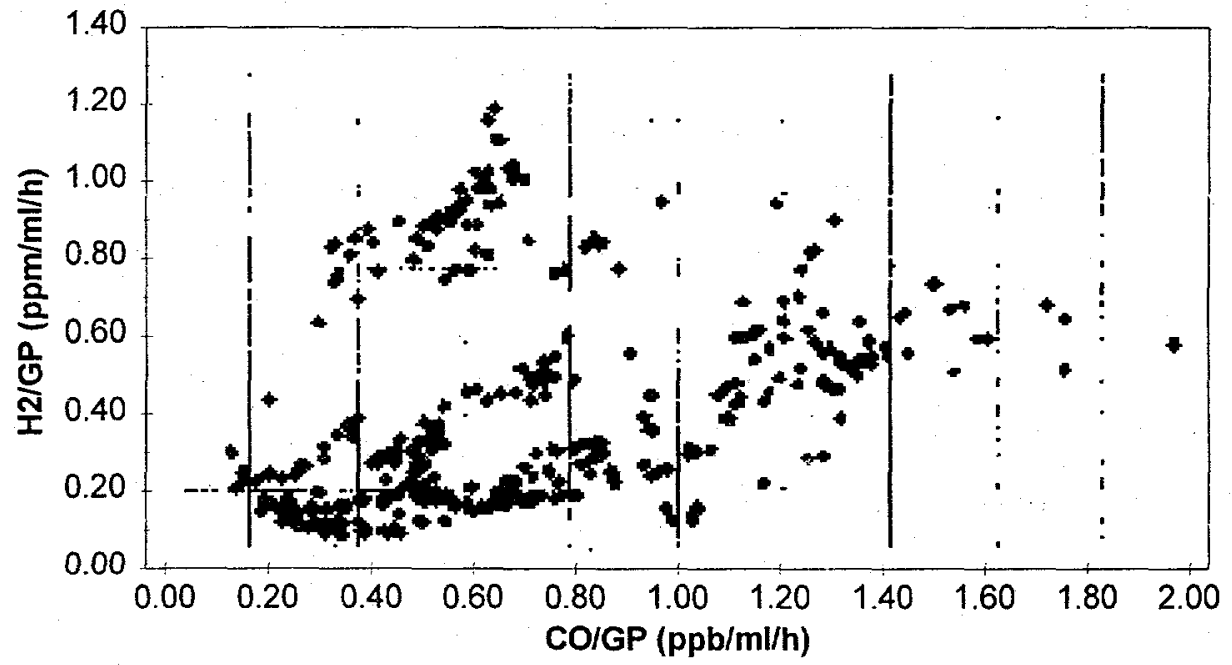

Figure 6-56. Bivariate plot of $\mathrm{CO} / \mathrm{GP}$ and $\mathrm{H}_{2} / \mathrm{GP}$ during OLR perturbation (5-10-15-20-15-10$5 \mathrm{~kg} \mathrm{COD} / \mathrm{m}^{3}-\mathrm{d}$ ) on bench UASB reactor (USS2). 


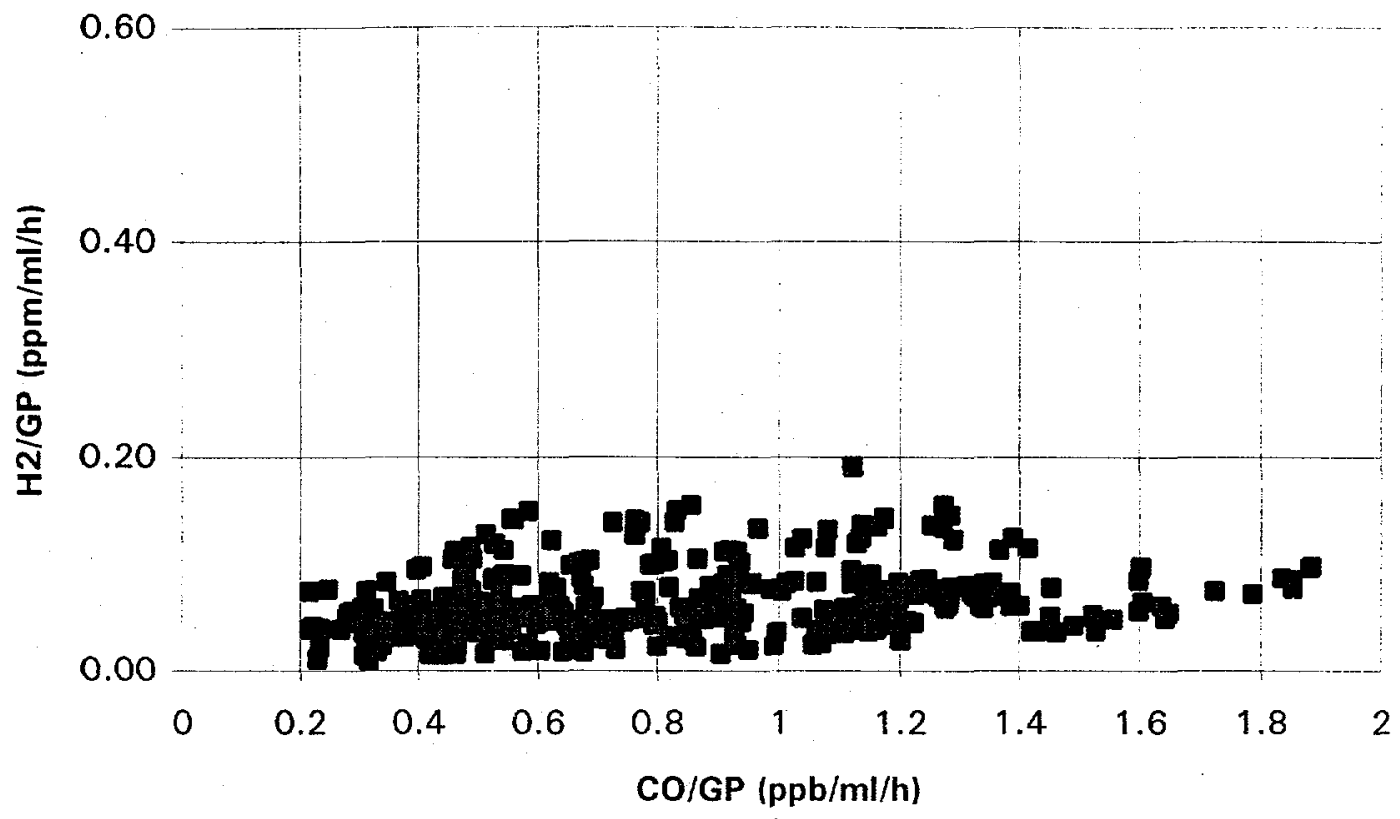

Figure 6-57. Bivariate plot of CO/GP and $\mathrm{H}_{2}$ /GP during OLR perturbation (10-15-20-25-30$60-104 \mathrm{~kg} \mathrm{COD} / \mathrm{m}^{3}-\mathrm{d}$ ) on bench UASB reactor (USS3).

\section{Transformation of Data from Unsteady State OLR Experiment When Failure Occurred (USS4)}

To obtain more information from the original headspace monitoring data collected every 10 minutes, trace gases $\mathrm{CO}$ and $\mathrm{H}_{2}$, methane content, and gas production rate were plotted using 10-minute interval data. These results were compared with the hourly averaged plots. The 10-minute data are presented in Figures 6-58 through 6-61. Plots of the 10-minute data were similar to those for the hourly data, but revealed greater fluctuations and/or more rapid response for $\mathrm{H}_{2}, \mathrm{CO}, \mathrm{CH}_{4}$ concentrations, and gas production rate. During the 60- to 80-hour time period, gas production rate and $\mathrm{CH}_{4}$ were essentially identical to those parameters for the hourly data. Low readings for $\mathrm{H}_{2}$ concentration during the peak period (Figure 6-59) were probably due to an instrument problem (i.e., the instrument did not properly integrate the raw data). These atypically low values were adjusted by extrapolating between points where the $\mathrm{H}_{2}$ values were normal. The results are plotted as shown in Figure 6-58. The adjusted $\mathrm{H}_{2}$ plot better describes the $\mathrm{H}_{2}$ behavior. CO had one low reading during $70-80$ hours which was averaged in the hourly plot. The cause of this anomaly is unknown. The same instrument sampling problem which occurred for the $\mathrm{H}_{2}$ integration could be responsible for this low reading. 


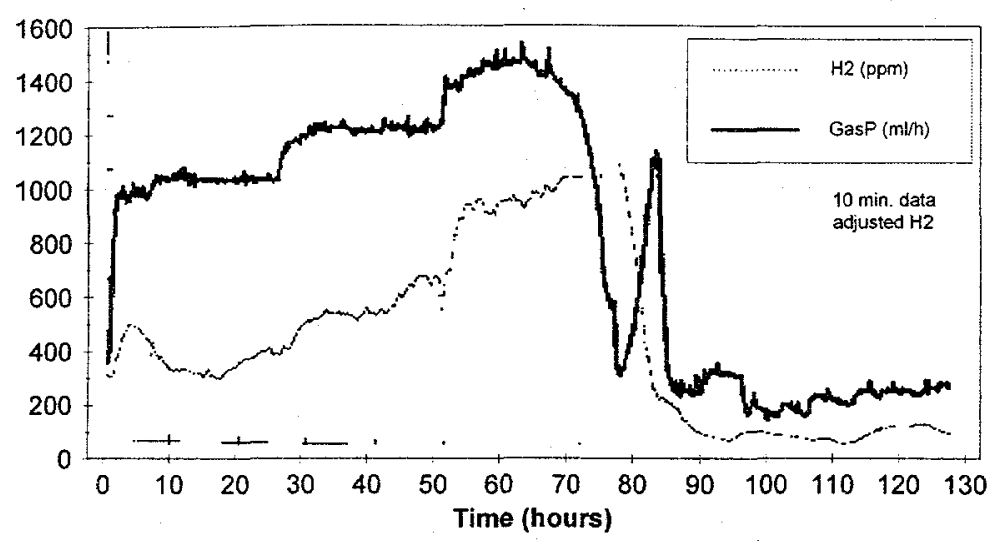

Figure 6-58. Headspace $\mathrm{H}_{2}$ and gas production rate during OLR shock loading experiment (10 minute data, $\mathrm{H}_{2}$ low readings adjusted).

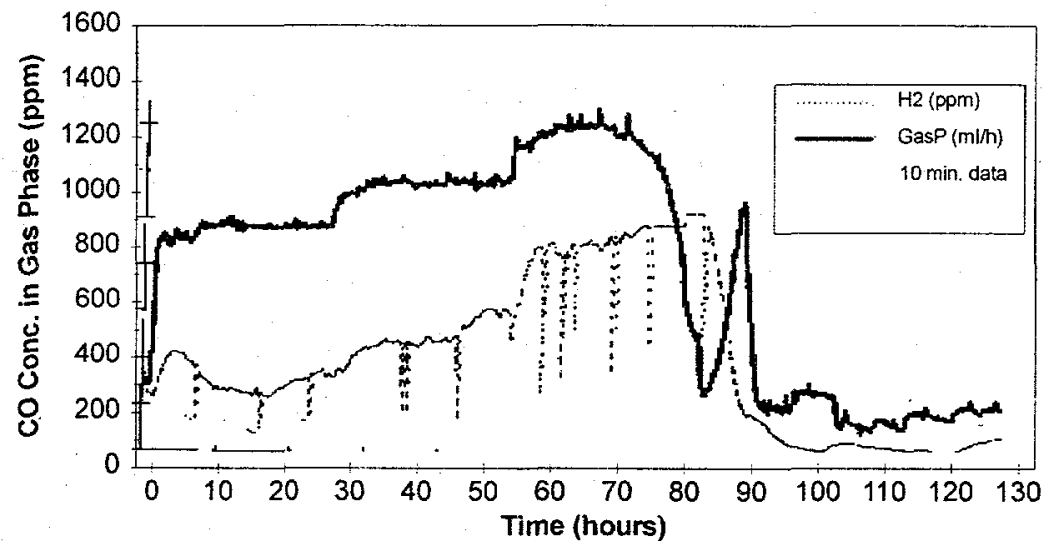

Figure 6-59. Headspace $\mathrm{H}_{2}$ and gas production rate during OLR shock loading experiment (10 minute data, $\mathrm{H}_{2}$ low readings not adjusted).

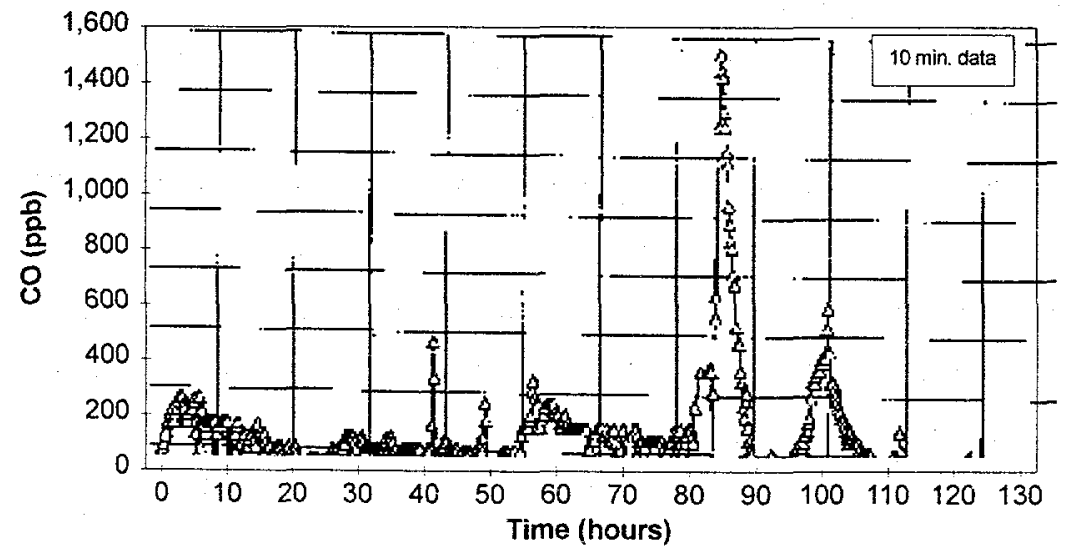

Figure 6-60. Headspace $\mathrm{CO}$ variation during OLR shock loading experiment (10 minute data). 


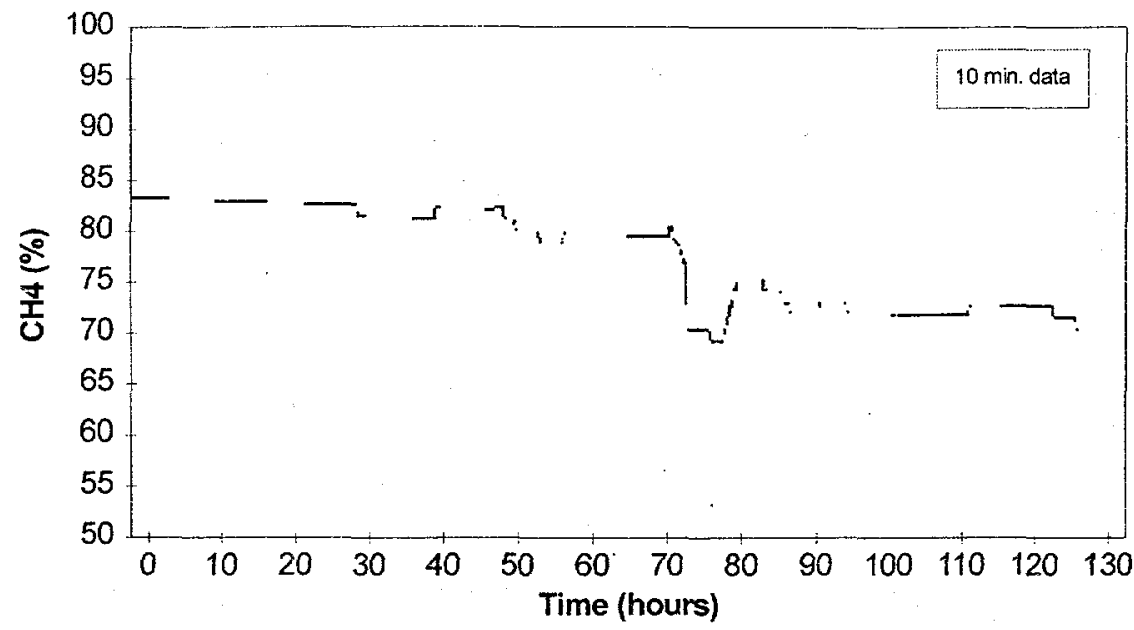

Figure 6-61. Methane content in headspace during OLR shock loading experiment (10 minute data).

Plots of the ratio of $\mathrm{CO}$ to gas production rate $(\mathrm{CO} / \mathrm{GP})$ and $\mathrm{H}_{2}$ to gas production rate $\left(\mathrm{H}_{2} / \mathrm{GP}\right)$ were constructed for the 10-minute data (Figures 6-62 and 6-63). A bivariate plot was then constructed (Figure 6-64). During the critical period (70-80 hours) when the reactor performance was not stable, gas production decreased continuously, while both $\mathrm{H}_{2}$ and $\mathrm{CO}$ exhibited large concentration changes. The $\mathrm{CO} / \mathrm{GP}$ and $\mathrm{H}_{2} / \mathrm{GP}$ ratios represented this change well. The CO/GP ratio was smooth and low (<0.4) before the OLR was increased to $60 \mathrm{~kg} \mathrm{COD} / \mathrm{m}^{3}-\mathrm{d}$ at 70 hours (Figure 6-63). The CO/GP ratio then increased rapidly to 6.0 within 6 hours. Immediately after the perturbation was stopped (OLR stepped down to its pre-perturbation level of $10 \mathrm{~kg} \mathrm{COD} / \mathrm{m}^{3}-\mathrm{d}$ ), the $\mathrm{CO} / \mathrm{GP}$ ratio decreased to background with about a 2-hour lag period. The $\mathrm{CO} / \mathrm{GP}$ displayed cyclic variations thereafter. The $\mathrm{H}_{2} / \mathrm{GP}$ ratio was observed to slightly increase over time during 0-70 hours (Figure 6-62), but remained at a low value $(<0.75$ ). After the 70 -hour mark, this ratio peaked at 3.7 ( 76 hours). It returned to its background level at 80 hours. Again, fluctuations were observed after the shock loading. Bivariate plots of $\mathrm{CO} / \mathrm{GP}$ and $\mathrm{H}_{2} / \mathrm{GP}$ were constructed using 10 minute and hourly averaged data (Figure 6-64). The majority of points fall in the lower range or lower left corner of the plot. During the periods when the system was "in-control," the CO/GP and $\mathrm{H}_{2} / \mathrm{GP}$ data all fell within the $\{1,2\}$ window (Table 6-16). This matches the data from the three other unsteady state and steady state experimental runs. Any point that falls outside of the "stable" region may be recognized as a sign of system disturbance due to OLR shock loading. The data outside this region are those collected during the 70 - to 80 -hour time period. 


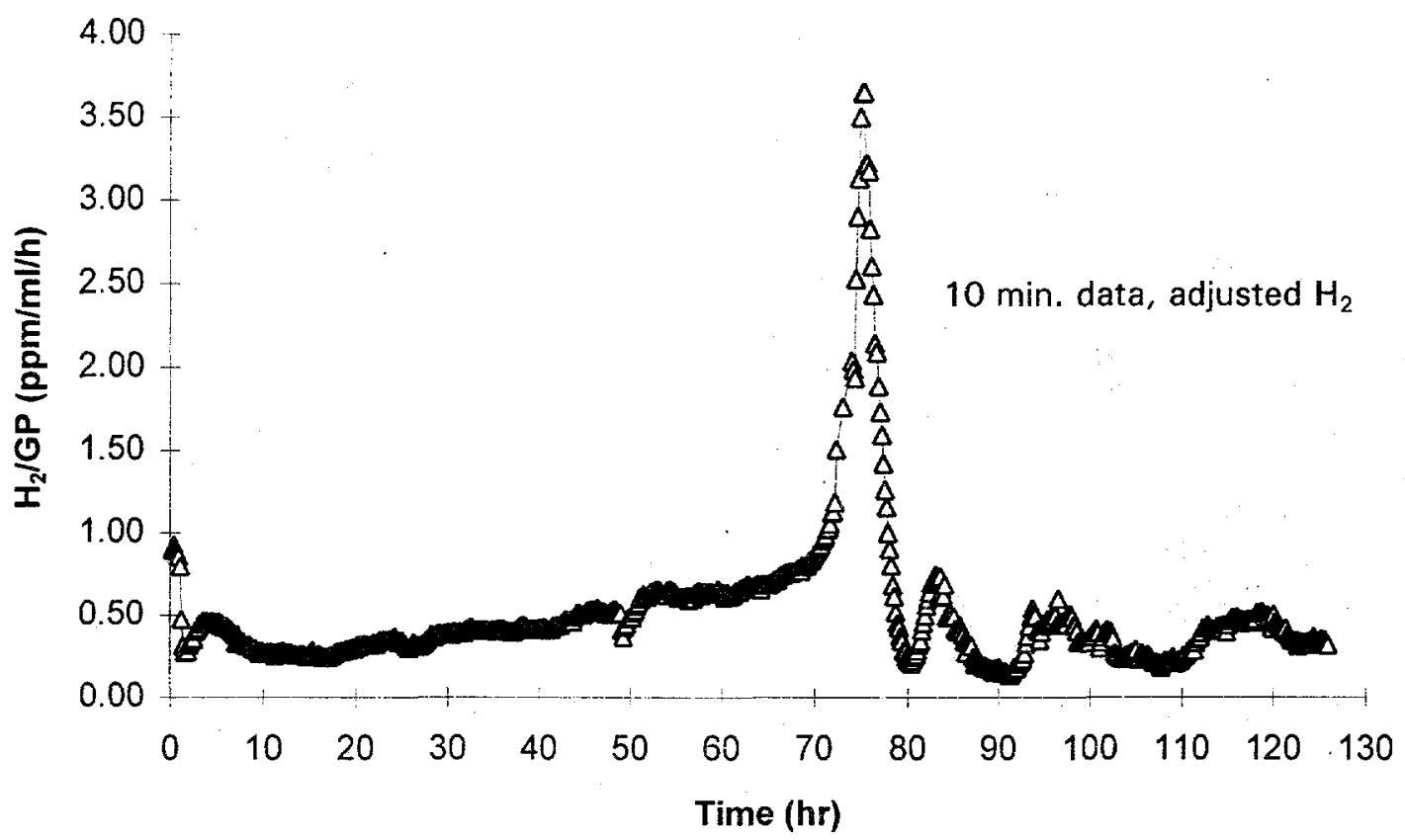

Figure 6-62. $\mathrm{H}_{2} /$ gas production versus time during OLR shock loading experiment (based on 10-minute data).

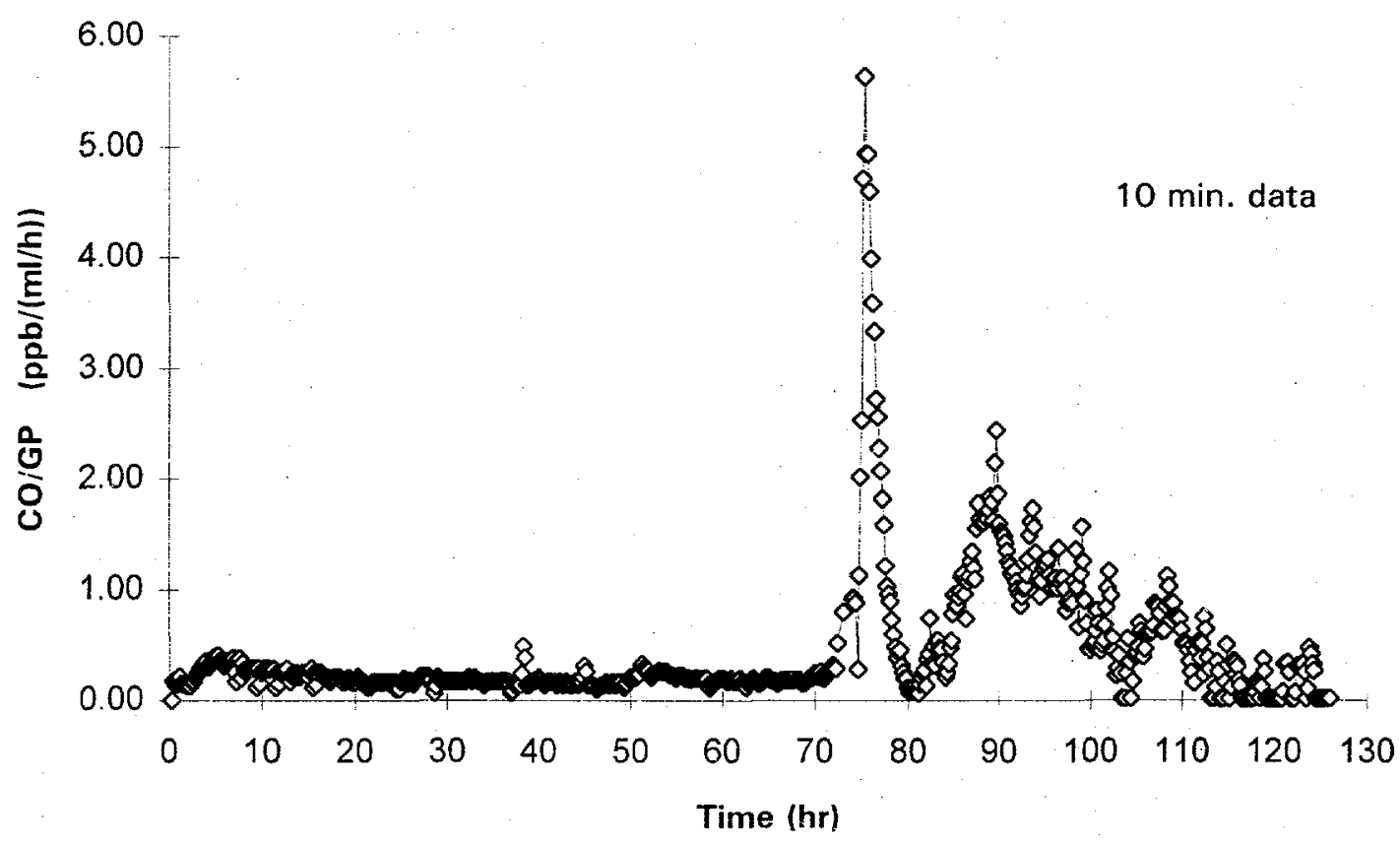

Figure 6-63. CO/gas production versus time during OLR shock loading experiment (based on 10-minute data). 


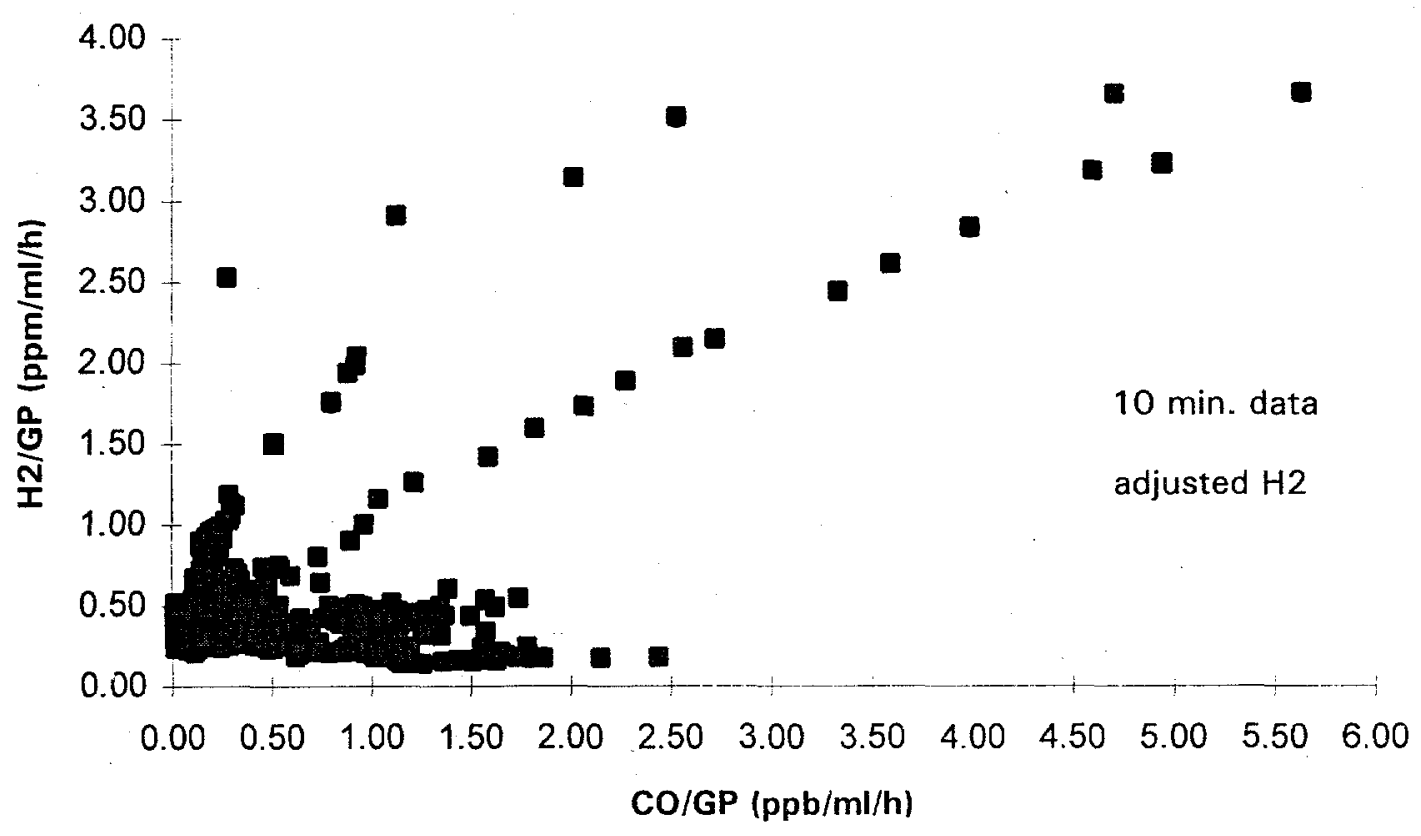

Figure 6-64. Bivariate plot of CO/GP and $\mathrm{H}_{2} / \mathrm{GP}$ during OLR shock loading experiment (based on 10-minute data).

\begin{tabular}{|c|c|c|c|c|c|}
\hline \multicolumn{6}{|c|}{$\begin{array}{l}\text { Table 6-16. Mean, SD and STDerr or } \mathrm{CO} / \mathrm{GP} \text { and } \mathrm{H}_{2} / \mathrm{GP} \text { at steady state (in-control) } \\
\text { during OLR shock loading experiment USS4. }\end{array}$} \\
\hline & \multicolumn{5}{|c|}{$\mathrm{CO} / \mathrm{GP}$} \\
\hline OLR & 10 & 10 & 30 & 40 & 60 \\
\hline MEAN & 0.157 & 0.356 & 0.229 & 0.171 & 0.209 \\
\hline SD & 0.015 & 0.306 & 0.075 & 0.045 & 0.041 \\
\hline STDerr & 0.007 & 0.024 & 0.006 & 0.004 & 0.005 \\
\hline $\mathbf{n}$ & 4 & 161 & 144 & 144 & 79 \\
\hline \multirow[t]{2}{*}{ Note: } & before start & after $100 \mathrm{hrs}$ & & & $\begin{array}{c}\text { before } 62 \\
\text { hours }\end{array}$ \\
\hline & \multicolumn{5}{|c|}{$\mathrm{H}_{2} / \mathrm{GP}$} \\
\hline OLR & 10 & 10 & 30 & 40 & 60 \\
\hline MEAN & 0.900 & 0.353 & 0.331 & 0.426 & 0.610 \\
\hline SD & 0.022 & 0.092 & 0.089 & 0.062 & 0.062 \\
\hline STDerr & 0.011 & 0.007 & 0.007 & 0.005 & 0.007 \\
\hline $\mathrm{n}$ & 4 & 161 & 144 & 144 & 79 \\
\hline Note: & before start & after $100 \mathrm{hrs}$ & & & $\begin{array}{c}\text { before } 62 \\
\text { hours }\end{array}$ \\
\hline \multicolumn{6}{|c|}{ 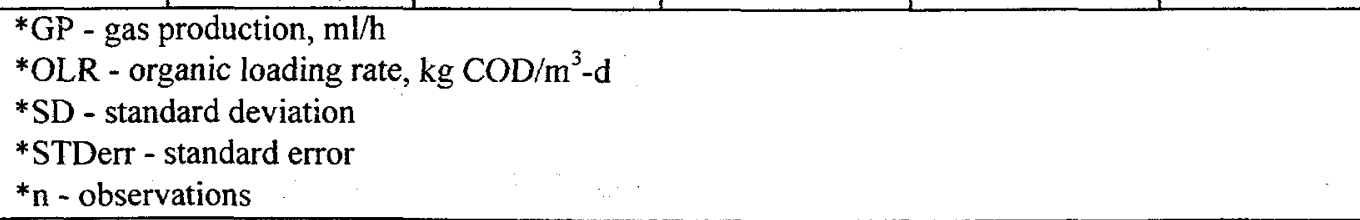 } \\
\hline
\end{tabular}


Identification of each of the scattered points in a bivariate plot was performed for the last perturbation experiment (USS4), to examine the UASB system behavior under system failure (or out of control). Results of this analysis are presented in Figure 6-65. The scattered points, from (a) to (g) represent the peak during 72 to 78 hours, when the system started to fail. That is, gas production was continuously dropping, VFAs were accumulating, and $\mathrm{pH}$ decreased to below 6.0. A region of $\{2,1\}$ for $\mathrm{CO} / \mathrm{GP}$ and $\mathrm{H}_{2} / \mathrm{GP}$ at lower left corner included all other points. $\mathrm{H}_{2} / \mathrm{GP}$ was more sensitive in responding to system failure than CO/GP. During 72 to 75 hours, when the UASB system started to go out of control, normalized trace gases represented by points c) to f) did not fall within this "stable" or "in-control" region but began moving toward the upper right corner. The worst case was at 76 hours when the system was totally out of control. At that time the bivariate point (a) was far away from the region $\{2,1\}(\mathrm{CO} / \mathrm{GP}$, $\mathrm{H}_{2} / \mathrm{GP}$ ). During the system recovery-points (b), (g) and (h), from 77 to 79 hours - the normalized trace gas ratio was observed to begin moving back to the lower left corner. After OLR shock, small variations were observed. These can be seen from 86 to 96 hours-points (i) to (p). These variations were within $\{0.5,2.0\}$ for $\mathrm{H}_{2} / \mathrm{GP}$ and $\mathrm{CO} / \mathrm{GP}$, respectively. The behavior of the $\mathrm{CO} / \mathrm{GP}$ and $\mathrm{H}_{2} / \mathrm{GP}$ combination in this experiment confirmed that a certain region in the bivariate plot contained most data points collected when the system was "in control."

The above results, steady state data and system failure data demonstrated that criteria can be established to recognize early signs of system failure caused by OLR overloading, using $\mathrm{CO} / \mathrm{GP}$ and $\mathrm{H}_{2} / \mathrm{GP}$. The region $\left\{\mathrm{CO} / \mathrm{GP}=2.0 \mathrm{ppb} / \mathrm{mL} / \mathrm{h}, \mathrm{H}_{2} / \mathrm{GP}=1.0 \mathrm{ppm} / \mathrm{mL} / \mathrm{h}\right\}$ appears to represent the OLR region where the system is operating under control. 


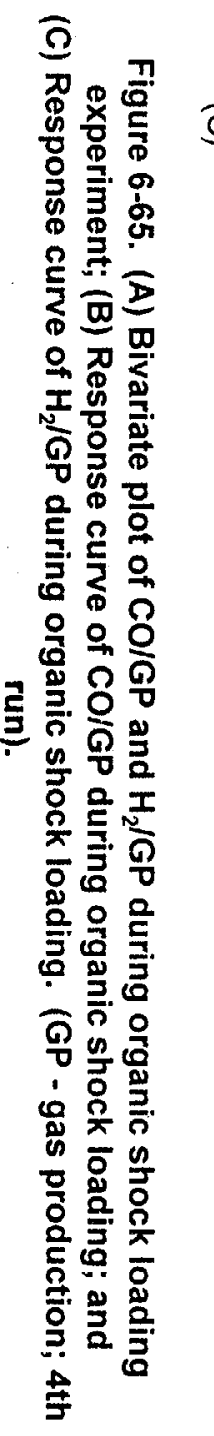

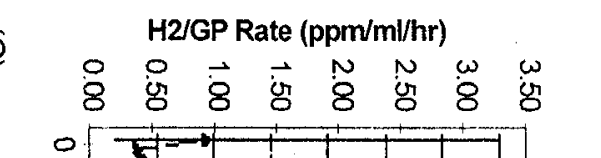

Ф్

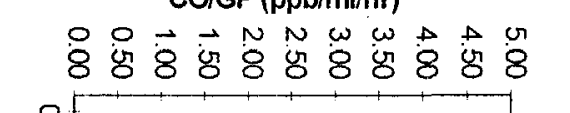

$$
\text { o }
$$

จ

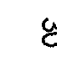

of

of

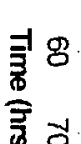

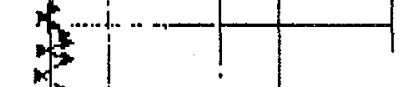

응

o

8

$\overrightarrow{8}$

$\overrightarrow{\vec{\sigma}}$

$\vec{\sigma}$

$\overrightarrow{\mathrm{o}}$
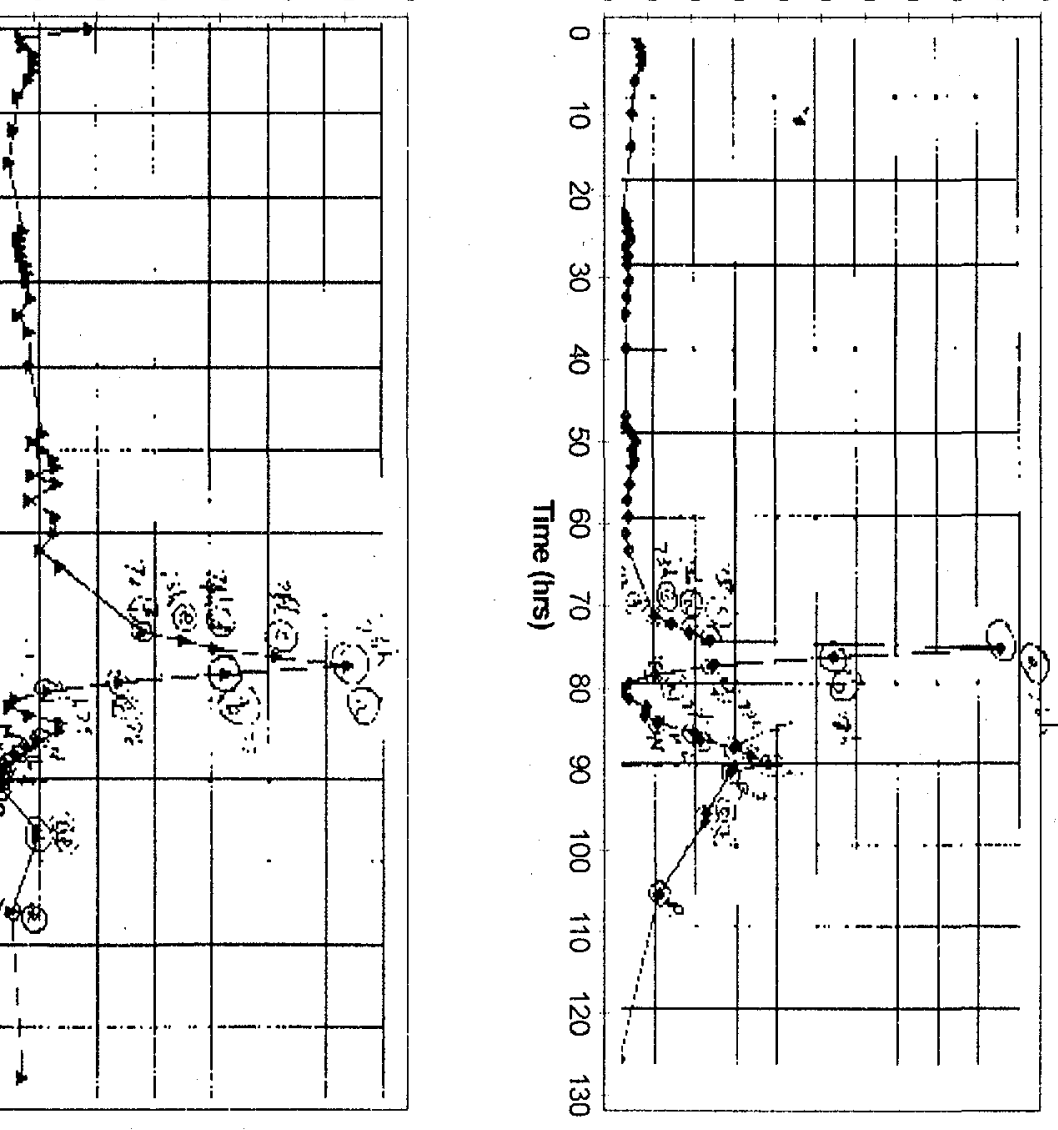

I

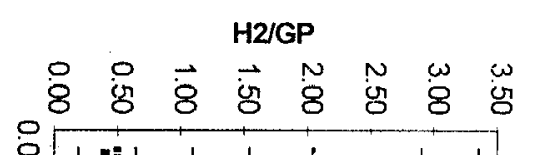

$$
\text { 8 }
$$

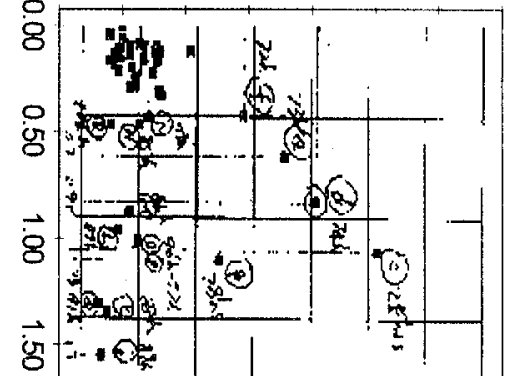

$$
\frac{1}{11}
$$

迎

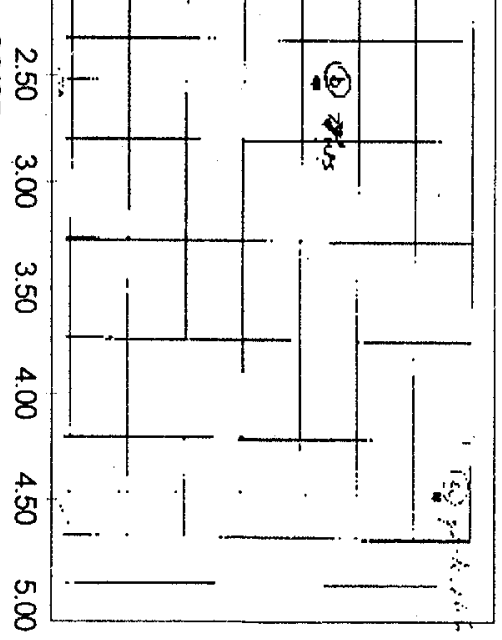


CONFIRMATION EXPERIMENT - UNSTEADY STATE (USS6) - NO PH CONTROL

Results and data analyses of a final OLR shock loading experiment (USS6) were developed to confirm that the control chart technique using bivariate plot of $\mathrm{CO} / \mathrm{GP}$ and $\mathrm{H}_{2} / \mathrm{GP}$ is a valid approach. This OLR perturbation was essentially a repeat of OLR shock loading experiment USS4. OLR was varied step-wise from 10 to $30,40,60,50 \mathrm{~kg} \mathrm{COD} / \mathrm{m}^{3-} \mathrm{d}$ (Figure 6-66). Each step change in OLR lasted for 24 hours. The background OLR level was at $10 \mathrm{~kg} \mathrm{COD} / \mathrm{m}^{3}-\mathrm{d}$. After a $60 \mathrm{~kg} \mathrm{COD} / \mathrm{m}^{3}-\mathrm{d}$ OLR was applied to the UASB reactor for 24 hours, the OLR was reduced down to $50 \mathrm{~kg} \mathrm{COD} / \mathrm{m}^{3-} \mathrm{d}$ from 72.6 to 74.6 hours. The applied OLR was then returned to the initial OLR $\left(10 \mathrm{~kg} \mathrm{COD} / \mathrm{m}^{3}-\mathrm{d}\right)$ at $\mathrm{t}=74.6$ hours. The experiment had to be terminated at 77 hours when the granular bed rose up to the gas collector and clogged gas flow and liquid effluent flows. During hours 23 to 29 , the OLR was at $10 \mathrm{~kg} \mathrm{COD} / \mathrm{m}^{3}-\mathrm{d}$ due to an operational accident. The HRT was varied from 12 to 5 hours during the course of the experiment. The feed concentration was $11.4 \mathrm{~kg} \mathrm{COD} / \mathrm{m}^{3}-\mathrm{d}$ throughout. The OLR variation was accomplished by varying feed rate only. Reactor operational temperature was $37^{\circ} \mathrm{C}$. The $\mathrm{H}_{2}, \mathrm{CO}, \mathrm{CH}_{4}$ concentrations, and gas production were monitored every 20 minutes. Liquid phase $\mathrm{pH}$, effluent, and VFAs were monitored hourly for the first 6 hours and at 8,12 , and 24 hours of each day.

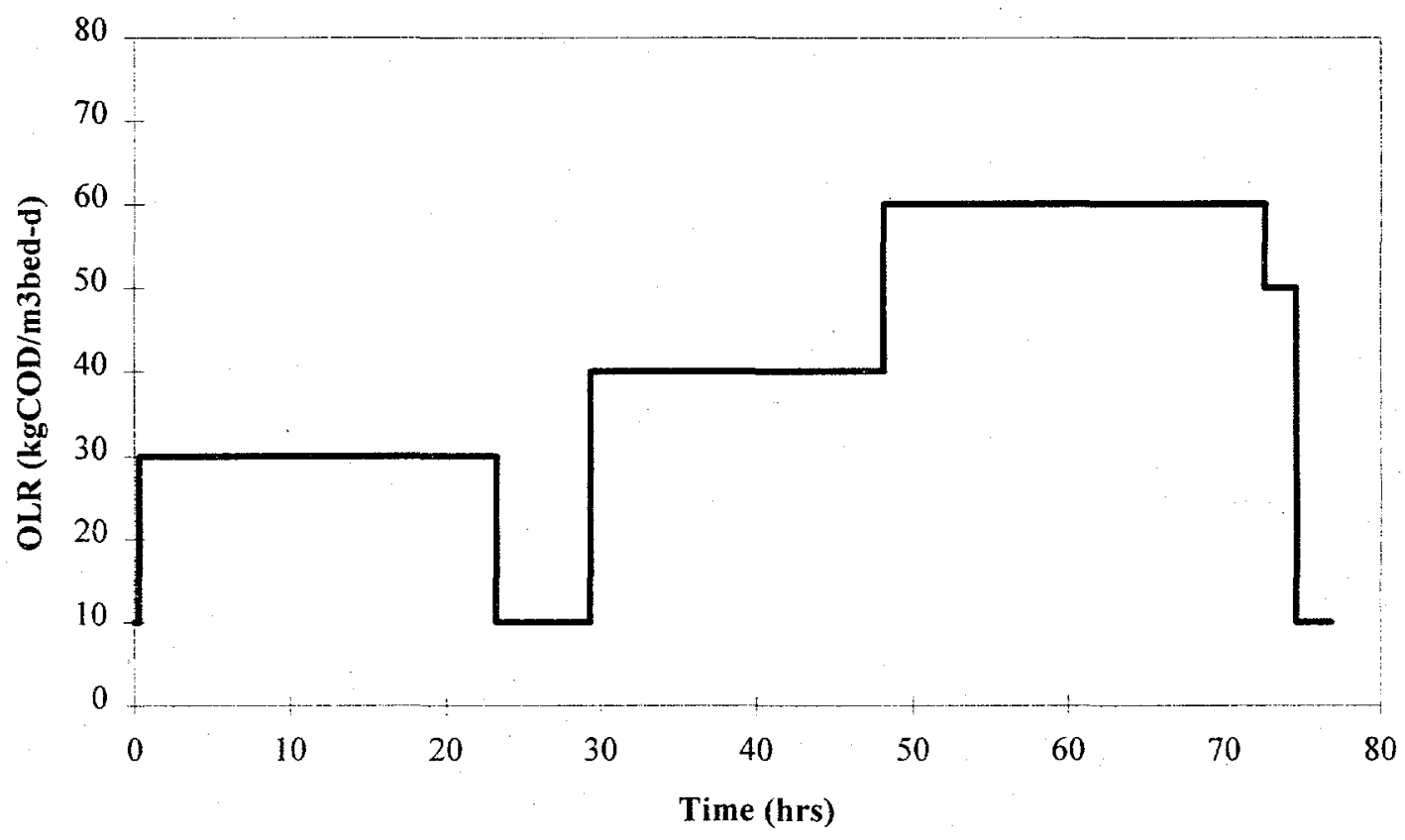

Figure 6-66. OLR variation during shock loading experiment USS6. 
Gas phase $\mathrm{H}_{2}$ concentration exhibited a similar trend compared with experiment USS4, although the absolute value of $\mathrm{H}_{2}$ was not the same. Little variation in $\mathrm{CO}$ was observed. The trend in $\mathrm{CO}$ concentration at unsteady state was reproducible. Gas production continued to decrease after the OLR was decreased to $50 \mathrm{~kg} \mathrm{COD} / \mathrm{m}^{3}-\mathrm{d}$ and subsequently to $10 \mathrm{~kg} \mathrm{COD} / \mathrm{m}^{3}-\mathrm{d}(\mathrm{t}=74.6 \mathrm{hr})$, which was identical to results observed during the previous run. Concentrations of $\mathrm{CH}_{4}, \mathrm{VFAs}, \mathrm{pH}$ and gas production rates were reproducible. Long-chain fatty acids ( 4 and 5-carbons), were observed in the reactor effluent. Ethanol and n-propanol were also detected. The UASB reactor system was in control for 60 hours, it handled the OLR of $60 \mathrm{~kg} \mathrm{COD} / \mathrm{m}^{3}-\mathrm{d}$ for 12 hours before system performance began to go out of control. The reactor system slowly recovered over five days after the shock loading was ended. The reactor was shut down at that time. Following is a detailed discussion of each parameter monitored.

\section{$\underline{\mathrm{H}}_{\underline{2}}, \mathrm{CO}$, and Gas Production Rate}

The responses of gas production rate and $\mathrm{H}_{2}$ are presented in Figure 6-67. The gas production rate followed the variation in OLR. Both the response trend and the levels were close to those observed previously. The background gas production rate was $320 \mathrm{~mL} / \mathrm{h}$. As the OLR reached $60 \mathrm{~kg} \mathrm{COD} / \mathrm{m}^{3}-\mathrm{d}$, the gas production rate started decreasing 12 hours after the step increase (at $t=60 \mathrm{hr}$ ). The decline of the gas production rate was accelerated at $t=65 \mathrm{hr}$ represented by a slope change at that time. The gas production rate became reduced to $40 \%$ of its steady state value at $t=70 \mathrm{hr}$, and $30 \%$ at $t=73 \mathrm{hr}$. After the OLR was reduced to $10 \mathrm{~kg} \mathrm{COD} / \mathrm{m}^{3}-\mathrm{d}$, gas production continued to decrease. Due to the complication caused by flotation of many of the granules in the reactor bed, the recovery data for the gas production rate could not be obtained.

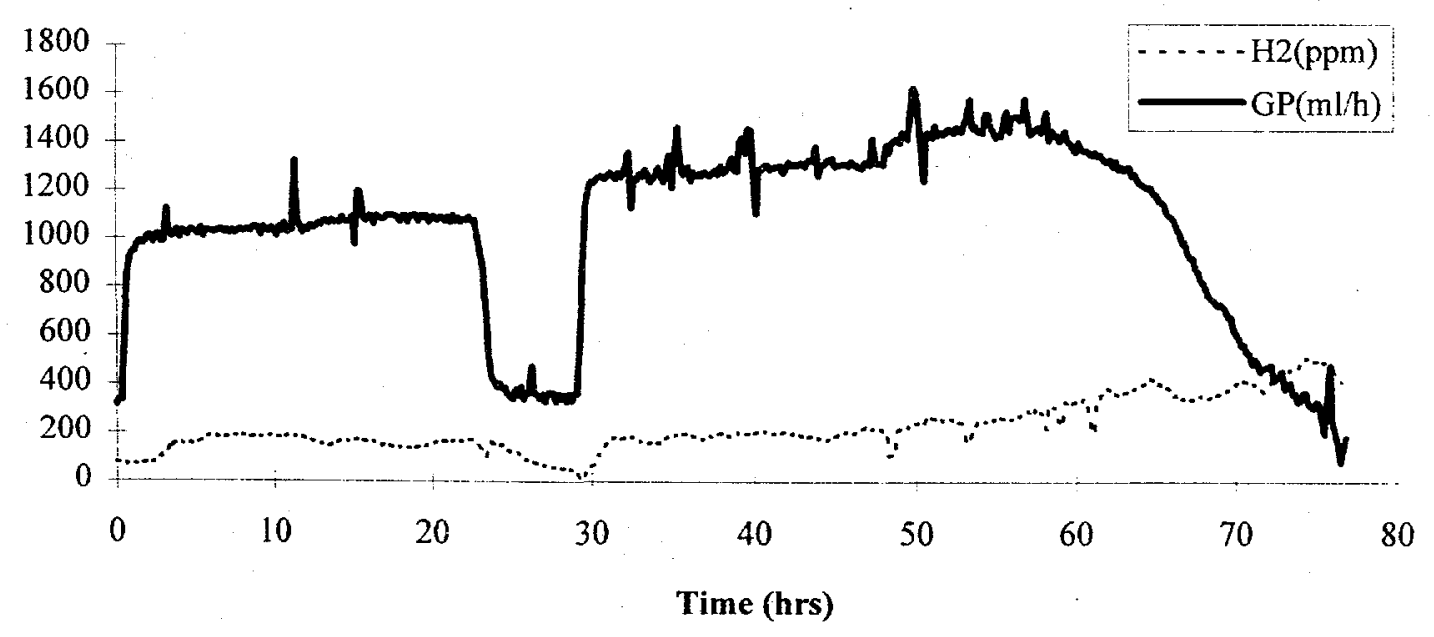

Figure 6-67. Responses of gas production and $\mathrm{H}_{2}$ during OLR shock loading. 
Headspace $\mathrm{H}_{2}$ concentration was much less sensitive to OLR compared to prior tests. The background $\mathrm{H}_{2}$ concentration averaged $67 \mathrm{ppm} . \mathrm{H}_{2}$ remained at $160-220 \mathrm{ppm}$ for the initial 48 hours (OLR 30 and $40 \mathrm{~kg}$ $\mathrm{COD} / \mathrm{m}^{3}-\mathrm{d}$ ) and then began to increase gradually at a rate of $10.8 \mathrm{ppm} / \mathrm{hr}$ until $\mathrm{t}=74.5 \mathrm{hr} . \mathrm{H}_{2}$ reached a peak of $510 \mathrm{ppm}$ and declined after the OLR was reduced to $10 \mathrm{~kg} \mathrm{COD} / \mathrm{m}^{3}-\mathrm{d}$. The behavior of $\mathrm{H}_{2}$ was similar to that observed during experiment USS4 at $t=48 \mathrm{hr}$. The absolute value of $\mathrm{H}_{2}$, however, was much lower ( $500 \mathrm{ppm}$ at the peak in this run, compared to $1000 \mathrm{ppm}$ in the previous run).

The CO background concentration was $4.0 \mathrm{ppb}$, which is the detection limit of the instrument, and was $2 \%$ of the $\mathrm{CO}$ in the previous run (200 ppb). During the experiment, $\mathrm{CO}$ remained at levels below $0.05 \mathrm{ppm}$ for the initial 72 hours (Figure 6-68) with little variation. After that point, $\mathrm{CO}$ increased rapidly at a rate of $0.21 \mathrm{ppm} / \mathrm{hr}$. CO reached a peak of $0.85 \mathrm{ppm}$ at 75.5 hours ( 1 hour after the OLR returned to $10 \mathrm{~kg}$ $\mathrm{COD} / \mathrm{m}^{3}-\mathrm{d}$ ). The $\mathrm{CO}$ concentration had decreased to $0.77 \mathrm{ppm}$ when the experiment was terminated. The highest $\mathrm{CO}$ concentration observed was about $60 \%$ of the $\mathrm{CO}$ values observed during the last run (1.5 ppm). Outside of the lower absolute value of $\mathrm{CO}$ at steady state $(\mathrm{t}=60 \mathrm{hr})$ and when the system was significantly perturbed $(t>60 \mathrm{hr}$ ), the trend of $\mathrm{CO}$ variation was similar to that observed previously.

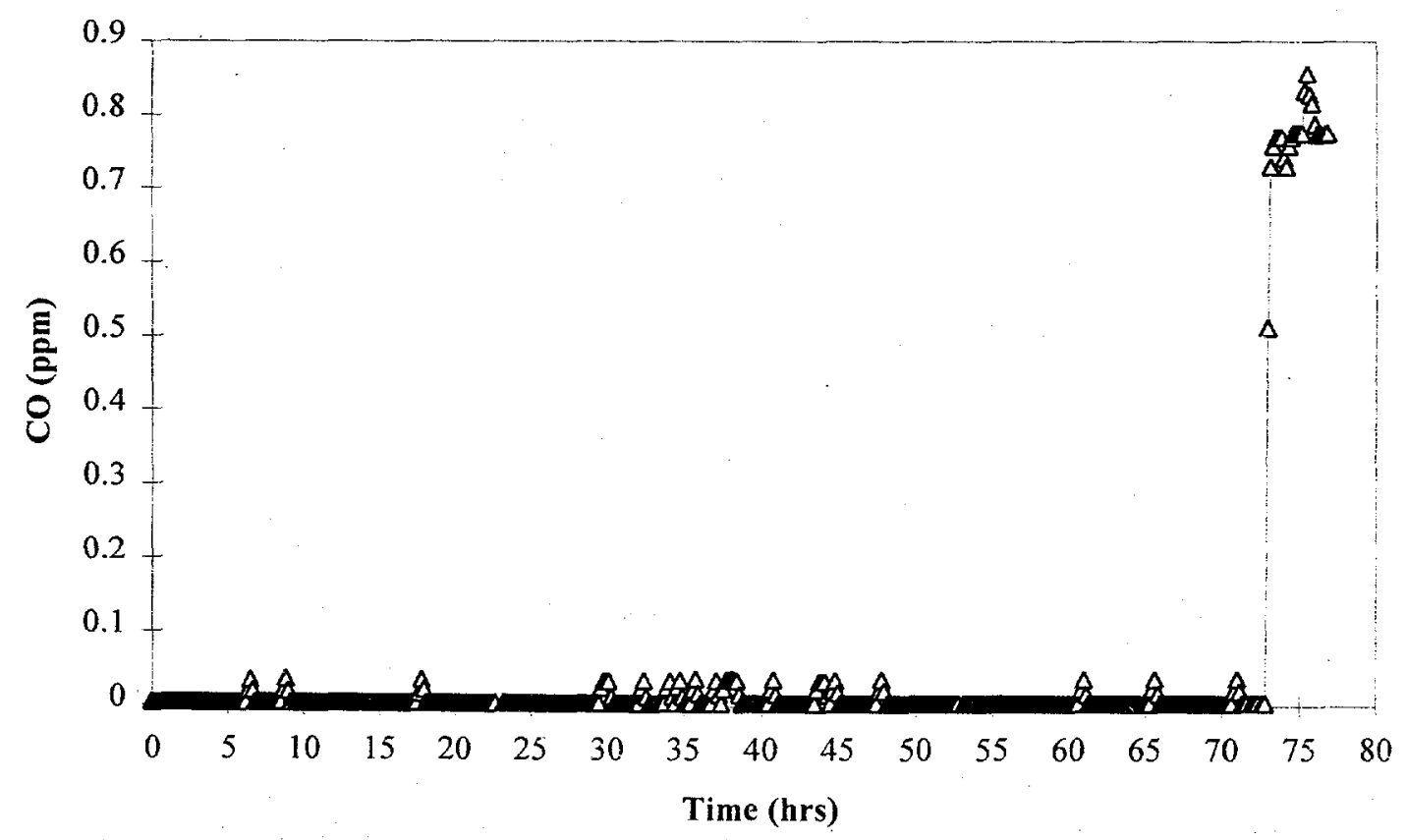

Figure 6-68. CO response during OLR shock loading. 
The normalized $\mathrm{H}_{2}$ and $\mathrm{CO}$ (using the gas production rate) were calculated. Results of $\mathrm{CO} / \mathrm{GP}$ and $\mathrm{H}_{2} / \mathrm{GP}$ and bivariate plots of $\mathrm{CO} / \mathrm{GP}-\mathrm{H}_{2} / \mathrm{GP}$ are shown in Figures 6-69 through 6-71. Both the $\mathrm{CO} / \mathrm{GP}$ and $\mathrm{H}_{2} / \mathrm{GP}$ ratios were very reproducible. The $\mathrm{CO} / \mathrm{GP}$ and $\mathrm{H}_{2} / \mathrm{GP}$ peaked 1 hour after the shock OLR was stopped. The $\mathrm{CO} / \mathrm{GP}$ was stable at low level during $\mathrm{t}=0$ to $t=71$ hours (Figure 6-69). Starting at 72 hours, it increased rapidly up to $6.8 \mathrm{ppb} / \mathrm{mL} / \mathrm{h}$ by 76 hours. The ratio of $\mathrm{H}_{2} / \mathrm{GP}$ remained below $0.5 \mathrm{ppm} / \mathrm{mL} / \mathrm{h}$ for 68 hours (Figure 6-70). Beginning at 69 hours, $\mathrm{H}_{2} / \mathrm{GP}$ increased, reaching $3.5 \mathrm{ppm} / \mathrm{mL} / \mathrm{h}$ at 76 hours. Bivariate plots of $\mathrm{CO} / \mathrm{GP}$ and $\mathrm{H}_{2} / \mathrm{GP}$ show that the data points initially fell within $\{0.1,0.5\}$ as $\mathrm{CO} / \mathrm{GP}$ and $\mathrm{H}_{2} / \mathrm{GP}$ (Figure 6-71). The first data that did not fall within the $\mathrm{CO} / \mathrm{GP}=2.0, \mathrm{H}_{2} / \mathrm{GP}=1.0$ range occurred at 72 hours. These data were similar to those from USS4. Data points from 72 to 76 hours were marked as "a" to "e" in Figures 6-69 through 6-71 (a" and a" represent the data at 71 and 72 hours, respectively). In bivariate plots, data points were away from the $\{2,1\}$ region $\left(\mathrm{CO} / \mathrm{GP}=2.0, \mathrm{H}_{2} / \mathrm{GP}=1.0\right)$ when the UASB reactor system was significantly perturbed (from a to e). This could be seen from the poor performance, i.e., continuous accumulation of VFAs ( $27 \mathrm{mM}$ acetate, $7 \mathrm{mM}$ propionate, $3.4 \mathrm{mM}$ ethanol, and $5.5 \mathrm{mM}$ propanol), low $\mathrm{pH}$ (5.3), and decreased biogas production rate ( $34 \%$ of steady state value).

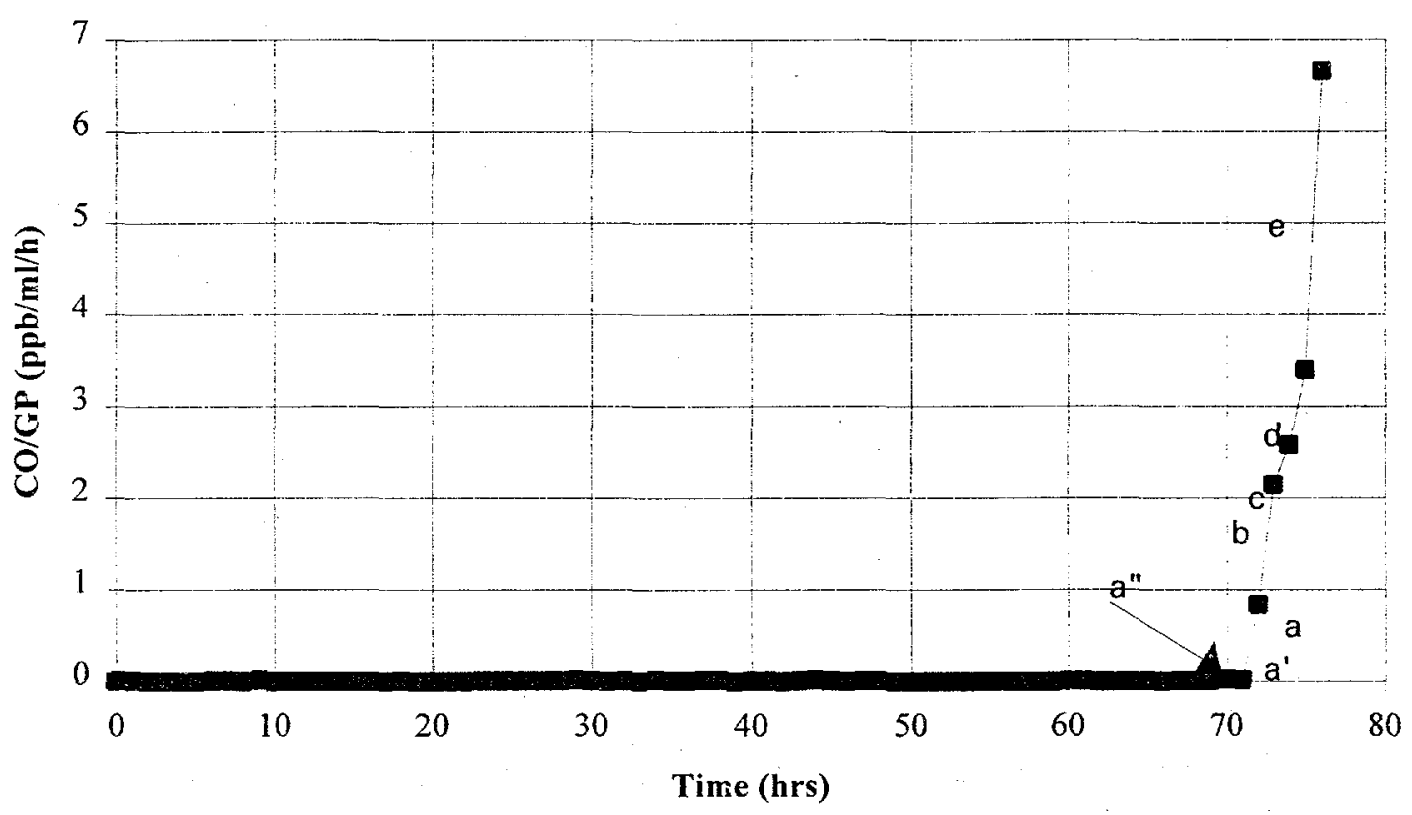

Figure 6-69. Normalized CO (CO/GP) variation where GP is gas production rate. 


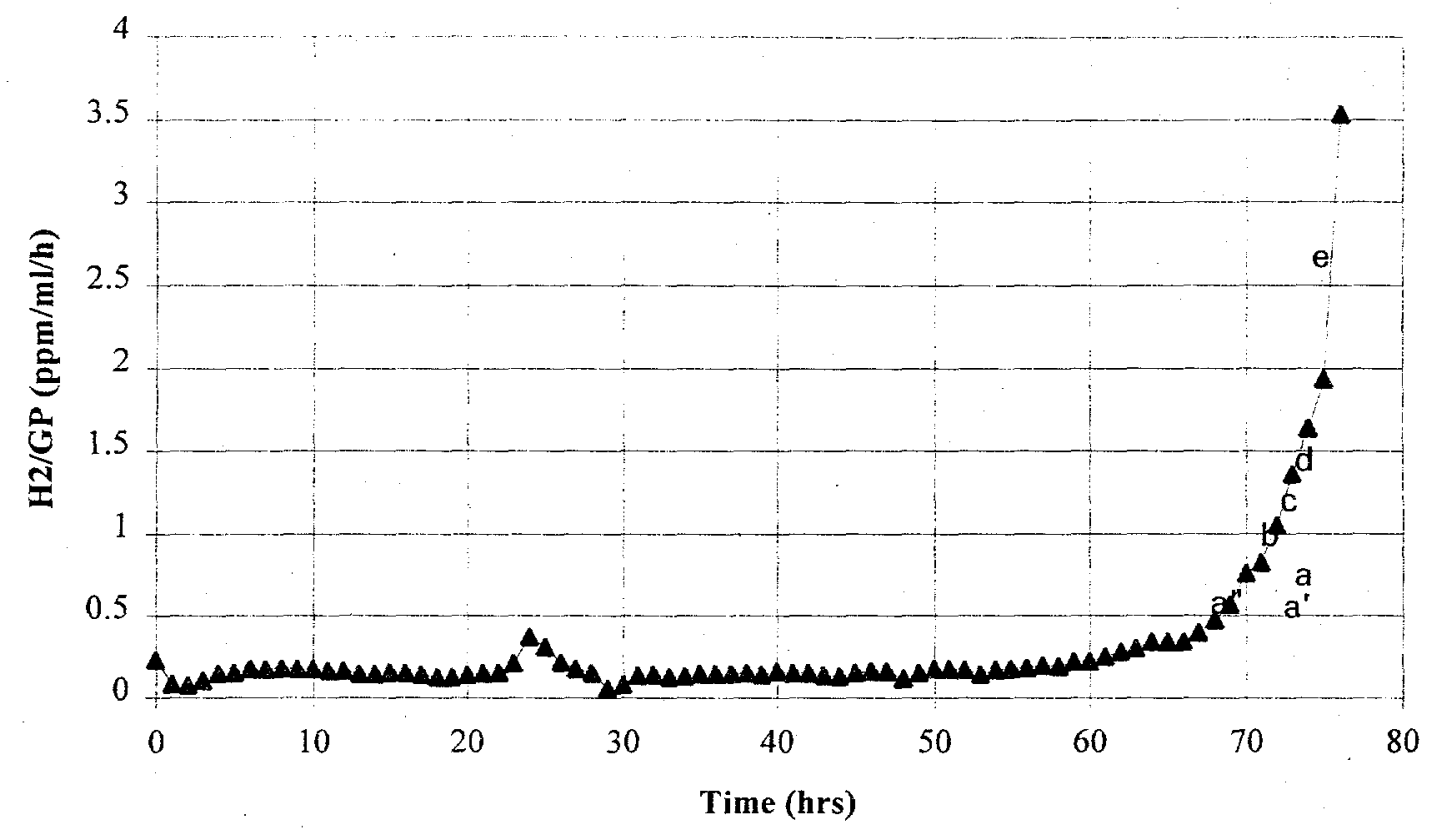

Figure 6-70. Normalized $\mathrm{H}_{2}\left(\mathrm{H}_{2} / \mathrm{GP}\right)$ variation where GP is gas production rate.

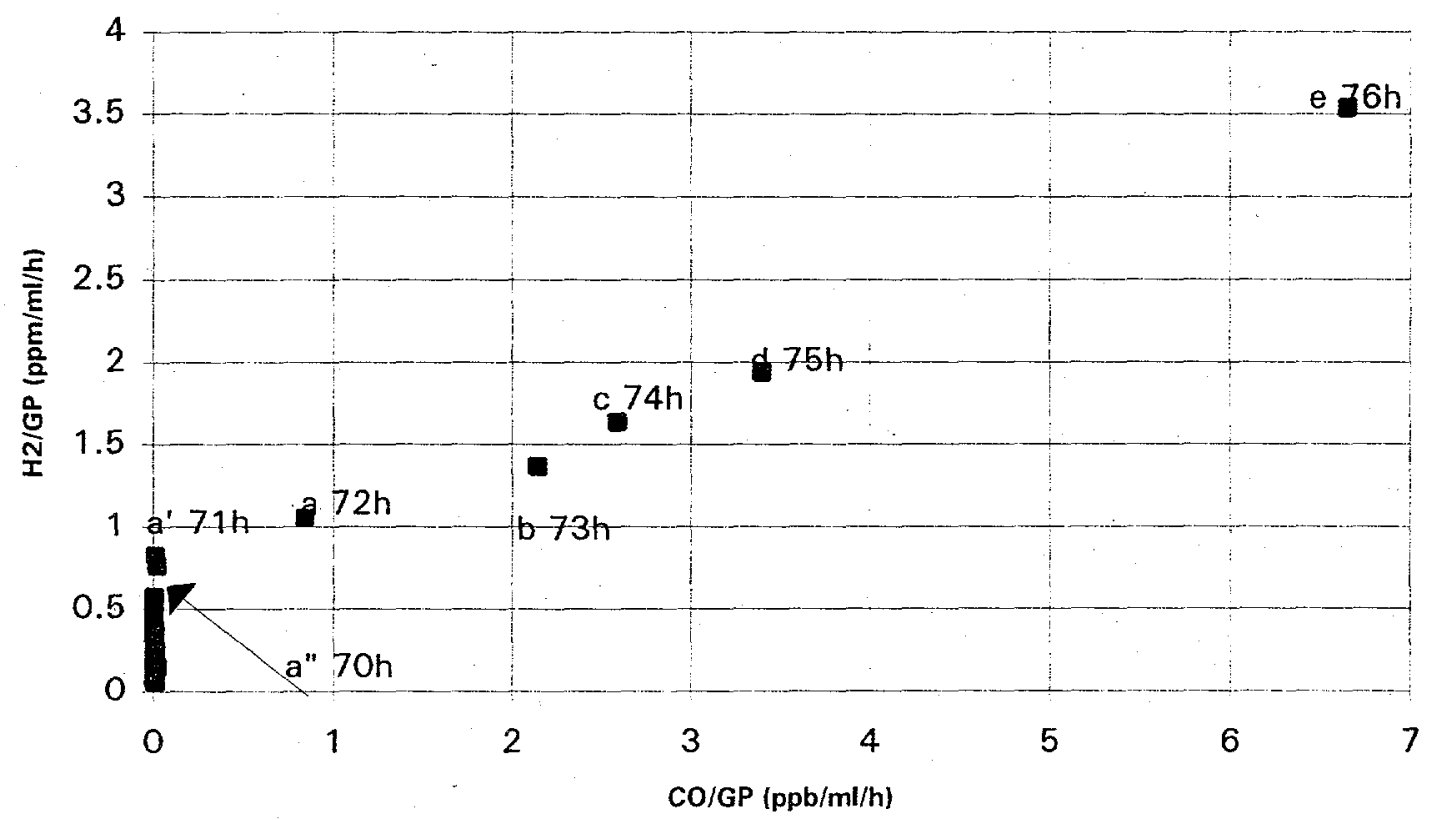

Figure 6-71. Bivariate plot of CO/GP and $\mathrm{H}_{2} / \mathrm{GP}$. 


\section{$\mathrm{CH}_{4}$ and $\mathrm{pH}$}

The change in methane concentration was slow in response to the OLR shock loading (Figure 6-72).

Methane was between $85 \%$ and $87 \%$ for the first 70 hours. It decreased slightly to $80 \%$ at the conclusion of the experiment. Clear indication of system perturbation could not be obtained by looking at the methane content. The change of methane content in the gas stream was less than observed previously at the same OLR shock loading (USS4).

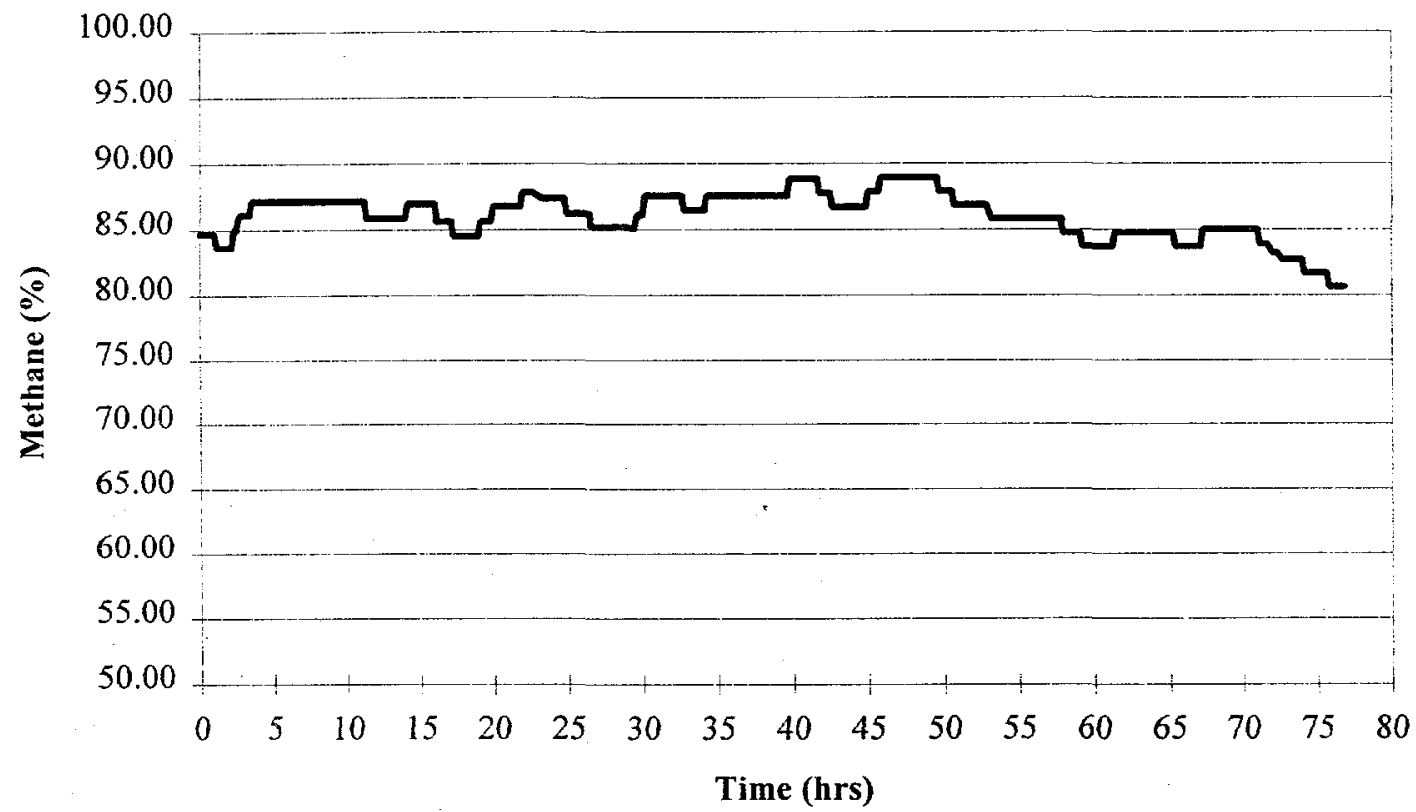

Figure 6-72. Methane content variation during OLR shock loading (USS6).

The variation in $\mathrm{pH}$ during the OLR shock loading is presented in Figure 6-73. The $\mathrm{pH}$ varied little during the first 53 hours of the experiment. The initial pH of 7.0 decreased 1 unit by $t=60 \mathrm{hr}$ as a result of accumulation of acids. The $\mathrm{pH}$ continued to decrease to $5.1 \mathrm{by} \mathrm{t}=83 \mathrm{hr}$. This trend was similar to the response observed during the last OLR perturbation. In both cases, the $\mathrm{pH}$ did indicate disturbance to the system when the reactor started going out of control. Reactor $\mathrm{pH}$ remained low after the shock loading was stopped. The $\mathrm{pH}$ returned to 6.6 , six days after the OLR was decreased to $10 \mathrm{~kg} \mathrm{COD} / \mathrm{m}^{3}-\mathrm{d}$. 


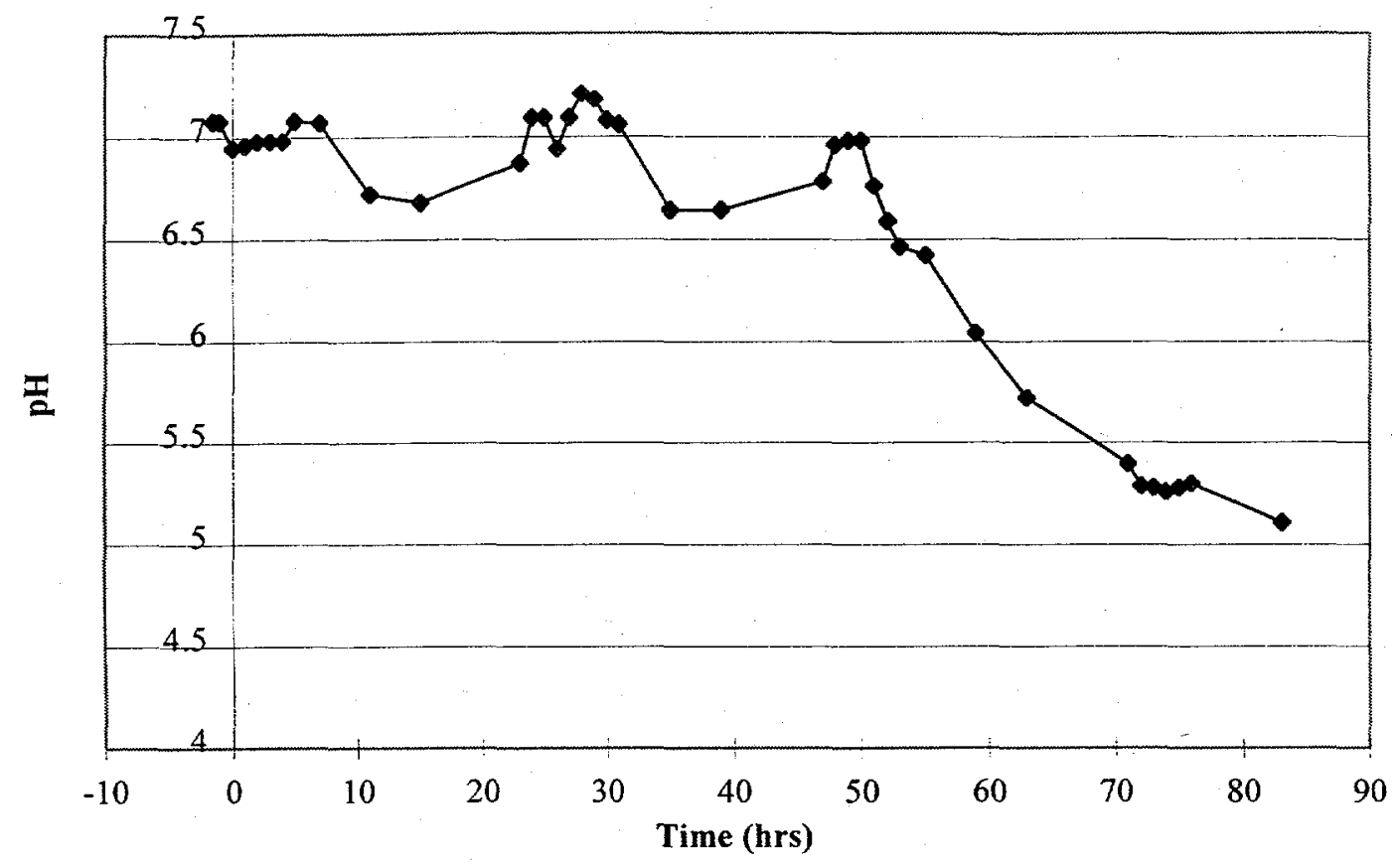

Figure 6-73. $\mathrm{pH}$ variation during OLR shock loading (USS6).

\section{VFAs, n-propanol, and Ethanol}

The concentration profile of acetate and propionate during the initial 83 hours of the perturbation is presented in Figure 6-74. Quantifiable concentrations of acetate and propionate were detected in the effluent when the OLR was increased to $40 \mathrm{~kg} \mathrm{COD} / \mathrm{m}^{3-} \mathrm{d}$ at $\mathrm{t}=30$ hours. A step to an organic loading rate of $60 \mathrm{~kg} \mathrm{COD} / \mathrm{m}^{3}-\mathrm{d}$ led to a rapid increase in acetate and propionate. Acetate accumulated at a rate of approximately $1.16 \mathrm{mM} / \mathrm{h}$, reaching $33.0 \mathrm{mM}$ at 74 hours, and then stabilizing at this level for 10 hours, even when the OLR shock was removed from the UASB system (OLR set back to $10 \mathrm{~kg} \mathrm{COD} / \mathrm{m}^{3}-\mathrm{d}$ at 74 hours). Similarly, propionate accumulated during this time period to a range of 6.4 to $7.4 \mathrm{mM}$. It remained at this concentration for 24 hours. Reduction in the OLR to 10 did not affect propionate concentration for 10 hours. Accumulation of VFAs were observed to occur parallel with a decrease in $\mathrm{pH}$ in the reactor effluent. When acetate and propionate reached their peak values, inhibition of ethanol conversion occurred. Ethanol and n-propanol were observed to be at their highest concentrations between the 73- to 74-hour time period (Figure 6-75), when acetate and propionate were at their highest level. After the OLR shock was stopped, ethanol and n-propanol immediately decreased; concentrations of $0.4 \mathrm{mM}$ were observed for both compounds at 83 hours. The disappearance of these two peaks may contribute, in part, to the delayed responses of acetate and propionate to the decrease in OLR. As observed previously, the appearance and disappearance of ethanol and n-propanol coincided with accumulation of $\mathrm{CO}$. 


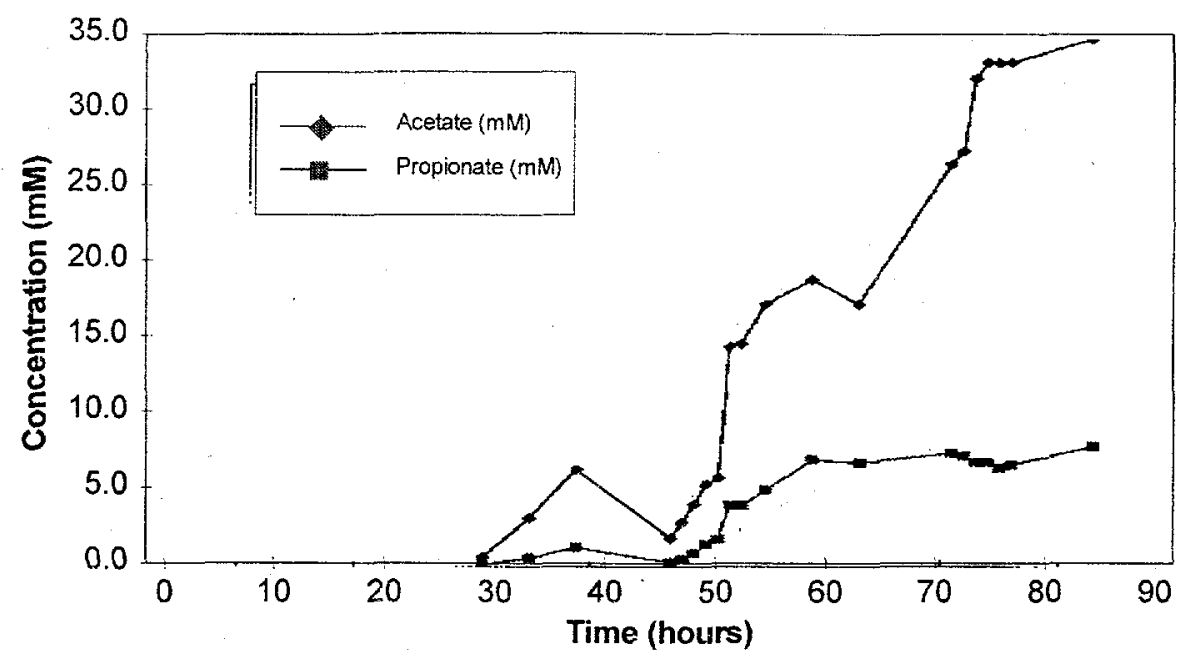

Figure 6-74. Acetate and propionate variations during OLR shock loading experiment.

The concentration of higher MW VFAs during this run are presented in Figures 6-76 and 6-77. VFA accumulation began at $\mathrm{t}=31 \mathrm{hr}$. Two-carbon (acetate), three-carbon (propionate), four-carbon (butyrate and isobutyrate), and five-carbon (2-methyl-butyrate, valerate, isovalerate) organic acids were observed in the reactor effluent. Acetate and propionate were the first to accumulate; they were observed shortly after the OLR was raised to $40 \mathrm{~kg} \mathrm{COD} / \mathrm{m}^{3}-\mathrm{d}$. Trace concentrations of isobutyrate and isovalerate appeared from $\mathrm{t}=35 \mathrm{hr}$. Butyrate was observed at $\mathrm{t}=48 \mathrm{hr}$. 2-methyl-butyrate appeared at $\mathrm{t}=50 \mathrm{hr}$. Valerate was detected at 83 hours and lasted 6 days in the reactor effluent. The accumulation responses pattern of butyrate and isobutyrate were similar to those observed during the previous OLR shock loading. After a 25-hour delay, 2-methyl-butyrate had about the same peak concentration as compared to the last run. Isovalerate remained at low concentration $(0.004 \mathrm{mM})$ for most of the experiment, similarly to the prior experiment. Accumulation of valerate, however, appeared very late ( $83 \mathrm{hr}$ ), compared to 28 hours at the last OLR shock loading. Valerate reached $0.2 \mathrm{mM}$ and remained at that level for six days after the shock loading.

The accumulation of propanol and ethanol were reproducible. Both compounds accumulated during the time period between 60 to 80 hours, which is similar to what occurred during USS4. The concentrations of propanoi and ethanol were higher for this run $(4.5 \mathrm{mM}$ versus $1.5 \mathrm{mM}$ for ethanol, and $7.5 \mathrm{mM}$ versus 1.2 $\mathrm{mM}$ for n-propanol). However, ethanol and propanol declined rapidly after the OLR was decreased to the normal level $\left(10 \mathrm{~kg} \mathrm{COD} / \mathrm{m}^{3}-\mathrm{d}\right)$. Both compounds were not detected in reactor effluent after four days. 


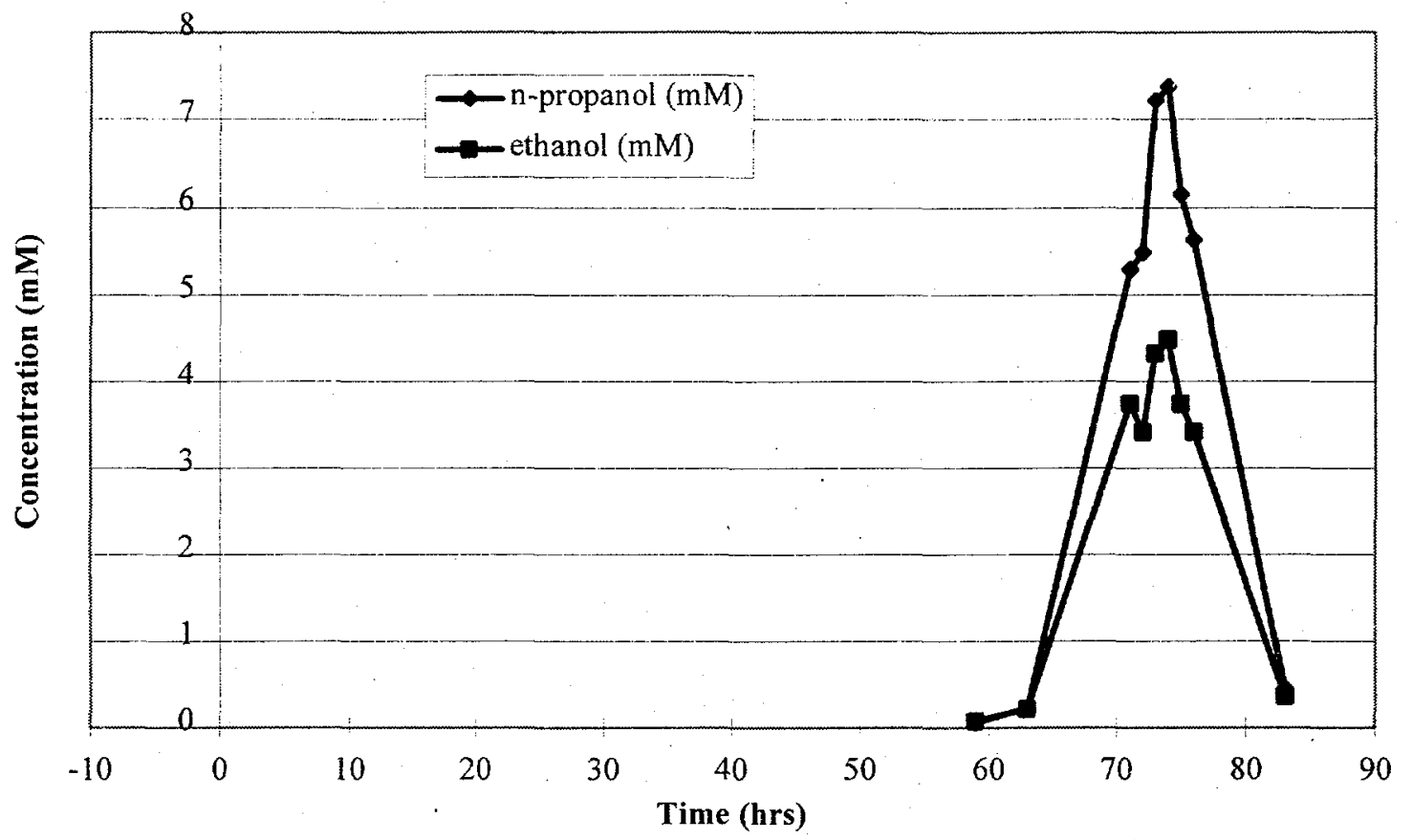

Figure 6-75. Ethanol and n-propanol variation during OLR shock loading.

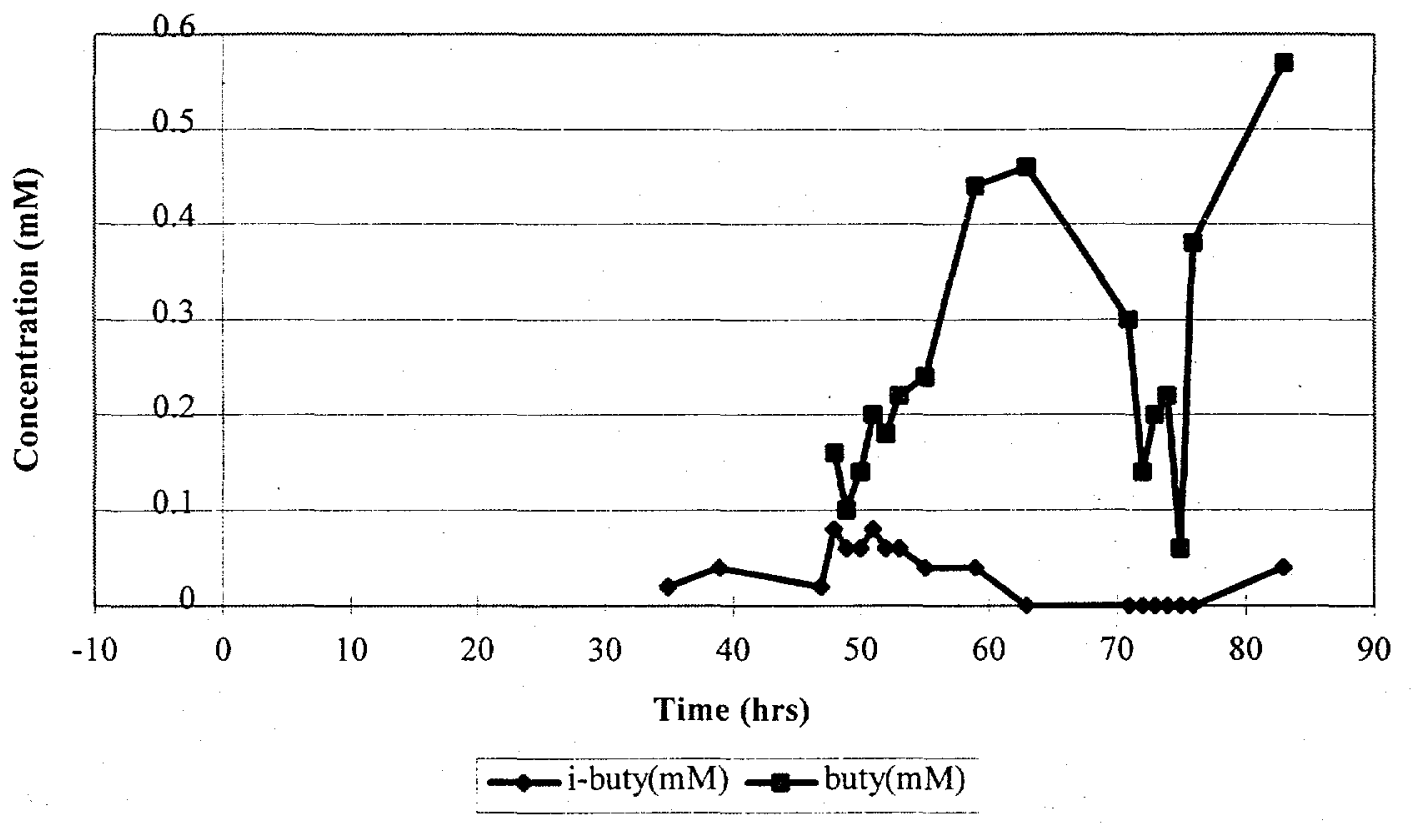

Figure 6-76. Butyrate and isobutyrate variation during shock loading. 


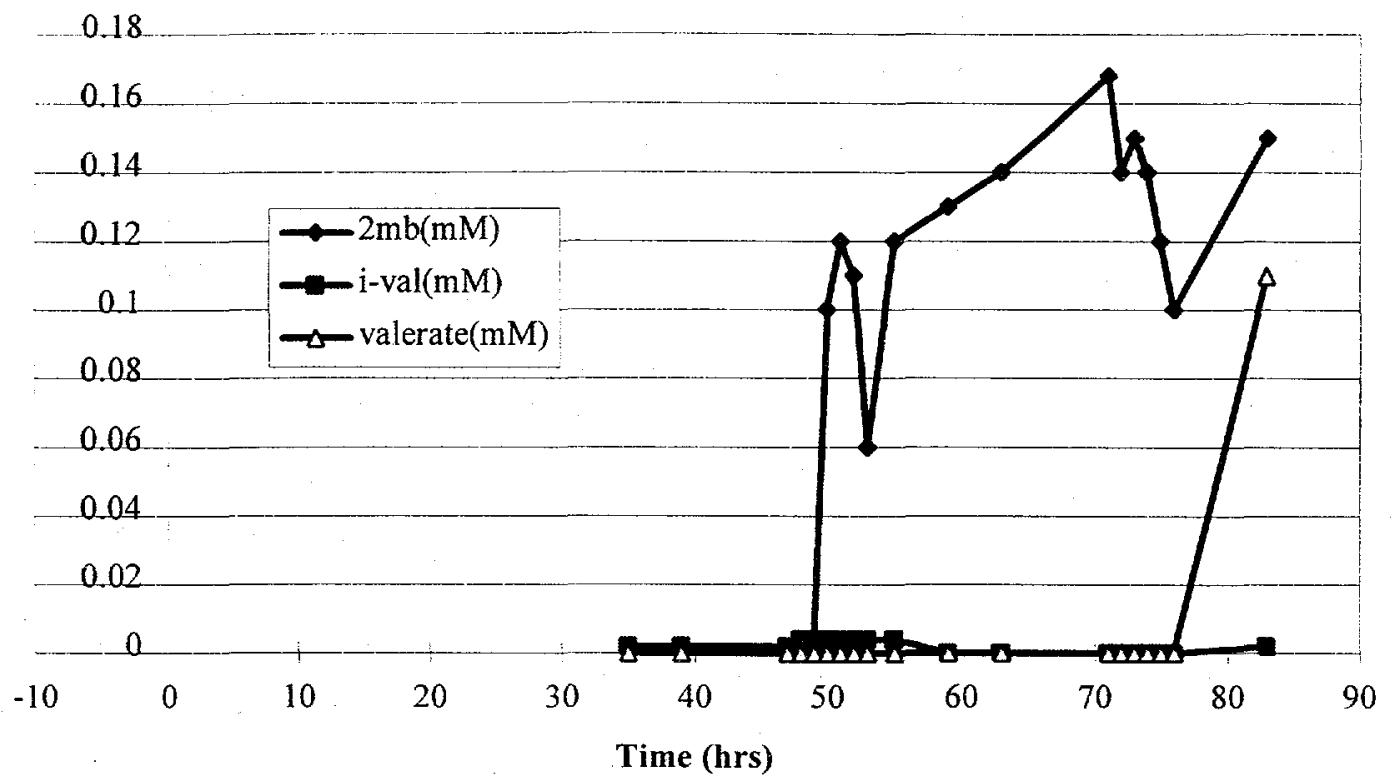

Figure 6-77. Valerate, isovalerate and 2-methyl-butyrate variation during shock loading.

\section{DISCUSSION}

The behavior of $\mathrm{H}_{2}$ and $\mathrm{CO}$ were quite different during the pseudo-steady state experiments. At a low OLR (4-6 $\mathrm{kg} \mathrm{COD} / \mathrm{m}^{3}-\mathrm{d}$ ) the mean response level of $\mathrm{H}_{2}$ did not exceed $30 \mathrm{ppm}$ (Table 6-6). When the reactor was operated at higher OLRs $\left(\geq 10 \mathrm{~kg} \mathrm{COD} / \mathrm{m}^{3}-\mathrm{d}\right.$ ) and longer HRTs ( $\left.>1 \mathrm{~d}\right)$ the mean of $\mathrm{H}_{2}$ concentration surpassed $100 \mathrm{ppm}$. Although the mean of the $\mathrm{H}_{2}$ concentration increased with increased OLR to some degree, and acetate followed OLR well, the bivariate plot of $\mathrm{H}_{2}$ and acetate appeared scattered (Figure 6-8). $\mathrm{H}_{2}$ had no correlation with any other variables monitored (Figure 6-6). Sensitive but high background noise of $\mathrm{H}_{2}$ during pseudo-steady state indicated from its $\mathrm{CV}$ and standard error value (Table 6-3) could contribute to this phenomena.

By contrast, $\mathrm{CO}$ had moderate variations and low background noise (Table 6-3). The mean of $\mathrm{CO}$ concentration remained at $0.1 \mathrm{ppm}$ at low $\mathrm{OLR}\left(4-6 \mathrm{~kg} \mathrm{COD} / \mathrm{m}^{3}-\mathrm{d}\right)$, and reached a high value of $0.59 \mathrm{ppm}$ at a high OLR $\left(23 \mathrm{~kg} \mathrm{COD} / \mathrm{m}^{3}-\mathrm{d}\right)$. The mean concentration of CO increased in response to increased OLR (Figure 6-4). $\mathrm{CO}$ correlated with other monitoring variables except $\mathrm{H}_{2}$ (Figure 6-6). Although correlated with acetate, $\mathrm{CO}$ did not show a particular pattern when compared with acetate. This could be caused by the mass transfer limitation of dissolved CO gas to the headspace, the variation of degree of the limitation, which has wide range (Table 6-12) and the variation of methanogenic activity. 
During OLR perturbations, when the same type and level of OLR variation was repeated following a strong perturbation (i.e., $60 \mathrm{~kg} \mathrm{COD} / \mathrm{m}^{3}$-d), the response of $\mathrm{H}_{2}$ increased while the response of $\mathrm{CO}$ decreased. $\mathrm{H}_{2}$ was very sensitive to high OLR but had no observable pattern at low OLRs. CO, by contrast, tended to stabilize at a new slightly higher level after an initial increase in OLR. When system failure occurred, $\mathrm{H}_{2}$ concentration exceeded $1000 \mathrm{ppm}$, greater than 10 times its pseudo-steady state concentration. CO, however, did not show a significant increase until 24 hours later, when the system began to recover.

Mean analysis of pseudo-steady state data from the bench UASB reactor indicated all monitoring variables (acetate, propionate, gas production rate, methane content, $\mathrm{pH}$, hydrogen, and carbon monoxide) varied with OLR (Table 6-3). This was confirmed by analysis of variance (Table 6-4). Results from both analyses show that gas production rate, $\mathrm{CO}$, methane content, acetate, and propionate, in general, were different between low and high OLRs (Figures 6-5, 6-6 and 6-9, Table 6-5), suggesting a possible threshold could exist at certain OLRs for acetate, propionate, $\mathrm{CO}$ and $\mathrm{CH}_{4}$. For gas production, however, because its behavior closely coupled to OLR (Figure 6-5), the threshold concept is not applicable. Acetate, propionate, gas production, and $\mathrm{CO}$ generally increased with increased $\mathrm{OLR} . \mathrm{CH}_{4}$ varied in the opposite direction.

Results demonstrate that OLR variation using either feed concentration (at constant HRT) or feed rate (at constant feed concentration) had the greatest impact on system response and trace gases $\mathrm{CO}$ and $\mathrm{H}_{2}$. Feed concentrations or HRT influenced the responses of monitoring variables to a much smaller extent. The feed concentration did not have any significant effect on the observed system responses (OLR $10 \mathrm{~kg}$ $\mathrm{COD} / \mathrm{m}^{3}-\mathrm{d}$, Table 6-6).

Acetate, propionate and methane content, $\mathrm{CO}$, and gas production rate were closely correlated. The correlation was positive for most monitoring variables except methane content. These variables varied with OLR; the negative correlation of methane content in response to OLR can also be seen in Figure 6-6.

The maximum frequency of each monitoring variable seems to be independent of the OLR imposed onto the system (Table 6-7). Based on results of frequency analysis, no cyclic pattern was detected for gas production, $\mathrm{H}_{2}, \mathrm{CO}$, methane, acetate and propionate. The variations of all monitoring variables were primarily caused by random noise or background fluctuations in the system, as reflected in results of the white noise test. Similar results were obtained from a separate cross-correlation test; there was no clear cross-correlation between pairs of monitoring variables due to lack of periodicity.

Results demonstrated that the pseudo-steady state brewery waste biodegradation can be described using Gibbs free energy. The free energy levels were relatively stable throughout the operation despite the OLR 
variation. $\mathrm{H}_{2}$ and $\mathrm{CO}$ present in the headspace did not necessarily represent the concentration in the liquid phase that the microorganisms actually experienced. Gibbs free energies based on dissolved gas concentration varied significantly from calculations based on headspace concentration, suggesting energetical analysis has a fundamental limitation as a monitoring tool for fixed film and UASB type systems. Results indicate that both $\mathrm{H}_{2}$ and $\mathrm{CO}$ liquid phase and headspace were not close to equilibrium (Table 6-11). It is not surprising, therefore, that no clear cut correlation between headspace $\mathrm{H}_{2}$ and $\mathrm{CO}$, and OLR was observed.

Results from six sets of OLR perturbation experiments (USS1 - USS6) indicated that the strength and duration of each step increase in OLR had a strong impact on the performance of bench UASB reactor. The reactor was able to accept OLRs up to $40 \mathrm{~kg} \mathrm{COD} / \mathrm{m}^{3}-\mathrm{d}$ without any significant deterioration in process performance. At an OLR of $60 \mathrm{~kg} \mathrm{COD} / \mathrm{m}^{3}$-d system performance degraded significantly. The system was able to tolerate this OLR and maintain a pseudo-steady state level for a maximum of 14 hours before becoming unstable. During this time period, system variables, such as VFAs, exhibited relatively steady concentration levels with little fluctuation. Once the reactor buffering capacity was exhausted, or microbial populations were overstressed, the dynamic balance no longer held and intermediates started to accumulate linearly and rapidly.

During the time period when reactor performance began to fail, gas production, VFAs and $\mathrm{H}_{2}$ were among the most sensitive variables to show changes. Methane content was the least sensitive. Gas production rate decreased from its steady state level; acetate and propionate concentration rapidly accumulated. During this period higher molecular-weight VFAs appeared and the major substrate, ethanol, was not completely degraded. As a result, $\mathrm{pH}$ decreased significantly (5.2) and a high $\mathrm{H}_{2}$ (1000 ppm) environment developed. These unfavorable conditions prevented both methanogenesis and acetogenesis from proceeding, finally leading to system failure.

During USS1, CO and acetate appeared to be correlated, although the response of $\mathrm{CO}$ generally lagged increases in acetate by several hours. There was no apparent correlation between $\mathrm{H}_{2}$ and system performance. Similar observations were made for USS2 and USS3. In all cases, GP tracked OLR extremely well.

During USS3, the most severe of the OLR perturbations where no failure occurred, both acetate and propionate accumulated at an OLR of $60 \mathrm{~kg} \mathrm{COD} / \mathrm{m}^{3}$-d. The concentration of $\mathrm{CO}$ did not track the increase in acetate well during this period of high acetate. A bivariate plot of $\mathrm{CO} / \mathrm{GP}$ and $\mathrm{H}_{2} / \mathrm{GP}$ revealed that the data fell within the same $\{2,1\}$ region observed for the pseudo-steady state data (Table 6-15). 
Perturbations of much longer duration were applied during USS4. The result was a significant decrease in reactor performance. As before, GP tracked OLR well up to the point when reactor performance began to spiral out of control. As before, $\mathrm{CO}$ did not increase dramatically when acetate did. The concentration of $\mathrm{H}_{2}$, however, did increase when the system became perturbed. CO finally did increase; it appeared to peak and decrease, however, more in relationship with the appearance and disappearance of $\mathrm{n}$-propanol and ethanol in the system effluent.

Samples taken from the liquid phase were concurrently analyzed for dissolved $\mathrm{H}_{2}$ and $\mathrm{CO}$. As during the prior work at steady state, the $\mathrm{H}_{2}$ (l) was much less than would be predicted based on $\mathrm{H}_{2}(\mathrm{~g})$ concentrations, and $\mathrm{CO}(\mathrm{l})$ was much greater than would be predicted based on equilibrium with $\mathrm{CO}(\mathrm{g})$. The ratio of the liquid and gaseous concentrations varied randomly and substantially.

Based on these observations, the use of $\mathrm{CO}$ or $\mathrm{H}_{2}$ as on-line process indicators appears limited. The results of experiment USS5, similar to USS4, during which $\mathrm{pH}$ control was used to maintain a pH of 6.8 , provided virtually the same results. The accumulation patterns of acetate, propionate, $\mathrm{H}_{2}$, and $\mathrm{CO}$ were all similar. The only major difference was that the accumulation of butyrate and higher-molecular-weight VFAs was reduced and recovery once the high OLR was decreased was more rapid. In both experiments, the accumulation of $\mathrm{CO}$ appeared to coincide with accumulation and disappearance of n-propanol and ethanol.

Despite the fact that $\mathrm{CO}$ and $\mathrm{H}_{2}$ alone were not found to be viable process monitors, the bivariate plot of the ratio of $\mathrm{CO} / \mathrm{GP}$ and $\mathrm{H}_{2} / \mathrm{GP}$ did appear to be a useful method to track system failure. In all cases, when the system was clearly out of control, the $\mathrm{CO} / \mathrm{GP}$ and $\mathrm{H}_{2} / \mathrm{GP}$ chart was out of the $\{2,1\}$ stable region. Unfortunately, it does not appear that this technique offers any significant early warning, but rather reflects current conditions.

A final verification experiment, essentially duplicating conditions used for USS4 was conducted (USS6). Results were similar for these experiments, indicating results are reproducible. 
Section 7

\section{N-PROPANOL FORMATION AND CONSUMPTION DURING ETHANOL OXIDATION BY ANAEROBIC BREWERY GRANULES}

\section{INTRODUCTION}

Anaerobic oxidation of ethanol to corresponding fatty acids is accomplished by syntrophic cultures of ethanol-fermenting, $\mathrm{H}_{2}$-producing bacteria coupled with $\mathrm{H}_{2}$-oxidizing bacteria. The syntrophic degradation of ethanol, therefore, can only occur if the reducing equivalents derived can be transferred to suitable electron acceptors keeping the hydrogen partial pressure low (Thauer et al. 1977). The energy available from ethanol degradation depends on the type of $\mathrm{H}_{2}$-oxidizing species and on the terminal electron acceptor used. Sulfate-reducing bacteria can reduce sulfate, as an electron acceptor, to sulfide during ethanol oxidation (Postgate and Camphell 1966). In the absence of sulfate, ethanol oxidation can be coupled with hydrogen transfer to methanogens (Wolin 1976; Bryant et al. 1977). For this latter case, ethanol is oxidized with a concurrent reduction of carbon dioxide to form acetate or propionate (Schink 1984; Eichler and Schink 1984; Braun et al. 1981; Samain et al. 1982), or condensed with acetate to form butyrate (reaction 9, Table 7-1) (Bornstein and Barker 1948). Bacteria able to oxidize ethanol to form acetate and propionate were isolated from sewage sludge and sediments (Eichler and Schink 1984; Schink 1984). Formation of acetate and propionate was also observed in another study using an ethanolfermenting bacterium (Samain et al. 1982). Addition of hydrogen inhibited ethanol degradation and resulted in an accumulation of ${ }^{14} \mathrm{C}$-labeled butyrate (Schink et al. 1985). Fermentation of ethanol to acetate and propionate by Desulfobulbus was strongly inhibited by high hydrogen concentrations (Schink, et al. 1987). Propionate-forming bacteria were believed to contribute significantly to ethanol degradation. The pathway of propionate formation from ethanol by Pelobacter propionicus and its energetics were extensively discussed (Laanbrock et al. 1982; Schink, et al. 1987). A hydrogen partial pressure less than $10^{-4} \mathrm{~atm}$ is necessary for anaerobic oxidation of propionate to be energetically favorable (Thauer et al. 1977; Gujer and Zehnder 1982). This low hydrogen concentration is maintained by interspecies transfer of hydrogen from $\mathrm{H}_{2}$-producing bacteria to $\mathrm{H}_{2}$-consuming bacteria. Chloroform did not inhibit ethanoloxidizing acetogens and formate was synthesized from bicarbonate and ethanol during syntrophic ethanol oxidation in flocs isolated from a whey digestor (Thiele and Zeikus 1988b). 


\begin{tabular}{|c|c|c|}
\hline & Reactions & $\begin{array}{c}\Delta \mathrm{G}^{\mathrm{o}} \\
(\mathrm{kcal} / \mathrm{mol})\end{array}$ \\
\hline reaction 1 & $\mathrm{CH}_{3} \mathrm{CH}_{2} \mathrm{OH}+3 \mathrm{H}_{2}+\mathrm{HCO}_{3}^{-}+\mathrm{H}^{+} \rightarrow \mathrm{CH}_{3} \mathrm{CH}_{2} \mathrm{CH}_{2} \mathrm{OH}+3 \mathrm{H}_{2} \mathrm{O}$ & -18.85 \\
\hline reaction 2 & $\begin{array}{l}\mathrm{CH}_{3} \mathrm{CH}_{2} \mathrm{OH}+\mathrm{HCO}_{3}^{-}+2 \mathrm{H}_{2} \rightarrow 1 / 2 \mathrm{CH}_{3} \mathrm{CH}_{2} \mathrm{CH}_{2} \mathrm{OH}+1 / 2 \mathrm{H}^{+}+1 / 2 \mathrm{CH}_{3} \mathrm{CH}_{2} \mathrm{COO}^{-} \\
+2.5 \mathrm{H}_{2} \mathrm{O}\end{array}$ & -17.41 \\
\hline reaction 3 & $\mathrm{CH}_{3} \mathrm{CH}_{2} \mathrm{OH}+\mathrm{CH}_{3} \mathrm{CH}_{2} \mathrm{COO}^{-} \rightarrow \mathrm{CH}_{3} \mathrm{CH}_{2} \mathrm{CH}_{2} \mathrm{OH}+\mathrm{CH}_{3} \mathrm{COO}^{-}$ & -0.57 \\
\hline reaction 4 & $\mathrm{CH}_{3} \mathrm{CH}_{2} \mathrm{COO}^{-}+2 \mathrm{H}_{2}+\mathrm{H}^{+} \rightarrow \mathrm{CH}_{3} \mathrm{CH}_{2} \mathrm{CH}_{2} \mathrm{OH}+\mathrm{H}_{2} \mathrm{O}$ & -12.4 \\
\hline reaction 5 & $\mathrm{CH}_{3} \mathrm{CH}_{2} \mathrm{OH}+1 / 2 \mathrm{H}_{2} \mathrm{O} \rightarrow 1 / 2 \mathrm{CH}_{3} \mathrm{CH}_{2} \mathrm{CH}_{2} \mathrm{OH}+1.5 \mathrm{H}_{2}+1 / 2 \mathrm{CO}_{2}$ & 3.65 \\
\hline reaction 6 & $\mathrm{HCO}_{3}^{-}+3 \mathrm{H}_{2}+\mathrm{H}^{+}+\mathrm{CH}_{3} \mathrm{COO}^{-} \rightarrow \mathrm{CH}_{3} \mathrm{CH}_{2} \mathrm{COO}^{-}+3 \mathrm{H}_{2} \mathrm{O}$ & -18.2 \\
\hline reaction 7 & $\mathrm{CH}_{3} \mathrm{CH}_{2} \mathrm{CH}_{2} \mathrm{OH}+2 / 3 \mathrm{CH}_{3} \mathrm{COO}^{-} \rightarrow 5 / 3 \mathrm{CH}_{3} \mathrm{CH}_{2} \mathrm{COO}^{-}+1 / 3 \mathrm{H}^{+}+2 / 3 \mathrm{HCO}_{3}^{-}+\mathrm{H}_{2} \mathrm{O}$ & -9.31 \\
\hline reaction 8 & $\mathrm{CH}_{3} \mathrm{CH}_{2} \mathrm{OH}+\mathrm{H}_{2} \mathrm{O} \rightarrow \mathrm{CH}_{3} \mathrm{COO}+2 \mathrm{H}_{2}+\mathrm{H}^{+}$ & 2.30 \\
\hline reaction 9 & $\mathrm{CH}_{3} \mathrm{CH}_{2} \mathrm{OH}+\mathrm{CH}_{3} \mathrm{COO}+\mathrm{H}^{+} \rightarrow \mathrm{CH}_{3} \mathrm{CH}_{2} \mathrm{CH}_{2} \mathrm{COO}^{-}+\mathrm{H}_{2} \mathrm{O}$ & 0.297 \\
\hline reaction 10 & $\mathrm{CH}_{3} \mathrm{CH}_{2} \mathrm{OH}+\mathrm{CO}+2 \mathrm{H}_{2} \rightarrow \mathrm{CH}_{3} \mathrm{CH}_{2} \mathrm{CH}_{2} \mathrm{OH}+\mathrm{H}_{2} \mathrm{O}$ & -22.51 \\
\hline
\end{tabular}

Syngas, a mixture of hydrogen and carbon monoxide, has been used as a feedstock for production of polymetric chemicals. Syngas is involved in chemical synthesis in the organic chemicals industry to produce alcohols since World War II. In the OXO process, hydroformylation occurs where hydrogen and carbon monoxide are added across an olefinic bond to produce aldehydes containing one more carbon atom than the olefin. Alcohols are obtained by reduction of the aldehydes. $\mathrm{N}$-propanol is one of the major products available from syngas (hydrogen and carbon monoxide) reactions with ethylene through the OXO process (Kirk, Othmer, Grayson and Eckroth 1982).

Hartmanis and Gatenbeck (1984) provided evidence for direct enzymatic conversion of butyrate to butanol during anaerobic energy metabolism of Clostridium beijerinckii in butyrate fermentations. Acetone yielded through the fermentation is reduced to isopropanol coupled with NADH oxidation (Linden 1988).

$\mathrm{N}$-propanol was observed to accumulate in the UASB reactors under out-of-control conditions (Section 6). There appeared to be a link between the appearance and disappearance of n-propanol and the accumulation of $\mathrm{CO}$ in the system.

Several reaction mechanisms which could contribute to propanol formation during ethanol fermentation. A list of possible reactions and their standard Gibbs free energy changes for ethanol consumption and propanol production and consumption during ethanol degradation are presented in Table 7-1. N-propanol could be produced from ethanol and carbon dioxide (reactions 1 and 2), ethanol and propionate (reaction 3), propionate and $\mathrm{H}_{2}$ (reaction 4), an ethanol condensation (reaction 5), or from carbon monoxide, $\mathrm{H}_{2}$ and ethanol (reaction 10). Schink (1984) described a new strain, Ott Bd 1, which was isolated from freshwater sediments and sewage sludge, that was able to oxidize propanol to propionate with concomitant reduction of acetate and bicarbonate (reaction 7). It has been demonstrated that hydrogen- 
utilizing methanogens can oxidize ethanol and isopropanol to produce acetate and acetone. The reducing equivalents.generated were used for methane production (Widdel and Wolfe 1986). Propanol was observed during impulses of ethanol, propionate and formate imposed on a chemostat containing ethanol or propionate enrichments (Smith and McCarty 1989). Hydrogen was not believed to be associated with propanol production. The possible pathway for propanol production under the experimental conditions used was proposed to be concurrent ethanol oxidation and propionate reduction to form acetate and propanol (reaction 3) (Smith and McCarty 1989).

The purpose of this study was to examine ethanol degradation by anaerobic granules from a UASB reactor fed with a synthetic brewery waste, to examine propanol formation and consumption during ethanol oxidation, and to identify the involvement, if any, of $\mathrm{CO}$ and $\mathrm{CO}_{2}$ in the formation of n-propanol. In this waste, $70 \%$ of COD was ethanol, $14 \%$ was acetate, and $14 \%$ was propionate. The study included ethanol degradation assays and an isotopic assay using ${ }^{13} \mathrm{C}$-labeled ethanol and bicarbonate. The interactions of ethanol, propanol, propionate, hydrogen, and $\mathrm{CO}$ during ethanol degradation are discussed.

\section{MATERIALS AND METHODS}

\section{Source of Methanogenic Granules}

The granules were taken from a 3.1-liter bench-scale laboratory UASB reactor operated at $37^{\circ} \mathrm{C}, \mathrm{pH}=7.0$ $(+0.2)$, organic loading rate of $10 \mathrm{~kg} \mathrm{COD} / \mathrm{m}^{3}-\mathrm{d}$ and HRT of 11 hours. These granules had been acclimated for more than six months to a synthetic brewery waste. The diameter of the granules ranged from $1.8 \mathrm{~mm}$ to $3.0 \mathrm{~mm}$, with an average of $2.5 \mathrm{~mm}$.

\section{Ethanol Degradation Assay using Granule Flocs}

The ethanol degradation assay was conducted at $37^{\circ} \mathrm{C}$ and $\mathrm{pH}$ of 7:0, in a 2-liter bench-top Multigen reactor with an impeller speed of $600 \mathrm{rpm}$. Flocs were derived or disrupted from anaerobic granules taken from a bench-scale UASB reactor. The Multigen reactor, methods for preparation of the granule flocs, and the UASB reactor are described elsewhere (Wu et al. 1995). Po:ssible intermediates and products, including acetate, propionate, n-propanol, formate, $\mathrm{H}_{2}, \mathrm{CO}, \mathrm{CO}_{2}$, and methane were measured. Carbon and electron balances were performed. Background concentrations of acetate and propionate, at the beginning of the assay, were $6.9 \mathrm{mM}$ and $0.19 \mathrm{mM}$, respectively. Biomass concentration was determined at the conclusion of the assay to be $0.94 \mathrm{~g}$ of volatile solids (VS) in the vessel. Aqueous samples were collected, transferred into 1.5-ml Eppendorf tubes, and centrifuged at 12,000 rpm (model 5415, Brinkmann Instruments Co., Westbury, NY) for 2 minutes. A $0.8-\mathrm{ml}$ aliquot of supernatant was then collected using a pipette and acidified with $0.3-\mathrm{M}$ oxalic acid at a volumetric ratio of $1 / 10$ (acid/sample). The samples were sealed with Teflon-lined caps and aluminum crimp seals, and refrigerated for analyses. 


\section{- 13 Ethanol Degradation Assay}

Three sets of isotopic assay:s were performed. Group A was with $\left[1-{ }^{13} \mathrm{C}\right]$ ethanol (Cambridge Isotope, $99 \%$ ) and ${ }^{12} \mathrm{C}$ bicarbonate (Baker Analyzed, sodium bicarbonate), with an ethanol concentration of $30 \%$ higher than that of group B or group C; group B used $\left[1-{ }^{13} \mathrm{C}\right]$ bicarbonate (Isotech, 99\%) and ${ }^{12} \mathrm{C}$ ethanol (Quantum, 200 proof). Group $\mathrm{C}$ had the same composition as group A except for ethanol concentration. Each set had two replicates. The assays were performed in serum vials $(158-\mathrm{mL})$ incubated at $37^{\circ} \mathrm{C}$. Serum vials were vacuum-flushed with $\mathrm{N}_{2}$ for $0.5 \mathrm{hr}$ before $50 \mathrm{~mL}$ of PBBM medium was transferred into serum vials. The contents were then adjusted to a $\mathrm{pH}$ of 7.0 by purging with a $20 / 80 ; \mathrm{CO}_{2} / \mathrm{N}_{2}$ gas mixture (AGA Specialty Gas, Maumee, Ohio). Granules from the UASB reactor $(0.3-\mathrm{mL})$ were injected into serum vials using a $1-\mathrm{mL}$ syringe equipped with an 18 -gauge needle. Ethanol $\left[1-{ }^{13} \mathrm{C}\right]$ was then added into the solution using a $3-\mathrm{mL}$ syringe equipped with a 21 -gauge needle. This procedure was conducted under a $\mathrm{N}_{2}$ atmosphere. Aqueous samples were withdrawn from serum vials using a 1-mL syringe with a 21 -gauge needle and were filtered through a $0.2-i \mathrm{~m}$ syringe filter. Samples prepared for ${ }^{13} \mathrm{C}$ analysis were then extracted with ethyl-acetate (Aldrich, 99.5\%), at 1:1 (sample:ethyl-acetate) twice. The extracted samples were collected in 1.2-mL autosampler crimp vials (Teflon-lined), sealed with an aluminum crimp, and refrigerated until analyzed, generally 2-4 hours. A screening test was conducted using the same method as the isotopic assay except that labeled compounds were not used. Ethanol concentrations tested were 30 , 50 , and $65 \mathrm{mM}$ for the initial screening tests. Based on the peak concentrations of $\mathrm{n}$-propanol observed, 50 and $65 \mathrm{mM}$ ethanol were used for the ${ }^{13} \mathrm{C}$ isotopic assays. The background concentration of ethanol for all of these assays was zero. Whole granules from the UASB were used as inocula for these assays.

PBB (phosphate buffered basal) Medium. The composition of PBBM used in $\mathrm{C}^{13}$ ethanol assay was: $\mathrm{NaCl} 0.9 \mathrm{~g} / \mathrm{L}, \mathrm{MgCl}_{2} .6 \mathrm{H}_{2} \mathrm{O} 0.2 \mathrm{~g} / \mathrm{L}, \mathrm{CaCl}_{2} .2 \mathrm{H}_{2} \mathrm{O} 0.1 \mathrm{~g} / \mathrm{L}, \mathrm{NH}_{4} \mathrm{Cl} 1.0 \mathrm{~g} / \mathrm{L}$, Trace mineral $10 \mathrm{ml} / \mathrm{L}$, Resazurin $(0.2 \%) 1 \mathrm{~mL}$ in a 1 -liter batch. The medium was prepared according to the following procedure: bring $\mathrm{pH}$ to 7.2 - 7.4; boil and dispense under desired gas phase; after autoclaving add combined phosphate buffer $\left(\mathrm{KH}_{2} \mathrm{PO}_{4}\right.$ and $\left.\mathrm{K}_{2} \mathrm{HPO}_{4}\right)$; add vitamin and reducing agent under sterile conditions.

\section{Sample Analyses}

Concentrations of ethanol, n-propanol, propionate and acetate were analyzed with a gas chromatograph (HP 5890A, Hewlett-Packard, Avondale, PA) equipped with a packed column (Supelco, Inc., Bellefonte, PA), a flame ionization detector, and automator injector (HP 7673A, Hewlett-Packard). Separation was accomplished using a 4\% Carbowax organic phase on an 80/120 Carbopac $P$ support in a 2-m, 2-mm ID glass column (Supelco). $\mathrm{N}_{2}$ was used as the carrier gas ( $\mathrm{AGA}$, Specialty Gas, Maumee, $\mathrm{OH}$ ). Operational conditions for the GC were: $\mathrm{N}_{2}$ flow rate of $16-20 \mathrm{~mL} / \mathrm{min}, \mathrm{H}_{2}$ flow rate of $30 \mathrm{~mL} / \mathrm{min}$, air flow rate of $300 \mathrm{~mL} / \mathrm{min}$. The injection port temperature was $190^{\circ} \mathrm{C}$. Column temperature was programmed from $140-$ $220^{\circ} \mathrm{C}$ with $5^{\circ} \mathrm{C} / \mathrm{min}$ ramp, for better peak separation. The detector temperature was $220^{\circ} \mathrm{C}$. Ethanol and 
n-propanol standards (external standards), were prepared without acidification. Standard calibration curves for VFAs were made using an internal standard method with propionate as the internal standard. The detection limits for ethanol, propanol, acetate, and propionate were $0.01 \mathrm{mM}, 0: 05 \mathrm{mM}, 0.1 \mathrm{mM}$, and 0.1 $\mathrm{mM}$, respectively. ${ }^{13} \mathrm{C}$ propanol was quantified using a gas chromatograph with a porapak $\mathrm{U}$ column (Hewlett-Packard, 5990), and a mass spectrometer (JEOL 505 magnetic mass spectrometer, Japan) at a scan wavelength of $471-485 \mathrm{~nm}$. Formate was analyzed for enzymatically using formate dehydrogenase, according to Bergmeyer (1974). The extinction change was measured using a spectrophotometer (UV160, Shimadzu Corp., Kyoto, Japan) at $365 \mathrm{~nm}$. The proportionality factor was determined by standardization of the assay with formate standards. Both standard and samples were adjusted with blanks (without NAD). All aqueous sample concentrations were determined based on standard curves.

$\mathrm{H}_{2}$ and $\mathrm{CO}$ were determined using a RGA2 gas chromatograph (Trace Analytical, Menlo Park, CA). Species were separated using a sphereocarb 60/80 packed column and quantified using a mercury oxide bed reduced gas detector (Trace Analytical). The operational conditions used were: column temperature of $90^{\circ} \mathrm{C}$ and a detector temperature of $265^{\circ} \mathrm{C}$. Carrier gas $\left(\mathrm{N}_{2}\right)$ flow rate was $16-18 \mathrm{~mL} / \mathrm{min}$. Calibration was made using $101 \mathrm{ppm}$ and $10.2 \mathrm{ppm}$ standard gases for $\mathrm{H}_{2}$ and $\mathrm{CO}\left(\mathrm{H}_{2}\right.$ and $\mathrm{CO}$ were in $\mathrm{N}_{2}$, Scott Specialty Gases), respectively. The detection limit of the RGD2 were $3.8 \mathrm{ppm}$ and $0.5 \mathrm{ppm}, \mathrm{for}_{2} \mathrm{H}_{2}$ and $\mathrm{CO}$, respectively. Methane was determined using a Hewlett-Packard 5890 gas chromatograph with a VOCOL capillary column $(30 \mathrm{~m}, 0.53 \mathrm{~mm} \mathrm{ID}, 3.0 \mathrm{~mm}$ film, Supelco) and a flame ionization detector. The temperatures of the oven, detector and injector were $45^{\circ} \mathrm{C}, 200^{\circ} \mathrm{C}$, and $150^{\circ} \mathrm{C}$, respectively. Calibration was made using $99.99 \%$ methane standard gas (AGA Specialty Gas). Carbon dioxide was measured using a GC (series 580, GOW-MAC, Bound Brook, NJ). The GC was equipped with a TCD using a carbosphere $80 / 100$ packed column (1/8 in stainless steel., $6 \mathrm{ft}$ ). The temperatures of the injector, detector and oven were $100^{\circ} \mathrm{C}, 150^{\circ} \mathrm{C}$, and $150^{\circ} \mathrm{C}$, respectively. Calibration was made using a $\mathrm{CO}_{2} / \mathrm{N}_{2}$ gas mixture $(20 / 80$, AGA, Specialty Gas, Maumee, $\mathrm{OH}$ ). The calculated response (peak area or height) factor was used to determine all gas concentrations.

\section{RESULTS}

\section{Ethanol Degradation Assay using Granule Flocs}

A study was initiated to examine the intermediate products during anaerobic ethanol oxidation by the granule flocs. Starting with an initial concentration of $20.7 \mathrm{mM}$ of ethanol (6.9 mM of acetate), substrate, intermediates and end products were measured over time. Carbon and electron balances were performed. A carbon recovery of $94.7 \%$ was obtained at the conclusion of the assay. Ethanol, acetate, $\mathrm{CO}_{2}$, and $\mathrm{CH}_{4}$ were the major sources of carbon during ethanol degradation, as expected. Methane and carbon dioxide accounted for $75.8 \%$ and $24.2 \%$ of carbon in the end products. Approximately $93.5 \%$ of the total electron 
equivalents were recovered. Electron equivalents in hydrogen, formate, $\mathrm{CO}$ and sampling loss were negligible. Ethanol was completely oxidized within 11 hours (Figure 7-1). Acetate accumulated up to a peak concentration of $24 \mathrm{mM}$ and then declined. Methane was produced rapidly until acetate was depleted, reaching a final value of $36 \mathrm{mM}$. Headspace concentration of $\mathrm{CO}$ increased 12-fold from an initial value of $4 \mathrm{ppm}$ to a plateau value of $50 \mathrm{ppm}(0.9 \mathrm{mM}$ in liquid phase, assuming equilibrium) within 5 hours (Figure 7-1), which is much higher in concentration than that commonly observed in anaerobic systems (i.e., ppb levels). At this time period, n-propanol increased rapidly to its peak value (Figure 7-1). The concentration of $\mathrm{CO}$ then decreased gradually to $1 \mathrm{ppm}(0.02 \mathrm{mM}$ in liquid phase $)$ at 26 hours and remained at that level.

From Figure 7-1, it can be seen that formate and hydrogen were produced almost immediately and simultaneously. Both of these electron sink products increased and decreased quickly during the initial 10 hours of the assay. The aqueous concentration of formate reached a peak of $430 \mu \mathrm{M}$ after one hour. The peak concentration of hydrogen in the gaseous phase was observed about one hour later. A peak hydrogen concentration of $1120 \mathrm{ppm}$ ( $20 \mathrm{mM}$ in liquid phase, assuming equilibrium) was observed two hours after the start of the assay; hydrogen decreased to $4 \mathrm{ppm}(0.07 \mathrm{mM})$ when ethanol was depleted (at 11 hours).

Production of $n$-propanol (Figure 7-1) was observed immediately after the assay was initiated. The concentration of n-propanol reached a peak of $0.4 \mathrm{mM}$ at the four-hour mark. Starting at the six-hour mark, the concentration of propanol began to decrease.

As shown in Figure 7-1, the propionate concentration decreased slightly during the initial two hours of the assay and then increased rapidly up $0.7 \mathrm{mM}$ by 12 hours when ethanol was depleted. This initial decrease in propionate concentration suggested there might be another reaction mechanism responsible for propionate removal in addition to being oxidized to acetate.

\section{$\stackrel{13}{-}$ Ethanol Degradation Assay}

Accumulation and depletion in the concentrations of reaction intermediates (acetate, propionate, and npropanol) from all three sets of serum bottle assays were similar to those observed in the previous assays Typical progress curves of ethanol, n-propanol, propionate, and acetate are shown in Figure 7-2. During ethanol oxidation, acetate began to accumulate immediately, followed by n-propanol and propionate. Propanol reached a peak value and then decreased rapidly while acetate and propionate increased continuously. Ethanol and $n$-propanol disappeared at approximately the same time for all assays conducted. Substrate and products variation during n-propanol appearance, from the screen tests performed prior to conducting the ${ }^{13} \mathrm{C}$ ethanol degradation assays are presented in Table 7-2. N-propanol and propionate peak concentrations increased with increased initial ethanol concentration. With one 
exception, n-propanol was observed to begin accumulating when the ethanol concentration was at 20-25 $\mathrm{mM}$ and the ratio of acetate to initial ethanol concentration (in $\mathrm{mM}$ ) ranged from 0.29-0.37 (Table 7-2). When the n-propanol concentration decreased to below detection limits, the acetate/ethanol (mM/mM) ratio ranged from 0.76-0.81 (Table 7-2). N-propanol appeared at the same time propionate did, or when propionate was in the medium at the start of the assay.
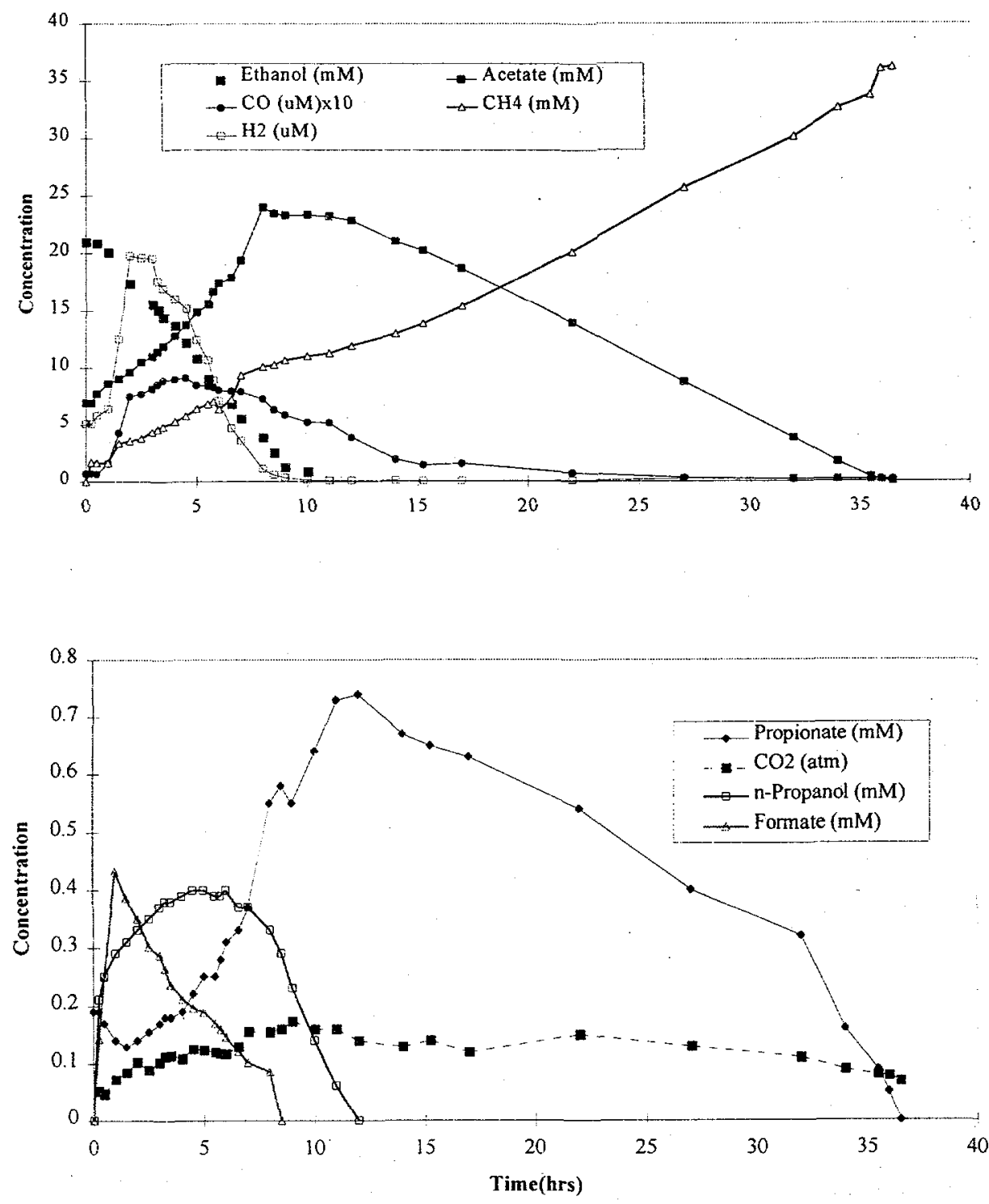

Figure 7-1. Substrate and products concentration profile (ethanol, acetate, propanol, propionate, hydrogen, formate, carbon monoxide, carbon dioxide, and methane) during ethanol fermentation. 

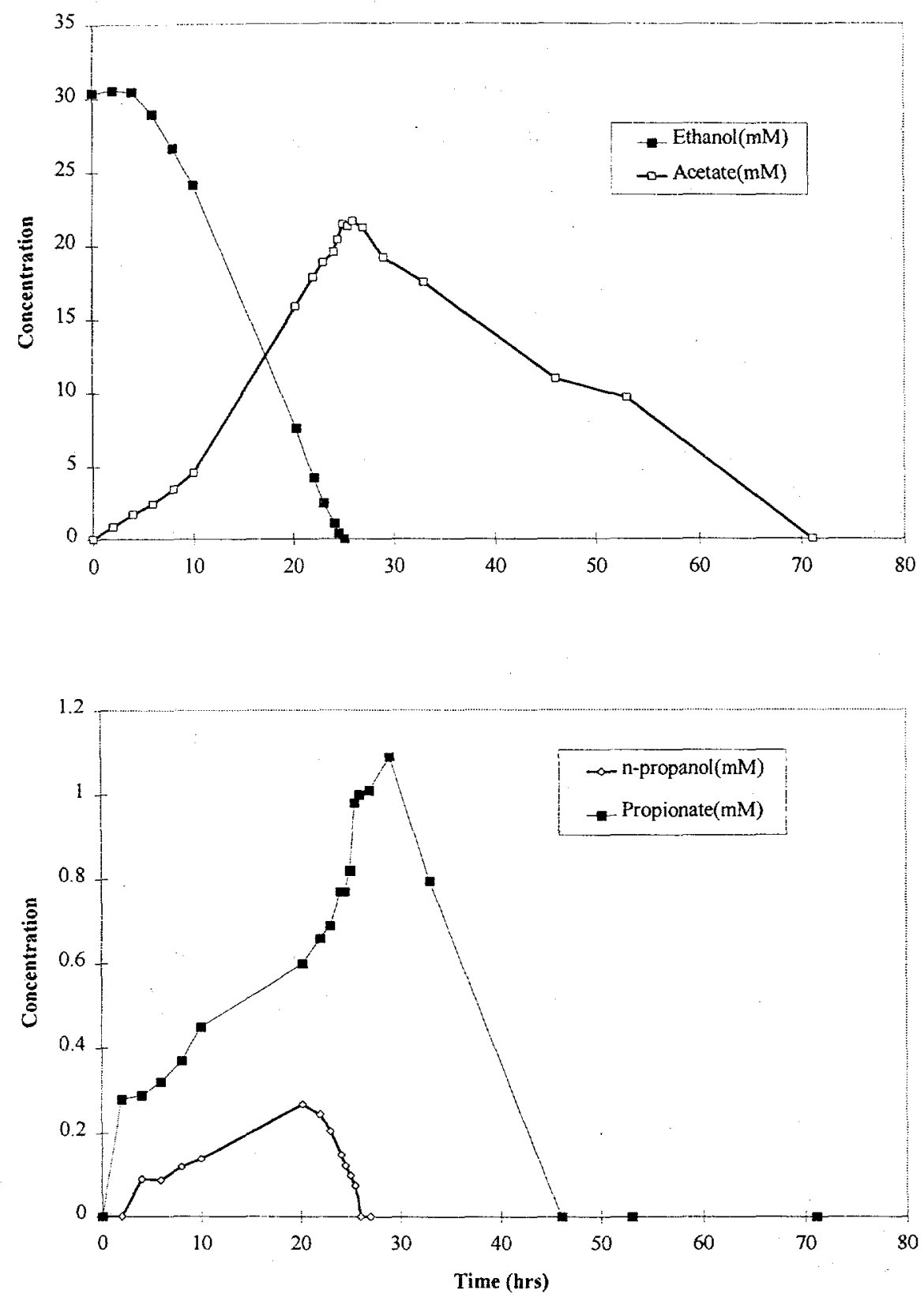

Figure 7-2. Typical progress curves of ethanol, acetate, propionate, and n-propanol during ethanol degradation using whole granules (experiment was stopped after 71 hours).

The ${ }^{13} \mathrm{C}$ ethanol degradation assays were concluded when $\mathrm{n}$-propanol concentration decreased below detection limits. Peak ${ }^{13} \mathrm{C}$ mass intensities of major fragments of $\mathrm{n}$-propanol were determined by gas chromatography and mass spectra. The ratio of the mass intensity for n-propanol, $\frac{{ }^{13} M^{+}}{{ }^{12} M^{+}+{ }^{13} M^{+}-H^{+}}$ 
(or 61/60; where $M$ is mass of n-propanol) and $\frac{{ }^{13} M^{+}}{{ }^{12} M-H^{+}}$(or 61/59) were then calculated (Table 7-3).

The control was unlabeled ethanol $(0.5 \mathrm{mM})$. Sample group A represents $1-\mathrm{C}$-labeled ethanol $(50 \mathrm{mM})$ and bicarbonate $(50 \mathrm{mM})$. Group B represents unlabeled ethanol $(50 \mathrm{mM})$ and $1-\mathrm{C}$-labeled bicarbonate (50 mM). Group C represents 1-C-labeled ethanol (65 mM) and bicarbonate $(65 \mathrm{mM})$, respectively. For group $\mathrm{C}$, only one sample was analyzed. Excess biomass inocula was inadvertently added to sample $\mathrm{C} 2$, resulting in the ethanol degradation proceeding faster than anticipated and the n-propanol peak being missed.

\begin{tabular}{|c|c|c|c|c|c|c|}
\hline \multirow[b]{2}{*}{$\begin{array}{c}\text { Initial } \\
\text { Ethanol } \\
\text { Conc. }(\mathrm{mM})\end{array}$} & \multirow[b]{2}{*}{ Time (hr) } & \multicolumn{3}{|c|}{ Products } & \multirow[b]{2}{*}{$\begin{array}{l}\text { Ethanol } \\
\text { Conc. } \\
\text { (mM) }\end{array}$} & \multirow[b]{2}{*}{$\begin{array}{c}\text { Ratio } \\
\text { acetate } \\
\text { initial ethanol }\end{array}$} \\
\hline & & $\begin{array}{c}\text { Acetate } \\
(\mathrm{mM})\end{array}$ & $\begin{array}{l}\text { Propionate } \\
\quad(\mathrm{mM})\end{array}$ & $\begin{array}{c}\text { Propanol } \\
(\mathrm{mM})\end{array}$ & & \\
\hline \multirow[t]{3}{*}{32} & 15 & 3.20 & 0.13 & 0.05 & 23.70 & 0.1 \\
\hline & 37 & 12.90 & 0.23 & 0.08 & 13.00 & \\
\hline & 61 & 26.00 & 0.39 & 0.01 & 0.90 & 0.81 \\
\hline \multirow[t]{3}{*}{50} & 47.2 & 16.60 & 0.26 & 0.04 & 24.96 & 0.33 \\
\hline & 69 & 29.66 & $0 . \overline{41}$ & 0.16 & 10.30 & \\
\hline & 100 & 38.04 & 0.62 & 0.01 & 0.24 & 0.76 \\
\hline \multirow[t]{3}{*}{67} & 56.5 & 19.32 & 0.31 & 0.13 & 34.90 & 0.29 \\
\hline & 73 & 40.26 & 0.37 & 0.18 & 20.70 & \\
\hline & 131 & 52.91 & 0.67 & 0.03 & 1.20 & 0.79 \\
\hline \multicolumn{7}{|c|}{$\begin{array}{l}\text { concentrations of acetate, propionate and propanol for the begining, peak, and end of the } \\
\text { propanol progress curve are presented. } \\
\text { assay using whole granules; background acetate and propionate were undetectable. } \\
\text { the ratio of acetate to initial ethanol concentration when propanol began accumulating and } \\
\text { disappearing were } 0.37 \text { and } 0.78 \text {, respectively, during ethanol degradation assays using } \\
\text { flocs. }\end{array}$} \\
\hline
\end{tabular}

The natural abundance of ${ }^{13} \mathrm{C}$ to ${ }^{12} \mathrm{C}$ (for n-propanol 61/60) is 3.3\%, as shown in the control $(0.032)$. Labeled n-propanol mass in group $A$ was 1.3 to 1.4 times that of group $C$ for the mass ratio $61 / 60$ and $61 / 59$, respectively. This is consistent with the ratio of initial ethanol concentration (1.3:1 as group A:C).

\section{DISCUSSION}

Results from several assays showed a consistent trend of ethanol being converted, primarily propionate and acetate, with some accumulation of $\mathbf{n}$-propanol. Progress curves of these compounds were not significantly different when using flocs or whole granules as the inocula. The formation and disappearance of $n$ - 
propanol during ethanol degradation using anaerobic granules were reproducible. Immediate production of n-propanol was observed when propionate, acetate, carbon monoxide, and hydrogen were present (Table 7-2; Figure 7-1). Propanol appeared in the medium after a short lag for assays conducted where there was no propionate and acetate initially in the medium (Figure 7-2), indicating that propionate may be a precursor in propanol formation. This was further supported by an observed initial decrease in propionate concurrent with a linear increase in propanol (Figure 7-1).

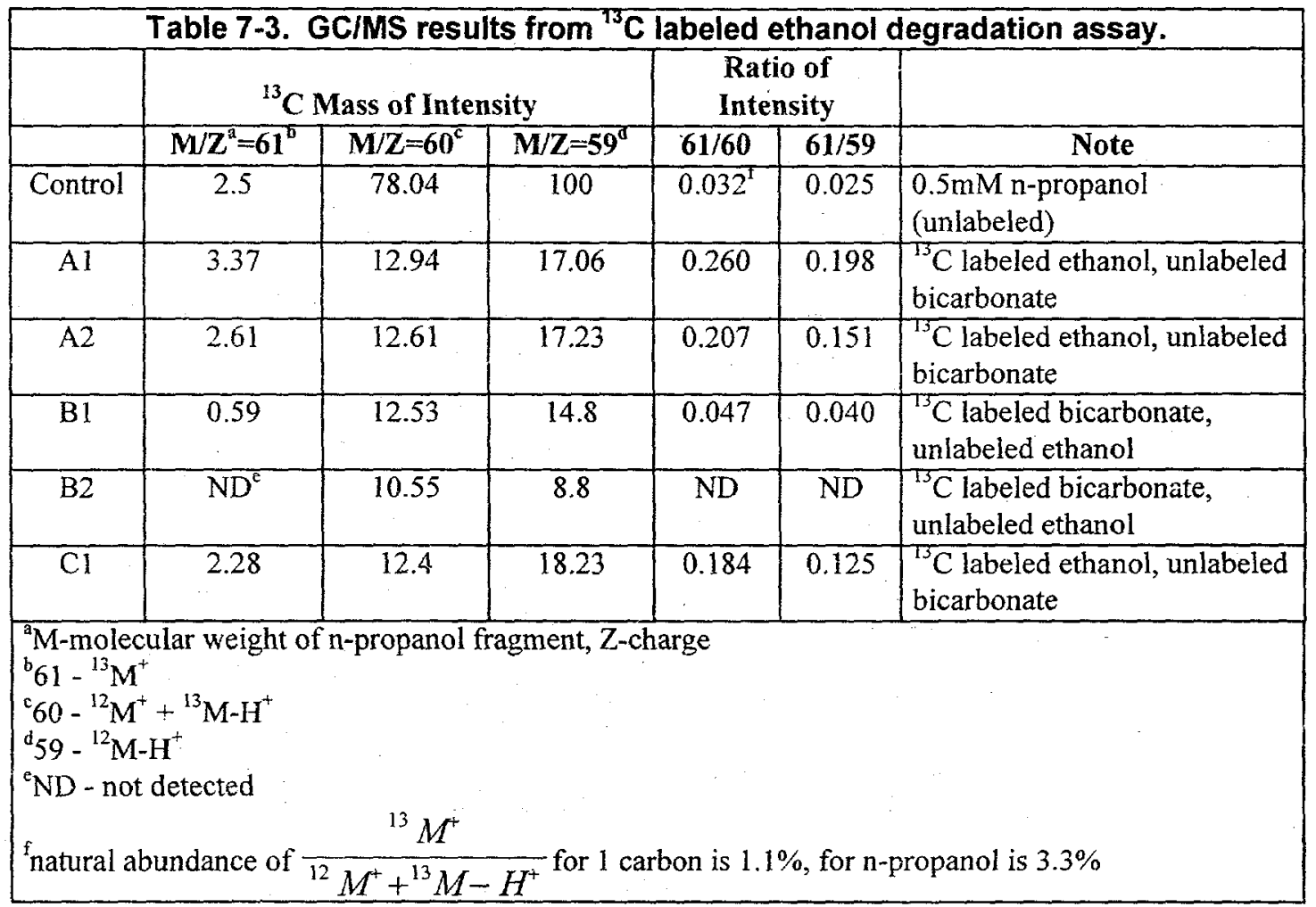

Isotopic assays using whole granules revealed that labeled $n$-propanol was formed as an intermediate of labeled ethanol degradation. The amount of ${ }^{13} \mathrm{C}$-propanol was high from labeled ethanol (group $\mathrm{A}$ and C) and present only at trace levels when labeled bicarbonate was used (group B; Table 7-3). The ratio of mass intensities, or the ratio of ${ }^{13} \mathrm{C}$-propanol to ${ }^{12} \mathrm{C} \mathrm{n}$-propanol, of $0.26,0.21,0.18$, and $0.20,0.15,0.13$ for molecular weight/charges $61 / 60$ and $61 / 59$, respectively, were observed from the group using ${ }^{13} \mathrm{C}$ labeled ethanol. This was about nine times the control ( 0.032 and 0.028 , respectively). These values for group B appeared in trace amount ( 0.05 for $61 / 60$ and 0.04 for $61 / 59$, respectively) which was near the natural abundance level. These results suggest that bicarbonate was not a significant contributor of carbon for n-propanol production. Thus, reactions 1 and 2 (Table 7-1) are not likely involved in n-propanol production. 
Reactions potentially responsible for propanol formation could then be reaction 4 (propionate reduction to propanol), 5 (ethanol condensation reaction), 3 (ethanol oxidation to acetate with concurrent propionate reduction to propanol), and 10 (hydroformylation through carbon monoxide and hydrogen).

Reactions 3, 4 and 10 have negative Gibbs free energy changes at standard conditions, while reaction 5 and 10 have a positive energy change. Free energy change calculations using data from the ethanol degradation assays revealed that a number of complex interactions were possible (Table 7-4). Reaction 5 had the highest available free energy levels $(-12$ to $-15 \mathrm{kcal} / \mathrm{mol})$ under the experimental conditions tested. Reaction 3 had the lowest available free energy $(-1 \mathrm{kcal} / \mathrm{mol})$. Reactions 5 and 10 were energetically favored throughout the entire 11 hours until ethanol was depleted, whereas reactions 3 and 4 had negative free energy values for only five or eight hours. Hydrogen appeared to play a strong role as a driving force governing reactions involving propionate (reactions 3 and 4). Propionate degraders are sensitive to hydrogen concentration in the medium. A low hydrogen partial pressure $\left(10^{-6}\right.$ to $10^{-4} \mathrm{~atm}$, or 1 to $100 \mathrm{ppm}$ ) is required to maintain a negative Gibbs free energy change and allow propionate degradation to proceed. This hydrogen level was maintained between hydrogen-producers and hydrogen-utilizers.

\begin{tabular}{|c|c|c|c|c|c|c|c|}
\hline \multirow[b]{2}{*}{ Time (hr) } & \multicolumn{7}{|c|}{$\Delta G^{\prime}(\mathrm{kcal} / \mathrm{mol})$ for reaction number: ${ }^{a, d}$} \\
\hline & 3 & 4 & 5 & 6 & 7 & 8 & 10 \\
\hline 0.5 & -1.19 & -2.29 & -13.55 & -3.72 & -9.77 & -8.44 & NA \\
\hline 1 & -0.95 & -2.18 & -13.12 & -4.47 & -10.38 & -8.00 & -8.20 \\
\hline 2 & NA & -3.50 & -11.83 & -6.65 & -10.52 & --6.45 & -10.36 \\
\hline 4 & -0.23 & -3.32 & -11.81 & -6.22 & -10.41 & -6.39 & -9.96 \\
\hline 5 & -0.13 & -3.16 & -11.85 & -5.30 & -10.21 & -6.46 & -9.45 \\
\hline 6 & $+^{5}$ & -2.60 & NA & -4.57 & -10.03 & $\mathrm{NA}^{\mathrm{C}}$ & NA \\
\hline 7 & + & -1.90 & -12.56 & -3.27 & -9.86 & -7.44 & -7.49 \\
\hline 8 & + & -0.83 & -13.42 & -1.03 & -9.44 & -8.47 & -5.90 \\
\hline 9 & + & + & -13.89 & $\mathrm{NA}^{\mathrm{c}}$ & $\mathrm{NA}$ & NA & -3.85 \\
\hline 10 & + & + & -14.68 & NA & NA & NA & -2.81 \\
\hline 11 & + & + & -14.13 & + & -8.10 & -9.51 & -1.21 \\
\hline \multicolumn{8}{|c|}{$\begin{array}{l}\text { a negative values are listed. } \\
\text { b، +" represents positive } \Delta G^{\prime} \text { value. } \\
\text { "NA, not available. } \\
{ }^{d} \text { reactions are referred to Table } 7-1 .\end{array}$} \\
\hline
\end{tabular}


Acetate disproportionation to methane and $\mathrm{CO}_{2}$ can be described as a two-step reaction with $\mathrm{CO}$ as an intermediate: 1) acetate splitted to $\mathrm{CO}$ and $\mathrm{CH}_{4} ; 2$ ) $\mathrm{CO}$ oxidized to $\mathrm{CO}_{2}$ (Zeikus et al., 1985; Hickey et al. 1987). Accumulation of $\mathrm{CO}$ could be the result of reversible equilibrium of $\mathrm{CO}$ between the liquid and gas phases. The concurrent increase in $\mathrm{CO}$ and acetate concentrations has been observed (Hickey and Switzenbaum 1990). The accumulated $\mathrm{CO}$ level resulted in propanol formation from $\mathrm{CO}$ and ethanol becoming energetically favorable. $\mathrm{CO}$ was consumed via oxidization to $\mathrm{CO}_{2}$ and/or reduction to form propanol. Both of these reactions were thermodynamically possible during the initial 11 hours (Table 7-4).

Gibbs free energy for reactions of propanol formation and consumption appeared to be time-dependent (Table 7-4). During the initial five hours, ethanol could have been converted to acetate, propionate and npropanol through reactions 3, 5, 8, 10 (Tables 7-1 and 7-4) and possibly other unknown reactions (Samain et al. 1982). Significant amounts of hydrogen and carbon monoxide gases were generated. The $\mathrm{H}_{2}$ content in the gas phase accumulated up to $1120 \mathrm{ppm}$ (20 mM in liquid phase assuming equilibrium; Figure 7-1). This made propionate oxidation to acetate energetically unfavorable, and the reverse reactions possible, namely, acetate reduction to propionate (reaction 6) and subsequent propionate reduction to propanol (reaction 4).

$\mathrm{CO}$ increased rapidly, following hydrogen, up to $50 \mathrm{ppm}(0.9 \mathrm{mM})$. The highly reduced environment during this period drove reactions towards consumption of $\mathrm{H}_{2}$ and $\mathrm{CO}$. Any reaction observed during this period was likely due to conversion to more reduced products. The potential sinks for $\mathrm{CO}$ were n-propanol formation (reaction 10) and oxidation to $\mathrm{CO}_{2}$. $\mathrm{CO}$ serves as a precursor or an additional carbon supply to ethanol during propanol formation. Reactions 4,6 , and 10 and hydrogenotrophic methanogenesis were potential sinks for hydrogen.

$\mathrm{N}$-propanol formation was energetically favorable almost immediately via propionate reduction (reactions 3 and 4), ethanol condensation (reaction 5) and hydroformylation through carbon monoxide and hydrogen (reaction 10). The concentration of n-propanol reached a plateau value of $0.4 \mathrm{mM}$ (Figure 7-1).

Propionate concentration decreased during the initial three hours, while propanol accumulated at a linear rate, and then increased concurrent with a reduction in propanol production. Propionate consumption via reactions 3 and 4 was energetically favorable during this period. Propionate could have been formed from acetate (reaction 6), propanol (reaction 7), or ethanol (Schink et al. 1985).

Between six and eight hours, the reduced concentration of ethanol and high acetate concentration resulted in reaction 3 becoming energetically unfavorable. Beginning at the nine-hour mark, another change occurred as shown in Table 7-4. The energy available for reduction reactions (reactions 4 and 6) changed in favor of formation of more oxidized products (propionate and acetate) as a result of a dramatic decrease 
in the hydrogen concentration to $\leq 20 \mathrm{ppm}$ ( $\leq 1 \mathrm{mM}$ of liquid phase; Figure 7-1). More hydrogenproducing reactions became favorable (reverse reactions of 4 and 6 and reaction 5); a hydrogen level of 3$12 \mathrm{ppm}$ (0.05-0.22 mM in liquid phase) was subsequently maintained. CO concentration decreased gradually to $0.5 \mathrm{mM}$ at the 11-hour mark. Formation of propanol was energetically favorable through reactions 5 and 10 during this period. Energetically, consumption of n-propanol proceeded via reduction (reaction 7) during the entire experimental time period. This reaction has been predicted (Schink 1984). Formation of propionate appears to be related to propanol oxidation via the reverse of reactions 4 and 7 . Thermodynamic calculations for hydrogen and $\mathrm{CO}$ were based on head space measurements. The mass transfer limitation of $\mathrm{H}_{2}$ from a granulst flocs matrix to a liquid phase was probably minimized (Wu et al., 1995). However, due to possible mass transfer limitations of hydrogen from liquid to gas phase, actual liquid concentration of $\mathrm{H}_{2}$ could be higher. As a result, such a reduced environment favors propionate reduction (reaction 4) and hydroformylation (reaction 10).

Smith and McCarty (1989) reported that reaction 3, formation of propanol and acetate from ethanol and propionate, was the most likely reaction to occur during a perturbation of ethanol, propionate, and formate to a propionate and ethanol enrichment in a CSTR. This was based on a free energy analysis. The mechanism and species which performed these two reactions were unknown. The amount of reducing power available had a strong impact on propionate consumption and propanol formation in this current work. This is in contrast to the conclusions of Smith (1987), who believed hydrogen was not associated with propanol production. Differences in the predominant microbial populations in the propionate and ethanol enrichment mixed cultures of Smith and McCarty (1989) and the ethanol-, propionate- and acetateutilizing mixed culture of this study could contribute to this discrepancy. However, the question is the source of the additional carbon molecule of propionate from ethanol degradation. This carbon molecule could not come from bicarbonate, derived from ${ }^{13} \mathrm{C}$ experiment. Therefore, reactions 3 and 4 are not likely to be the primary routes of propanol formation.

Reaction 10, hydroformylation through ethanol, carbon monoxide, and hydrogen, to form n-propanol, is more likely responsible for the n-propanol formation. The $\mathrm{CO}$ is likely produced from acetate decarboxylation; acetate is derived from ethanol (reaction 8). Thus it is consistent with results of the ${ }^{13} \mathrm{C}$ assays. Syngas ( $\mathrm{CO}$ and $\mathrm{H} 2$ ) has been widely used in the chemical industry for synthesis of aldehyde, ethanol, and other plasticides. Similar reactions of hydroformyl addition have been used in OXO process to produce alcohols (Kirk, Othmer, Grayson and Eckroth 1982). This reaction (reaction 10) is energetically favored during the time period when propanol was present. The free energy level of reaction 10 correlated well with the appearance and disappearance of propanol. However, it has not been reported that reaction 10 can be carried out biologically. Reaction 5 , condensation of ethanol to release a carbon dioxide and form n-propanol, is another candidate for n-propanol production. The mechanism and 
pathway of this reaction are not clear. The above discussion is based solely on reaction thermodynamics. Among those reactions that are energetically favorable, the predominant reaction will also depend on reaction kinetics and pathways present. These need to be further studied.

\section{CONCLUSIONS}

- N-propanol formation during anaerobic biodegradation of ethanol was observed in a mixed anaerobic consortia.

- ${ }^{13} \mathrm{C}$ isotopic study showed that carbon dioxide was not involved in propanol formation from ethanol in this culture.

- N-propanol could be formed from four reactions, derived from thermodynamic analyses. They are: ethanol oxidation coupled with propionate reduction (reaction 3), propionate reduction (reaction 4), ethanol condensation (reaction 5), and, hydroformylation (reaction 10). The last two reactions (condensation and hydroformylation) are the most likely candidates for the n-propanol formation. 


\section{Section 8}

KINETICS OF SUBSTRATE UTILIZATION BY BREWERY GRANULES

\section{INTRODUCTION}

Recent work investigating granule systems from UASB reactors has focused on defining the composition, kinetics, and mass transfer within the anaerobic granules. Metabolic performance of granular sludge has been extensively studied (Zinder et al. 1984; Koster 1986; Koster and Cramer 1987; Koster et al. 1986; Fukuzaki et al. 1990a, 1990b, 1991; Wu 1991a; Wu et al. 1991b; Peterson and Ahring 1991; DeBeer et al. 1992; van Lier et al. 1993). Kinetic studies of the granules were proceeded by studies using both defined cultures (Smith and Mah 1980; Zehnder 1980; Ahring and Westermann 1985; Ahring and Westermann 1987; Zinder et al. 1987; Huser et al. 1982; Patel 1984) and mixed cultures (Lawrence and McCarty 1969; Kugelman and Chin 1971; Lin et al 1989; Gujerw and Zehnder 1983; Chang et al. 1982, 1983; Zinder 1984; Smith 1987; Kaspar 1978; Heyes 1983): Various substrates were examined, including acetate, propionate, butyrate, isobutyrate, valerate, ethanol, methanol, formate, $\mathrm{H}_{2}-\mathrm{CO}_{2}$ and glucose $(\mathrm{Wu}, 1991 \mathrm{a}$; Schmidt et al. 1993).

Metabolic performance, granule physical, chemical, and biological composition and species distribution as well as ultrastructure were observed to be related to the wastewaters the granules were grown on/acclimated to. Substrate conversion rates were observed to be closely related to the composition of the wastewater that the granules were acclimated to. In one study, sulfate reduction accounted for $28 \%$ and $60 \%$ of ethanol and propionate conversion, respectively, but did not play a significant role in the metabolism of $\mathrm{H}_{2}$, formate, and acetate (Wu et al. 1991b). Schmidt et al. (1993) reported that addition of hydrogen-utilizing methanogen and sulfate-reducing bacteria to disintegrated granules improved both propionate and butyrate degradation rates. It was also observed that interspecies formate transfer does not play an important role for stimulation of propionate and butyrate degradation (Schmidt et al. 1993).

Due to the complexity of substrate and product transfer processes within granules, a result of mass transfer limitation, description of substrate conversion rates of the granule has been characterized using apparent substrate utilization rates. The kinetics of substrate utilization by anaerobic granules appears to be considerably different from dispersed cells or biofilms with slab geometry for which explicit solutions are available (Bailey and Ollis, 1986). Substrate flux, temperature, $\mathrm{pH}$, granule size, and liquid film all contribute to the observed overall substrate utilization rate. A mathematical model was developed to describe the substrate utilization and mass transfer within biofilms (Williamson and McCarty, 1976) (Rittmann and McCarty, 1980). Thermophilic granules grown on acetate from a UASB reactor were 
examined for mass transfer resistance (Schmidt and Ahring, 1991). Disintegrated granules showed a higher specific methanogenic activity than intact granules when $\mathrm{H}_{2} / \mathrm{CO}_{2}$ were used as substrates. The reduction in mass transfer resistance depended on the method used to disrupt the granules when acetate was used as substrate. An effective diffusion coefficient for acetate in anaerobic sludge, measured using a diaphragm diffusion cell, was reported to be $22-33 \%$ of the diffusion coefficient in pure water (Nilsson and Karlsson 1989). DeBeer et al. (1992) measured the $\mathrm{pH}$ profile inside granules using a pH micro-electrode. The $\mathrm{pH}$ inside was higher than in the bulk liquid. An unsteady state effectiveness factor, $(\eta)$, of $0.57-0.62$ was reported for acetate conversion based on the acetate profile calculated using the $\mathrm{pH}$ profile data. Alphenaar et al. (1993) showed that substrate transport limitations and substrate release (diffusion) velocity all increased with granule sizes. The overall effective diffusion coefficient was observed to be $40-80 \%$ of the diffusion coefficient in pure water in this study. An effectiveness factor was reported to be $0.48-0.67$ during propionate degradation using whole granules and disintegrated granules (Schmidt and Ahring 1993). Numeric methods have been used for determining effectiveness factors with Michaelis-Menten kinetics and high theiele moduli (Chang 1982). Controversies on the effect of diffusional and masstransfer resistance to substrate utilization still exist (Henze and Harremoes, 1983). No diffusional limitations in biofilms of $2.6 \mu \mathrm{m}$ were reported (Kennedy and Droste 1986). Other researchers concluded that diffusion is not rate limiting during acetate utilization (DeBeer et al. 1992). The degradation rate of propionate and butyrate in granules from a thermophilic UASB reactor decreased 35 and $25 \%$, respectively, after disintegration of the granules (Schimidt and Ahring 1993). Overall, however, diffusional and mass transfer resistances within the granular sludge, its role and significance with respect to the utilization rates of different substrates, and its interaction with temperature effect and granule size, have not been fully investigated. A detailed discussion of modeling anaerobic granular sludges for substrate utilization including liquid film mass transfer, diffusion limitations, and intrinsic kinetics is presented in Section 4.

Considerable work has been performed in studying reaction thermodynamics and substrate thresholds of anaerobic bacteria, particularly methanogens. From a thermodynamic point of view, threshold levels represent the minimal energy required for a particular reaction to proceed. This minimal energy is required for ATP synthesis. Schink $(1988,1992)$ suggested that during butyrate oxidation in anaerobic systems, a minimum of $20 \mathrm{~kJ} / \mathrm{mol}$ is required for each reaction step. This is approximately $1 / 3$ of the energy required for formation of 1 mole ATP (75 KJ/mole ATP) (Schink 1992). The remaining energy is conserved via a membrane electron chain in a process of reversed electron flow. This reduces the $\mathrm{H}_{2}$ concentration and through an energy-sharing process anaerobes are able to conserve and utilize a minimal amount of energy for growth. The minimal energy for a reaction is species-dependent. 
It is believed that the substrate threshold model provides a description of population competition in different habitats. The prevailing population for a particular substrate may be determined by the substrate concentration level within that environment. Bacteria will not consume a substrate when it falls below the threshold level. Different organisins each have thcir own threshold for a particular substrate. The organisms with a threshold at or lower than the environmental level of a particular substrate are able to outcompete other organisms for the substrate (assuming no other factors are involved). This competition could occur between different species or within a species. Lovely (1985) observed that a Methanobacterium did not consume $\mathrm{H}_{2}$ below a threshold of 6.5 Pa. Cord-Ruwisch (1988) demonstrated that hydrogenotrophic anaerobic bacteria compete for $\mathrm{H}_{2}$. Successful competition was a function of the redox potential and electron transfer efficiency. Acetate decarboxylation is performed by two methanogens: Methanosarcina and Methanothrix (Zehnder et al. 1980; Mah 1978). After extensive study of anaerobic acetate decarboxylation, Westermann (1989), Zinder (1990), and Hang and Zinder (1989) indicated a high acetate threshold $(1-2.5 \mathrm{mM})$ for Methanosacrina sp. and a low threshold $(12-75 \mu \mathrm{M})$ for Methanothrix sp. The higher the electron transfer efficiency between electron donor and electron acceptor, the lower the substrate threshold. Large amounts of electron transfer produce high energy yields, thus lowering the $\mathrm{H}_{2}$ threshold required for energy conservation. The high-acetate-threshold Methanosarcina sp. conserves more free energy from acetoclastic methanogenesis than the low-acetatethreshold Methanothrix sp. In this case, the Methanothrix sp. require less energy to carry out the biochemical reactions and thus are more energy-efficient.

In this study, granules obtained from a system treating brewery wastewater were characterized for the kinetics of substrate utilization, liquid film resistance, and diffusional resistance. Temperature effects, reaction thermodynamics, and substrate thresholds of the populations within the granules during acetoclastic methanogenesis were examined in order to better understand the physicochemical and biological process occurring. Experiments were performed using a batch-mode CSTR. The carbon source used was acetate for mass transfer, temperature effects, and threshold determinations. Acetate, propionate and ethanol were used for intrinsic kinetics and diffusion limitation studies. The mineral medium used and inoculum preparation are described in Appendices A and BI, respectively. Biomass determination and microscopy protocols are presented in Appendices B7 and C2, respectively. A linear regression was used to estimate the initial rate of degradation of each substrate. These analytical techniques are detailed in Appendix C2. 


\section{INTRINSIC KINETICS OF ACETATE, PROPIONATE, ETHANOL AND H $\mathrm{H}_{2}$ UTILIZATION}

\section{Description of Laboratory Batch System}

Activity assays for brewery granular sludge were performed in a two-liter Multigen Convertible BenchTop Reactor (Model F1000, New Brunswick Scientific Co.). A schematic representation of the system used is depicted in Figure 8-1. The reactor was operated in batch mode. Temperature was controlled by means of a heating system equipped with a thermosensor. Reactor mixing was provided by two impellers, with a speed range of 100 to $1000 \mathrm{rpm}$. The reactor was sealed with a rubber ring top to prevent air from entering the vessel. The reactor head space was connected, using small-diameter tubing, to a flask that was used as a water seal. Sampling and drainage ports were sealed with butyl rubber stoppers and aluminum crimps. Target compounds were introduced through the injection port using 3-ml to $25-\mathrm{ml}$ syringes (depending on the starting concentrations desired) equipped with 21 -gauge needles. Liquid samples were taken from the sampling port using a $1-\mathrm{ml}$ syringe and a 21 -gauge needle. Operational conditions are presented in Table 8-1.

(8)

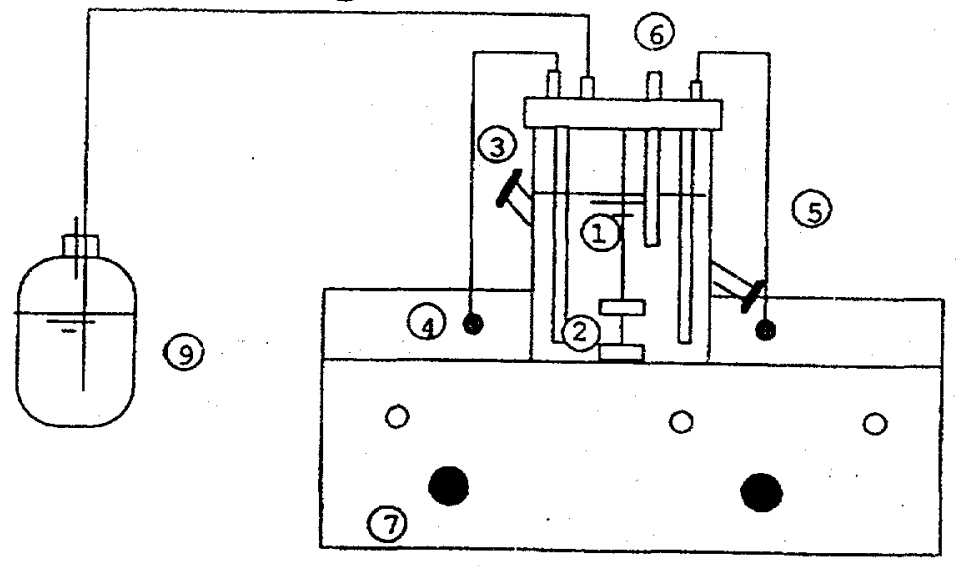

(1) $2 \mathrm{~L}$ multigen reactor

(2) Impellers

(3) Sampling port

(4) Heating wire

(5) Thermosensor

(6) Thermometer

(7) Impeller speed controller

(8) Gas line

(9) Water seal

Figure 8-1. Schematic diagram of bench-top CSTR set-up.

\begin{tabular}{|l|c|}
\hline $\begin{array}{l}\text { Table 8-1. Environmental and operational conditions used for the bench- } \\
\text { top reactor. }\end{array}$ \\
\hline Operation mode & batch CSTR \\
\hline Temperature & $37^{\circ} \mathrm{C}$ \\
\hline $\mathrm{pH}$ & $7.00 \pm 0.01$ \\
\hline Working volume & $1.4-1.5 \mathrm{~L}$ \\
\hline Gas space volume & $0.5-0.6 \mathrm{~L}$ \\
\hline Inoculum & $0.5-2 \mathrm{~g}$ \\
\hline
\end{tabular}




\section{Experimental Design and Methods}

To minimize diffusional resistance within the granules, which could mask the intrinsic properties of substrate utilization, the activity assays for acetate, propionate, ethanol and $\mathrm{H}_{2}$ were performed using fine floc particles ( $\sim 33 \mu \mathrm{m}$ diameter) obtained by disrupting granules from a laboratory bench-scale UASB reactor (Figure 8-1). These granules had been acclimated for more than six months to a synthetic brewery waste. The composition of this synthetic waste was based on the results of a one-week sampling program at the brewery (Appendix A). The anaerobic technique used to produce the flocs is described in Appendix B1. The Multigen reactor was operated using the mixing condition determined during a separate experiment (see below). Mass transfer within brewery granules was required to ensure that the liquid film mass transfer resistance was minimized. Single carbon sources, acetate, propionate, and ethanol, which are major components in the brewery waste, were used to assess the activity for each group of microorganisms (acetoclastic methanogens, propionate degraders, and ethanol utilizers, respectively). Sodium salts of propionate and acetate were used. Medium, stock solutions and the inoculum preparation technique used are described in detail in Appendices A and B1. Acetate and propionate degradation rate assays were performed using a series of substrate concentrations. The initial concentrations covered the entire range of Monod kinetics, from the expected $K s$ to a value 10 times higher. This was done to allow observation of both the zero and the first-order reaction periods. The sampling frequencies used, which were varied with initial doses used, are presented in Tables 8-2 and 8-3 for acetate and propionate, respectively. Assays were repeated at low and high concentration ranges. Substrate consumption was modeled using Monod kinetics. The maximum specific substrate utilization rate $(\mathrm{km})$, and half velocity constant $(\mathrm{Ks})$, for acetate and propionate were estimated by applying a non-linear least squares technique (software SYSTAT) on the differential form of the Monod equation.

$$
-\frac{\partial S}{\partial t}=V_{i}=\frac{k_{m} X S_{i}}{K_{s}+S_{i}}
$$

\begin{tabular}{|c|c|c|}
\hline \multicolumn{3}{|c|}{ Table 8-2. Sampling frequency for the acetate utilization assays. } \\
\hline Acetate (mmol/L) & Sampling Frequency & Experiment Period (hr) \\
\hline $0-1$ & $2 \mathrm{~min}$ & 0.5 \\
\hline $1-2$ & $3 \mathrm{~min}$ & 1 \\
\hline $2-3$ & $5 \mathrm{~min}$ & 1 \\
\hline $3-5$ & $5 \mathrm{~min}$ & 1 \\
\hline$>5$ & $10 \mathrm{~min}$ & 2 \\
\hline
\end{tabular}

\begin{tabular}{|c|c|c|}
\hline \multicolumn{3}{|c|}{ Table 8-3. Sampling frequency for the propionate utilization assays. } \\
\hline Propionate (mM) & Sampling Frequency & Experiment Period (min) \\
\hline $0-1$ & $1 \mathrm{~min}$ & 20 \\
\hline $1-2$ & $2 \mathrm{~min}$ & 30 \\
\hline$>2$ & $3 \mathrm{~min}$ & 60 \\
\hline
\end{tabular}


where $S$ is substrate (mM), $t$ is time $(\mathrm{hr}), V i$ is utilization rate of substrate $I(\mathrm{mM} / \mathrm{h}), k_{m}$ is maximum substrate utilization rate (g/gVS-d), $X$ is biomass as volatile solids ( $\mathrm{gVS}$ ), $K_{s}$ is half velocity constant $(\mathrm{mM})$.

Ethanol utilization assays were performed by injection of a concentrated solution $(20 \mathrm{mM})$ into the reactor to obtain a high initial substrate concentration. Concentrations of ethanol and $\mathrm{H}_{2}$ were then tracked over time. The progress curve for ethanol degradation, adjusted for an initial lag period, was fitted to the integrated form of the Monod equation. A non-linear least squares technique was used to evaluate $\mathrm{km}$ and Ks.

$$
t_{i}=\frac{l}{k_{m} X}\left[K s L n \frac{S_{o}}{S_{i}}+\left(S_{o}-S_{i}\right)\right] \quad \ldots
$$

where $t_{i}$ is time (hr), $i=1,2,3, \ldots \mathrm{n}, k_{m}$ is maximum substrate utilization rate (g/gVS-d), $X$ is biomass at the conclusion (gVS), $K_{S}$ is half velocity concentration $(\mathrm{mM}), S_{o}$ is initial substrate concentration (mM), $S_{i}$ is substrate concentration at time $t i(\mathrm{mM})$. For details of the ethanol assay see Section 7. For all kinetic parameters estimated, the quantity of curve fitting is judged by $\mathrm{r}^{2}$.

Analytical methods for acetate, propionate, ethanol and $\mathrm{H}_{2}$ are given in Appendix $\mathrm{C}$. Derivation of the non-linear least squares procedure for equations 8-1 and 8-2 are provided in Appendix D. Microscopic observations were performed using an epifluoresence microscope (Olympus, BH-2, Appendix B7).

Biomass was collected and dry weight determined after each assay.

\section{Kinetic Parameter Estimation for Acetate, Propionate, Ethanol, and $\mathbf{H}_{2}$}

The initial acetate concentrations used ranged from $0.27 \mathrm{mM}$ to $8.65 \mathrm{mM}$ and for propionate from $0.1 \mathrm{mM}$ to $2.1 \mathrm{mM}$. At each initial concentration, substrate conversion was measured with time. The linear range was chosen for calculation of the initial rate at that substrate concentration using a linear regression. Kinetic parameters $(K s, \mathrm{~km})$ were determined using initial utilization rates and the corresponding substrate concentrations from these assays. The ethanol degradation rate was measured at an initial concentration of $20 \mathrm{mM}$. Concentrations of ethanol and $\mathrm{H}_{2}$ were then tracked over time. Kinetic parameters for ethanol $(K s, k m)$ and $\mathrm{H}_{2}(K s)$ were solved analytically using the integrated form of the Monod equation. The $\mathrm{H}_{2}$ consumption rate was calculated considering the observed $\mathrm{H}_{2}$ disappearance rate and a calculated $\mathrm{H}_{2}$ production rate from ethanol, based on the stoichiometric relationship: 


$$
\mathrm{CH}_{3} \mathrm{CH}_{2} \mathrm{OH}+\mathrm{H}_{2} \mathrm{O} \rightarrow 2 \mathrm{H}_{2}+\mathrm{CH}_{3} \mathrm{COOH}
$$

and the following equation:

$$
\frac{d H_{2}}{d t}=\left[\frac{d H_{2}}{d t}\right]_{a p p}+2 \frac{d E T O H}{d t}
$$

where $\left.\frac{d H_{2}}{d t}\right]_{a p p}$ is the apparent hydrogen consumption rate, that is, the change of hydrogen concentration with time in the system $\frac{d E T O H}{d t}$ is the ethanol consumption rate. The influence of n-propanol and propionate on the hydrogen consumption rate were ignored because the concentrations of n-propanol and propionate ( $<0.4 \mathrm{mM}$ and $<0.7 \mathrm{mM}$, respectively) were relatively low compared to that of ethanol (20 $\mathrm{mM})$.

The fitted curves for acetate, propionate, ethanol, and $\mathrm{H}_{2}$ utilization are presented in Figures 8-2 through 85. The estimated half velocity constant $(K s)$, and maximum specific utilization rate, $(\mathrm{km})$ for acetate, propionate and ethanol were $0.45 \mathrm{mM}, 0.40 \mathrm{mM}$, and $3.37 \mathrm{mM}$, and $5.11 \mathrm{~g} / \mathrm{g}$ VS-d, $6.25 \mathrm{~g} / \mathrm{g} \mathrm{VS}-\mathrm{d}$, and $5.49 \mathrm{~g} / \mathrm{g}$ VS-d, respectively. The apparent $K s$ for $\mathrm{H}_{2}$ was $150 \mathrm{ppm}$ or $5.9 \mu \mathrm{M}$ (gas phase concentration). The $\mathrm{H}_{2}$ consumption rate was $5.4 \mathrm{mM} / \mathrm{g}$ VS-h. Fitted curves had $\mathrm{r}^{2}$ of 0.993 for acetate, 0.986 for propionate, 0.950 for ethanol and 0.820 for hydrogen, respectively. Background acetate, propionate, and ethanol levels were less than $0.1 \mathrm{mM}$. Literature values of $\mathrm{k}$ and $\mathrm{K}_{\mathrm{s}}$ for acetate, propionate, ethanol, and hydrogen are compared to results obtained in this work for Tables 8-4 and 8-5.

\section{MASS TRANSFER WITHIN BREWERY GRANULES}

\section{Liquid Film Resistance}

Mass transfer through the liquid film around the granules was studied using a bench-top Multigen reactor system (Figure 8-1). Granules were collected from a laboratory bench-scale UASB reactor treating a synthetic brewery waste (Figure 6-1). Reactor environmental and operational conditions are shown in Table 8-1. Sodium acetate was the sole carbon and energy source used in mass transfer experiments. Acetate utilization was initially measured at different mixing levels. The experimental design is listed in Table 8-6. Impeller speeds were varied from 200 to $800 \mathrm{rpm}$ to determine the point at which liquid film diffusion was minimized. The initial acetate consumption utilization rate was determined by linear regression. 


\begin{tabular}{|c|c|c|c|c|l|l|}
\hline \multicolumn{7}{|c|}{ Table 8-4. Summary of literature values of acetate and propionate utilization kinetics } \\
compared to results from this study.
\end{tabular}

\begin{tabular}{|c|c|c|c|c|c|}
\hline \multicolumn{2}{|c|}{$K s$} & \multicolumn{2}{|c|}{$k m$} & \multirow[b]{2}{*}{ Culture } & \multirow[b]{2}{*}{ Reference } \\
\hline $\begin{array}{c}\mathrm{H}_{2} \\
(\mu \mathrm{M})\end{array}$ & $\begin{array}{c}\text { Ethanol } \\
(\mathrm{mM})\end{array}$ & $\begin{array}{l}\text { Ethanol } \\
(\mathrm{g} / \mathrm{g}-\mathrm{d})\end{array}$ & $\begin{array}{l}\text { Temp } \\
\left({ }^{\circ} \mathrm{C}\right)\end{array}$ & & \\
\hline 4.3 & & & 32 & sludge & Mosey, 1989 \\
\hline $6.0^{3}$ & & & 30 & sludge & Robinson \& Tiedje, 1982 \\
\hline 0.3 & 100 & 3.83 & 35 & sludge & Smith, 1987 \\
\hline & & 0.19 & 35 & granule & Wu, 1991a \\
\hline & & 2.98 & 35 & granule & $\mathrm{Wu}, 1991 \mathrm{a}$ \\
\hline 8.5 & & & 60 & triculture & $\begin{array}{l}\text { Ahring \& Westermann, } 1987 \\
\text { dissolved } \mathrm{H}_{2}\end{array}$ \\
\hline $5.9^{\mathrm{a}, \mathrm{b}}$ & $3.37^{\mathrm{a}}$ & $5.49^{a}$ & 37 & brewery granule & this work \\
\hline
\end{tabular}




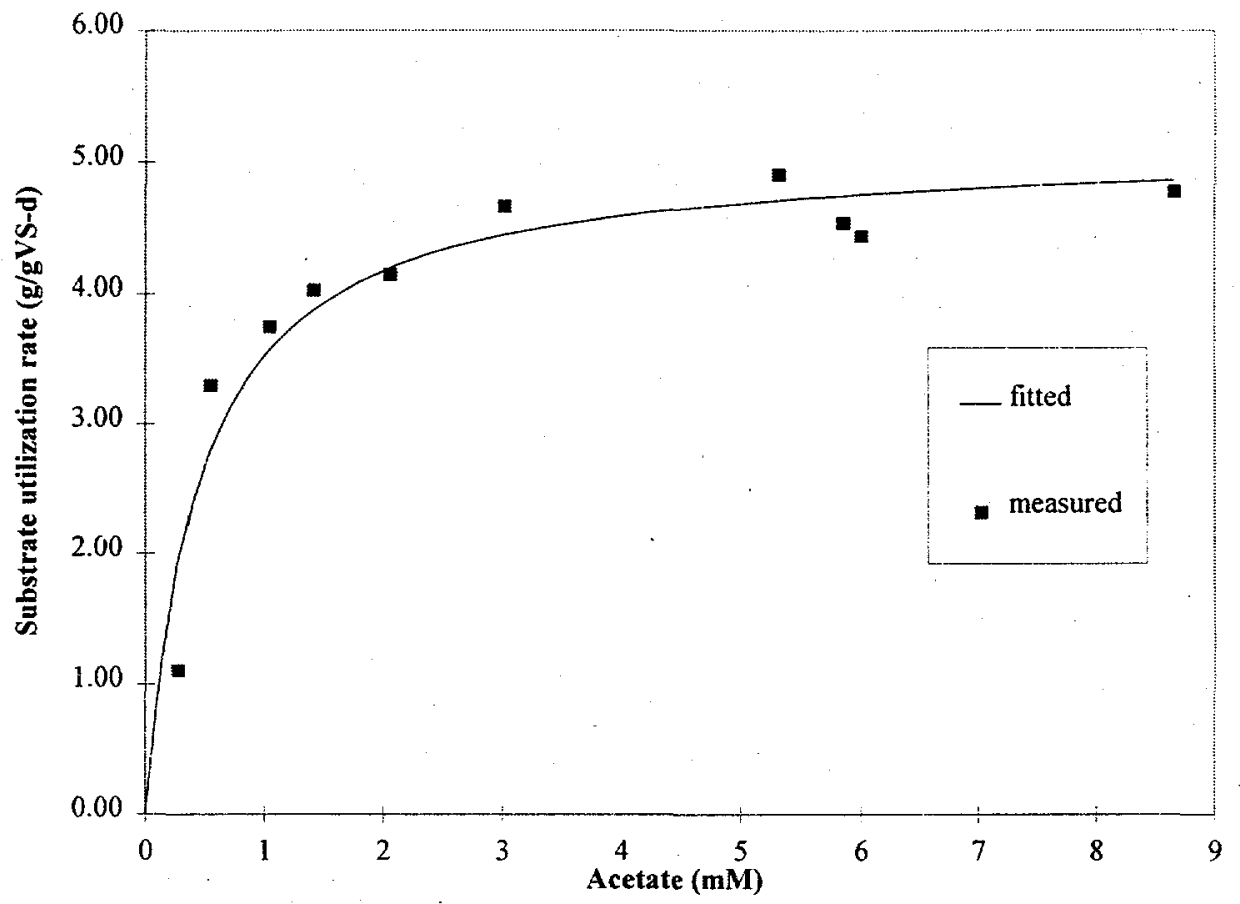

Figure 8-2. Acetate utilization by brewery granules flocs and fitted Monod kinetics (Ks = $0.45 \mathrm{mM}, \mathrm{km}=5.11 \mathrm{~g} / \mathrm{g}$ VS-d).

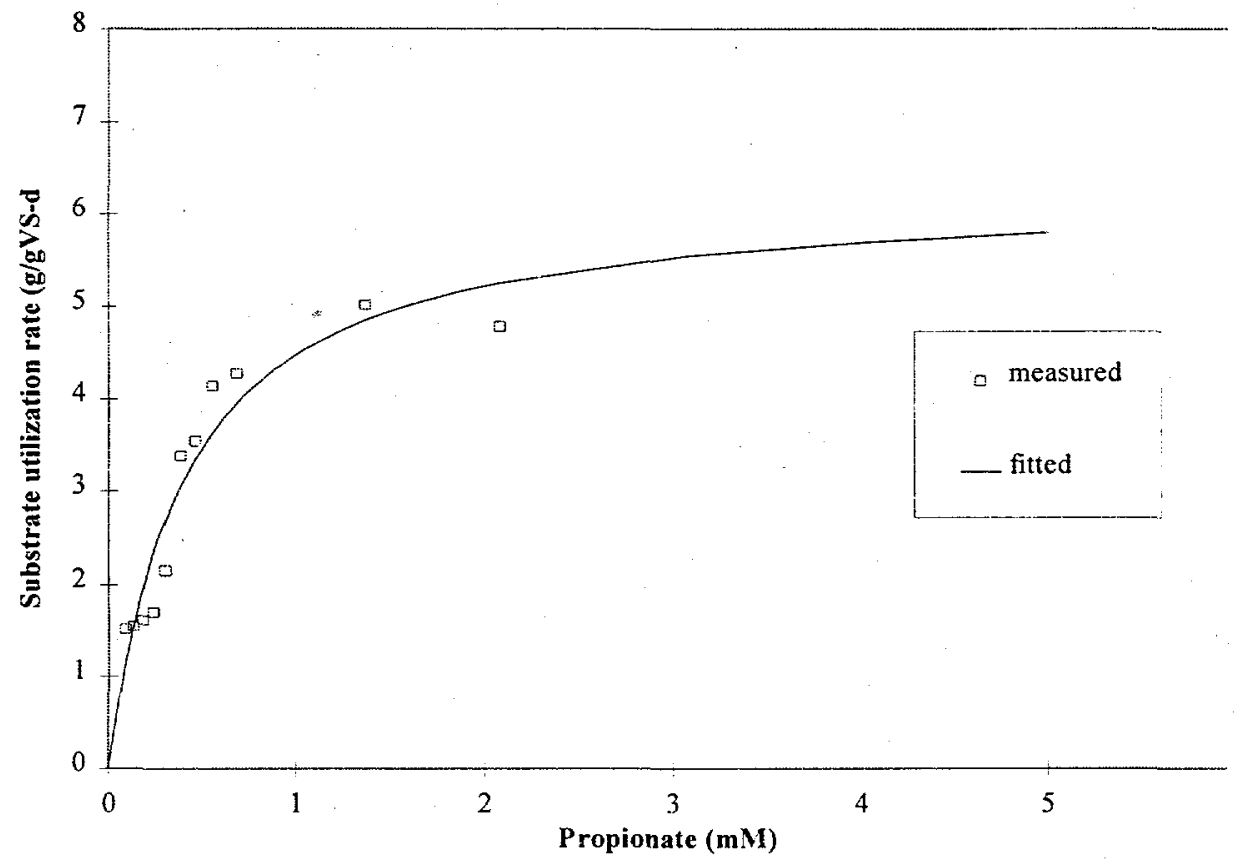

Figure 8-3. Propionate utilization by brewery granule flocs and fitted Monod kinetics (Ks = $0.40 \mathrm{mM}, \mathrm{km}=6.25 \mathrm{~g} / \mathrm{g}$ VS-d). 


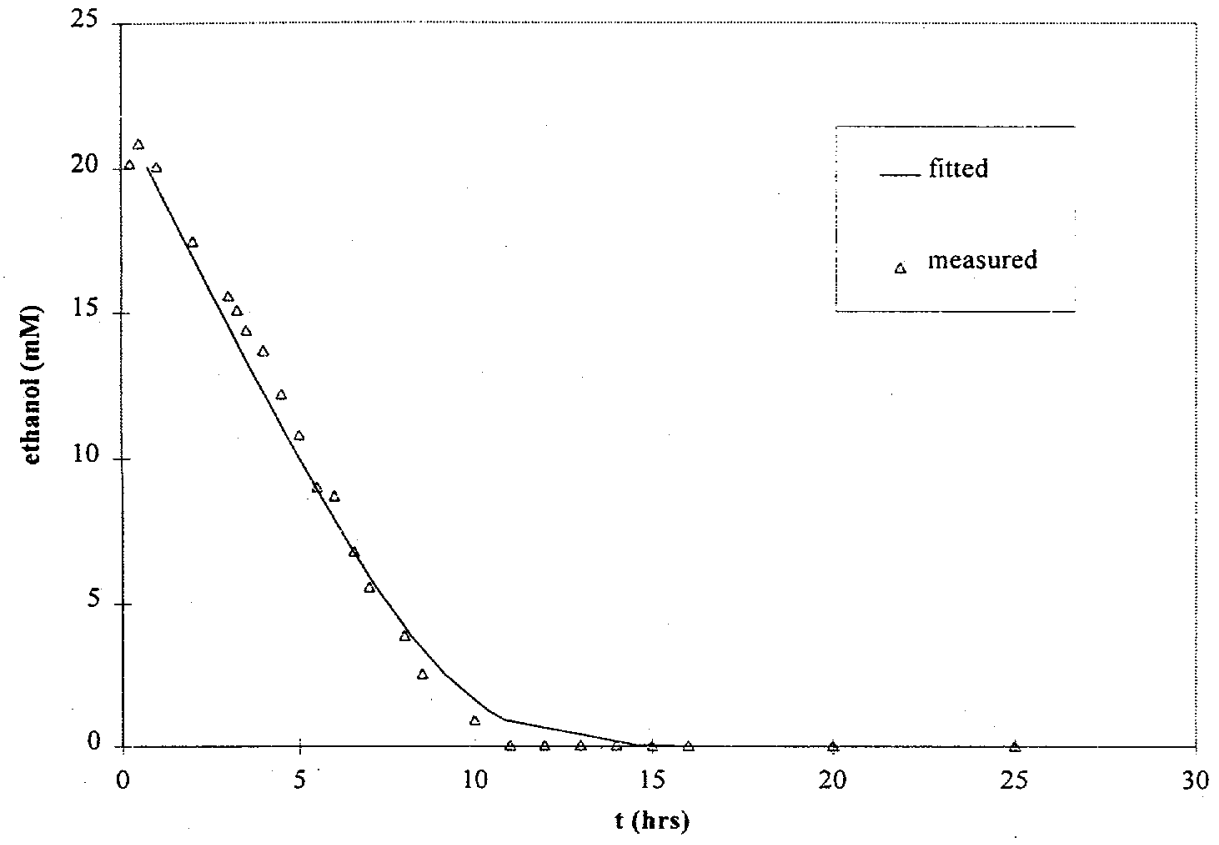

Figure 8-4. Ethanol utilization by brewery granule flocs with fitted Monod kinetics (Ks = $5.49 \mathrm{~g} / \mathrm{g}$ VS-d, $\mathrm{km}=3.37 \mathrm{mM}$ ).

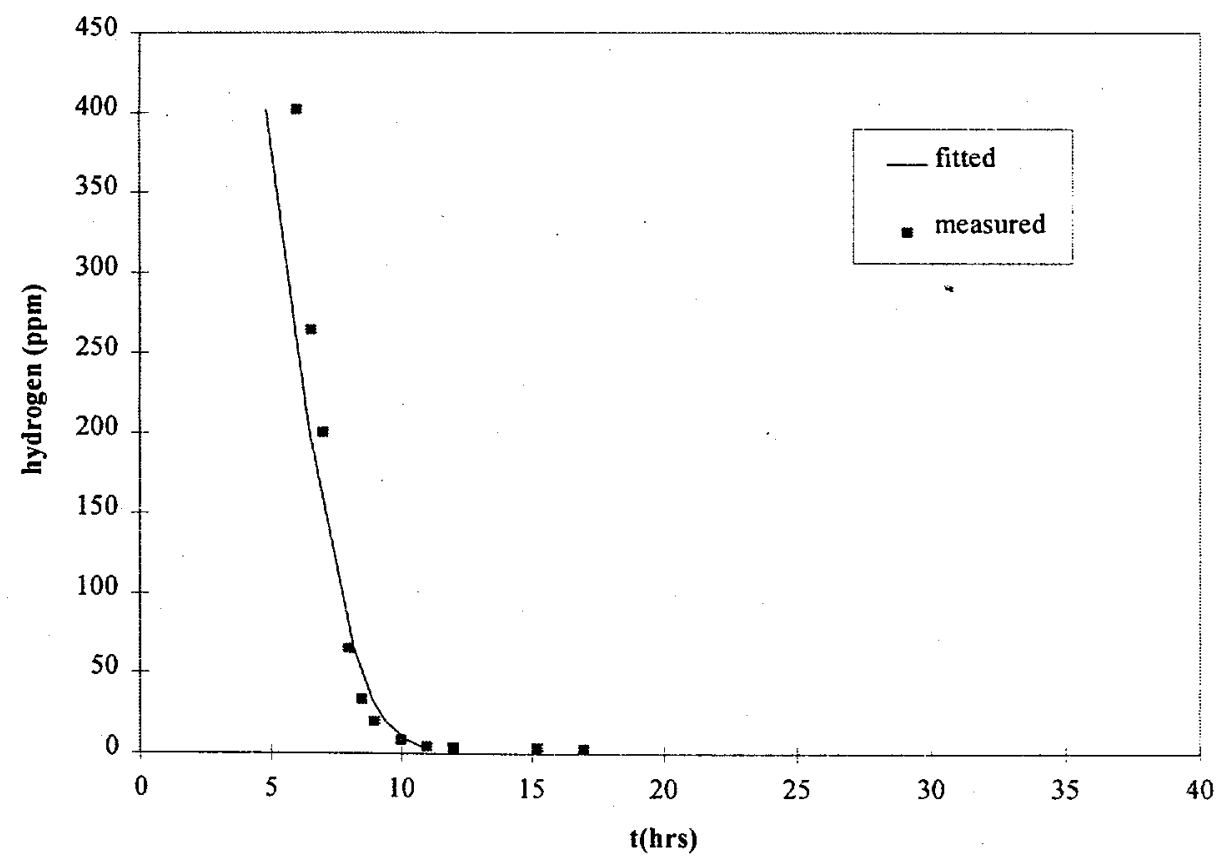

Figure 8-5. Hydrogen consumption by brewery granule flocs during ethanol conversion $(\mathrm{Ks}=5.9 \mu \mathrm{M})$. Hydrogen consumption rate $=5.4 \mathrm{mM} / \mathrm{g}$ VS-h. 


\begin{tabular}{|c|c|c|}
\hline \multicolumn{3}{|c|}{$\begin{array}{l}\text { Table 8-6. Experimental design of liquid film resistance } \\
\text { experiment for the brewery granules. }\end{array}$} \\
\hline $\begin{array}{l}\text { Acetate } \\
(\mathrm{mM})\end{array}$ & $\begin{array}{l}\text { Impeller Speed } \\
(\mathrm{rpm})\end{array}$ & $\begin{array}{l}\text { Biomass } \\
\text { (gVS) }\end{array}$ \\
\hline 7 & 200 & 2 \\
\hline 7 & 300 & 2 \\
\hline 7 & 500 & 2 \\
\hline 7 & 600 & 2 \\
\hline 7 & 700 & 2 \\
\hline 7 & 800 & 2 \\
\hline
\end{tabular}

A graphical presentation of acetate utilization at different mixing levels is given in Figure 8-6. The error bar ( $+/-1 \mathrm{SD})$ at $600 \mathrm{rpm}$ represents results of three different experimental runs. Acetate utilization rate increased with increasing impeller speed. Above $600 \mathrm{rpm}$, the variation of acetate utilization rate became small, indicating negligible influence of liquid film on acetate consumption at or above $600 \mathrm{rpm}$. At a speed of $800 \mathrm{rpm}$, a liquid vortex formed within the reactor and the granules became physically disrupted. To ensure liquid film resistance was minimized for studying diffusional effect without disrupting the physical integrity of the granules, an impeller speed of $600 \mathrm{rpm}$ was chosen for all subsequent experiments.

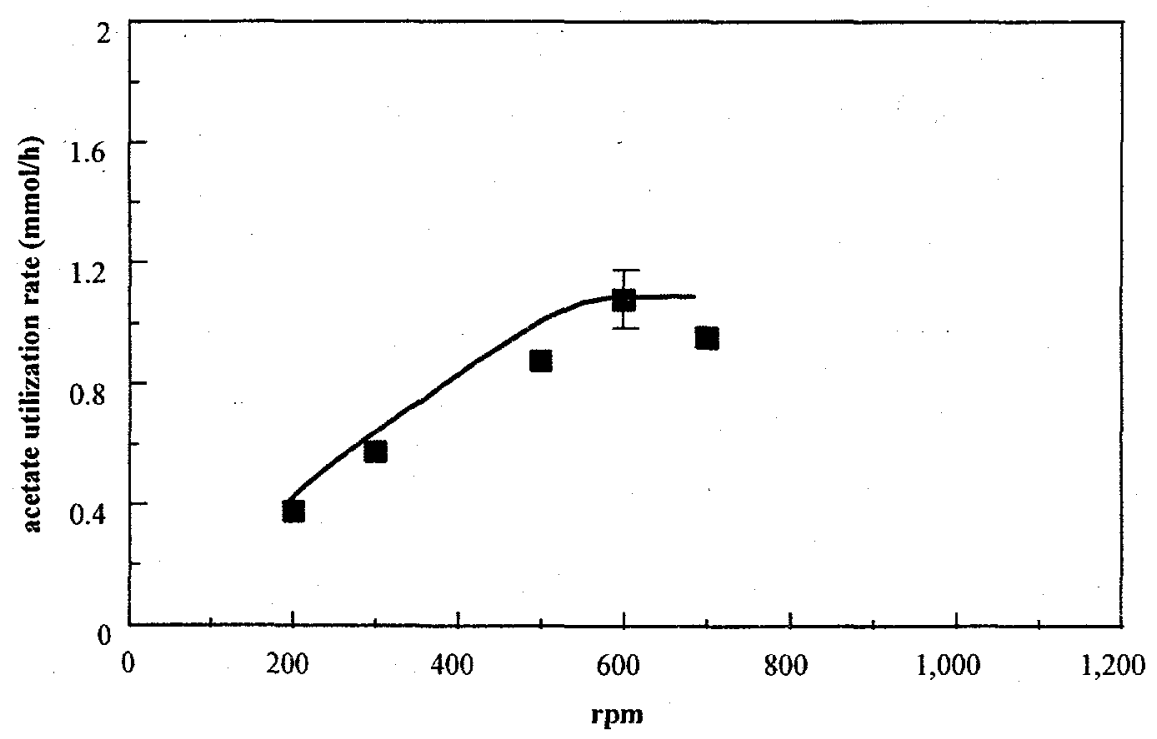

Figure 8-6. Acetate utilization rate at various impeller speeds (acetate $=7 \mathrm{mM}$, biomass $=2 \mathrm{~g}, \mathrm{pH}=7.0$, temperature $=37^{\circ} \mathrm{C}$ ).

\section{Effect of Granule Size on Substrate Diffusion}

In this portion of the work, the specific utilization rates for different granule sizes were compared to examine the effect of diffusional resistance on substrate utilization. Mass transfer limitation is described by the effectiveness factor $(\eta)$, which was estimated by determining the ratio of apparent substrate utilization rate of whole granules to the intrinsic substrate utilization rates obtained previously. The $\eta$ 
included diffusional resistance only. Theoretical development of the reaction-diffusion function within the granule is given in Section 4.

All three major carbon sources in the brewery waste - acetate, propionate and ethanol - were studied. Three sizes of granules were used: whole granules $(1.8-3.0 \mathrm{~mm}$, average $2.5 \mathrm{~mm})$, partially disrupted granules $(0.1-3.0 \mathrm{~mm}$, average $1.1 \mathrm{~mm})$, and flocs $(20-75 \mathrm{~mm}$, average $33 \mathrm{~mm})$. Whole granules were mechanically disrupted, without filtering, to produce granules with an average size of $1.1 \mathrm{~mm}$. These were further fractionated into small flocs (average size of $33 \mu \mathrm{m}$ ). A typical size distribution of partially disrupted granules is presented in Figure 8-10. The partially disrupted granules had a size ranging from 0.1 $\mathrm{mm}$ to $3.0 \mathrm{~mm}$, with an average size of $1.1 \mathrm{~mm}$. Both partially disrupted granules and flocs were prepared immediately before each experiment. Methods of formation of disrupted granules and flocs are described in Appendix B. The reactor impeller speed for the diffusion experiments was $600 \mathrm{rpm}$. Particle sizes were measured using a microscope (Appendix B). Biomass concentration and particle size were determined at the conclusion of each assay.

To start each experiment, a concentrated substrate solution was injected into the reactor to obtain a starting substrate concentration of $6 \mathrm{mM}$ acetate, $8 \mathrm{mM}$ propionate, and $30 \mathrm{mM}$ ethanol. Background substrate levels prior to the addition of substrate were less than $0.1 \mathrm{mM}$ for each substrate for all assays. Apparent substrate utilization by the granules was measured with time. The initial rate was determined using a linear regression. All experiments were conducted in duplicate.

Typical progress curves of acetate utilization, using different sized granules, are shown in Figures 8-7 and 8-8. A Monod type curve of acetate utilization versus granule size and concentration is given in Figure 8-9. Utilization rates closely followed the granule size for the range studied. The apparent specific acetate utilization rate for the flocs was much higher than that of whole granules. The maximum apparent specific substrate utilization rate (zero order portion of the Monod curve) of the whole granules was only $1 / 3$ of the rate observed for the flocs. The estimated unsteady state effectiveness factors, $(\eta)$ were calculated to be $0.32,0.41$, and 0.75 for acetate, propionate and ethanol, respectively (Table 8-7).

\section{TEMPERATURE EFFECTS}

The effect of temperature on substrate utilization was also examined using acetate as the sole carbon and energy source. The inocula included whole granules and flocs. Assays were conducted at $26^{\circ} \mathrm{C}, 31^{\circ} \mathrm{C}$, and $37^{\circ} \mathrm{C}$. An initial acetate concentration of $6 \mathrm{mM}$ was used for all assays. A time course of substrate utilization was obtained and apparent specific substrate utilization rate determined for each assay. At the 
conclusion of each assay, biomass and particle sizes were determined and fluorescence microscopy observations were performed (Appendix B). A typical acetate utilization curve for whole granules at $26^{\circ} \mathrm{C}$, $31^{\circ} \mathrm{C}$, and $37^{\circ} \mathrm{C}$ is presented in Figure $8-11$. Because of the heat generated by the mixing system during the experiment, it was impossible to maintain a temperature of $26^{\circ} \mathrm{C}$ for an entire assay. Only a few hours' worth of data were available at $26^{\circ} \mathrm{C}$. Estimated apparent specific utilization rates for whole granules and flocs at the three temperatures are presented in Table 8-8. As expected, the rates increased with increasing temperature. A plot of acetate utilization rate versus temperature is presented in Figure 8-12.

Effectiveness factors of granules for acetate utilization were $0.36,0.35$, and 0.32 at $26^{\circ} \mathrm{C}, 31^{\circ} \mathrm{C}$, and $37^{\circ} \mathrm{C}$, respectively. To characterize the effect of temperature, an attempt was made to describe results obtained from the flocs using the Van't Hoff-Arrhenius equation. A linearized plot of temperature versus specific acetate utilization rate is presented in Figure 8-13. A linear regression on natural $\log$ of $\mathrm{km}$ resulted in a typical Arrenhnus equation $\left(r^{2}=0.95\right)$

$$
k m=3.359 \times 10^{14} \exp \left[\frac{-9888.54}{T}\right]
$$

where $k m$ is in $\mathrm{g} / \mathrm{g}$ VS-d, $T$ in $\mathrm{K}$, applied range $\left\{26^{\circ} \mathrm{C}, 37^{\circ} \mathrm{C}\right\}$

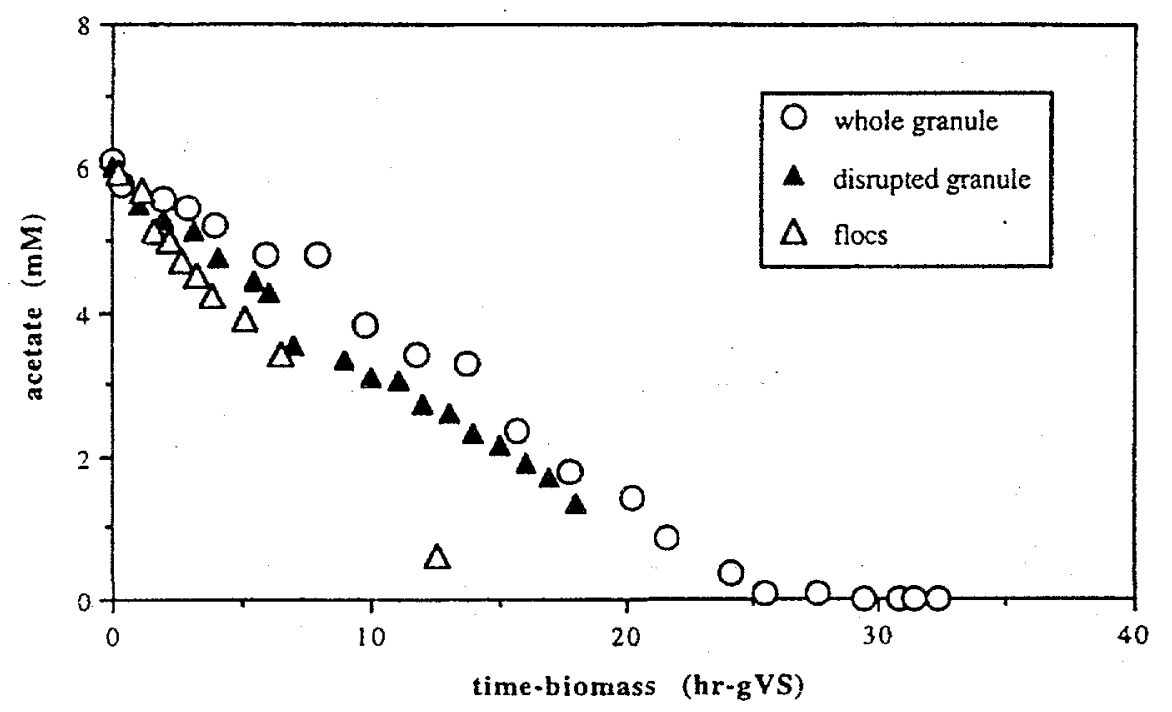

Figure 8-7. Acetate utilization by whole granules, disrupted granules and flocs in batch assays $\left(31^{\circ} \mathrm{C}\right)$. Time scale was adjusted by biomass (VS, $g$ ). The slope represents utilization rate in $\mathrm{mM}$ acetate/g VS-h. 


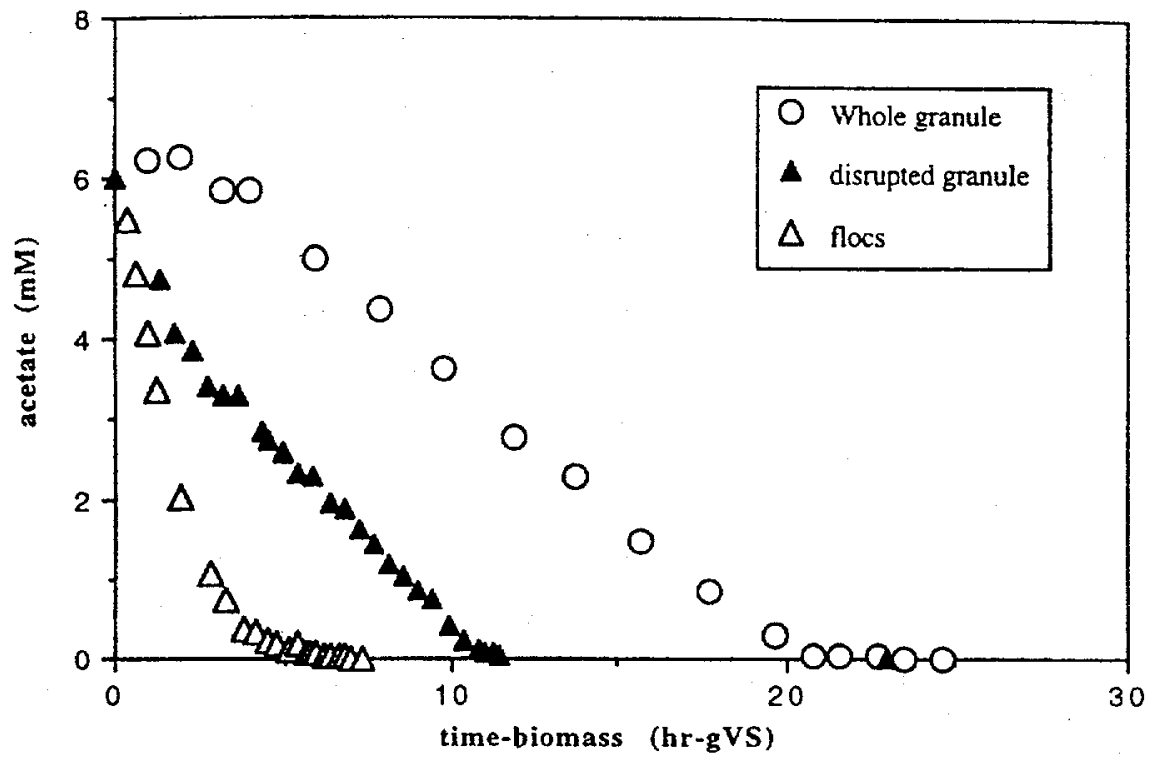

Figure 8-8. Acetate utilization by whole granules, disrupted granules and flocs in batch assays $\left(31^{\circ} \mathrm{C}\right)$. Time scale was adjusted by biomass (VS, g). The slope represents utilization rate in $\mathbf{m M}$ acetate/g VS-h.

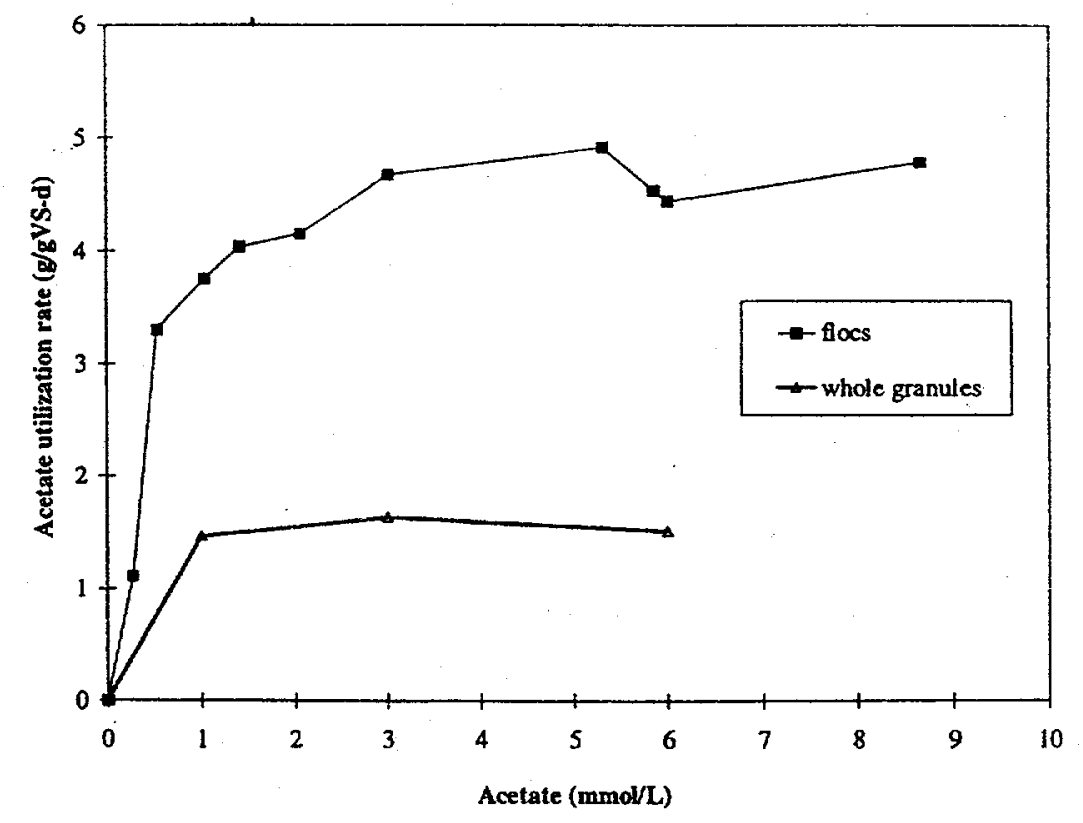

Figure 8-9. Acetate utilization rate at different acetate concentrations and granule sizes (temperature $=37^{\circ} \mathrm{C}$, granule diameter - flocs $=33 \mu \mathrm{m}$, whole granules $=1.85 \mathrm{~mm}$ ). 


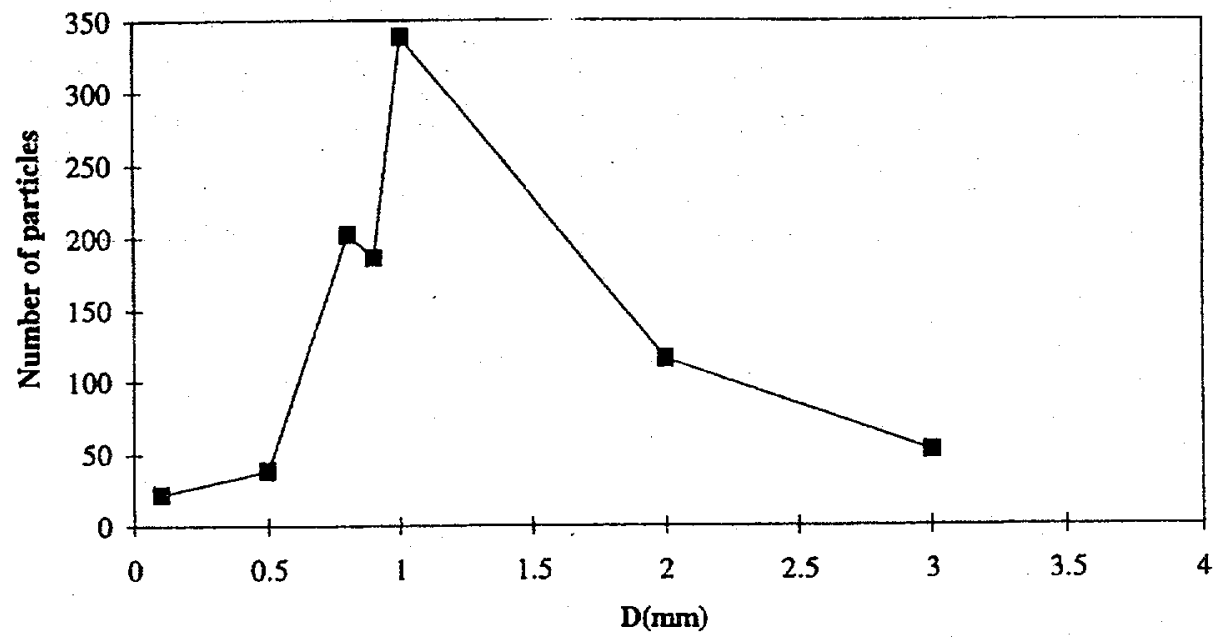

Figure 8-10. Size distribution of disrupted granules.

\begin{tabular}{|c|c|c|c|}
\hline \multicolumn{4}{|c|}{$\begin{array}{l}\text { Table 8-7. Estimated unsteady state effectiveness factor for substrate } \\
\text { utilization using brewery granules at } 37^{\circ} \mathrm{C} \text { and } \mathrm{pH}=7.0 \text {. }\end{array}$} \\
\hline Substrate & $\begin{array}{l}\text { km, intrinsic } \\
\text { (g/g VS-d) }\end{array}$ & $\begin{array}{l}k m, \text { apparent } t^{* *} \\
\text { (g/g VS-d) }\end{array}$ & $\begin{array}{l}\eta \\
(\%)\end{array}$ \\
\hline Acetate & 5.11 & 1.66 & 32 \\
\hline Propionate & 6.25 & 2.62 & 41 \\
\hline Ethanol & 5.49 & 4.16 & 75 \\
\hline \multicolumn{4}{|c|}{$\begin{array}{l}\text { * flocs }^{*} \\
* * \text { whole granules }\end{array}$} \\
\hline
\end{tabular}

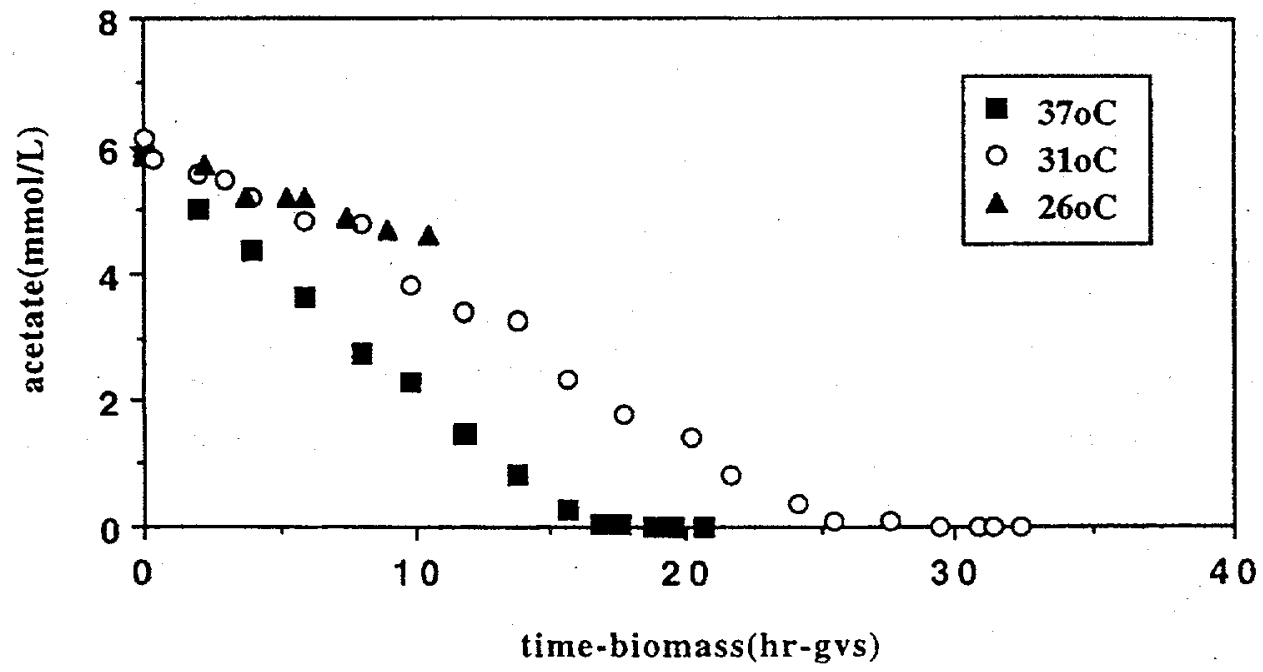

Figure 8-11. Acetate utilization at $37^{\circ} \mathrm{C}, 31^{\circ} \mathrm{C}, 26^{\circ} \mathrm{C}$ by whole granules. Time scale was adjusted by biomass (VS, $g$ ). The slope represents utilization rate in $\mathrm{mM}$ acetate/g VS-h. 


\begin{tabular}{|l|l|c|c|}
\hline \multicolumn{4}{|c|}{ Table 8-8. Estimated $\mathbf{k m}$ of whole granule and flocs at $37^{\circ} \mathrm{C}, 31^{\circ} \mathrm{C}$, and $26^{\circ} \mathrm{C}$, in $\mathbf{~} / \mathbf{g}$} \\
VS-d. \\
\hline \multicolumn{4}{|c|}{ Temperature } \\
\hline Inoculum Source & $37^{\circ} \mathrm{C}$ & $31^{\circ} \mathrm{C}$ & $26^{\circ} \mathrm{C}$ \\
\hline Flocs & $5.08 \pm 1.322$ & $2.13 \pm 0.852$ & $1.85 \pm 0.641$ \\
\hline Whole granules & $1.66 \pm 0.720$ & $0.74 \pm 0.223$ & $0.58 \pm 0.410$ \\
\hline *acetate as substrate. & \multicolumn{4}{|l}{} \\
\hline
\end{tabular}

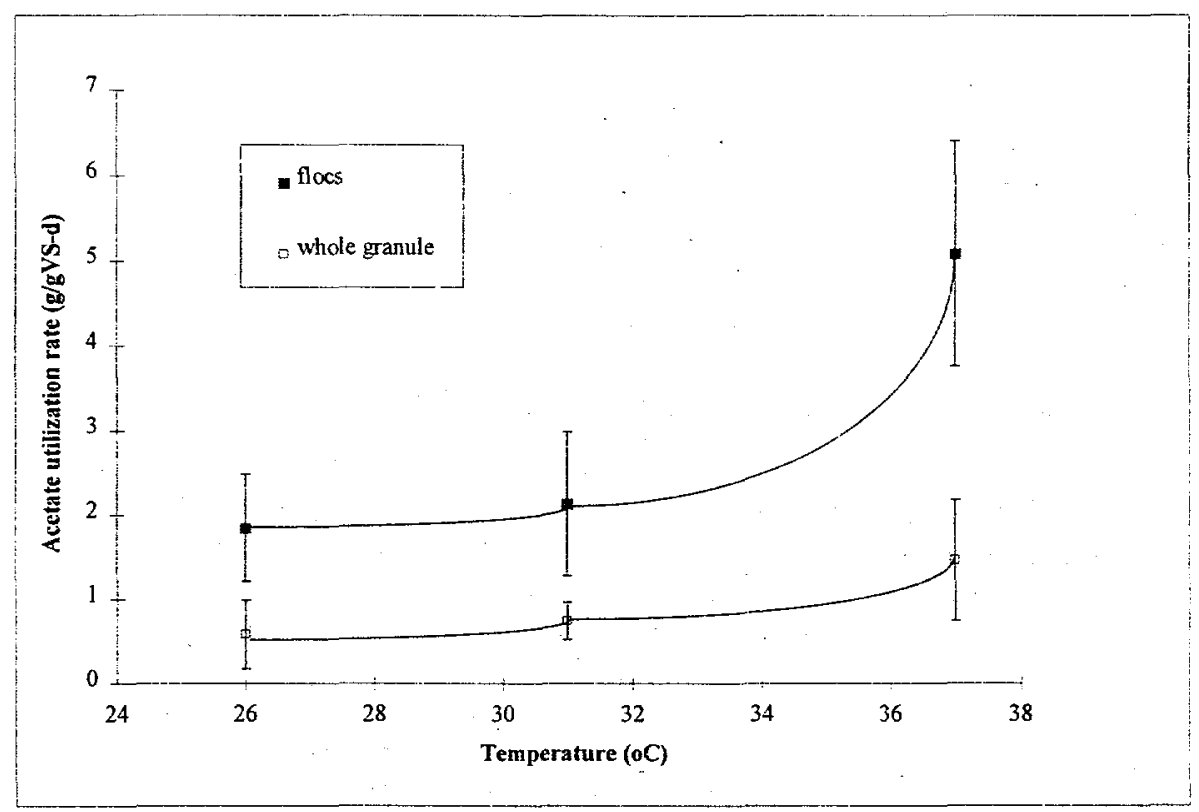

Figure 8-12. Acetate consumption rate of flocs and whole granules at $37^{\circ} \mathrm{C}, 31^{\circ} \mathrm{C}$, and $26^{\circ} \mathrm{C}$ (bars represent \pm SD of two repeated assays).

The above equation can been rewritten as :

$$
\operatorname{Ln}\left[\frac{k m_{2}}{k m_{1}}\right]=\frac{E}{R}\left[\frac{1}{T_{1}}-\frac{1}{T_{2}}\right]
$$

where $E$ is activation energy. Estimated activation energy was $19,380 \mathrm{kcal} / \mathrm{mole}$, which is within the common range of anaerobic wastewater treatment systems (Metcalf \& Eddy 1991). Another form of this equation is

$$
\frac{k m_{37}}{k m_{27}}=1.12^{37-27}
$$


with the assumption that $\frac{E}{R T_{1} T_{2}}$ in equation (4) is constant and where $1.12=e^{\frac{E}{R T_{1} T_{2}}}$. For the whole granules this constant was 1.09 . The estimated activation energy was $15,400 \mathrm{kcal} / \mathrm{mole}$.

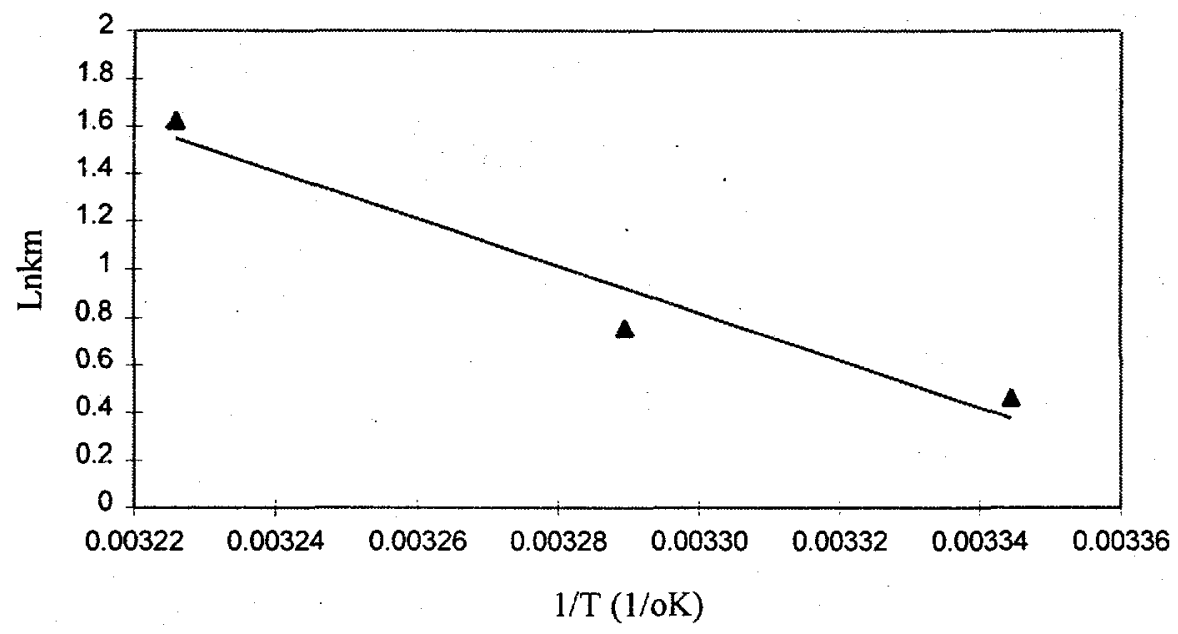

Figure 8-13. Linearization of $\mathrm{km}$ and temperature effects for acetate utilization by flocs $\left(y=33.44793-9888.54 \times R^{2}=0.95\right)$.

\section{THRESHOLD AND REACTION THERMODYNAMICS OF SUBSTRATE UTILIZATION}

A study of minimum acetate and hydrogen levels and reaction thermodynamics was conducted. Substrate threshold levels were determined by measuring the concentration at which further substrate utilization did not proceed. The $\mathrm{pH}$ and temperature were recorded in order to determine the minimal Gibbs free energy for acetate decarboxylation and hydrogen oxidation. It was assumed that the end products during acetoclastic methanogenesis were stoichiometrically $1: 1$ for $\mathrm{CO}_{2}$ and $\mathrm{CH}_{4}$. A separate $\mathrm{GC}$ program was used to accurately quantify low concentrations of acetate (Appendix C). Hydrogen from the headspace of the Multigen reactor was analyzed using a Reduced Gas Analyzer (Trace Analytical, RGD2) equipped with a mercuric oxide reaction bed (Appendix C).

Results of acetate threshold and minimal Gibbs free energy during acetate metabolism are presented in Table 8-9. There were no significant differences in the acetate threshold and minimal free energy levels for the different granule sizes (flocs and whole granules). The threshold acetate level ranged from 4 to 70 $\mu \mathrm{M}$. This threshold values agrees well with reported literature values (Table 8-10). The minimal Gibbs free energy available for acetate decarboxylation ranged from -1.40 to $-4.44 \mathrm{kcal} / \mathrm{mol}$ acetate $(-5.9$ to $18.6 \mathrm{~kJ} / \mathrm{mol})$, with an average of $-2.53 \mathrm{kcal} / \mathrm{mol}$ acetate $(-10.6 \mathrm{~kJ} / \mathrm{mol})$. The $\mathrm{H}_{2}$ threshold concentrations 
were observed to vary from 5.2 to $26.3 \mathrm{ppm}$. These values are within the literature values but fall into the lower region of previously reported values (Table 8-11). The minimum Gibbs free energy available for $\mathrm{H}_{2}$ oxidation was calculated to be $-1.3 \mathrm{kcal} / \mathrm{mol} \mathrm{H}_{2}(-5.4 \mathrm{~kJ} / \mathrm{mol})$.

\begin{tabular}{|c|c|c|c|}
\hline \multicolumn{4}{|c|}{$\begin{array}{l}\text { Table 8-9. Acetate threshold and calculated minimum available Gibbs free energy } \\
\text { during acetate metabolism. }\end{array}$} \\
\hline $\begin{array}{l}\text { Acetate Threshold } \\
\text { Range (mM) }\end{array}$ & $\begin{array}{c}\Delta \mathbf{G}^{\prime} \\
-(\mathbf{k c a l} / \mathbf{m o l})\end{array}$ & $\begin{array}{l}\text { Temp } \\
\left({ }^{\circ} \mathrm{C}\right)\end{array}$ & Culture \\
\hline $10-70$ & $2.80 \pm 0.49^{*}$ & 31 & Methanogenic brewery granule/flocs \\
\hline $10-20$ & $2.20 \pm 0.05$ & 31 & Methanogenic brewery granule/whole granule \\
\hline $10-60$ & $1.97 \pm 0.95$ & 37 & Methanogenic brewery granule/flocs \\
\hline $4-20$ & $2.17 \pm 1.14$ & 37 & Methanogenic brewery granule/whole granule \\
\hline \multicolumn{4}{|c|}{$\begin{array}{l}\text { average acetate threshold } 16.6 \mathrm{mM}, \Delta \mathrm{G}-2.53 \mathrm{kcal} / \mathrm{mol}(-10.55 \mathrm{KJ} / \mathrm{mol}) \text { reaction: acetate }+\mathrm{H}_{2} \mathrm{O} \rightarrow \\
\mathrm{CH}_{4}+\mathrm{HCO}_{3}^{-} \\
\text {bstandard deviation } \\
\text { c'methanogenic brewery granules }\end{array}$} \\
\hline
\end{tabular}

\section{DISCUSSION}

For our defined reactor system, operated under controlled hydrodynamic conditions, we assumed that results obtained using flocs ( $33 \mu \mathrm{m}$ diameter) were representative of the intrinsic kinetics of the brewery granules. Results from substrate utilization assays using flocs were well described by Monod kinetics. A summary of kinetic parameters for acetate, propionate, ethanol, and $\mathrm{H}_{2}$ obtained from different sources is presented in Tables 8-4 and 8-5 for comparison. Results obtained for acetate, propionate and $\mathrm{H}_{2}$ intrinsic kinetics during this study agree well with reported literature values. The maximum specific utilization rate $(\mathrm{km})$, obtained using flocs, for each substrate is in the higher region of previously reported values for propionate and acetate $(6.25,5.11, \mathrm{~g} / \mathrm{g}$ VS-d). The $K s$ values are in the lower region of reported values for acetate $(0.45 \mathrm{mM})$ and ethanol $(3.37 \mathrm{mM})$, probably as a result of minimal diffusion limitations. The $K s$ for hydrogen $(5.9 \mu \mathrm{M})$ agreed well with Robinson and Tiedje (1982). There was a discrepancy in the half velocity constant $(K s)$ observed for ethanol (3.37 mM) compared to other work (100 mM (Smith 1987)). This could be the result of variations in experimental conditions. A single carbon source (ethanol or propionate) was used in the previous study compared to a complex substrate mixture in this work. Differences in the predominant ethanol utilization population could also account for these differences in kinetic constants.

The mixing intensity applied during the liquid film mass transfer experiments can be expressed using the Reynolds numbers $\left(N_{R}\right)$. Reynolds number was calculated according to following equation: 


$$
N_{R}=\frac{D^{2} n \rho}{\mu}
$$

where $D$ is impeller diameter, $(0.05556 \mathrm{~m}) ; n$ is rpmx60; $\rho$ is density of reactor fluid, $\left(1000 \mathrm{~kg} / \mathrm{m}^{3}\right) ; \mu$ is viscosity, $\left(0.6965 \mathrm{~N}^{5} / \mathrm{m}^{2}\right)$. At $N_{R}$ in a range of $53000-106000$, which corresponds to an impeller speed of 200 to $400 \mathrm{rpm}$, liquid-film mass transfer resistance still had a significant influence on substrate utilization (Figure 8-6). A Reynolds number of 159,000 (600 rpm) was necessary to ensure good mixing and minimize liquid-film resistance. Beyond that point, the effect of liquid film on mass transfer could be neglected. When the Reynolds number was increased to greater than 186,000 (700 rpm), physical disruption of the granules occurred. An assumption was made that physical properties density $(\rho)$ and viscosity $(\mu)$ of the reactor fluid could be approximated by those of water. The region of Reynolds number applied in this study was much higher than that of the bench-scale UASB reactor. Hydraulic characterization experiments for the UASB reactor indicated when $N_{R}$ was $700,74 \%$ of the reactor total volume represents CSTR (model 1; Section 5). It would appear, therefore, that liquid-film mass transfer resistance played a strong role in substrate utilization in the UASB reactor system.

Substrate utilization of partially disnupted or whole granules could not be adequately described using Monod kinetics due to the effect of mass transfer resistance. The apparent utilization rate decreased as the granule size increased (Figure 8-12). At low concentrations, the differences in rates between whole granules and flocs were small. As the initial substrate concentration increased, the influence of concentration on substrate utilization rate appeared stronger. At $6 \mathrm{mM}$ acetate, the apparent utilization rate of the flocs was three times the rate of whole granules. This phenomenon is typical for cell systems with mass transfer limitations.

Temperature had a strong influence on the specific utilization rate of acetate (Table 8-8). This impact was greatest when the temperature exceeded $31^{\circ} \mathrm{C}$. The magnitude of change in the utilization rate generally correlated with the granule size. Whole granules were less sensitive to temperature changes, while flocs were most affected. When the temperature was increased from $31^{\circ} \mathrm{C}$ to $37^{\circ} \mathrm{C}$, substrate utilization by the flocs increased by about $3.0 \mathrm{~g} / \mathrm{g}$ VS-d, and whole granules by, $0.7 \mathrm{~g} / \mathrm{g}$ VS-d (Table 8-8). The apparent utilization rate does not increase exponentially with temperature when there are significant mass transfer limitations. Variation of effectiveness factor under the temperature range $(0.32$ to 0.36$)$ was not significant. This also demonstrated that effects of temperature on substrate utilization were much less than the effects of diffusional limitations within the granules. Substrate utilization is influenced by temperature and diffusion when substrate concentration is fixed. The magnitude of this influence depends strongly on biofilm size, geometry, and the diffusion coefficient of the particular system. In slab geometry biofilm 
systems, substrate flux $(J)$ increases with the square root of the maximum specific utilization rate $(\mathrm{km})$, or $J$ $\propto \mathrm{km}^{1 / 2}$ (Rittmann and McCarty 1980). For free cell systems, $J \propto k m$ is indicated by Monod kinetics. Since $\mathrm{km}$ is a function of temperature, as specified by Van't Hoff-Arrhenius equation, biofilm systems such as granules are less affected by temperature changes than dispersed cell systems. The influence of $\mathrm{km}$ on substrate flux in a granular sludge system is more complex due to the geometry and does not have an explicit analytical solution (Bailey and Ollis 1986). The behavior of flocs was well described by the Van't Hoff-Arrhenius equation (Figure 8-13). This strongly supports the assumption that results obtained using flocs represent the intrinsic kinetics of the organisms in the granules. As the size of granules increase, diffusion limitations become more significant than temperature. Thus, the response to changes in temperature was limited for whole granules. The differences between flocs and whole granules was smoothed in linearization results (Van't Hoff-Arrenhnus equation) of flocs and whole granules (Figures 8-13 and 8-14) primarily due to $\log$ transformation.

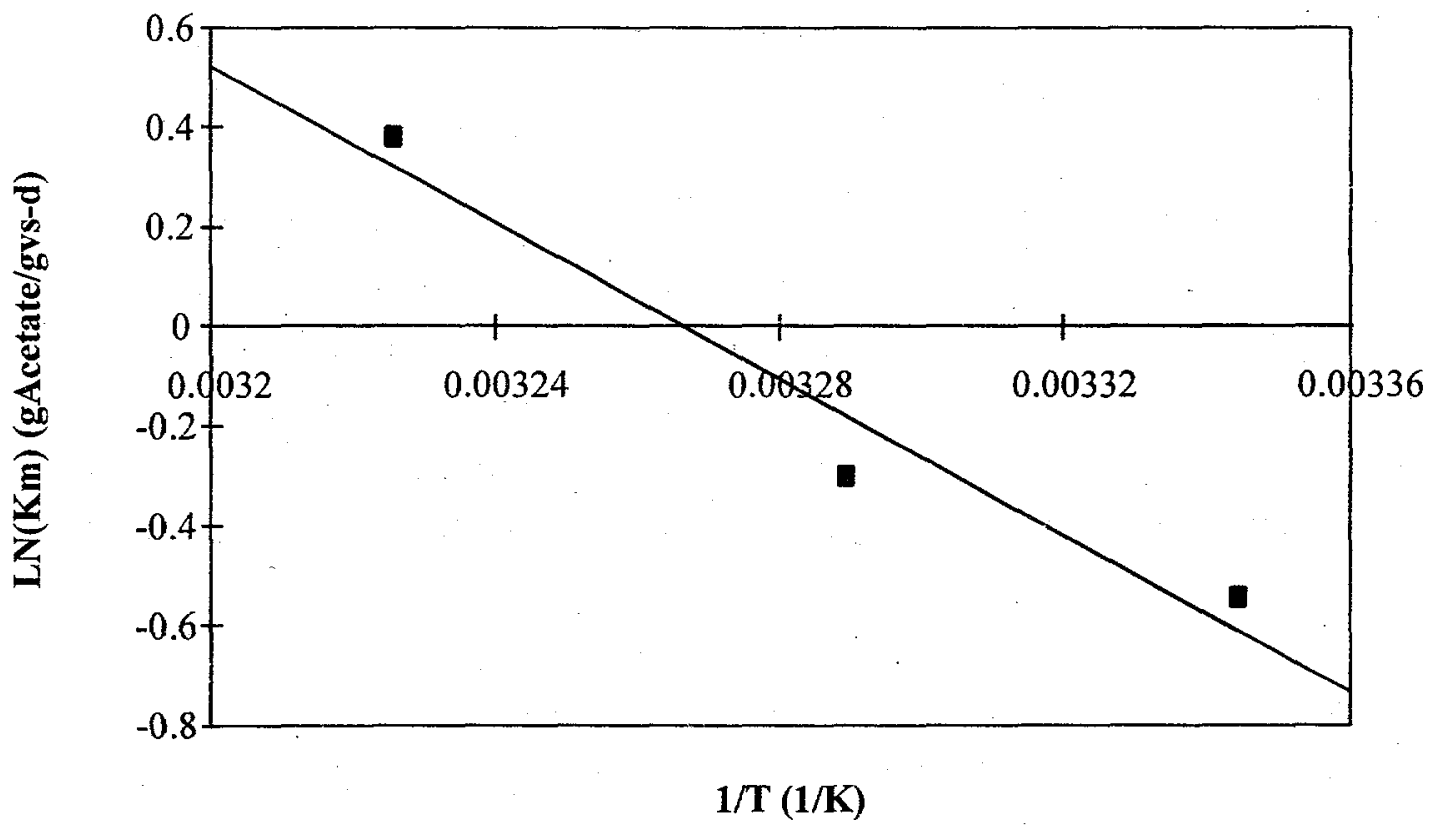

Figure 8-14. Linearization of $\mathrm{km}$ and temperature effects for acetate utilization by whole granules $\left(y=25.658-7854.31 \times R^{2}=0.95\right)$.

A substrate threshold was observed for anaerobic utilization of acetate and $\mathrm{H}_{2}$ during the experiment. The observed acetate threshold concentration $(17 \mu \mathrm{M})$ agreed well with literature values. The $\mathrm{H}_{2}$ threshold $(13.4 \mathrm{ppm})$ fell into the lower region of values reported in the literature. These results demonstrated that acetate decarboxylation and $\mathrm{H}_{2}$ oxidation by methanogens can be described well by the threshold model. Substrate threshold reflected energy conservation for a substrate species. Minimal free energy 
requirements during methanogenesis were well below the available energy required for ATP synthesis. This is common in anaerobic systems and is possibly due to the energy-sharing processes. The specific growth rate $(\mu)$ and substrate affinity (half saturation constant, $K s$ ), play a role in the threshold level or minimal energy required for a reaction step to occur. Methanothrix sp. have a half saturation constant $(K s)$ of $0.7 \mathrm{mM}-0.5 \mathrm{mM}$ (Table 8-4, expressed as $K s$ ). Acetate thiokinase found in Methanothrix soghngenii has a substrate affinity $(\mathrm{Km})$ close to $0.7 \mathrm{mM}$ (Kohler and Zehnder 1984). A high level of acetate kinase with a $\mathrm{Km}$ for acetate of $3 \mathrm{mM}$ was observed for Methanosarcina barkeri (Kenealy and Zeikus 1982). The low $\mathrm{Km}$ of acetate thiokinase in Methanothrix indicates a high substrate affinity. These findings suggested the activation of the specific enzyme has a strong influence on the overall affinity of Methanothrix $s p$. and Methanosarcina sp. for acetate. Another important parameter in determining the predominant organism in an environment is the specific growth rate, $\left(\mu_{\max }\right)$. Methanosarcina sp. has a higher $\mu_{\max }\left(1.8 \mathrm{~g} / \mathrm{mol} \mathrm{CH}_{4}\right)$ than Methanothrix sp. $\left(1.1 \mathrm{~g} / \mathrm{mol} \mathrm{CH}_{4}\right.$ ) (Zinder et al. 1987). At acetate levels lower than $1 \mathrm{mM}$, Methanothrix sp. can out-compete Methanosarcina sp. due to their high affinity for acetate. When the acetate level is elevated, both organisms are able to utilize acetate. Methanosarcina sp., by virtue of their higher growth rate, are favored. Other factors such as growth factors and key vitamin can be important factors as well. In sediments where acetate concentration are low (less than $400 \mu \mathrm{M}$ ), Methanothrix $s p$. are generally the predominant methanogen (Table 8-10). Methanosarcina sp., are not able to compete effectively for acetate; they use other substrates for growth (i.e., methanol and methylamines). When the acetate concentration is at a level of $3-5 \mathrm{mM}$, as in some sludge digestors, Methanosarcina sp. outcompete Methanothrix sp. and become the predominant acetoclastic methanogens. Changes in the acetate level can result in variations in populations of acetoclastic methanogens over a long period of time, despite the fact that the growth rates for methanogens are relatively low. In UASB reactor systems, the acetate concentration depends on operational conditions such as the organic loading rate, hydraulic retention time, type of substrate, temperature, $\mathrm{pH}$, and bacteria interactions. Under the selected operational conditions, the concentration of acetate in the laboratory bench-scale UASB reactor was maintained at $0.01 \mathrm{mM}$ to $0.5 \mathrm{mM}$. Therefore, it is reasonable that Methanothrix $s p$. were the prevailing population of acetoclastic methanogens (Section 7) in the brewery granules.

Similar phenomena occur for $\mathrm{H}_{2}$ utilization within the anaerobic consortia, where the syntrophic relationships between $\mathrm{H}_{2}$ producers and $\mathrm{H}_{2}$ consumers are established to maintain a minimal $\mathrm{H}_{2}$ level. Different groups of hydrogenotrophic anaerobic bacteria can compete for $\mathrm{H}_{2}$ as an electron acceptor. This preference, energetically, is nitrate and fumarate $>$ sulfate $>\mathrm{CO}_{2} / \mathrm{CH}_{4}>$ sulfur $>\mathrm{CO}_{2}$ /acetate. It was reported that the $\mathrm{H}_{2}$ thresholds ranges from 0.33 to $950 \mathrm{ppm}$ according to this order of electron acceptor energetics (Cord-Ruwisch 1988). Both sulfate reducers and hydrogenotrophic methanogens were observed 
to be present in the brewery granules, with Methanobacterium sp. being the predominant $\mathrm{H}_{2}$ utilizer (Section 7). The $\mathrm{H}_{2}$ concentration in the bench-scale UASB varied between 10 and $200 \mathrm{ppm}$. Either sulfate reducers or hydrogenotrophic methanogens could be responsible for controlling the $\mathrm{H}_{2}$ level (Table 8-11). During the propionate and ethanol degradation assays, no sulfate was supplied. The hydrogenotrophic methanogens were, therefore, the main $\mathrm{H}_{2}$ consumers in these assays. An $\mathrm{H}_{2}$ threshold level of 50-260 ppm was observed under these assays conditions. It would appear, therefore, that the Methanobacterium sp. may have controlled the $\mathrm{H}_{2}$ concentration in the system.

\begin{tabular}{|c|l|l|l|}
\hline \multicolumn{4}{|c|}{ Table 8-10. Reported acetate threshold values. } \\
\hline $\begin{array}{c}\text { Temp } \\
\left({ }^{\circ} \mathrm{C}\right)\end{array}$ & \multicolumn{1}{|c|}{$\begin{array}{c}\text { Acetate } \\
(\mathrm{mM} / \mathrm{mM})\end{array}$} & \multicolumn{1}{c|}{ Culture } & \multicolumn{1}{|c|}{ Resources } \\
\hline 60 & $25-75 \mathrm{mM}$ & TAM & Ahring \& Westermann, 1987 \\
\hline 58 & $12-21 \mathrm{mM}$ & Methanothrix & Hang \& Zinder, 1989 \\
\hline 58 & $0.3-1.5 \mathrm{mM}$ & Methanothrix & Zinder \& Koch, 1984 \\
\hline 58 & $0.8-2.5 \mathrm{mM}$ & Methanosarcina & Hang \& Zinder, 1989 \\
\hline 37 & $69 \mathrm{mM}$ & Methanothrix & Westermann, 1989 \\
\hline 37 & $0.4-1.1 \mathrm{mM}$ (dissociated) & M. barkeri & Fukuzaki, 1990a \\
\hline & $4.43 \mathrm{mM}$ (undissociated) & & \\
\hline 37 & $1.18 \mathrm{mM}$ & M. barkeri & Westermann, 1989 \\
\hline 37 & $0.396 \mathrm{mM}$ & M. mazei s-6 & Westermann, 1989 \\
\hline
\end{tabular}

\begin{tabular}{|l|c|l|}
\hline \multicolumn{1}{|c|}{ Table 8-11. Reported hydrogen threshold values for different hydrogenotrophic } \\
anaerobes.
\end{tabular}




\section{Section 9}

\section{INHIBITION OF AN UASB BY PHENOL ADDITION}

An experiment was conducted to examine the effect of a toxic episode on the laboratory-pilot UASB reactor and response of trace gases. Phenol was chosen as the model toxicant. A two-step increase in phenol concentration of $2000 \mathrm{mg} / \mathrm{L}$ and $4000 \mathrm{mg} / \mathrm{L}$ in the feed stream was tested. Other components in the synthetic brewery waste feed were left unchanged. Operational conditions during the perturbation experiment were: OLR $10 \mathrm{~kg} \mathrm{COD} / \mathrm{m}^{3}-\mathrm{d}$, HRT 18 hours, reactor temperature $37^{\circ} \mathrm{C}$, and $\mathrm{pH} 7.0$. Gas phase components $\mathrm{CO}, \mathrm{H}_{2}$, and $\mathrm{CH}_{4}$ and gas production rate were monitored using the on-line data acquisition system. Samples for effluent VFAs, ethanol, propanol and phenol were collected manually. Sampling frequencies were one hour for all liquid phase components. Feed concentrations were measured daily. The $\mathrm{pH}$ was maintained at $7.0 \pm 0.1 \mathrm{using}$ a $\mathrm{pH}$ controller and bicarbonate solution. During the first 26 hours the phenol concentration in the system feed was $2000 \mathrm{mg} / \mathrm{L}$. A step increase in phenol concentration, to $4000 \mathrm{mg} / \mathrm{L}$, was imposed for the next 12 hours (Figure 9-1). After the feed of influent containing phenol was stopped, the reactor was fed mineral media for only 9 hours before carbon supply was resumed. Monitoring of reactor response was continued for a total of 110 hours. Results of phenol addition are presented in Figures 9-2 through 9-9. The UASB system was inhibited by $44 \%$ and $71 \%$ during the addition of 2000 and $4000 \mathrm{mg} / \mathrm{L}$ phenol, respectively, compared to steady state, based on reactor gas production rates (Figure 9-2).

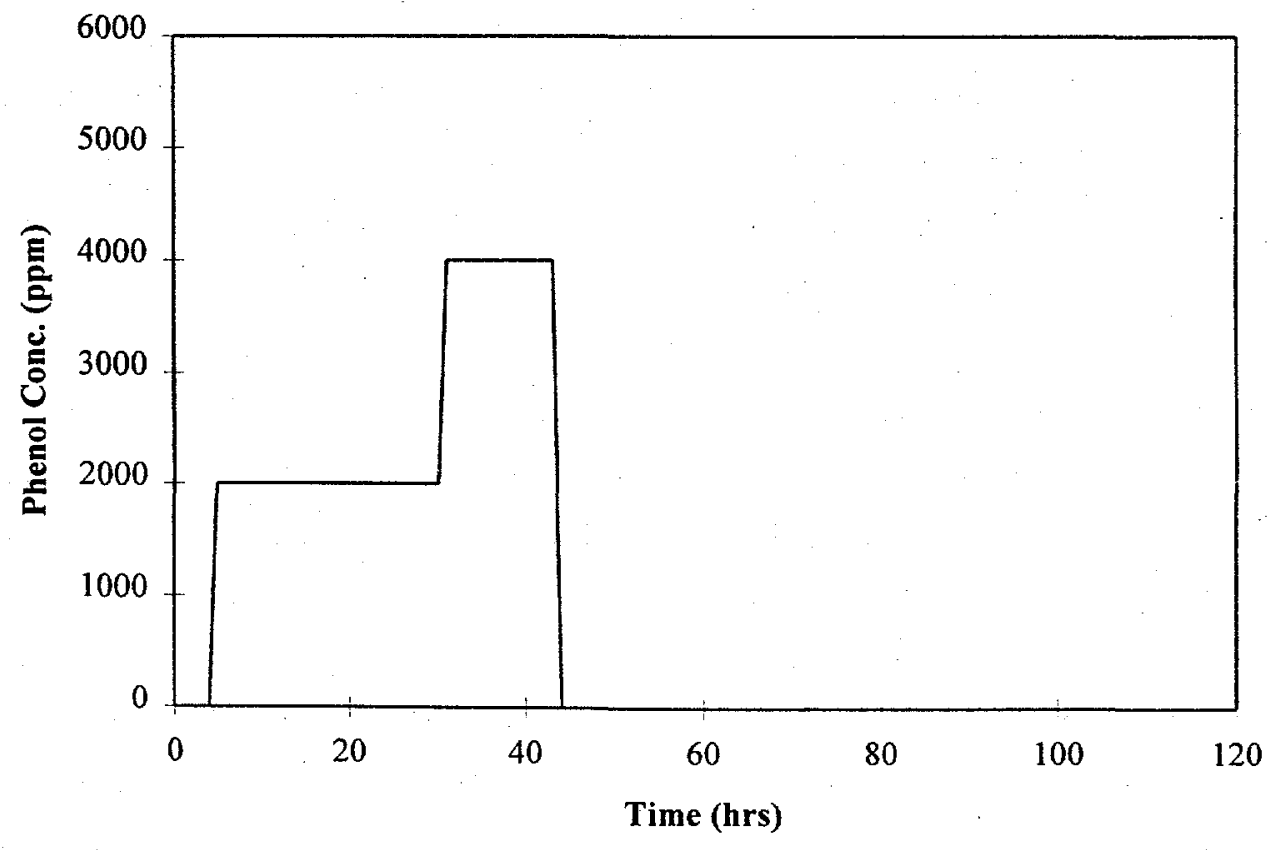

Figure 9-1. Influent phenol concentration during inhibition experiment (7/13/94). 


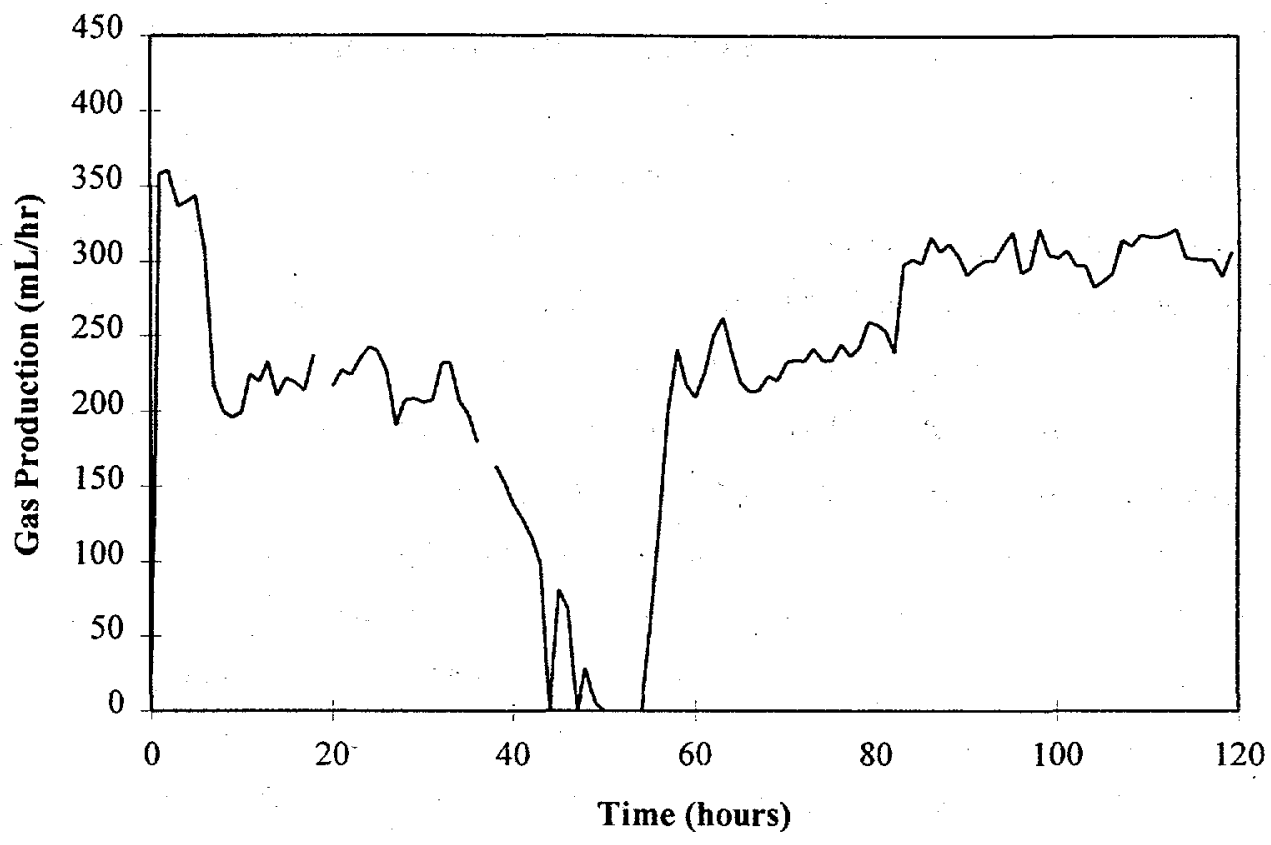

Figure 9-2. Gas production response during phenol inhibition experiment (7/13/94).

\section{RESPONSE OF $\mathrm{H}_{2}$ AND CO}

The headspace concentration of $\mathrm{CO}$ accumulated immediately as the phenol containing feed was added to the reactor (Figure 9-3). The concentration subsequently increased when the phenol concentration in the feed was increased to $4000 \mathrm{mg} / \mathrm{L}$. The CO concentration reached $10,200 \mathrm{ppb}$ (the upper limit of the RGA3) at 64 hours, 20 hours after phenol was removed from the feed. CO concentration then began to decrease. It took more than 60 hours for the $\mathrm{CO}$ concentration to decrease to near the normal steady state level. At the conclusion of the experiment (110 hours), CO was still at $960 \mathrm{ppb}$ level, six times higher than the normal background concentration (160 ppb).

Hydrogen responded slowly and recovered quickly in response to the phenol inhibition episode (Figure 9-4) compared to $\mathrm{CO}$. Gas phase hydrogen did not vary during the period when phenol was added to the influent at $2000 \mathrm{mg} / \mathrm{L}$. Beginning at the 30 -hour mark, when the phenol concentration in the feed was increased to $4000 \mathrm{mg} / \mathrm{L}, \mathrm{H}_{2}$ began to accumulate. A peak $\mathrm{H}_{2}$ concentration of $1000 \mathrm{ppm}$ (upper limit of RGA3) was reached after 43 hours, one hour before phenol addition was stopped. The accumulation of $\mathrm{H}_{2}$ continued until the 72-hour mark (28 hours after phenol was stopped). $\mathrm{H}_{2}$ began to decline at approximately the same time as $\mathrm{CO}$. The concentration of $\mathrm{H}_{2}$ peaked at 23 hours, which was about onethird of that for $\mathrm{CO}$, and then returned to the background level of 120 ppm by the 95 -hour mark. 


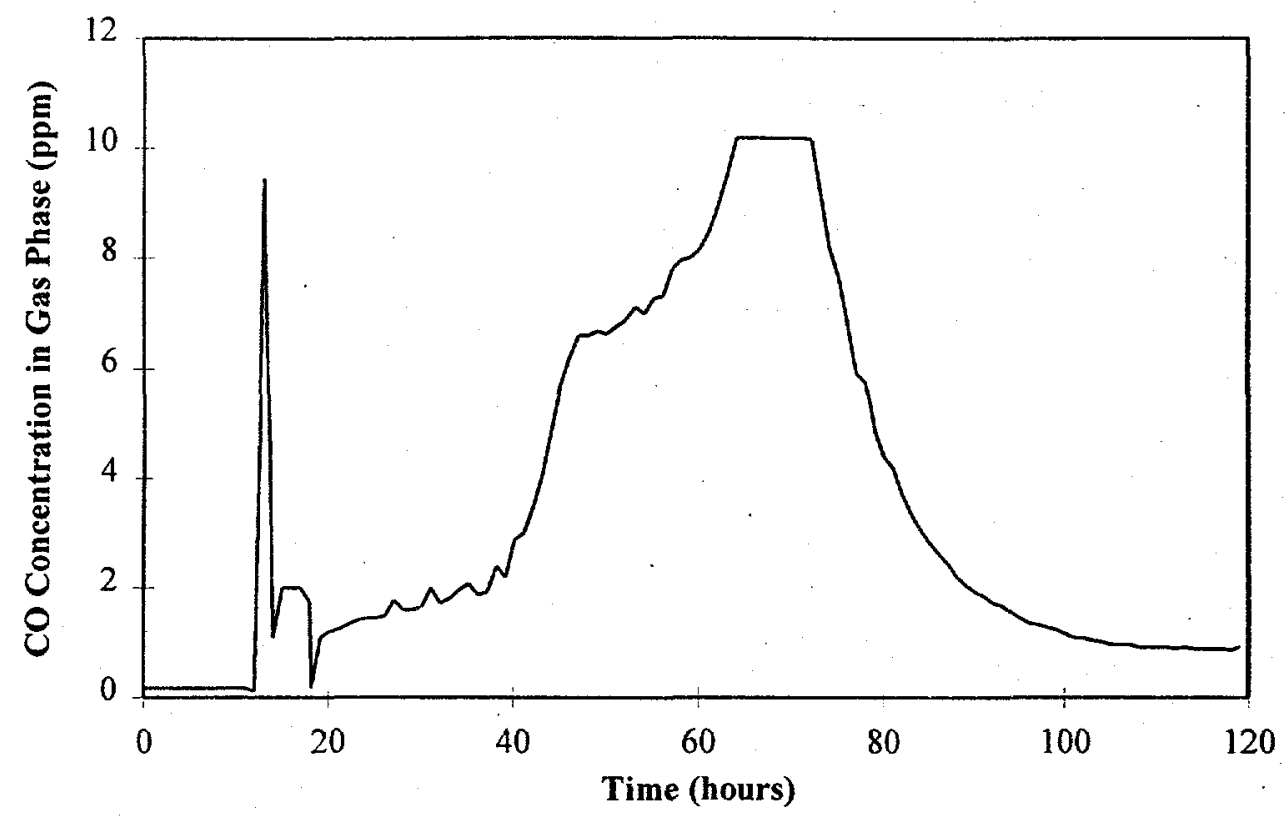

Figure 9-3. CO Response during phenol OLR experiment (7/13/94).

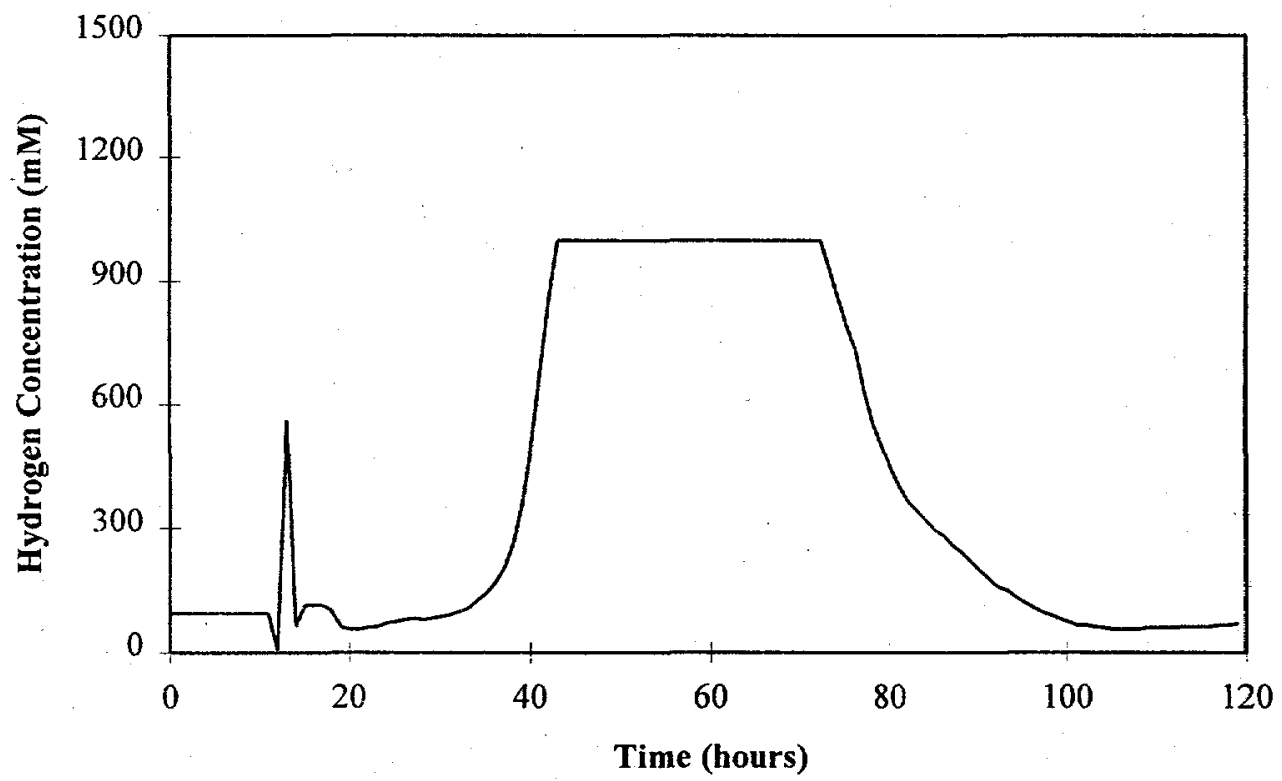

Figure 9-4. Hydrogen variation during phenol OLR experiment (7/13/94).

The long period with elevated $\mathrm{CO}$ concentration in the gas phase was likely because accumulated $\mathrm{CO}$ in gas phase could not be used by the microorganisms in the system. The concentration of $\mathrm{CO}$ was reduced only through dilution of additional gas that was produced. This was also observed during the organic overload experiments (Section 6). By contrast, gas phase $\mathrm{H}_{2}$ did appear to dissolve into the liquid phase 
and was utilized. The magnitudes of accumulation of $\mathrm{CO}$ and $\mathrm{H}_{2}$ were approximately 100 and 10 times the normal headspace concentrations, respectively.

\section{RESPONSE OF GAS PRODUCTION RATE AND METHANE CONTENT}

The response of the gas production rate step to phenol addition included a decrease from $350 \mathrm{~mL} / \mathrm{h}$ to 200 $\mathrm{mL} / \mathrm{h}$ during the first step, followed by a reduction to $100 \mathrm{~mL} / \mathrm{h}$ during the second step. When the feed was switched to mineral media only (to dilute the phenol concentration while avoiding further buildup of intermediate products), gas production went to zero within 6 hours (59-hour mark). The gas production rate increased soon after feed of brewery wastewater was restored. Gas production recovered at the 84hour mark. A new stable level of $300 \mathrm{~mL} / \mathrm{h}$, which was less than that of background level $(350 \mathrm{~mL} / \mathrm{h})$, was established. This new level of gas production was maintained until the end of the experiment.

The methane content in reactor headspace was sensitive to the phenol input (Figure 9-5). Methane concentration decreased gradually from 86 to $68 \%$ during phenol addition. Methane content started to increase 4 hours after the reactor feed was restored (57-hour mark). In took 27 hours for the $\mathrm{CH}_{4}$ concentration to reach $84 \%$, the same time required for gas production to stabilize.

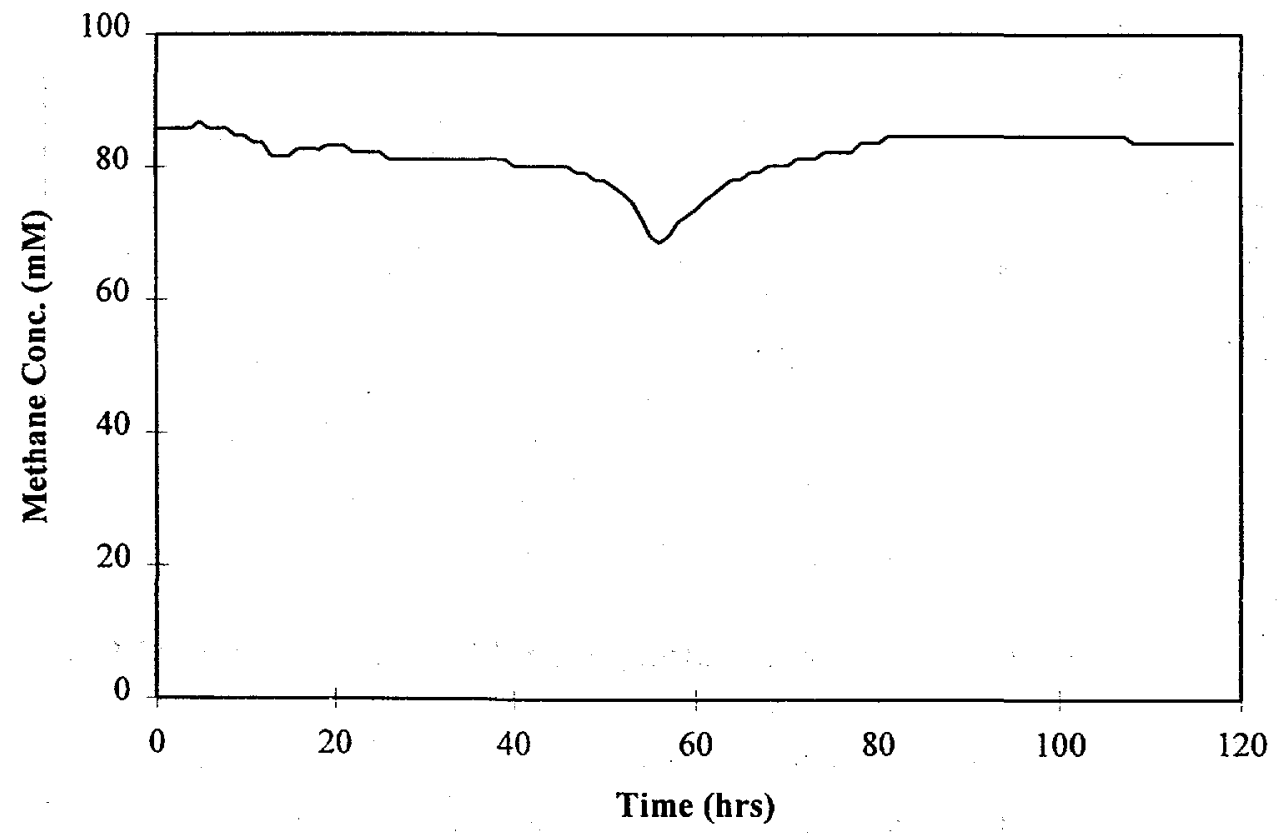

Figure 9-5. Methane content variation during phenol inhibition experiment (7/13/94). 
Reduction in the gas production rate of $44 \%$ during the first phenol step and by $71 \%$ during the second step, along with an $18 \%$ decrease in methane content, indicated serious inhibition. Gas production during this period may be related to acetate degradation since only limited accumulation of acetate was observed.

\section{RESPONSE OF VFAS}

As mentioned above, acetate did not accumulate to a large extent due to phenol addition (Figure 9-7). During the first step, the acetate concentration increased slightly. During the second step, acetate concentration increased up to $2.0 \mathrm{mM}$. Acetate concentration declined to detection limits immediately after phenol addition was stopped.

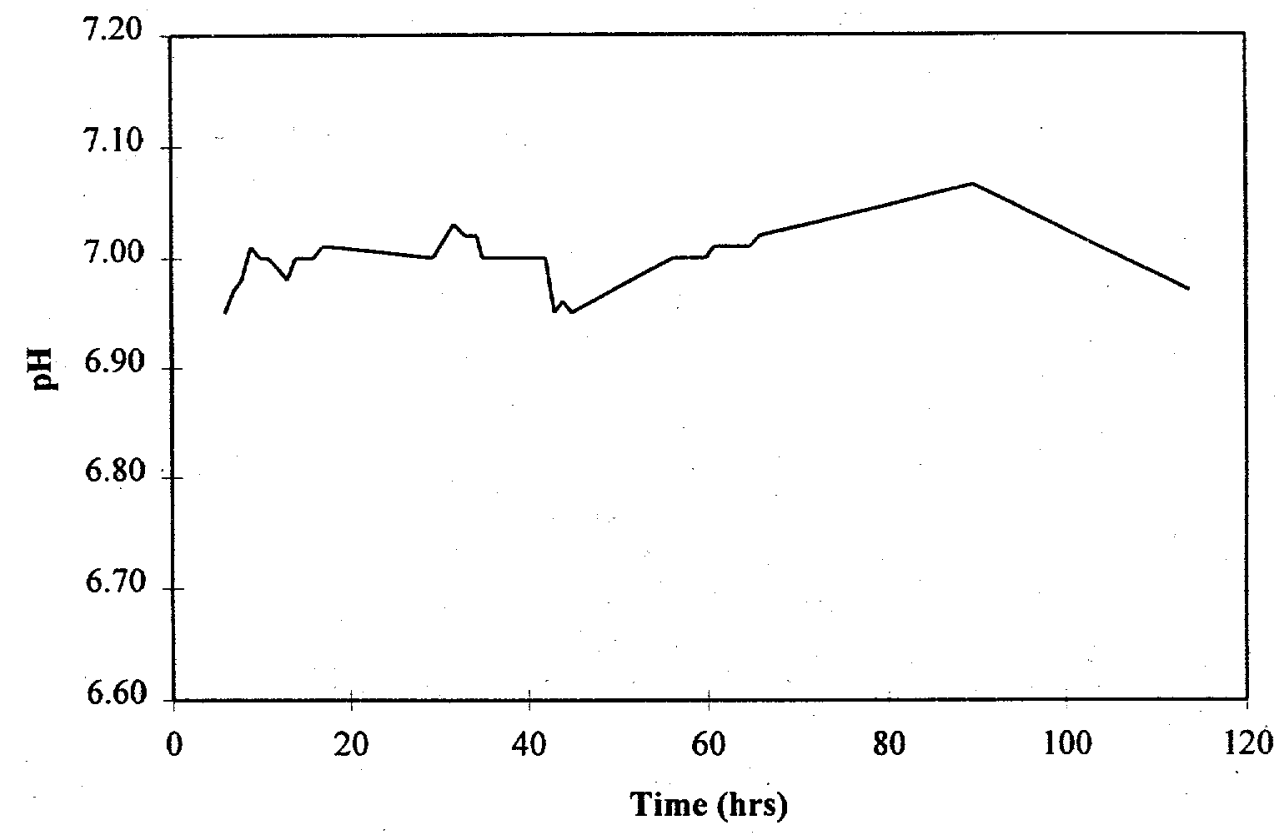

Figure 9-6. $\mathrm{pH}$ response during phenol inhibition experiment (7/13/94).

Propionate accumulated in a similar fashion as acetate, but to a slightly greater degree. A peak concentration of $2.6 \mathrm{mM}$ of propionate was observed (Figure 9-7). However, during the period of 44 to 62 hours, propionate behaved differently from acetate. After the propionate concentration declined to $1 \mathrm{mM}$, a direct result of cessation in phenol addition, propionate concentration again increased. A second peak appeared at 60 hours ( $3 \mathrm{mM}$ ). Propionate concentration then quickly deceased to 0.1-0.2 mM during the next hour and remained at this level. 
Four- and five-carbon VFAs were detected in reactor effluent during the perturbation. Isobutyrate, 2methyl-butyrate, and iso-valerate were first observed during the second step in phenol addition. Butyrate was present in only trace levels (Figure 9-7). 2-methyl-butyrate and iso-valerate accumulated up to 0.1 $\mathrm{mM}$ (Figure 9-8). There were two peaks for each of these components, one at 44 hours and the second between 50 and 55 hours. The appearance of the second peak was similar in timing to that observed for propionate. Isobutyrate has a much higher response than butyrate. Beginning after the second phenol step, iso-butyrate accumulated up to $0.48 \mathrm{mM}$ and remained at this concentration until 50 hours, 6 hours after phenol addition was stopped. Two peaks of iso-butyrate concentration were observed during the first 60 hours. The first peak appeared at 44 hours, the second at 50-55 hours. Iso-butyrate then decreased to 0.2 $\mathrm{mM}$ at 62 hours.

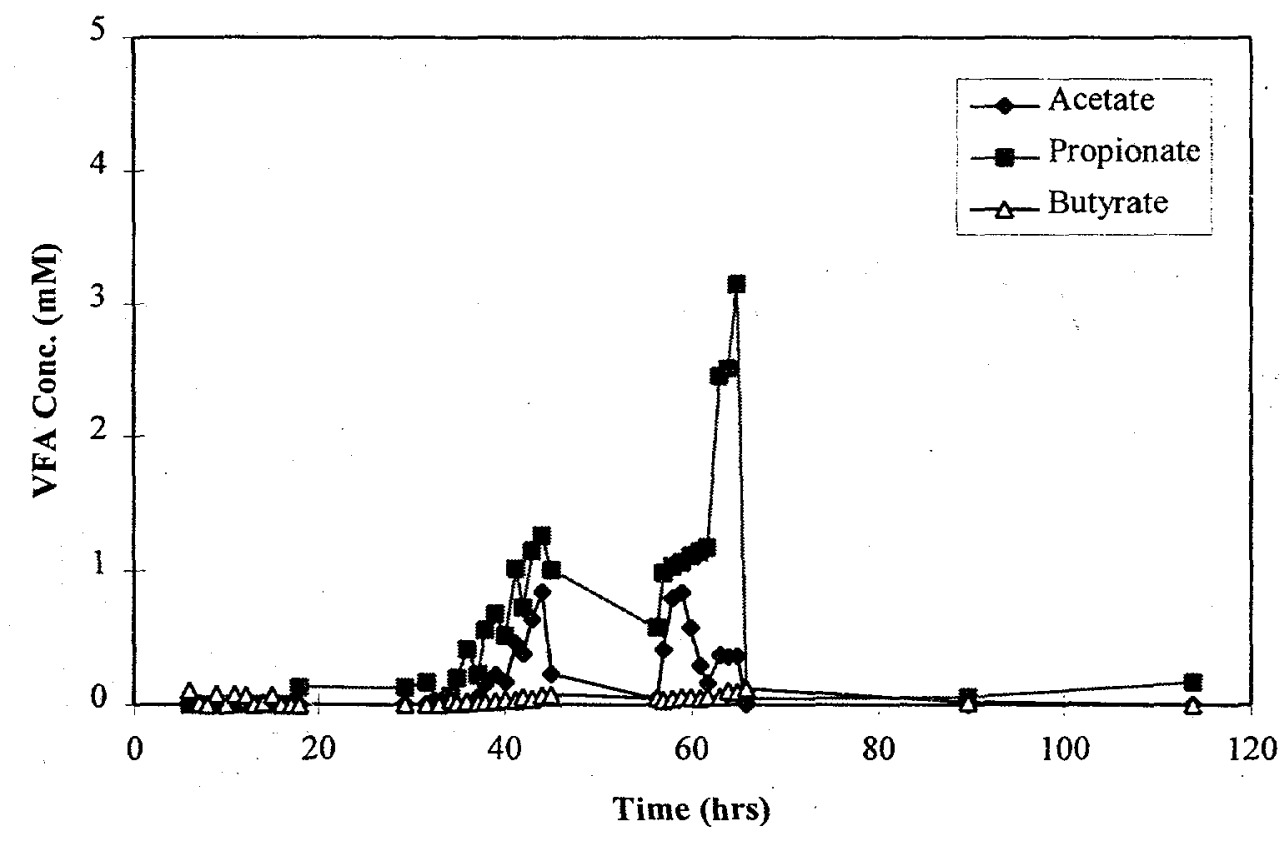

Figure 9-7. VFA concentration during phenol inhibition experiment (7/13/94).

All two- to five-carbon VFAs showed some degree of accumulation. With the exception of acetate, the response patterns were very consistent. Besides accumulation due to phenol steps, a second peak of VFAs was observed before phenol was completely diluted out of the system ( 62 hours). This second peak may be a result of degradation of accumulated ethanol and n-propanol (Figure 9-9). 


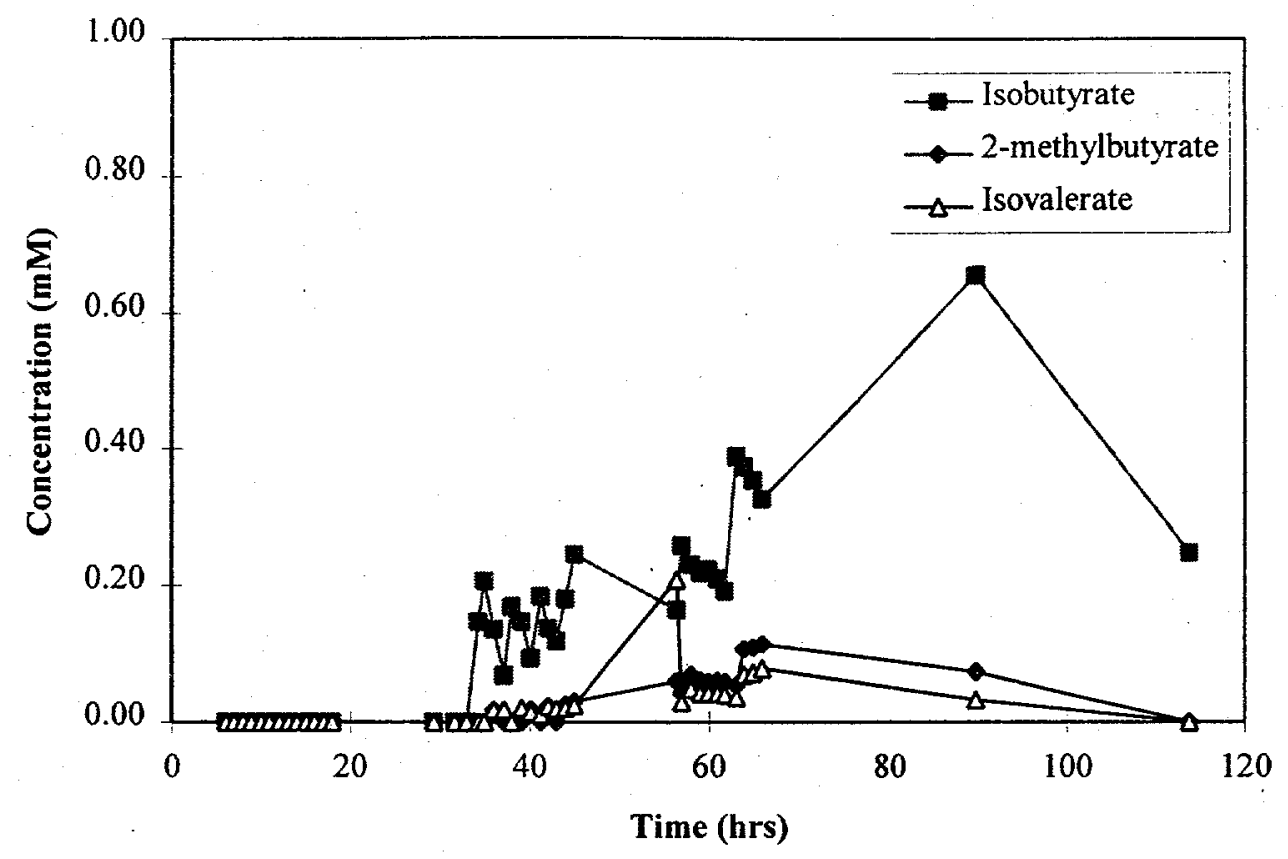

Figure 9-8. Isobutyrate, 2-methyl butyrate and iso-valerate concentration during phenol inhibition experiment (7/13/94).

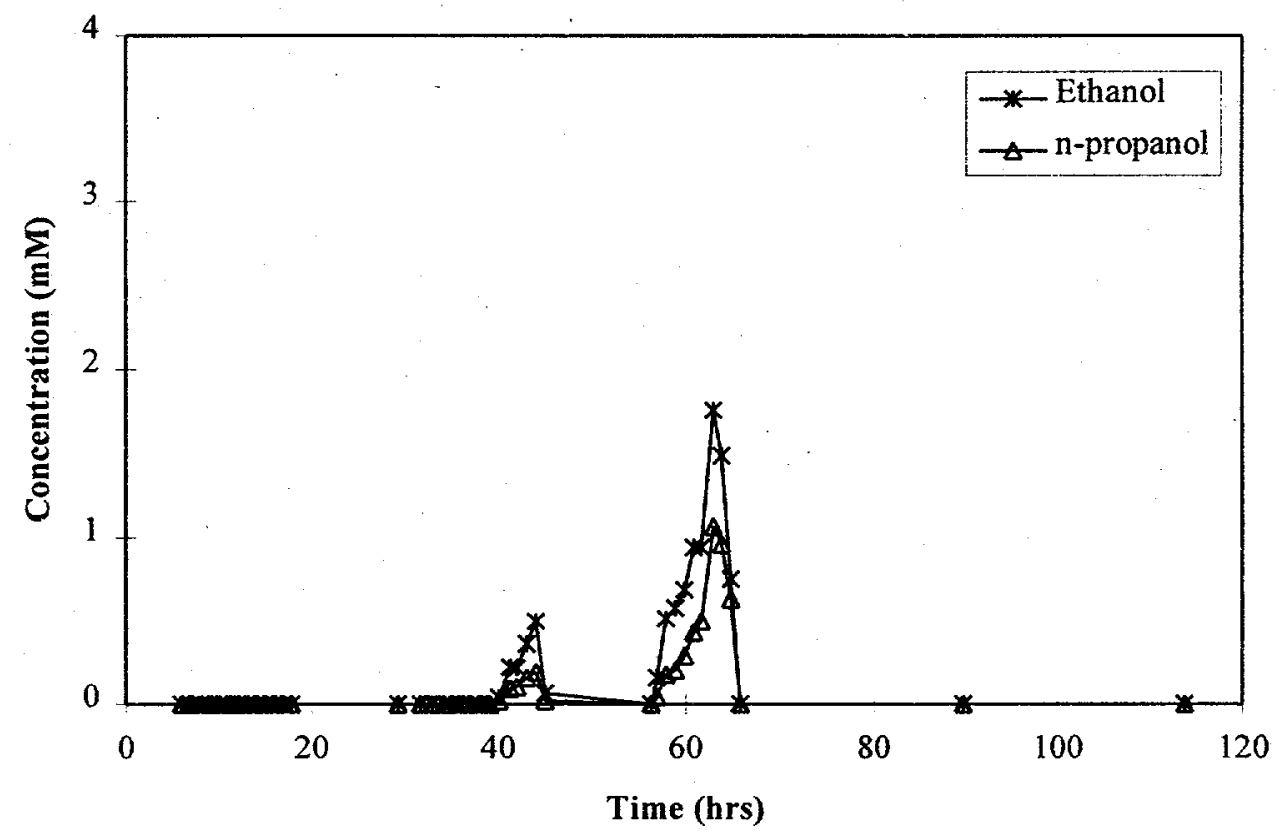

Figure 9-9. Ethanol and n-propanol response during phenol inhibition experiment (7/13/94). 


\section{RESPONSE OF ETHANOL AND PROPANOL}

Accumulation of both ethanol and $n$-propanol was observed. Ethanol did not appear in the effluent until the second step (Figure 9-9). Peak concentrations of $1.8 \mathrm{mM}$ and $2.2 \mathrm{mM}$ appeared in effluent at 40 hours and 55 hours, respectively. Ethanol concentration then decreased to below detection limit at the 60-hour mark. The pattern of ethanol accumulation followed that of propionate accumulation. Propanol accumulation was observed at around 40 hours (to $0.5 \mathrm{mM}$ ). No second peak was detected.

\section{ANALYSIS OF CO/GP AND $\mathrm{H}_{2}$ /GP RESPONSE}

The ratio of $\mathrm{CO} / \mathrm{GP}$ and $\mathrm{H}_{2} / \mathrm{GP}$ are presented in Figures 9-10 and 9-11, respectively. The CO/GP ratio rose rapidly in response to phenol due to a concurrent and immediate increase in $\mathrm{CO}$ and decrease in gas production. This resulted in an out-of-control warning, based on the bivariate plot of $\mathrm{H}_{2} / \mathrm{GP}$ and CO/GP (Figure 9-12) within nine hours. This was a much more rapid response than accumulation of VFAs. As judged by the bivariate plot, the UASB system remained out of control until the experiment was concluded even when all accumulated VFAs and alcohols had been degraded and gas production had stabilized at the new level of c. $300 \mathrm{~mL} / \mathrm{hr}$. In other words, by all other measures the system had recovered and was operating well. This latter result was due to the fact that $\mathrm{CO}$ that accumulates in the headspace can only be reduced by dilution from new gas being produced.

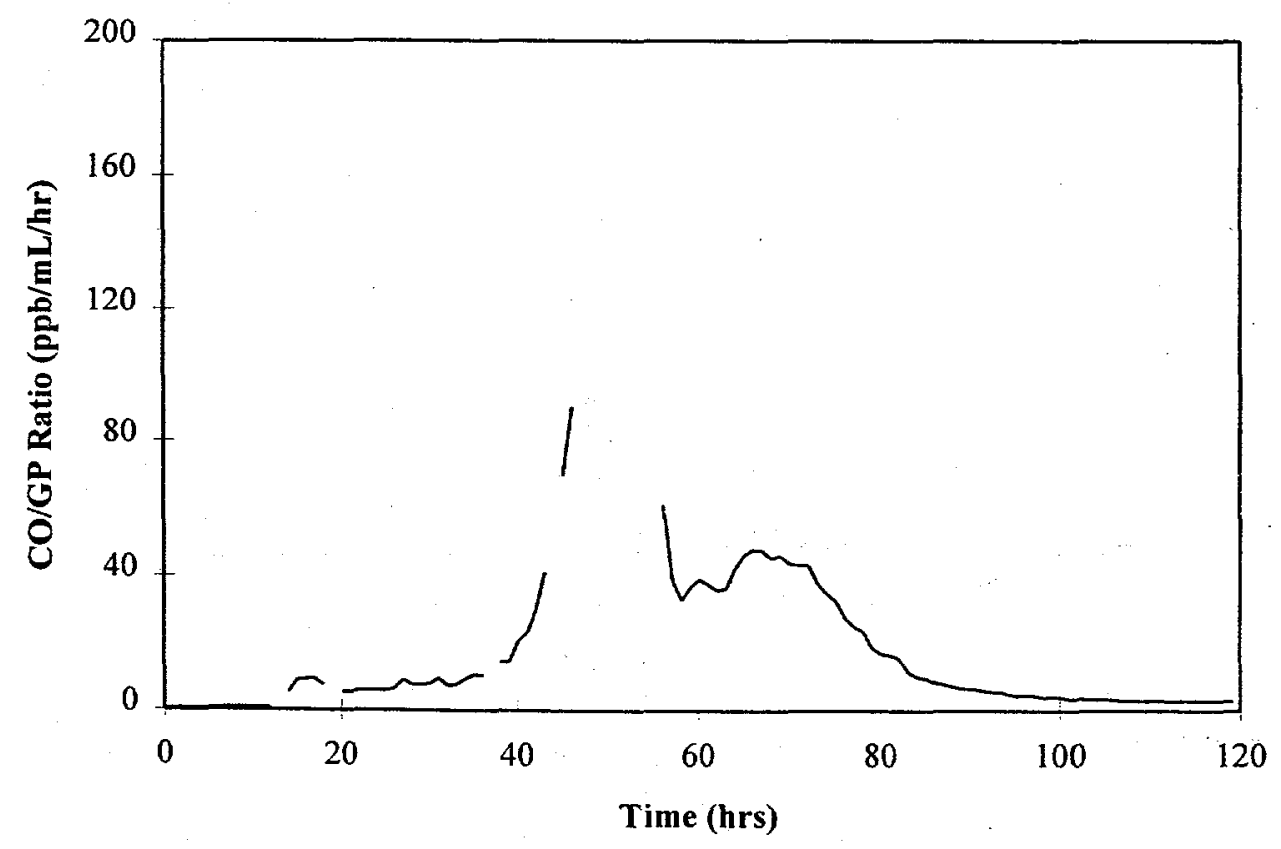

Figure 9-10. CO/GP response during phenol inhibition experiment (7/13/94). 


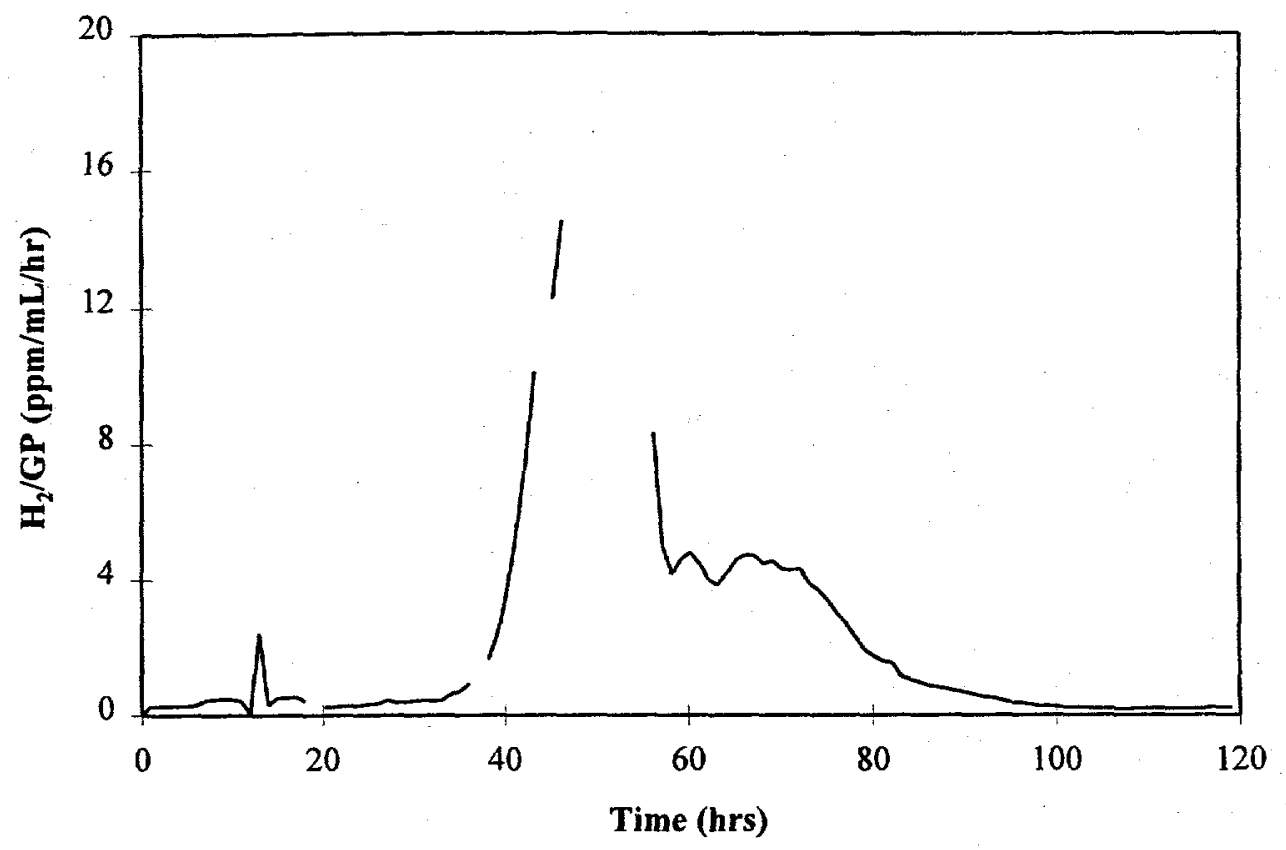

Figure 9-11. $\mathrm{H}_{2}$ /GP response during phenol inhibition experiment (7/13/94).

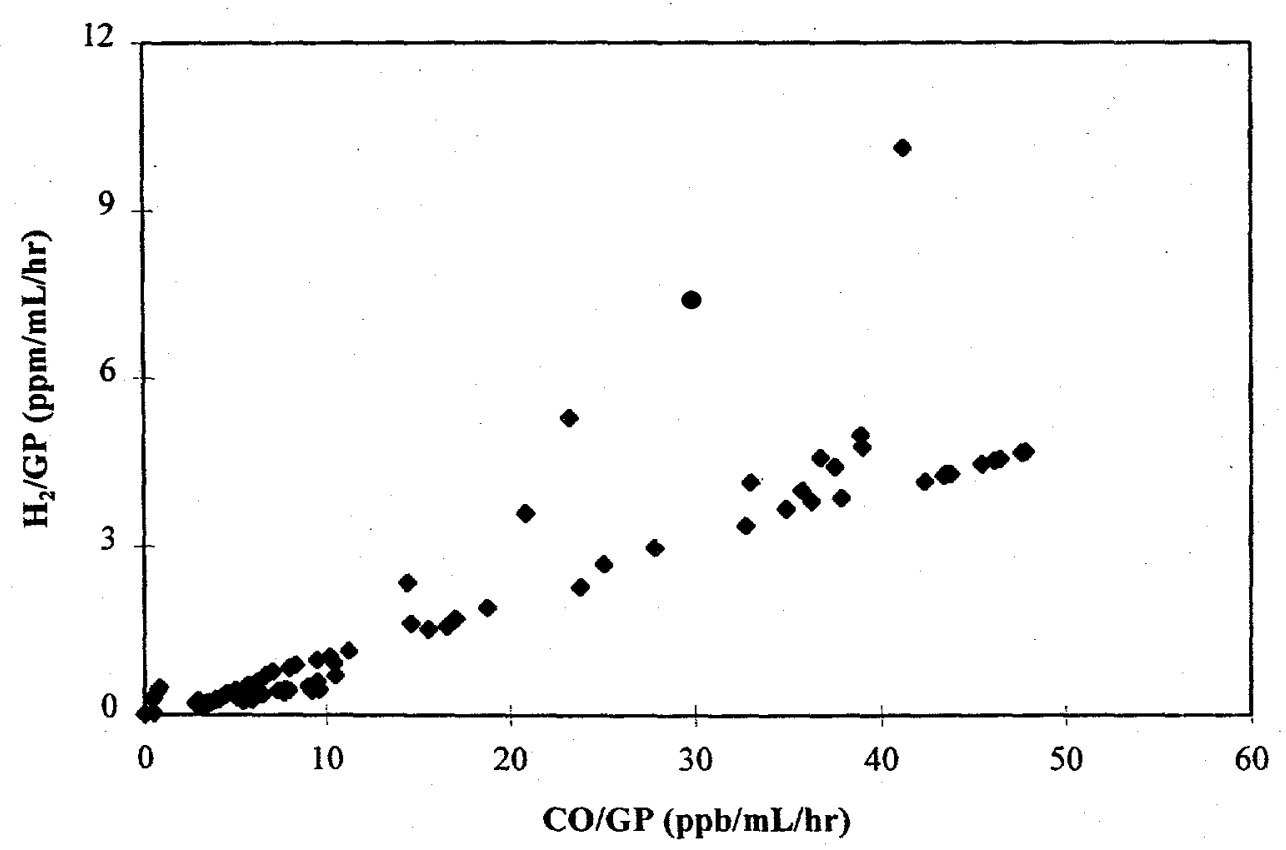

Figure 9-12. Bivariate plot of $\mathrm{CO} / \mathrm{GP}$ and $\mathrm{H}_{2} / \mathrm{GP}$ during phenol inhibition experiment (7/13/94). 


\section{SUMMARY}

As a result of phenol addition, all two- to five-carbon VFAs and ethanol and propanol accumulated. Headspace concentrations of $\mathrm{CO}$ and $\mathrm{H}_{2}$ increased significantly. Gas production was reduced to as low as $29 \%$ of the normal steady state value, while methane content decreased to $68 \%$. Gas production, CO, propionate, and methane all showed an immediate response to phenol addition at a feed concentration of $2000 \mathrm{mg} / \mathrm{L}$. The variations were greatest for $\mathrm{CO}$ and gas production rate. $\mathrm{CO}$ response was the most rapid. $\mathrm{H}_{2}$ had a significant response to phenol addition of $4000 \mathrm{mg} / \mathrm{L}$, long after significant inhibition of methane production had occurred.

Based on the observed results, $\mathrm{CO}$ appears to be a good indicator of process upset due to toxicant addition. A significant increase in $\mathrm{CO}$ was observed prior to any indication of process upset as measured by gas production or accumulation of VFAs. The concentration of $C O$ rose by a factor of 6 after 9 hours, approximately 5 hours before any decrease in gas production was observed. Use of the bivariate plot of $\mathrm{CO} / \mathrm{GP}$ and $\mathrm{H}_{2} / \mathrm{GP}$ was effective in detecting the onset of inhibition conditions. Because $\mathrm{CO}$ concentration in the headspace can be removed only by dilution, the use of this approach to signal recovery is somewhat limited. 


\section{Section 10}

CONCLUSIONS

Data from steady state and during perturbations caused by applying pulse and step increases in OLR to a UASB pilot system were used to assess using trace gases $\mathrm{CO}$ and $\mathrm{H}_{2}$ as process and early-warning indicators. The hydraulics and kinetics of the UASB system were also delineated in hopes that an integrated control algorithm combining hydraulics, mass transfer, kinetics, and trace gases could be developed. The major conclusions of this work were:

1. The response of $\mathrm{CO}$ and $\mathrm{H}_{2}$ in the UASB system were not consistent enough nor could they be sufficiently correlated with reactor performance for stand-alone on-line process monitoring or control.

2. Neither $\mathrm{H}_{2}$ (g) nor $\mathrm{CO}(\mathrm{g})$ was in equilibrium with the liquid phase. In general $\mathrm{H}_{2}(\mathrm{~g})$ was well above what would have constituted equilibrium with the liquid phase, while $\mathrm{CO}(\mathrm{g})$ was well below equilibrium with the liquid phase. No correlation was evident in comparing data collected during a non-steady state period.

3. A method was developed to determine whether the reactor was "in-control". The method consisted of normalizing $\mathrm{H}_{2}$ and $\mathrm{CO}$ on gas production (GP) (i.e., $\mathrm{H}_{2} / \mathrm{GP}$ and $\mathrm{CO} / \mathrm{GP}$ ) and using a bivariate plot of these two new parameters. For all steady state and unsteady state testing, data for $\mathrm{CO} / \mathrm{GP}\left(\mathrm{ppb} / \mathrm{mL} / \mathrm{hr}\right.$ ) versus $\mathrm{H}_{2} / \mathrm{GP}(\mathrm{ppm} / \mathrm{mL} / \mathrm{hr}$ ) fell within a $\{2,1\}$ envelope. When reactor performance declined, the transformed data fell outside of this "safe" operating zone.

4. The use of the bivariate plot to identify process upset due to a toxic episode caused by phenol addition was examined. Results indicated that the bivariate plot could be used to identify process failure well before any other parameter.

5. The relationship previously observed between acetate concentration and $\mathrm{CO}$ digester sludges was not clearly evident in this work, although in many cases $\mathrm{CO}$ concentration rose concurrent with increases in the acetate concentration. Several factors likely contribute to this: 1) the fact that there was no equilibrium or consistent ratio between $\mathrm{CO}\left(\right.$ and $\mathrm{H}_{2}$ ) in the gaseous and aqueous phases; and 2) $\mathrm{CO}$ in some instances appeared to be related to biological transformations other than acetate decarboxylation.

6. N-propanol was produced during periods when the UASB began to fail. Large increases and decreases in $\mathrm{CO}$ were observed to coincide with the accumulation and disappearance of $\mathbf{n}$ propanol.

7. The formation of n-propanol was further investigated. Results indicated that CO may play a role in the formation of $n$-propanol. 
8. Due to the inconsistent nature of the response of $\mathrm{CO}$, an integrated control algorithm could not be developed.

9. Although the use of a bivariate plot of $\mathrm{CO} / \mathrm{GP}$ versus $\mathrm{H}_{2} / \mathrm{GP}$ appears to be a useful tool for process monitoring, it is doubtful that the marginal improvement that might be afforded is worth the additional cost of equipment and operation of a trace gas monitoring system. 
APPENDIX A 
Appendix A

\section{Appendix A}

\section{Medium and feed composition}

In order to prevent precipitation and growth in the feed to the UASB reactor, two separate media feeds were made: one to supply the minerals and trace nutrients required(mineral medium) and the second to supply the organics(synthetic brewery waste feed). Trace minerals were prepared separately and added as a solution to the mineral medium. The composition of the mineral media solution and trace minerals used are presented in Tables A-1 and A-2, respectively. All chemicals were of reagent grade.

Table A-1. Mineral medium composition (prepared in 16 litter batches)

\begin{tabular}{|l|l|l|}
\hline \multicolumn{1}{|c|}{ Chemical } & \multicolumn{1}{|c|}{ Amount } & \multicolumn{1}{c|}{ Supplier } \\
\hline $\mathrm{NaCl}$ & $3.2 \mathrm{~g}$ & Baker Analytical \\
\hline $\mathrm{NH}_{4} \mathrm{Cl}$ & $3.2 \mathrm{~g}$ & Baker Analytical \\
\hline $\mathrm{MgCl}_{2} \cdot 6 \mathrm{H}_{2} \mathrm{O}$ & $3.2 \mathrm{~g}$ & Mallinckrodt \\
\hline $\mathrm{CaCl}_{2} \cdot 2 \mathrm{H}_{2} \mathrm{O}$ & $1.6 \mathrm{~g}$ & Sigma Chemical \\
\hline $\mathrm{K}_{2} \mathrm{HPO}_{4}$ & $0.1 \mathrm{~g}$ & Columbus \\
\hline $\mathrm{KH}_{2} \mathrm{PO}_{4}$ & $0.05 \mathrm{~g}$ & Baker Analytical \\
\hline $\mathrm{NaHCO}_{3}$ & $30.24 \mathrm{~g}$ & Mallinckrodt \\
\hline Trace mineral* & $32 \mathrm{ml}$ & \\
\hline
\end{tabular}

* prepared separately

A total of four different organic concentrations for the synthetic brewery waste feed were used to feed the laboratory-pilot UASB reactor. Feed I was 
Appendix A

$11.4 \mathrm{kgCOD} / \mathrm{m}^{3}$, feed II was $5.7 \mathrm{kgCOD} / \mathrm{m}^{3}$, feed III was $9.1 \mathrm{kgCOD} / \mathrm{m}^{3}$ and feed

IV was $13.7 \mathrm{kgCOD} / \mathrm{m}^{3}$. The feeds were adjusted using sodium hydroxide to obtain a final $\mathrm{pH}$ of $5.0 \pm 0.1$. Feed $\mathrm{I}$ was used during steady state operation(Chapter VIII). The composition of Feeds I-IV are are presented in Tables A-3 and A-4.

Table A-2. Composition of trace mineral solution (prepared in 1 liter batches)

\begin{tabular}{|l|c|l|}
\hline \multicolumn{1}{|c|}{ Chemical } & Amount & \multicolumn{1}{|c|}{ Supplier } \\
\hline Nitrilotriace-tic acid & $12.8 \mathrm{~g}$ & Sigma Chemical \\
\hline FeSO ${ }_{4} \cdot 7 \mathrm{H}_{2} \mathrm{O}$ & $0.1 \mathrm{~g}$ & Sigma Chemical \\
\hline $\mathrm{MnCl}_{2} \cdot 4 \mathrm{H}_{2} \mathrm{O}$ & $0.1 \mathrm{~g}$ & Sigma Chemical \\
\hline $\mathrm{CoCl}_{2} \cdot 6 \mathrm{H}_{2} \mathrm{O}$ & $0.17 \mathrm{~g}$ & Columbus \\
\hline $\mathrm{CaCl}_{2} \cdot 2 \mathrm{H}_{2} \mathrm{O}$ & $0.1 \mathrm{~g}$ & Sigma Chemical \\
\hline $\mathrm{ZnCl}_{2}$ & $0.1 \mathrm{~g}$ & Fisher Scientific \\
\hline $\mathrm{CuCl}_{2} \cdot 2 \mathrm{H}_{2} \mathrm{O}$ & $0.02 \mathrm{~g}$ & Fisher Scientific \\
\hline $\mathrm{H}_{3} \mathrm{BO}_{3}$ & $0.01 \mathrm{~g}$ & Aldrich \\
\hline $\mathrm{Na} \mathrm{molybdate}$ & $0.01 \mathrm{~g}$ & Sigma Chemical \\
\hline $\mathrm{NaCl}$ & $1.00 \mathrm{~g}$ & Baker Analytical \\
\hline $\mathrm{Na}_{2} \mathrm{SeO}_{3}$ & $0.017 \mathrm{~g}$ & Sigma Chemical \\
\hline $\mathrm{NiSO}_{4} \cdot 6 \mathrm{H}_{2} \mathrm{O}$ & $0.026 \mathrm{~g}$ & Fisher Scientific \\
\hline
\end{tabular}


Table A-3. Synthetic brewery waste feed composition (prepared in 8 liter batches)

Feed I

\begin{tabular}{|l|c|l|}
\hline \multicolumn{1}{|c|}{ Chemical } & Amount & Supplier \\
\hline $\mathrm{NaOH}$ & $9.6 \mathrm{~g}$ & Mallincrodt \\
\hline Resazurin $(0.2 \%)$ & $10 \mathrm{ml}$ & Sigma Chemical \\
\hline Acetic acid & $12 \mathrm{ml}$ & Fisher seientific \\
\hline Propionic acid & $8.88 \mathrm{ml}$ & Mallincrodt \\
\hline Glucose & $7.2 \mathrm{~g}$ & Sigma Chemical \\
\hline FeSO ${ }_{4} .7 \mathrm{H}_{2} \mathrm{O}$ & $1.335 \mathrm{~g}$ & Sigma Chemical \\
\hline Ethanol(190proof) & $36.8 \mathrm{ml}$ & Quantum \\
\hline
\end{tabular}

Table A-4. Synthetic brewery waste feed composition (prepared in 8 liter batches) Feeds II, III, IV *

\begin{tabular}{|l|l|l|l|}
\hline \multicolumn{1}{|c|}{ Chemical } & Feed II & Feed III & Feed IV \\
\hline $\mathrm{NaOH}$ & $4.80 \mathrm{~g}$ & $7.68 \mathrm{~g}$ & $11.52 \mathrm{~g}$ \\
\hline Resazurin (0.2\%) & $10 \mathrm{ml}$ & $10 \mathrm{ml}$ & $10 \mathrm{ml}$ \\
\hline Acetic acid & $6.0 \mathrm{ml}$ & $9.6 \mathrm{ml}$ & $14.4 \mathrm{ml}$ \\
\hline Propionic acid & $4.4 \mathrm{ml}$ & $7.1 \mathrm{ml}$ & $10.7 \mathrm{ml}$ \\
\hline Glucose & $3.60 \mathrm{~g}$ & $5.76 \mathrm{~g}$ & $8.64 \mathrm{~g}$ \\
\hline FeSO $4.7 \mathrm{H}_{2} \mathrm{O}$ & $0.6675 \mathrm{~g}$ & $1.068 \mathrm{~g}$ & $1.6 \mathrm{~g}$ \\
\hline Ethanol(190proof) & $18.4 \mathrm{ml}$ & $29.4 \mathrm{ml}$ & $66.2 \mathrm{ml}$ \\
\hline
\end{tabular}

* for chemical supplier see Table A-3. 
Appendix A

Phosphate buffered basal medium (PBBM) was used during n-propanol assay. Medium pH was brought to 7.2-7.4, boiled and flushed with $\mathrm{N}_{2}$. After autoclaving, Phosphate buffer $\left(15 \% \mathrm{KH}_{2} \mathrm{PO}_{4}\right.$ and $\left.29 \% \mathrm{~K}_{2} \mathrm{HPO}_{4}\right)$, redusing agent ( $\left.2.5 \% \mathrm{Na}_{2} \mathrm{~S}\right)$, and sterilized vitamins were then added. Table A-5 presents the composition of PBBM.

Table A-5 Phosphate Buffered Basal Medium (prepared in 1 Litter batch)

\begin{tabular}{|c|c|}
\hline Chemicals & Quantity \\
\hline Double Distilled Water & $945 \mathrm{ml}$ \\
\hline $\mathrm{NaCl}$ & $0.9 \mathrm{~g}$ \\
\hline $\mathrm{MgCL}_{2} \cdot 6 \mathrm{H}_{2} \mathrm{O}$ & $0.2 \mathrm{~g}$ \\
\hline $\mathrm{CaCl}_{2} .2 \mathrm{H}_{2} \mathrm{O}$ & $0.1 \mathrm{~g}$ \\
\hline $\mathrm{NH}_{4} \mathrm{Cl}$ & $1.0 \mathrm{~g}$ \\
\hline Trace Mineral I & $10 \mathrm{ml}$ \\
\hline Resazurin Solution, $2 \%$ & $1 \mathrm{ml}$ \\
\hline
\end{tabular}

* see Table A-2 
APPENDIX B 
Appendix B

\section{Materials and Methods}

\section{B-1. Activity assays for acetate, propionate and ethanol using brewery granules}

\section{B-1.1. Inoculum and media}

\section{B-1.11. Inoculum preparation and biomass estimation}

Granules were obtained from a laboratory bench-scale UASB

reactor(Figure VIII-1) which was acclimated to the synthetic brewery waste(Table A-3) for 6 months. Granules taken from the bench-scale UASB were stored at room temperature in an $8 \mathrm{~L}$ carboy equipped with a water seal. Before the start of this experiment, the inocula were incubated overnight at $37^{\circ} \mathrm{C}$ with a trace amount(ca. 1-2 mg/l) of ethanol to stimulate the activity of different populations and reduce any lag phase in the assay. At the conclusion of the assays, the granules were subjected to microscopic examination for particle size measurements and population observations. Granule size was estimated by geometric averaging. Several fields under the microscpe were randomly selected for the particle size distribution measurement. The geometric mean for each field was determined and particle size was estimated using the following equation:

$$
\text { Mean size }=\Sigma\left[\mathrm{P}_{\mathrm{i}} \mathrm{Q}_{\mathrm{i}} / \mathrm{Q}_{\mathrm{i}}\right]_{\mathrm{j}} / \mathrm{n} \quad \ldots
$$

where $P_{i}$ is particle size in each field $(i=1,2,3 . . m), Q_{i}$ is the number of that particle in size $\mathrm{i}$ within that field(ranging $1-80), \mathrm{j}$ is the number of field $(\mathrm{j}=1,2,3 \ldots \mathrm{n}$ ). 
Appendix B

Biomass concentrations were analyzed for total solids and volatile solids(TS and VS) for experiments conducted using the Multigen reactor contents(Appendix C).

\section{B-1.12. Medium preparation and inoculum transfer technique}

Between 1.2 and $1.4 \mathrm{~L}$ of medium (composition in Table A-1)in a $2 \mathrm{~L}$ glass flask was flushed with nitrogen gas(AGA Inc.) for 20 minutes. The solution pH was adjusted to $7.00 \pm 0.01$ using $3 \mathrm{~N} \mathrm{HCL}$ or $3 \mathrm{~N} \mathrm{NaOH}$ (under nitrogen). After transferring the medium to a Multigen reactor, a known amount $(80-100 \mathrm{ml})$ of inocula(granules or flocs) was transferred promptly to the multigen reactor(New Brunswick Scientific, modelF1000) (Figure VI-1). The reactor was then sealed, heated and stirred(for detail description of the multigen system refer to Chapter VI). To reduce any oxygen brought into the reactor during transfer, $0.25 \mathrm{ml}$ of $2.5 \% \mathrm{Na}_{2} \mathrm{~S}$ (Fisher Scientific) was injected into the reactor from the sampling port. The experiment was initiated immediately after the desired temperature was attained in the reactor.

\section{B-1.2. Assays for intrinsic kinetic parameters for} acetate, propionate and ethanol degradation

Brewery granules, obtained from the laboratory bench-scale UASB reactor were first disrupted using a motar and pestle. This was sufficient to disrupt the granules to an average size of $1.1 \mathrm{~mm}$ in diameter. These small granules were then further fractionated in a Multigen reactor(impeller speed 600rpm) for several hours and examined under microscope until flocs of about $33 \mu \mathrm{m}$ in diameter were 
Appendix B

formed. During this process, 3-4 mmole/L of acetate was maintained in the reactor to avoid endogenous metabolism. The Flocs were then transferred to a water sealed flask. The flask was then amended with $0.2 \mathrm{ml}$ of $2.5 \% \mathrm{Na}_{2} \mathrm{~S}$, and stored at room temprature. Analytical methods for VFA, ethanol, n-propanol, formate, $\mathrm{H}_{2}$, $\mathrm{CO}$, and $\mathrm{CH}_{4}$ are decribed in Appendix $\mathrm{C}$. Protocols for the intrinsic kinetic assays were described in Chapter VI. Typical sampling frequency for these assays are presented in Tables VI-2 and VI-3.

\section{B-2. Residence time distribution(RTD) experiments for the laboratory bench-scale UASB reactor}

A concentrated tracer, lithium chloride(Sigma Chemical) or acetate solution was injected into the inlet of the reactor using a $50 \mathrm{ml}$ syringe equipped with a 21 -gauge needle. Liquid samples $(1.0 \mathrm{ml})$ were collected from the sampling port at recirculation line(Figure VIII-1). Samples were directly transferred into 1.5 $\mathrm{ml}$ polypropylene eppendorf micro test tubes(Brinkmann) using a $3 \mathrm{ml}$ syringe and a 21-gauge needle. Samples were then centrifuged in an eppendorf centrifuge(Brinkmann, model 5415) at 12000rpm for 2 minutes. The supernatant was collected for analysis. Analytical methods for determining Lithium chloride and acetate concentration is described in C2 and C6, Appendix C. A sampling frequency of 2 minutes was used for the organic and hydraulic flux assays. A sampling frequency of $10 \%$ of the hydraulic retention time(HRT) was used during flow modeling experiments using lithum and 10 to 15 minutes using acetate. 
Appendix B

B-3. Tracer recovery test for adsorption on granular
sludge

The extent of lithium chloride adsorption on the granular sludge was determined to examine any influence of adsorption during the tracer study. The tracer recovery test was conducted in $58 \mathrm{ml}$ serum bottles sealed with rubber stopper and aluminum crimps. The step by step procedure is described below: (1) $58 \mathrm{ml}$ serum bottles with $5 \mathrm{ml}$ nutrient media(pH=7.0) were vacuum flushed with $\mathrm{N}_{2}$ for $0.5 \mathrm{hr}$, and sealed. A $3 \mathrm{ml}$ volume of synthetic brewery waste was added to the bottles using a $3 \mathrm{ml}$ syringe with a 21 -gauge needle. These media had the same composition as the reactor feed and mineral media(Appendix A).

(2) $0.1 \mathrm{ml}$ of $2.5 \% \mathrm{Na}_{2} \mathrm{~S}$ was added into the serum bottles to scavenge any $\mathrm{O}_{2}$.

(3) the serum bottles were flushed with $20 \% \mathrm{CO}_{2} / 80 \% \mathrm{H}_{2}$ for 5 minutes to adjust the $\mathrm{pH}$ range to between 6.8-7.0.

(4) $5.0 \mathrm{ml}$ of anaerobic granules were added into the serum bottles, using a $5 \mathrm{ml}$ syringe with a 18-gauge needle.

(5) $0.5 \mathrm{ml}$ of $3.2 \mathrm{~g} / \mathrm{LiCl}$ solution was added into the bottle to obtain a final liquid volume of $13 \mathrm{ml}$ and $\mathrm{LiCl}$ concentration of $120 \mathrm{mg} /$.

(6) The serum bottles were incubated at $37^{\circ} \mathrm{C}$ (same as the reactor temperature) in an Incubator Shaker(New Brunswick, model G25) at $170 \mathrm{rpm}$ for 24 hours to reach equilibrium.

(7) A $1.2 \mathrm{ml}$ of liquid sample was withdrawn from each of the serum bottles into $1.5 \mathrm{ml}$ eppendorf test tubes. The tubes were then centrifuged at $12000 \mathrm{rpm}$ for 2 minutes in an eppendorf centrifuge. The supernatant was then collected for analysis.

(8) Lithum concentration was determined by a Ion Chromatography(Dionex model 2000) 
Appendix B

B-4. Unsteady state perturbation experiment using the laboratory bench-scale UASB reactor

An organic loading rate(OLR) perturbation was introduced using the online monitoring and control syetem PARAGON(Intec) through an analog/digital(A/D) interface (OPTO-22) and a Watson-Marlow pump(503 U)(Figure VIII-1, Appendix C-4). A Typical feed control program for step OLR variation is presented below:

Table B-1. Typical sequency preogram during unsteadystate perturbation experiment

(block SEQ INFLUENT in PARAGON)

\begin{tabular}{|l|l|l|l|l|}
\hline Step & Slope/min & End Value & Hold Time(min) & Next Step \\
\hline 1 & 0 & 3.0 & 60 & $\mathrm{y}$ \\
\hline 2 & 0 & 4.75 & 180 & $\mathrm{y}$ \\
\hline 3 & 0 & 7.0 & 420 & $\mathrm{y}$ \\
\hline 4 & 0 & 4.75 & 180 & $\mathrm{y}$ \\
\hline 5 & 0 & 3.0 & 600 & $\mathrm{y}$ \\
\hline
\end{tabular}

Impulse OLR were performed manually by injecting the desired mass of organic carbon directly into the reactor inlet. Trace gas $\left(\mathrm{H}_{2}\right.$ and $\left.\mathrm{CO}\right)$ monitoring settings for PARAGON program and Integrater/controller module(ICM) of trace gas analyzer are presented in Table B-2. 
Appendix B

Table B-2. Unsteady state monitoring parameters setting for Paragon and ICM

\begin{tabular}{|l|l|}
\hline PARAGON blocks & RGA3 ICM \\
\hline Traux $\mathrm{H}_{2}$ range:0.04-1000ppm & Span: $\mathrm{H}_{2}=0.04-1000 \mathrm{ppm}$ \\
\hline Traux CO range:0.004-10.4ppm & CO=0.004-10.4ppm \\
\hline SEQ tracegas:hold time $=16.9667 \mathrm{~min}$ & Sense: 500 \\
\hline or $26.9667 \mathrm{~min}$ & \\
\hline Hist: data collect $=10 \mathrm{~min}$ & \\
\hline
\end{tabular}

Other portions of the PARAGON program and the ICM program remained same

as these presented in Appendix C-2 and Appendix C-4, respectively.

\section{B-5. Dissolved $\mathrm{H}_{2}$ and $\mathrm{CO}$ measurements}

B-5.1. RGA3 trace gas analyzer ICM module program sense $=100$

for other settings see Appendix C-2.

\section{B-5.2. Procedure for dissolved $\mathrm{H}_{2}$ and $\mathrm{CO}$ measurements}

A serum bottle technique was used for the dissolved gas analyses. To prevent any biological activity(uptake or production of $\mathrm{CO}$ and $\mathrm{H}_{2}$ ) during the measurements of dissolved gases, which could interfere with the results, a strong alkali(NaOH) solution was added into the serum bottle prior to adding the sample. After the aqueous sample reached equilibrium with gas phase in the serum bottle, the gas phase $\mathrm{H}_{2}$ and $\mathrm{CO}$ concentration were measured. Dissolved gas concentration in the sample was estimated according to Henry's law. For 
Appendix B

calculations of the dissolved $\mathrm{H}_{2}$ and $\mathrm{CO}$ refer to Chapter VIII-F. A detailed description of the serum bottle procedure used is presented below:

Initially, $25 \mathrm{ml}$ serum bottles were vacuum flushed and pressurized with $\mathrm{N}_{2}$ (AGA, Inc) for 12 minutes and sealed with a rubber stopper and aluminum crimp. The bottles were then autoclaved to ensure sterility. $2 \mathrm{ml}$ of a $3 \mathrm{~N} \mathrm{NaOH}$ solution was added under $\mathrm{N}_{2}$ atmosphere. The following steps were then executed: * warm up serum bottles in a $37^{\circ} \mathrm{C}$ shaking water bath(American Scientific YB-521)

* flush a $5 \mathrm{ml}$ glass gas syringe(SGE) with a mininert valve(SVLLMA) and a 21 gauge needle in an anaerobic sterile bottle

* flush the syringe with the head space of the serum bottles twice, slowly take $1 \mathrm{ml}$ gas sample, inject to RGD2 trace gas analyzer, checking for the background

* flush a $10 \mathrm{ml}$ syringe with reactor effluent twice from the reactor sampling port

* slowly take $10 \mathrm{ml}$ liquid sample to ensure no bubble formation due to a vaccum forming using the syringe.

* inject the sample immediately into the anaerobic serum bottles using a 21gauge needle. The concentration of $\mathrm{NaOH}$ in the serum bottles was ca. $0.5 \mathrm{~N}$. * shake serum bottles for 5 minutes in $37^{\circ} \mathrm{C}$ water bath(American Scientific YB-521) to reach equilibrium 
Appendix B

* flush a $5.0 \mathrm{ml}$ glass gas syringe with a mininert valve and a 21-gauge needle

in an anaerobic sterile bottle filled with $\mathrm{N}_{2}$ gas

* take a $1.0 \mathrm{ml}$ gas sample from the serum bottle head space

* inject into trace gas analyzer(RGD2) for analysis

\section{B-6. Isotopic assay for determining n-propanol pathway}

n-propanol assay was performed on serum vials $(158 \mathrm{ml}) .{ }^{13} \mathrm{C}(1-\mathrm{C})$ ethanol

(Cambridge Isotope, 95\%) was used as substrate. Serum vials were vacuum

flushed with $\mathrm{N}_{2}$ for $0.5 \mathrm{hr}$. $50 \mathrm{ml}$ PBBM medium (Table A-5) was transfered into serum vials and the content $\mathrm{pH}$ was adjusted to 7.0 using $80 \% \mathrm{CO} / 20 \% \mathrm{H}_{2}$ gas.

$0.3 \mathrm{ml}$ of granule was injected in to senum vials using a $1 \mathrm{ml}$ syringe with a 18-gauge needle. ${ }^{13} \mathrm{C}(1-\mathrm{C})$ ethanol was then added in to the solution using a $3 \mathrm{ml}$ syringe with a 21-gauge needle. Above procedure was conducted under $\mathrm{N}_{2}$ atomsphere.

Aqueous samples were withdrawn from serum vials using a $1 \mathrm{ml}$ syringe with a 21 gauge needle and were filtered through a $0.2 \mu \mathrm{m}$ syringe filter. Samples were then

extracted with ethyl-acetate(see following section). ${ }^{13} \mathrm{Cn}$-propanol was determined using gas chromatography/mass spectra, at a scan wavelength of $471-485 \mathrm{~nm}$.

\section{B-6.1 Protocol for extraction of n-propanol}

* in a $4 \mathrm{ml}$ glass vial, add $1 \mathrm{ml}$ sample mixed with $1 \mathrm{ml}$ ethyl-acetate(Aldrich, 99.5\%), shake well

* pipet $0.5 \mathrm{ml}$ top layer of the solution into a $1.2 \mathrm{ml}$ auto sampler crimp vail(toflon lined) 
Appendix B

* add $0.5 \mathrm{ml}$ ethyl-acetate, seal the vial with aluminum crimp, mix well

* $\quad$ store sample in refregerator for analyses

\section{B-7. Microscopy}

Granule and flocs size distributions were estimated using an Olympus DF plan bright field microscope. Microbial population observations were performed on an Olympus phase contrast microscope(model BH-2) equipped with a mercury lamp, and a Confoco laser bean microscope. The autofluorecence of methanogens was observed with a B(IF-490) excitation filter. Transmission electron microscopy(TEM) was performed with a Philips CM-10 electron microscope.

Thin section granule samples were immersed into a $2.5 \%$ Glutaraldehyde solution containing a $0.1 \mathrm{M}$ phosphate buffer $(\mathrm{pH}=7.2)$. The ratio of fixative to sample was approximately 10:1(v/v). Samples were left submerged for a week at $4^{\circ} \mathrm{C}$ to ensure complete penetration of fixative. The fixed samples were rinsed three times at room temperature using a $0.1 \mathrm{mM}$ phosphate buffer(pH 7.2), and then postfixed with $1 \% \mathrm{OsO}_{4}$ in the same buffer. The samples were then dehydrated through a graded series of ethanol solutions and propylene oxide. Finally, the samples were embedded in polybed 812 plastics. Thin sections were cut with a LKB ultratome and stained with $0.5 \%$ toluidine blue. 
APPENDIX C 
Appendix C

Appendix C

\section{Quality Assurance and Quality Control}

This section details the monitoring, sampling, storage, analyses and calibration procedures established to assure and control the quality of analytical measurements. These procedures were used for the batch kinetics experiments and the laboratory bench-scale UASB reactors. Unless specified here, the QA/QC plan follows the recommendations given in the Radian Corporation document: "Guidelines for the Preparation of GRI Quality Assurance Project Plans" (August 1990).

\section{C-1. Monitoring and sample recording during laboratory bench-scale UASB reactor operation}

Critical reactor components and parameters were monitored and recorded daily. The Daily Monitoring Sheet was filled out during each monitoring check. A Daily Monitoring Sheet used for the laboratory bench-scale UASB reactor is attached (Appendix C4). During unsteady state perturbation experiments, a separate monitoring sheet was used(Appendix C4). Gas phase sample data were available through an on-line data acquisition system equipped with a personal computer(386). Separate files were created twice a week. Data was in general monitored hourly. The Daily Monitoring Sheet along with the gas monitoring file served as the official record of the conditions in a reactor on any given day of an experiment. The sheet also served as the official record of some directly measured parameters, mineral media and feed preparation, changes made in reactor parameters, problems encountered and samples collected. A generic list of the information recorded on Daily Monitoring Sheet is presented in Table C-1. 
Appendix C

Table C-1. List of information recorded on Daily Monitoring Sheets

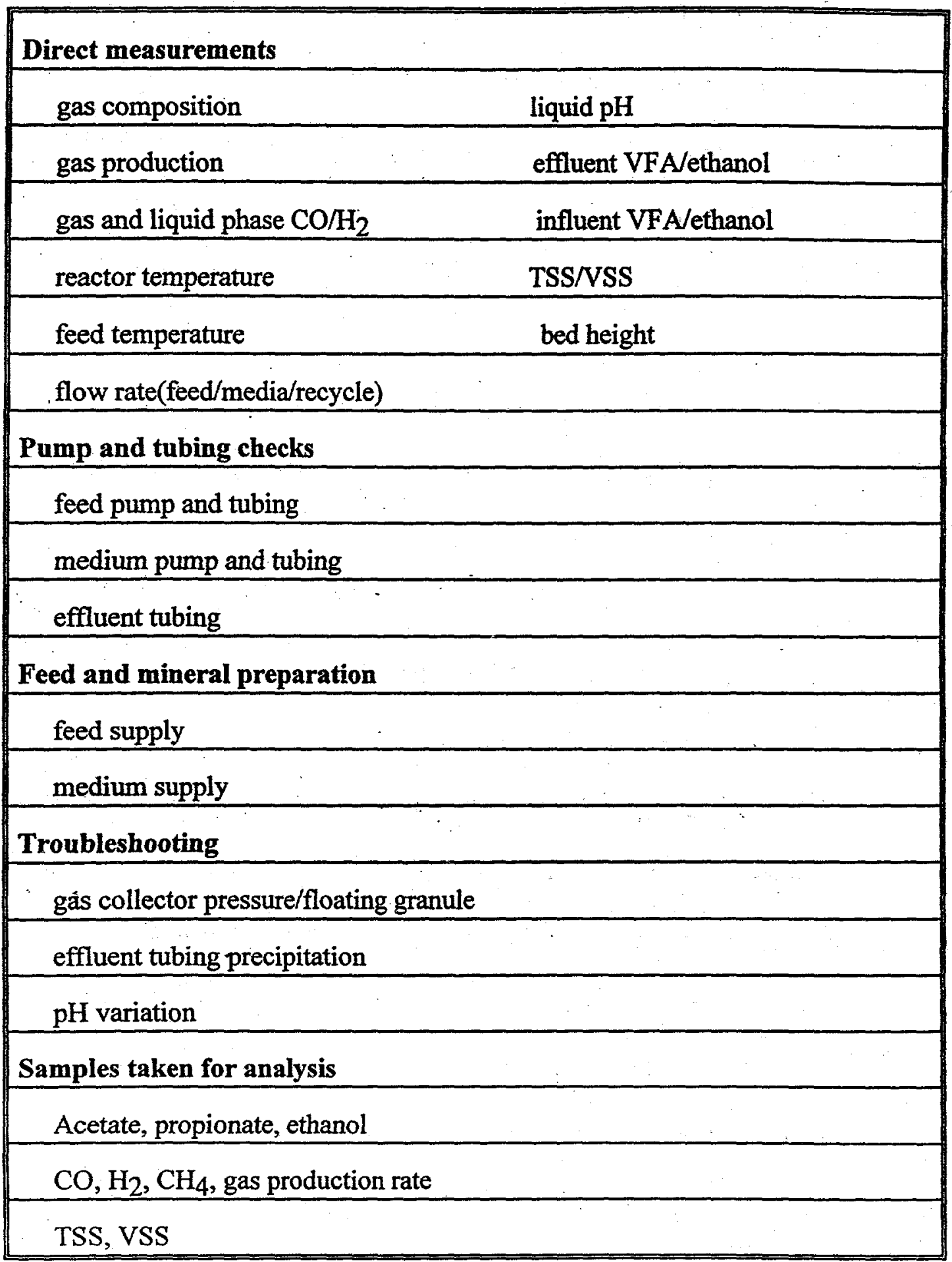


Appendix C

Gas phase monitoring and analysis records were stored in the "History File" of Paragon data acquisition package. Data in the file was transferred and rearranged biweekly into a "Lotus 1-2-3" working file via a W00 file. The records were stored on a hard disk and backup copies were maintained on floppy disks. The bi-weekly data files were combined through the Excel spread sheet weekly. Gas production rate computation was conducted and gas phase monitoring variables $\left(\mathrm{H}_{2} \mathrm{CO}, \mathrm{CH}_{4}\right.$ and gas production) plotted with time for further analysis.

\section{C-2. Sampling, storage, analysis and calibration}

A summary of the various analyses performed and the methods employed are presented in Table C-2.

\section{C-2.1 VFAs, ethanol and n-propanol}

\section{C-2.11 Sampling and storage}

The laboratory bench-scale UASB reactor and Multigen bench top reactor samples were taken with a $5 \mathrm{ml}$ polyethylene syringe which has been flushed with reactor fluid prior to sampling. The samples were slowly withdrawn into the syringe to avoid any gas bubbles from forming in the solution. Samples were collected, transferred into $1.5 \mathrm{ml}$ eppendorf tubes and centrifuged at $12000 \mathrm{rpm}$ in an eppendorf centrifuge(Brinkmann model 5415) for 2 minutes. A $0.8 \mathrm{ml}$ aliquot of supernatant was then collected using a pipette and acidified with $0.3 \mathrm{M}$ oxalic acid at a ratio of $1 / 10$ (acid/sample) in a $1.2 \mathrm{ml}$ auto sampler crimp vial. 
Appendix C

Table C-2. Analytical methods for samples from laboratory bench-scale UASB and batch experiments

\begin{tabular}{|l|l|}
\hline Parameter & Method \\
\hline VFAs/ethanol,propanol & Gas Chromatography with packed column/FID \\
\hline $\mathrm{CO} / \mathrm{H}_{2}$ & $\begin{array}{l}\text { Reduction Gas Detection using a Hg reaction bed } \\
\text { and photo diode detector }\end{array}$ \\
\hline $\mathrm{CH}_{4}$ & Infra red gas analyzer \\
\hline Gas production & liquid displacement/ conductivity \\
\hline TSS & dry at $105^{\circ} \mathrm{C}{ }^{*}$ \\
\hline TS & evaporate at $60^{\circ} \mathrm{C}$, dry at $105^{\circ} \mathrm{C} *$ \\
\hline VSS & ignition at $550^{\circ} \mathrm{C}^{*}$ \\
\hline VS & ignition at $550^{\circ} \mathrm{C}^{*}$ \\
\hline
\end{tabular}

* in accordance with Standard Methods [16th ed.]

Finally, the samples were sealed with a Teflon liner and aluminum crimp. The sample vials were either immediately analyzed or stored at $0^{\circ} \mathrm{C}$. Stored samples were all analyzed within one week.

\section{C-2.12 Analysis and calibration}

Liquid samples were analyzed for VFA with a HP 5890 Gas Chromatograph, equipped with a packed column, FID, and HP7673A automator injector. Separation was accomplished using a 4\% Carbowax organic phase on a 80/120 carbopac P column, ID $2 \mathrm{~mm}, 2 \mathrm{~m}$ in length(Supelco). $\mathrm{N}_{2}$ was used as the carrier gas $(16-20 \mathrm{ml} / \mathrm{min})$. Column 
Appendix C

temperature was programmed for better peak separation. Three different

programs(working files $5,7,8$ ) were used for sample analysis according to the

concentration range and species of interest. Analysis conditions are listed in Table C-3.

Standard calibration curves were made using an internal standard method. Propionate was selected as an internal standard for acetate calibration.

Eight levels of acetate standard concentrations, ranging from 0.1 to $20 \mathrm{mM}$, were used for calibration using both work file 7 and 8 , and were compared for linearity at low range and high range(Figure $\mathrm{C}-1$ and $\mathrm{C}-2$ ). Standard concentrations of acetate at $0.01-0.05$ $\mathrm{mM}$ were used for calibration with work file 5 . Linearity did not exist for work file 7 at concentrations lower than $1 \mathrm{mM}$ (Figure $\mathrm{C}$-1). It was determined that the conditions in work file 8 were better for accurately quantifying low concentrations $(0.1-1 \mathrm{mM})$ of acetate, work file 7 was best for the high concentration range $(>1 \mathrm{mM})$ and work file 5

Table C-3. GC operational conditions for VFAs analysis

\begin{tabular}{|ll|l|l|l|}
\hline Parameters & work file 7 & work file 8 & work file 5 \\
\hline Gas flow rate $\quad \mathrm{N}_{2}$ & $16-20 \mathrm{ml} / \mathrm{min}$ & $16-20 \mathrm{ml} / \mathrm{min}$ & $16-20 \mathrm{ml} / \mathrm{min}$ \\
& $\mathrm{H}_{2}$ & $30 \mathrm{ml} / \mathrm{min}$ & $30 \mathrm{ml} / \mathrm{min}$ & $30 \mathrm{ml} / \mathrm{min}$ \\
air & $300 \mathrm{ml} / \mathrm{min}$ & $300 \mathrm{ml} / \mathrm{min}$ & $300 \mathrm{ml} / \mathrm{min}$ \\
column head pressure & $50 \mathrm{psi}$ & $50 \mathrm{psi}$ & $50 \mathrm{psi}$ \\
Temperature & & & \\
injection port & $200^{\circ} \mathrm{C}$ & $190^{\circ} \mathrm{C}$ & $190^{\circ} \mathrm{C}$ \\
column & $175^{\circ} \mathrm{C}$ & $140-220^{\circ} \mathrm{C}$, & $140^{\circ} \mathrm{C}$ \\
detector & $200^{\circ} \mathrm{C}$ & $220^{\circ} \mathrm{C}$ & $220^{\circ} \mathrm{C}$ \\
\hline
\end{tabular}


Appendix C

for micromolar level quantitation. Since the response of propionate, butyrate and isobutyrate were proportional to acetate under the conditions used, butyrate and propionate standards were made together with acetate, at $5 \mathrm{mM}$ for each component. The acetate, propionate, and butyrate standard was analyzed along with samples to check any change in response scale. Adjustment was made as required. Sample concentration was calculated based on the standard curve. The detection limit for acetate was $4 \mathrm{~mm}, 0.1 \mathrm{mM}$ and $1 \mathrm{mM}$ using work files 5,8 and 7 , respectively. Propionate, iso-butyrate and butyrate detection limits were $0.1 \mathrm{mM}, 0.1 \mathrm{mM}$ and $0.1 \mathrm{mM}$ with work file 8 . Standard curves for 2-methyl-butyrate, n-valerate, iso-valerate were made separately, as external standards. These acids were analyzed using work file 8 . Detection limits were $0.04 \mathrm{mM}, 0.3 \mathrm{mM}$ and $0.1 \mathrm{mM}$ for 2-methyl-butyrate, $\mathrm{n}$-valerate and iso-valerate, respectively. The VFA standard was fixed with $0.3 \mathrm{M}$ oxalic acid at $1 / 10$ (acid/standard), prepared once a month and stored at $0^{\circ} \mathrm{C}$ when not in use.

Ethanol and n-propanol standards(external standards), were prepared without acidification. The ethanol standard was made once a month and stored at $0^{\circ} \mathrm{C}$. Ethanol and n-propanol were analyzed using work file 8 . The detection limit for ethanol was 0.01 $\mathrm{mM}$ and for n-propanol it was $0.05 \mathrm{mM}$.

\section{C-2.2 Formate}

\section{C-2.21 Sampling, analysis and calibration}

Formate was analyzed for enzymatically using formate dehydrogenase. Formate dehydrogenase have the following reaction when NAD is present using formate as 
Appendix C

substrate:

$$
\mathrm{HCOO}^{-}+\mathrm{NAD}^{+}+\mathrm{H}_{2} \rightarrow \mathrm{HCO}_{3}^{-}+\mathrm{NADH}+\mathrm{H}^{+}
$$

The amount of $\mathrm{NADH}$, as measured by the extinction change at $365 \mathrm{~nm}$, is proportional to the amount of formate present. The extinction change was measured using a spectrophotometer(UV160,Shimadzu). The proportionality factor was determined by standardization of the assay with formate standards. The maximum value of the extinction-time curve was recorded. Both standard and samples were adjusted with blanks(without NAD). Sample formate concentration was determined using the standard curve. Samples were first adjusted to $\mathrm{pH}$ of 7.0-7.5 using $1 \mathrm{~N} \mathrm{NaOH}$. Details of the procedure were conducted according to "Methods of enzymatic analysis"[ Bergmeyer,H.R.].

\section{C-2.3 Gas phase analysis}

\section{C-2.31 Gas sampling loop and instrumentation}

Gas phase $\mathrm{CO}, \mathrm{H}_{2}, \mathrm{CH}_{4}$ and gas production from bench-scale UASB were sampled and analyzed on-line. Gas samples were collected from a gas loop connected to reactor head space $(200 \mathrm{ml})$. To remove moisture in gas stream, a condenser was placed at the top of the reactor prior to where the gas entered the gas loop, to dry the gas and prevent condensation in the gas loop itself. The reactor gas loop set-up is presented in Figure VIII-1.

The gas stream was pumped at a flow rate of $0.5 \mathrm{~L} / \mathrm{min}$ continuously into an infrared Methane Analyzer(ADC SB100) for on-line quantitation. Gas produced was 
Appendix C

collected into a three-way valve. The valve also connected to a gas meter(house made by MBI) and a exhaust pipe. Gas produced was continuously forwarded through the gas meter and then vented out of the system.

Gas samples were introduced into a trace gas analyzer(RGA3) for $\mathrm{CO}$ and $\mathrm{H}_{2}$ analysis from reactor head space via automated actuated gas sampling valves. A 10-port, in-line gas sampling valve was connected to a trace gas loop ( $250 \mathrm{ml}$, within the instrument) that reactor headspace was continuously pumped through. During load position, trace gas loop is separated from column. Carrier gas $\mathrm{N}_{2}$ flow in column is reversed. The components remaining in column are back flushed to vent with the carrier gas. In the inject position, trace gas sample loop and column are connected in series. CO and $\mathrm{H}_{2}$ are allowed to elute from column to detector. Sample inlet and outlet lines were shorted in order to provide continuity of sample flow.

\section{C-2.32 $\mathrm{CO}$ and $\mathrm{H}_{2}$ analysis and calibration}

Sample components of interest $\left(\mathrm{H}_{2}\right.$ and $\mathrm{CO}$ )were separated chromatographically within an isothermal mandrel-heated column oven in a Reduced Gas Analyzer(RGA3, Trace Analytical) and quantitated by a reduced gas detection method. Species eluting from the chromatographic column pass immediately into the detector which contains a heated bed of mercuric oxide. The following reduction reaction occurs:

$$
\mathrm{HgO}_{2}+\mathrm{X} \rightarrow \mathrm{XO}+\mathrm{Hg}(\mathrm{v})
$$

where $\mathrm{X}$ is the reduced gas species. The mercury vapor produced by the reaction is quantitated by a ultraviolet photo diode. The detection limits for $\mathrm{H}_{2}$ and $\mathrm{CO}$ were $40 \mathrm{ppb}$ and $4.0 \mathrm{ppb}$, respectively. A spherocarb 60/80 packed column was used in Reduced Gas Analyzer(RGA3, and RGA2). Operational conditions are presented in Table C-4. 
Appendix C

Data analysis was performed automatically by the integrator/controller module(ICM) in the RGA3. The ICM consisted of a single board computer. It was programmed for complete operation, including sample collection(timed events), zeroing, detector signal noise filtering, peak detection and integration, components identification, calibration and self-testing. The operation of ICM was monitored by the program in the host computer through the Opto-22 analog/digital interface board. ICM program set-up for $\mathrm{CO}$ and $\mathrm{H}_{2}$ used in the study is shown in Table C-5.

Table C-4. Reduced Gas Analyzer operating conditions

\begin{tabular}{|l|l|}
\hline Column temperature & $90^{\circ} \mathrm{C}$ \\
Detector temperature & $265^{\circ} \mathrm{C}$ \\
Carrier gas flow rate & $16 \pm 0.5 \mathrm{ml} / \mathrm{min}$ \\
Sample volume & $250 \mathrm{~mL}$ \\
Injection time & $70 \mathrm{~s}$ \\
Backflush time & $19 \mathrm{~min}-55 \mathrm{~min}$ \\
$\mathrm{~N}_{2}$ gas pressure & $30 \mathrm{psig}$ \\
Air pressure & $25 \mathrm{psig}$ \\
\hline
\end{tabular}

Trace gas $\mathrm{H}_{2}$ and $\mathrm{CO}$ calibration was conducted using the ICM with $10.4 \mathrm{ppm}$ $\mathrm{CO}$ (in $\mathrm{N}_{2}$, Specialty Gas) and 50.3 and $95.2 \mathrm{ppm} \mathrm{H}_{2}$ (in $\mathrm{N}_{2}$, Specialty Gas).

For kinetic assays, $\mathrm{H}_{2}$ and $\mathrm{CO}$ were determined on a RGA2 gas chromatograph with a RGD2 reduced gas detector. The operation conditions were $90^{\circ} \mathrm{C}$ for the column and $265^{\circ} \mathrm{C}$ for the detector. Backflush time was set at four minutes using a timer(Eagle Signal). Carrier gas $\left(\mathrm{N}_{2}\right)$ flow conditions were same as RGA3. Calibration was made by inject $1 \mathrm{ml}$ aliquots of $101 \mathrm{ppm}$ and $50.3 \mathrm{ppm} \mathrm{H}_{2}$ standard(in $\mathrm{N}_{2}$, Specialty Gas), and $1 \mathrm{ml}$ aliquots of $10.2 \mathrm{ppm}$ and $5.37 \mathrm{ppm} \mathrm{CO}$ standard(in $\mathrm{N}_{2}$, Specialty Gas). All sample $\mathrm{H}_{2}$ and 
Appendix C

CO concentrations were calculated from a standard response(peak heights) factor calculated from the standard injections. Standards were injected with every batch of samples. The detection limit of RGD2 were $3.8 \mathrm{ppm}$ and $0.5 \mathrm{ppm}$, for $\mathrm{H}_{2}$ and $\mathrm{CO}$, respectively. 
Appendix C

Table C-5. ICM parameters programming

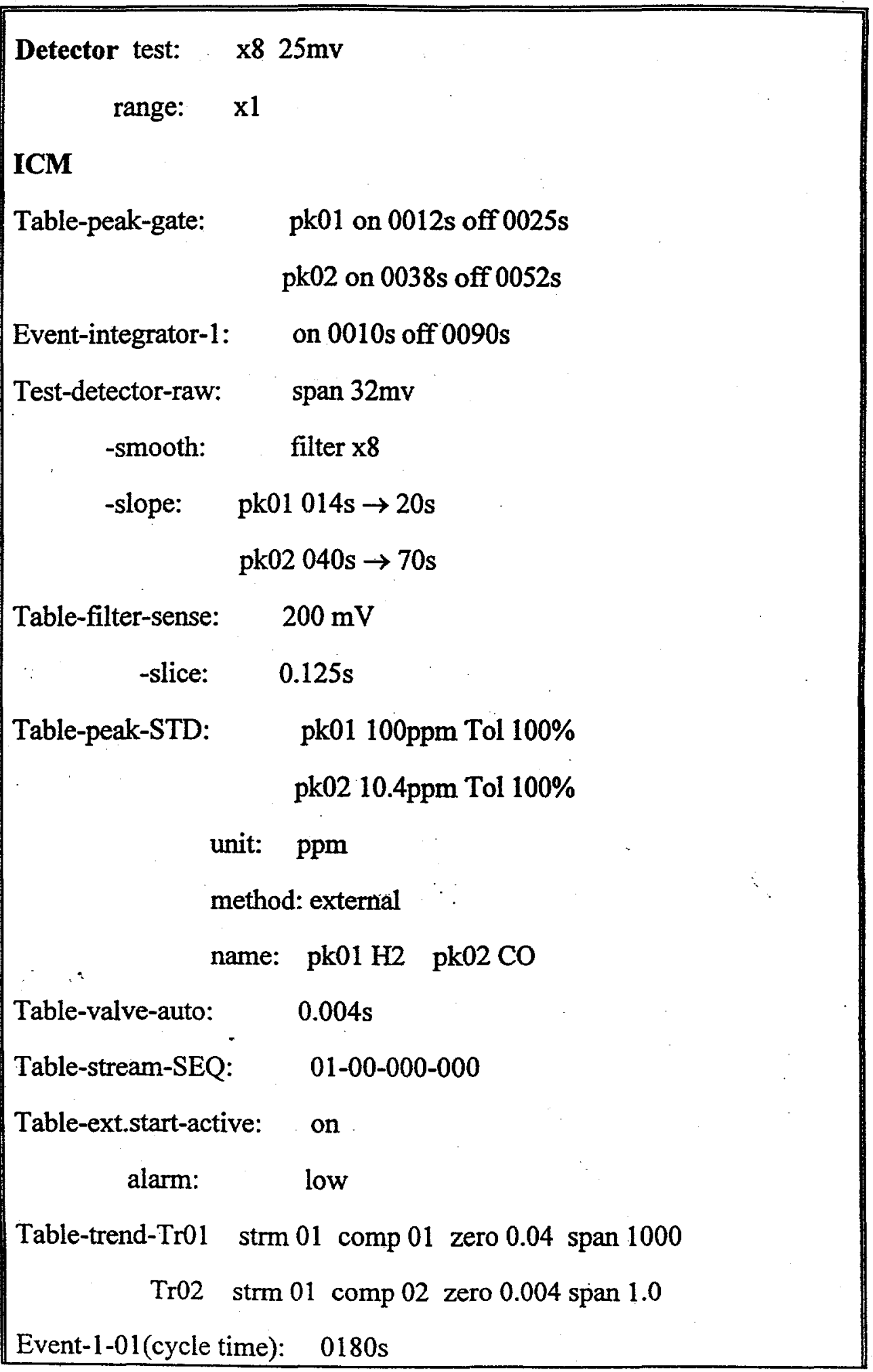


Appendix C

Table 5-C. (Cont'd)

\begin{tabular}{ll|}
$1-02$ (step time): $0001 \mathrm{~s}$ \\
$1-03$ (process data): & $0170 \mathrm{~s}$ \\
$1-04$ (integrator on): & $0014 \mathrm{~s}$ \\
$1-05$ (integrator off): & $0090 \mathrm{~s}$ \\
$1-10$ (zero): & $0001 \mathrm{~s}$ \\
$1-13$ (filter on): & $0001 \mathrm{~s}$ \\
\hline
\end{tabular}

\section{C-2.33 Dissolved $\mathrm{H}_{2}$ and $\mathrm{CO}$}

C-2.331 Sampling and storage

Liquid samples $(10 \mathrm{ml})$ were taken from bench UASB reactor using a $10 \mathrm{ml}$ syringe. The samples were injected into $58 \mathrm{ml}$ anaerobic sterilized serum bottle sealed with a rubber stopper and aluminum crimp. Bottles were then brought into equilibrium in a water shaker(American Scientific YB-521) at $37^{\circ} \mathrm{C}$ at setting 8 for 5 minutes. $\mathrm{NaOH}$ was placed in the bottle to obtain a final concentration of $0.5 \mathrm{~N}$. Dissolved $\mathrm{H}_{2}$ and $\mathrm{CO}$ were analyzed immediately.

\section{C-2.332 Analyses and Calibration}

Dissolved $\mathrm{H}_{2}$ and $\mathrm{CO}$ were measured by injecting $1 \mathrm{ml}$ serum bottle headspace sample into a reduced gas analyzer(RGA2 and RGD2). GC conditions were exactly same as described in sectionC2-3.2. Background sample of the serum bottles were taken. 
Appendix C

Replicate injections were made for each sample. All sample $\mathrm{H}_{2}$ and $\mathrm{CO}$ concentrations were calculated from a standard response(peak heights) factor calculated from the standard injections. Standards were injected with every batch of samples. Detailed protocol for dissolved $\mathrm{H}_{2}$ and $\mathrm{CO}$ analyses refer to Appendix B5-2.

\section{C-2.34 $\quad \mathrm{CH}_{4}$}

C-2.341 Sampling, Storage, Analyses and Calibration

The gaseous sample in the bench UASB reactor flowed continuously through the analysis cell of the instrument(ADC), which is situated between a hot wire source and the infra red(IR) detector. Methane absorbs energy from the IR source and reduces the amount reaching the detector. Output signal from the detector was collected, and stored in the Paragon program of the host computer. Calibration and zeroing were performed weekly. The zero was adjusted separately at power off(mechanical adjustment) and power on using air. The span was adjusted with $99.9 \% \mathrm{CH}_{4}$ standard gas at flow rate of $0.5 \mathrm{~L} / \mathrm{min}$ for 15 minutes after warming up the instrument.

For kinetic assays, methane was determined by a gas chromatograph using manual injection. Gas sample was collected from the Multigen reactor headspace and injected $0.1 \mathrm{ml}$ aliquots into the $\mathrm{GC}$ immediately. Two aliquots were injected and averaged. The GC used was a Hewlett-Packard 5890 with a flame ionization detector. Saparation was accomplished with a Supelco Inc. VOCAL capillary column $(30 \mathrm{~m}, 0.53 \mathrm{mmID}$, $3.0 \mathrm{mmfilm}$ ). $\mathrm{GC}$ conditions were: Oven $45^{\circ} \mathrm{C}$, Detector $200^{\circ} \mathrm{C}$, Injector $150^{\circ} \mathrm{C}$. Calibration was made by injecting $0.1 \mathrm{ml}$ aliquots of $99.99 \%$ methane standard gas(AGA, spectialty). All sample methane concentrations were determined based on standard response(peak area) factor calculated from the standard injections. Standards were injected with every batch of samples. 
Appendix C

\section{C-2.35 Gas production}

Gas volume produced in the reactor was measured by means of liquid displacement and change of conductivity. A three-way valve was connected to the reactor head space, the gas meter, and an exhaust part. The gas produced depressed the liquid level in the gas meter(Figure C-3, positionl) from first to second electrode until the volume between the two electrodes was completely displaced replaced by the gas (position2). The change of conductivity(from water to gas) was then transmitted into a digital signal to a counter. The gas count was recorded and stored in the Paragon. The three-way valve was then actuated and the "packet" of gas vented(position2). The valve was immediately placed back to the original position while the liquid level in the gas meter returned to the first electrode level(position1).

The gas meter was calibrated by injecting air through the gas meter using a $15 \mathrm{ml}$ syringe. The gas counts and volume injected were recorded. Five to ten injections were made to obtain an averaged gas volume per count for calculation of gas production. The calibration was made every six months. Liquid level of gas meter reservoir was filled every 2 months. Gas meter electrodes were cleaned with $0.3 \mathrm{M}$ oxalic acid solution every 2 months to remove any biofilm build . 
Appendix C

$\mathrm{C}-2.36 \quad \mathrm{CO}_{2}$

C-2.361 Sampling and storage

Gas samples $(0.6 \mathrm{ml})$ were taken in $1.0 \mathrm{ml}$ gas tight syringe from the Multigen reactor headspace. Samples were taken directly to the gas chromatograph for immediate analyses.

\section{C-2.362 Analyses and Calibration}

Carbon dioxide were measured by injecting Multigen reactor headspace samples into the gas chromatograph. The GC used was a GOW-MAC series 580 with a TCD. Separation was accomplished with a Supelco, Inc. carbosphere 80/100 packed column(1/8 in S.S., $6 \mathrm{ft}) . \mathrm{GC}$ conditions were: Injector $100^{\circ} \mathrm{C}$, Detector $150^{\circ} \mathrm{C}$, Oven $150^{\circ} \mathrm{C}$

Calibration was made by injecting $0.6 \mathrm{ml}$ aliquots of $20 \% \mathrm{CO}_{2} / 80 \% \mathrm{~N}_{2}$ (AGA, specialty). The calculated response(peak area) factor was used to calculate all concentrations. Standards were injected with every batch of samples.

\section{C-2.4. Total Suspended Solids(TSS) and Volatile Suspended Solids(VSS)}

\section{C-2.41 Sampling and storage}

Effluent samples from the laboratory bench-scale UASB reactor were withdrawn from the effluent port continuously over 20-24 hours to provide a time-integrated sample. The effluent flow was collected in a $2 \mathrm{~L}$ cylinder. Since occasionally some floating granules escaped from the reactor bed into the effluent (which may interfere with the 
Appendix C

suspended solids measurement), any granules settled in the bottom of the cylinder were

removed. For analyses, $50 \mathrm{ml}$ mixed aliquots were filtered in a vacuum filter through 4.5 cm Whatman 934 AH glass fiber filter paper.

\section{C-2.42 Analysis}

Filters were dried at $105^{\circ} \mathrm{C}$ overnight for TSS, ignited at $550^{\circ} \mathrm{C}$ for VSS, using an aluminum dish, and weighed as described in section 209C\&D of Standard Methods $[1985$ ]. All weights and volumes were recorded on a Solids Data Sheet(attached Appendix C4.)

Blank filters were prepared prior to sample analysis. For blanks, $50 \mathrm{ml}$ deionized distilled water was filtered, dried, ignited according to the same procedure as for the samples. The blanks were stored in a vacuum dessicator. Blanks were weighed prior to sample filtering.

\section{C-2.5. Total Solids(TS) and Volatile Solids(VS) for granules}

\section{C-2.51 Sampling and storage}

Granular sludge samples were collected from the laboratory bench-scale UASB reactor through the bed discharge port. The granule samples from the Multigen reactor was collected using a $3 \mathrm{ml}$ syringe connected to a piece of $1.6 \mathrm{~mm}$ ID Teflon tubing. Samples were settled in a $25 \mathrm{ml}$ glass cylinder covered with parafilm for 20-30 minutes. Solids volume was then recorded. Samples were transferred into preweighed porcelain crucibles for analysis. 
Appendix C

C-2.52 Analysis

The samples were evaporated in a $60^{\circ} \mathrm{C}$ oven overnight and dried at $105^{\circ} \mathrm{C}$ for one hour and then weighed for total solids analysis. Volatile Solids(VS) were determined after ignition at $550^{\circ} \mathrm{C}$ for one hour, as described in Standard Method, section 209C\&D[1985]. All weights and volumes were recorded.

Blanks were prepared in the same way as described for samples. After drying, ignition and cooling, blank crucibles were stored in a vacuum dessicator. Blanks were weighed prior to sample collection.

\section{C-2.6 Lithium}

\section{C-2.61 Sampling and storage}

Lithium samples of $5 \mathrm{ml}$ were collected from the sampling port of the bench UASB reactor, filtered through a $0.2 \mu \mathrm{m}$ syringe filter, and transferred into a $10 \mathrm{ml}$ glass tube. The samples were stored at $0^{\circ} \mathrm{C}$. Stored samples were all analyzed within one week.

\section{C-2.62 Analysis and calibration}

Lithium concentration was determined by Flame Emission Spectroscopy. The FES used was a Spectra AA-20 Plus using air-acetylene. Analyses conditions were: wavelength $670.8 \mathrm{~nm}$, slit width $1.0 \mathrm{~nm}$. A series dilutions of five standards were made. Triplets were injected into the FE for each standard concentration. Results were averaged to obtain a standard curve. Samples were injected into the FES and the concentrations were calculated according to the standard curve. Standards were injected with every batch 
Appendix C

of samples. Ion Chromatography was also used in determining Lithuim concentration during the organic and hydraulic flux effect experiment(Chapter V B). The IC used was a Dionex, model 2000) equipped with a conductivity detector. Calibration was performed using the same method described above.

\section{C-3. Data sheets}

The data sheets for steady state daily monitoring and unsteady state monitoring are presented as Table C-6 to 7, respectively. 


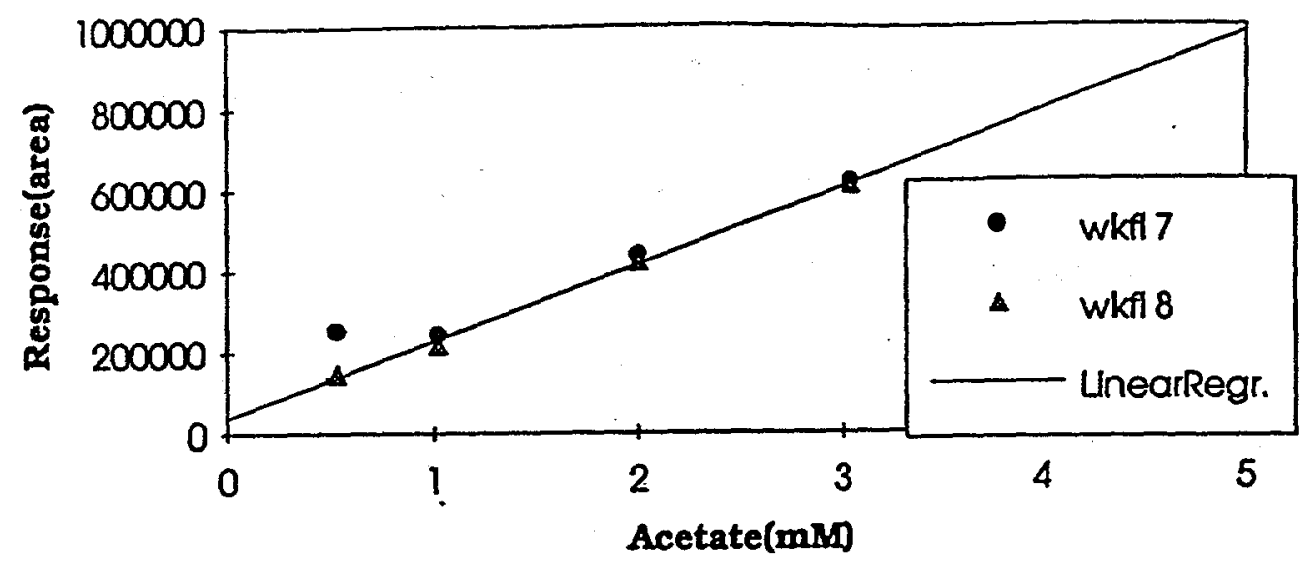

Figure C-1. Response of work file 7 and 8 to low concentration of acetate

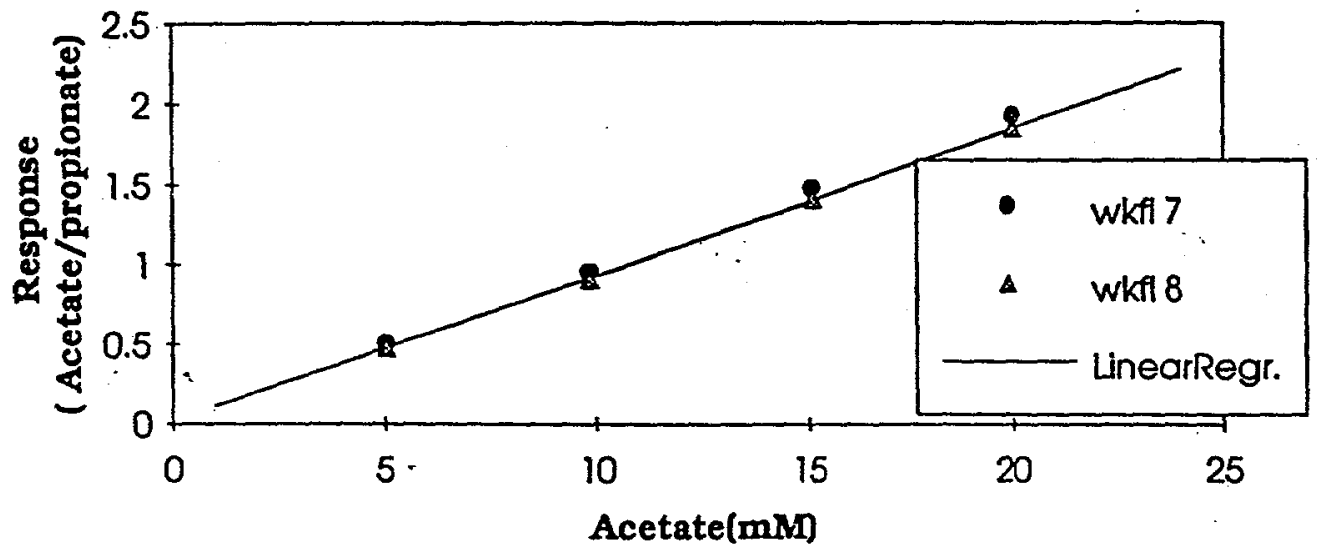

Figure $\mathrm{C}-2$. Response of work file 7 and 8 to high concentration of acetate 


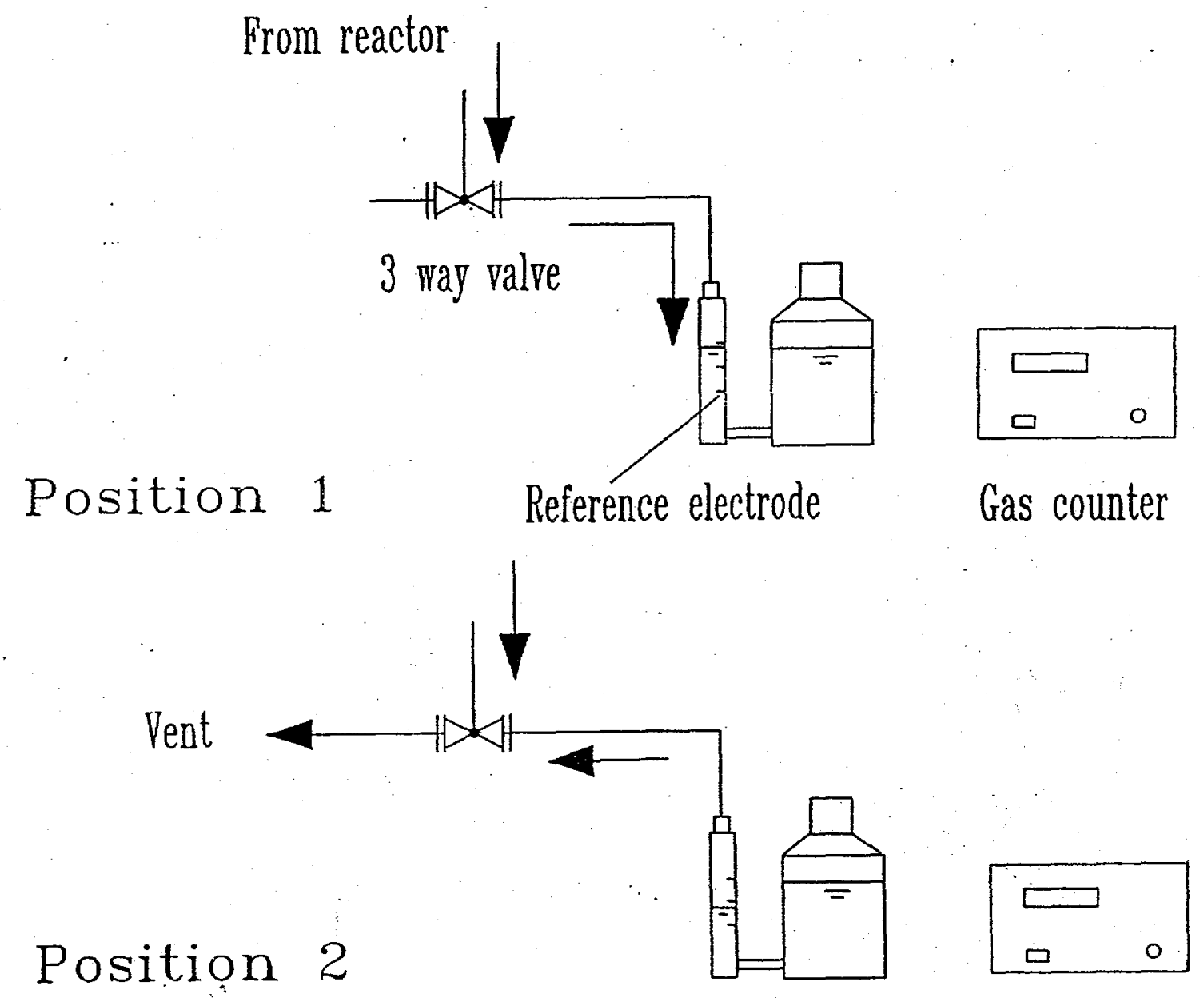

Figure $\mathrm{C}-3$. Schematic diaghram of on-line gas volume measurement 
Table C-6. pseudo-steady state daily monitoring sheet

\begin{tabular}{|c|c|c|c|c|c|c|c|c|}
\hline PARAMIETER & $\begin{array}{l}\text { FREQUENCY } \\
\text { OF MEASUR- } \\
\text { MENT }\end{array}$ & MON & TUE & WED & THUR & ERI & SAT & SUN \\
\hline \multicolumn{9}{|l|}{ Date } \\
\hline \multicolumn{9}{|l|}{ Time } \\
\hline pH (ML.L.) & daily & & & & & & & \\
\hline Eff. (ml) & daily & & & & & & & \\
\hline Bed (ml) & daily & & & & & & & \\
\hline Flow rate (ml/d) & daily & & & & & & & \\
\hline \multicolumn{9}{|l|}{ hange carbouy(M/E) } \\
\hline \multicolumn{9}{|l|}{ Inf. Act. (mM) } \\
\hline \multicolumn{9}{|l|}{ Prop. (mM) } \\
\hline \multicolumn{9}{|l|}{ Ethanol (mM) } \\
\hline \multicolumn{9}{|l|}{ Gluc. (mM) } \\
\hline \multicolumn{9}{|l|}{ Eff. $\quad$ Tss (mg/) } \\
\hline \multicolumn{9}{|l|}{ Vss (mg/l) } \\
\hline CODs (mg/1) & weekly & & & & & & & \\
\hline Eff. Act. (mM) & daily & & & & & & & \\
\hline Prop. (mM) & daily & & & & & & & \\
\hline \multicolumn{9}{|l|}{$\mathrm{H}_{2}(\mathrm{mM})$} \\
\hline \multicolumn{9}{|l|}{$\mathrm{CO}(\mathrm{mM})$} \\
\hline \multicolumn{9}{|l|}{ Feed level(L) } \\
\hline Gas meter reading & daily & & & & & & & \\
\hline Total gas $(\mathrm{ct} / \mathrm{h})$ & daily & & & & & & & \\
\hline $\mathrm{CH} 4(\%)$ & daily & & & & & & & \\
\hline $\mathrm{H}_{2}$ (ppm) & daily & & & & & & & \\
\hline CO (ppm) & daily & & & & & & & \\
\hline Recyc. pump'reading & daily & & & & & & & \\
\hline eed pump reading & daily & & & & & & & \\
\hline Feed tubing check & daily & & & & & & & \\
\hline Med.pump reading & daily & & & & & & & \\
\hline Med.tubing check & daily & & & & & & & \\
\hline Temp. heater (oC) & daily & & & & & & & \\
\hline remp. cooler (oC) & daily & & & & & & & \\
\hline Effluent tubing & daily & & & & & & & \\
\hline Note & & & & & .. & & & \\
\hline
\end{tabular}


Table C-7. Unsteady state monitoring sheet

\begin{tabular}{|c|c|c|c|c|c|c|c|c|}
\hline Time/date & \# & $\mathrm{pH}$ & $\mathrm{CH} 4(\%)$ & gusmeter & VFA & COD & initial & Nore \\
\hline & & & & & & & & \\
\hline & & & & & & & & \\
\hline & & & & & & & & \\
\hline & & & & & & & & \\
\hline & & & & & & & & \\
\hline & & & & & & & & \\
\hline & & & & & & & & \\
\hline & & & & & & & & \\
\hline & & & & & & & & \\
\hline & & & & & & & & \\
\hline & & & $\ldots$ & & & & & \\
\hline & & & & & & & & \\
\hline & & & & & & & & \\
\hline & & & & & & & & \\
\hline & & & & & & & & \\
\hline & & & & & & & & \\
\hline & & & & & & & & \\
\hline & & & & & & & & \\
\hline & & & & & & & & \\
\hline & & & & & & & & \\
\hline & & & & & & & & \\
\hline & & & & & & & & \\
\hline & & & & & & & & \\
\hline & & & & & & & & \\
\hline
\end{tabular}


APPENDIX D 
Appendix D

Determination of Monod Kinetic Constants $k_{m}$ and $K_{s}$ by Nonlinear Least Square Method

\section{D-1. Differential form.}

The differential form of Monod equation is given by

$$
v=f(s)=\frac{1}{x} \frac{d s}{d t}=-\frac{k_{m} s}{K_{s}+s}
$$

where $s$ is substrate in $\mathrm{g} / \mathrm{l}, x$ is biomass in $\mathrm{g}, v$ is uptake rate in $\mathrm{g} / \mathrm{g} x-\mathrm{d}, k_{m}$ is the maximum uptake rate in $\mathrm{g} / \mathrm{g} x-\mathrm{d}, s_{i}, v_{i}$ are measured data, $f\left(s_{i}\right)$ is the estimated uptake rate at $s_{i}$ as determined using equation (1). The residual sum of square $S S$ is defined by

$$
S S=\sum_{i=1}^{n}\left(v_{i}-f\left(s_{i}\right)\right)^{2} .
$$

The derivative of $f$ and $S S$ become

$$
\begin{aligned}
& \frac{\partial f}{\partial k_{m}}=\frac{s}{K_{s}+s} \\
& \frac{\partial f}{\partial K_{s}}=-\frac{k_{m} s}{\left(K_{s}+s\right)^{2}} \\
& \frac{\partial S S}{\partial k_{m}}=-\sum_{i=1}^{n} 2\left(v_{i}-f\left(s_{i}\right)\right) \frac{\partial f\left(s_{i}\right)}{\partial k_{m}} \\
& \frac{\partial S S}{\partial K_{s}}=-\sum_{i=1}^{n} 2\left(v_{i}-f\left(s_{i}\right)\right) \frac{\partial f\left(s_{i}\right)}{\partial K_{s}}
\end{aligned}
$$

Setting $\frac{\partial S S}{\partial k_{m}}=0$ and $\frac{\partial S S}{\partial K_{s}}=0$, we see from (3c) and (3d) that

$$
\begin{aligned}
& \sum_{i=1}^{n}\left(v_{i}-\frac{k_{m} s_{i}}{K_{s}+s_{i}}\right) \frac{s_{i}}{K_{s}+s_{i}}=0, \\
& \sum_{i=1}^{n}\left(v_{i}-\frac{k_{m} s_{i}}{\left(K_{s}+s_{i}\right)^{2}}\right) \frac{s_{i}}{K_{s}+s_{i}}=0 .
\end{aligned}
$$


Hence

$$
\begin{aligned}
\sum_{i=1}^{n} \frac{v_{i} s_{i}}{K_{s}+s_{i}} & =\sum_{i=1}^{n} \frac{k_{m} s_{i}^{2}}{\left(K_{s}+s_{i}\right)^{2}}, \\
\sum_{i=1}^{n} \frac{v_{i} s_{i}}{\left(K_{s}+s_{i}\right)^{2}} & =\sum_{i=1}^{n} \frac{k_{m} s_{i}^{2}}{\left(K_{s}+s_{i}\right)^{3}} .
\end{aligned}
$$

Define $S(1), S(2), S(3)$ and $S(4)$ by

$$
\begin{gathered}
S(1)=\sum_{i=1}^{n} \frac{v_{i} s_{i}}{K_{s}+s_{i}}, \quad S(2)=\sum_{i=1}^{n} \frac{s_{i}^{2}}{\left(K_{s}+s_{i}\right)^{3}}, \quad \text { and } \\
S(3)=\sum_{i=1}^{n} \frac{v_{i} s_{i}}{\left(K_{s}+s_{i}\right)^{2}}, \quad S(4)=\sum_{i=1}^{n} \frac{s_{i}^{2}}{\left(K_{s}+s_{i}\right)^{2}} .
\end{gathered}
$$

Then in terms of $S(i), i=1, \ldots, 4$, the solution for $k_{m}$ using equations (5a) and (5b) can be written as either

$$
k_{m}=S(1) / S(4) \quad \text { or } \quad k_{m}=S(3) / S(2)
$$

This implies that $S(1) S(2)=S(3) S(4)$, or equivalently,

$$
\sum_{i=1}^{n} \frac{v_{i} s_{i}}{K_{s}+s_{i}} \sum_{i=1}^{n} \frac{s_{i}^{2}}{\left(K_{s}+s_{i}\right)^{3}}=\sum_{i=1}^{n} \frac{v_{i} s_{i}}{\left(K_{s}+s_{i}\right)^{2}} \sum_{i=1}^{n} \frac{s_{i}^{2}}{\left(K_{s}+s_{i}\right)^{2}}
$$

In solving equation (4) for $K_{s}, k_{m}$ can be found by substituting $K_{s}$ into either one of equations in (6).

\section{D-2. Integrated form.}

The integrated form of Monod equation is given by

$$
t_{i}=\frac{1}{k_{m} x}\left[\operatorname{Vol} \times K_{s} \ln \left(\frac{s_{0}}{s_{i}}\right)+\operatorname{Vol} \times\left(s_{0}-s_{i}\right)\right]
$$

where $t_{i}$ is the measuring time in day, $V o l$ is reaction volume in liters. Let

$$
a=\frac{K_{s}}{k_{m} x}, \quad b=\frac{1}{k_{\mathrm{m}} x}
$$


Equation (8) then becomes

$$
t_{i}=a \times V o l \times \ln \left(\frac{s_{0}}{s_{i}}\right)+b \times \operatorname{Vol} \times\left(s_{0}-s_{i}\right)
$$

The residual sum of square is given by

$$
S S=\sum_{i=1}^{n}\left[a \times V o l \times \ln \left(\frac{s_{0}}{s_{i}}\right)+b \times V o l \times\left(s_{0}-s_{i}\right)-t_{i}\right]^{2} .
$$

Setting $\frac{\partial S S}{\partial a}=0$ and $\frac{\partial S S}{\partial b}=0$ results in

$$
\begin{aligned}
a \times \sum\left[V o l \times \ln \left(\frac{s_{0}}{s_{i}}\right)\right]^{2} & +b \times \sum\left[V o l \times \ln \left(\frac{s_{0}}{s_{i}}\right)\right]\left[V o l \times\left(s_{0}-s_{i}\right)\right] \\
& =\sum\left[t_{i} \times V o l \times \ln \left(\frac{s_{0}}{s_{i}}\right)\right]
\end{aligned}
$$

and

$$
\begin{aligned}
a \times \sum\left[\operatorname{Vol} \times \ln \left(\frac{s_{0}}{s_{i}}\right)\right] & {\left[\operatorname{Vol} \times\left(s_{0}-s_{i}\right)\right]+b \times \sum\left[\operatorname{Vol} \times\left(s_{0}-s_{i}\right)\right]^{2} } \\
= & \sum\left[t_{i} \times \operatorname{Vol} \times\left(s_{0}-s_{i}\right)\right] .
\end{aligned}
$$

The solution $a, b$ of equations (10a) and (10b) can be simplified by denoting

$$
\begin{gathered}
A C=t_{i} \times V o l \times \ln \left(\frac{s_{0}}{s_{i}}\right), \quad C D=\left[V o l \times\left(s_{0}-s_{i}\right)\right]\left[V o l \times \ln \left(\frac{s_{0}}{s_{i}}\right)\right] \\
A D=t_{i} \times V o l \times\left(s_{0}-s_{i}\right), \quad D=V o l \times\left(s_{0}-s_{i}\right), \\
Q=\left|\begin{array}{cc}
\sum C^{2} & \sum C D \\
\sum C D & \sum D^{2}
\end{array}\right| .
\end{gathered}
$$

Then

$$
a=\frac{\left|\begin{array}{ll}
\sum A C & \sum C D \\
\sum A D & \sum D^{2}
\end{array}\right|}{Q}, \quad b=\frac{\left|\begin{array}{ll}
\sum C^{2} & \sum A C \\
\sum C D & \sum A D
\end{array}\right|}{Q}
$$


APPENDIX E 
Appendix E

Appendix E.

Fortran program of the hydraulic-reaction-diffusion model

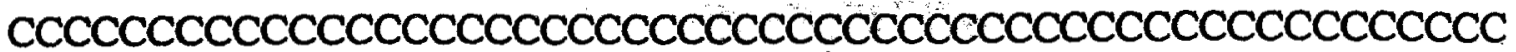

C

C THIS PROGRAM SEARCHES PARAMETERS TO FIT THE impluse CURVE. C

C C

C THE VARIABLE PARAMETERS ARE: $\mathrm{D}, \mathrm{Kl}, \mathrm{Rtn}, \mathrm{Vb}, \mathrm{Db}, \mathrm{Dp}$

C OTHER READ-IN PARAMETERS ARE: Sbo (EITHER 0.0 OR 0.1) AND C

C NRCT. C

C

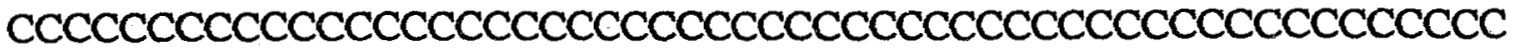

C Specifications for Parameters

C

C System parameters

INTEGER NSTEP, NPAR, I, J, JR, KR, I1, I2, ICR, NAL, MXIT

PARAMETER (NPAR $=6)$

INTEGER IC(NPAR), IP(NPAR), NC(NPAR), IFUN(NPAR, NPAR)

DOUBLE PRECISION Rl, RX, Rs, Rd, Sbo, Sbi, RAV, QAV

DOUBLE PRECISION TFINAL, $Q, T d, T, S b j$

DOUBLE PRECISION D, Rf, Rtn, Vb, Db, Dp, EMIN

DOUBLE PRECISION CRf, CRtn, CVb, $\mathrm{CDb}, \mathrm{CDp}, \mathrm{CD}$

DOUBLE PRECISION ERf, ERtn, EVb, EDb, EDp, ED

PARAMETER (NSTEP $=46$, TFINAL $=9.0 \mathrm{D0}, \mathrm{Nd}=20$ )

DOUBLE PRECISION TOL, ERROR, EDATA(10), TDATA(NSTEP)

DOUBLE PRECISION FLOAT, EXP, SQRT

LOGICAL SCAN

INTRINSIC FLOAT, EXP, SQRT

COMMON /PARAM/ D, Rl, RX, Rs, Rd, Sbo, Sbi, RAV, QAV, Td, Db

COMMON /QVB/ Q, Vb

C

C Parameters used in DBVPFD

INTEGER MXGRID, NEQNS, NINIT

INTEGER NCUPBC, NFINAL, NLEFT

PARAMETER (MXGRID $=45$, NEQNS $=2, \mathrm{NINIT}=10$ )

PARAMETER (NLEFT $=1$, NCUPBC $=1$ )

DOUBLE PRECISION TINIT(NINIT), YINIT(NEQNS,NINIT)

DOUBLE PRECISION ERREST(NEQNS), PISTEP, XFINAL(MXGRID),

\& XLEFT, XRIGHT, YFINAL(NEQNS,MXGRID)

SAVE TINIT, YINTT 
LOGICAL LINEAR, PRINT

EXTERNAL DBVPFD, UMACH

EXTERNAL FSSBC, FCNEQN, FCNJAC, FCNPBC, FCNPEQ

C

C Parameters used in DCSINT

INTEGER NINTV

DOUBLE PRECISION BREAK(NSTEP), CSCOEF(4,NSTEP), DCSVAL

DOUBLE PRECISION YTEMP(MXGRID)

C

EXTERNAL DCSINT, DCSVAL

C Parameters used in DPLOTP

DOUBLE PRECISION RANGE(4); AP(MXGRID,10), XP(MXGRID)

CHARACTER TITLE*25, XTITLE*10, YTTTLE*10, SYMBOL*10

INTEGER INC, NFUN

EXTERNAL DPLOTP, DCONST, PGOPT

C

C Parameters used in DIVPAG

INTEGER NPARAM, IDO, INORM, IMETH, NEQ, MTYPE, IATYPE, \& MITER, MXSTEP, NRCT, MXNEQ, NIN

PARAMETER (NPARAM=50, MXNEQ $=1000$ )

DOUBLE PRECISION HINIT, PARAM(NPARAM), $X$,

\& TEND, Y(MXNEQ), SB(NSTEP), SD(NSTEP)

EXTERNAL FCN, DIVPAG, FCNJ

C

COMMON /DIM/ NIN, NRCT, Dp

C Common parameters

C

DATA EDATA/0.1D0,2.37D0,10.08D0,9.95D0,7.41D0,5.95D0,

\& 2.85D0,0.74D0,0.27D0,0.22D0/

$\mathrm{Rd}=15.0 \mathrm{D} 0$

$\mathrm{Rs}=0.45 \mathrm{DO}$

$\mathrm{Q}=0.46518 \mathrm{DO}$

$\mathrm{Sbj}=17.0 \mathrm{DO}$,

CDefine TDATA

DO $10 \mathrm{I}=1$, NSTEP

TDATA(I) $=$ TFINAL*FLOAT(I-1)/FLOAT(NSTEP-1)

10 CONTINUE

OPEN (UNIT=NOUT, FILE='impls.txt', STATUS='UNKNOWN')

PRINT*, 'ENTER SEARCH TYPE: $1=$ SCAN, $2=$ TEST'

READ*, I

IF (I.EQ. 1) THEN

SCAN $=$.TRUE.

ELSE

SCAN $=$. FALSE.

END IF 
PRINT*, 'ENTER Sbo, Td AND NRCT'

READ*, Sbo, Td, NRCT

NIN $=$ NINIT

$N E Q=N I N+N R C T+1$

IF (.NOT. SCAN) THEN

PRINT*, 'ENTER Kl, Rtn, Vb, Db, Dp, AND D'

READ*, CRf, CRtn, CVb, CDb, CDp, CD

C CHANGE OTHER PARAMETERS

PRINT*, 'ENTER RX, Rs, Sbj'

READ*, RX, Rs, Sbj

WRITE (NOUT, *) 'D, Dp, Db, Kl, RX, Rs, Sbj'

WRTTE (NOUT, 7000) CD, CDp, CDb, CRf, RX, Rs, Sbj

7000 FORMAT (7F9.4)

GOTO 1010

END IF

PRINT*, 'ENTER INITIAL GUESS OF Kl, Rtn, Vb, Db, Dp, RX AND D'

READ*, CRf, CRtn, CVb, CDb, CDp, RX, CD

PRINT*, 'ENTER INITIAL STEPS OF Kl, Rtn, Vb, Db, Dp, RX AND D'

READ*, ERf, ERtn, EVb, EDb, EDp, RX, ED

PRINT*, ENTER ACCURACY LEVEL AND NUMBER OF ITERATIONS'

READ*, NAL, MXIT

WRITE $(*, *)$ 'THE WINNERS ARE'

WRITE $(*, 2000)$

2000 FORMAT(2X, 'KR', 3X, 'Kl', 6X,'Rtn',6X,'Vb',7x, Db', 7x, 'Dp',

\& $7 \mathrm{X}$, 'D', 8X, 'Error')

$\mathrm{EMIN}=100.0$

$\mathrm{JR}=0$

$\mathrm{KR}=0$

DO $5 \mathrm{I}=1$, NPAR

DO $5 \mathrm{~J}=1$, NPAR

$\operatorname{IFUN}(\mathrm{I}, \mathrm{J})=0$

5 CONTINUE

DO $6 \mathrm{I}=1$, NPAR

$\operatorname{IFUN}(\mathrm{I}, \mathrm{I})=1$

6 CONTINUE

100 WRTTE $(*, *)^{\prime}\left(\mathrm{JR}={ }^{\prime}, \mathrm{JR},\right)^{\prime}$

WRITE(NOUT, *) '(JR = ', JR, ')'

DO $12 \mathrm{I}=1$, NPAR

$\mathrm{IC}(\mathrm{I})=3$

12 CCNTINUE

$101 \mathrm{KR}=\mathrm{KR}+1$

DO $11 \mathrm{I}=1$, NPAR

$\mathrm{NC}(\mathrm{I})=0$

11 CONTINUE

DO $1000 \mathrm{I} 1=1$, NPAR 
DO $1000 \mathrm{I} 2=1,2$

C SET COORDINATES

DO $15 \mathrm{I}=1$, NPAR

$\operatorname{IP}(\mathrm{I})=(-1)^{* *} \mathrm{I} 2 * \operatorname{IFUN}(\mathrm{I}, \mathrm{I} 1)$

15 CONTINUE

C CHECK FOR OVERLAP

$\mathrm{ICR}=0$

DO $20 \mathrm{I}=1$, NPAR

$\mathrm{ICR}=\mathrm{ICR}+\mathrm{ABS}(\mathrm{IP}(\mathrm{I})+\mathrm{IC}(\mathrm{I}))$

20 CONTINUE

IF (ICR .EQ. 0) GOTO 1000

C SET PARAMETERS

$\mathrm{Rf}=\mathrm{CRf}+\mathrm{ERf} * \mathrm{FLOAT}(\mathrm{IP}(1)) / 2.0 * * \mathrm{JR}$

$\mathrm{Rtn}=\mathrm{CRtn}+\mathrm{ERtn} * \mathrm{FLOAT}(\mathrm{IP}(2)) / 2.0 * * \mathrm{JR}$

$\mathrm{Vb}=\mathrm{CVb}+\mathrm{EVb} * \mathrm{FLOAT}(\mathrm{IP}(3)) / 2.0^{* *} \mathrm{JR}$

$\mathrm{Db}=\mathrm{CDb}+\mathrm{EDb} * \mathrm{FLOAT}(\mathrm{IP}(4)) / 2.0 * * \mathrm{JR}$

$\mathrm{Dp}=\mathrm{CDp}+\mathrm{EDp} * \mathrm{FLOAT}(\mathrm{IP}(5)) / 2.0 * * \mathrm{JR}$

$\mathrm{D}=\mathrm{CD}+\mathrm{ED} * \mathrm{FLOAT}(\mathrm{IP}(6)) / 2.0^{* *} \mathrm{JR}$

$\mathrm{Sbi}=\mathrm{Sbj} * \mathrm{R}$ tn

$\mathrm{Rl}=\mathrm{Rf} * 600.0 \mathrm{D} 0$

$\mathrm{RAV}=1.05 \mathrm{D} 0 * \mathrm{R} 1 / \mathrm{Vb}$

$\mathrm{QAV}=\mathrm{RAV}+\mathrm{Q}^{*} \mathrm{R} \mathrm{t} / \mathrm{Vb}$

$C$ CHECK FOR CONSTRAINTS

IF (Rf .LE. 0.0D0 .OR. D .LE. 0.0D0) GOTO 1000

IF (Rtn .GT. 1.0DO .OR. Rtn .LE. 0.0D0) GOTO 1000

IF (Db .LE. 0.0D0 .OR. Dp .LE. 0.0D0) GOTO 1000

C SET INITIAL CONDITION FOR S(X, T)

IF (Sbo .LE. 0.01D0) THEN

DO $61 \mathrm{I}=1$, NINIT

$$
Y(I)=\text { Sbo }
$$

61 CONTINUE

GOTO 5000

END IF .

C FIND Ss(X) BY DBVPFD (IN LOOP)

DO $30 \mathrm{I}=1$, NINIT

TINIT(I)=FLOAT(I-1)/FLOAT(NINIT-1)

YINIT(1, I)=FLOAT(NINIT-1)/FLOAT(NINIT-1)

$\operatorname{YINIT}(2, \mathrm{D})=0.0 \mathrm{D} 0$

30 CONTINUE

TOL $=1 . D-06$

$\operatorname{TINIT}(1)=0.0 \mathrm{D} 0$

TINIT(NINIT) $=1.0 \mathrm{D} 0$

$\mathrm{XLEFT}=0.0 \mathrm{D} 0$

$\mathrm{XRIGHT}=1.0 \mathrm{D} 0$

PISTEP $=0.1 \mathrm{D0}$ 
PRINT $=$.FALSE.

LINEAR $=$. FALSE.

CALL DBVPFD (FCNEQN, FCNJAC, FSSBC, FCNPEQ, FCNPBC, NEQNS, \& NLEFT, NCUPBC, XLEFT, XRIGHT, PISTEP, TOL, NINIT, TINIT,

\& YINIT, NEQNS, LINEAR, PRINT, MXGRID, NFINAL,

\& XFINAL, YFINAL, NEQNS, ERREST)

$C$ Interpolate $\mathrm{Ss}(\mathrm{x})$

DO $40 \mathrm{I}=1$, NFINAL

YTEMP(I) $=$ YFINAL $(1, \mathrm{I})$

40 CONTINUE

CALL DCSINT (NFINAL, XFINAL, YTEMP, BREAK, CSCOEF)

NINTV $=$ NFINAL- 1

DO $60 \mathrm{I}=1$, NINIT

$Y(I)=$ DCSVAL(TINIT(I), NINTV, BREAK, CSCOEF)

60 CONTINUE

C Solve $S \_i(t)$ by DIVPAG (IN LOOP)

5000 HINIT $=1.0 \mathrm{D}-3$

INORM $=1$

IMETH $=2$

MTTER $=2$

MTYPE $=0$

IATYPE $=0$

MXSTEP $=1000$

DO $50 \mathrm{I}=1$, NPARAM

$\operatorname{PARAM}(\mathrm{T})=0.0 \mathrm{D} 0$

50 CONTINUE

$\operatorname{PARAM}(1)=$ HINIT

$\operatorname{PARAM}(4)=$ MXSTEP

$\operatorname{PARAM}(10)=\mathbb{N} O R M$

$\operatorname{PARAM}(12)=$ IMETH

PARAM(13) $=$ MITER

$\operatorname{PARAM}(14)=$ MTYPE

PARAM(19) $=$ IATYPE

IDO $=1$

$\mathrm{X}=0.0 \mathrm{D} 0$

TOL $=1.0 \mathrm{D}-4$

DO $70 \mathrm{I}=\mathrm{NIN}+1$, NEQ

$\mathrm{Y}(\mathrm{I})=\mathrm{Sbo}$

70 CONTINUE

$\mathrm{SB}(1)=\mathrm{Y}(\mathrm{NEQ})$

$\mathrm{SD}(1)=\mathrm{Y}(1)$

DO $80 \mathrm{I}=2$, NSTEP

TEND $=$ TDATA(I)

CALL DIVPAG(DO, NEQ, FCN, FCNJ, A, X, TEND, TOL, PARAM, Y)

$\mathrm{SB}(\mathrm{I})=\mathrm{Y}(\mathrm{NEQ})$ 
$80 \quad \begin{aligned} & \mathrm{SD}(\mathrm{I})=\mathrm{Y}(1) \\ & \text { CONTINUE }\end{aligned}$

$\mathrm{IDO}=3$

CALL DIVPAG (IDO, NEQ, FCN, FCNJ, A, X, TEND, TOL, PARAM, Y)

$C$ Estimate the error in $\mathrm{Sb}(1, \mathrm{t})$. (IN LOOP)

CALL DCSINT (NSTEP, TDATA, SB, BREAK, CSCOEF)

NINTV $=$ NSTEP -1

$\mathrm{ERROR}=0.0 \mathrm{DO}$

DO $90 \mathrm{I}=1,10$

$\mathrm{T}=\mathrm{FLOAT}(\mathrm{I}-1)$

$X=D C S V A L(T, N I N T V, B R E A K$, CSCOEF)

ERROR $=E R R O R+(X-E D A T A(I))^{* * 2}$

90 CONTINUE

ERROR=SQRT(ERROR)

C UPDATE MINIMUM ERROR

IF (ERROR .LT. EMIN) THEN

EMIN $=$ ERROR

DO 400 I=1, NPAR

$\mathrm{NC}(\mathrm{I})=\mathbb{I P}(\mathrm{I})$

400 CONTINUE

END IF

1000 CONTINUE

C CHECK IF THE CENTER IS CHANGED

$\mathrm{ICR}=0$

DO $500 \mathrm{I}=1$, NPAR

$\mathrm{ICR}=\mathrm{ICR}+\mathrm{ABS}(\mathrm{NC}(\mathrm{I}))$

500 CONTINUE

IF (ICR .EQ. 0) GOTO 600

C UPDATE CENTER

DO $700 \mathrm{I}=1$, NPAR

$\mathrm{IC}(\mathrm{I})=\mathrm{NC}(\mathrm{I})$

700 CONTINUE

$\mathrm{CRf}=\mathrm{CRf}+\mathrm{ERf} * \mathrm{FLOAT}(\mathrm{IC}(1)) / 2.0 * * \mathrm{JR}$

CRtn $=$ CRtn + ERtn*FLOAT(IC(2))/2.0**JR

$\mathrm{CVb}=\mathrm{CVb}+\mathrm{EVb} * \mathrm{FLOAT}(\mathrm{IC}(3)) / 2.0 * * \mathrm{JR}$

$\mathrm{CDb}=\mathrm{CDb}+\mathrm{EDb} * \mathrm{FLOAT}(\mathrm{IC}(4)) / 2.0 * * \mathrm{JR}$

$\mathrm{CDp}=\mathrm{CDp}+\mathrm{EDp} * \mathrm{FLOAT}(\mathrm{IC}(5)) / 2.0 * * \mathrm{JR}$

$\mathrm{CD}=\mathrm{CD}+\mathrm{ED} * \mathrm{FLOAT}(\mathrm{IC}(6)) / 2.0 * * \mathrm{JR}$

WRITE (*, 2100) KR, CRf, CRtn, CVb, CDb, CDp, CD, EMIN

2100 FORMAT (I5, 7(F9.4))

IF (KR .GE. MXIT) GOTO 601

GOTO 101

$600 \mathrm{JR}=\mathrm{JR}+1$

IF(JR .LE. NAL) GOTO 100

601 PRINT*, 'THE FINAL RESULT IS' 
WRITE (*, 2200) KR, CRf, CRtn, CVb, CDb, CDp, CD, EMIN 2200 FORMAT (I5, 7(F9.4))

WRITE (NOUT, *) 'Kl = ', CRf

WRITE (NOUT, *) 'Rtn $=$ ', CRtn

WRITE (NOUT, *) ' $\mathrm{Vb}={ }^{\prime}, \mathrm{CVb}$

WRITE (NOUT, *) $\mathrm{Db}=$ ', $\mathrm{CDb}$

WRITE (NOUT, *) 'Dp = ', CDp

WRITE (NOUT, *) 'D = ', CD

C LOOP FINISHED, RERUN TO FIND $S b(1, t)$ AND PLOT CURVES

$1010 \mathrm{Rf}=\mathrm{CRf}$

$\mathrm{Rtn}=\mathrm{CRtN}$

$\mathrm{Vb}=\mathrm{CVb}$

$\mathrm{Db}=\mathrm{CDb}$

$\mathrm{Dp}=\mathrm{CDp}$

$\mathrm{D}=\mathrm{CD}$

$\mathrm{Sbi}=\mathrm{Sbj} * \mathrm{R}$ tn

$\mathrm{Rl}=\mathrm{Rf} * 600.0 \mathrm{D} 0$

$\mathrm{RAV}=1.05 \mathrm{D} 0 * \mathrm{R} / \mathrm{Vb}$

$\mathrm{QAV}=\mathrm{RAV}+\mathrm{Q}^{*} \mathrm{Rt} / \mathrm{Vb}$

C SET INITIAL CONDITION FOR S(X, T)

IF (Sbo .LT. 0.01D0) THEN

DO $141 \mathrm{I}=1$, NINIT

$$
\mathrm{Y}(\mathrm{I})=0.0 \mathrm{D} 0
$$

141 CONTINUE

GOTO 5100

END IF

C FIND Ss $(X)$ BY DBVPFD

DO $111 \mathrm{I}=1$, NINIT

TINIT(T)=FLOAT(I-1)/FLOAT(NINIT-1)

YINIT(1, I)=FLOAT(NINIT-I)/FLOAT(NINIT-1)

$\operatorname{YINIT}(2, \mathrm{I})=0.0 \mathrm{D} 0$

111 CONTINUE

TOL $=1: D-06$

$\operatorname{TINIT}(1)=0.0 \mathrm{D} 0$

$\operatorname{TINIT}(\mathrm{NINIT})=1.0 \mathrm{D} 0$

$\mathrm{XIEFT}=0.0 \mathrm{D} 0$

$\mathrm{XRIGHT}=1.0 \mathrm{D} 0$

PISTEP $=0.1 D 0$

PRINT $=$.FALSE.

LINEAR $=$.FALSE.

CALL DBVPFD (FCNEQN, FCNJAC, FSSBC, FCNPEQ, FCNPBC, NEQNS, NLEFT,

\& NCUPBC, XLEFT, XRIGHT, PISTEP, TOL, NINIT, TINIT,

\& YINIT, NEQNS, LINEAR, PRINT; MXGRID, NFINAL,

\& XFINAL, YFINAL, NEQNS, ERREST) 
C Interpolate $\mathrm{Ss}(\mathrm{x})$

DO $120 \mathrm{I}=1$, NFINAL

YTEMP(I) = YFINAL $(1, \mathrm{I})$

120 CONTINUE

CALL DCSINT (NFINAL, XFINAL, YTEMP, BREAK, CSCOEF)

NINTV $=$ NFINAL-1

DO 140 I=1, NINIT

$\mathrm{Y}(\mathrm{I})=\mathrm{DCSVAL}(\mathrm{TINIT}(\mathrm{I})$, NINTV, BREAK, CSCOEF $)$

140 CONTINUE

C Solve $S \_i(t)$ by DIVPAG

$5100 \mathrm{HINIT}=1.0 \mathrm{D}-3$

INORM $=1$

IMETH $=2$

MITER $=2$

MTYPE $=0$

IATYPE $=0$

MXSTEP $=1000$

DO $130 \mathrm{I}=1$, NPARAM

PARAM(I) $=0.0 \mathrm{D} 0$

130 CONTINUE

$\operatorname{PARAM}(1)=$ HINIT

$\operatorname{PARAM}(4)=$ MXSTEP

$\operatorname{PARAM}(10)=\mathbb{I N O R M}$

PARAM $(12)=$ IMETH

PARAM(13) $=$ MITER

PARAM(14) = MTYPE

PARAM(19) = IATYPE

$\mathrm{IDO}=1$

$\mathrm{X}=0.0 \mathrm{D} 0$

TOL $=1.0 \mathrm{D}-4$

DO $150 \mathrm{I}=\mathrm{NIN}+1$, NEQ

$Y(I)=$ Sbo

150 CONTINUE

$\mathrm{SB}(1)=\mathrm{Y}(\mathrm{NEQ})$

$S D(1)=Y(1)$

DO $160 \mathrm{I}=2$, NSTEP

TEND $=$ TDATA(I)

CALL DIVPAG(IDO, NEQ, FCN, FCNJ, A, X, TEND, TOL, PARAM, Y)

$\mathrm{SB}(\mathrm{I})=\mathrm{Y}(\mathrm{NEQ})$

$\mathrm{SD}(\mathrm{I})=\mathrm{Y}(1)$

160 CONTINUE

$\mathrm{IDO}=3$

$\mathrm{C}$

CALL DIVPAG (IDO, NEQ, FCN, FCNJ, A, X, TEND; TOL, PARAM, Y)

CALL DCSINT (NSTEP, TDATA, SB, BREAK, CSCOEF) 
NINTV $=$ NSTEP- 1

WRITE (NOUT, 2300)

2300 FORMAT (7X, 'Ti', 11X, 'Sb')

DO $165 \mathrm{I}=1$, NSTEP

WRITE (NOUT, 2500) TDATA(I), SB(I)

2500 FORMAT (2F13.4)

165 CONTINUE

WRITE (NOUT, *) 'EDATA(D)-Sb(T_i)='

ERROR=0.0D0

DO $170 \mathrm{I}=1,10$

$\mathrm{T}=\mathrm{FLOAT}(\mathrm{I}-1)$

$\mathrm{X}=$ DCSVAL $(\mathrm{t}, \mathrm{NINTV}, \mathrm{BREAK}, \mathrm{CSCOEF})$

WRITE (NOUT, *) EDATA(I) - X

ERROR=ERROR+(X-EDATA(I))**2

170 CONTINUE

ERROR=SQRT(ERROR)

WRITE(NOUT, *) 'Error =', ERROR

PRINT*, 'EMIN = ', ERROR

C Plot $\mathrm{Sb}(\mathrm{t}), \mathrm{S}($ delta, $t)$

NFUN $=2$

INC $=1$

SYMBOL $=$ 'B*'

XTITLE $=$ 'T AXIS'

YTITLE $=$ 'CONCENTRATION'

TITLE $={ }^{\circ}=S($ delta, $t), B=S b(t)^{\prime}$

RANGE(1) $=0.0$

RANGE(2) $=$ TFINAL

RANGE(3) $=0.0$

RANGE(4) $=30.0$

DO $180 \mathrm{I}=1$, NSTEP

$\mathrm{XP}(\mathrm{I})=\mathrm{TDATA}(\mathrm{I})$

$\mathrm{AP}(\mathrm{I}, 1)=\mathrm{SB}(\mathrm{I})$

$\mathrm{AP}(\mathrm{I}, 2)=-1.0 \mathrm{DO}$

180 CONTINUE

DO $190 \mathrm{I}=1,10$

$\mathrm{J}=(\mathrm{I}-1) * 5+1$

$\operatorname{AP}(\mathrm{J}, 2)=\operatorname{EDATA}(\mathrm{I})$

190 CONTINUE

CALL DPLOTP (NSTEP, NFUN, XP, AP, MXGRID, INC, RANGE, \& SYMBOL, XTITLE, YTITLE, TITLE) END

$\mathrm{C}$

C SUBROUTINES USED IN DBVPFD.

$\mathrm{C}$

SUBROUTINE FCNEQN (NEQNS, T, Y, P, DYDT) 
INTEGER NEQNS

DOUBLE PRECISION T, P, Y(NEQNS), DYDT(NEQNS)

DOUBLE PRECISION D, Rl, RX, Rs, Rd, Sbo, Sbi, RAV, QAV, Td, $\& \mathrm{Db}$

COMMON /PARAM/ D, Rl, RX, Rs, Rd, Sbo, Sbi, RAV, QAV, Td, Db

$\operatorname{DYDT}(1)=\mathrm{Y}(2)$

$\operatorname{DYDT}(2)=\mathrm{P} * \mathrm{RX} * \mathrm{Y}(1) / \mathrm{D} /(\mathrm{Rs}+\mathrm{Y}(1))+2.0 \mathrm{D} 0 * \mathrm{Y}(2) /(\mathrm{Rd}-\mathrm{T})$

RETURN

END

C

SUBROUTINE FCNJAC (NEQNS, T, Y, P, DYPDY)

INTEGER NEQNS

DOUBLE PRECISION T, P, Y(NEQNS), DYPDY(NEQNS,NEQNS)

DOUBLE PRECISION D, Rl, RX, Rs, Rd, Sbo, Sbi, RAV, QAV, Td,

$\& \mathrm{Db}$

COMMON /PARAM/ D, Rl, RX, Rs, Rd, Sbo, Sbi, RAV, QAV, Td, Db

$\operatorname{DYPDY}(1,1)=0.0 \mathrm{D} 0$

$\operatorname{DYPDY}(1,2)=1.0 \mathrm{D} 0$

$\operatorname{DYPDY}(2,1)=\mathrm{P} * \mathrm{Rs} * \mathrm{RX} / \mathrm{D} /(\mathrm{Rs}+\mathrm{Y}(1)) * *_{2}$

$\operatorname{DYPDY}(2,2)=2.0 \mathrm{DO} /(\mathrm{Rd}-\mathrm{T})$

RETURN

END

C

SUBROUTINE-FSSBC (NEQNS, YLEFT, YRIGHT, P, F)

INTEGER NEQNS

DOUBLE PRECISION P, YLEFT(NEQNS), YRIGHT(NEQNS), F(NEQNS)

DOUBLE PRECISION DCONST

DOUBLE PRECISION D, Rl, RX, Rs, Rd, Sbo, Sbi, RAV, QAV, Td,

\& $\mathrm{Db}$

COMMON /PARAM/ D, Rl, RX, Rs, Rd, Sbo, Sbi, RAV, QAV, Td, Db

EXTERNAL DCONST

$\mathrm{F}(1)=-\mathrm{D} * \mathrm{YLEFT}(2)+\mathrm{R} 1 * \mathrm{YLEFT}(1)-\mathrm{R} 1 *$ Sbo

$F(2)=$ YRIGHT $(2)$

RETURN

END

C

SUBROUTINE FCNPEQ (NEQNS, T, Y, P, DYPDP)

INTEGER NEQNS

DOUBLE PRECISION T, P, Y(NEQNS), DYPDP(NEQNS)

DOUBLE PRECISION D, Rl, RX, Rs, Rd, Sbo, Sbi, RAV, QAV, Td,

\& $\mathrm{Db}$

COMMON /PARAM/ D, Rl, RX, Rs, Rd, Sbo, Sbi, RAV, QAV, Td, Db

$\operatorname{DYPDP}(1)=0.0 \mathrm{D} 0$

$\operatorname{DYPDP}(2)=R X^{*} \mathrm{Y}(1) / \mathrm{D} /(\mathrm{Rs}+\mathrm{Y}(1))$

RETURN 
END

C

SUBROUTINE FCNPBC (NEQNS, YLEFT, YRIGHT, P, DFDP)

INTEGER NEQNS

DOUBLE PRECISION P, YLEFT(NEQNS), YRIGHT(NEQNS), DFDP(NEQNS), A

EXTERNAL SSET

$A=0.0 D 0$

CALL SSET (NEQNS, A, DFDP, 1)

RETURN

END

C

C SUBROUTINES USED IN DIVPAG.

C

SUBROUTINE FCN (NEQ, $X, Y$, YPRIME)

INTEGER NEQ, NIN, I, NRCT

DOUBLE PRECISION X, Y(NEQ), YPRIME(NEQ), H1, H2, C1, C2, C3, E

DOUBLE PRECISION D, Rl, RX, Rs, Rd, Sbo, Sbi, RAV, QAV, Td,

\& $\mathrm{Db}, \mathrm{Q}, \mathrm{Vb}, \mathrm{Dp}$

DOUBLE PRECISION FLOAT, DCONST, SQRT, EXP

INTRINSIC FLOAT, SQRT, EXP

EXTERNAL DCONST

COMMON /PARAM/ D, Rl, RX, Rs, Rd, Sbo, Sbi, RAV, QAV, Td, \& $\cdot \mathrm{Db}$

COMMON/QVB/Q, Vb

C

COMMON/DIM/NIN, NRCT, Dp

$\mathrm{H} 1=1.0 \mathrm{D} 0 / \mathrm{FLOAT}(\mathrm{NIN}-1)$

$\mathrm{H} 2=1.0 \mathrm{D} 0 / \mathrm{FLOAT}(\mathrm{NRCT})$

$\mathrm{Cl}=2.0 \mathrm{DO} * \mathrm{D} / \mathrm{H} 1 * * 2$

$\mathrm{C} 2=2.0 \mathrm{DO} * \mathrm{R} 1 / \mathrm{H} 1+2.0 \mathrm{DO} * \mathrm{R} 1 / \mathrm{Rd} / \mathrm{D}$

$\mathrm{YPRIME}(1)=\mathrm{C} 1 * \mathrm{Y}(2)+\mathrm{C} 2 * \mathrm{Y}(\mathrm{NIN}+1)-(\mathrm{C} 1+\mathrm{C} 2) * \mathrm{Y}(1)-\mathrm{RX} * \mathrm{Y}(1) /(\mathrm{Rs}+\mathrm{Y}(1))$

DO $10 \mathrm{I}=2, \mathrm{NIN}-1$

C3 $=1.0 \mathrm{D} 0 /(\mathrm{Rd}-\mathrm{H} 1 * \mathrm{FLOAT}(\mathrm{I}-1)) / \mathrm{H} 1$

$\mathrm{YPRIME}(\mathrm{I})=(\mathrm{C} 1 / 2.0 \mathrm{D} 0+\mathrm{C} 3)^{*} \mathrm{Y}(\mathrm{I}-1)+(\mathrm{Cl} 1 / 2.0 \mathrm{D} 0-\mathrm{C} 3) * \mathrm{Y}(\mathrm{I}+1)-\mathrm{C} 1 * \mathrm{Y}(\mathrm{I})$

\& $\quad-\mathrm{RX}^{*} \mathrm{Y}(\mathrm{I}) /(\mathrm{Rs}+\mathrm{Y}(\mathrm{I}))$

10 CONTINUE

$\mathrm{YPRIME}(\mathrm{NIN})=\mathrm{Cl} * \mathrm{Y}(\mathrm{NIN}-1)-\mathrm{C} 1 * \mathrm{Y}(\mathrm{NIN})-\mathrm{RX} * \mathrm{Y}(\mathrm{NIN}) /(\mathrm{Rs}+\mathrm{Y}(\mathrm{NIN}))$

IF (X .LT. Td) THEN

$\mathrm{E}=(\mathrm{Sbi}-\mathrm{Sbo}) / \mathrm{Td}+\mathrm{Q}^{*} \mathrm{Sbo} / \mathrm{Vb}$

ELSE

$\mathrm{E}=\mathrm{Q} * \mathrm{Sbo} / \mathrm{Vb}$

END IF

YPRIME $(N I N+1)=E-Q A V * Y(N I N+1)+R A V * Y(1)$

$\mathrm{C} 1=\mathrm{Dp} / \mathrm{H}_{2} * * 2$ 


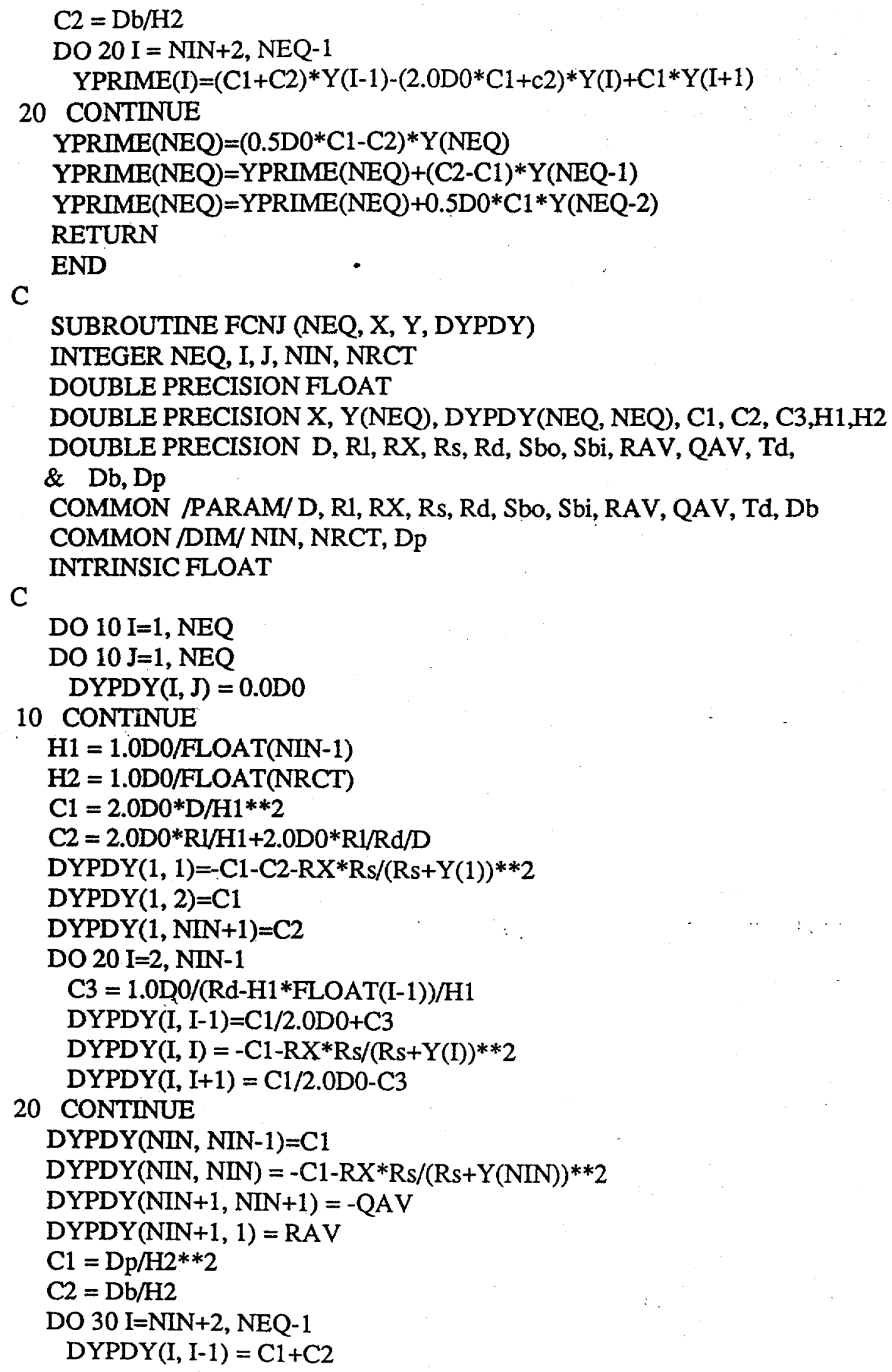


$\operatorname{DYPDY}(\mathrm{I}, \mathrm{I})=-2.0 \mathrm{D} 0 * \mathrm{C} 1$

$\operatorname{DYPDY}(\mathrm{I}, \mathrm{I}+1)=\mathrm{C} 1$

30 CONTINUE

DYPDY(NEQ, NEQ-2) $=\mathrm{C} 1 / 2.0 \mathrm{D} 0$

DYPDY (NEQ, NEQ -1$)=\mathrm{C} 2-\mathrm{C} 1$

DYPDY(NEQ, NEQ) $=\mathrm{C} 1 / 2.0 \mathrm{D} 0-\mathrm{C} 2$

RETURN

END 


\section{LIST OF REFERENCES}


Agardy, F. J. and Shepherd, W. C. DNA-A rational basis for digester loadings. J. WPCF. Vol. 37, pp 1236$1239,1965$.

Agardy, F. J., Cole, R. D. and Pearson, E. A. Enzyme activity as a parameter of digester performance. pp 51-65, In Proceedings of the 18th Purdue Industrial Waste Conference, Engineering extension series No. 115, Purdue University, West Lafayette, IN, 1963.

Ahring, B. K. and Schmidt, J. E., Winther-nielsen, M., Macario, A. J. L., Macario, E. C., Effect of medium composition and sludge removal on the production, composition, and architecture of thermophilic $\left(55^{\circ} \mathrm{C}\right)$ acetate-utilizing granules from an Upflow Anaerobic Sludge Blanket reactor, Appl. Environ. Microbiol. Vol. 59, No. 8, pp 2538-2545, 1993.

Ahring, B. K. and Westermann, P., Kinetics of butyrate, acetate and hydrogen metabolism in a thermophilic, anaerobic butyrate-degrading triculture, Appl. Environ. Microbiol. Vol. 53, No. 2, pp 434$439,1987$.

Ahring, B.K. and Westermann, P., Methanogenesis from acetate: Physiology of a thermophilic acetateutilizing methanogenic bacteria, FEMS Microbiol. Lett. Vol. 28, pp 15-19, 1985.

Alibhai K. R. K. and Forster, C.F., Physicochemical and biological characteristics of sludges produced in anaerobic upflow sludge blanket reactors, Enzyme Microb. Technol. Vol. 8, Oct., pp 601-606, 1986.

Alphenaar, P.A., Perez, M. C. and Lettinga, G., The influence of substrate transport limitation on porosity and methanogenic activity of anaerobic sludge granules. Appl. Microbiol. Biotechnol., Vol. 39, pp 276$280,1993$.

Ames, W.F., Numerical methods for partial differential equations. Computer Science and applied mathematics series, Ed. Rheinboldt, W., Academic press, New York, 1977.

Andrews, J. F. and Graef, S. P, Dynamic modeling and simulation of the anaerobic digestion process. Anaerobic Biological Treatment Process., Advances in Chemistry Series, Vol. 105, pp 126-162, American Chemical Society, Washington, DC, 1971.

Andrews, J. F., A mathematical model for the continuous culture of microorganisms utilizing inhibitory substrate. Biotechnol. Bioeng., Vol. 10, pp 707-723, 1969. 
Andrews, G. F. and Tien, C. The expansion of a fluidized bed containing biomass, AICHE J. Vol. 25, No. $4,1979$.

APHA-AWWA-WPCF Standard Methods, part 209 C \& D, pp 96-98, 16th edition, 1985.

Asinari di San Marzano, C. A. Volatile fatty acids, an important state parameter for the control of the reliability and the productivities of methane anaerobic digestions. Biomass. Vol. 1, pp 47-59, 1981.

Atkinson, B. and Davies, I. J., The overall rate of substrate uptake (reaction) by microbial films. Part I. A biological rate equation. Trans. Inst. Chem. Engrs., Vol. 52, pp 248-259, 1974.

Bae, J. and McCarty, P. L. Variation of carbon monoxide production during methane fermentation of glucose. Wat. Environ. Res. Vol. 65, No. 7, pp 890-898, 1993.

Bailey, J. E. and Ollis, D. F. 1986. Chapter 4, Biochemical Engineering Fundamentals, 2nd edition, McGraw-Hill, New York.

Barnett, M. and Andrews, J. F. Expert system for anaerobic digestion process operation. J. of Environ. Eng. Vol. 118, No. 6, pp 949-963, 1992.

Benefield, L. and Molz, F., A model for the activated sludge process which considers wastewater characteristics, floc behavior and microbial population. Biotechnol. Bioeng., Vol. 26, pp 352-361,1984.

Benefield, L. and Molz, F., An activated sludge model which considers toxicant concentration: simulation and sensitivity analysis. Applied Mathematical Modelling, Vol. 9, pp 454-465, 1985.

Bennett, C.O. and Myers, J. E., Momentum, heat and mass transfer. Chemical engineering series, $3^{\text {rd }}$ ed., McGraw-Hill, 1982.

Bergmeyer, Hans Ulrich edi. Methods of Enzymatic Analysis, Vol. 3, 1974.

Berthouex, P.M. Constructing control charts for wastewater treatment plant operation. J. WPCF, Vol. 61, No. 9, pp 1534-1551, 1989.

Bolle, W. L., van Breugel, J., van Eybergen, G. C., Kossen, N. W. F. and van Gils, W., An integral dynamic model for the UASB reactor, Biotechnol. Bioeng., Vol. 28, pp 1621-1636, 1985. 
Bolle, W. L. et al "Modeling the liquid flow in upflow anaerobic sludge blanket reactors, Biotechnology and Bioengineering, Vol. 28, No. 11, 1986.

Bolte, J. P and Hill, D. T, A comprehensive dynamic model of attached growth anaerobic fermentors. Trans. ASAE, Vol. 36(6), pp 1805-1814, 1993.

Boone, D. R, Johnson, R. L. and Lin, Y., Diffusion of the interspecies electron carriers $\mathrm{H}_{2}$ and formate in methanogenic ecosystems and its implications in the measurements of $K_{m}$ for $\mathrm{H}_{2}$ and formate uptake, Appl. Environ. Microbiol. Vol. 55, pp 1735-1741, 1989.

Bornstein, B. T. and Barker, H. A., The energy metabolism of Clostridium kluyveri and the synthesis of fatty acids, J. Biological Chemistry, Vol. 172, pp 659-669, 1948.

Boscolo, A., Mangiavacchi, C., Drius, F., Rongione, F., Pavan, P. and Cecchi, F. Fuzzy control of an anaerobic digester for the treatment of the organic fraction of municipal solid waste (MSW). Wat. Sci. Technol. Vol. 27, No. 2, pp 57-68, 1993.

Braun, M., Mayer, F., Gottschalk, G. Clostridium aceticum (Wieringa), a microorganism producing acetic acid from molecular hydrogen and carbon dioxide. Arch. Microbiol. Vol. 128, pp 288-293.

Brockwell, P. J. and Davis, R. A. Tìme Series: theory and methods. Springer-Verlag, 1987.

Bryant, M. P., Campbell, L. L., Reddy, C:A., Crabill, M. R., Growth of Desulfovibrio in lactate or ethanol media low in sulfate in association with H2-utilizing methanogenic bacteria, Appl. Environ. Microbiol, Vol. 33, pp 1162-1169, 1977.

Bryant, M. P., Wolin, E. A., Wolin, M. J., Wolfe, R. S., Methanobacillus omelianskii, a symbiotic association of two species of bacteria. Arch. Microbiol., Vol. 59, pp 20-31, 1967.

Bryers, J.D., Structured modeling of the anaerobic digestion of biomass particulates. Biotechnol. Bioeng., Vol. 27, pp 638-649, 1985.

Buhr, H.O. and Andrews, J.F., The thermophilic anaerobic digestion process. Water Res., Vol. 11(2), pp 129-144, 1977. 
Carr, A.D. and O'Donnell, R.C., The dynamic behavior of an anaerobic digestor. Prog. in Water Technol., Vol. 9, pp 727-738, 1977.

Chang, H.N., Numerical calculation of effectiveness factors for the Michaelis-Menten type kinetics with high thiele moduli, J. A.I.ChE., Vol. 28, No. 6, 1982.

Chang, J.E., Noike, T., Matsumoto, J. 1982. Effect of retention time and feed substrate concentration of methanogenesis in anaerobic digestion, Proc. of J.S.C.E., No. 320, pp 67-76.

Chang, J.E., Noike, T., Matsumoto, J. 1983. Effect of $\mathrm{pH}$ on methanogenesis in anaerobic digestion, Proc. of J.S.C.E., No. 335, pp 79-87.

Chapman, D.T. Mixing efficiency as estimated by nonlinear least squares Canadian J. of Civil engineering, Vol. 10, pp 703-712, 1983.

Chartrain, M. and Zeikus, J.G., Microbial ecophysiology of whey biomethanation: Characterization of trophic populations and prevalent species composition in continuous culture, Appl. Environ. Microbiol., Vol. 51, pp 188-196, 1986.

Cholette, A. and Cloutier, L. Mixing efficiency determinations for continuous flow systems, Canadian $J$. of Chemical engineering, June, 1959.

Chung, K.T. Inhibitory effects of $\mathrm{H}_{2}$ on growth of Clostridium cellobioparum. Appl. Environ. Microbiol., Vol. 31, pp 342-348, 1976.

Chung, Y.C. and Neethling, J.B. ATP as a measure of anaerobic sludge digester activity. J. WPCF Vol. 60, pp 107-112, 1988.

Clark, R.H. and Speece, R.E. The pH tolerance of anaerobic digestion. In Advances in Water Pollution Research Proceedings of the fifth International Conference on Water Pollution Research., San Francisco and Hawaii, 1970, II-27, pp 1-14, Pergamon Press, Oxford UK, 1971.

Colin, F. Development of an automatic equipment for the study of acid-base equilibria for the control of anaerobic digestion. In Anaerobic digestion and carbohydrate hydrolysis of waste. pp 391-394, eds. Ferrero, G.L., Ferranti, M.P. and Naveau, H., Elsevier Applied Scince Publishers, London, 1984. 
Cord-Ruwisch et al. , The capacity of hydrogenotrophic anaerobic bacteria to compete for traces of hydrogen depends on the redox potential of the terminal electron acceptor, Arch. Microbiol. Vol. 149, pp 350-357, 1988.

Costello, D.J., Greenfield, P.F. and Lee, P.L., Dynamic modeling of a single-stage high-rate anaerobic reactor-I. Model derivation. Water Res. Vol. 25 (7), pp 847-858, $1991 \mathrm{a}$.

Costello, D.J., Greenfield, P.F. and Lee, P.L., Dynamic modeling of a single-stage high-rate anaerobic reactor-II. Model verification. Water Res. Vol. 25 (7), pp 859-871, 1991 b.

Dague, R.R. Application of digester theory to digester control. J. WPCF. Vol.40, pp 2021-2032, 1968.

Daniels, L. Sparling, R. And Sprott, G.D. The bioenergetics of methanogenesis. Biochem. Biophys., Acta Vol. 768, pp 113-163, 1984.

De Beer, D., Huisman, J.W., Van den Heuvel, J.C. and Ottengraf, S.P.P., The effect of pH profiles in methanogenic aggregates on the kinetics of acetate conversion. Wat. Res. Vol.26 (10), pp 1329-1336, 1992.

Dirasian, H.A., Molof, A.H. and Borchardt, J.A. Electrode potentials developed during sludge digestion. J.WPCF. Vol.35, pp 424-439, 1963.

Eichler, B., Schink, B., Oxidation of primary aliphatic alcohols by Acetobacterium carbinolicum sp. nov., a homoacetogenic anaerobe., Arch. Microbiol., Vol.140, pp 147-152, 1984.

Eikmanns, B., Thauer, R.K. Catalysis of an isotropic exchange between $\mathrm{CO}_{2}$ and the carboxyl group of acetate by Methanosarcina barkeri grown on acettae. Arch. Microbiol. Vol.138, pp 365-370, 1984.

Fouda,A.E. and Capes,C.E. Hydrodynamic particle volume and fluidized bed expansion, The Canadian J. of Chem. Engr. Vol.55, August, 1977.

Fukuzaki S., Nishio, N., Nagai, S., Kinetics of the methanogenic fermentation of acetate, Appl. Environ. Microbiol. Vol.56, No. 10, pp 3158-3163, Oct., 1990a.

Fukuzaki S., Nishio, N., Shobayashi, M., Nagai, S., Inhibition of the fermentation of propionate to methane by hydrogen, acetate and propionate, Appl. Environ. Microbiol. Vol.56, No. 3, pp 719-723, Mar. 1990b. 
Fukuzaki, S., Nishio, N., Sakurai, H., Nagai, S., Characteristics of methanogenic granules grown on propionate in an upflow anaerobic sludge blanket (UASB) reactor. J. Ferment. Bioeng., Vol. 71, No. 1, pp 50-57, 1991.

Garside,J. and Al-Dibouni,M.R. "Velocity-voidage relationships for fluidization and sedimentation in solid-liquid system, Ind.Eng.Chem.Process Des.Dev., Vol.16, No 2, 1977.

Graef, S.P. and Andrews, J.F., Mathematical modeling and control of anaerobic digestion. Water-1973 (Ed.G.F.Bennett), Symposium Series No. 136, Vol.70, pp 101-113, AIChE, New York, New York, 1974.

Gujer, W. and Zehnder, A.J.B., Conversion process in anaerobic digestion. Water Sci. Technol., Vol.15, pp 127-167, 1982.

Gujer, W. and Zehnder, A.J.B., Conversion process in anaerobic digestion, Water Science and Technology, Vol.15, pp 127-167, 1983.

Hall, E.R. 'Improving hydraulic efficiency in high rate anaerobic systems, $A$ seminar sponsored by Pollution Control Association of Ontario, March, 1984, Burlington, Ontario.

Hall, E.R. Non-intrusive estimation of active volume in anaerobic reactors, Water Poll. Res. J. Canada Vol.20, No. 2, 1985.

Hamelers, H.V.M. and Koster, I.W., Estimation of the kinetic constants of acetoclastic methanogens from batch experiments, Proc. EWPCA conf. on anaerobic waste water treatment. Industrial presentations., Amsterdam, The Netherlands, pp 625-628, 1986.

Hang Min and Zinder, S.H., Kinetics of acetate utilization by two thermophilic acetotrophic methanogens: Methanosarcina sp. strain CALS-1 and Methanothrix sp. strain CALS-1, Appl. Environ. Microbiol. pp 488-491, Feb. 1989.

Harper, S.R. and Pohland, F.G. Enhancement of anaerobic treatment efficiency through process modification. J.WPCF, Vol. 59, No. 3, pp 152-161, 1987.

Harremoës, P., The significance of pore diffusion to filter denitrification. J. Water Pollu. Control. Fed., Vol. 48 (2), pp 377-388, 1976. 
Henson, J.M., McInerney, M.J., Shawn Beaty, P., Nickels, J. and White, D.C. Phospholipid fatty acid composition of the syntrophic bacterium Syntrophomonas wolfei. Appl. Environ. Microbiol. Vol. 54, pp $1570-1574,1988 \mathrm{~b}$.

Henson, J.M., Smith, P.H. and White, D.C. Examination of thermophilic methane-producing digerters by analysis of bacterial lipids. Appl. Environ. Microbiol., Vol. 50, pp 1428-1433, 1988a.

Henze, M. and Harremoës, $P$., Anaerobic treatment of waste-water in fixed film reactors-a literature review., Wat. Sci. Technol., Vol. 15, pp 1-101, 1983.

Heyes, R.H. and Hall, R.J., Anaerobic digestion modelling-The role of $\mathrm{H}_{2}$. Biotechnol. Lett., Vol. 3, pp $431-436,1981$.

Heyes, R.H. and Hall, R.J., Kinetics of two subgroups of propionate-using organisms in a anaerobic digestion, Appl. Environ. Microbiol. Vol. 46, pp 710-715, 1983.

Hickey, R.F. and Switzenbaum, M.S. Behavior of carbon monoxide as a trace component of anaerobic digester gases and methanogenesis from acetate. J. Environ. Sci. Technol., Vol. 24, pp 1642, 1990.

Hickey, R.F. and Swizenbaum, M.S. The role of intermediate and product gases as regulators and indicators of anaerobic digestion. In Poster Papers, Anaerobic Digestion. pp 43-47, eds. Tilche, A and Rozzi, A., Monduzzi Editore, Bologna, Italy, 1988.

Hickey, R.F., Vanderwielen, J. and Swizenbaum, M.S. . Production of trace levels of çarbon monoxide during methanogenesis on acetate and methanol. Biotechnol. Lett., Vol. 9, pp 63-66, 1987b.

Hickey, R.F., Vanderwielen, J. and Swizenbaum, M.S. The effect of heavy metals on methane production and hydrogen and carbon monoxide during batch anaerobic sludge digestion. Wat. Res., Vol. 23, pp 207$218,1989$.

Hickey, R.F., Vanderwielen, J. and Swizenbaum, M.S. The effects of organic toxicants on methane production and hydrogen gas levels during the anaerobic digestion of waste activated sludge. Wat. Res., Vol. 21, pp 1417-1427, 1987a.

Hill, D.T. and Barth, C.L., A dynamic model for simulation of animal waste digestion. J. Wat: Pollut. Control. Fed. Vol. 10, pp 2129-2143, 1977. 
Hill, D.T., A comprehensive dynamic model for animal waste methanogenesis. Trans. ASAE, Vol. 25, pp 1374-1380, 1982.

Huser, B.A., Methanbilding aus acetat, phD thesis, Swiss Federal Institute of Tech. Zurich, 1981.

Inoue, Y. and Koyama, K., Mechanism of volatile fatty acid removal in a fixed biofilm methane fermentation reactor. Wat. Sci. Tech. Vol. 20 (11), pp 377-383, 1988.

Iza,J. et al Anaerobic fluidized bed reactors (AFBR): performance and hydraulic behaviour, 5 th International symposium on anaerobic digestion, 1988.

Jones, R.M. and Hall, E.R., Assessment of dynamic models for a high rate anaerobic treatment process, Environ. Technol. Lett., Vol. 10, pp 551-566, 1989.

Jones, R.M., MacGregor, J.F., Murphy, K.L. and Hall, E.R., Towards a useful dynamic model of the anaerobic wastewater treatmetn process: A practical illustration of process identification. Wat. Sci. Technol., Vol. 25 (7), pp 61-71, 1992.

Jones, R.M., Nagle, D.P., Jr., Whitman, W.B. Methanogens and the diversity of archaebacteria. Microbiol. Rev., Vol. 51, No. 1, pp 135-177, 1987.

Kaspar, H. and Wuhrmann, K., Kinetic parameters and relative turnovers of some important catabolic reactions in digesting sludge, Appl. Environ. Microbiol. Vol. 36, pp 1-7, 1978.

Kaspar, H.F. and Wuhrmann, K. Product inhibition in sludge digestion. Microbial Ecol. Vol. 4, pp 241$248,1978$.

Kenealy, W.R. and Zeikus, J.G., One-carbon metabolism in methanogens: evidence for synthesis of a two-carbon cellular intermediate and unification of catabolism and anabolism in Methanosarcina barkeri. J. Bacteriol., Vol. 151, pp 932-941, 1982.

Kennedy, K.J. and Droste, R.L., Anaerobic fixed film reactor treating carbohydrate wastewater, Wat. Res. Vol. 20, No. 6, pp 685-696, 1986. 
Kissel, J.C., McCarty, P.L. and Street, R.L., Numerical simulation of mixed culture biofilm. J. Environ. Eng., ASCE, Vol. 110 (EE2), pp 393-411, 1984.

Kohler, H.P.E. and Zehnder, A.J.B., Carbon monoxide dehydrogenase and acetate thiokinase in Methanothrix soehngenii, FEMS Microbiol. Lett., Vol. 21, pp 287-292, 1984.

Koster, I.W. and Cramer, A. Inhibition of methanogenesis from acetate in granular sludge by long-chain fatty acids, Appl. Environ. Microbiol. Vol. 53, No. 2, pp 403-409, 1987.

Koster, I.W., Characteristics of the pH-influenced adaptation of methanogenic sludge to ammonium toxicity, J. Chem. Technol. Biotechnol., Vol. 36, No. 10, pp 445-455, 1986.

Koster, I.W., Rinzema, A.L., Lettinga, G., Sulfide inhibition of the methanogenic activity of granular sludge at various pH-levels, Wat. Res. Vol. 20, No. 12, pp 1561-1568, 1986.

Krzycki, J.A. and Zeikus, G. Characterization and purification of carbon monoxide dehydrogenase from Methanosarcina barkeri. J. Bacteriol. Vol. 158, pp 231-237, 1984.

Krzycki, J.A., Wolkin, R. and Zeikus, G. Comparison of unitrophic and mixtrophic substrate metabolism by an acetate-adapted strain of Methanosarcina barkeri. J. Bacteriol. Vol. 149, pp 247-254, Jan. 1982.

Kugelman, I.J. and Chin, K.K. Toxicity, synergism and antagonism in anaerobic waste treatment processes, Anaerobic Biological Treatment Process, Aug. 1970.

La Motta, E.J. and Shich, W.K., Diffusion and reaction on biological nitrification. J. Environ. Eng. Div. ASCE, Vol. 105 (EE4), pp 655-673, 1979.

Laanbroek, HJ, Abee, T., Voogd, JL, Alcohol conversion by Desulfobulbus propionicus Lindhorst in the presence and absence of sulfate and hydrogen, Arch. Microbiol., Vol. 133, pp 178-184, 1982.

Lawrence, A.W. and McCarty, P.L. Kinetics of methane fermentation in anaerobic treatment, J. W.P.C.F. Vol. 41 No. 2, Res. Suppl. R1-R17, 1969.

Lee, M.J. and Zinder, S.H., Hydrogen partial pressures in a thermophilic acetate-oxidizing methanogenic coculture, Appl. Environ. Microbiol., Vol. 54, pp 1457-1461, 1988. 
Lenhard, G. A standarized procedure for the determination of dehydrogenase activity in samples from anaerobic treatment system. Wat. Res., Vol. 2, pp 161-167, 1968.

Lens, P.N.L., De Beer, D., Cronenberg, C.C.H., Houwen, F.P., Ottengraf, S.P.P. and Verstraete, W.H., Heterogeneous distribution of microbial activity in methanogenic aggregates: $\mathrm{pH}$ and glucose microprofiles. Appl. Environ. Microbiol., Vol. 59 (11), pp 3803-3815, 1993.

Levenspiel, O. Chemical Reaction Engineering, 2nd edition, chapter 9. 1972.

Lin C.Y., Noike, T., Furumai, H., Matsumoto, J., A kinetic study on the methanogenesis process in anaerobic digestion, Water Science and Technology, Vol. 21, pp 175-186, 1989.

Locher, G., Sonnleitner, B. and Fiechter A. Pattern recognition: a useful tool in technological processes. Bioprocess engineering, Vol. 5, pp 181-187, 1990.

Lovely, D.R., Minimum threshold for hydrogen metabolism in methanogenic bacteria, Appl. Environ. Microbiol. Vol. 49, No. 6, June 1985.

Macario, A.J.L. and Conway de Macario, E. Antigenic fingerprinting of methanogenic bacteria with polyclonal antibody probes. System. Appl. Microbiol. Vol. 4, pp 451-458, 1983.

MacLeod, F.A. et al., Layered structure of bacterial aggregates produced in an UASB and filter reactor, Appl. Environ. Microb. Vol. 56, No. 6, pp 1598-1607, June, 1990.

Macmullen, R.B. and Weber, M. The theory of short circuiting in continuous flow mixing vessels in series and the kinetics of chemical reactions in such systems, Trans. AICHE, Vol. $31 \mathrm{pp} \mathrm{409,} 1935$.

Mah, R.A., Smith, M.R. and Baresi, L., Studies on an acetate-fermenting strain of Methanosarcina, Appl. Environ. Microbiol., Vol. 35, pp 1174-1184, 1978.

Manjunath, D.L. et al Treatment of cane sugar mill waste water in upflow anaerobic sludge blanket reactors, Proceedings of the 44th Purdue Industrial Waste Conference, 1989. 
McCarty, P.L. One hundred years of anaerobic treatment, pp 3-22, in Anaerobic Digestion, eds. Hughes, D.E., Stafford, D.A., Wheatley, B.J., Baader, W., Lettinga, G., Nyns, E.J. and Verstraeten, W., Elsevier, Amsterdam, 1981.

McCarty, P.L. and Smith, P.D., Anaerobic wastewater treatment. Environ. Sci. Technol., Vol. 20, pp 1200-1206, 1986.

McInerney, M.J., Bryant, M.P., Hespell, R.B., Costerton, J.W., Syntrophomonas wolfei gen. nov. spec.nov., an anerobic syntrophic fatty acid oxidizing bacterium. Appl. Environ. Microbiol. Vol. 41, pp 1029-1039, 1981.

Metcalf \& Eddy. Wastewater Engineering: treatment, disposal, reuse. $3^{\text {rd }}$ edi. McGraw-Hill, 1991.

Monteith,H.D. and Stephenson,J.P., Mixing efficiencies in full scale anaerobic digesters by tracer methods, J. Water Pollution Control Federation, Vol 53, pp 78-84, Jan. 1981.

Morgan, J.W. et al. , A comparative study of the nature of biopolymers extracted from anaerobic and activated sludges, Wat. Res. Vol. 24, No. 6, pp 743-750, 1990.

Mosey, F.E. Kinetic description of anaerobic digestion. $3^{\text {rd }}$ International symposium on anaerobic digestion, Boston, 1983.

Mosey, F.E., and Fernandes, X.A. Patterns of Hydrogen in biogas from the anaerobic digestion of milksugars, Water Science and Technology, Vol. 21, pp 187-196, 1989.

Mosey, F.E., Matnematical modeling of the anaerobnic digestion process: Regulatory mechanisms for the formation of short-chain volatile acids from glucose. Water Sci. Technol., Vol. 15 (8), pp 209-219, 1983.

Nilsson, B.K. and Karlsson, H.T., Diffusion rates in a dense matrix of methane-producing microorganisms. J. Chem. Tech. Biotechnol., Vol. 44, pp 255-260, 1989.

Olsson, G., Andersson, B., Hellstrom, B.G., Holmstrom, H., Reinius, L.G. and Vopatek, P. Measurements, data analysis and control methods in wastewater treatment plants-state of the art and future trends. Wat. Sci. Tech. Vol. 21, pp 1333-1345, 1989. 
Patel, G.B., Characterization and nutritional properties of Methanothrix concilii sp. nov., a mesophilic acetoclastic methanogen., Can. J. Microbiol. Vol. 30, pp 1383-1396, 1984.

Pauss, A., and Guiot, S.R. Hydrogen monitoring in anaerobic sludge bed reactors at various hydraulic regimes and loading rates. Water Environ. Res. Vol. 65, No. 3, pp 276-280, 1993.

Pauss, A., Andre, G., Perrier, M. and Guiot, S. Liquid to gas mass transfer in anaerobic process: Inevitable transfer limitations of methane and hydrogen in the biomethanation process. Appl. Environ. Microbiol., June, pp 1636-1644, 1990b.

Pauss, A., Guiot, S.R., Samson, R. and Beauchemin, C. Continuous measurement of dissolved $\mathrm{H}_{2}$ in an anaerobic reactor using a new hydrogen air fuel cell detector. Biotechnol. Bioeng., Vol. 35, pp 492-501, 1990a.

Peterson, S.P. and Ahring, B.K., Acetate oxidation in a thermophilic anaerobic sewage-sludge digestor: the importance of non-aceticlastic methanogenesis from acetate, FEMS Microbiol. Ecol. Vol. 86, pp 149$158,1991$.

Phelps, T.J., Conrad, R. and Zeikus, J.G., Sulfate dependent interspecies $\mathrm{H}_{2}$ transfer between Methanosarcina barkeri and Desulfovibrio vulgaris during metabolism of acetate and methanol. Appl. Eniron. Microbiol., Vol. 50, pp 589-594, 1985.

Postgate, J.R. and Campbell, L.L., Classification of Desulfovibrio species, the nonsporulating sulfatereducing bacteria. Bacteriol. Rev., Vol. 30, pp 732-738.

Powell, G.E. and Archer, D.B. On line titration method for monitoring buffer capacity and total volatile fatty acid levels in anaerobic digesters. Biotechnol. Bioeng., Vol. 33, pp 570-577, 1989.

Radian Co. Guidelines for the preparation of GRI quality assurance project plans, Aug. 1990.

Rebhun,M., Argaman,Y. Evaluation of hydraulic efficiency of sedimentation basins, J. San.Eng.Div. Proceedings ASCE SA5, pp 37, Oct. 1965.

Richardson,J.F. and Zaki,W.N. "Sedimentation and fluidisation, Trans. Inst. Chem. Engr., Vol. 32, No. 35, 1954. 
Riemer,M., Kristensen,G.H. and Harremoes,P., Residence time distribution in submerged biofilters, Water Research, Vol. 14, 1980.

Rittmann, B.E. and McCarty, P.L., Model of steady-state-biofilom kinetics. Biotechnol. Bioeng., Vol. 22, pp 2343-2357, 1980.

Rittmann, B.E., The effect of loading fluctuations on the effluent concentration produced by fixed-film reactors. Water Sci. Technol., Vol. 16, pp 45-55, 1985.

Rittmann, B.E., The effect of shear stress on biofilm loss rate. Biotehnot. Bioeng., Vol. 24, pp 501-506, 1982.

Robinson, J. A. and Tiedje, J.M. Kinetics of hydrogen consumption by rumen fluid, anaerobic digestor sludge, and sediment, Appl. Environ. Microbiol., Vol. 44, pp 1374-1384, 1982.

Rozzi, A., Di Pinto, A.C. and Brunetti, A. Anaerobic process control by bicarbonate monitoring. Environ. Technol. Lett., Vol. 6, pp 594-601, 1985.

Rozzi, A.S., Merlinio, S., and Passino, R., Development of a four population model of the anaerobic degradation of carbohydrates. Environ. Technol. Letters, Vol. 6, pp 610-619, 1985.

Saez, P.B. and Rittmann, B.E., Improved pseudoanalytical solution for steady state biofilm kinetics, Biotech. Bioeng., Vol. 32, pp 379-385, 1988.

Samain, E., Albaniac, G., Dubourgier, HC., Touzel, JP., Characterization of a new propionaic acid bacterium that ferments ethanol and displays a growth factor dependent association with a Gram negative homoacetogen, FEMS Microbiology Lett. Vol. 15, pp 69-74, 1982.

Schauer, N.L. and Ferry, J.G., Metabolism of formate in Methanobacterium formicicum. J. Bacteriol. Vol. 42, pp 800-807, 1980.

Schauer, N.L., Brown, D. P. and Ferry, J.G., Kinetics of formate metabolism in Methanobacterium formicicum and Methanospirillum hungatei. Appl. Environ. Microbiol., Vol 44, pp 549-554, 1982.

Schink, B, Kremer, D.K., Hansen, T.A., Pathway of propionate formation from ethanol in Pelobacter propionicus, Arch Microbiol Vol. 147, pp 321-327, 1987. 
Schink, B. and Thauer, R.K. Energetics of syntrophic methane formation and the influence of aggregation. In Granular anaerobic sludge; microbiology and technology. Proceedings of the GASMAT-workshop, pp 517, Lunteeren, Netherlands, 25-27 Oct., 1987.

Schink, B., Phelps, T., Eichler, B., Zeikus, J.G., Comparison of ethanl degradation pathways in anoxic freshwater environments, J. of General Microbiol. Vol. 131, pp 651-660, 1985.

Schink, B., Fermentation of 2,3-butanediol by Pelobacter carbinolicus sp. nov. nd Pelobacter propionicus sp.nov., and evidence for propionate formation from C2 compounds, Arch Microbiol. Vol. 137, pp 33-41, 1984.

Schmidt, J.E. and Ahring, B.K, Effects of hydrogen and formate on the degradation of propionate and butyrate in thermophilic granules from an Upflow Anaerobic Sludge Blanket reactor. Appl. Environ. Microbiol., Vol. 59, No. 8, pp 2546-2551, 1993.

Schmidt, J.E. and Ahring, B.K. Acetate and hydrogen metabolism in intact and disintegrated granules from an acetate-fed, $55^{\circ} \mathrm{C}$, UASB reactor, Appl. Microbiol. Biotechnol. 35:pp 681-685, 1991.

Schmidt, J.E. and Ahring, B.K., Effects of hydrogen and formate on the degradation of propionate and butyrate in thermophilic granules from an upflow anaerobic sludge blanket reactor, Appl. Environ. Microbiol., Vol. 59, No. 8, pp 2546-2551, 1993.

Schulze, D., Mehkhous, M., Fiebig, R., and Dellweg, H. Anaerobic treatment of protein-containing waste waters: correlation between coenzyme $\mathrm{F}_{420}$ and methane production. Appl. Environ. Microbiol. Vol. 29, pp 506-510, 1988.

Seitz, H.J., Schink, B., Pfenning, N., Conrad, R., Energetics of syntrophic ethanol oxidation in defined chemostat cocultures 1. Energy requirement for $\mathrm{H}_{2}$ production and $\mathrm{H}_{2}$ oxidation, Arch. Microbiol. Vol. $155, \mathrm{pp} 82-88,1990$.

Seitz, H.J., Schink, B., Pfenning, N., Conrad, R., Energetics of syntrophic ethanol oxidation in defined chemostat cocultures 2. Energy sharing in biomass production, Arch. Microbiol. Vol. 155, pp 89-93, 1990.

Shrink, B., Energetics of anaerobic system, speech at Center of Microbial Ecology, Michigan State University, Aug.11, 1992. 
Shrink, B., Principles and limits of anaerobic degradation: environmental and technological aspects, Biology of anaerobic microorganisms edi. Zehnder, 1988.

Smith, D., PhD Thesis, Stanford University, 1987.

Smith, P.H. and Mah, R.A., Growth and methanogenesis by methanosarcina strain 227 on acetate and methanol, Appl. Environ. Microbiol. Vol. 37, pp 993-999, 1978.

Speece, R.E., A survey of municipal anaerobic sludge digesters and diagnostic activity assays. Wat. Res. Vol. 22, pp 365-372, 1988.

Stevens, D.K. et al., The effect of tracer diffusion in biofilm on residence time distributions, Water. Research, Vol. 20, No. 3, 1986.

Strayer, R.F. and Tiedje, J.M. Application of the fluorescent-antibody technique to the study of a methanogenic bacterium in lake sediments. Appl. Environ. Microbiol. Vol. 35, pp 192-198, 1978.

Stupperich, E., Hammel, K.E., Fuchs, G. and Thauer, R.K. Carbon monoxide fixation into the carboxyl group of acetyl coenzyme A during autotrophic growth of Methanobacterium. FEBS Lett., Vol. 152, pp 21-23, 1983.

Switzenbaum, M.S., Giraldo-Gomez, E., Hickey, R.F. Control of anaerobic digestors. presented at the Regional workshop and conference on anaerobic treatment of wastewater in Latin America., Mexico City, Mexico, Nov. 6-9, 1990.

Thauer, R.K., Fuchs, G. and Jungerman, K., Role of iron-sulfur proteins in formate metabolism. In Iron Sulfur Proteins, W. Lowenberg (Ed.), Academic Press, New York, pp 121-156, 1973.

Thauer, R.K., Jungermann, K., Decker, K., Energy conservation in chemotrophic anaerobic bacteria, Bacteriological Reviews. Vol. 41, No. 1, Mar. 1977, pp 100-180.

Thiel, P.G. and Hattingh,W.H.J. Determination of hydrolytic enzyme activities in anaerobic digestion sludge. Wat. Res., Vol. 1, pp 191-196, 1967. 
Thiele, J.H. and Zeikus, J.G., Interactions between hydrogen- and formate-producing bacteria and methanogens during anaerobic digestion, Handbook on anaerobic fermentations, edi. Erickson, L.E. and Fung, D.Y., 1988a.

Thiele, J.H. and Zeikus, J.G., Control of interspecies electron flow during anaerobic digestion: The role of formate versus hydrogen transfer during syntrophic methanogenesis in flocs, Appl. Environ. Microbiol Vol. 54 , No. 1, pp 20-29, 1988c.

Thiele, J.H., Chartrain, M. Zeikus, J.G., Control of electron flow during anaerobic digestion: The role of floc formation in syntrophic methanogenesis, Appl. Environ. Microbiol, Vol. 54, No. 1, pp 10-19, 1988 b.

Van der Meer, R.R. Anaerobic treatment of wastewater containing fatty acids in upflow reactors, $p h D$ thesis, Delft university press, 1979.

van Lier, J.B., Crolle, K.C.F., Frijters, C.T.M.J., Stams, A.J.M. and Lettinga, G., Effects of acetate, propionate and butyrate on the thermophilic anaerobic degradation of propionate by methanogenic sludge and defined cultures, Appl. Environ. Microbiol., Vol. 59, No. 4, pp 1003-1011, 1993.

van Lier, J.B., Grolle, K.C.F., Stams, A.J.M., Conway de Macario, E. and Lettinga, G. Start-up of a thermophilic upflow anaerobic sludge bed (UASB) reactor with mesophilic granular sludge. Appl. Microbiol. Biotechnol. Vol. 37, pp 130-135, 1992.

Visser, F.A. et al., Diversity and population dtnamics of methanogenic bacteria in a granular consortium, Appl. Environ. Microb. Vol. 57, No. 6, pp 1728-1734, June, 1991:

Wen,C.Y. and Yu,Y.H. Mechanics of fluidization, Chem.Eng. Process Symp.Series, Vol. 62, 1966.

Westermann, P. et al., Threshold acetate concentration for acetate catabolism by aceticlastic methanogenic bacteria, Appl. Environ. Microbiol. pp 514-515, Feb. 1989.

Widdel, F., Wolfe, R.S., Growth of methanogenic bacteria in pure culture with 2-propanol as sole hydrogen donor, 86th Annual meeting of the American Society for Microbiology. Abstract 1126, 1986.

Williamson, K. and McCarty, P.L., A model of substrate utilization by bacterial films. J. Water Pollu. Control Fed., Vol. 48 (1), pp 9-24, 1976. 
Wolin M.J., Interactions between $\mathrm{H}_{2}$-producing and methane-producing species. In "Microbial formation and utilization of gases $\left(\mathrm{H}_{2}, \mathrm{CH}_{4} \mathrm{CO}\right) "$, Schlegel, Gottschalk and Pfennig, eds. pp 141-150, Goltze, Gt ttingrn, 1976.

Woods, D.D., Hydrogen lyases. The synthesis of formic acid by bacteria, J. Biol. Chem., Vol. 77, pp 515$518,1936$.

Wu, W-M, 1991(a), phD thesis, Michigan State University.

Wu, W-M, Hickey, R.F., Zeikus, J.G., 1991(b), Characterization of metabolic performance of methanogenic granules treating brewery wastewater: role of sulfate-reducing bacteria, App. Environ. Microbiol. Vol. 57, No. 12, pp 3438-3449, 1991.

Xu, B.J. Principles of water supply and waste water treatment, Qing-Hua University press, pp 50-60, P.R.China, 1983.

Zehnder, A.J., Ingvorsen, B.K. and Marti, T. Microbiology of methane bacteria. Pp 45-68, in Anaerobic Digestion, eds. Hughes, D.E., Stafford, D.A., Wheatley, B.J., Baader, W., Lettinga, G., Nyns, E.J. and Verstraeten, W., Elsevier, Amsterdam, 1981.

Zehnder, A.J.B., Huser, B.A., Brock, T.D. and Wuhrmann, K., Characterization of an acetate decarboxylating non-hydrogen-oxidizing methane bacteria, Arch. Microbiol. Vol. 124, pp 1-11, 1980.

Zeikus, J.G., Microbial populations in digestors, In First International Symposium on Anaerobic Digestion, D.A.Stafford, et al.(Ed.). A.D. Cardiff Scientific Press, Cardiff, U.K., pp 75-103, 1979.

Zinder, S.H. and Koch, M., Non-aceticlastic methanogenesis from acetate: acetate oxidation by a thermophilic syntrophic coculture, Arch. Microbiol. Vol. 138, pp 263-272, 1984.

Zinder, S.H., Anguish, T., Lobo, A.L., Isolation and characterization of a thermophilic acetotrophic strain of Methanothrix, Arch. Microbiol. Vol. 146, No. 4, pp 315-322, 1987. 
Zinder, S.H., Cardwell, S.C., Anguish, T., Lee, M. and Koch, M., Methanogenesis in a thermophilic $\left(58^{\circ} \mathrm{C}\right)$ anaerobic digestor: Methanothrix sp. as an important aceticlastic methanogen., Appl. Environ. Microbiol., Vol. 47, No. 4, pp 796-807, 1984.

Zinder, S.H., Conversion of acetic acid to methane by thermophiles, FEMS.

Zoetemayer, R.J., Matthusen, A.J.C.M., Cohen, A. and Boelhouwer, C. Product inhibition in the acid forming stage of the anaerobic digestion process. Wat. Res., Vol. 16, pp 633-639, 1982. 